\title{
José Luís Olivan Birindelli
}

\section{Relações filogenéticas da superfamília Doradoidea (Ostariophysi, Siluriformes)}

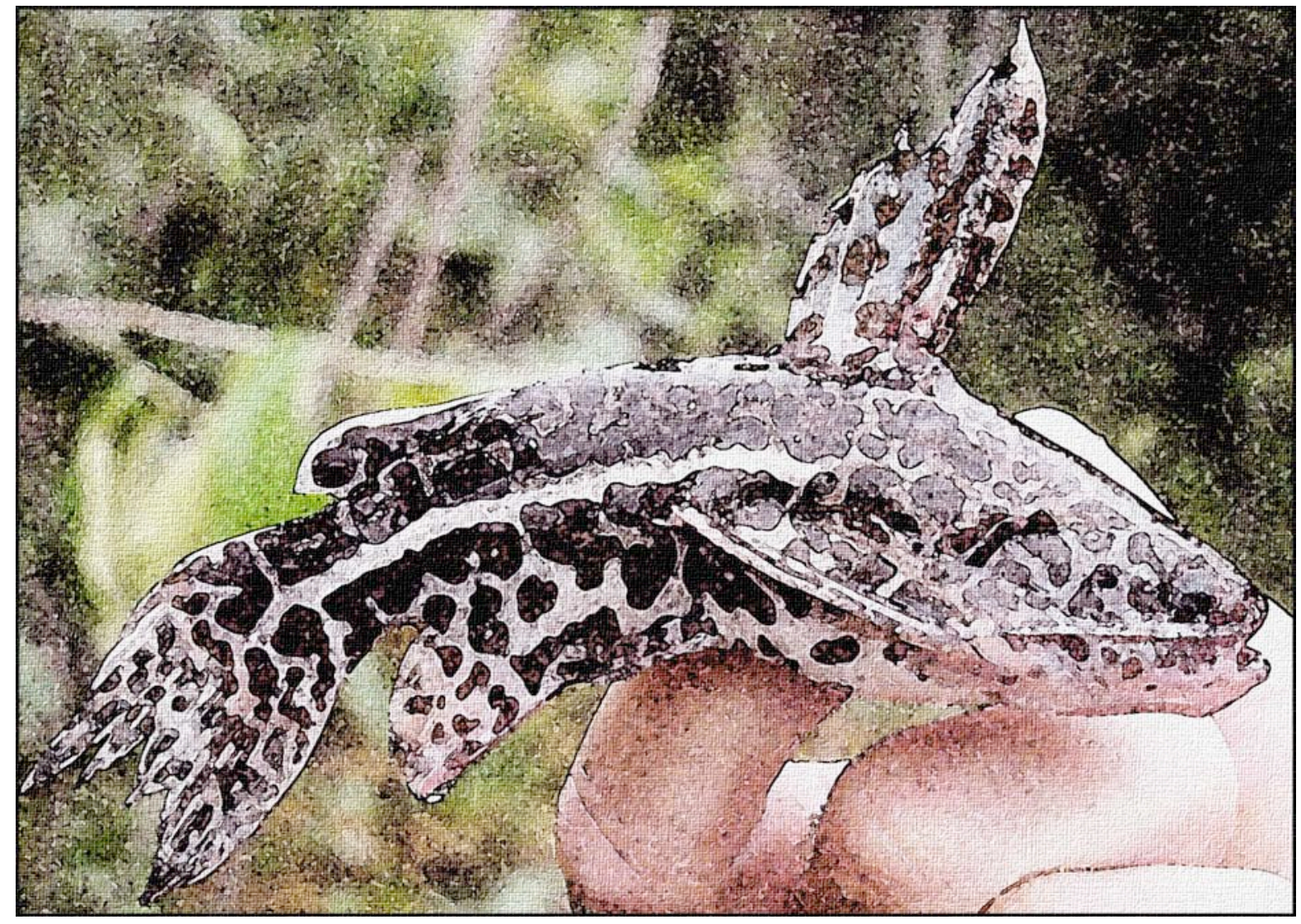

Tese de Doutorado Museu de Zoologia Universidade de São Paulo

Orientador Prof. Dr. Heraldo A. Britski 


\section{José Luís Olivan Birindelli}

\section{Relações filogenéticas da superfamília Doradoidea (Ostariophysi, Siluriformes)}

Tese apresentada ao Instituto de Biociências da Universidade de São Paulo, para a obtenção do título de Doutor em Ciências, na área de Zoologia.

Orientador: Prof. Dr. Heraldo Antonio Britski 
Birindelli, José Luís Olivan

Relações filogenéticas da superfamília Doradoidea (Ostariophysi, Siluriformes)

376 páginas

Tese (Doutorado) - Instituto de Biociências da Universidade de São Paulo, São Paulo.

Departamento de Zoologia.

1. Sistemática 2. Filogenia 3. Taxonomia 4.

Doradidae 5. Auchenipteridae 6. Mochokidae

Foto da capa: Liosomadoras oncinus, rio Ventuari, tributário do rio Orinoco na Venezuela, foto e edição pelo próprio autor.

Foto da quarta-capa: Rhynchodoras woodsi, ANSP 181042, $87 \mathrm{~mm}$, exemplar corado e diafanizado, foto de Leandro Sousa.

Comissão Julgadora:

$\operatorname{Prof}(a) \cdot \operatorname{Dr}(a)$.

Prof(a). Dr(a).
Prof(a). Dr(a).

$\operatorname{Prof}(a) \cdot \operatorname{Dr}(a)$

Prof. Dr. Heraldo Antonio Britski

Orientador 


\begin{abstract}
Aviso
A presente tese é parte dos requisitos necessários para obtenção do título de Doutor em Zoologia, e como tal, não deve ser vista como uma publicação no senso do Código Internacional de Nomenclatura Zoológica, apesar de disponível publicamente sem restrições. Dessa forma, quaisquer informações inéditas, opiniões, hipóteses e conceitos novos apresentados aqui não estão disponíveis na literatura zoológica. Pessoas interessadas devem estar cientes de que referências públicas ao conteúdo deste estudo somente devem ser feitas com aprovação prévia do autor.
\end{abstract}

\title{
Notice
}

This thesis is presented as partial fulfillment of the dissertation requirement for the Ph.D. degree in Zoology and, as such, is not intended as a publication in the sense of the International Code of Zoological Nomenclature, although available without restrictions. Therefore, any new data, opinions, hypothesis and new concepts expressed hererin are not available in the zoological literature. Readers are advised that further copying or public reference to this documents should only be done after previously acceptance of the author. 
"Strange is our situation on Earth. Each of us comes for a short visit, not knowing why, yet sometimes seeming to divine a purpose. From the standpoint of daily life, however, there is one thing we do know: that man is here for the sake of other men - above all for those upon whose smiles and well-being our own happiness depends" Albert Einstein

\footnotetext{
"Cambiaré de opinión tantas veces y tan a menudo como adquiera conocimientos nuevos; el dia en que me aperciba de que mi cérebro ha dejado de ser apto para los câmbios, dejaré de trabajar. Compadezco de todo corazón a los que después de haber adquirido y expressado una opinión, no pueden abandonarla más" Florentino Ameghino 1854-1911
}

"These are wonderful times, and

it is thrilling to be living now, though it would thrill me even more to know that I could still be here a houndred or a thousand years hence, for this immediate future promises to be of intense interest, even excitement, certainly to the scientist"

J.L.B.Smith (apud. Samantha Weinberg, 2000:109)

"Quando a última árvore tiver caído, quando o último rio houver secado, quando o último peixe for pescado, vocês vão entender que dinheiro não se come" Autor desconhecido

"In nature's infinite book of secrecy,

A little I can read" William shakespeare 


\section{Agradecimento}

Gostaria primeiramente de agradecer a toda minha família, especialmente aos meus pais por terem apoiado meus projetos de vida, desde meus primeiros aquários e excurções de mergulho à defesa dessa tese. Agradeço à minha esposa Marcela, por ter me contagiado com sua força e determinação.

Agradeço ao meu orientador, professor Heraldo Britski, por ter me aceitado como seu aluno, me orientado durante meu mestrado e doutorado, e por ter compartilhado comigo sua pesquisa e um pouco do seu vasto conhecimento ictiológico.

Agradeço aos outros professores da Seção de Peixes do Museu de Zoologia da USP, Mario de Pinna, Naércio Menezes e José Lima de Figueiredo, pela convivência nesses quase 7 anos, pelos exemplos de competência profissional, e por terem participado das minhas bancas de mestrado, qualificação e doutorado. Ao Osvaldo Oyakawa, por ter compartilhado comigo muitos projetos e viagens de campo.

Agradeço ao Leandro Sousa e Mark Sabaj Pérez pela amizade e colaboração nos estudos dos doradídeos. Muito do que está nessa tese é resultado do trabalho que temos realizado em conjunto nesses últimos anos.

Agradeço a todos os meus amigos e colegas da Universidade de São Carlos, da Universidade de São Paulo, e do Museu de Zoologia da USP, em especial àqueles da Seção de Peixes do MZUSP, que me acompanharam mais de perto: Alberto Akama, Flávio Lima, Cristiano Moreira, Isabel Landim, Janice Cunha, Ilana Fichberg, Carine Chamon, André Ferreira, Pedro Hollanda Carvalho, Eduardo Baena, Manuela Marinho, Henrique Varella, Marina Loeb, Rodrigo Caires, Katiane Ferreira, Alexandre Ribeiro e André Mendonça.

Gostaria também de agradeçer aos muitos pesquisadores brasileiros e estrangeiros por terem me recebido em suas instituições, ou me enviarem material, entre eles: Paulo Buckup e Marcelo Britto do MNRJ, Roberto Reis, Mariangeles Arce e Margarete Lucena do MCP, Lúcia Rapp Py-Daniel e Jansen Zuanon do INPA, Angela Zanata da UFBA, Carla Pavanelli e Claudio Zawadzki do NUPELIA, Luiz Queiroz da UNIR, John Lundberg e Mark Sabaj Pérez do ANSP, Tomio Iwamoto e Dave Catania do CAS, Richard Vari do USNM, Scott Schaefer do AMNH, Patrice Provost do MNHN, Mary Anne Rogers do FMNH, Jonhatan Armbruster e Nathan Lujan do AUM, e todos os estudantes que estavam nessas intituições durante minhas visitas.

Esse estudo foi financiado pela FAPESP (processo $n^{\circ}$ 06/53737-7). Algumas visitas a coleções e expedições científicas relacionadas à esse estudo foram financiadas pela CAPES-PROAP 2006 (IB-USP), CAS, ANSP e All Catfish Species Inventory (NSF DEB0315963). 


\section{Resumo}

A superfamília Doradoidea (Siluriformes) é composta por duas famílias Neotropicais: Doradidae e Auchenipteridae. A relação de grupo irmão entre essas famílias foi bem corroborada por estudos prévios baseados em dados morfológicos e moleculares. As relações filogenéticas entre gêneros e espécies de Doradoidea foram parcialmente estudadas por alguns autores. Contudo, as relações filogenéticas entre a superfamília Doradoidea e os demais Siluriformes, e entre vários dos gêneros e espécies de Doradidae e Auchenipteridae permanecem controvérsias. O objetivo dessa tese foi estabelecer uma hipótese sobre as relações entre espécies e gêneros da superfamília Doradoidea, e determinar o posicionamento dela entre as demais famílias de Siluriformes. Para isso, foi realizada uma análise filogenética extensa incluindo a maioria das espécies de Doradidae, 21 dos 22 gêneros de Auchenipteridae, e representantes de outras 16 famílias de Siluriformes. Para cada um desses táxons, 328 caracteres foram descritos, ilustrados e discutidos com base nos estudos prévios de outros autores. A análise de parcimônia resultou em quatro árvores igualmente parcimoniosas com 1086 passos. Em todas as árvores, a superfamília Doradoidea foi considerada como grupo irmão da família africana Mochokidae, que juntas formam a subordem Doradoidei. O monofiletimo da superfamília Doradoidea e da subordem Doradoidei foi corroborado por nove e cinco sinapomorfias exclusivas, respectivamente. Seis sinapomorfias não exclusivas serviram de suporte para a relação entre Doradoidei e um clado formado pela família africana Amphiliidae e pela superfamília asiática/neotropical Sisoroidea. O monofiletismo das famílias Auchenipteridae e Doradidae foi corroborado por uma série de cinco e três caracteres exclusivos, respectivamente. As espécies da família Auchenipteridae foram classificadas em duas subfamílias: Centromochlinae, com Glanidium (Tatia, Centromochlus), e Auchenipterinae, com (Asterophysus, Liosomadoras, Tocantinsia, ((Pseudotatia, Pseudauchenipterus), Trachelyopterini, Auchenipterini), sendo Trachelypterini formado por Trachelyichthys (Auchenipterichthys, ((Parauchenipterus, Trachelyopterus), (Trachycorystes, Trachelyoperichthys))), e Auchenipterini por ("Amplexiglanis", (Tetranematichthys, Ageneiosus)), (Entomocorus, (Auchenipterus, (Pseudepapterus, Epapterus))). A família Doradidae foi considerada como formada por (Wertheimeria, Kalyptodoras), (Franciscodoras, (Astrodoradinae, (Platydoradinae, Doradinae))), sendo Agamyxis e Acanthodoras incluídos em Astrodoradinae, Platydoradinae composta por Platydoras e Centrochir, e Doradinae composta por "Pterodoradini", ("Rhinodoradini", Doradini). "Pterodoradini" foi considerada como composta por (Megalodoras, Centrodoras), (Doraops, (Pterodoras, Lithodoras)), "Rhinodoradini" por Rhynchodoras, (Rhinodoras, Orinocodoras), e Doradini por Oxydoras, ("Petalodoras", (Trachydoras, (Doras, (Nemadoras, ("Nemadoras", (Hassar, (Anduzedoras, Leptodoras))))))). O gênero Hemidoras foi considerado sinônimo sênior de Opsodoras, e as espécies Nemadoras leporhinus, $N$. trimaculatus e Opsodoras ternetzi como mais relaciondas a Hassar, Anduzedoras e Leptodoras, do que aos seus congêneres. Um resumo sistemático com diagnose de cada gênero, tribo, subfamília e família da superfamília Doradoidea foi elaborado, bem como uma chave de identificação para todos os gêneros do grupo. 


\begin{abstract}
The superfamily Doradoidea (Siluriformes) is composed of two Neotropicalendemic families: Doradidae and Auchenipteridae. The sister-group relationship between these families has been corroborated by previous studies of both morphological and molecular data. Previous studies have also provided support for evolutionary relationships between doradoid genera and species. However, relationships between the superfamily Doradoidea and remaining Siluriformes, and between several genera of Doradidae and Auchenipteridae remain controversial. The aim of my study is to recover evolutionary relationships between genera and species of the superfamily Doradoidea, and to find support for its position within Siluriformes. To accomplish this, a comprehensive phylogenetic analysis including a majority of the Doradidae species, 21 of 22 genera of Auchenipteridae, and representatives of another 16 families of Siluriformes was performed. For each of these taxa, 328 characters were described, illustrated, or discussed, based on the literature. Parsimony analysis of these characters resulted in four equally parsimonious trees with 1086 steps. In all trees, the superfamily Doradoidea was recovered as sister to the Africa-endemic family Mochokidae, together forming the suborder Doradoidei. Monophylies of the superfamily Doradoidea and suborder Doradoidei were respectively corroborated by nine and five exclusive synapomorphies. Six non-exclusive synapomorphies supported Doradoidei as sister to a clade composed of the Africa-endemic Amphiliidae and the Asia/Neotropical-endemic Sisoroidea. Monophylies of the families Auchenipteridae and Doradidae were also corroborated by sets of five and three characters, respectively. The family Auchenipteridae was found to be composed of two subfamilies: Centromochlinae, with Glanidium (Tatia, Centromochlus), and Auchenipterinae, with (Asterophysus, Liosomadoras, Tocantinsia, ((Pseudotatia, Pseudauchenipterus), Trachelyopterini, Auchenipterini), in which Trachelypterini is composed of Trachelyichthys (Auchenipterichthys, ((Parauchenipterus, Trachelyopterus), (Trachycorystes, Trachelyoperichthys))), and Auchenipterini composed of ("Amplexiglanis", (Tetranematichthys, Ageneiosus)), (Entomocorus, (Auchenipterus, (Pseudepapterus, Epapterus))). The family Doradidae was considered to be composed of (Wertheimeria, Kalyptodoras), (Franciscodoras, (Astrodoradinae, (Platydoradinae, Doradinae))), in which Agamyxis and Acanthodoras were included in Astrodoradinae, Platydoradinae composed of Platydoras and Centrochir, and Doradinae composed of "Pterodoradini", ("Rhinodoradini", Doradini). "Pterodoradini" comprised (Megalodoras, Centrodoras), (Doraops, (Pterodoras, Lithodoras)), "Rhinodoradini" included Rhynchodoras, (Rhinodoras, Orinocodoras), and Doradini comprised Oxydoras, ("Petalodoras", (Trachydoras, (Doras, (Nemadoras, ("Nemadoras", (Hassar, (Anduzedoras, Leptodoras))))))). The genus Hemidoras was considered a senior synonym of Opsodoras, and Nemadoras leporhinus, N. trimaculatus and Opsodoras ternetzi as more closely related to Hassar, Anduzedoras and Leptodoras, than to their congeners. A systematic summary with diagnoses of every genus, tribe, subfamily, and family of the superfamily Doradoidea is provided, as well as an artificial key allowing identification of all genera of the group.
\end{abstract}


Agradecimentos _

Resumo vi vi

Abstract _ vii

Capítulo 1. Introdução ___ 1

1.1. Introdução geral sobre os peixes da superfamília Doradoidea ......................... 1

1.2. Histórico taxonômico da superfamília Doradoidea .......................................... 4

1.3. Histórico taxonômico da família Doradidae ................................................... 17

1.4. Histórico taxonômico da família Auchenipteridae ......................................... 21

Capítulo 2. Objetivos 27

Capítulo 3. Materiais e métodos_ 28

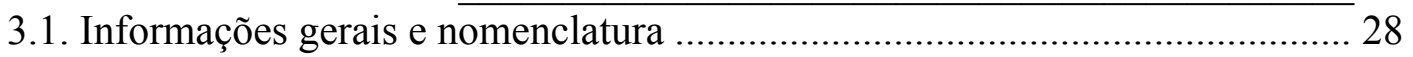

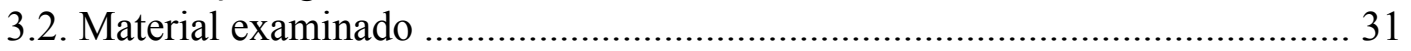

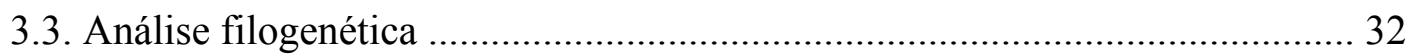

Capítulo 4. Resultados — 34

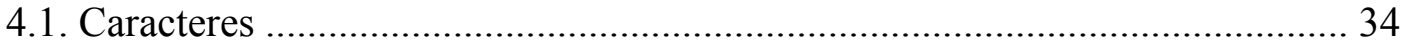

4.1.1. Morfologia externa (\#1 a \#6) .......................................................... 34

4.1.2. Barbilhões (\#7 a \#22) ................................................................ 38

4.1.3. Pele e anexos dérmicos (\#23 a \#34) ............................................... 44

4.1.4. Bexiga natatória (\#35 a \#48) ...................................................... 51

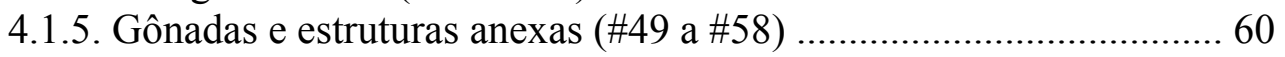

4.1.6. Neurocrânio (\#59 a \#105) .................................................................. 67

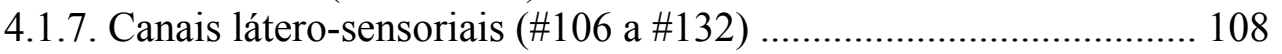

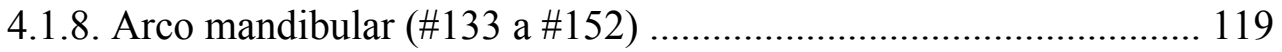

4.1.9. Suspensório (\#153 a \#173) ........................................................ 128

4.1.10. Série opercular (\#174 a \#176) .................................................. 135

4.1.11. Arco hióide (\#177 a \#185) .......................................................... 136

4.1.12. Arco branquial (\#186 a \#207) .................................................. 142

4.1.13. Esqueleto axial (\#208 a \#236) ................................................... 158

4.1.14. Nadadeira dorsal (\#237 a \#261) ................................................ 177

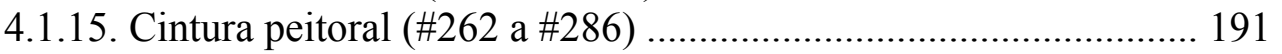

4.1.16. Cintura pélvica (\#287 a \#302) ................................................... 204

4.1.17. Nadadeira anal (\#303 a \#316) ..................................................... 212

4.1.18. Nadadeira caudal (\#317 a \#328) ............................................... 217

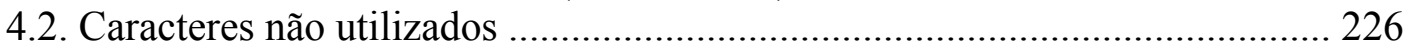

4.3. Análise de parcimônia ............................................................................. 233

4.4. Sistemática da superfamília Doradoidea ................................................. 236

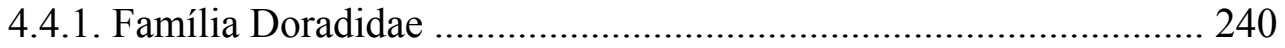

4.4.2. Família Auchenipteridae ....................................................... 273

Capítulo 5. Discussão 304

5.1. Relações filogenéticas da superfamília Doradoidea .................................... 304

5.2. Relações filogenéticas da família Doradidae ............................................. 306

5.3. Relações filogenéticas da família Auchenipteridae ..................................... 308

5.4. Padrões biogeográficos da superfamília Doradoidea ................................. 309

Referência bibliográficas citas _ 313

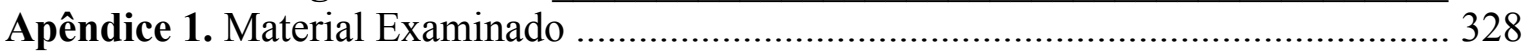

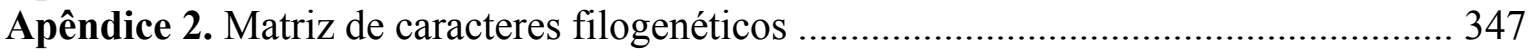

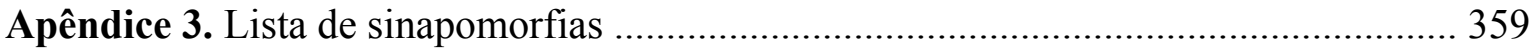

Apêndice 4. Chave de identificação dos gêneros da superfamília Doradoidea ................ 369 


\section{Capítulo 1. Introdução}

\subsection{Introdução geral sobre os peixes da superfamília Doradoidea}

A ordem Siluriformes contém os peixes morfologicamente mais diversos e amplamente distribuídos do grupo Ostariophysi, com aproximadamente 36 famílias, 477 gêneros e 3088 espécies (Ferraris, 2007), ocorrendo por todos os continentes, havendo inclusive fósseis na Antártica (Grande \& Eastman, 1986). A maioria é restrita às águas continentais, porém algumas espécies são resistentes à águas salobras e duas famílias, Ariidae e Plotosidae, são quase exclusivamente marinhas (Nelson, 2006).

Dentro da ordem Siluriformes, as famílias Doradidae e Auchenipteridae (sensu Ferraris, 2007) constituem a superfamília Doradoidea (sensu de Pinna, 1998), exclusivamente neotropical. Os peixes da superfamília Doradoidea variam de poucos centímetros (e.g., Physopyxis spp., Gelanoglanis spp.) a pouco mais de um metro de comprimento (e.g., Oxydoras niger). A maioria das espécies é bentônica (e.g., Leptodoras spp.) mas algumas são pelágicas (e.g., Ageneiosus spp.). São predominantemente de água doce e ocorrem na América do Sul nas bacias dos rios da Prata, São Francisco, Parnaíba, Mearim, Jequitinhonha, Paraguassú, Doce, Paraíba do Sul, Ribeira de Iguape, Orinoco, Essequibo, Magdalena, Maracaibo e nos rios das Guiana e do Suriname, predominando porém na bacia Amazônica (Burgess, 1989). Elas podem ser facilmente reconhecidas por possuírem escudo cefálico bem desenvolvido, largo e contínuo até o acúleo da nadadeira dorsal, processo posterior do cleitro geralmente bem desenvolvido, ligamento entre a placa nucal posterior e a primeira costela (ossificado e normalmente visível, ou ligamentoso e normalmente apalpável externamente), e nadadeira anal de machos maduros modificada num gonopódio (auchenipterídeos) ou pela presença de uma fileira de escudos ósseos laterais no corpo 
(doradídeos).

Os peixes da família Doradidae, popularmente chamados cuiú-cuiús, bacus, botoados, armaos e rebecas, podem ser facilmente identificados pela presença de uma fileira de escudos ósseos laterais, cada um geralmente com um espinho retrorso. Informações gerais sobre a biologia das espécies da família Doradidae foram sumarizadas por Vono \& Birindelli (2007). Duas das espécies de maior tamanho, Lithodoras dorsalis e Megalodoras uranoscopus alimentam-se de moluscos quando pequenas, e frutos e sementes quando grandes (Miranda Ribeiro, 1911; Starks, 1913; Eigenmann, 1925; Goulding, 1979, 1980). Outras espécies malacófagas incluem Franciscodoras marmoratus (Ihering \& Azevedo, 1934) e Rhinodoras dorbignyi (Veitenheimer \& Mansur, 1975). Doraops zuloagai e Kalyptodoras bahiensis alimentam-se de moluscos e crustáceos (Schultz, 1944; Higuchi et al., 1990; obs. pess.). Platydoras brachilecis e Hassar affinis são onívoras, alimentando-se de insetos, crustáceos e itens vegetais (Menezes \& Menezes, 1948; Menezes, 1949). As espécies da tribo Doradini, que têm focinho comprido e boca pequena, são geralmente bentônicas: Oxydoras niger é detritívora (Goulding, 1980), Leptodoras cf. cataniai alimenta-se de larvas de quironomídeos, ingeridas com detrito e grãos de areia (Sabaj, 2005), e Trachydoras paraguayensis é onívora, alimentando-se de microcrustáceos, protozoários, nemátodas, ácaros, larvas de insetos e algas, também ingeridos com detrito e grãos de areia (Hahn et al., 1991; Fugi et al., 2001). A única espécie predominantemente herbívora é Pterodoras granulosus (Devincenzi \& Teague, 1942; Hahn et al., 1992; Ferriz et al., 2000). Informações sobre a reprodução de espécies da família Doradidae são ainda mais raras. Aquaristas descrevem que algumas espécies podem fazer ninhos para reproduzir (Burgess, 1989). Algumas espécies são conhecidas por migrarem grandes distâncias, terem fecundação externa e nenhum cuidado parental 
(Agostinho et al., 2003; Sato et al., 2003). Algumas espécies exibem dimorfismo sexual, com machos maduros tendo o acúleo da nadadeira dorsal prolongado por uma extensão cartilaginosa (Rapp Py-Daniel \& Cox-Fernandez, 2005; obs. pess.).

As espécies da família Auchenipteridae, popularmente conhecidas como carataí, fidalgo, mandubé, palmito, judeu, ximbé, cangati e cachorro-de-padre, são caracterizadas pelo dimorfismo sexual, que envolve diversas características secundárias, e fecundação interna através de inseminação. A biologia da maioria das espécies de auchenipterídeos é ainda pouco conhecida. Os poucos estudos relatam o hábito noturno de algumas espécies, como Tatia spp. (Lowe McConnel, 1975), o hábito de vida pelágico de outras, como Ageneiosus spp. (Walsh, 1990), a migração reprodutiva de espécies de grande porte na Amazônia (Goulding, 1979, 1980), a tolerância de algumas espécies a água salobra (Akama, 1999) e a predominância de itens alóctones na dieta de outras espécies (Carvalho \& Resende, 1984). Já a taxonomia e filogenia das espécies da família é relativamente bem estudada, principalmente se comparada às outras famílias de peixes neotropicais. Os gêneros com maior número de espécies já foram revisados taxonomicamente, e muitas são as hipóteses filogenéticas inter-genéricas propostas para a família (ver histórico de Auchenipteridae).

A posição da superfamília Doradoidea em Siluriformes é ainda controversa. A maioria dos estudos morfológicos aponta a família africana Mochokidae como seu grupo irmão. Por sua vez, este grande clado estaria relacionado à família Ariidae (Royero, 1987; Lundberg, 1993; de Pinna, 1998; fig. 1a), à família Malapteruridae (Diogo, 2004; fig. 1c) ou seria um clado pouco derivado, relacionado a grandes grupos de Siluriformes (de Pinna, 1993; Britto, 2002; fig. 1b). Entretanto, trabalhos recentes baseados em dados moleculares (Sullivan et al., 2006; 2008; fig. 1d) têm encontrado suporte para a relação entre a superfamília Doradoidea e a família neotropical 
Aspredinidae, este sendo um clado de relações incertas dentro de Siluriformes; enquanto Mochokidae estaria relacionada às famílias africanas de Siluriformes, como por exemplo, Amphiliidae e Malapteruridae. Com base nos caracteres morfológicos, Aspredinidae seria relacionada a famílias asiáticas, estando dentro da superfamília Sisoroidea (de Pinna, 1996).

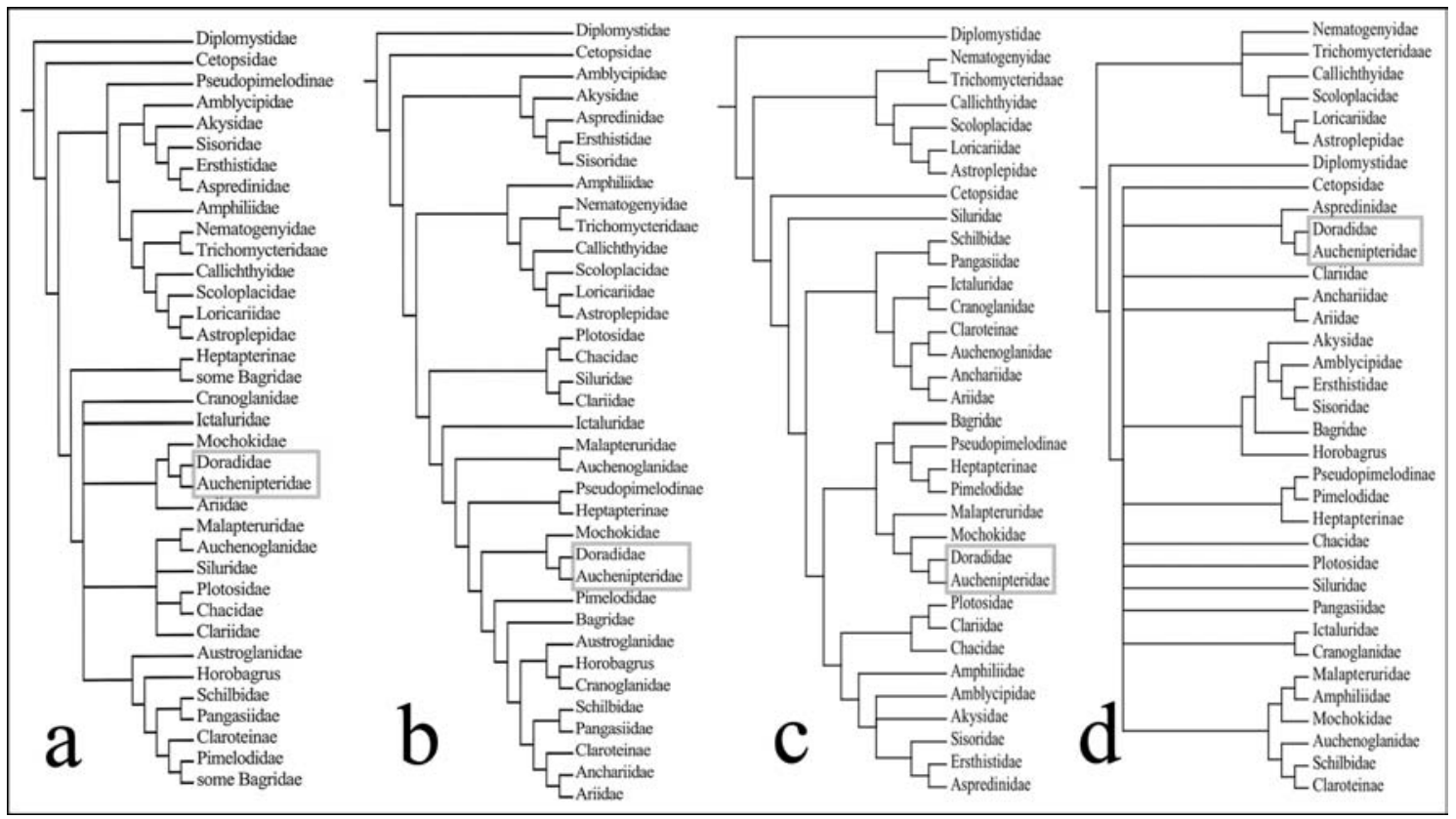

Figura 1. Hipóteses das relações filogenéticas entre famílias de Siluriformes, segundo de Pinna, 1998 (a), Britto, 2002 (b), Diogo, 2004 (c), e Sullivan et al., 2006 (d).

\subsection{Histórico taxonômico da superfamília Doradoidea}

Na décima edição do Systema Naturae, Linnaeus (1758: 304, 307) descreveu dois gêneros para acomodar os peixes hoje incluídos na ordem Siluriformes, Silurus, com as espécies: S. asotus, S. glanis, S. aspredo, S. mystus, S. anguillaris, S. batrachus, S. undecimalis, S. militaris, S. catus, S. clarias (mochokídeo), S. ascita, S. costatus (doradídeo), S. callichthys, S. cataphractus (doradídeo), e o gênero monotípico Loricaria, com a espécie L. cataphractus. Além destas espécies, Linnaeus (1758: 238) descreveu Acipenser plecostomus (um loricarí́deo) num gênero que englobava espécies 
de esturjões, atual família Acipenseridae, ordem Acipenseriformes. Oito anos mais tarde, na décima-segunda edição do Systema Naturae, Linnaeus descreveu $\boldsymbol{S}$. inermis (auchenipterídeo), S. felis, S. galeatus (auchenipterídeo), S. cous, S. carinatus (doradídeo), S. fasciatus, S. bagre, e realocou A. plecostomus no gênero Loricaria (Linnaeus, 1766: 508). Apesar da taxonomia zoológica moderna ter como ponto de partida a classificação proposta por Linnaeus, é bom lembrar que tal classificação foi, na verdade, desenvolvida em 1738 por seu colega Peter Artedi, cujo conhecimento ictiológico sobrepujava o de Linnaeus (Jordan, 1917).

De Linnaeus ao fim do século XVIII, poucos foram os trabalhos de descrição de espécies e gêneros de Siluriformes. Entre eles, destacam-se: a criação do gênero Cataphractus Edwards (em Casteby, 1771: apêndice), para reunir S. callichthys, $\boldsymbol{S}$. cataphractus e S. costatus; o trabalho de Scopoli, no qual muitos gêneros foram criados, como por exemplo, Aspredo, Clarias, Callichthys e Mystus; e o de Bloch (1794), no qual algumas espécies e gêneros novos foram descritos, como por exemplo, o gênero Platystacus, e as espécies Cataphractus punctatus, Silurus nodosus (auchenipterídeo), Platystacus cotylephorus e Loricaria maculata.

Já no século XIX, Bloch \& Schneider (1801) classificaram os peixes em cinco classes. Dentro de uma das três ordens da classe Octopteriygii, eles reuniram as espécies de Cataphractus e Loricaria (além de outros gêneros de peixes não Siluriformes); e dentro de uma das três ordens da classe Heptapterygii, eles reuniram as espécies de Silurus (que incluíam mochokídeos e auchenipterídeos, além dos outros Siluriformes) e Platystacus (para aspredinídeos). Pouco depois, Lacepède (1803), descreveu outros tantos gêneros de Siluriformes: Ompok, Macropteronotus, Malapterurus, Pimelodus, Doras, Plotosus, Ageneiosus, Hypostomus, Corydoras, Tachysurus (além de reconhecer Silurus, Loricaria, Cataphractus), incluindo diversos gêneros não relacionados (e.g., 
Anableps, Salmo, Centranodon) na sua quarta ordem de peixes ósseos. Quanto às espécies, Lacepède (1803) incluiu S. aspredo, S. cotylephorus, S. verucosus em Silurus (juntamente com espécies de Bagridae, Siluridae, entre outras); $\boldsymbol{S}$. nodosus e $\boldsymbol{S}$. galeatus em Pimelodus (juntamente com espécies de Ariidae, Mochokidae e Pimelodidae, entre outras); S. costatus e $S$. carinatus em Doras; Ageneiosus armatus (sinônimo de S. inermis) e S. inermis em Ageneiosus; e S. callichthys, Cataphractus americanus (=S. cataphractus) e C. punctatus em Cataphractus.

Rafinesque (1815) foi o primeiro autor a reunir as espécies de Siluriformes num grupo exclusivo, batizado por ele de Ophlophoria (ver detalhes em de Pinna, 1998). Quase concomitantemente, Cuvier (1817) num grande trabalho de anatomia (ver também Cuvier, 1836-1847) e classificação de peixes, reuniu os Siluriformes num grupo exclusivo nomeado "Des Siluroïdes", diagnosticado dos demais peixes por possuírem a pele nua ou coberta por grandes placas ósseas, intermaxilares (=prémaxilares) suspensos sob o etmóide (=mesetmóide), maxilares reduzidos ou alongados na base do barbilhão maxilar, canal intestinal amplo e repleto de cecos, bexiga natatória grande e aderida a um aparelho ósseo particular, nadadeiras dorsal e peitoral quase sempre com o primeiro raio transformado em espinho e presença de nadadeira adiposa na maioria ('como nos salmões'). Esta é uma diagnose bastante precisa e muitos destes caracteres são ainda hoje usados para sustentar o grupo (ver discussão mais detalhada em de Pinna, 1998). Cuvier (1817) subdividiu os "Siluroïdes" em: "Silures" com os gêneros Silurus, Schilbes, Mystus, Pimelodus (que incluía P. galeatus), Synodontis (gênero criado por Cuvier, para abrigar as espécies $S$. clarias, $S$. schall e $S$. membranaceus, reunindo pela primeira vez os mochokídeos num grupo exclusivo), Ageneiosus (que incluía $A$. militaris e $A$. inermis), Doras (que incluía D. costatus, D. cataphractus, D. americanus, e D. carinatus), Heterobranchus, Plotosus, Callichthys 
(que incluía apenas $C$. callichthys), além dos grupos Malapterures, Asprèdes e Loricaires. Ao contrário de Edwards (1771) e Bloch (1794), que reuniram os doradídeos e callichthyídeos em Cataphractus, Cuvier (1817) reconheceu, pela primeira vez, um grupo exclusivo para os doradídeos (Doras) e outro para callichthyídeos (Callichthys).

Spix \& Agassiz (1829), examinando os peixes coletados no Brasil por Spix anos antes, dividiram os Siluriformes estudados em duas famílias dentro dos "Malacopterygii Abdominales" (que também incluía outras duas famílias de peixes de escama), a família Gonyodontes, criada naquele trabalho e que incluía os loricariídeos, e a família Siluroidei que incluía os demais Siluriformes, representados pelos gêneros Cetopsis, Doras (que incluía a então nova espécie D. humboldti), Hypophthalmus (que incluía $H$. edentatus e $\boldsymbol{H}$. nuchalis [=Auchenipterus nuchalis]), Pimelodus, Phractocephalus, Platystoma e Heterobranchus.

Cuvier \& Valenciennes (1840) criaram mais alguns gêneros de Siluriformes, como Arges, Arius (que incluía todos os ariídeos e A. nodosus), Galeichthys, Pangasius, Silundia, Saccobranchus, Auchenipterus (que inclui A. nuchalis e as espécies novas $A$. dentatus, A. furcatus, A. trachycorystes, A. maculosus, $A$. immaculatus e A. punctatus), e Trachelyopterus (que incluía $T$. coriaceus, também descrita como nova). Eles consideraram Ageneiosus (com as espécies $\boldsymbol{A}$. militaris, $\boldsymbol{A}$. inermis e $A$. brevifilis, esta última descrita como nova na ocasião) relacionado a Hypophthalmus; e reconheceram os "Schals" como um grupo distinto que incluía o gênero Synodontis com as espécies $S$. clarias, $S$. membranaceus, $S$. serratus, $S$. maculosus, S. schall, S. humeratus e $S$. nigrita (as duas últimas descritas como novas). Cuvier \& Valenciennes (1840: 244) notaram ainda a semelhança do escudo cefálico de Synodontis, Auchenipterus e Doras. Dentro do gênero Doras, eles reconheceram D. costatus, D. cataphractus, D. granulosus, D. crocodili, D. carinatus, descrevendo 
como novas D. armatulus, D. hancockii, D. dorsalis e D. niger. É interessante notar que os autores reconheceram dois grupos dentro de Doras, separando as espécies $D$. carinatus e D. niger das demais (Cuvier \& Valenciennes, 1840: 288), por não possuírem dentes na mandíbula e terem cabeça comprimida ( $v s$. deprimida nos demais).

Müller \& Troschel (1849: 203) criaram o gênero Euanemus para sua nova espécie E. colymbetes (sinônimo de Auchenipterus dentatus Valenciennes, 1840); e transferiram S. nodosus para o gênero Auchenipterus.

Kner (1854) num estudo baseado num manuscrito de Heckel, seu orientador, sobre dimorfismo sexual em Callichthys e bexigas natatórias em Doras, ilustrou a bexiga natatória de Doras polygramma (species inquirendae em Acanthodoras, de acordo com Sabaj \& Ferraris, 2003), D. loricatus (=D. fimbriatus), D. ophthalmus (=D. oxyrhynchus), D. asterifrons, D. punctatus, D. brevis, D. armatulus, D. Hancoki (sic), D. dorsalis, sendo as seis primeiras espécies apresentadas naquele trabalho. Um ano mais tarde, Kner (1855), num trabalho mais abrangente, descreveu formalmente as espécies apresentadas no ano anterior, além de várias espécies e gêneros de Siluriformes, entre os quais destacam-se os gêneros Bunocephalus e Oxydoras, e as espécies D. fimbriatus, D. affinis, D. stenopeltis, D. humeralis, D. murica, D. dorbignyi e D. heckelii. Já em 1858, Kner descreveu Asterophysus batrachus (gênero e espécie), Centromochlus megalops (gênero e espécie), C. aulopygia, Auchenipterus thoracatus e A. ceratophysus.

Um autor contemporâneo a Kner foi Bleeker que, apesar de ter descrito poucas espécies de peixes neotropicais, criou muitos gêneros e grupos supra-genéricos dentro de Siluriformes. Seus trabalhos $(1858,1862,1863 \mathrm{a}$ e 1864) foram complementares e podem ser resumidos no trabalho intitulado Systema Silurorum Revisum (Bleeker, 1863b), cuja classificação pode ser resumida da seguinte forma (o asterisco indica os 
gêneros criados por Bleeker):

Ordem Siluri

Família I. Loricarioidei

Subfamília I. Plecostomiformes - stirps Plecostomini e Acanthicini

Subfamília II. Loricariaformes - stirps Loricariini e Acestrini

Família II. Callichthyoidei

Família III. Siluroidei

Subfamília I. Sisoriformes

Subfamília II. Bagriformes

Stirp Claroteini

Stirp Doradini (gêneros Doras, Rhinodoras*, Centrochir, Oxydoras, Lithodoras*, Pterodoras*, Platydoras*, Acanthodoras*, Amblydoras*)

Stirp Synodontini (gêneros Synodontis, Brachysynodontis*, Pseudosynodontis*, Hemisynodontis*, Leiosynodontis*)

Stirp Pseudauchenipterini - phalanx Pseudauchenipteri (gêneros Pseudauchenipterus*, Trachycorystes*, Parauchenipterus*, Auchenipterichthys*), phalanx Centromochli (gênero Centromochlus), phalanx Asterophysi (gênero Asterophysus)

Stirp Bagrini (com muitas phalanx e gêneros de bagrídeos, ariídeos, diplomystídeos, pimelodídeos, pseudopimelodídeos, akysiídeos)

Stirp Pangasini - phalanx Pangasii, phalanx Ageneiosi (gêneros Tetranematichthys*, Pseudageneiosus*, Ageneiosus), phalanx Auchenipterini (gênero Auchenipterus), phalanx Hypophthalmini, phalanx Heptapterini, phalanx Argeini

Trachelyopterichthys*)

Subfamília III. Astroblepiformes

Subfamília IV. Trachelyopteriformes

Stirp Cetopsini

Stirp Trachelyopterini (gêneros Trachelyopterus,

Subfamília V. Trichomycteriformes

Subfamília VI. Siluriformes

Subfamília VII. Malapteruriformes

Família IV. Aspredinoidei

Família V. Chacoidei

Família VI. Heterobranchoidei

Nessa classificação, é interessante notar: 1. a proximidade entre Doradini, Synodontini e Pseudauchenipterini; 2. a proximidade entre Ageneiosini e Auchenipterini e entre estes e Hypophthalmini, Pangasini e Heptapterini. 3. o “polifiletismo" dos auchenipterídeos; 4. o "monofiletismo" dos doradídeos.

Günther (1864), no importante "Catalogue of Fishes of the Britsh Museum”, reclassificou todas as espécies conhecidas de Siluriformes ("família Siluridae") 
designando dentro de sua quinta subfamília "Siluridae Stenobranchiae", que também incluía os grupos Rhinoglanina (=mochokídeos, em parte) e Malapterurina, o seu “décimo grupo - Doradina”, com os gêneros Ageneiosus (espécies A. militaris, A. sebae, A. brevifilis, A. axillaris, A. dentatus, A. davalla), Tetranematichthys (T. quadrifilis), Euanemus (E. nuchalis), Auchenipterus (A. nodosus, A. thoracicus, A. trachycorystes, A. obscurus, A. longimanus, A. ceratophysus, A. maculosus, A. galeatus, A. robustus, A. oncina), Centromochlus (C. heckelii, C. aulopygius), Trachelyopterus (T. coriaceus, T. taeniatus), Cetopsis (C. caecutidens, C. candira, C. gobioides), Asterophysus (A. batrachus), Doras (D. costatus, D. armatulus, D. dentatus, D. hanchockii, D. muricus, D. affinis, D. truncatus, D. weddellii, D. asterifrons, D. heckelii, D. cataphractus, D. dorsalis, D. lithogaster, D. papilionatus, D. crocodili, D. castaneo-ventralis, D. brunnescens), Oxydoras (O. carinatus, O. humeralis, O. punctatus, O. brevis, O. fimbriatus, O. stenopeltis, O. lipophthalmus), Rhinodoras (R. niger, R. kneri, R. orbignyi) e Synodontis (S. sorex, S. macrodon, S. serratus, S. schal, S. nebulosus, S. omias, S. nigritus, S. humeratus, S. gambiensis, $S$. zambosensis, S. xiphias, S. membranaceus).

Portanto, Günther $(1864,1880)$ foi o primeiro a reunir a maioria dos doradídeos, auchenipterídeos e mochokídeos num grupo exclusivo, nomeado "Doradina” (mas que também incluía cetopsídeos).

Gill (1870, 1872), num trabalho amplo porém com pouco detalhe, reconheceu os Siluriformes como “ordem Nematognathi” (Gill achava o nome Nematognathi, portador de fitas (barbilhões) nas maxilas, mais apropriado).

No fim do século XIX, muitos autores apresentaram contribuições mais focadas na descrição de espécies (ver exemplos no histórico taxonômico das famílias). Uma importante espécie de Doradidae descrita nesta época foi Wertheimeria maculata 
Steindachner, inicialmente proposta como um auchenipterídeo (Steindachner, 1877a).

Outros marcos para a classificação dos Siluriformes foram os trabalhos de Eigenmann \& Eigenmann (1888, 1889 e 1890, mais focalizados nos Siluriformes da América do Sul e o de 1891, um catálogo de peixes da América do Sul). Eigenmann \& Eigenmann (1890) dividiram os peixes neotropicais da ordem "Nematognathi" nas seguintes famílias e subfamílias:

I. Bunocephalidae - Bunocephalinae e Platystacinae

II. Diplomystidae

III. Siluridae - Tachisurinae, Callophysinae, Pimelodinae, Doradinae (Physopyxis, Doras, Oxydoras, Hemidoras), Auchenipterinae (Asterophysus, Trachelyopterichthys, Wertheimeria, Centromochlus, Trachycorystes, Auchenipterichthys, Felichthys, Epapterus, Auchenipterus, Tetranematichthys), Ageneiosinae (Ageneiosus)

IV. Hypophthalmidae

V. Pygididae - Cetopsinae, Pygidinae

VI. Argiidae

VII. Loricariidae - Loricariinae, Hypoptopomatinae, Plecostominae

VIII. Callichthyidae

Eigenmann \& Eigenmann (1890), portanto, consideraram os cetopsídeos não relacionados aos doradídeos e auchenipterídeos, e classificaram os auchenipterídeos em dois grupos, sendo um deles composto exclusivamente por Ageneiosus.

Bridge \& Haddon (1892) e Sörensen (1895) em trabalhos extremamente detalhados sobre a anatomia do aparelho de Weber e bexiga natatória de espécies de Siluriformes, comprovaram a semelhança nas estruturas do aparelho de Weber em doradídeos, auchenipterídeos (incluindo ageneiosídeos) e mochokídeos, e destacaram a presença de elastic spring apparatus nestes táxons. Cabe lembrar que o elastic spring apparatus foi descrito inicialmente por Müller (1842a, 1842b, 1843) em Auchenipterus, Doras, Synodontis e Malapterurus, e posteriormente descrito em Pangasius por Bridge \& Haddon (1892).

Regan (1911), num breve trabalho sobre classificação dos "Siluroidea", descreve 
como ele vê a evolução do grupo: "I place first the Diplomystidae, more generalized than any of the others in the normally formed toothed maxillary and on the simple attachment of the fifth vertebrae to the complex. Next the Ariidae and Doradidae are considered, generalized in form and in fin structure, but aberrant in the loss of the mesocoracoid, and they are followed by the Plotosidae and Siluridae, which have a very long anal fin, but are primitive in some other characters, such as the many-rayed pelvic fins. Then come the Bagridae, widely distributed in Asia and Africa, and they are followed by the North-American Amiuridae and by a number of Old-World families which may be regarded as specialized Bagrids, Amblycepidae, Sisoridae, Amphiliidae, Chacidae, Schilbeidae, Clariidae, Pangasidae, Synodontidae, and Malapteruridae. The neotropical Silurids (except the Doradidae) come last, and these begin with the Pimelodidae, which represent the Bagridae in South America, and are followed by the Helogenidae, Hypophthalmidae, Trichomycteridae, and Bunocephalidae, ending with the highly specialized Callichthyidae and Loricariidae, which are the most aberrant of the order (Regan, 1911: 556)". Regan (1911) incluiu os auchenipterídeos e ageneiosídeos dentro da família Doradidae, e ainda notou semelhanças entre Synodontidae e Doradidae (sensu Regan, 1911), porém as considerou convergentes: "The Synodontidae resemble the South American Doradidae to a certain extent in their restricted gill-openings, nuchal shield, and elastic spring apparatus. But in the Doradidae the epiotics are proeminent cranial roof-bones which join the nuchal plates, a mesopterygoid is present but a mesocoracoid absent, the fourth parapophysis is not divided into anterior and posterior rami and its distal plate is attached to the lateral instead of the anterior wall of the air-bladder, and the fifth parapophysis is vestigial or absent".

Miranda Ribeiro (1911) por ver que seria "sempre vantagem eliminar um gráo, 
quando possível fôr, para melhor concisão (p. 20)" subdividiu os gêneros neotropicais de "Scleracanthi" (Miranda Ribeiro criou o termo Scleracanthi por considerar o termo mais apropriado do que Nematognathi, pois entendia que havia outros peixes com barbilhões enquanto que apenas os Siluriformes possuem acúleos nas nadadeiras dorsal e peitorais) em 11 famílias, desta forma, elevando à família: Doradidae, Trachycorystidae (com os gêneros Pseudauchenipterus, Glanidium, Centromochlus, Tatia, Asterophysus, Trachycorystes, Auchenipterichthys, Trachelyopterus, Trachelyopterichthys), Auchenipteridae (Epapterus, Auchenipterus) e Ageneiosidae (Tetranematichthys, Ageneiosus, Pseudageneiosus). Ele ainda descreveu os gêneros Mormyrostoma (sinônimo de Doras, ver Sabaj Pérez \& Birindelli, 2008) e Tatia; e moveu o gênero monotípico Wertheimeria, descrito em Auchenipteridae, para a família Doradidae.

Eigenmann (1925), na revisão das espécies de Doradidae, dividiu os "Nematognathi" neotropicais em 16 famílias: Diplomystidae, Ariidae, Auchenipteridae, Doradidae, Ageneiosidae, Helogenidae, Hypophthalmidae, Pimelodidae, Bunocephalidae, Aspredinidae, Pygididae, Nematogenyidae, Cetopsidae, Astroblepidae, Callichthyidae e Loricariidae.

Jordan (1929) e Berg (1940), em estudos amplos de classificação de peixes, consideraram Auchenipteridae, Doradidae e Ageneiosidae famílias independentes em Siluriformes.

$\mathrm{Na}$ metade do século XX, outros dois catálogos de peixes neotropicais foram importantes para estruturar a classificação dos Siluriformes na época. Gosline (1945) dividiu os "Nematognatos" em: Diplomystidae, Ariidae, Ameiuridae, Doradidae (com as subfamílias Auchenipterinae, que incluía Wertheimeria, e Doradinae), Ageneiosidae (com apenas Ageneiosus e Tympanopleura), Pimelodidae, Helogeneidae, 
Hypophthalmidae, Cetopsidae, Pygididae, Bunocephalidae, Callichthyidae, Loricariidae, Astroblepidae. E Van der Stigchel (1947), no catálogo de peixes dos museus de Leiden e Amsterdam, considerou os doradídeos, auchenipterídeos e ageneiosídeos como famílias independentes dentro de "Nematognathi”.

Fowler (1951) no mais completo catálogo de peixes brasileiros, utilizou a “ordem Siluriformes nova (=Siluri Bonaparte, 1838)" (sic) em vez de "Nematognathi" (nome mais usado na época) e classificou os Siluriformes brasileiros no mesmo arranjo apresentado por Gosline (1945).

Greenwood et al. (1966) num detalhado estudo evolutivo, apresentaram sinapomorfias para a ordem Siluriformes, contudo pouco discutiram as relações entre as famílias da ordem, reconhecendo como famílias: Doradidae, Auchenipteridae (incluindo Trachycorystidae), Ageneiosidae, Mochokidae (reconhecendo Synodidae, Mochockidae, Mochochidae, Mochocidae como sinônimos).

Chardon (1968), estudando a anatomia do aparelho de Weber e estruturas anexas em Siluriformes, propôs dividir a ordem Siluriformes nas seguintes subordens: Diplomystoidei, Siluroidei, Malapteruroidei, Bagroidei (com as superfamílias Bagroidae [famílias Bagridae, Pimelodidae, Ictaluridae, Ariidae, Olyrida], Plotosoidae, Schilbeoidae, Pangasioidae, Chacoidae, Doradoidae [Mochokidae, Auchenipteridae, Doradidae, Ageneiosidae], Sisoroidae, Akysoidae, Clarioidae), Cetopsoidei, Hypophthalmoidei, Loricarioidei (Aspredinoidae, Trycomycteroidae, Loricarioidae). Chardon (1968) diagnosticou a superfamília Doradoidae (sensu Chardon, 1968) com os seguintes caracteres: 1 . caracteres fundamentais de Bagroidei modificados em razão do elastic spring apparatus, 2. esqueleto muito forte, ossos da face dorsal do crânio profundamente esculturados, exceto em Ageneiosus, 3. escudo nucal suturado ao parieto-supra-occipital por intermédio de uma "écaille supplémentaire" (=placa nucal 
anterior), exceto em Ageneiosus, 4. pós-temporal (=pós-têmporo-supracleitro) soldado ao crânio, 5. ligamento ou processo ossificado ligando o epiótico (=epoccipital) ao ramo posterior da parapófise da vértebra complexa, 6. fenda articular do cleitro com o póstemporal profunda. Além disso, ele ainda diagnosticou as famílias com caracteres anatômicos, destacando que o único caráter que distingue as famílias Auchenipteridae e Doradidae seria a fileira de placas ósseas, presente nos doradídeos.

Britski (1972) estudando os Doradoidae (sensu Chardon, 1968) neotropicais (Doradidae, Auchenipteridae, Ageneiosidae) considerou Ageneiosidae grupo irmão da família Auchenipteridae baseado na presença de dimorfismo sexual. Britski (1972), reanalisando os caracteres de Chardon (1968), considerou os caracteres 2 e 6 irrelevantes por se tratarem de variações inter-específicas dentro da família, o 3 falho por estar ausente em algumas espécies de Doradidae, Auchenipteridae e Mochokidae, e o 5 incorreto porque os Doradoidea sulamericanos não possuem o ramo posterior da parapófise da vértebra complexa; concluindo ser ainda prematuro estabelecer relação entre Mochokidae e os Doradoidae neotropicais. Outra importante contribuição de Britski foi confirmar a posição de Wertheimeria em Doradidae através do exame do material tipo, e remover Taunayia de Auchenipteridae, tratando-a como um pimelodídeo.

A partir da década de 80 , alguns estudos enfocaram as relações filogenéticas em Siluriformes, mais especificamente entre espécies de auchenipterídeos e doradídeos, fundamentados na metodologia cladística.

Royero (1987) estudando a nadadeira dorsal (incluindo as placas nucais) em Siluriformes considerou Ariidae relacionado a Mochokidae, Doradidae, Auchenipteridae (incluindo Centromochlidae) e Ageneiosidae, sucessivamente. Quase concomitantemente, Ferraris (1988) propôs Doradidae como grupo irmão do clado 
formado pelas famílias Centromochlidae e Auchenipteridae (esta incluindo a família Ageneiosidae, considerada relacionada a gêneros derivados dentro dos auchenipterídeos). E Curran (1989), num estudo problemático, baseado em poucos caracteres e táxons, obteve uma hipótese na qual Centromochlidae estava incluída em Auchenipteridae (Ageneiosidae não foi incluída na análise).

Mo (1991), através do estudo da família Bagridae, propôs uma hipótese de relações de várias famílias de Siluriformes, na qual a hipótese de Royero foi corroborada por outros caracteres. Um ano depois, Arratia (1992) realizou uma analise filogenética com 8 famílias basais de Siluriformes. Entretanto, estes dois estudos apresentaram uma série de problemas metodológicos, como a falta de representatividade dos táxons (de Pinna \& Ferraris, 1992).

A primeira análise filogenética mais abrangente sobre as relações entre as famílias de Siluriformes foi realizada por de Pinna (1993), na qual Mochokidae foi considerado grupo irmão das famílias Doradidae e Auchenipteridae (incluindo Ageneiosidae e Centromochlidae).

No mesmo ano, ao apresentar o fóssil "Titonoglanis", Lundberg (1993) discutiu a relação deste com os Doradoidea e Ariidae, corroborando a hipótese de Royero (1987).

A família neotropical Aspredinidae foi proposta como possivelmente relacionada a Mochokidae, Doradidae, Auchenipteridae por Friel (1994). E, pouco depois, de Pinna (1996) a incluiu em Sisoroidea, um grupo formado basicamente por bagres asiáticos.

Num capítulo de revisão de todas as propostas de relações filogenéticas em Siluriformes, de Pinna (1998, fig. 1a) estabeleceu os termos "superfamília Doradoidea" para o clado Doradidae + Auchenipteridae (incluindo Centromochlidae e 
Ageneiosidae), e “subordem Doradoidei” para o clado Mochokidae + Doradoidea, aceitando a proposta de relação entre Ariidae e Doradoidei.

Royero (1999) corroborou sua hipótese inicial de relações: Ariidae (Mochokidae (Doradidae, Auchenipteridae)), ao realizar uma análise filogenética enfocada em Auchenipteridae. Contrariamente, Britto (2002, fig. 1b), re-analisando todos os caracteres apresentados pelos autores anteriores, concluiu que Doradidae, Auchenipteridae e Mochokidae formam um clado monofilético não relacionado a Ariidae.

E, finalmente, Diogo (2004, fig. 1c) analisando todas as famílias de Siluriformes, propôs a relação entre Auchenipteridae, Doradidae, Mochokidae e Malapteruridae.

Mais recentemente, com o advento da biologia molecular como ferramenta para análise filogenética, Sullivan et al. (2006, fig. 1d) e Sullivan et al. (2008) apresentaram forte suporte para o clado Aspredinidae (Doradidae, Auchenipteridae), este não relacionado às famílias Mochokidae e Ariidae.

Resumindo, as famílias Doradidae e Auchenipteridae são consideradas grupos monofiléticos e irmãos bem corroborados tanto por dados morfológicos como moleculares. Já a relação entre a superfamília Doradoidea e as demais famílias de Siluriformes é ainda assunto de debate. Historicamente os Doradoidea foram considerados relacionados às famílias: 1. Mochokidae, Malapteruridae (principalmente pela presença do elastic spring apparatus), 2. Mochokidae e Ariidae (por características do escudo nucal), 3. Mochokidae e Aspredinidae (por características da cintura peitoral), e 4. Aspredinidae (por dados moleculares). 


\subsection{Histórico taxonômico da família Doradidae}

As espécies da família Doradidae são conhecidas desde Linnaeus $(1758,1766)$ que descreveu Silurus costatus, S. cataphractus e S. carinatus.

O primeiro gênero de doradídeo descrito foi Cataphractus Edwards in Casteby, 1771, (espécie tipo S. cataphractus Linnaeus por tautonomia). Entretanto, ele é considerado um nomen oblitum por não ter sido usado desde 1889 e, como tal, sinônimo júnior de Acanthodoras (Sabaj \& Ferraris, 2003; Ferraris, 2007; Eschmeyer, 2010).

Lacepède (1803) criou o gênero Doras no qual foram descritas as espécies de doradídeos até a metade do século XIX. Kner $(1854,1855)$, além de ter descrito várias espécies, descreveu o subgênero Oxydoras, para alocar espécies com cabeça comprimida (vs. deprimida como em D. costatus, D. cataphractus). Seguindo esta divisão entre espécies "caput elevatum" e "caput depressum", Bleeker (1858, 1862, 1863a, 1863b, 1864) descreveu outros tantos gêneros da família.

Em 1925, Eigenmann, em um de seus últimos trabalhos, realizou a primeira e única revisão taxonômica completa dos doradídeos, definindo a família Doradidae com base em caracteres anatômicos relativamente bem detalhados. Ele agrupou as 68 espécies válidas conhecidas até então em 26 gêneros, sendo muitas destas espécies e gêneros descritos naquele trabalho. Seguindo os autores precedentes, Eigenmann (1925) considerou a família dividida em dois grupos de espécies: o primeiro com espécies com cintura peitoral larga, cabeça deprimida, pré-maxilar normal com fileiras de dentes e barbilhões simples, e o segundo com espécies com cintura peitoral estreita, cabeça comprimida, focinho às vezes alongado e cônico, pré-maxilar subcircular, com poucos ou sem dentes, e barbilhões frequentemente fimbriados. Eigenmann (1925) não incluiu Wertheimeria maculata na família, aparentemente ignorando o trabalho de Miranda Ribeiro (1911). 
Depois de Eigenmann (1925), outra importante revisão das espécies de Doradidae foi realizada por Fernández-Yépez $(1950,1968)$. Embora esta revisão tenha se restringido às espécies da Venezuela, muitas confusões taxonômicas foram criadas por ele, principalmente através da descrição de espécies e gêneros considerados hoje sonônimos, e do agrupamento de espécies extremamente diferentes e não relacionadas num mesmo gênero, como por exemplo, Hildadoras orinocensis (=Oxydoras niger) e Hildadoras bolivarensis (= Amblydoras bolivarensis).

Higuchi (1992, fig. 2a) realizou a primeira tentativa de conhecer as relações filogenéticas entre os gêneros de Doradidae, com base na metodologia cladística. Os resultados da análise foram parcialmente publicado em de Pinna (1998). Higuchi confirmou o monofiletismo da família, propondo alguns caracteres para sustentar o grupo, além de resolver muitos problemas taxonômicos dentro da família através de uma lista taxonômica de todas as espécies da família. Ele reconheceu três subfamílias dentro da família Doradidae, além dos respectivamente basais Wertheimeria e Franciscodoras.

Moyer et al. (2004, fig. 2c) estudaram as relações filogenéticas em Doradidae com base em dados moleculares, obtendo resultados apenas parcialmente congruentes com os de Higuchi (1992). 


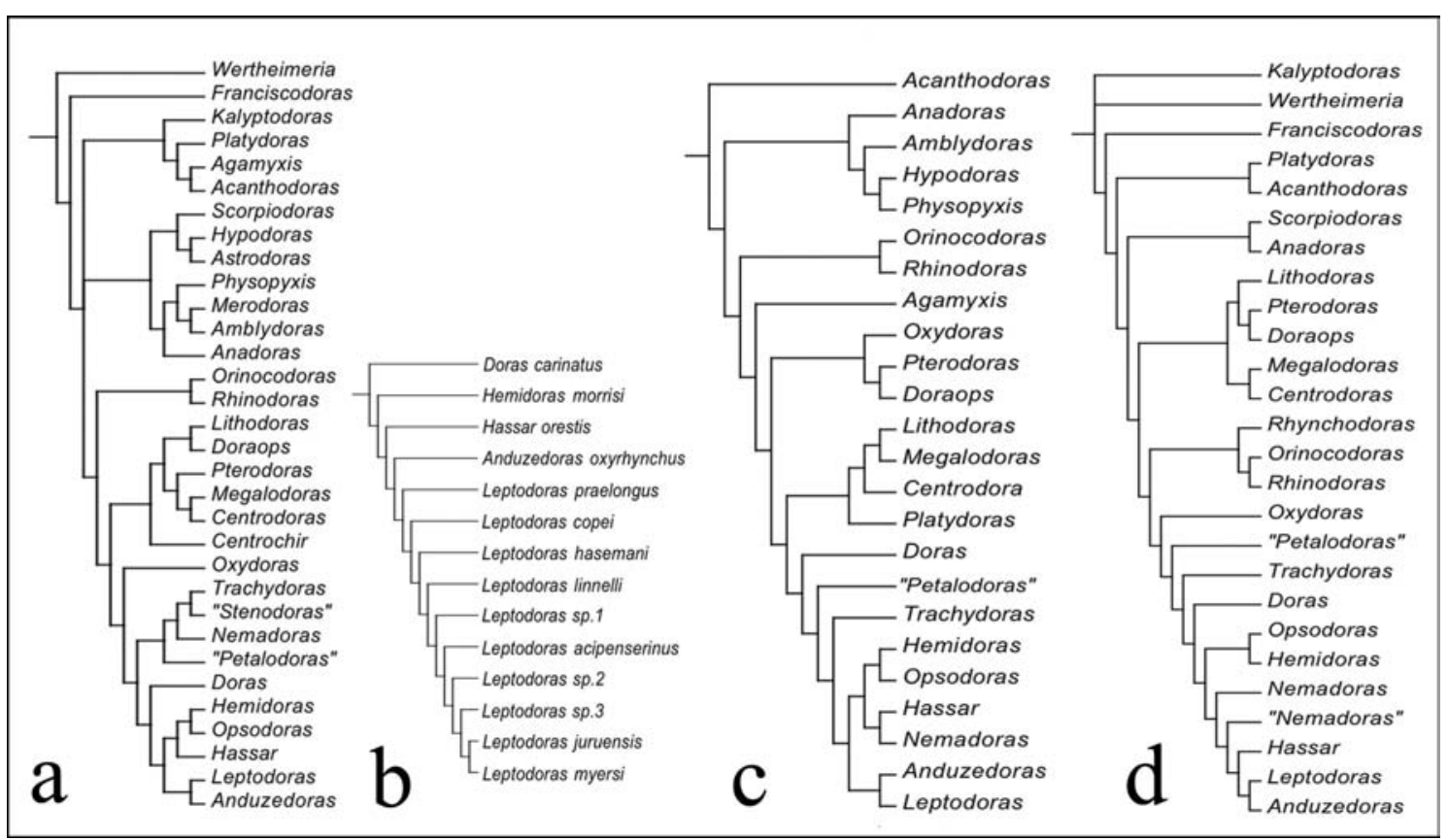

Figura 2. Hipóteses das relações filogenéticas entre os gêneros de Doradidae, segundo Higuchi, 1992 (a),

Sabaj, 2002 (b), Moyer et al., 2004 (c), e Birindelli, 2006 (d).

Sabaj (2002) e Sabaj \& Ferraris (2003) elaboraram uma lista taxonômica de todas as espécies da família, resolvendo vários problemas taxonômicos (desta vez formalmente), reconhecendo 30 gêneros e 72 espécies válidas na família Doradidae. Sabaj (2002, fig. 2b) ainda apresentou uma hipótese de relações entre as espécies do gênero Leptodoras.

Birindelli (2006, fig. 2d), estudando as espécies da subfamília Doradinae (sensu Higuchi, 1992), mas incluindo também representantes de todos os outros grupos, propôs uma nova hipótese de relações da família. Esta difere da proposta de Higuchi (1992) principalmente pela posição relativamente mais basal de Kalyptodoras (que havia sido considerada relacionada a Platydoras, Acanthodoras e Agamyxis por Higuchi), e por considerar as subfamílias Astrodoradinae e Doradinae (sensu Higuchi) grupos irmãos (a hipótese prévia continha uma politomia entre as três subfamílias).

O conhecimento sistemático das espécies da família Doradidae foi intensamente melhorado nos últimos cinco anos. Sabaj (2005) fez uma revisão taxonômica do gênero 
Leptodoras, com a descrição de três espécies como novas. Sousa \& Rapp Py-Daniel (2005) revisou o gênero Physopyxis, descrevendo duas espécies. Birindelli et al. (2007) descreveram Rhynchodoras castilloi, re-diagnosticando suas duas congêneres. Higuchi et al. (2007) descreveram Merodoras nheco como gênero novo e espécie nova, nomearam e diagnosticaram a subfamília Astrodoradinae que inclui os gêneros Astrodoras, Amblydoras, Physopyxis, Merodoras, Scorpiodoras, Anadoras e Hypodoras. Sabaj Pérez et al. (2007) descreveram uma espécie de Doras a partir de material fóssil da Venezuela. Sabaj et al. (2008) descreveram duas espécies de Rhinodoras. Sabaj Pérez \& Birindelli (2008) fizeram a revisão do gênero Doras com a descrição de três espécies. Birindelli et al. (2008) descreveram Leptodoras oyakawai com base no material dos rios Tapajós e Xingu. Piorski et al. (2008) descreveram Platydoras brachylechis a partir de exemplares dos rios do Nordeste Brasileiro e ressuscitaram $P$. hancockii, considerada como species inquirendae por Sabaj \& Ferraris (2003). Birindelli \& Sousa (2010) descreveram Leptodoras marki do rio Xingu. Sousa \& Birindelli (no prelo), revisaram o gênero Scorpiodoras, ressuscitando $S$. calderonensis e descrevendo uma espécie como nova. Com isto, a família Doradidae é atualmente constituída por 31 gêneros e 90 espécies válidas recentes e uma fóssil.

Entretanto, algumas questões referentes à sistemática da família ainda não estão satisfatoriamente resolvidas. Entre elas estão: a posição filogenética dos táxons mais basais da família (i.e., Wertheimeria, Kalyptodoras, Franciscodoras, Centrochir, Platydoras, Acanthodoras e Agamyxis); a relação entre as três tribos da subfamília Doradinae; e a relação entre espécies de Trachydoras e Nemadoras.

\subsection{Histórico taxonômico da família Auchenipteridae}


As espécies da família Auchenipteridae são conhecidas desde Linnaeus (1766), que descreveu duas espécies: Silurus inermis e $S$. galeatus. A terceira espécie de auchenipterídeo descrita foi S. nodosus Bloch, 1794. Ageneiosus Lacepède, 1803 foi o primeiro gênero, descrito para a espécie $A$. inermis e a então nova $A$. armatus (sinônimo de inermis). Lacepède (1803) ainda descreveu as espécies Pimelodus nodosus e $P$. galeatus, porém as colocou no então diversificado gênero Pimelodus. Spix \& Agassiz (1829) descreveram uma quarta espécie do grupo, Hypophthalmus nuchalis, alocando-a em Hypophthalmus. Poucos anos depois, Valenciennes, em Cuvier \& Valenciennes (1840), descreveu o gênero Auchenipterus para A. nuchalis, e Trachelyopterus para a nova espécie T. coriaceus. E Müller \& Troschel, em Müller (1842b), descreveram Euanemus colymbetes (sinônimo de Auchenipterus dentatus Valenciennes, 1840).

Durante o fim do século XIX e começo do século XX, muitos autores descreveram espécies e gêneros de auchenipterídeos (como, por exemplo, Jardine, 1841; Castelnau, 1855; Kner, 1858; Bleeker, 1858, 1864; Lütken, 1874; Cope, 1878; Steindachner, 1880, 1910, 1915; Eigenmann \& Eigenmann, 1888; Miranda Ribeiro, 1918), dentre os quais destacam-se Kner e Bleeker, pelo maior número de contribuições. De um modo geral, as espécies e gêneros de auchenipterídeos foram colocados em diversos táxons dentro de Siluriformes no fim do século XIX, desde Hypophthalmus, a pimelodídeos e até pangasiídeos. Foi apenas com Günther (1864) que os auchenipterídeos foram agrupados com os doradídeos. E apenas com Eigenmann \& Eigenmann (1890), que eles foram reunidos num grupo exclusivo, apesar de terem sido inicialmente divididos em Ageneiosinae e Auchenipterinae. Miranda Ribeiro (1911), revisando o grupo, dividiu-o em Trachycorystidae, Auchenipteridae e Ageneiosidae, o que não foi seguido por autores estrangeiros, como por exemplo, Eigenmann (1925) que continuou usando as famílias Auchenipteridae e Ageneiosidae. 
Em 1937, Rodolpho von Ihering, baseado na presença de "pseudo-pênis" e fecundação interna através de inseminação, propôs a reunião de Trachycorystes, Asterophysus, Pseudauchenipterus, Auchenipterichthys, Tatia e Ceratocheilus, na subfamília Trachycorystinae que, juntamente com Auchenipterinae, formariam a família Auchenipteridae, separada por sua vez de Ageneiosidae e Doradidae. Já Gosline (1945) e Fowler (1951) consideraram Auchenipterinae uma subfamília de Doradidae, junto com Doradinae (atualmente Doradidae), e Ageneiosidae uma família independente em Siluriformes. Entretanto, isto também não foi aceito e autores posteriores voltaram a usar Ageneiosidae e Auchenipteridae (ver, por exemplo, Greenwood et al., 1966; Chardon, 1968).

Paulo Miranda Ribeiro (1968a, 1968b, 1968c) revisou alguns gêneros e espécies de Auchenipteridae, focando principalmente nas mudanças relacionadas ao dimorfismo sexual, re-arranjando os gêneros de auchenipterídeos nas famílias Ageneiosidae (Ageneiosus, Tympanopleura), Auchenipteridae (Auchenipterus, Epapterus, Pseudepapterus), Trachycorystidae (Trachycorystes, Tetranematichthys, Auchenipterichthys), Centromochlidae (Centromochlus, Glanidium, Pseudauchenipterus, Entomocorus, Tatia) e Asterophysidae (Asterophysus).

Naquele momento, Britski (1972, fig. 3a) defendeu a primeira tese de doutorado voltada à este assunto, na qual ele estudou detalhadamente a anatomia e evolução dos auchenipterídeos, confirmando a presença de dimorfismo sexual para todas as espécies de auchenipterídeos e separando-as em duas famílias irmãs, Auchenipteridae e Ageneiosidae.

Quase concomitantemente, Mees (1974), sem conhecer o estudo de Britski, realizou uma revisão taxonômica das espécies de Auchenipteridae, com base principalmente no material procedente do Suriname. Ele considerou Auchenipteridae 
(Ageneiosidae não incluído) um grupo "natural” e, portanto, não viu motivo para manter as 4 famílias sugeridas por Miranda Ribeiro (1968b). Mees (1974) descreveu várias espécies e gêneros, além de transferir Arius oncinus para o gênero Liosomadoras, e este de Doradidae para Auchenipteridae.

Ferraris (1988, fig. 3b), já no paradigma cladístico, realizou uma análise filogenética de quase todos os gêneros de auchenipterídeos, propondo a distinção entre Centromochlidae e Auchenipteridae; e sugerindo que Ageneiosus e Tetranematichthys têm uma posição derivada dentro de Auchenipteridae, ou seja, Auchenipteridae não seria monofilética sem a inclusão de Ageneiosidae. Quase concomitantemente, Curran (1989, fig. 3c) numa análise problemática por ter incluído poucos caracteres e táxons, obteve um arranjo bastante diferente do de Ferraris. 


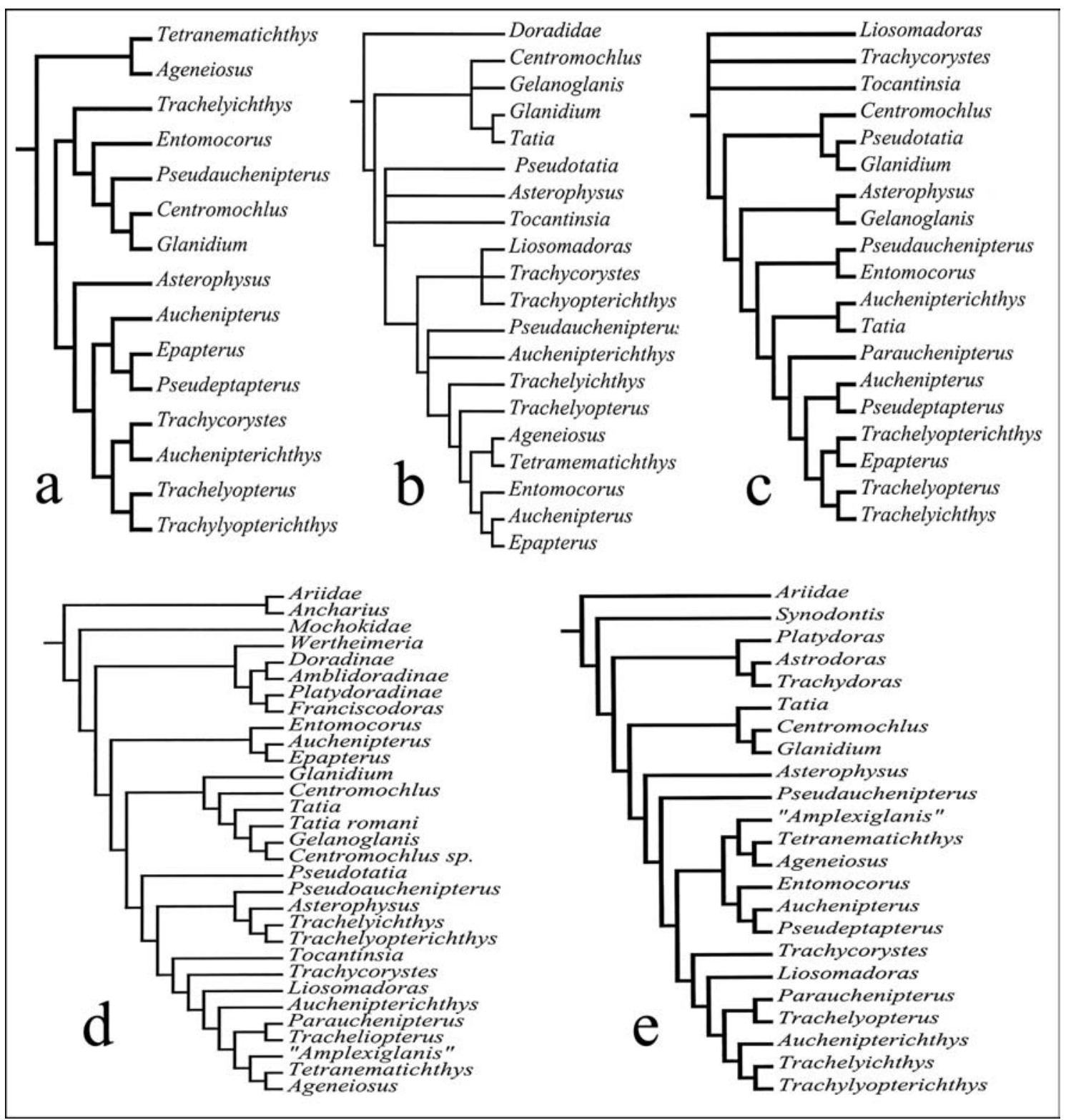

Figura 3. Hipóteses de relações filogenéticas entre os gêneros de Auchenipteridae, segundo: Britski, 1972 (a), Ferraris, 1988 (b), Curran, 1989 (c), Royero, 1999 (d), e Akama, 2004 (e).

Walsh (1990) fez uma análise filogenética das espécies do gênero Ageneiosus e de seu grupo irmão Tetranematichthys. Soares-Porto (1998) estudou as relações entre as espécies de Centromochlidae. Um ano depois, Royero (1999, fig. 3d) refazendo a análise de Ferraris, obteve uma hipótese bem diferente da de Ferraris. Mais recentemente, Akama (2004, fig. 3e) tentando posicionar Parauchenipterus e Trachelyopterus, re-analisou os caracteres de Ferraris e Royero, introduzindo vários 
caracteres relacionados a dimorfismo sexual, obtendo uma topologia ainda diferente da dos autores anteriores.

Os principais pontos de discordância entre todos estes estudos são: (1) a posição da subfamília Centromochlinae, considerada basal por Ferraris (1988) e Akama (2004), porém derivada por Britski (1972), Curran (1989) e Royero (1999); (2) a relação entre os clados (Entomocorus, Auchenipterus, Pseudepapterus e Epapterus) e ("Amplexiglanis", Tetranematichthys e Ageneiosus), considerados clados irmãos por Ferraris (1988) e Akama (2004), mas como grupos não relacionados por Britski (1972) e Royero (1999); (3) a posição dos táxons basais: Tocantinsia, Asterophysus, Pseudauchenipterus, Trachycorystes e Liosomadoras, considerados ora basais (Ferraris, 1988; Curran, 1989), ora derivados em diferentes níveis (Britski, 1972; Royero, 1999; Akama, 2004).

Simultaneamente aos estudos de filogenia, a taxonomia das espécies da família Auchenipteridae tem sido profundamente melhorada através de revisões taxonômicas de gêneros e descrições de algumas espécies. Ferraris \& Fernandez (1987) descreveram Trachelyopterichthys anduzei, rediagnosticando T. taeniatus. Walsh (1990) numa tese não publicada, fez uma extensa revisão taxonômica das espécies dos gêneros Ageneiosus, com 10 espécies válidas e 1 ainda não descrita, além de Tetranametichthys. Vari \& Ferraris (1998) revisaram o gênero Epapterus, com 2 espécies. Ferraris \& Vari (1999) revisaram o gênero Auchenipterus, descrevendo 2 espécies, além das 9 reconhecidas como válidas. Akama (1999), numa dissertação não publicada, revisou o gênero Pseudauchenipterus, com 4 espécies válidas. Ferraris \& Vari (2000) revisaram o gênero Pseudepapterus, descrevendo uma espécie e redescrevendo outras duas. Akama (2004), na sua tese de doutorado não publicada, revisou as espécies de Parauchenipterus e Trachelyopterus, reconhecendo os gêneros como válidos, apesar 
deles serem atualmente considerados sinônimos (Ferraris, 2007; Eschemeyer, 2010). Ferraris et al. (2005) revisaram o gênero Auchenipterichthys, reconhecendo 3 espécies válidas. Reis \& Borges (2006) descreveram uma espécie de Entomocorus e rediagnosticaram outras 3, sendo uma delas recentemente descrita (Akama \& Ferraris, 2003). Vari \& Ferraris (2006) descreveram uma espécie do então monotípico gênero Tetranematichthys. Sarmiento-Soares \& Martins-Pinheiro (2008) revisaram o gênero Tatia, com 12 espécies, incluindo 3 descritas pelos autores. E mais recentemente, Peixoto \& Wosiacki (2010) descreveram Tetranematichthys barthemi; e Ribeiro \& Rapp Py-Daniel (2010) descreveram Ageneiosus uranophthalmus. Com isso, a família Auchenipteridae apresenta atualmente aproximadamente 20 gêneros e 99 espécies válidas (Ferraris, 2007; Sarmento-Soares \& Martins-Pinheiro, 2008; Peixoto \& Wosiaki, 2010; Ribeiro \& Rapp Py-Daniel, 2010). 


\section{Capítulo 2. Objetivos}

1. Propor uma hipótese sobre as relações filogenéticas entre gêneros e espécies da superfamília Doradoidea.

2. Determinar a posição filogenética da superfamília Doradoidea entre as demais famílias de Siluriformes. 


\section{Capítulo 3. Materiais e métodos}

\subsection{Informações gerais e nomenclatura}

O estudo de anatomia foi realizado em exemplares preservados em álcool (para estudo de vísceras e miologia), e em exemplares diafanizados (seguindo o método de Taylor \& Van Dyke, 1985), ou preparados como esqueletos secos utilizando uma colônia de dermestídeos (para estudo osteológico).

A nomenclatura para a musculatura estriada segue Winterbottom (1974). A nomenclatura osteológica segue principalmente Weitzman (1962), e a tradução para o português feita por Castro \& Castro (1987) e modificada por Britto (2002: 13). Seguindo Fink \& Fink (1981), autopalatino é usado em vez de palatino, mesetmóide em vez de etmóide, vômer em vez de pré-vômer, epoccipital em vez de epiótico, póstêmporo-supracleitro em vez de supracleitro ou pós-temporal, faringo-branquial em vez suspensory pharyngeal, parieto-supra-occipital é usado em vez de supra-occipital (de Lundberg \& McDade, 1986) ou pós-parieto-supra-occipital (de Arratia, 2003a), ânguloarticular em vez de ângulo-artículo-retroarticular (de Nelson, 1973). O primeiro osso da série infra-orbital é chamado de infra-orbital 1, em vez de lacrimal (de Lundberg \& McDade, 1982), ou de antorbital (de Arratia \& Huaquin, 1995). Arratia \& Huaquin (1995: 25-26) sugeriam que esse elemento seria, na verdade, homólogo ao antorbital de outros peixes pela posição, por ser o primeiro elemento derivado do canal sensorial infra-orbital a se ossificar, e por conter o ramo antorbital do canal infra-orbital. Entretanto, o antorbital da grande maioria dos Teleostei não apresenta canal sensorial, e, em Siluriformes, o infra-orbital 1 se ossifica a partir de um centro de ossificação único sobre o canal infra-orbital e o ramo antorbital (observação feita no presente estudo em exemplares de Franciscodoras, MZUSP 97145, e Steindachneridion, MZUSP 90279), 
indicando que esse elemento é homologo a apenas um osso, ossificado sobre o canal infra-orbital. Isso também sugere que o osso antorbital está ausente em Siluriformes, apesar do ramo antorbital do canal sensorial estar presente. 'Endopterigóide' é usado em vez de mesopterigóide, e 'ectopterigóide' em vez de ectopterigóide, seguindo as recomendações de Arratia (1992). Processo posterior do cleitro é usado em vez de "processo umeral do cleitro" (Higuchi, 1992) ou "processo pós-cleitral” (Lundberg \& McDade, 1986). Basipterígio é usado em vez de osso pélvico, seguindo Shelden (1937) e Lundberg (1970). Cerato-hial anterior e cerato-hial posterior são usados em vez de cerato-hial e epi-hial, seguindo Vari (1983). Paruro-hial é usado em vez de uru-hial, seguindo Arratia \& Schultz (1990). O termo nódulo cartilaginoso é usado para a cartilagem acessória presente entre os epibranquiais 1 e 2 e o faringo-branquial 3 , seguindo Bockmann (1998: 132); esta estrutura foi erroneamente chamada de faringobranquial 2 ou faringo-branquiais 1 e 2 por diversos autores (e.g., Fink \& Fink, 1981; Mo, 1991; Higuchi, 1992; Reis, 1998a; Birindelli et al., 2008). Em Siluriformes, o supraneural e o primeiro e o segundo pterigióforos da nadadeira dorsal são expandidos dorsalmente como placas que formam o escudo cefálico, e são aqui denominadas placas nucais anterior, mediana e posterior, respectivamente. Em Doradidae, os túbulos da linha lateral são ossificados e expandidos em escudos, sendo nomenclaturalmente divididos em: escudos timpânicos (=três primeiras ossificações localizadas sob as placas nucais), escudo infranucal (=ossificação originada do quarto túbulo da linha lateral e do ligamento que se estende da placa nucal posterior à costela da sexta vértebra) e escudos laterais (=restante dos escudos, pós-infranucais) (Birindelli et al, 2007; Higuchi et al, 2007). As estruturas da bexiga natatória seguiram a terminologia apresentada por Birindelli et al. (2009: fig. 2). As abreviações usadas incluem: \# - caráter, CP comprimento padrão; todas as medidas de comprimento dos exemplares dadas referem- 
se ao CP.

A nomenclatura taxonômica seguiu a classificação mais recente, sumarizada por Ferraris (2007) e constantemente aperfeiçoada (ver Histórico Taxonômico), com exceção do conceito dos gêneros Trachelyopterus e Parauchenipterus, que seguiu Akama (2004). Todos os nomes ainda não formalmente disponíveis, seguindo o ICZN, foram citados entre aspas, como é o caso de "Amplexiglanis", proposto por Royero (1999: 238), e "Petalodoras", diagnosticado primeiramente por Higuchi (1992) e em fase de descrição (Birindelli \& Sabaj-Pérez, em preparação). De maneira similar, o grupo composto pelas espécies Nemadoras leporhinus, N. trimaculatus e Opsodoras ternetzi, diagnosticado previamente (Birindelli, 2006) como um gênero não descrito, foi tratado como "Nemadoras". E o gênero Hemidoras foi considerado sinônimo sênior de Opsodoras, como também havia sido sugerido anteriormente (Birindelli, 2006). A família Doradidae foi considerada como composta de três subfamílias: Astrodoradinae (sensu Higuchi et al., 2007), "Platydoradinae" (composta apenas por Centrochir e Platydoras), e Doradinae (sensu Higuchi, 1992), sendo esta última composta por três tribos: "Pterodoradini" (com Centrodoras, Doraops, Lithodoras, Megalodoras e Pterodoras), "Rhinodoradini" (com Orinocodoras, Rhinodoras e Rhynchodoras) e Doradini (sensu Higuchi, 1992). A família Auchenipteridae foi considerada como composta por duas subfamílias: Centromochlinae (sensu Ferraris, 1988; ver também Soares-Porto, 1998) e Auchenipterinae (sensu Ferraris, 1988), sendo esta última composta por duas tribos: Trachelyopterini (com Auchenipterichthys, Parauchenipterus, Trachelyichthys, Trachelyopterus, Trachycorystes e Trachelyopterichthys) e Auchenipterini (com Ageneiosus, "Amplexiglanis", Auchenipterus, Entomocorus, Epapterus, Pseudepapterus e Tetranematichthys). A nomenclatura da subordem Doradoidei e superfamília Doradoidea seguiu de Pinna (1998). 


\subsection{Material examinado}

A escolha dos táxons terminais foi feita com base no levantamento bibliográfico dos estudos de taxonomia e filogenia de cada família, bem como no estudo direto de espécimes de coleções de peixes (MZUSP, INPA, MNRJ, MCP, ANSP, USNM, CAS). De modo geral, foram escolhidos táxons com conhecida posição basal dentro de cada família (ou grupo), ou que apresentavam poucas modificações quando comparados à formas basais de outras famílias (ou grupos), e que apresentavam espécimes disponíveis para serem preparados para estudo de anatomia interna e osteologia. No total, 98 táxons terminais foram incluídos. A lista de material examinado segue no apêndice 1.

Cinquenta e cinco táxons da família Doradidae foram incluídos. Dentro da subfamília Doradinae, só não foram incluídas: Rhinodoras gallagheri e R. armbrusteri, recentemente descritas por Sabaj et al. (2007) e muito similares a R. boelhkei; Rhynchodoras xingui, recentemente redescrita por Birindelli et al. (2007); Oxydoras sifontesi, muito similar à Oxydoras niger; Doras micropoeus, relacionada à $D$. carinatus e D. higuchii, e D. zuanoni, relacionada à D. phlyzakion (Sabaj Pérez \& Birindelli, 2008); e oito das doze espécies de Leptodoras, gênero de monofiletismo bem corroborado (Sabaj, 2002; Sabaj, 2005; Birindelli et al., 2008; Birindelli \& Sousa, 2010). Dos demais doradídeos, foram incluídas uma espécie de cada gênero, com exceção da subfamília Astrodoradinae (Higuchi, et al., 2007), grupo de taxonomia complicada em estudo por Leandro M. Sousa, da qual foram incluídas apenas duas das aproximadamente 15 espécies válidas. Além dessas, Platydoras sp. "xingu", uma espécie ainda não descrita que apresenta característica presentes em Platydoras (como o colorido) e Centrochir (como o formato da bexiga natatória), foi também incluída.

Vinte e dois táxons da família Auchenipteridae foram incluídos. Foi incluída 
uma espécie de cada gênero, com exceção do gênero Gelanoglanis, cujas espécies são raras em coleções. Foram ainda incluídas duas espécies do gênero Ageneiosus, que possui um número relativamente grande de espécie e é bastante variado morfologicamente.

Para tentar posicionar a superfamília Doradoidea entre os Siluriformes, foram incluídas diversas outras famílias da ordem, cada uma delas representadas na matriz de caracteres por uma espécie, com exceção de Ariidae e Mochokidae. Para preencher as lacunas no conhecimento da variação anatômica destas famílias, dados da literatura foram utilizados (e.g., Arratia, 1987, para Diplomystidae). As famílias foram incluídas de acordo com as hipóteses de de Pinna (1998), Britto (2002), Diogo (2004) e Sullivan et al. (2006). Desta forma, foram incluídas as famílias: Diplomystidae, Nematogenyidae (representado a superfamília Loricarioidea), Ictaluridae, Amphiliidae, Pimelodidae, Pseudopimelodidae, Heptapteridae, Siluridae, Claroteidae, Pangasiidae, Malapteruridae, Erethistidae, Sisoridae, Aspredinidae, Ariidae e Mochokidae. Destas, Ariidae, considerada por alguns como possivelmente relacionada a Doradidae, Auchenipteridae e Mochokidae (Lundberg, 1993; Royero, 1999), foi representada por duas espécies, Galeichthys peruvianus e Genidens genidens, representando as duas subfamílias de Ariidae (Acero \& Betancur, 2007). E Mochokidae, considerado grupo irmão de Doradidae e Auchenipteridae (e.g., de Pinna, 1998), foi representada por cinco espécies: Chiloglanis disneyi, Mochokiella paynei, Mochokus niloticus, Synodontis batensi, Synodontis schall, incluindo táxons basais e representantes dos principais clados da família (Vigliotta, 2008).

\subsection{Análise filogenética}


As hipóteses sobre relações de parentesco foram inferidas de acordo com a metodologia cladística ou sistemática filogenética, originalmente proposta por Hennig $(1950,1966)$ e posteriormente discutida e aprimorada por outros autores (e.g. Wiley, 1981; de Pinna, 1991; Amorim, 2002).

A polarização dos estados de caráter foi inferida a partir do enraizamento entre o grupo interno (Siluriformes, exceto Diplomystes) e o grupo externo (Diplomystes). Diplomystidae foi escolhida como grupo externo, por ser considerada a família mais basal em Siluriformes, segundo diversos estudos morfológicos (ver, por exemplo, de Pinna, 1998). Os caracteres multi-estado foram tratados como ordenados sempre que denotavam uma variação morfoclinal, inferida de acordo com o grau de semelhança entre os estados. A delimitação dos estados de caracteres contínuos, como número de raios da nadadeira anal, número de costelas, número de vértebras e número de escudos laterais, foi feita a partir de uma tabela de distribuição dos dados; os limites entre os estados foram aqueles que separavam os táxons examinados em alguns poucos grupos.

A matriz de dados foi editada no programa MacClade, versão 4.08 (Maddison \& Maddison, 2005), e a análise de parcimônia realizada através do programa TNT (Goloboff et al., 2008). A busca empregada foi heurística, através do algoritmo TreeBisection-Reconnection (TBR), com 10.000 réplicas. A partir das árvores fundamentais encontradas, uma árvore de consenso foi obtida pelo método de consenso estrito. Através do próprio TNT, uma lista de sinapomorfias comuns à todas as árvores fundamentais foi gerada (Goloboff et al., 2008), e o valor de suporte de Bremer calculado (Bremer, 1994), usando o algoritmo TBR. Os índices de constância e retenção das árvores fundamentais foi calculado pelo TNT e o de cada caráter pelo MacClade. 


\section{Capítulo 4. Resultados}

\subsection{Caracteres}

\subsubsection{Morfologia externa}

1. Pálpebra adiposa bem desenvolvida: (0) ausente (fig. 4a-b); (1) presente (fig. 4c). CI: 0,50; RI: 0,88.

A presença de uma pálpebra adiposa bem desenvolvida é característica de várias espécies de Doradidae, como "Nemadoras", Hassar, Anduzedoras e as espécies basais de Leptodoras (L. oyakawai, L. marki, L. praelongus, L. copei e L. hasemani) (Sabaj, 2002: \#7; Birindelli, 2006: \#6). 


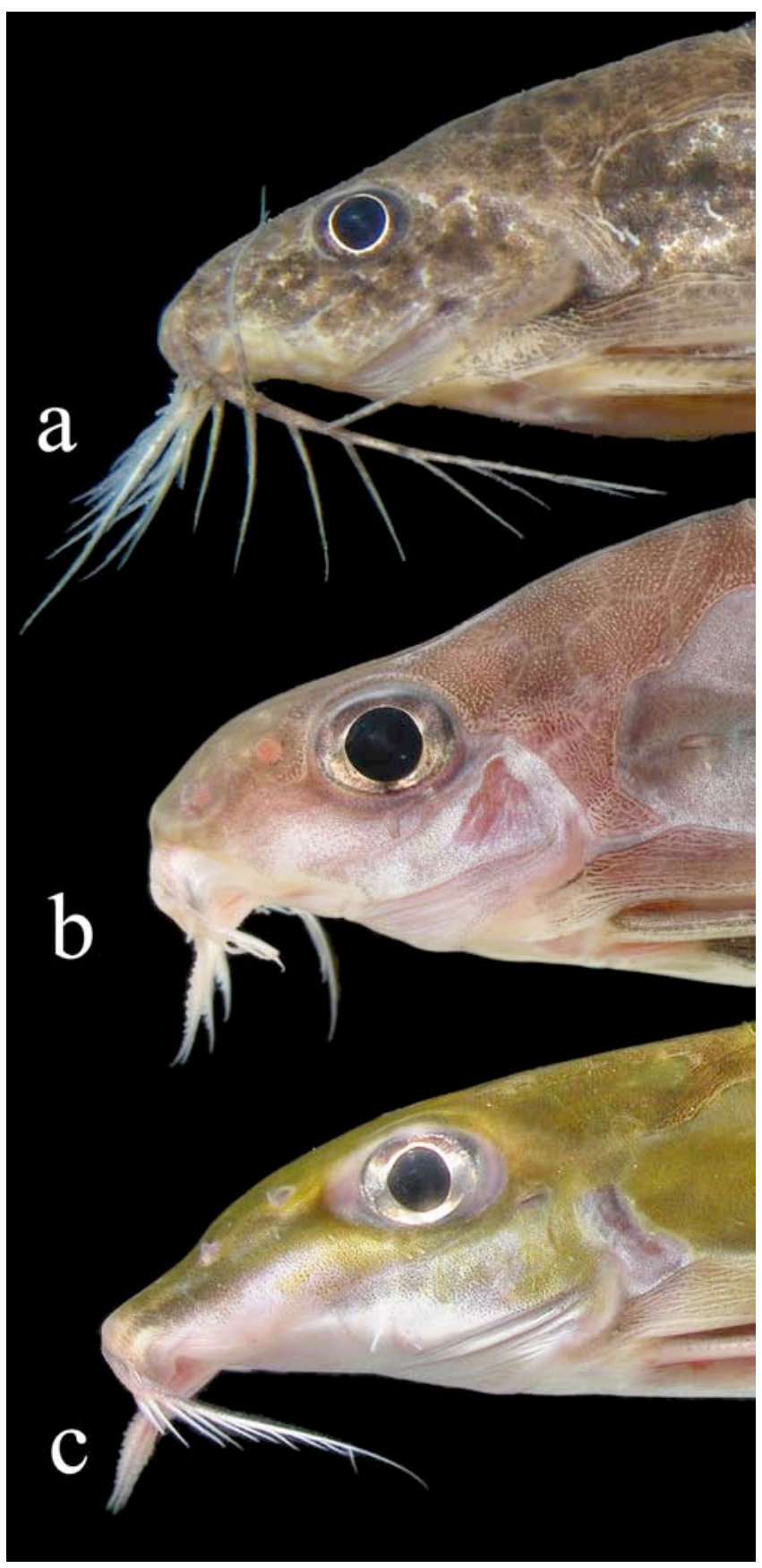

Figura 4. Cabeça, em vista lateral, de: Petalodoras aff. eigenmanni (a), MZUSP 92783 (c.60 mm) (foto por Leandro Sousa); Trachydoras brevis (b), MZUSP 103087 (c.70 mm); e Hassar orestis (c), MZUSP $103327(104.0 \mathrm{~mm})$.

2. Forma dos lábios: (0) finos, sem projeções látero-posteriores; (1) grossos, com projeções látero-posteriores (fig. 5a). CI: 1,00; RI: 1,00.

Os lábios em Rhinodoras e Orinocodoras são grossos e com projeções látero- 
posteriores (Birindelli, 2006: \#3; Sabaj et al., 2008), o que levou alguns autores a apelidarem esses táxons de thicklip thornycat (Sabaj et al., 2008).

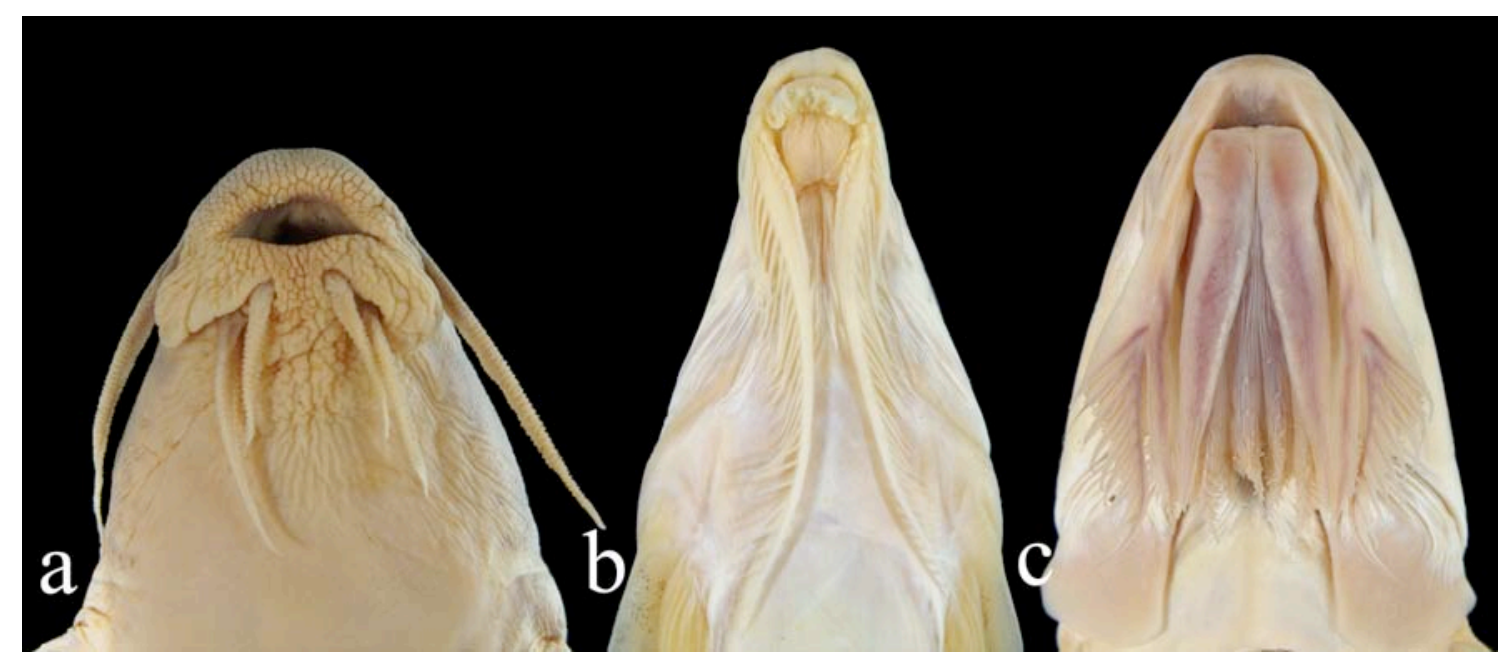

Figura 5. Boca, em vista ventral, de: Rhinodoras dorbignyi (a), MCP12419 (160.8 mm); "Nemadoras" trimaculatus (b), MZUSP 93421 (107.3 mm); Leptodoras hasemani (c), MZUSP 37009 (133.7 mm).

3. Nadadeira adiposa: (0) presente; (1) ausente. CI: 0,14; RI: 0,00.

A nadadeira adiposa está primitivamente presente em Siluriformes, apesar de estar ausente em alguns Loricarioidea, Cetopsiinae, Aspredinidae, Siluridae, Clariidae, Heteropneustidae, e diversas espécies de Schilbidae. Entre os Doradoidea, apenas os auchenipterídeos Epapterus, Trachelyichthys, Trachelyopterichthys e Trachelyopterus não possuem nadadeira adiposa (Ferraris, 1988: \#O2; Curran, 1989: \#12; Royero, 1999: \#143; Akama, 2004: \#186). Duas espécies do gênero Physopyxis podem não apresentar nadadeira adiposa, sendo, portanto, polimórficas para esse caráter (Eigenmann, 1925: 283; Sousa \& Rapp Daniel, 2005).

4. Forma da nadadeira adiposa (não ordenado): (0) longa e volumosa; (1) alongada anteriormente por uma quilha baixa; (2) curta em forma de gota. CI: 0,50; RI: 0,85 . 
Em muitas espécies de Siluriformes, como as de Diplomystidae, Sisoridae, Erethistidae, Pimelodidae (maioria), Pseudopimelodus, Heptapteridae, Malapteruridae, Claroteidae, Mochokidae, Ancharius e Galeichthys (entre outros gêneros de Ariidae, ver Marceniuk, 2003: \#186), a nadadeira adiposa é longa e volumosa, com a base aproximadamente do mesmo comprimento ou mais longa do que a da nadadeira anal. A mesma condição ocorre na maioria dos doradídeos e em todos os mochokídeos. Entretanto, alguns doradídeos, como Centrodoras, Megalodoras, e alguns exemplares de Centrochir e Platydoras, apresentam a nadadeira adiposa alongada anteriormente por uma quilha baixa, com a base mais longa do que a da nadadeira anal (característica já reconhecida por Eigenmann, 1925: 283). Por outro lado, Acanthodoras, Agamyxis, Astrodoradinae, Doradini (exceto Oxydoras), todos os auchenipterídeos e diversos Siluriformes, como Ictaluridae (Lundberg, 1970: \#1), Pangasiidae, Schilbidae e Genidens (entre outros ariídeos, Marceniuk, 2003: \#186), apresentam a nadadeira adiposa curta em forma de gota, com a base mais curta do que a da nadadeira anal.

Esse caráter foi codificado como inaplicável nos seguintes táxons: Epapterus, Trachelyichthys, Trachelyopterichthys, Trachelyopterus, Aspredinidae, Nematogenyidae, Siluridae, por não possuírem nadadeira adiposa. Centrochir $(0,1)$ e Platydoras $(1,2)$ foram codificados como polimórficos para esse caráter.

\section{Membrana branquial (não ordenado): (0) livre do istmo; (1) unida ao istmo} somente por um ponto; (2) unida ao istmo por uma área extensa (fig. 5); (3) unidas entre si e livres do istmo. CI: 0,50; RI: 0,73.

Entre os táxons estudados, Nematogenyidae, Ictaluridae, Pimelodidae, Pseudopimelodidae, Heptapteridae, Siluridae, Pangasiidae, Claroteidae e Amphiliidae possuem a membrana branquial livre do istmo (Britto, 2002: \#299). Diplomystidae, 
Eresthistidae e Sisoridae possuem a membrana branquial presa ao istmo apenas por um ponto. Em Aspredinidae, Auchenipteridae, Doradidae, Malapteruridae e Mochokidae (Vigliotta, 2008: \#92), a membrana é unida ao istmo por uma área extensa (Fig. 5); e em Anchariidae e Ariidae, as membranas branquiais são unidas entre si e livres do istmo, numa condição única em Siluriformes (Royero, 1999: \#114).

6. Distância entre as narinas anteriores e posteriores: (0) relativamente grande; (1) relativamente pequena. CI: 0,25 ; RI: 0,25 .

Dentre os táxons de Siluriformes estudados, apenas em Diplomystidae, Ariidae, Eresthistidae e Sisoridae, as narinas são próximas uma da outra (Mo, 1991; Britto, 2002: \#297).

\subsubsection{Barbilhões}

7. Capuz oral: (0) ausente; (1) presente (fig. 5c). CI: 1,00; RI: 1,00.

Como apresentado e discutido por diversos autores (Higuchi, 1992: \#A07, \#A08; Sabaj, 2002: \#8, \#9, \#10, \#11; Sabaj, 2005; Birindelli, 2006: \#15; Birindelli et al., 2008; Birindelli \& Sousa, 2010), em Anduzedoras e Leptodoras, a membrana labial é expandida posteriormente incorporando os barbilhões mentonianos, formando um capuz oral ("oral hood" de Sabaj, 2005). O capuz oral é mais desenvolvido nas espécies mais derivadas de Leptodoras (Birindelli et al., 2008).

8. Membrana dorso-lateral do barbilhão maxilar: (0) ausente; (1) presente. CI: 1,00; RI: 0,00.

A membrana dorso-lateral é uma extensão do barbilhão maxilar que está presente apenas nas espécies mais derivadas do gênero Leptodoras e, portanto, ausente em L. 
oyakawai, L. marki, L. praelongus, L. copei (Sabaj, 2002: \#12; Sabaj, 2005), assim como em Anduzedoras e nos demais táxons analisados.

9. Membrana medial do barbilhão maxilar: (0) ausente; (1) presente. CI: 1,00; RI: $\mathbf{0 , 0 0 .}$

O barbilhão maxilar possui uma membrana medial em Synodontis batensoda e $S$. membranaceus (anteriormente alocados em Brachysynodontis e Hemisynodontis, respectivamente) (Poll, 1971; Vigliotta, 2008: \#90).

10. Comprimento do barbilhão maxilar: (0) longo, barbilhão maxilar ultrapassando a margem anterior da órbita; (1) curto, barbilhão maxilar não alcançando a margem anterior da órbita. CI: 1,00; RI: 1,00.

Em Ageneiosus e Tetranematichthys, o barbilhão maxilar é pouco desenvolvido, e não alcança a margem anterior da órbita (Ferraris, 1988: \#J14; Royero, 1999: \#117; Akama, 2004: \#62). Nos demais táxons analisados, o barbilhão maxilar ultrapassa a margem anterior da órbita.

11. Barbelas na face ventral do barbilhão maxilar: (0) ausentes; (1) presentes (figs. 4-5). CI: 1,00; RI: 1,00 .

Todas as espécies de Doradini (exceto Oxydoras), possuem o barbilhão maxilar com barbelas em sua face ventral (Higuchi, 1992: \#6; Birindelli, 2006: \#11). Em Mochokidae, as únicas espécies que possuem barbelas na face ventral do barbilhão maxilar são Synodontis clarias e S. annectes (Poll, 1971), não incluídas no presente estudo. 
12. Barbelas na face dorsal do barbilhão maxilar: (0) ausentes (fig. 4b, c); (1) presentes (fig. 4a). CI: 1,00; RI: 1,00 .

Além das barbelas na face ventral do barbilho maxilar, "Petalodoras" aff. eigenmanni, "Petalodoras" eigenmanni e "Petalodoras" fimbriatus possuem ainda barbelas na face dorsal do mesmo barbilhão.

13. Movimentação do barbilhão maxilar: (0) ventral; (1) dorsal (fig. 6). CI: 1,00; RI: $\mathbf{1 , 0 0 .}$

Em Auchenipteridae, a movimentação do barbilhão maxilar é modificada num plano inclinado no qual o barbilhão é movido para cima (dorsalmente) (Ferraris, 1988: \#J12; Akama, 2004: \#60). Akama (2004) considerou a movimentação do barbilhão em Trachydoras steindachneri modificada látero-ventralmente, o que parece também ter sido visto por Eigenmann (1925: 297) para espécies de barbilhões com barbelas. Entretanto, como isto não pode ser verificado na maioria das espécies, esta característica não pode ser adequadamente estudada, e, por isso, não foi incluída no presente estudo.

14. Sulco suborbital para abrigar o barbilhão maxilar: (0) ausente; (1) presente (fig. 6). CI: 1,00; RI: 1,00.

As espécies de Auchenipteridae possuem um sulco suborbital para abrigar o barbilhão maxilar, quando este encontra-se junto ao corpo (Ferraris, 1998: \#J16; Curran, 1989: \#2; Royero, 1999: \#116; Akama, 2004: \#61), característica não encontrada em nenhum outro Siluriformes examinado. 


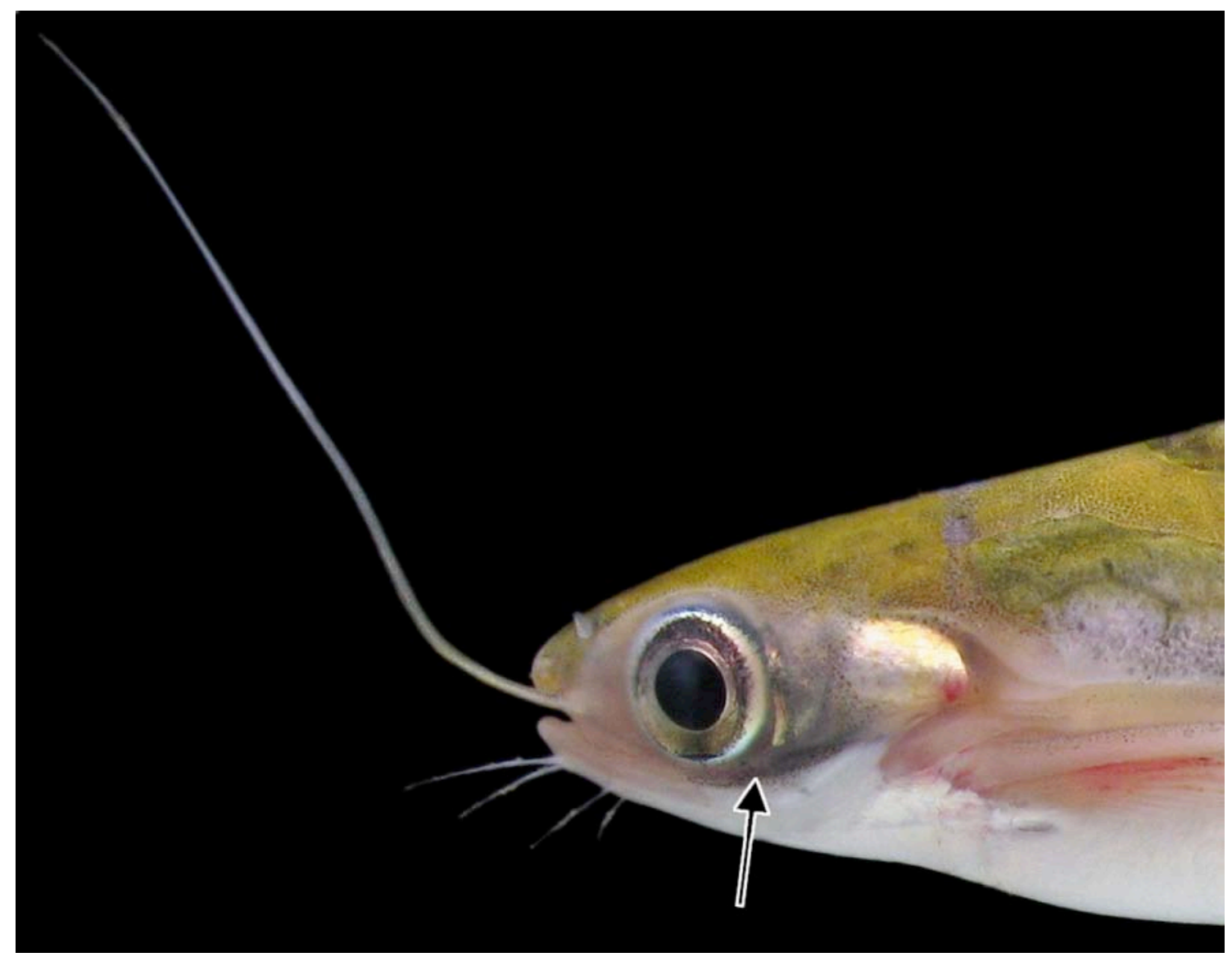

Figura 6. Cabeça, em vista lateral, de Centromochlus heckelii, MZUSP 104793 (100.0 mm). Seta indica o sulco suborbital.

15. Estrias nos barbilhões: (0) ausentes; (1) presentes (fig. 5a). CI: 1,00; RI: 1,00.

Nas espécies do gênero Rhinodoras, os barbilhões apresentam estrias transversais (Birindelli, 2006: \#16).

16. Número de pares de barbilhões mentonianos (ordenado): (0) nenhum, barbilhões mentonianos ausentes; (1) um par; (2) dois pares. CI: 0,40; RI: 0,57.

Dois pares de barbilhões mentonianos estão presentes na maioria dos Siluriformes. Entretanto, Gelanoglanis, Tetranematichthys, Pangasiidae e Nematogenys não possuem o par externo, e Ageneiosus, Astroblepidae, Loricariidae não têm nenhum dos dois pares (Britski, 1972: 11; Ferraris, 1988: \#J19, \#J22; Curran, 1989: \#23; Walsh, 
1990: \#20, \#21; Royero, 1999: \#118; Akama, 2004: \#63). Em Tetranematichthys, Ageneiosus e Pangasiidae essa ausência pode ser interpretada como uma perda relacionada ao modo de vida pelágico. Diplomystidae não possui barbilhões mentonianos, o que foi interpretado como uma condição primitiva (e não uma perda como nas demais famílias) por Arratia (1987). Em Trichomycteridae, Callichthyidae e Scoloplacidae o par de barbilhões mentonianos externo foi deslocado lateralmente, tendo sua base próxima à do barbilhão maxilar, e é chamado de barbilhão "rictal" por alguns autores (Baskin, 1973; Britto \& Lima, 2003: 84).

17. Número de fileiras de barbelas nos barbilhões mentonianos (não ordenado): (0) nenhuma, barbelas ausentes; (1) uma fileira; (2) duas fileiras. CI: 0,40; RI: 0,67.

"Petalodoras" aff. eigenmanni, "Petalodoras" eigenmanni, Mochokus e Mochokiella (Vigliotta, 2008: \#88, \#89), apresentam uma, e "Petalodoras" fimbriatus, Hemidoras (Birindelli, 2006: \#12) e os mochokídeos Microsynodontis e Synodontis (Vigliotta, 2008: \#89) possuem duas fileiras de barbelas nos barbilhões mentonianos. Nos demais táxons analisados não há barbelas nos barbilhões mentonianos.

Esse caráter foi codificado como inaplicável nos seguintes táxons: Diplomystidae, Ageneiosus (por não possuírem barbilhões mentonianos), e Chiloglanis (por possuí-los incorporados ao disco oral).

18. Comprimento dos barbilhões mentonianos (um em relação ao outro): (0) externo distintamente mais longo que interno (fig. 5a); (1) comprimentos semelhantes (figs. 4, 5b-c). CI: 0,50; RI: 0,97.

Os barbilhões mentonianos são aproximadamente de mesmo comprimento em Doradini (exceto Oxydoras) (Higuchi, 1992: \#8; Birindelli, 2006: \#13), e em 
Auchenipterus, Pseudepapterus e Epapterus. Nos demais Siluriformes estudados, os barbilhões mentonianos externos são distintamente mais longos que os internos.

19. Comprimento dos barbilhões mentonianos (em relação ao corpo): (0) curtos, não ultrapassando a base da nadadeira peitoral; (1) longos, ultrapassando a base da nadadeira peitoral. CI: 0,20 ; RI: 0,50 .

Barbilhões mentonianos longos, que ultrapassam a base da nadadeira peitoral, são encontrados em Auchenipterus, Entomocorus, Pseudauchenipterus, Pseudepapterus, Epapterus e Trachelyopterus (Curran, 1989: \#6; Akama, 2004: \#64). Essa característica está presente em diversos outros Siluriformes, como em espécies de Pimelodidae, Ariidae, Bagridae e Clariidae.

20. Posição da base dos barbilhões mentonianos: (0) bases relativamente separadas e oblíquas (em relação ao eixo do corpo), sendo a base do barbilhão mentoniano externo mais posterior; (1) bases próximas entre si, à sínfise mandibular e à borda do lábio inferior. CI: 1,00; RI: 1,00 .

Os barbilhões mentonianos possuem suas bases próximas entre si, à sínfise mandibular e à borda do lábio inferior em Auchenipterus, Epapterus e Pseudepapterus (Ferraris \& Vari, 1999; Ferraris, 1998: \#J18; Curran, 1989: \#13; Walsh, 1990: \#12; Royero, 1999: \#119; Akama, 2004: \#65).

21. União das bases dos barbilhões mentonianos: (0) ausente; (1) presente. CI: 1,00; RI: 1,00.

Em Rhynchodoras, os barbilhões mentonianos são unidos na base (Birindelli et al., 2007; Birindelli, 2006: \#14). 
22. Barbilhão nasal associado à narina posterior: (0) ausente; (1) presente. CI: 0,20; RI: 0,00.

Um par de barbilhões nasais associados às narinas posteriores está presente em Akysidae, Amblycipitidae, Bagridae, Chacidae, Clariidae, Claroteidae, Cranoglanidae, Eresthistidae, Ictaluridae, Pangasiidae, Plotosidae, Schilbidae e Sisoridae (Britto, 2003: 277). Um condição convergente está presente em Trichomycteridae e Nematogenyidae, nos quais há um par de barbilhões nasais associados às narinas anteriores (Lundberg, 1970; de Pinna, 1993: \#238; Britto, 2002: \#295).

\subsubsection{Pele e anexos dérmicos}

A presença de tubérculos dérmicos com células unculíferas é um caráter plesiomórfico para Ostariophysi, como discutido por Roberts (1982). Apesar de estarem ausentes em Diplomystidae (Arratia \& Huaquin, 1995), tais tubérculos estão presentes em diversas famílias de Siluriformes, como em Akysidae, Amphiliidae, Aspredinidae, Loricariidae, Mochokidae, Sisoridae (Wiley \& Collette, 1970; Collette, 1977; Roberts, 1982; de Pinna, 1996), Nematogenyidae, Pimelodidae, Trichomycteridae (Arratia \& Huaquin, 1995), Erethistidae (de Pinna, 1996), Doradidae (ver fig. 7), e possivelmente Auchenipteridae (Akama, 1999; Ferraris \& Vari, 1999; Akama, 2004), Ariidae (Kailola, 2004: 116), Pseudopimelodidae e Heptapteridae. Auchenipteridae é a única família de Siluriformes na qual os tubérculos podem ser, em alguns casos, chamados nupciais, por estarem relacionados à reprodução (ver caracteres abaixo). Em muitos casos, o tamanho, forma e distribuição dos tubérculos têm implicações taxonômicas e filogenéticas (e.g., Birindelli et al., 2007).

Vários grupos de Siluriformes apresentam escudos ósseos sobre o corpo, entre 
eles: algumas famílias de Loricarioidea (Loricariidae, Callichthyidae, Scoloplacidae, Astroblepidae) (Bailey \& Baskin, 1976: 4; Britto, 2002), Andersonia e Phractura (Doumeinae, Amphiliidae; Diogo, 2003: 425), Sisor (Sisoridae; de Pinna, 1996: 52), Hoplomyzontinae (Aspredinidae; Stewart, 1985) e Doradidae. Em cada um desses grupos, os escudos ósseos possuem características diferentes, indicando sua evolução independente. Os escudos laterais de Doradidae são ossificações formadas à partir dos túbulos da linha lateral (ver item "sistema látero-sensorial”). Apenas algumas espécies de doradídeos possuem escudos dérmicos não relacionados à linha lateral (veja caracteres a seguir).

23. Tubérculos dérmicos unculíferos: (0) pequenos, às vezes imperceptíveis; (1) grandes, visívies a olho nú (fig. 7). CI: 0,17; RI: 0,74.

Nos doradídeos Rhinodoras, Orinocodoras, Rhynchodoras, Pterodoras, Lithodoras, Megalodoras, Centrodoras, Oxydoras, Leptodoras myersi e L. juruensis (Sabaj, 2005; Birindelli, 2006: \#4), os tubérculos dérmicos são grandes (fig. 14). Outros grupos de Siluriformes, como Chiloglanis (Mochokidae), Astroblepidae, Amblycipitidae e algumas espécies de Pseudopimelodidae (i.e., Cephalosilurus fowleri e Lophiosilurus alexandri) possuem uma condição semelhante. Já as famílias Aspredinidae, Sisoridae, Akysidae e Eresthistidae possuem tubérculos dérmicos extremamente bem desenvolvidos (ver figs. 20, 21, 22 em Roberts, 1982). 


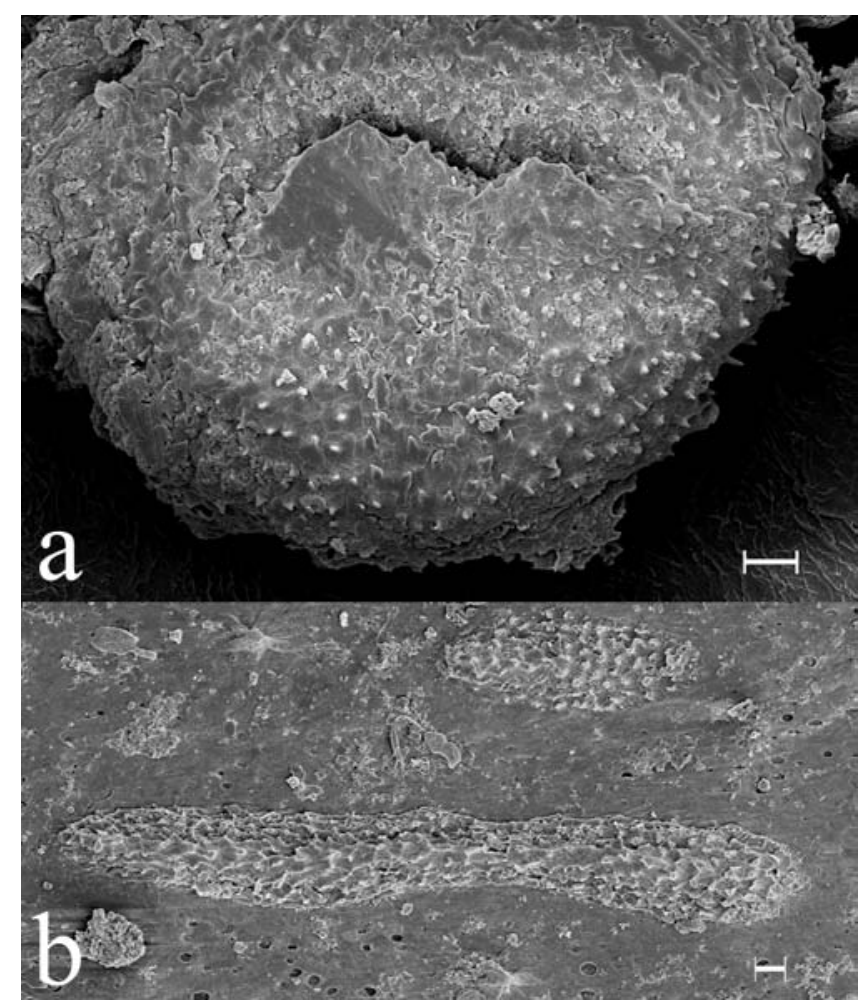

Figura 7. Tubérculos dérmicos, através de microscopia eletrônica de varredura, de: Rhinodoras dorbignyi (a), MZUSP 62688 (102 mm); e Leptodoras myersi (b), MZUSP 56676 (118.0 mm). Escala igual a 20 micrômetros.

24. Disposição dos tubérculos dérmicos unculíferos: (0) tubérculos independentes, não reunidos em placas; (1) tubérculos reunidos em placas. CI: 0,50; RI: 0,00.

As espécies das famílias Sisoridae, Akysidae e Eresthistidae possuem tubérculos dérmicos unculíferos extremamente bem desenvolvidos e reunidos em placas (ver figs. 20, 21 e 22A-C em Roberts, 1982).

Esse caráter foi codificado como inaplicável nos demais táxons examinados (exceto Rhinodoras, Orinocodoras, Rhynchodoras, Pterodoras, Lithodoras, Megalodoras, Centrodoras, Oxydoras, Leptodoras juruensis, Chiloglanis, Aspredinidae, Sisoridae, Erethistidae) pois eles não possuem tubérculos dérmicos. 
maduros: (0) ausentes; (1) presentes. CI: 0,50; RI: 0,00.

Tubérculos dérmicos sobre o acúleo da nadadeira dorsal de machos maduros estão presente apenas nos gêneros Entomocorus e "Amplexiglanis" (Akama, 2004: $\# 176)$.

26. Tubérculos dérmicos (nupciais) sobre o barbilhão maxilar de machos maduros: (0) ausentes; (1) presentes. CI: 0,50; RI: 0,80.

Em Entomocorus, “Amplexiglanis", Auchenipterus, Pseudepapterus, Epapterus e Tetranematichthys há tubérculos dérmicos sobre o barbilhão maxilar de machos maduros (Ferraris \& Vari, 1999; Akama, 2004: \#177).

27. Tubérculos dérmicos (nupciais) na superfície dorsal do crânio de machos maduros: (0) ausentes; (1) presentes. CI: 0,50; RI: 0,67.

Em Entomocorus, “Amplexiglanis”, Auchenipterus, Epapterus e Pseudepapterus há tubérculos dérmicos sobre a superfície dorsal do crânio de machos maduros. Estes tubérculos são cônicos e grandes nos dois primeiros táxons, pontuados em Auchenipterus, anostomosados em Pseudepapterus (ver Akama, 2004: \#178) e tracejados e pontuados em Epapterus.

28. Tubérculos dérmicos (nupciais) sobre o abdôme e região gular de machos maduros: (0) ausente; (1) presente. CI: 1,00; RI: 0,00 .

Entomocorus possui tubérculos dérmicos nupciais sobre o abdômen (Akama, 2004: \#179) e a região gular (Akama, 2004: \#180) de machos maduros.

29. Tubérculos dérmicos (nupciais) na extremidade do gonopódio de machos 


\section{maduros: (0) ausentes; (1) presentes. CI: 1,00; RI: 1,00 .}

Auchenipterus, Epapterus e Pseudepapterus possuem tubérculos na extremidade do gonopódio de machos maduros, sendo que em Auchenipterus os tubérculos são anastomosados formando faixas e nos outros dois táxons eles são pontuados e espaçados (Ferraris \& Vari, 1999; Akama, 2004: \#182).

\section{Tubérculos dérmicos em forma de papilas sobre a região timpânica: (0) ausentes; (1) presentes. CI: 1,00; RI: 0,00.}

As espécies de Pseudauchenipterus possuem tubérculos dérmicos em forma de papilas sobre a região timpânica, o que pode estar relacionado à tolerância a altas taxas de salinidade (Akama, 1999; Royero, 1999: \#148; Akama, 2004: \#183).

31. Múltiplos poros imediatamente ventrais ao processo posterior do cleitro: (0) ausentes; (1) presentes (fig. 8). CI: 0,25; RI: 0,86.

Múltiplos poros imediatamente ventrais ao processo posterior do cleitro foram descritos em Rhynchodoras (Birindelli et al., 2007), em Doras (Sabaj Pérez \& Birindelli, 2008: fig. 2), e são também encontrados em Trachydoras, Nemadoras, "Nemadoras", Hassar, Anduzedoras (Birindelli, 2006: \#7) e nas espécies mais basais de Leptodoras (L. marki, L. oyakawai, L. praelongus, L. copei, L. hasemani; Sabaj, 2002: \#30; Sabaj, 2005). Em Siluriformes há primitivamente um poro único na axila do processo posterior do cleitro ligado a uma glândula mucosa. Nos doradídeos mencionados acima, esse poro é acompanhado por um aglomerado de tecido glandular com múltiplas saídas. Assim como o poro único, a função dos múltiplos poros é produzir muco (Burgess, 1989: 201; obs. pess.). 


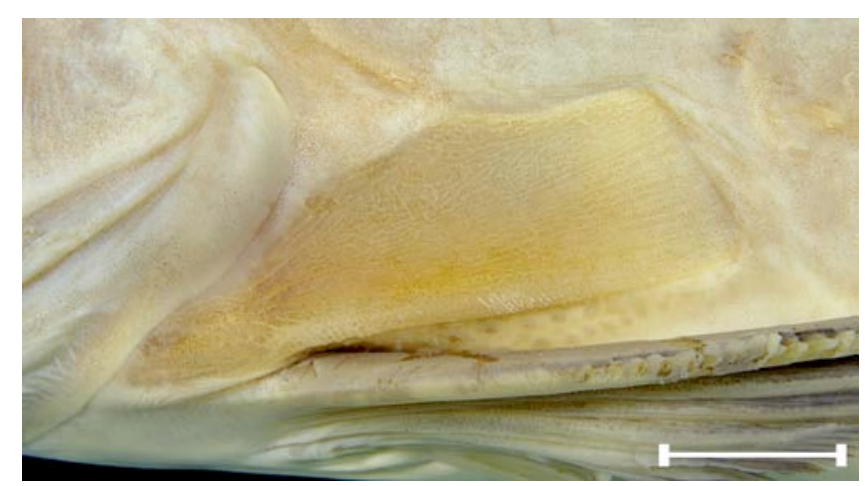

Figura 8. Processo posterior do cleitro em Doras micropoeus, ANSP 177880 (274.0 mm). Foto por Mark Sabaj Pérez. Escala igual a $10 \mathrm{~mm}$.

32. Múltiplos poros na parte ventral do corpo: (0) ausentes; (1) presentes (fig. 9). CI: 1,00; RI: 1,00 .

Múltiplos poros na parte ventral do corpo estão presentes nas espécies de Doras, sendo restritos à pele ao redor do ânus em D. carinatus, D. micropoeus e D. higuchii e espalhados sobre todo ventre em D. phlyzakion e D. zuanoni (Sabaj Pérez \& Birindelli, 2008; Birindelli, 2006: \#8). Tais poros assemelham-se em muito aos poros localizados sob o processo posterior do cleitro e, assim como estes, sua função deve estar relacionada à produção de muco. 


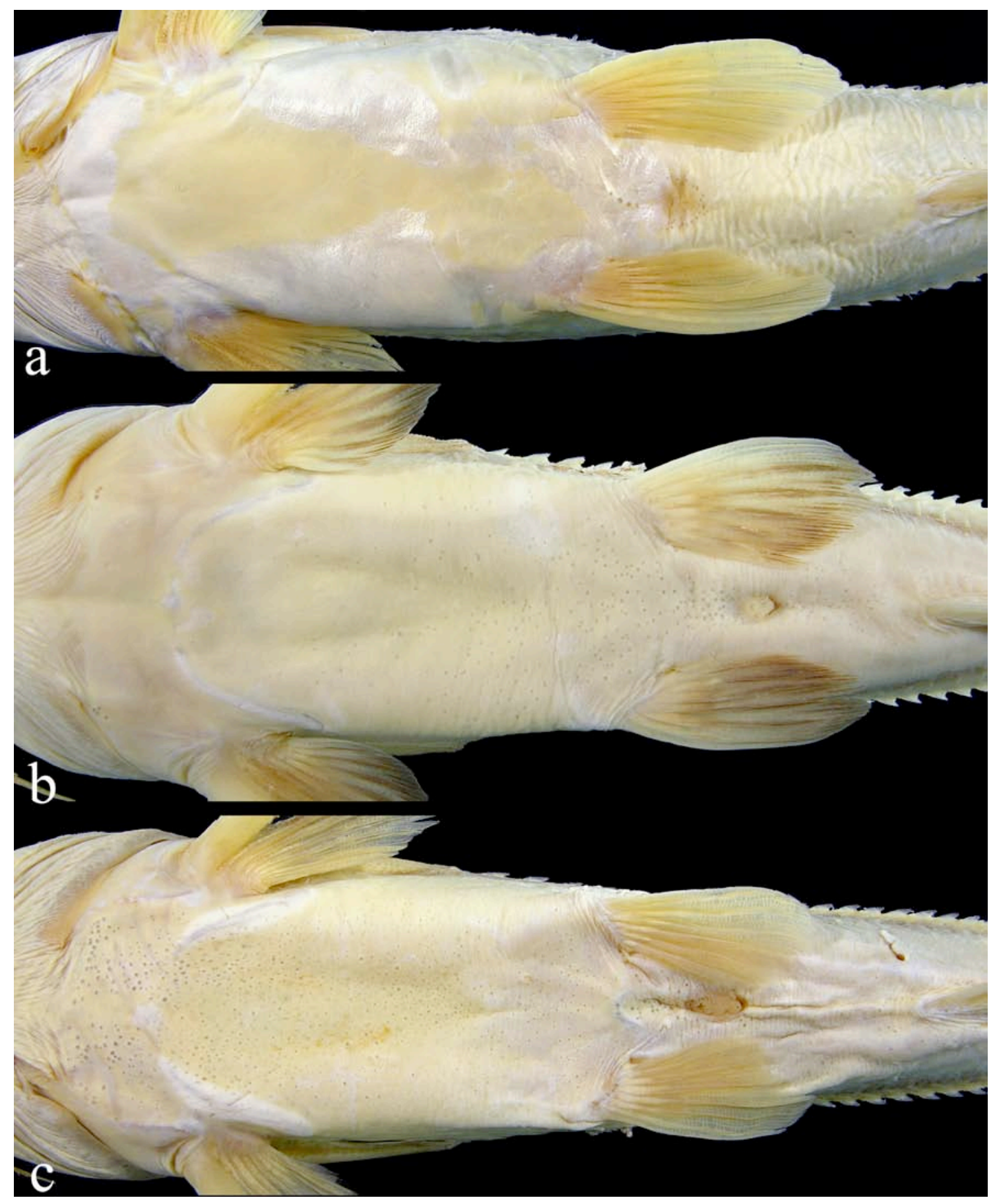

Figura 9. Porção ventral do corpo de: Doras higuchii (a), INPA 4052 (153.0 mm); D. zuanoni (b), INPA 5244 (124.0 mm); e D. phlyzakion (c), ANSP 181055 (169.0 mm).

33. Escudos ósseos entre as nadadeiras dorsal e adiposa e entre o ânus e a nadadeira anal: (0) ausentes; (1) presentes. CI: 0,50; RI: 0,00.

As duas espécies formalmente alocadas no gênero Hemidoras (sensu Ferraris, 
2007) possuem escudos ósseos dérmicos entre as nadadeiras dorsal e adiposa e entre o ânus e a nadadeira anal (Eigenmann, 1925: 346; Higuchi, 1992: \#A85; Birindelli, 2006: \#9). Em alguns exemplares de Hemidoras boulengeri (formalmente Opsodoras boulengeri, sensu Ferraris, 2007), incluindo o holótipo da espécie, há um escudo préadiposa, provavelmente homólogo à fileira de escudos presente em $H$. morrisi e $H$. stenopeltis (Birindelli, 2006).

34. Escudos ósseos cobrindo o corpo todo, nos exemplares de grande porte: (0) ausentes; (1) presentes. CI: 1,00; RI: 1,00 .

Em Lithodoras dorsalis, há escudos ósseos cobrindo todo o corpo, nos exemplares de grande porte (Eigenmann, 1925: 318; Higuchi, 1992: \#A84; Birindelli, 2006: \#10). Tais escudos possuem margens irregulares, formato mais ou menos estrelado, e se formam em exemplares relativamente pequenos $(15 \mathrm{~cm} \mathrm{de} \mathrm{CP})$, crescendo a partir de ossificações dérmicas independentes até se encontrarem e envolverem todo o corpo dos exemplares grandes (40 a $80 \mathrm{~cm}$ de $\mathrm{CP}$ ).

\subsubsection{Bexiga natatória}

Siluriformes é a ordem de peixes com maior diversidade morfológica na bexiga natatória e estruturas associadas, em especial no aparelho de Weber (Bridge \& Haddon, 1892: 66). Entre os autores que se propuseram a estudar a morfologia da bexiga natatória e estruturas anexas em Siluriformes, destacam-se Bridge \& Haddon (1892), Sörensen (1895) e Chardon (1968). Dentre os Siluriformes, Doradidae e Auchenipteridae são as famílias com maior diversidade morfológica de bexiga natatória (Birindelli et al., 2009; Marceniuk \& Birindelli, no prelo; Birindelli \& Shibatta, em preparação). Mesmo os primeiros estudos sobre a família Doradidae (e.g. Kner, 1854) já 
haviam anotado a incrível variação inter-especifica que existe. Birindelli et al. (2009) analisaram a bexiga natatória de praticamente todas as espécies da família Doradidae, ilustrando e descrevendo-as detalhadamente. Apesar da diversidade morfológica da bexiga natatória não ser tão grande nas demais famílias, esta é uma boa fonte da caracteres ainda sub-amostrada.

35. Tamanho da bexiga natatória: (0) bexiga natatória não reduzida em tamanho, como um todo; (1) bexiga natatória reduzida em tamanho, como um todo. CI: 0,33; RI: 0,50.

Nos doradídeos Rhynchodoras (Birindelli et al., 2007) e Leptodoras (exceto L. oyakawai e L. marki) (Sabaj, 2005; Birindelli et al., 2008; Birindelli \& Sousa, 2010), a bexiga natatória é reduzida em tamanho, ocupando um pequeno espaço na cavidade abdominal, e tem parede espessa (Sabaj, 2002: \#3, \#4; Birindelli, 2006: \#23; Birindelli et al., 2009: fig. 18). No gênero Ageneiosus, a bexiga natatória é normalmente desenvolvida em $A$. atronasus, A. brevis, A. pardalis e $A$. piperatus, e reduzida em tamanho nos demais congêneres (Bridge \& Haddon, 1892: 156; Chardon, 1968; Britski, 1972: 23; Ferraris, 1988: \#V9; Walsh, 1990: \#24; Royero, 1999: \#147; Akama, 2004: \#74). Outros táxons que possuem uma condição similar são: Rheoglanis dendrophorus (Bagridae, ver Chardon, 1968: fig. 35), Callophysus (Pimelodidae, Chardon, 1966) e Pinirampus (Pimelodidae, obs. pess.).

36. Ossificação da túnica externa da bexiga natatória: (0) ausente; (1) presente (fig. 54d). CI: 1,00; RI: 0,00.

Em Ageneiosus inermis, A. polystictus, A. ucayalensis, A. marmoratus, A. vittatus, A. militaris e Ageneiosus sp. (=Ageneiosus sp.n. sensu Walsh, 1990), a túnica externa 
da bexiga natatória é ossificada (fig. 54d). A ossificação da bexiga natatória em Ageneiosus é similar a que ocorre em Hypophthalmus (Chardon, 1968), entretanto a morfologia da bexiga natatória e das estruturas associadas é completamente diferente.

37. Forma da bexiga natatória (ordenado): (0) cordiforme (não modificada a um par bulbos laterais); (1) bexiga natatória parcialmente modificada a um par de bulbos laterais (fig. 10a); (2) bexiga natatória completamente modificada a um par de bulbos laterais (fig. 10b). CI: 0,29; RI: 0,44.

A bexiga natatória é modificada a um par de bulbos laterais em diversos táxons de Siluriformes. Bridge \& Haddon (1892) notaram que, em diversos táxons, há modificação da bexiga natatória e redução dos ossículos do aparelho de Weber, e reuniram esses táxons no grupo "Siluridae Abnormales" (vs. "Siluridae Normales" que reunia táxons com bexiga natatória e ossículos do aparelho de Weber normais).

Em Siluriformes, a bexiga parcialmente modificada a um par de bulbos laterais é característica de: Pseudopimelodus (Birindelli \& Shibatta, em preparação), Aspredinidae, Amphiliidae, Clariidae, Heteropneustidae, (Chardon, 1968), Cetopsidae (de Pinna et al., 2007) e Chiloglanidinae (Vigliotta, 2008: \#93). Já a bexiga completamente modificada a um par de bulbos laterais está presente em: Sisoridae, Erethistidae, Amblycipitidae, Hypophthalmus, Loricarioidea (Alexander, 1965: 426; Chardon, 1968; Arratia, 1992: \#53). Em dois grupos, há uma condição intermediária entre os estados 1 e 2 deste caráter. Em Akysidae (táxon não incluído no presente estudo) os bulbos laterais estão ligados apenas por um ligamento (remanescente da túnica externa), sem que haja ligação entre os espaços internos dos bulbos. Em Loricarioidea basais (como, por exemplo, Nematogenys, Trichomycteridae basais como Copionodon e Trichogenys, e Callichthyidae) e Amphiliidae há ligação entre os bulbos 
laterais por um canal ósseo imediatamente ventral à vértebra complexa (Britto, 2002: \#241). No presente estudo, estes táxons foram tratados como possuindo o estado 2 desse caráter. A redução do tamanho da bexiga natatória ocorreu em diversas famílias não relacionadas, possivelmente relacionada a adaptação à vida mais bentônica ou como uma compensação dos mecanismos respiratórios acessórios (Alexander, 1964: 438; Alexander, 1966: 147).

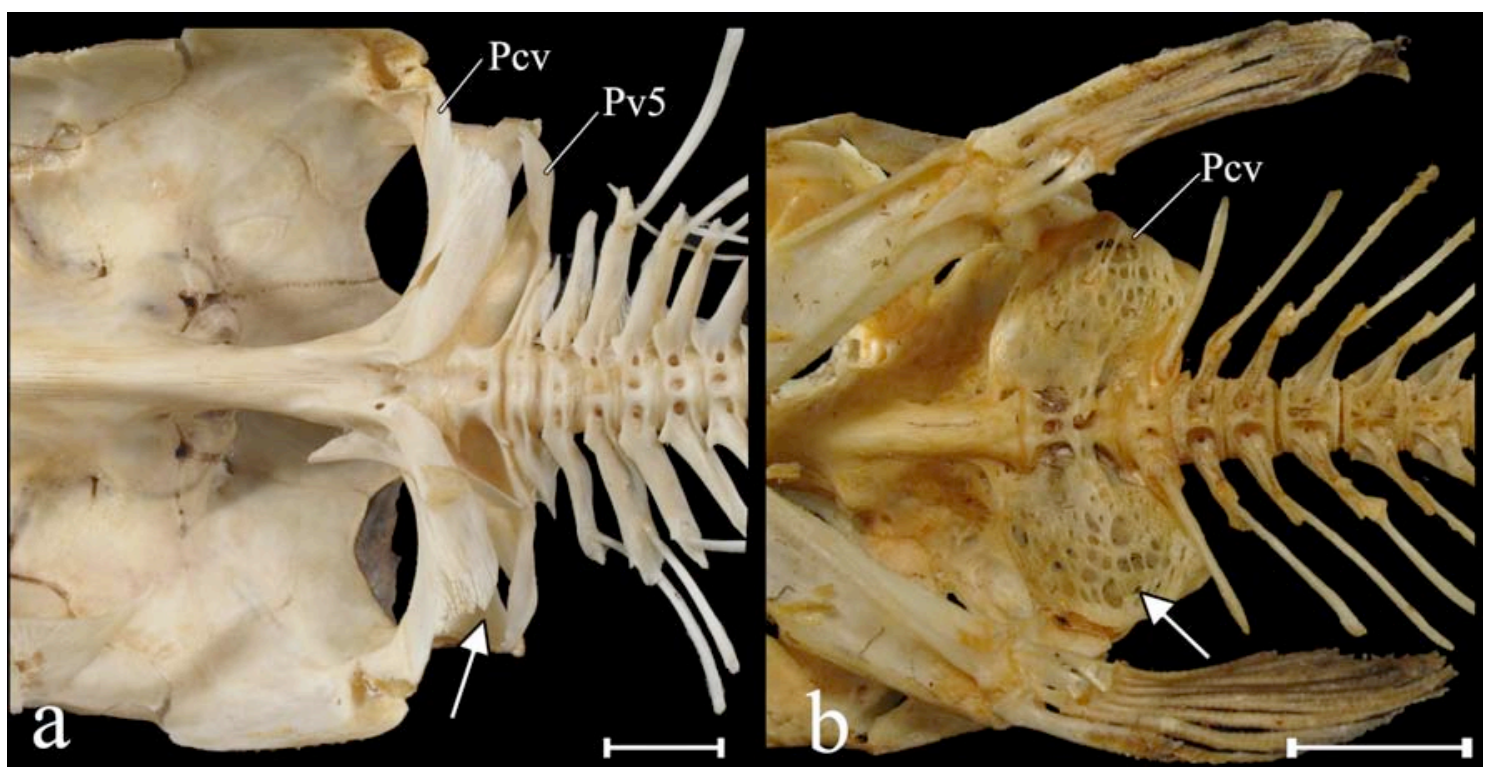

Figura 10. Região posterior do crânio e primeiras vértebras, em vista ventral, de: Clarias sp. (a), MZUSP 91656 (430.0 mm); e Nematogenys inermis (b), MZUSP 75256 (210.0 mm). Pcv: parapófise da vértebra complexa, Pv5: parapófise da quinta vértebra. Setas indicam local onde se localiza a bexiga natatória. Escala igual a $10 \mathrm{~mm}$.

38. Encapsulamento da bexiga natatória (não ordenado): (0) ausente; (1) bulbos laterais da bexiga natatória envolvidos pelas parapófises da vértebra complexa e (normalmente) da vértebra 5, sem participação dos ossos do crânio (fig. 10a); (2) bulbos laterais da bexiga natatória envolvidos pela parapófise da vértebra complexa, e dos ossos da porção posterior do crânio (fig. 10b). CI: 0,67; RI: 0,50.

O encapsulamento da bexiga natatória ocorre apenas nos táxons que possuem a 
bexiga natatória reduzida a bulbos laterais, e varia conforme a relação da capsula da bexiga natatória com a porção posterior do crânio. Em Cetopsidae (de Pinna et al., 2007), Clariidae, Heteropneustidae, Amphiliidae, Erethistidae, Sisoridae, Amblycipitidae e Akysidae os bulbos laterais da bexiga natatória são envolvidos pela expansão da parapófise da vértebra complexa, e na maioria dos casos, da parapófise da quinta vértebra (e sem paricipação dos ossos do crânio) (Alexander, 1964: 427; Chardon, 1968). Contudo, em Hypophthalmus e Loricarioidea os bulbos laterais da bexiga natatória são envolvidos pela expansão da parapófise da vértebra complexa e pelos ossos da porção posterior do crânio (Alexander, 1964: 428; Chardon, 1968; Arratia, 1992: \#54).

39. Divertículos terminais da bexiga natatória (não ordenado): (0) ausentes; (1) presentes e unidos; (2) presentes e distalmente separados. CI: 0,29; RI: 0,62.

Em várias espécies de Doradidae e Auchenipteridae, as câmaras láteroposteriores da bexiga natatória podem apresentar expansões posteriores sem constrição basal, definidas por Birindelli et al. (2009) como divertículos terminais. Tais divertículos podem estar completamente unidos, como em Acanthodoras, Agamyxis, Astrodoras, Hemidoras, Centromochlus heckelii e Trachycorystes trachycorystes, ou distalmente separados, como em Trachydoras, "Petalodoras" punctatus, Doras zuanoni (Birindelli, 2006: \#21) e Parauchenipterus (Akama, 2004: \#71).

Esse caráter não foi observado em Pseudotatia.

40. Câmara secundária da bexiga natatória (não ordenado): (0) ausente; (1) presente e com septo interno; (2) presente e sem septo interno. CI: 0,15; RI: 0,42.

Algumas espécies apresentam os divertículos terminais extremamente 
expandidos e com uma constrição basal, formando uma câmara secundaria ("secondary bladder" de Birindelli et al., 2009). Esta pode ser formada por ambas câmaras láteroposteriores e, portanto, com septo longitudinal, ou apenas pela câmara de um dos lados, e, portanto, sem septo interno. Entre Doradoidea, Scorpiodoras, Centrodoras, Megalodoras, Lithodoras, Pterodoras rivasi, Doraops, Orinocodoras, Rhinodoras thomersoni, R. dorbignyi, Auchenipterichthys, "Amplexiglanis" e Tetranematichthys possuem câmara secundária com septo (Brtiski, 1972: 33; Higuchi, 1992: \#114; Birindelli, 2006: \#17, \#20; Akama 2004: \#72); e Platydoras (exceto Platydoras sp. “xingu”), Oxydoras, Doras carinatus, D. micropoeus e D. higuchii a possuem sem septo interno. Uma câmara secundária é também encontrada em malapterurídeos (fig. 11a; Bridge \& Haddon, 1892: fig. 71), alguns ictalurídeos (Lundberg, 1970: \#91), pangasiídeos (fig. 11b; Bridge \& Haddon, 1892: fig. 93) e alguns pimelodídeos (ver por exemplo Lundberg \& Akama, 2005).

Esse caráter não foi observado em Pseudotatia.

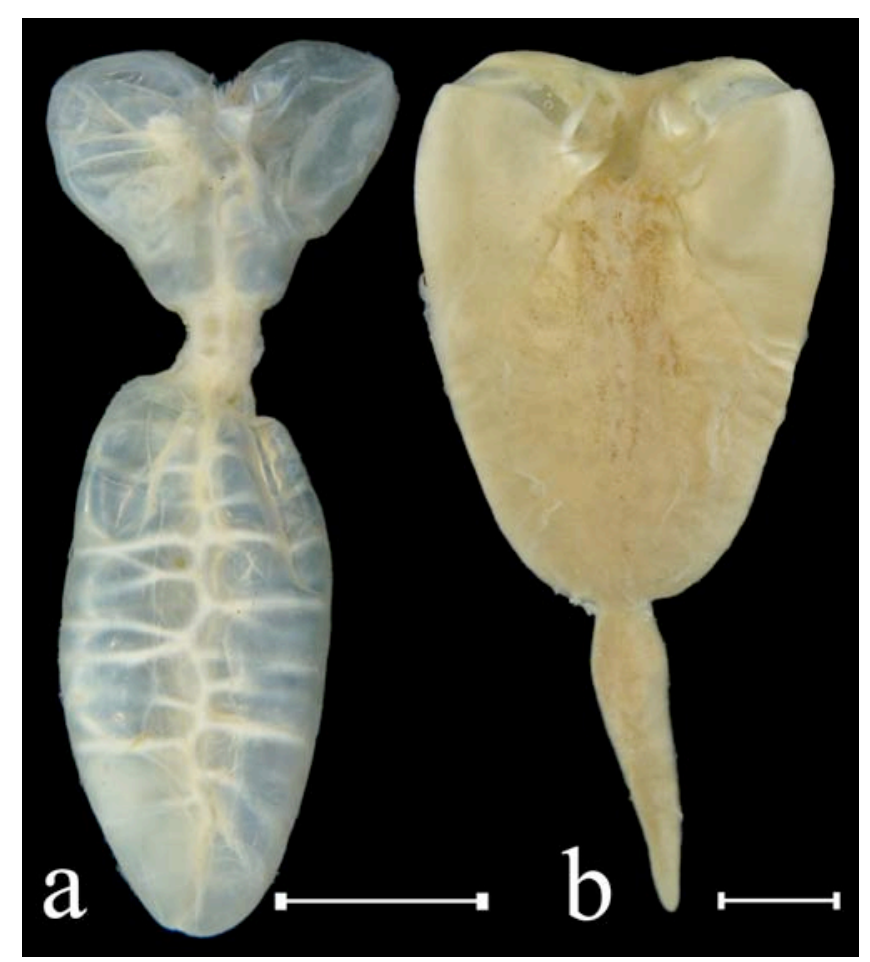

Figura 11. Bexiga natatória em vista dorsal em: Malapterurus beninensis (a), MZUSP 84464 (69.6 mm); 
e Pangasius pangasius, MZUSP $63587(130.0 \mathrm{~mm})$. Escala igual a $5 \mathrm{~mm}$.

41. Divertículo posterior da bexiga natatória (não ordenado): (0) ausente; (1) digitiforme, com constrição basal; (2) em forma de chifre, sem constrição basal; (3) extremamente bem desenvolvido e ramificado. CI: 0,38; RI: 0,38 .

Em Agamyxis, Doras phlyzakion, Tocantinsia e Trachycorystes a bexiga natatória apresenta um par de divertículos posteriores digitiformes com constrição basal (Birindelli et al., 2009; Sabaj Pérez \& Birindelli, 2008). Já em Rhynchodoras woodsi, Leptodoras (exceto L. marki e L. oyakawai) e Ageneiosus (exceto A. pardalis, A. ucayalensis), que apresentam bexiga natatória reduzida em tamanho, há um par de divertículos posteriores em forma de chifre, sem constrição basal (Walsh, 1990; Sabaj, 2002: \#5; Akama, 2004; \#71; Birindelli, 2006: \#23; Birindelli et al., 2007; Birindelli et al., 2009). Em Pterodoras granulosus há um par de divertículos extremamente grandes e ramificados (Birindelli et al., 2009).

Esse caráter não foi observado em Pseudotatia.

42. Trabéculas internas na bexiga natatória: (0) ausentes; (1) presentes. CI: 0,14; RI: $\mathbf{0 , 6 0 .}$

Trabéculas internas na bexiga natatória ocorrem na maioria dos doradídeos de médio a grande porte, como Pterodoras, Doraops, Lithodoras, Megalodoras, Rhinodoras, Orinocodoras e Oxydoras (Birindelli, 2006: \#26). Tais trabéculas também ocorrem em outros Siluriformes, como em algumas espécies de Bagridae (Bridge \& Haddon, 1892: fig. 18), Heptapteridae (Chardon, 1968: fig. 57), Pimelodidae (Bridge \& Haddon, 1892: fig. 34) e Ariidae (Bridge \& Haddon, 1892: fig. 44; Marceniuk \& Birindelli, no prelo). 
Esse caráter não foi observado em Pseudotatia.

43. Aparência da superfície ventral da bexiga natatória: (0) lisa; (1) com pregas. CI: 1,00; RI: 1,00.

Orinocodoras e Rhinodoras apresentam a superfície ventral da bexiga natatória com pregas, resultado dos septos internos bem desenvolvidos associados à pequena espessura da parede da bexiga natatória (Birindelli, 2006: \#24).

Esse caráter não foi observado em Pseudotatia.

44. Divertículos laterais na bexiga natatória: (0) ausentes; (1) presentes. CI: 0,14; RI: $\mathbf{0 , 8 4 .}$

Divertículos laterais na bexiga natatória ocorrem na maioria dos Doradinae (Higuchi, 1992: \#113, \#115; Sabaj, 2002: \#4; Birindelli, 2006: \#25). As exceções incluem Rhinodoras thomersoni, Rhynchodoras, "Petalodoras" punctatus, Leptodoras oyakawai, Doras carinatus, D. micropoeus, D. higuchii e D. phlyzakion. Em Auchenipteridae, tais divertículos ocorrem apenas em Asterophysus (Britski, 1972; Akama, 2004).

Esse caráter não foi observado em Pseudotatia.

45. Divertículos laterais na câmara secundária da bexiga natatória: (0) ausentes; (1) presentes. CI: 1,00; RI: 1,00 .

Em Pterodoras, Doraops, Megalodoras, Centrodoras e Lithodoras a câmara secundária da bexiga natatória apresenta divertículos laterais.

Esse caráter foi codificado como inaplicável em Siluriformes (exceto Malapteruridae, Auchenipterichthys, Tetranematichthys, Scorpiodoras, Doras 
carinatus, D. higuchii), por não possuírem câmara secundária. Esse caráter não foi observado em Pseudotatia.

46. Divertículo anterior na bexiga natatória: (0) ausente; (1) presente. CI: 0,33; RI: 0,75 .

Como definido por Birindelli et al. (2009), alguns divertículos laterais são caracterizados por possuírem localização precisa e serem maiores que os demais, permitindo traçar a homologia entre eles. Há um par de divertículos diferenciados na porção anterior da bexiga natatória em Centrodoras, Megalodoras, "Petalodoras" aff. eigenmanni e "Petalodoras" fimbriatus, Trachydoras microstomus, T. steindachneri, Hemidoras, Nemadoras, "Nemadoras", Hassar orestis e Anduzedoras (Birindelli, 2006: \#27).

Esse caráter foi codificado como inaplicável para os seguintes táxons: Rhynchodoras, "Petalodoras" punctatus, Doras, Leptodoras oyakawai e demais táxons analisados (exceto Asterophysus e Doradinae), por não possuírem divertículos laterais. Esse caráter não foi observado para Pseudotatia. "Petalodoras" eigenmanni $(0,1)$ foi codificado como polimórfico para esse caráter.

47. Divertículo ântero-lateral na bexiga natatória: (0) ausente; (1) presente. CI: 0,50; RI: 0,80 .

Um divertículo ântero-lateral distinto dos demais divertículos laterais está presente em Pterodoras, Doraops, Lithodoras, Centrodoras, Megalodoras, e nas espécies de Doradini (exceto "Petalodoras" punctatus, Doras carinatus, D. micropoeus, D. higuchii, Oxydoras e Leptodoras oyakawai) (Birindelli, 2006: \#28).

Esse caráter foi codificado como inaplicável para os seguintes táxons: 
Rhynchodoras, "Petalodoras" punctatus, Doras, Leptodoras oyakawai e demais táxons analisados (exceto Asterophysus e Doradinae), por não possuírem divertículos laterais. Esse caráter não foi observado para Pseudotatia. "Petalodoras" eigenmanni $(0,1)$ foi codificado como polimórfico para esse caráter.

48. Divertículos nas superfícies ventral e dorsal da bexiga natatória: (0) ausentes; (1) presentes. CI: 0,50; RI: 0,67.

Divertículos extremamente abundantes e presentes inclusive nas superfícies ventral e dorsal da bexiga natatória caracterizam Nemadoras elongatus, $N$. hemipeltis e N. humeralis (Birindelli, 2006: \#30), sendo que neste último táxon os divertículos são ligeiramente menos abundantes do que nos dois primeiros, principalmente em espécimes de menor porte. A mesma condição é encontrada no auchenipterídeo Asterophysus (Britski, 1972: 33; Akama, 2004: \#73).

\subsubsection{Gônadas e estruturas anexas}

As modificações encontradas no aparelho reprodutor estão relacionadas à fecundação interna através de inseminação e ao extremo dimorfismo sexual dos auchenipterídeos e foram primeiramente descritas por Ihering (1937), Britski (1978), Loir et al. (1989), e exaustivamente estudadas por Akama (2004). Estas modificações são únicas em Siluriformes.

49. Lóbulos posteriores do testículo (não ordenado): (0) semelhantes aos anteriores, sem modificações (fig. 12a-c); (1) modificados em bolsas armazenadoras hipertrofiadas (fig. 12d); (2) rudimentares ou ausentes (fig. 12e). CI:0,40-0,50; RI: 0,79-0,86. 
Os Siluriformes, no geral, apresentam lóbulos anteriores e posteriores doo testículo semelhantes (indiferenciados) e sobre o ducto principal tubular (Ihering, 1937; Britski, 1972: 35; Loir, 1989; Royero, 1999: \#120). Entretanto, a maioria dos auchenipterídeos (exceto Ageneiosus, Auchenipterus, Asterophysus, Centromochlus e Tatia) possui os lóbulos posteriores modificados em bolsas armazenadoras hipertrofiadas (Akama, 2004: \#142). Já em Ageneiosus e Auchenipterus os lóbulos posteriores são reduzidos ou ausentes.

Esse caráter não foi observado em Pseudotatia, Epapterus e Entomocorus. 


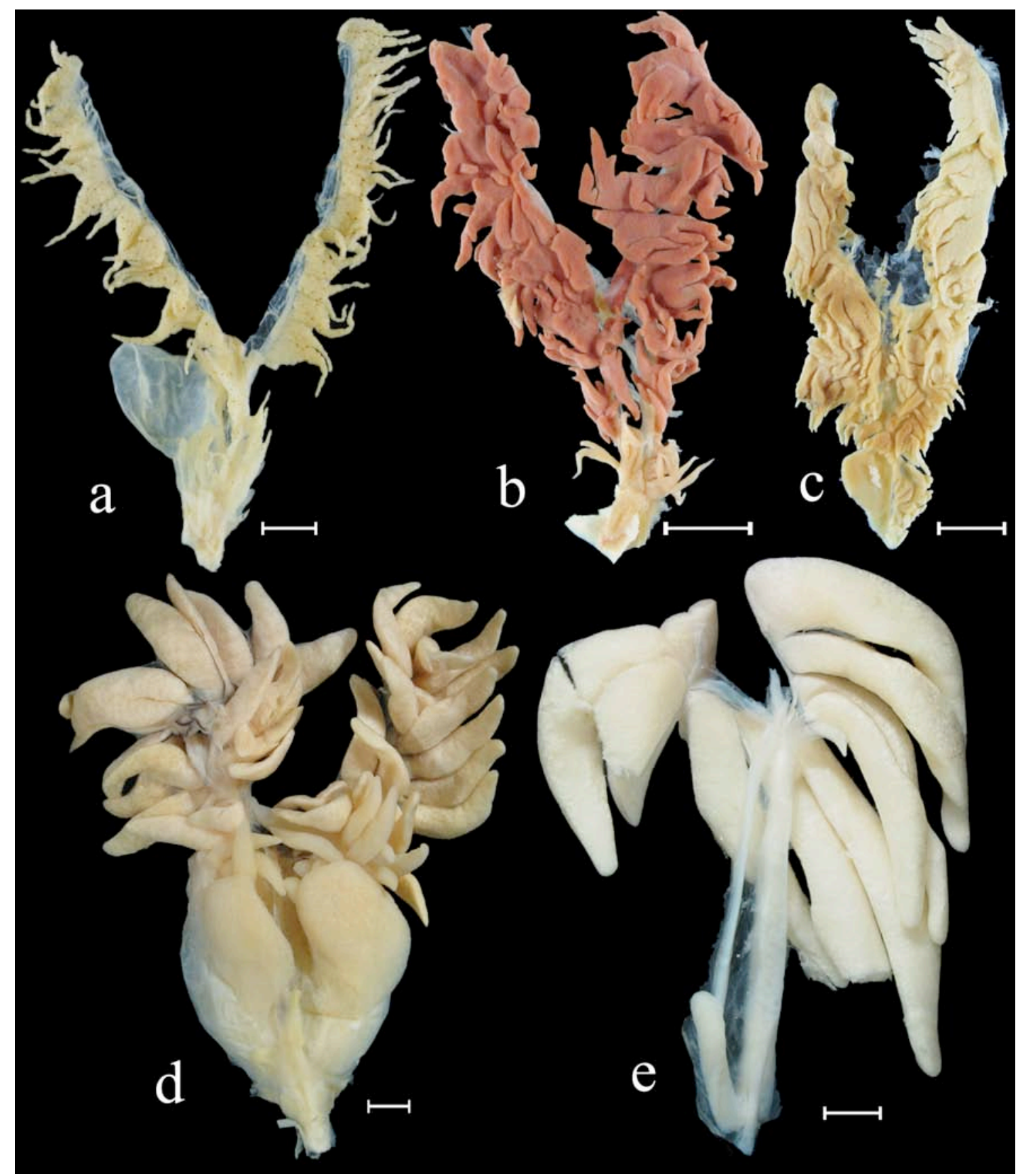

Figura 12. Testículos em vista ventral de: Wertheimeria maculata (A), MZUSP 93658 (173.0 mm); Acanthodoras cataphractus (b), MZUSP 6831 (116.0 mm); Hemidoras morei (c), MZUSP 31104 (166.0 mm); Parauchenipterus striatulus (c), MZUSP 90742 (154.0 mm); Ageneiosus ucayalensis (d), MZUSP $98333(165.0 \mathrm{~mm})$. Escala igual a $5 \mathrm{~mm}$.

50. Ducto principal do testículo: (0) tubular (sem modificação); (1) modificado numa vesícula armazenadora. CI: 0,50; RI: 0,50. 
Em Asterophysus, Centromochlus e Tatia, o ducto principal do testículo é modificado numa vesícula armazenadora (Akama, 2004: \#142).

Esse caráter não foi observado em Pseudotatia, Epapterus e Entomocorus.

51. Posição da abertura urogenital em machos (ordenado): (0) próxima ao ânus; (1) na base da nadadeira anal (fig. 13a); (2) na extremidade do raios anteriores da nadadeira anal (figs. 13b-f). CI: 1,00; RI: 1,00.

A maioria dos auchenipterídeos possui o tubo urogenital longo, carnoso e com abertura na extremidade dos raios anteriores da nadadeira anal (Ihering, 1937; Britski, 1972: 36; Ferraris, 1988: \#A12, \#A3; Royero, 1999: \#121, \#122, \#125 Akama, 2004: \#143). Entretanto, os Centromochlinae apresentam a abertura localizada na base da nadadeira anal (Soares-Porto, 1998; Reis \& Borges, 2006). Em Entomocorus a abertura urogenital de machos maduros está localizada numa papila que segue paralela até aproximadamente a metade da margem anterior da nadadeira anal (Reis \& Borges, 2006), numa condição similar a encontrada em exemplares machos não completamente maduros de algumas outras espécies de Auchenipterinae, como Asterophysus ou Liosomadoras. Os demais Siluriformes apresentam o tubo urogenital curto, com a abertura próxima ao ânus. 


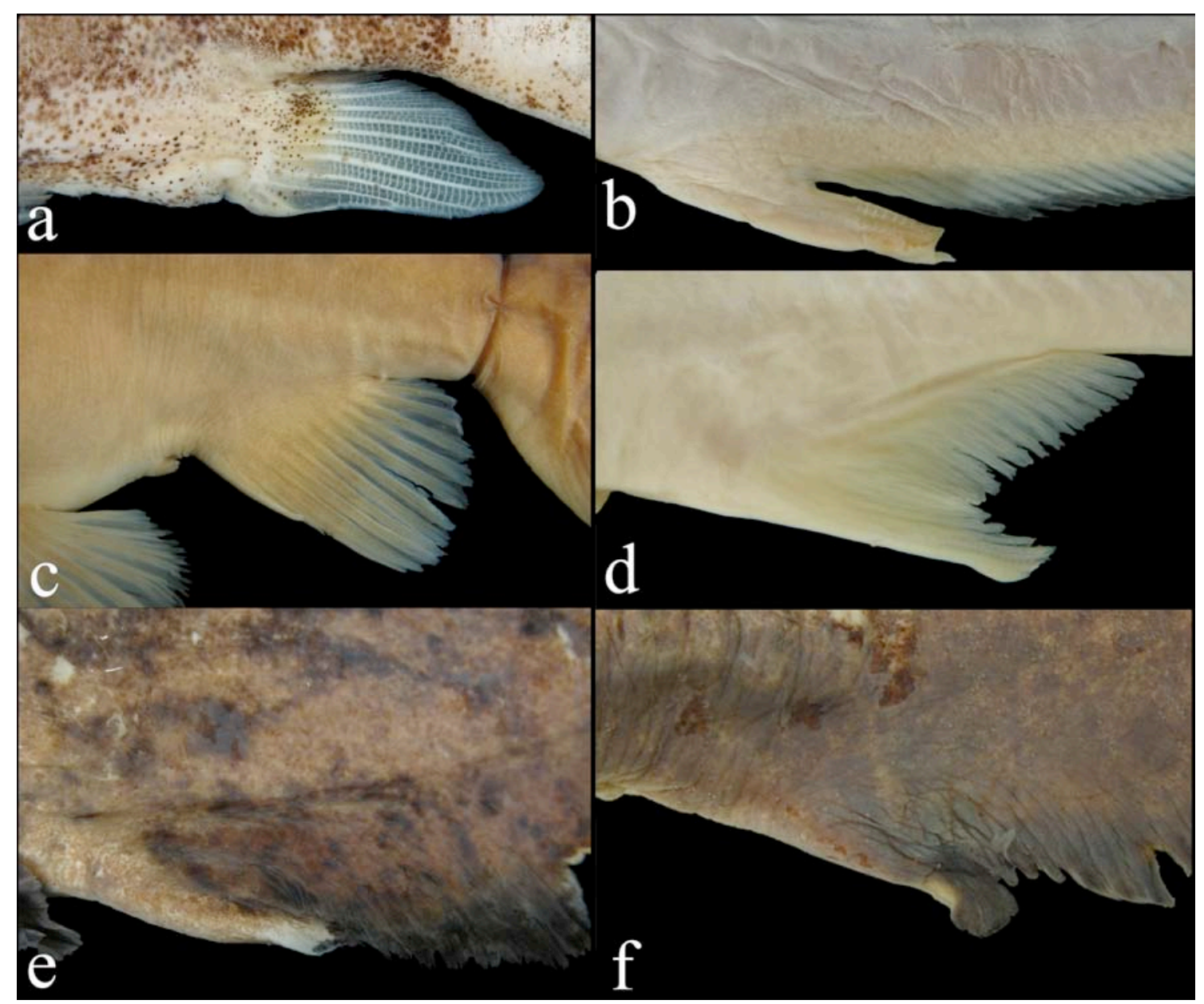

Figura 13. Nadadeira anal de machos maduros (a-b,d-f) e em maturação (c) de: Glanidium melanodermatum (a), MZUSP 64256 (105 mm); Epapterus dispilurus (b), MZUSP 26183 (107.0 mm); Asterophysus batrachus (c), MZUSP 12420 (129.7 mm); Pseudauchenipterus jequitinhonhae (d), MZUSP 51734 (100.9 mm); Parauchenipterus galeatus (e), MZUSP 90831 (138.0 mm); e Trachelyopterus sp. (f), MZUSP 79345 (106.3 mm).

52. Forma da abertura urogenital de machos maduros: (0) arredondada; (1) estreita, como uma fenda longitudinal. CI: 1,00; RI: 1,00.

Em Auchenipterus, Pseudepapterus e Epapterus a abertura urogenital de machos é estreita, como uma fenda longitudinal (Akama, 2004: \#149).

Esse caráter não foi observado em Pseudotatia. 
53. Vesícula terminal no gonopódio de machos maduros: (0) ausente (fig. 13a-c,ef); (1) presente (fig. 13d). CI: 1,00; RI: 0,00.

Em Pseudauchenipterus, há uma vesícula terminal no gonopódio de machos maduros (Akama, 2004: \#149).

Esse caráter foi codificado como não aplicável na maioria dos táxons analisados (exceto Auchenipteridae), por não possuírem gonopódio. Esse caráter não foi observado em Pseudotatia.

54. Espaço entre o gonopódio e o restante da nadadeira anal: (0) ausente (fig 13a,cf); (1) presente (fig. 13b). CI: 1,00; RI: 0,00.

Em Epapterus há um espaço separando o gonopódio do restante da nadadeira anal.

Esse caráter foi codificado como não aplicável na maioria dos táxons analisados (exceto Auchenipteridae), por não possuírem gonopódio. Esse caráter não foi observado em Pseudotatia.

55. Aba na extremidade do gonopódio: (0) ausente (fig. 13a-e); (1) presente (fig. 13f). CI: 1,00; RI: 0,00 .

Em Trachelyopterus há uma aba na extremidade do gonopódio formada pela expansão dos primeiros raios ramificados da nadadeira anal (Akama, 2004: \#151).

Esse caráter foi codificado como não aplicável na maioria dos táxons analisados (exceto Auchenipteridae), por não possuírem gonopódio. Esse caráter não foi observado em Pseudotatia.

56. Largura da abertura urogenital em fêmeas: (0) estreita (figs. 14a-c); (1) larga, 
modificada para inseminação (figs. 14d-f). CI: 0,50; RI: 0,95.

A abertura urogenital alargada em fêmeas, modificada para inseminação é uma característica da maioria das espécies de Auchenipteridae (exceto Centromochlus e Tatia) (Royero, 1999: \#124; Akama, 2004: \#144).

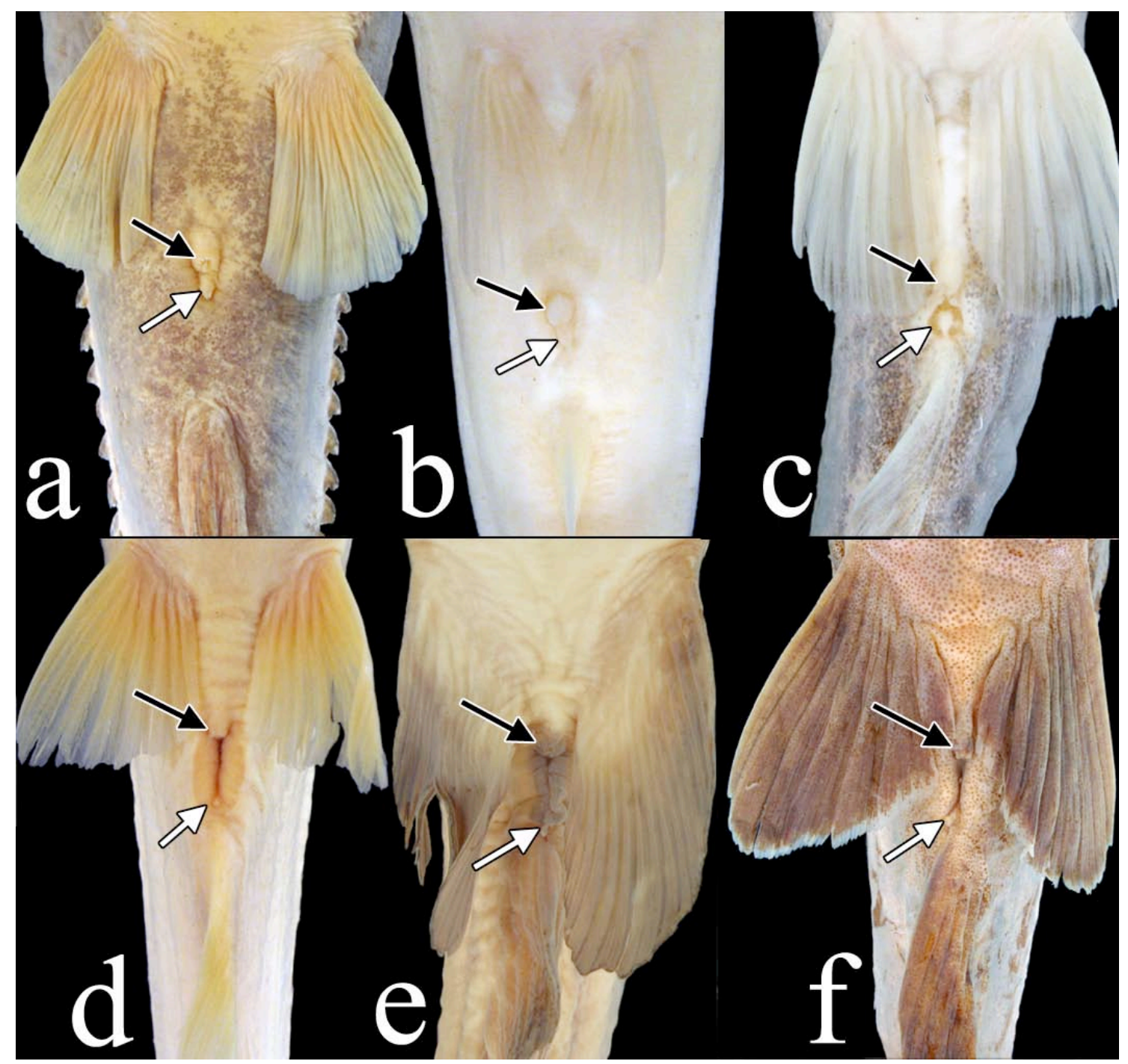

Figura 14. Aberturas anal e urogenital em vista ventral em: Franciscodoras marmoratus (a), MZUSP 95398 (190.0 mm); Centromochlus heckelii (b), MZUSP 104793 (106.0 mm); Tatia intermedia (c), MZUSP 104786 (102.0 mm); Pseudauchenipterus affinis (d), MZUSP 93092 (112.0 mm); Trachelyopterichthys taeniatus (e), MZUSP 8496 (113.0 mm); Tetranematichthys wallacei (f), MZUSP $85497(191.0 \mathrm{~mm})$. Seta preta indica a abertura anal e seta branca a papila urinária. 
57. Posição da abertura urogenital em fêmeas: (0) aproximadamente no meio do espaço entre as nadadeiras pélvica e anal (figs. 14a-b); (1) imediatamente anterior à nadadeira anal (figs. 14c-f). CI: 0,50; RI: 0,95 .

A abertura urogenital nas fêmeas das espécies de Auchenipteridae (exceto em Centromochlus heckelli e C. existimatus) localiza-se imediatamente anterior à nadadeira anal, enquanto que em outros Siluriformes, ela fica aproximadamente no meio do espaço entre as nadadeiras pélvicas e a anal.

58. Forma da borda da abertura urogenital de fêmeas (não ordenado): (0) fina (figs. 14a-c,f); (1) espessa e marcada (em relação a pele no entorno) (fig. 14d); (2) espessa e intumescida (fig. 14e). CI: 1,00; RI: 0,00.

Pseudepapterus apresenta a abertura urogenital das fêmeas com borda espessa e marcada, distinta em relação a pele no entorno, e Trachelyopterichthys apresenta a abertura com borda espessa e intumescida (Akama, 2004: \#145). Os demais táxons examinados, possuem a borda da abertura urogenital fina, nas fêmeas.

\subsubsection{Neurocrânio}

59. Origem do músculo adductor mandibulae: (0) na crista cefálica mediana (parieto-supra-occipital) (fig. 15); (1) no ossos laterais do crânio (esfenótico, pterótico) (figs. 16-34). CI: 0,50; RI: 0,67.

Em algumas famílias de Siluriformes, como em Diplomystidae, Cetopsidae, Nematogenyidae, Ictaluridae e Malapteruridae, o músculo adductor mandibulae origina-se na crista cefálica mediana (no parieto-supra-occipital) e cobre os ossos laterais do crânio (esfenótico, pterótico) (Alexander, 1965: 103; Lundberg, 1970: 25; de Pinna et al., 2007: \#7). Entretanto, nas demais famílias de Siluriformes estudadas o 
crânio é livre dessa musculatura, que se origina apenas na borda dos ossos laterais do crânio: esfenótico e pterótico. A extensão da musculatura sobre o teto do crânio varia, sendo que Ictaluridae possui uma porção do crânio coberta por musculatura menor do que em Diplomystidae e Nematogenyidae.

60. Forma do mesetmóide (não ordenado): (0) em forma de $X$ (figs. 15, 17, 19, 20 , 33); (1) quadrangular, largo (figs. 16, 18, 29-32, 34); (2) ponteagudo, com dilatação mediana (figs. 21-28). CI: 0,33; RI: 0,93.

Em Siluriformes, no geral, o mesetmóide apresenta a forma de X, com dois ramos anteriores divergentes e uma constrição mediana. Entretanto, em alguns grupos, como nos mochokídeos Acanthocleitron, Synodontis e Microsynodontis (Vigliotta, 2008: \#2), o mesetmóide é algo quadrangular, largo e sem constrição mediana.

Os auchenipterídeos Entomocorus, Pseudepapterus, Epapterus e Auchenipterus possuem o mesetmóide como em Siluriformes generalizados (em forma de X), porém todos os demais membros da família possuem o mesetmóide quadrangular (Royero, 1999: \#9, \#10; Britto, 2002: \#1; Akama, 2004: \#30).

Já entre os doradídeos, enquanto alguns possuem o mesetmóide em forma de X, Wertheimeria, Kalyptodoras, Pterodoras, Lithodoras e Doraops o apresentam quadrangular (Higuchi, 1992: \#9), e os Doradini o possuem ponteagudo, com uma dilatação mediana formando processos laterais (Higuchi, 1992: \#11; Birindelli, 2006: \#31). Uma condição semelhante a encontrada nos Doradini ocorre em Gagata (de Pinna, 1996: fig. 15).

Esse caráter foi codificado como inaplicável para Aspredinidae e Chiloglanis, que apresentam o mesetmóide muito modificado. 


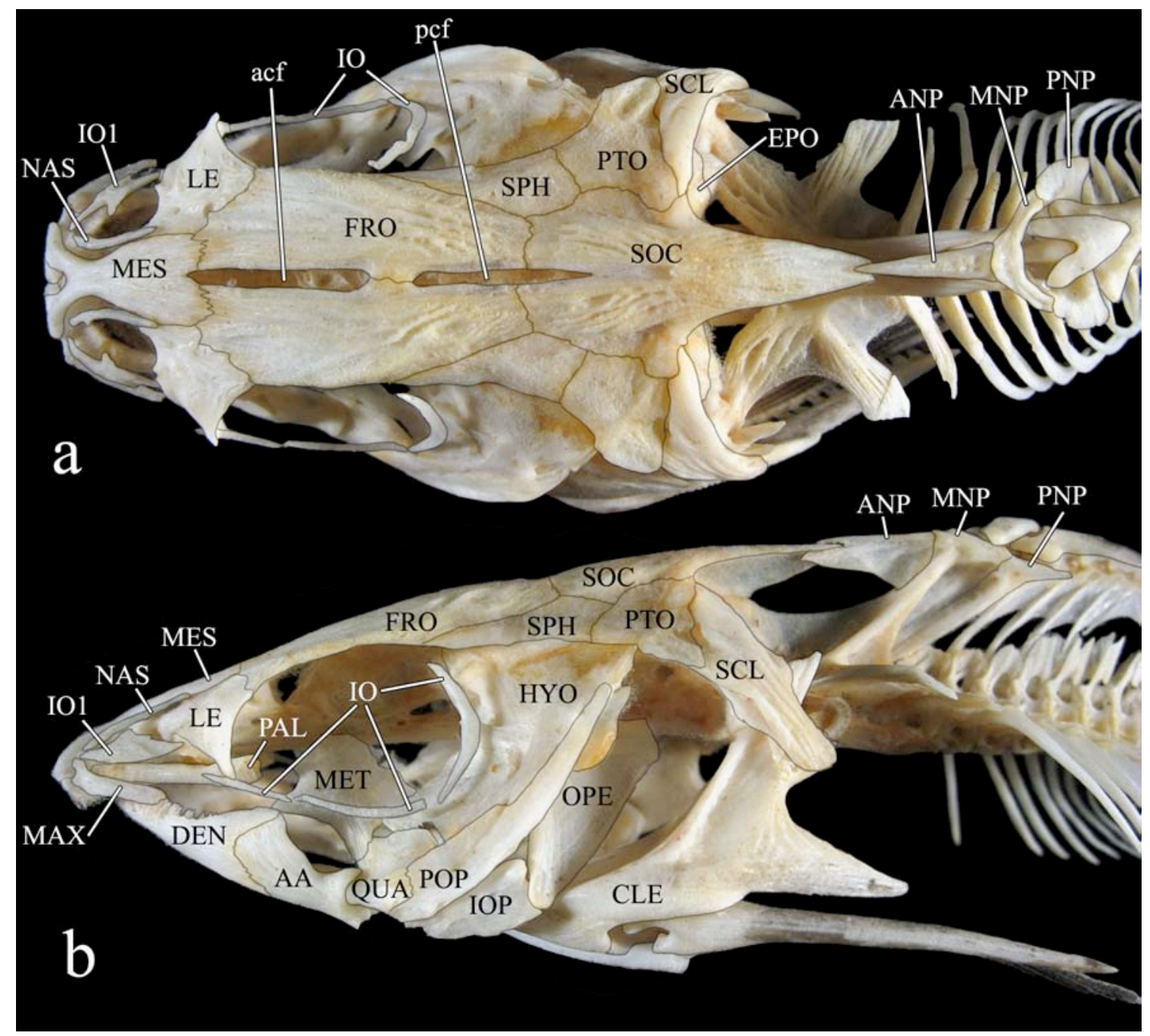

Figura 15. Crânio de Ictalurus punctatus, MZUSP 103256 (155 mm), em vista dorsal (a) e lateral (b). AA: ângulo-articular, acf: fontanela craniana anterior, ANP: placa nucal anterior, CLE: cleitro, DEN: dentário, EPO: epoccipital, FRO: frontal, HYO: hiomandibular, IO: infra-orbital(is), IOP: interopérculo, LE: etmóide lateral, MAX: maxilar, MES: mesetmóide, MET: metapterigóide, MNP: placa nucal mediana, NAS: nasal, OPE: opérculo, PAL: autopalatino, pcf: fontanela craniana posterior, PNP: placa nucal posterior, POP: pré-opérculo, PTO: pterótico, QUA: quadrado, SCL: pós-têmporo-supracleitro, SOC: parieto-supra-occipital, SPH: esfenótico. 


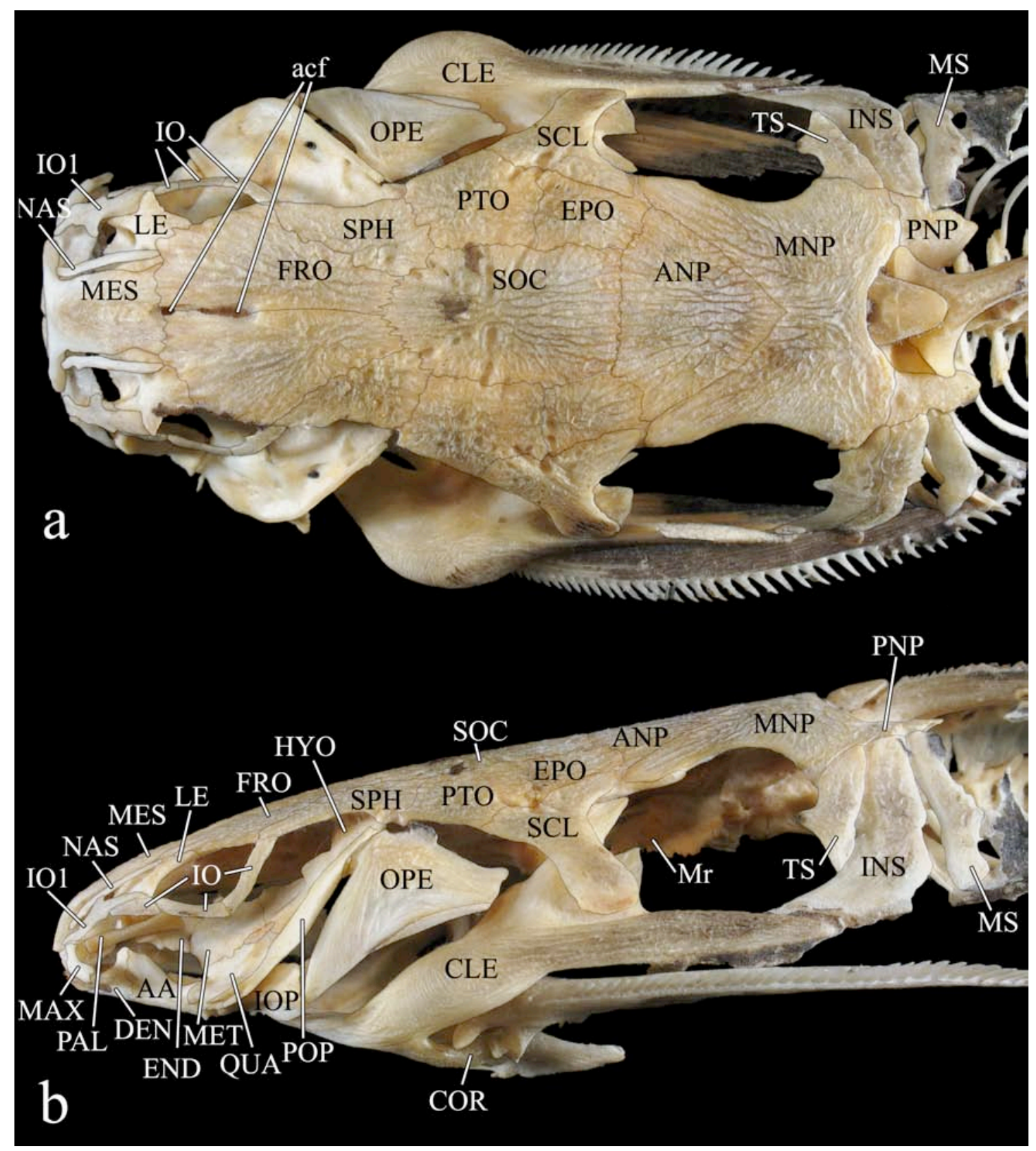

Figura 16. Crânio de Wertheimeria maculata, MZUSP 93659 (217.0 mm), em vista dorsal (a) e lateral (b). AA: ângulo-articular, acf: fontanela craniana anterior, ANP: placa nucal anterior, CLE: cleitro, COR: coracóide, DEN: dentário, EPO: epoccipital, FRO: frontal, HYO: hiomandibular, INS: escudo infra-nucal, IO: infra-orbital(is), IOP: interopérculo, LE: etmóide lateral, MAX: maxilar, END: 'endopterigóide', MES: mesetmóide, MET: metapterigóide, MNP: placa nucal mediana, Mr: ramo de Müller, MS: escudo(s) lateral(is), NAS: nasal, OPE: opérculo, PAL: autopalatino, PNP: placa nucal posterior, POP: pré-opérculo, PTO: pterótico, QUA: quadrado, SCL: pós-têmporo-supracleitro, SOC: parieto-supraoccipital, SPH: esfenótico, TS: escudo(s) timpânico(s). 


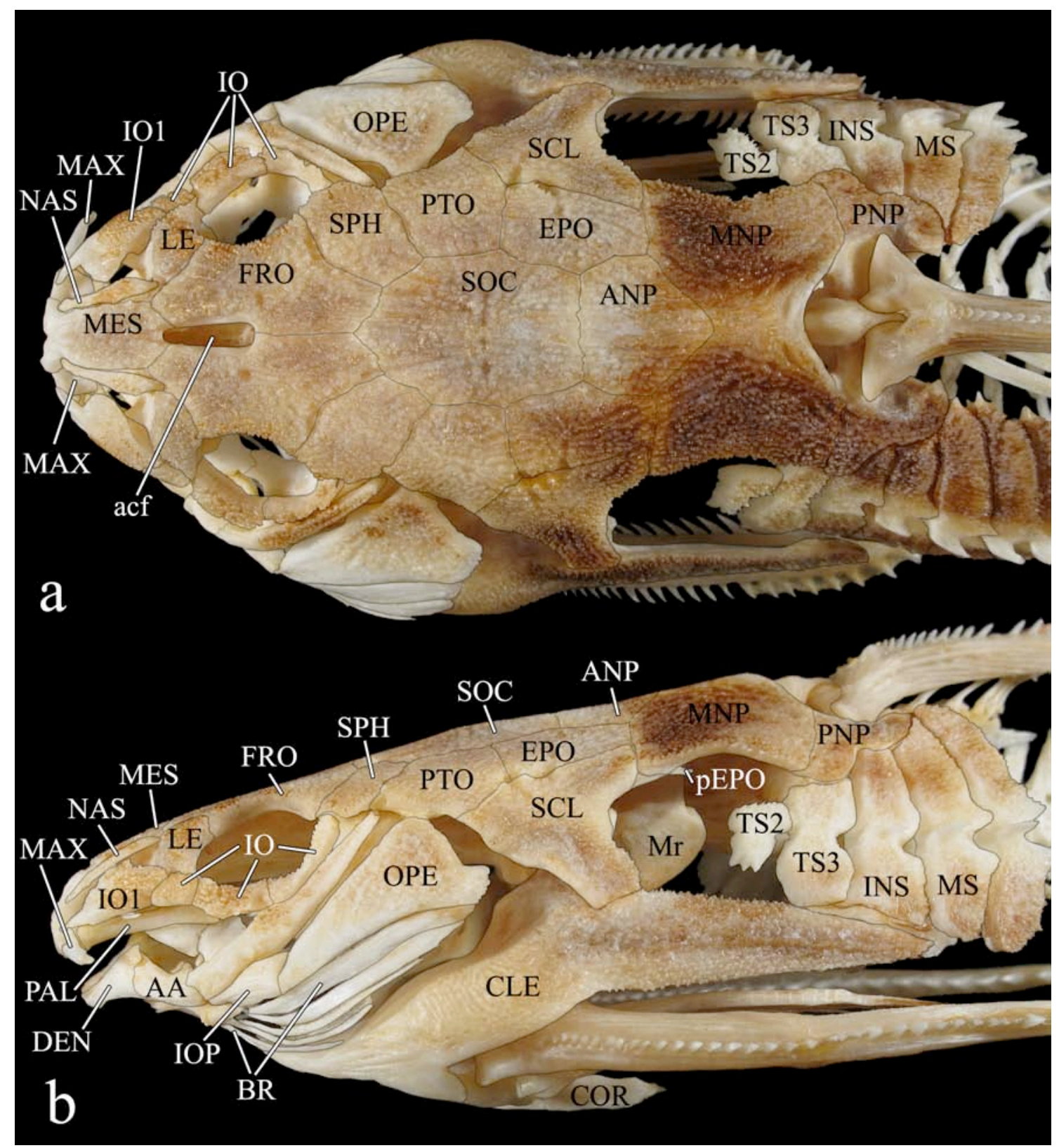

Figura 17. Crânio de Platydoras armatulus, MZUSP 91686 (151.7 mm), em vista dorsal (a) e lateral (b). AA: ângulo-articular, acf: fontanela craniana anterior, ANP: placa nucal anterior, BR: raios branquiostégios, CLE: cleitro, COR: coracóide, DEN: dentário, EPO: epoccipital, FRO: frontal, INS: escudo infra-nucal, IO: infra-orbital(is), IOP: interopérculo, LE: etmóide lateral, MAX: maxilar, MES: mesetmóide, MNP: placa nucal mediana, Mr: ramo de Müller, MS: escudo(s) lateral(is), NAS: nasal, OPE: opérculo, PAL: autopalatino, pEPO: processo do epoccipital, PNP: placa nucal posterior, PTO: pterótico, SCL: pós-têmporo-supracleitro, SOC: parieto-supra-occipital, SPH: esfenótico, TS: escudo(s) timpânico(s). 


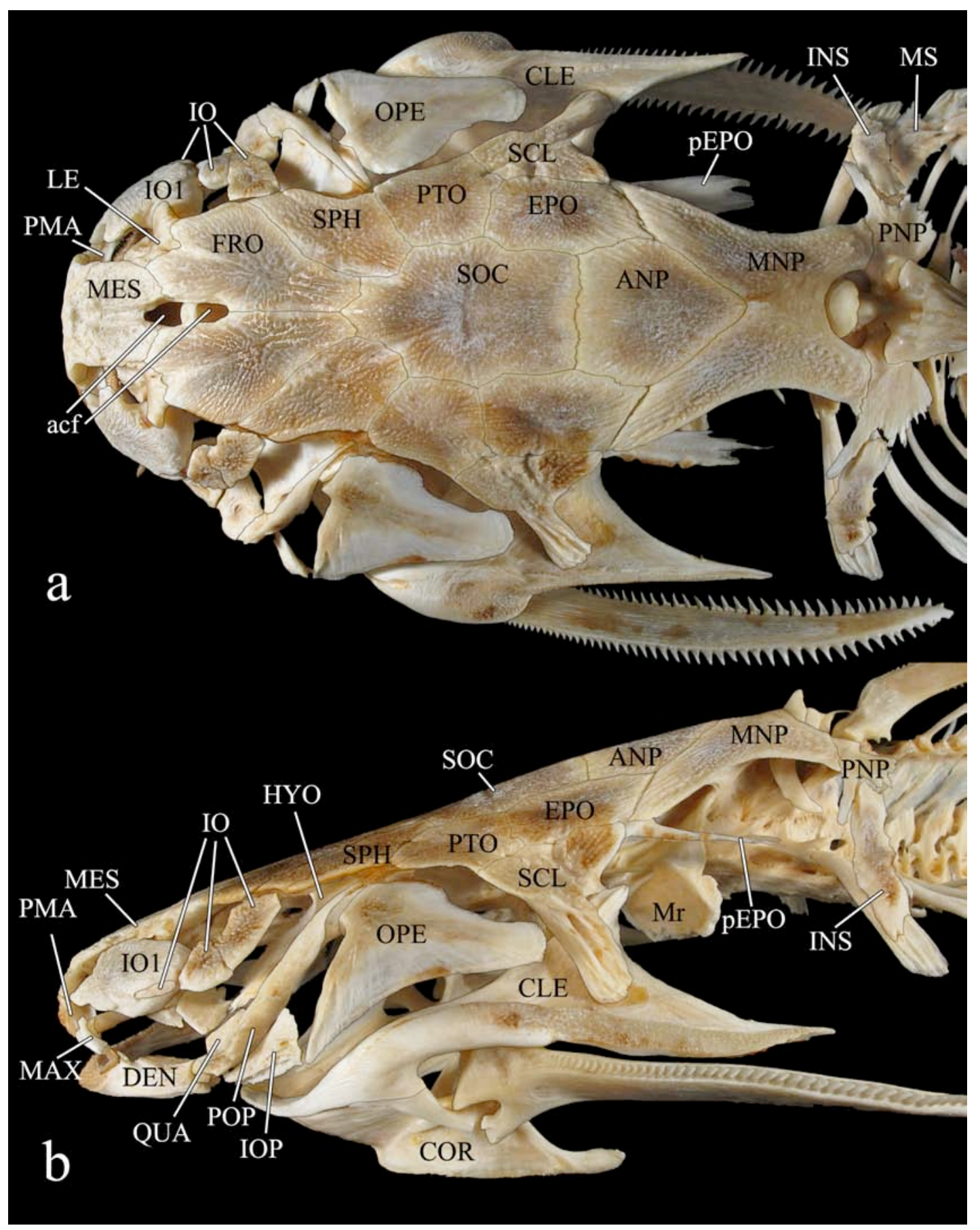

Figura 18. Crânio de Pterodoras granulosus, MZUSP 91655 (410.0 mm), em vista dorsal (a) e lateral (b). acf: fontanela craniana anterior, ANP: placa nucal anterior, CLE: cleitro, COR: coracóide, DEN: dentário, EPO: epoccipital, FRO: frontal, HYO: hiomandibular, INS: escudo infra-nucal, IO: infraorbital(is), IOP: interopérculo, LE: etmóide lateral, MAX: maxilar, MES: mesetmóide, MNP: placa nucal mediana, Mr: ramo de Müller, MS: escudo(s) lateral(is), OPE: opérculo, pEPO: processo do epoccipital, PMA: pré-maxilar, PNP: placa nucal posterior, POP: pré-opérculo, PTO: pterótico, QUA: quadrado, SCL: pós-têmporo-supracleitro, SOC: parieto-supra-occipital, SPH: esfenótico. 


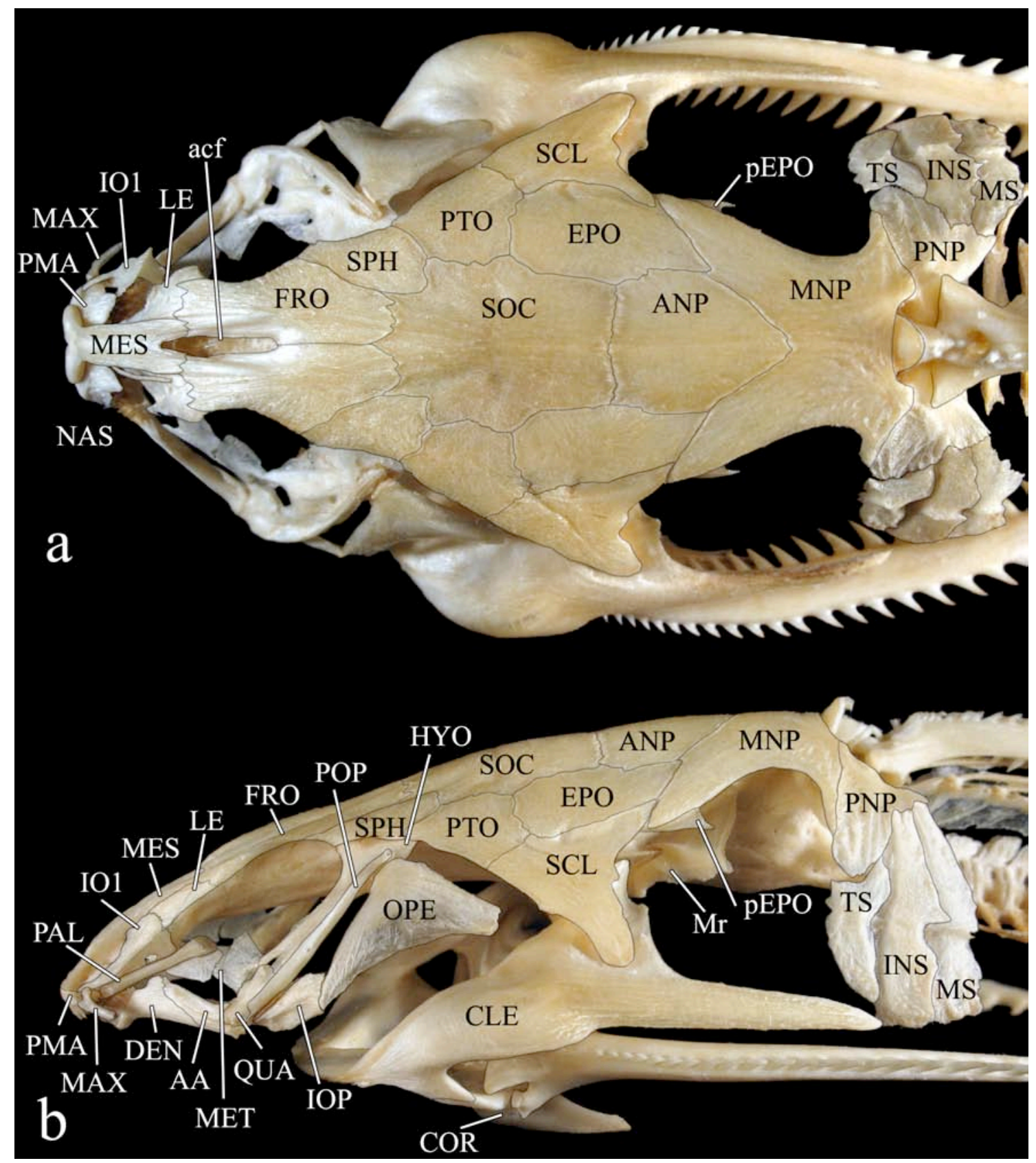

Figura 19. Crânio de Centrodoras brachiatus, MZUSP 83313 (160 mm), em vista dorsal (a) e lateral (b). AA: ângulo-articular, acf: fontanela craniana anterior, ANP: placa nucal anterior, CLE: cleitro, COR: coracóide, DEN: dentário, EPO: epoccipital, FRO: frontal, HYO: hiomandibular, INS: escudo infra-nucal, IO: infra-orbital(is), IOP: interopérculo, LE: etmóide lateral, MAX: maxilar, MES: mesetmóide, MET: metapterigóide, MNP: placa nucal mediana, Mr: ramo de Müller, MS: escudo(s) lateral(is), NAS: nasal, OPE: opérculo, PAL: autopalatino, pEPO: processo do epoccipital, PMA: pré-maxilar, PNP: placa nucal posterior, POP: pré-opérculo, PTO: pterótico, QUA: quadrado, SCL: pós-têmporo-supracleitro, SOC: parieto-supra-occipital, SPH: esfenótico, TS: escudo(s) timpânico(s). 


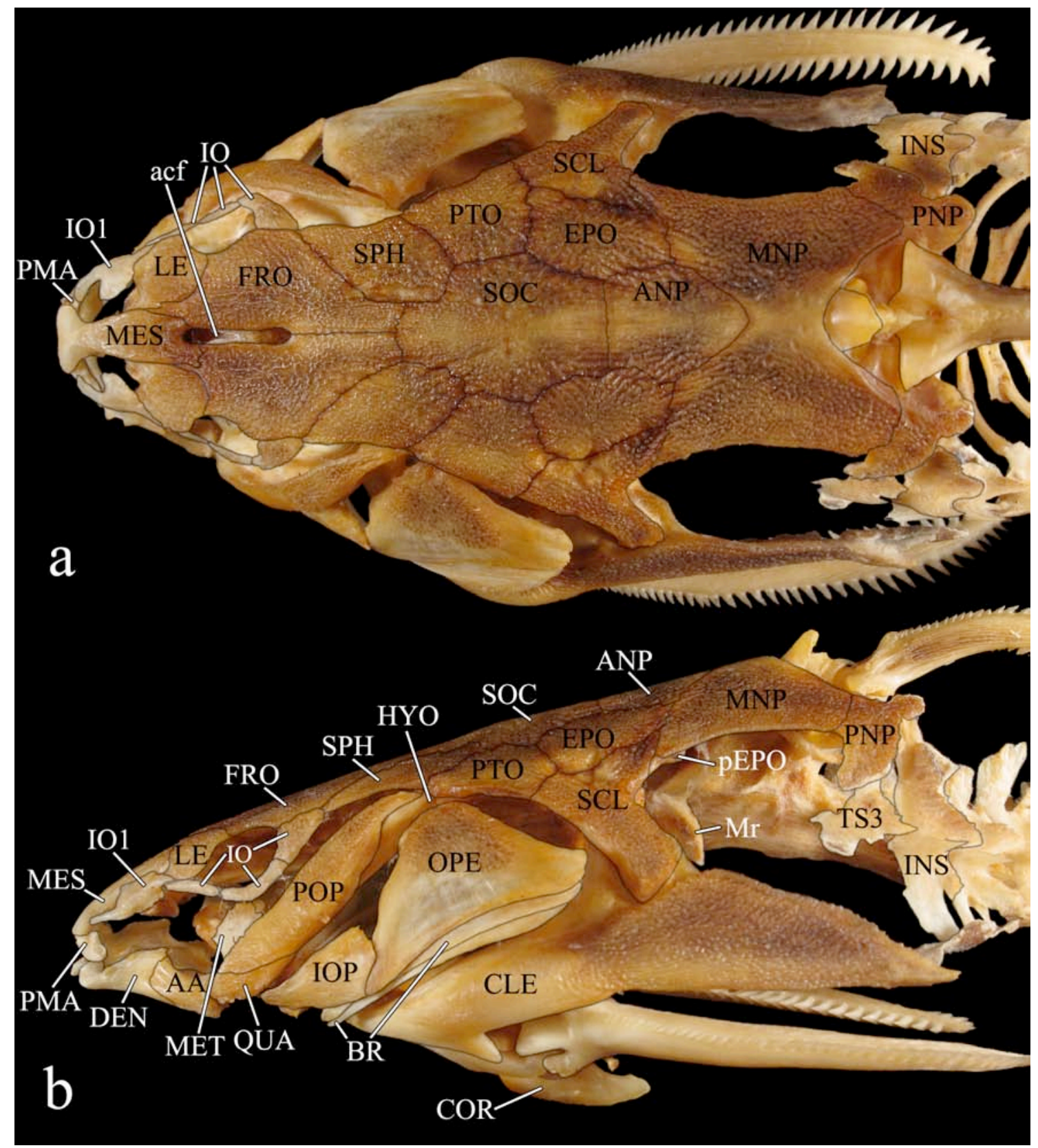

Figura 20. Crânio de Orinocodoras eigenmanni, FMNH 105276 (193.0 mm), em vista dorsal (a) e lateral (b). AA: ângulo-articular, acf: fontanela craniana anterior, ANP: placa nucal anterior, BR: raios branquiostégios, CLE: cleitro, COR: coracóide, DEN: dentário, EPO: epoccipital, FRO: frontal, HYO: hiomandibular, INS: escudo infra-nucal, IO: infra-orbital(is), IOP: interopérculo, LE: etmóide lateral, MES: mesetmóide, MET: metapterigóide, MNP: placa nucal mediana, Mr: ramo de Müller, OPE: opérculo, pEPO: processo do epoccipital, PMA: pré-maxilar, PNP: placa nucal posterior, POP: préopérculo, PTO: pterótico, QUA: quadrado, SCL: pós-têmporo-supracleitro, SOC: parieto-supra-occipital, SPH: esfenótico, TS: escudo(s) timpânico(s). 


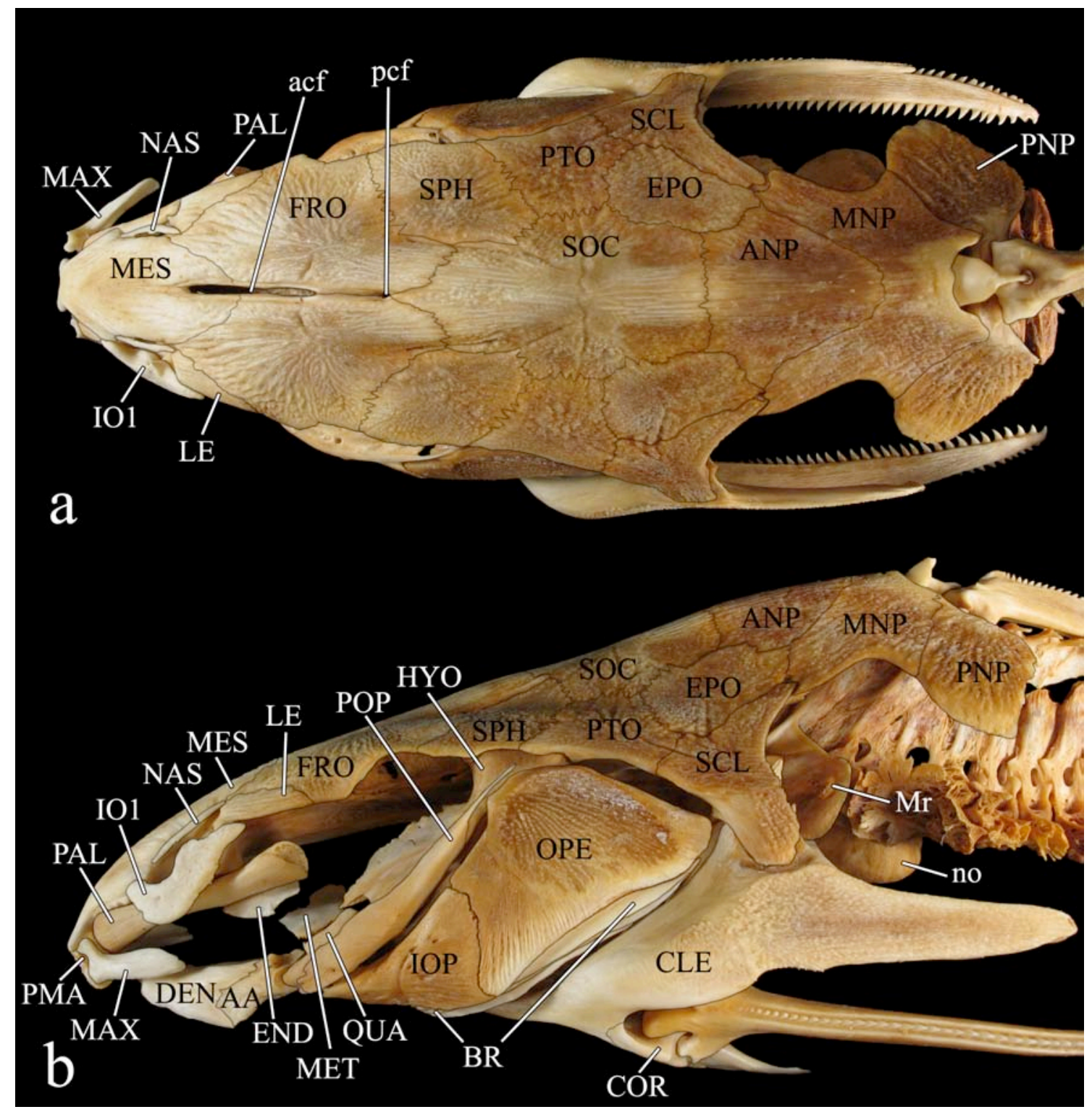

Figura 21. Crânio de Oxydoras niger, MZUSP 91654 (550.0 mm), em vista dorsal (a) e lateral (b). AA: ângulo-articular, acf: fontanela craniana anterior, ANP: placa nucal anterior, BR: raios branquiostégios, CLE: cleitro, COR: coracóide, DEN: dentário, EPO: epoccipital, FRO: frontal, HYO: hiomandibular, IO: infra-orbital(is), IOP: interopérculo, LE: etmóide lateral, MAX: maxilar, END: 'endopterigóide', MES: mesetmóide, MET: metapterigóide, MNP: placa nucal mediana, Mr: ramo de Müller, NAS: nasal, no: nódulo ósseo, OPE: opérculo, PAL: autopalatino, pcf: fontanela craniana posterior, PMA: pré-maxilar, PNP: placa nucal posterior, POP: pré-opérculo, PTO: pterótico, QUA: quadrado, SCL: pós-têmporosupracleitro, SOC: parieto-supra-occipital, SPH: esfenótico. 


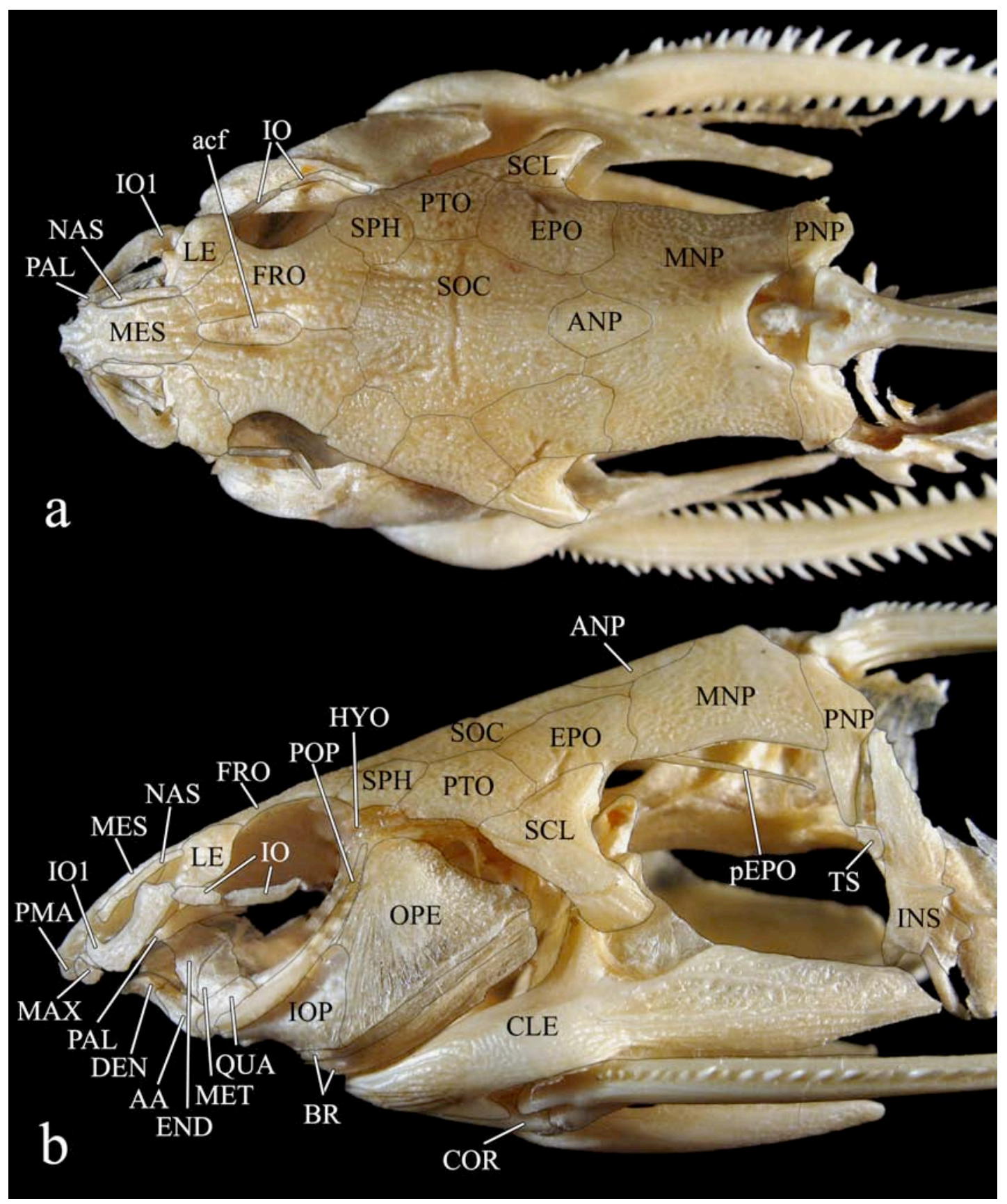

Figura 22. Crânio de "Petalodoras" aff. eigenmanni, MZUSP 7838 (65.0 mm), em vista dorsal (a) e lateral (b). AA: ângulo-articular, acf: fontanela craniana anterior, ANP: placa nucal anterior, BR: raios branquiostégios, CLE: cleitro, COR: coracóide, DEN: dentário, EPO: epoccipital, FRO: frontal, HYO: hiomandibular, INS: escudo infra-nucal, IO: infra-orbital(is), IOP: interopérculo, LE: etmóide lateral, MAX: maxilar, END: ‘endopterigóide', MES: mesetmóide, MET: metapterigóide, MNP: placa nucal mediana, NAS: nasal, OPE: opérculo, PAL: autopalatino, pEPO: processo do epoccipital, PMA: prémaxilar, PNP: placa nucal posterior, POP: pré-opérculo, PTO: pterótico, QUA: quadrado, SCL: póstêmporo-supracleitro, SOC: parieto-supra-occipital, SPH: esfenótico, TS: escudo(s) timpânico(s). 


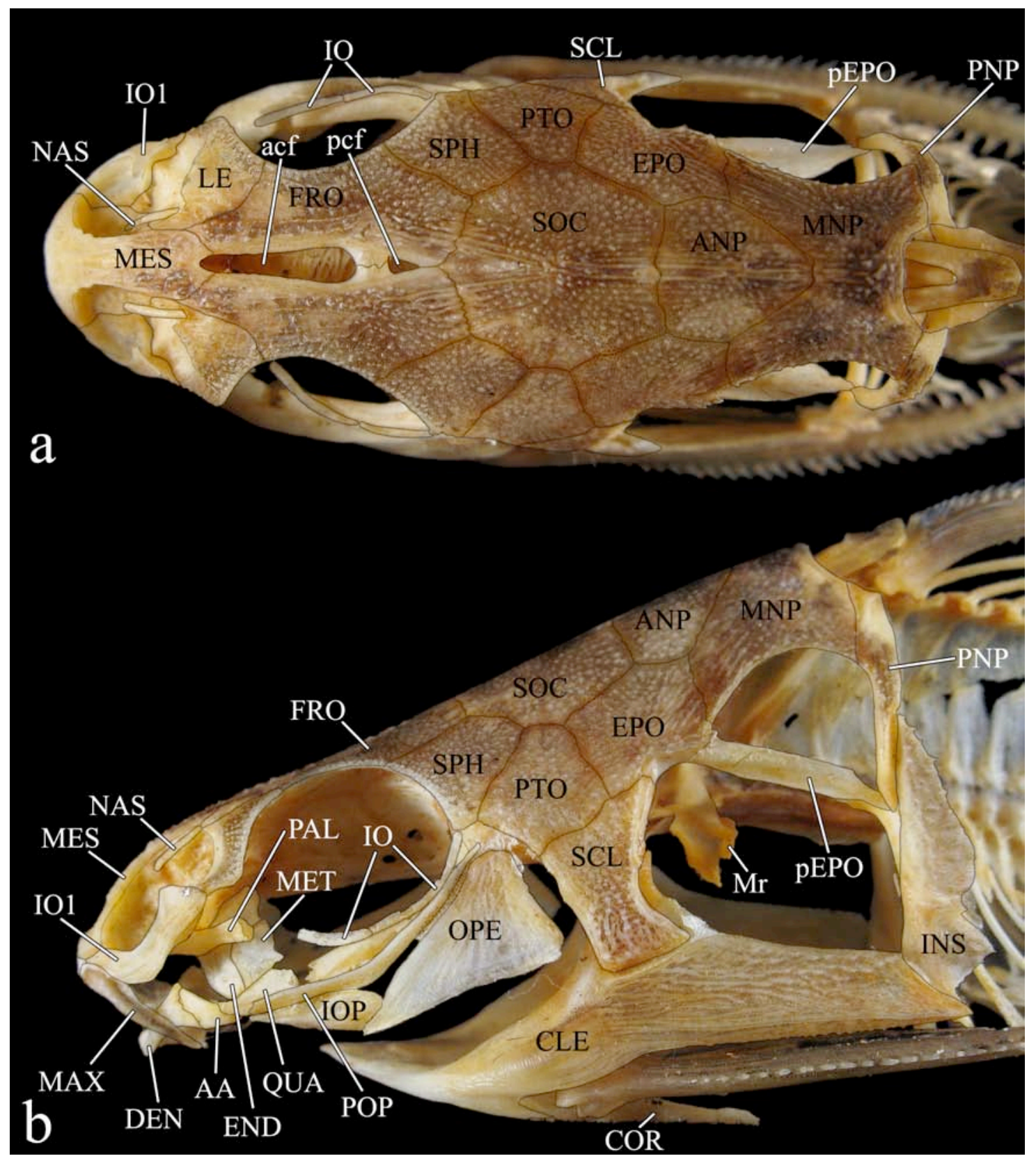

Figura 23. Crânio de Trachydoras brevis, MZUSP 103087 (75 mm), em vista dorsal (a) e lateral (b). AA: ângulo-articular, acf: fontanela craniana anterior, ANP: placa nucal anterior, CLE: cleitro, COR: coracóide, DEN: dentário, EPO: epoccipital, FRO: frontal, INS: escudo infra-nucal, IO: infra-orbital(is), IOP: interopérculo, LE: etmóide lateral, MAX: maxilar, END: ‘endopterigóide', MES: mesetmóide, MET: metapterigóide, MNP: placa nucal mediana, Mr: ramo de Müller, NAS: nasal, OPE: opérculo, PAL: autopalatino, pcf: fontanela craniana posterior, pEPO: processo do epoccipital, PNP: placa nucal posterior, POP: pré-opérculo, PTO: pterótico, QUA: quadrado, SCL: pós-têmporo-supracleitro, SOC: parieto-supra-occipital, SPH: esfenótico. 


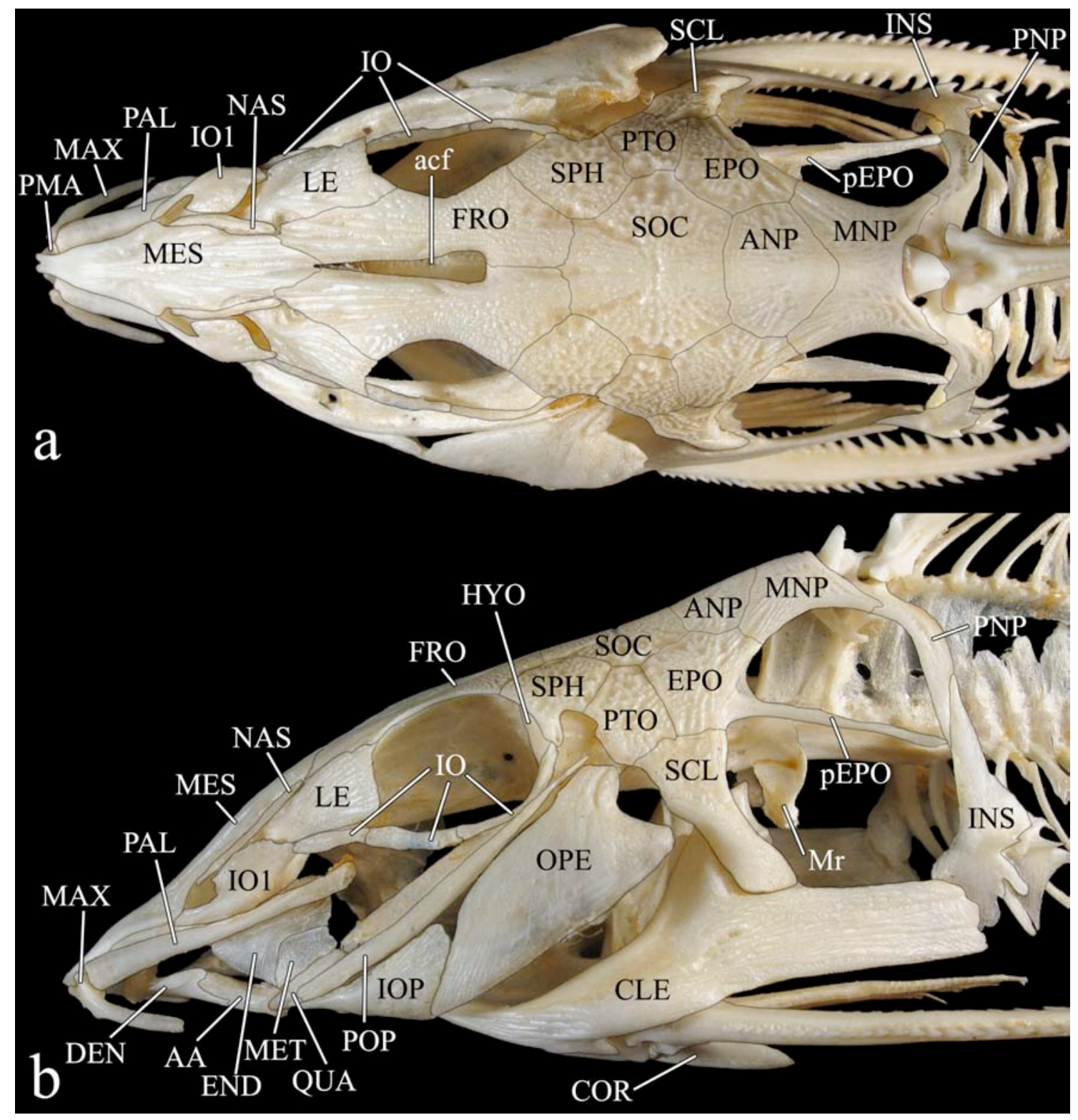

Figura 24. Crânio de Doras phlyzakion, MZUSP 82294 (162.0 mm), em vista dorsal (a) e lateral (b). AA: ângulo-articular, acf: fontanela craniana anterior, ANP: placa nucal anterior, CLE: cleitro, COR: coracóide, DEN: dentário, EPO: epoccipital, FRO: frontal, HYO: hiomandibular, INS: escudo infra-nucal, IO: infra-orbital(is), IOP: interopérculo, LE: etmóide lateral, MAX: maxilar, END: 'endopterigóide', MES: mesetmóide, MET: metapterigóide, MNP: placa nucal mediana, Mr: ramo de Müller, NAS: nasal, OPE: opérculo, PAL: autopalatino, pEPO: processo do epoccipital, PMA: pré-maxilar, PNP: placa nucal posterior, POP: pré-opérculo, PTO: pterótico, QUA: quadrado, SCL: pós-têmporo-supracleitro, SOC: parieto-supra-occipital, SPH: esfenótico. 


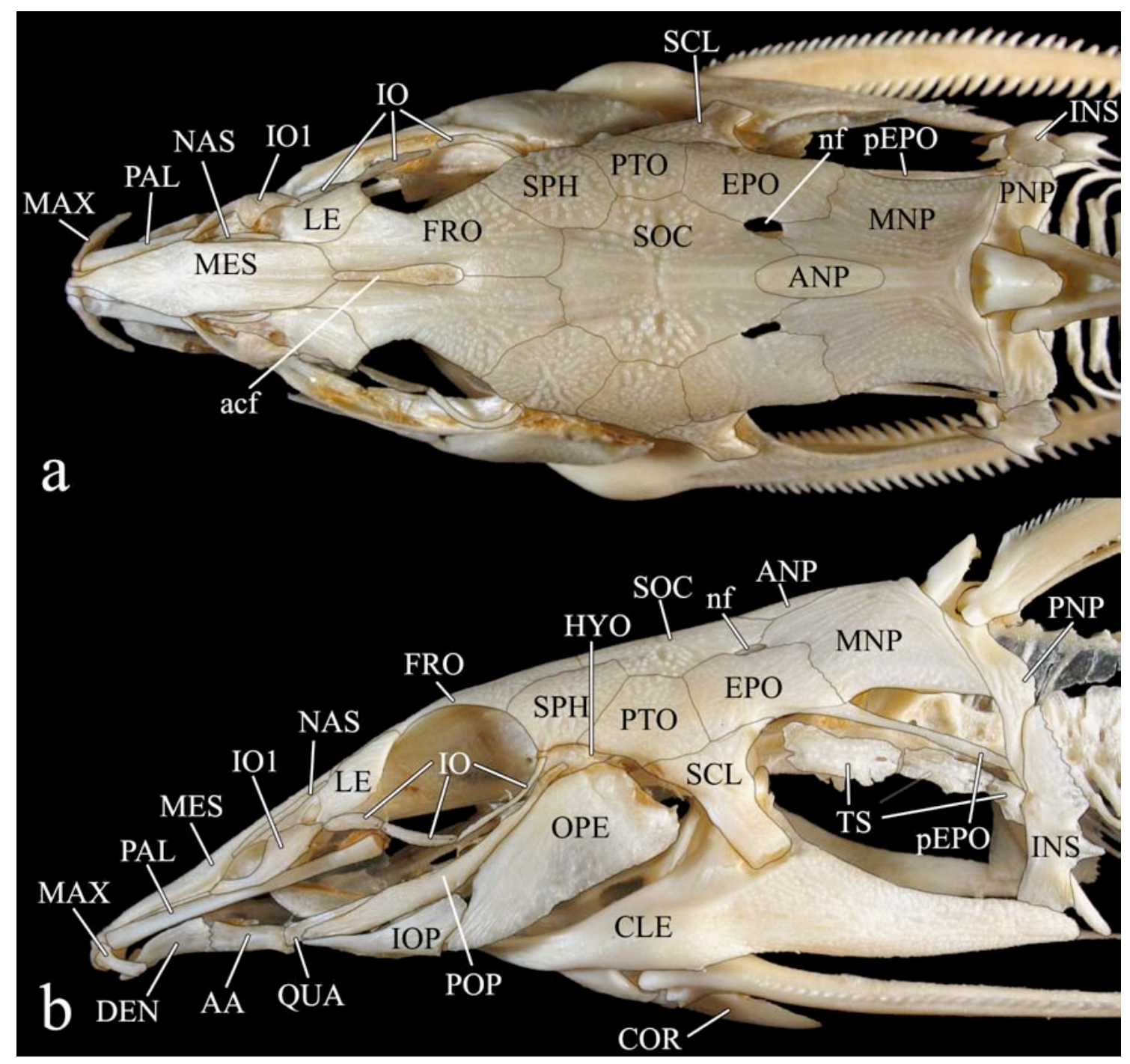

Figura 25. Crânio de Hemidoras morei, MZUSP 32526 (152.0 mm), em vista dorsal (a) e lateral (b). AA: ângulo-articular, acf: fontanela craniana anterior, ANP: placa nucal anterior, CLE: cleitro, COR: coracóide, DEN: dentário, EPO: epoccipital, FRO: frontal, HYO: hiomandibular, INS: escudo infra-nucal, IO: infra-orbital(is), IOP: interopérculo, LE: etmóide lateral, MAX: maxilar, MES: mesetmóide, MNP: placa nucal mediana, NAS: nasal, nf: forame nucal, OPE: opérculo, PAL: autopalatino, pEPO: processo do epoccipital, PNP: placa nucal posterior, POP: pré-opérculo, PTO: pterótico, QUA: quadrado, SCL: pós-têmporo-supracleitro, SOC: parieto-supra-occipital, SPH: esfenótico, TS: escudo(s) timpânico(s). 


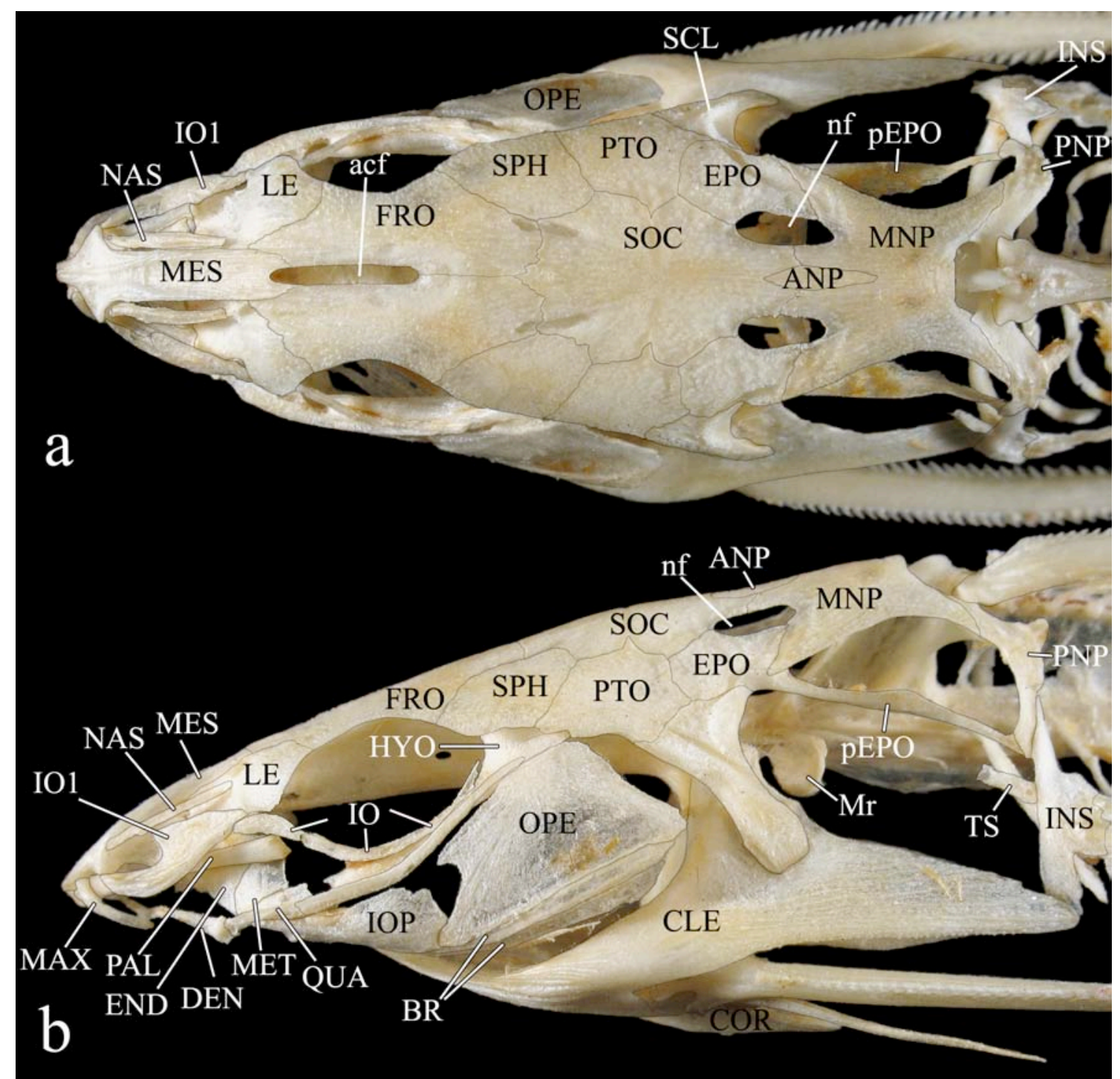

Figura 26. Crânio de Nemadoras elongatus, MZUSP 56013 (101.6 mm), em vista dorsal (a) e lateral (b). acf: fontanela craniana anterior, ANP: placa nucal anterior, BR: raios branquiostégios, CLE: cleitro, COR: coracóide, DEN: dentário, EPO: epoccipital, FRO: frontal, HYO: hiomandibular, INS: escudo infra-nucal, IO: infra-orbital(is), IOP: interopérculo, LE: etmóide lateral, MAX: maxilar, END: 'endopterigóide', MES: mesetmóide, MET: metapterigóide, MNP: placa nucal mediana, Mr: ramo de Müller, NAS: nasal, nf: forame nucal, OPE: opérculo, PAL: autopalatino, pEPO: processo do epoccipital, PNP: placa nucal posterior, PTO: pterótico, QUA: quadrado, SCL: pós-têmporo-supracleitro, SOC: parieto-supra-occipital, SPH: esfenótico, TS: escudo(s) timpânico(s). 


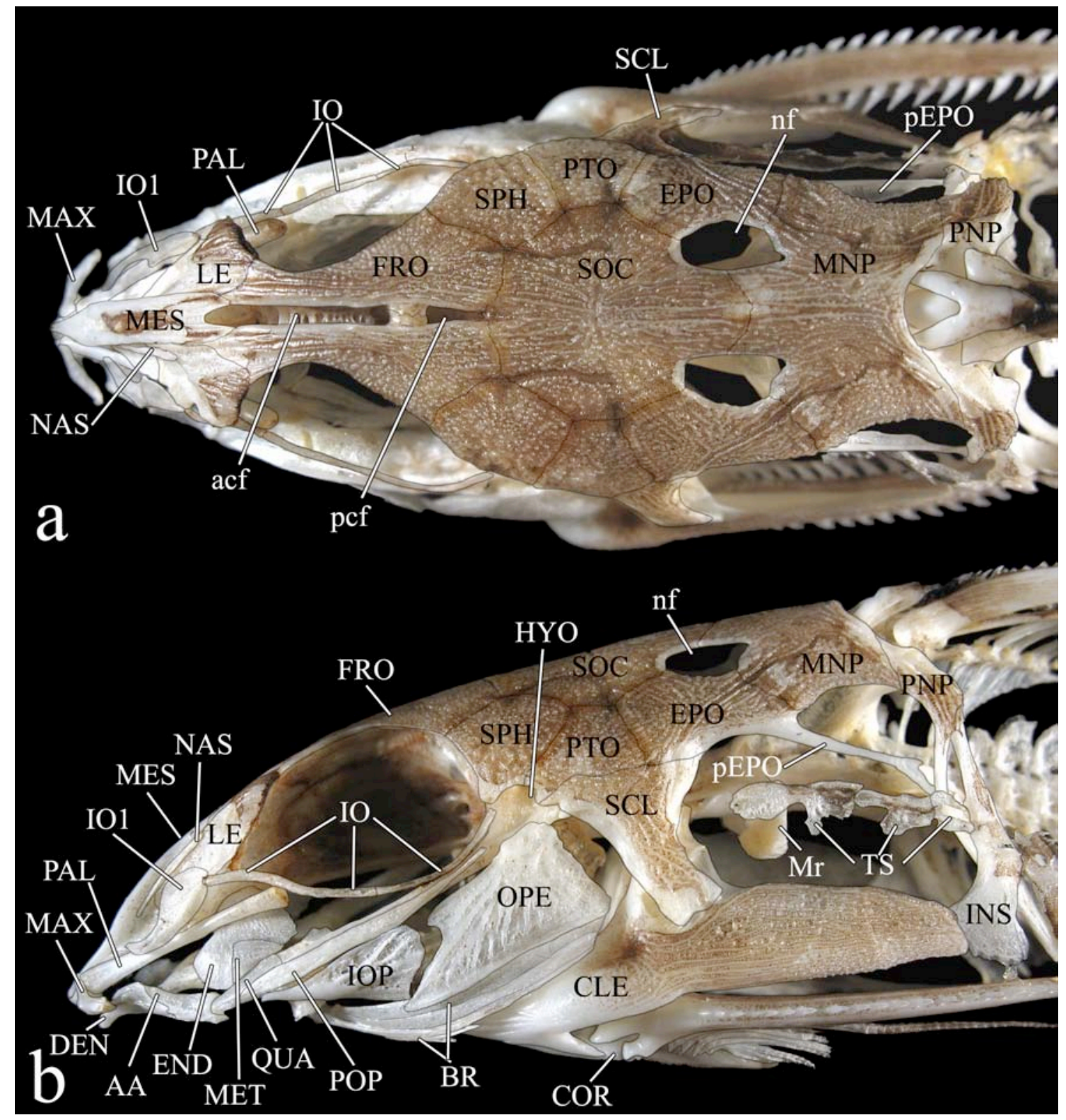

Figura 27. Crânio de "Nemadoras" ternetzi, MZUSP 103246 (94.0 mm), em vista dorsal (a) e lateral (b). AA: ângulo-articular, acf: fontanela craniana anterior, BR: raios branquiostégios, CLE: cleitro, COR: coracóide, DEN: dentário, EPO: epoccipital, FRO: frontal, HYO: hiomandibular, INS: escudo infra-nucal, IO: infra-orbital(is), IOP: interopérculo, LE: etmóide lateral, MAX: maxilar, END: 'endopterigóide', MES: mesetmóide, MET: metapterigóide, MNP: placa nucal mediana, Mr: ramo de Müller, NAS: nasal, nf: forame nucal, OPE: opérculo, PAL: autopalatino, pcf: fontanela craniana posterior, pEPO: processo do epoccipital, PNP: placa nucal posterior, POP: pré-opérculo, PTO: pterótico, QUA: quadrado, SCL: póstêmporo-supracleitro, SOC: parieto-supra-occipital, SPH: esfenótico, TS: escudo(s) timpânico(s). 


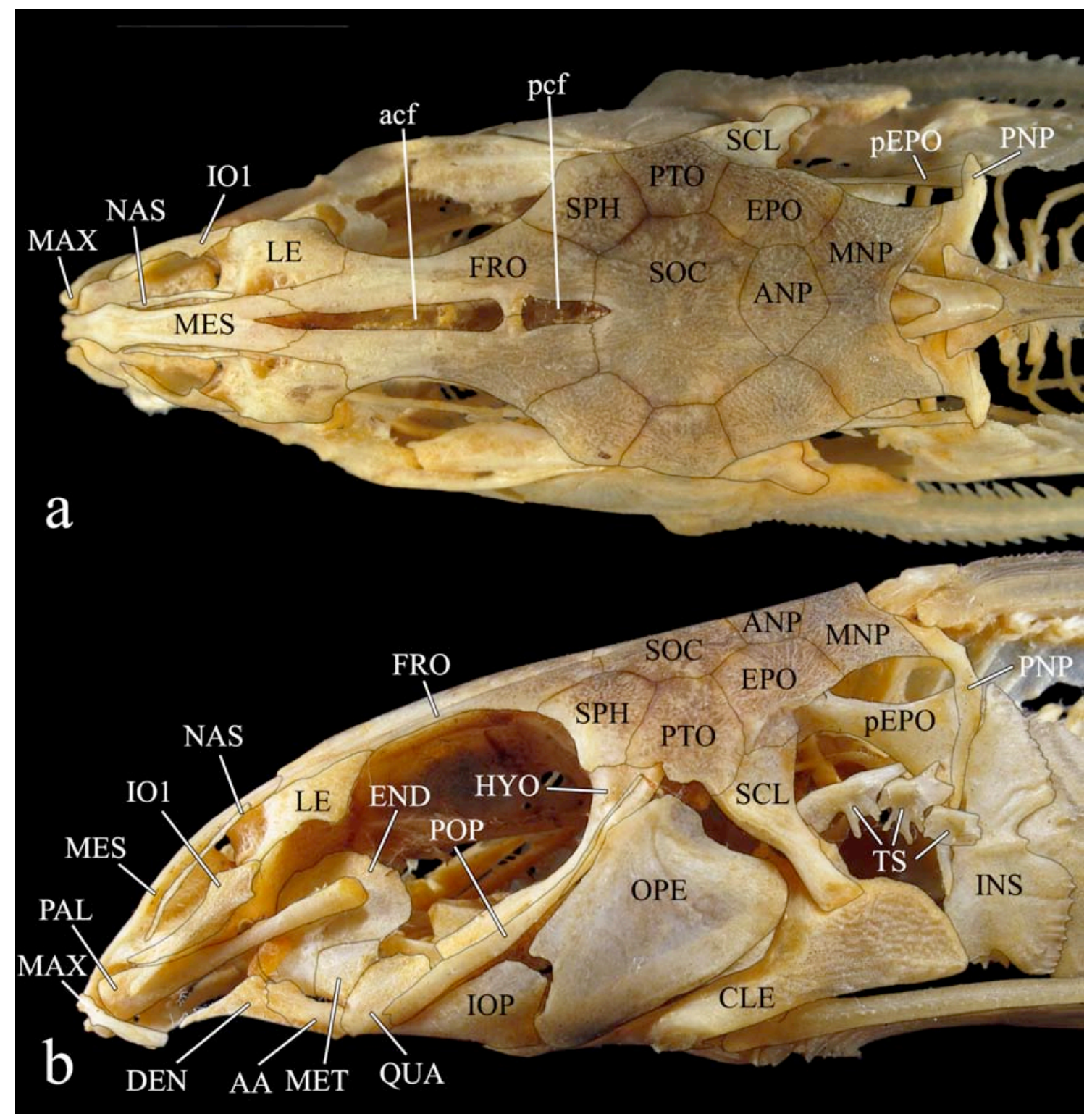

Figura 28. Crânio de Leptodoras hasemani, ANSP 179209 (não medido), em vista dorsal (a) e lateral (b). AA: ângulo-articular, acf: fontanela craniana anterior, ANP: placa nucal anterior, CLE: cleitro, CDEN: dentário, EPO: epoccipital, FRO: frontal, HYO: hiomandibular, INS: escudo infra-nucal, IO: infraorbital(is), IOP: interopérculo, LE: etmóide lateral, MAX: maxilar, END: 'endopterigóide', MES: mesetmóide, MET: metapterigóide, MNP: placa nucal mediana, NAS: nasal, OPE: opérculo, PAL: autopalatino, pcf: fontanela craniana posterior, pEPO: processo do epoccipital, PNP: placa nucal posterior, POP: pré-opérculo, PTO: pterótico, QUA: quadrado, SCL: pós-têmporo-supracleitro, SOC: parieto-supra-occipital, SPH: esfenótico, TS: escudo(s) timpânico(s). 


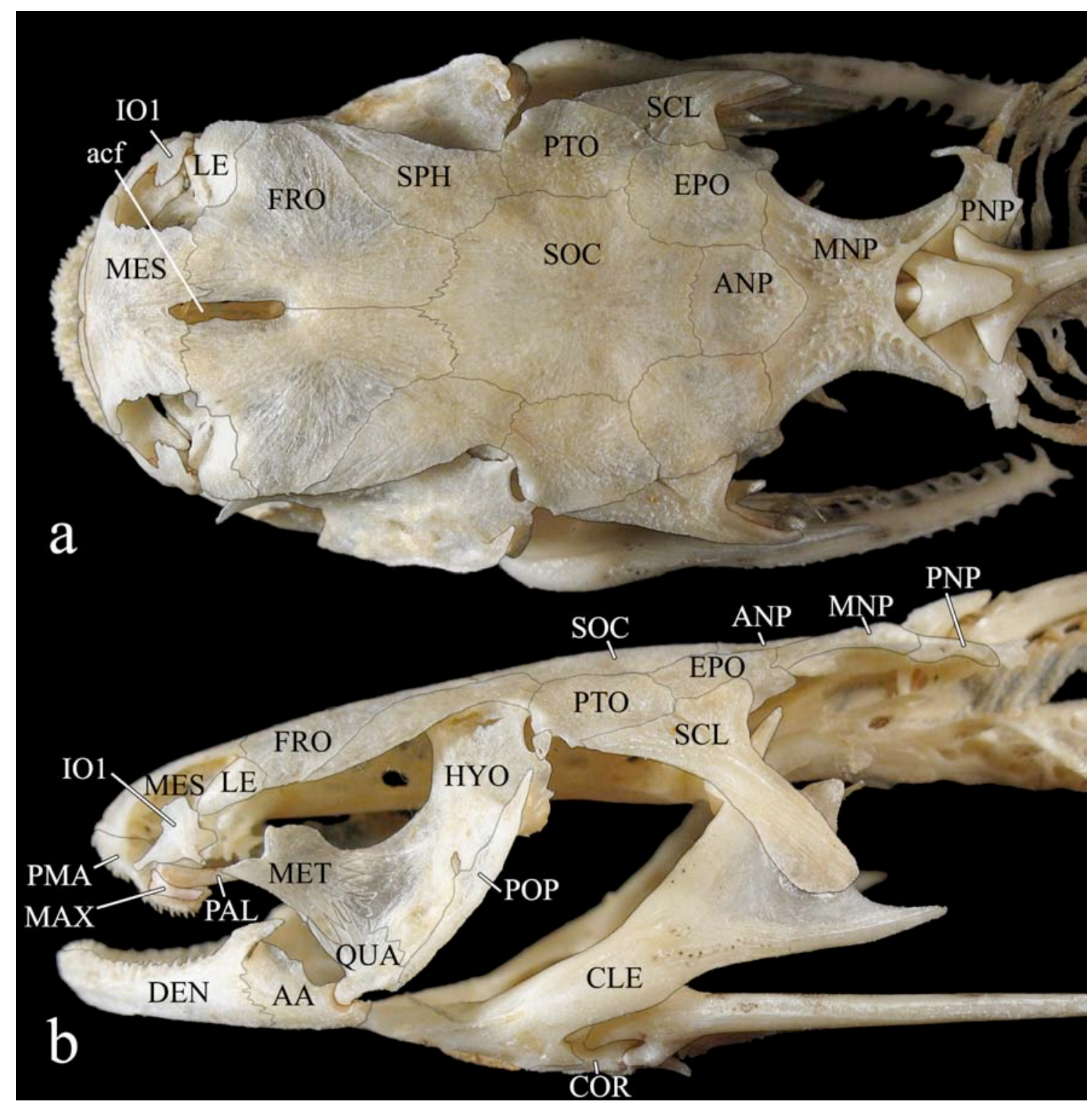

Figura 29. Crânio de Glanidium melanodermatum, MZUSP 64256 (112.0 mm), em vista dorsal (a) e lateral (b). AA: ângulo-articular, acf: fontanela craniana anterior, ANP: placa nucal anterior, CLE: cleitro, COR: coracóide, DEN: dentário, EPO: epoccipital, FRO: frontal, HYO: hiomandibular, IO: infraorbital(is), LE: etmóide lateral, MAX: maxilar, MES: mesetmóide, MET: metapterigóide, MNP: placa nucal mediana, MPAL: autopalatino, PMA: pré-maxilar, PNP: placa nucal posterior, POP: pré-opérculo, PTO: pterótico, QUA: quadrado, SCL: pós-têmporo-supracleitro, SOC: parieto-supra-occipital, SPH: esfenótico. 


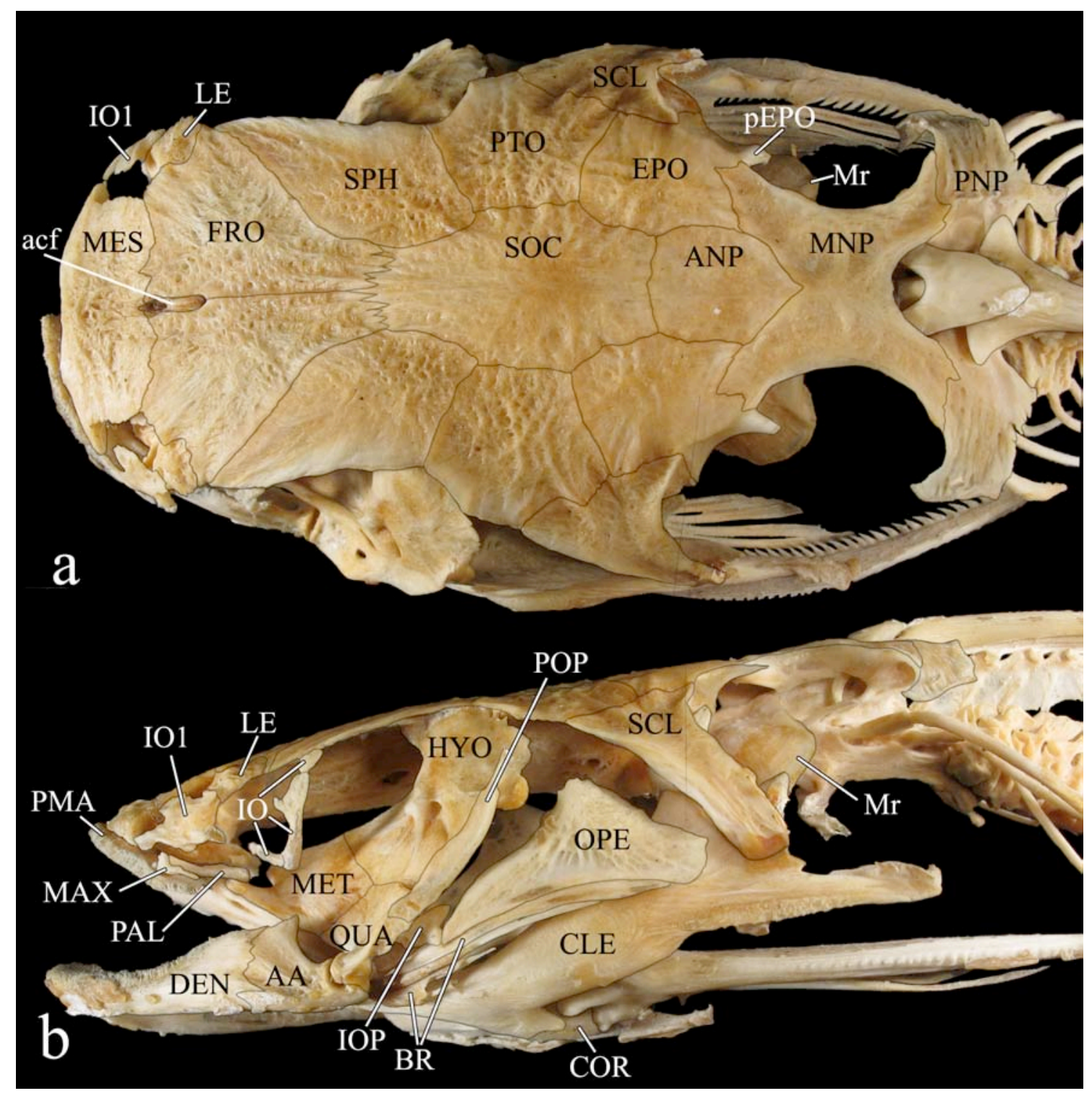

Figura 30. Crânio de Tocantinsia piresi, MZUSP 100031 (440.0 mm), em vista dorsal (a) e lateral (b). AA: ângulo-articular, acf: fontanela craniana anterior, ANP: placa nucal anterior, BR: raios branquiostégios, CLE: cleitro, COR: coracóide, DEN: dentário, EPO: epoccipital, FRO: frontal, HYO: hiomandibular, IO: infra-orbital(is), IOP: interopérculo, LE: etmóide lateral, MAX: maxilar, MES: mesetmóide, MET: metapterigóide, MNP: placa nucal mediana, Mr: ramo de Müller, OPE: opérculo, PAL: autopalatino, pEPO: processo do epoccipital, PMA: pré-maxilar, PNP: placa nucal posterior, POP: pré-opérculo, PTO: pterótico, QUA: quadrado, SCL: pós-têmporo-supracleitro, SOC: parieto-supraoccipital, SPH: esfenótico. 


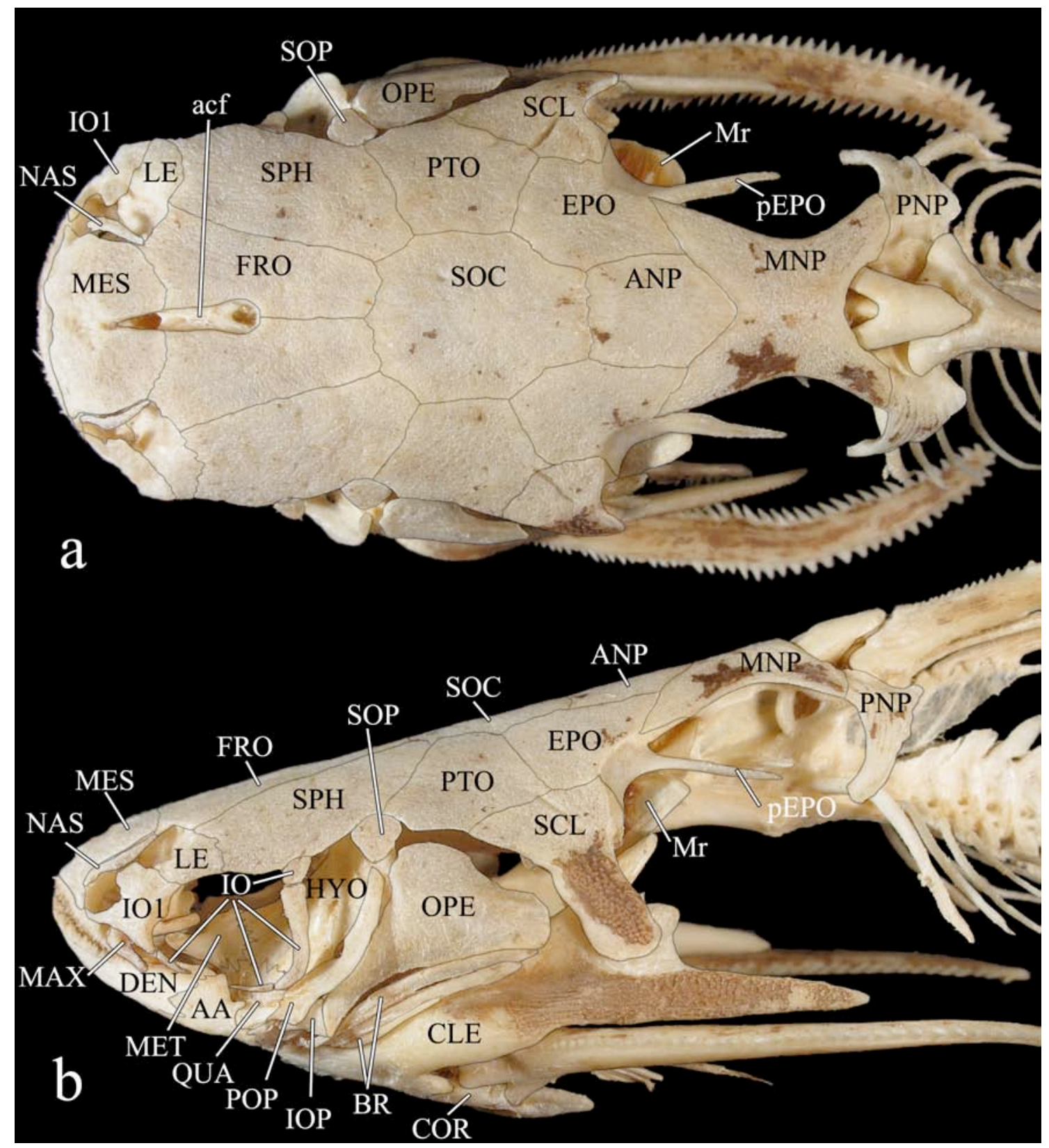

Figura 31. Crânio de Auchenitperichthys longimannus, MZUSP 52103 (161 mm), em vista dorsal (a) e lateral (b). AA: ângulo-articular, acf: fontanela craniana anterior, ANP: placa nucal anterior, BR: raios branquiostégios, CLE: cleitro, COR: coracóide, DEN: dentário, EPO: epoccipital, FRO: frontal, HYO: hiomandibular, IO: infra-orbital(is), IOP: interopérculo, LE: etmóide lateral, MAX: maxilar, MES: mesetmóide, MET: metapterigóide, MNP: placa nucal mediana, Mr: ramo de Müller, NAS: nasal, OPE: opérculo, pEPO: processo do epoccipital, PNP: placa nucal posterior, POP: pré-opérculo, PTO: pterótico, QUA: quadrado, SCL: pós-têmporo-supracleitro, SOC: parieto-supra-occipital, SOP: supra-opérculo, SPH: esfenótico. 


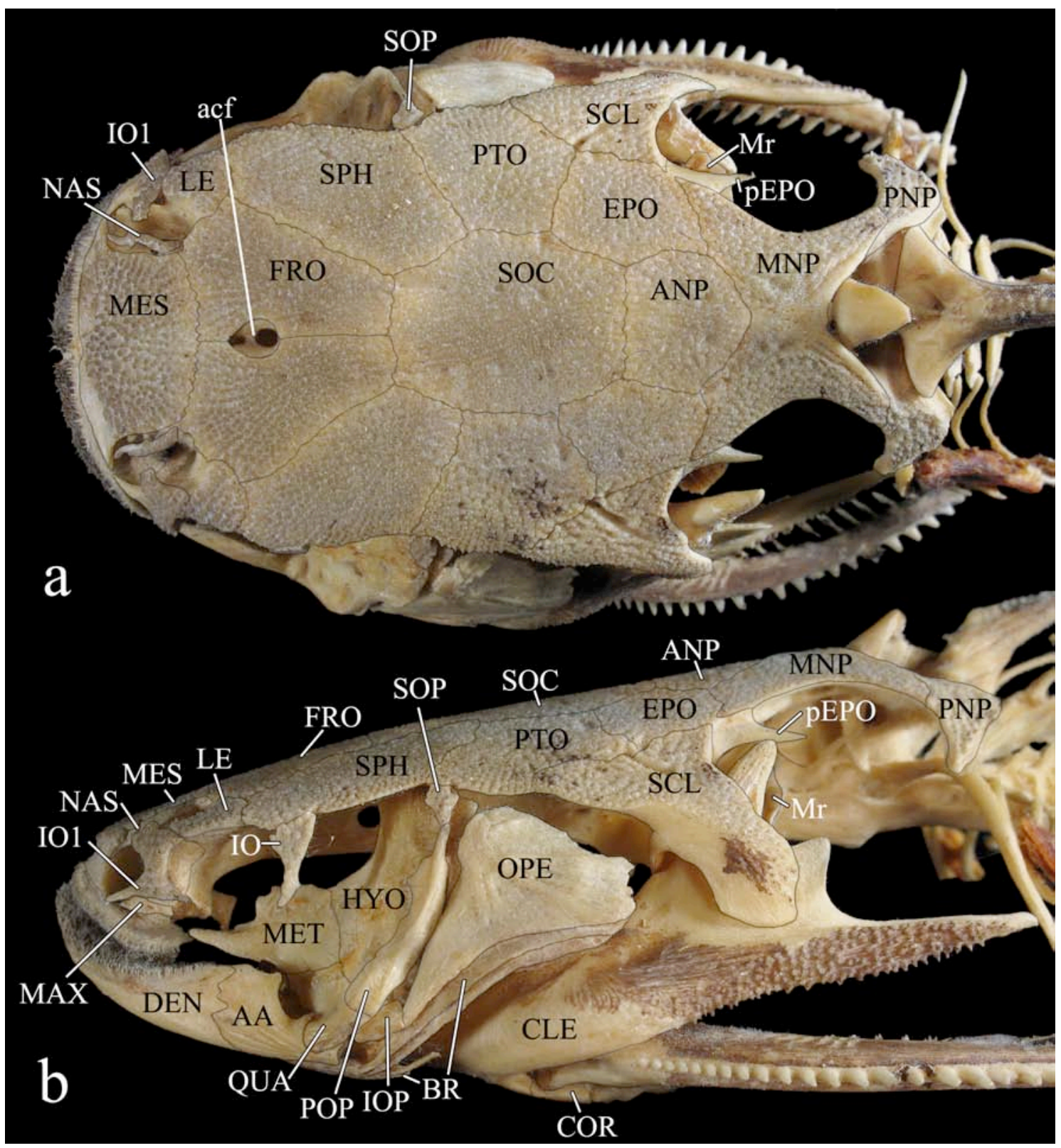

Figura 32. Crânio de Trachycorystes trachycorystes, MZUSP 104547 (180 mm), em vista dorsal (a) e lateral (b). AA: ângulo-articular, acf: fontanela craniana anterior, ANP: placa nucal anterior, BR: raios branquiostégios, CLE: cleitro, COR: coracóide, DEN: dentário, EPO: epoccipital, FRO: frontal, HYO: hiomandibular, IO: infra-orbital(is), IOP: interopérculo, LE: etmóide lateral, MAX: maxilar, MES: mesetmóide, MET: metapterigóide, MNP: placa nucal mediana, Mr: ramo de Müller, NAS: nasal, OPE: opérculo, pEPO: processo do epoccipital, PNP: placa nucal posterior, POP: pré-opérculo, PTO: pterótico, QUA: quadrado, SCL: pós-têmporo-supracleitro, SOC: parieto-supra-occipital, SOP: supra-opérculo, SPH: esfenótico. 


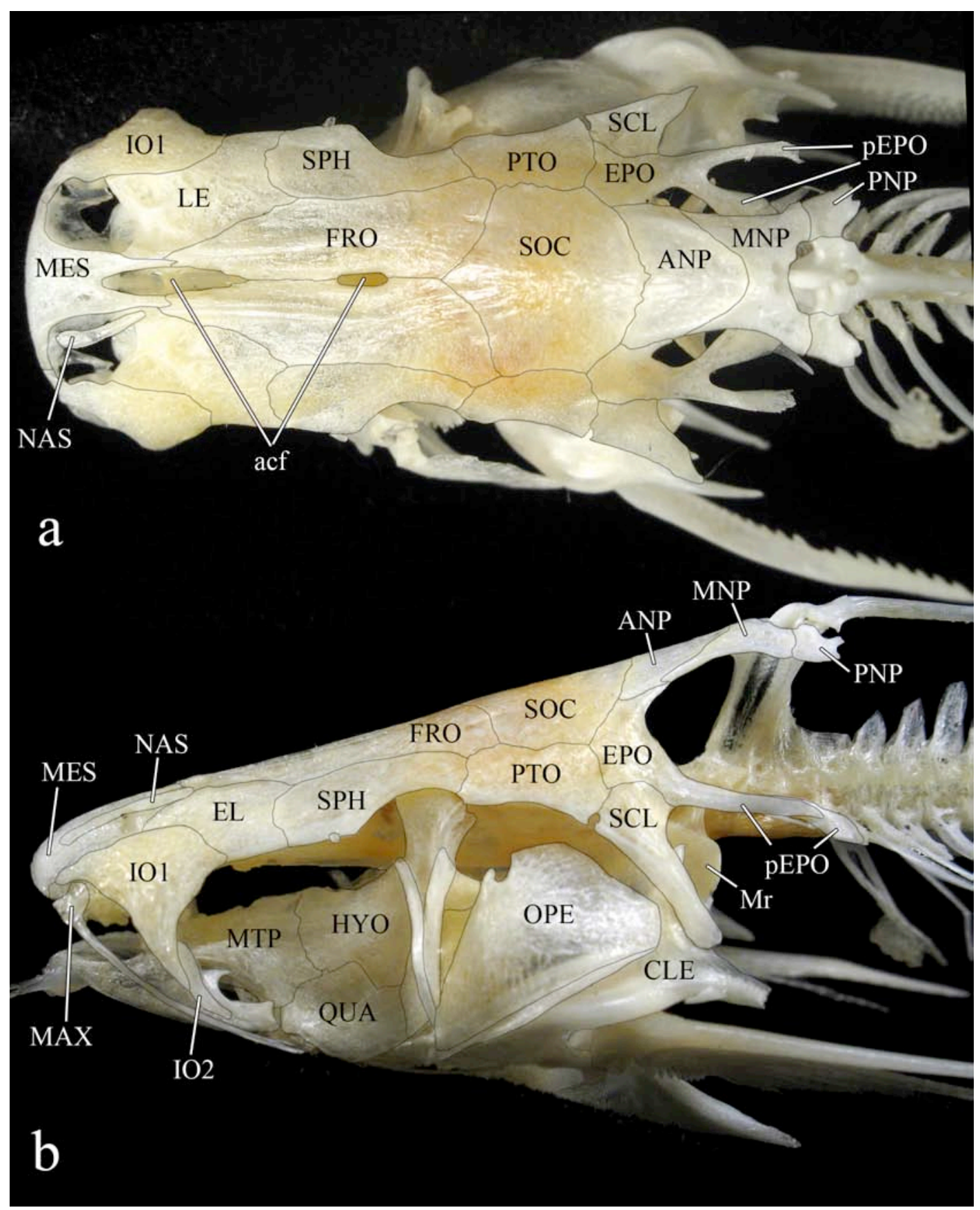

Figura 33. Crânio de Auchenipterus osteomystax, MZUSP 97375 (120.0 mm), em vista dorsal (a) e lateral (b). AAacf: fontanela craniana anterior, ANP: placa nucal anterior, CLE: cleitro, EPO: epoccipital, FRO: frontal, HYO: hiomandibular, IO: infra-orbital(is), LE: etmóide lateral, MAX: maxilar, MES: mesetmóide, MET: metapterigóide, MNP: placa nucal mediana, Mr: ramo de Müller, MNAS: nasal, OPE: opérculo, pcf: fontanela craniana posterior, pEPO: processo do epoccipital, PNP: placa nucal posterior, PTO: pterótico, QUA: quadrado, SCL: pós-têmporo-supracleitro, SOC: parieto-supra-occipital, SPH: esfenótico. 


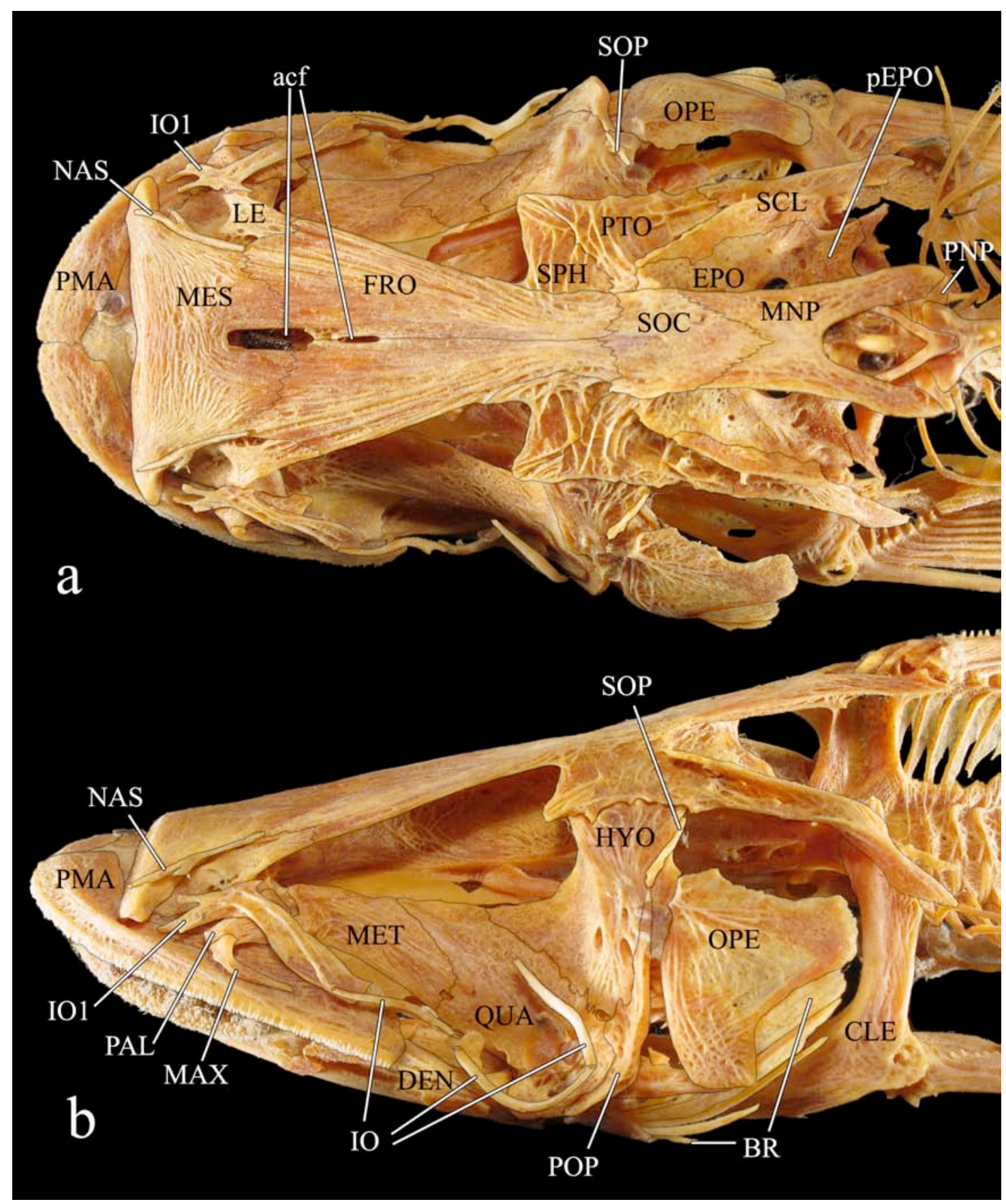

Figura 34. Crânio de Ageneiosus inermis, MZUSP 91661 (320.0 mm), em vista dorsal (a) e lateral (b). acf: fontanela craniana anterior, BR: raios branquiostégios, CLE: cleitro, DEN: dentário, EPO: epoccipital, FRO: frontal, HYO: hiomandibular, IO: infra-orbital(is), , LE: etmóide lateral, MAX: maxilar, MES: mesetmóide, MET: metapterigóide, MNP: placa nucal mediana, OPE: opérculo, PAL: autopalatino, pEPO: processo do epoccipital, PMA: pré-maxilar, PNP: placa nucal posterior, POP: préopérculo, PTO: pterótico, QUA: quadrado, SCL: pós-têmporo-supracleitro, SOC: parieto-supra-occipital, SOP: supra-opérculo, SPH: esfenótico. 
61. Comprimento do mesetmóide: (0) relativamente curto (figs. 15-23, 29-34); (1) relativamente longo (figs. 24-28). CI: 1,00; RI: 1,00 .

O mesetmóide em Doras, Hemidoras, Nemadoras, "Nemadoras", Hassar, Anduzedoras e Leptodoras é extremamente longo (mais longo do que o diametro orbital) e estreito (mais de 3 vezes mais longo do que largo) (Higuchi, 1992: \#13; Birindelli, \#33).

62. Porção anterior do mesetmóide: (0) semelhante à posterior, coberta por pele fina (figs. 15-31, 33-34); (1) distinta da posterior, coberta por uma camada espessa de pele (fig. 32 ). CI: 0,33 ; RI: 0,60 .

Nos auchenipterídeos Parauchenipterus, Trachelyopterus, Trachycorystes, Liosomadoras e Trachelyopterichthys, o mesetmóide possui a superfície da porção anterior desnivelada, mais baixa em relação ao restante, e coberta por pele espessa (o restante do mesetmóide é coberto por pele fina, visualmente exposto). Uma condição semelhante ocorre em Trachydoras steindachneri (Higuchi, 1992: \#12; Birindelli, 2006: \#36).

63. Coalescência dos ramos anteriores do mesetmóide: (0) ausente (figs. 15-19, 2134); (1) presente (fig. 20). CI: 1,00; RI: 1,00.

Nas espécies de Rhynchodoras, Rhinodoras e Orinocodoras os ramos anteriores do mesetmóide estão coalescidos, formando um leque anterior (Higuchi, 1992: \#A09, \#A10; Birindelli, 2006: \#35).

Esse caráter foi codificado como inaplicável em Aspredinidae e Chiloglanis, por possuírem os ramos anteriores do mesetmóide. 
64. Protuberância dorso-mediana no mesetmóide: (0) ausente; (1) presente. CI: 1,00; RI: 0,00 .

Em Scorpiodoras e algumas outras espécies de Astrodoradinae, há uma protuberância dorso-mediana no mesetmóide (Birindelli, 2006: \#37).

65. Quilha ântero-ventral no mesetmóide (ordenado): (0) ausente; (1) presente, mas não diferenciada num processo ventral (fig. 35a); (2) presente e diferenciada num processo ventral (fig. 35b). CI: 1,00; RI: 1,00 .

Em Doradini o mesetmóide apresenta ventralmente um quilha onde se encaixam os pré-maxilares, que são reduzidos em Doradini. Esta quilha lembra um pouco aquela presente em alguns Loricarioidea (Britto, 2002: \#3) e em alguns Chiloglanidinae (Vigliotta, 2008: \#1). Em Trachydoras, a quilha ântero-ventral é diferenciada num processo ventral (Birindelli, 2006: \#32). 


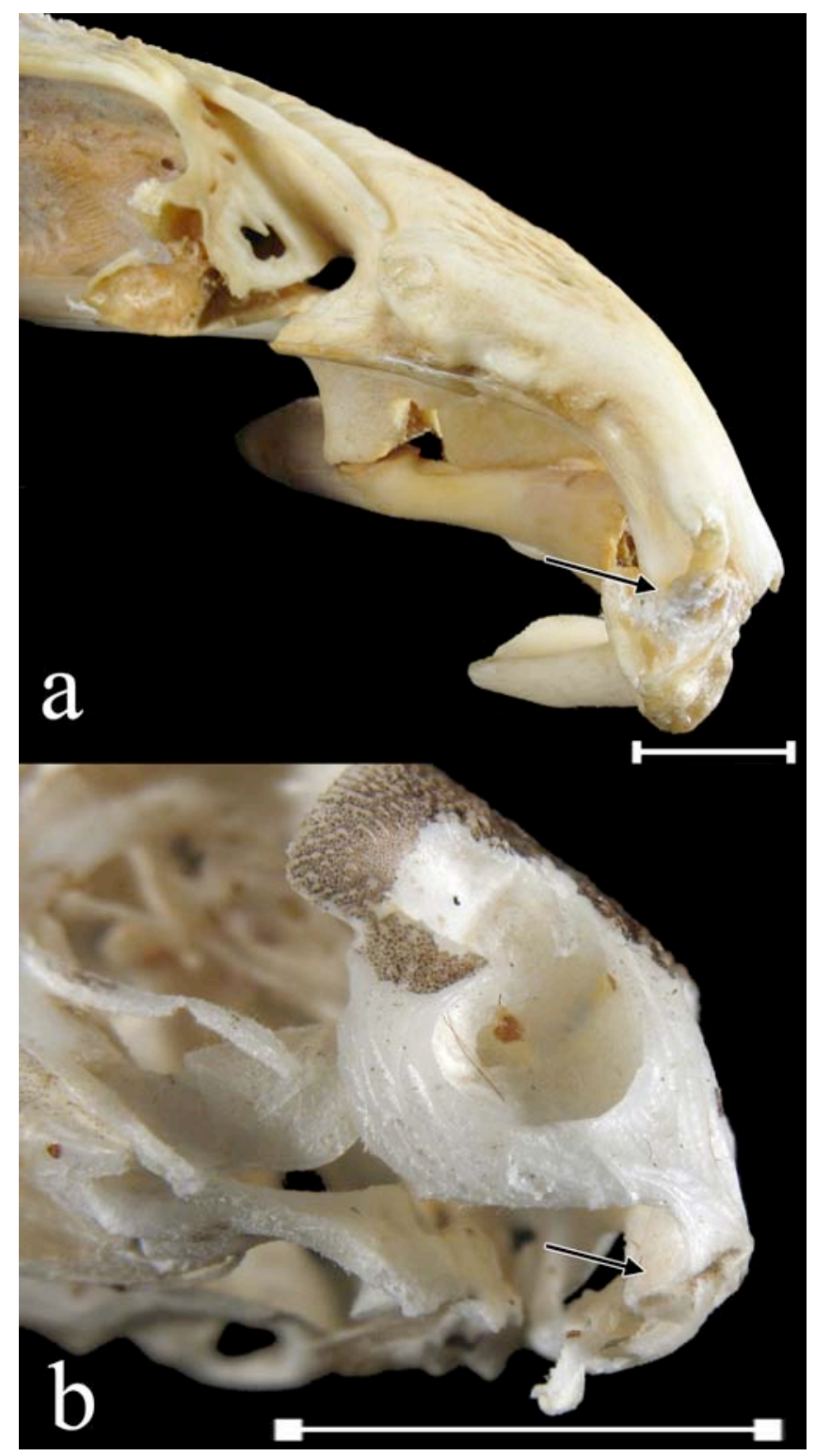

Figura 35. Porção anterior do crânio de: Oxydoras niger (a), MZUSP 91654 (550.0 mm); e Trachydoras brevis (b), MZUSP $103087(74.0 \mathrm{~mm})$. Seta indica a quilha ântero-ventral do mesetmóide. Escala igual a $10 \mathrm{~mm}$.

66. Forma da fontanela anterior: (0) alongada (figs. 15-34); (1) arredondada. CI: 0,33; RI: 0,00.

Em Siluriformes, no geral, a fontanela anterior é alongada, entre os frontais e o mesetmóide. Entretanto, em alguns táxons examinados, como em Trachelyichthys (Royero, 1999: \#4), Aspredinidae e Mochokus a fontanela anterior é arredondada e 
relativamente grande. Visto que esse é o formato da fontanela em exemplares de pequeno porte de diversas espécies, essa característica pode ser pedomórfica em Trachelyichthys, Aspredinidae e Mochokus.

67. Divisão da fontanela anterior (não ordenado): (0) ausente (figs. 15, 17, 19-29);

(1) fontanela anterior dividida em duas partes por uma ponte estreita entre os frontais (figs. 16, 18, 30-32, 34); (2) fontanela anterior dividida em duas porções por uma ponte extensa entre os frontais (fig. 33). CI: 0,44; RI: 0,40.

Em Siluriformes, no geral, a fontanela anterior é uma fenda contínua entre o mesetmóide e frontais. Contudo, em alguns táxons, como em Anadoras, Agamyxis, Doraops, “Amplexilganis", Tatia, Centromochlus, Liosomadoras, Auchenipterichthys, Ageneiosus inermis, Tetranematichthys, Trachelyopterichthys, Trachelyopterus, Parauchenipterus, Tocantinsia, Trachycorystes, e em alguns exemplares de Wertheimeria, Kalyptodoras, Pterodoras granulosus, Acanthodoras e Platydoras (Eigenmann, 1925: 284; Higuchi, 1992: \#10, \#A19; Birindelli, 2006: \#43, \#44), a fontanela anterior é dividida por uma ponte estreita entre os frontais (ou eventualmente restrita a um orifício no meio dos frontais em Trachycorystes e em alguns exemplares de Parauchenipterus, Liosomadoras e Tatia) (Royero, 1999: \#3; Akama, 2004: \#12, \#13, \#14). Em Auchenipterus, a fontanela anterior é dividida por uma ponte extensa entre os frontais.

Os táxons Platydoras, Acanthodoras, Wertheimeria, Kalyptodoras e Pterodoras foram codificados como polimórficos para esse caráter $(0,1)$.

68. Fontanela posterior (ordenado): (0) grande (figs. 15, 23, 27-28, 33); (1) pequena, quase completamente fechada (figs. 21, 26); (2) ausente (fechada) (figs. 
16-20, 22-25, 29-32, 34). CI: 0,11; RI: 0,74.

A fontanela posterior, formada entre os frontais e o parieto-supra-occipital, e limitada anteriormente pela barra epifisiana, está ausente em diversos Siluriformes (Lundberg, 1970: \#16), incluindo a maioria dos Doradoidea. Dentre os táxons examinados, a fontanela posterior está ausente em Pimelodidae, Pseudopimelodidae, Heptapteridae, Malapteruridae, Sisoridae, Erethistidae, e nos mochokídeos Microsynodontis, Synodontis nigriventris e Chiloglanis disneyi (Vigliotta, 2008: \#6).

Dentre os Doradoidea, a fontanela posterior está ausente em Auchenipteridae e Doradidae (exceto Hassar, Anduzedoras, Leptodoras, Trachydoras, Nemadoras, “Nemadoras", Oxydoras) (Higuchi, 1992: \#17; \#31; Birindelli, 2006: \#44).

A fontanela posterior é grande nos seguintes táxons estudados: Diplomystidae, Nematogenyidae, Ictaluridae, Ariidae, Pangasiidae, Aspredinidae, Claroteidae, Siluridae, Amphiliidae, Mochokidae (exceto táxons mencionados acima) e nos Doradoidea Trachydoras, Nemadoras hemipeltis, "Nemadoras", Hassar, Anduzedoras, Leptodoras (Higuchi, 1992: \#31); e pequena, quase completamente fechada em: Oxydoras, Nemadoras elongatus, Nemadoras humeralis (Birindelli, 2006: \#45, \#60).

Esse caráter foi ordenado de acordo com o estudo de ontogenia dos táxons estudados: a fontanela posterior está presente em larvas, porém apresenta-se fechada em exemplares maiores.

69. Orifício no parieto-supra-occipital (resquício da fontanela posterior): (0) ausente; (1) presente. CI: 0,50; RI: 0,00.

Em Pseudopimelodus, Mochokus, Microsynodontis, algumas espécies de Synodontis (e.g., S. zambezensis) e Chiloglanis polypogon há um forame no parietosupra-occipital, resquício do fechamento da fontanela posterior (Vigliotta, 2008: \#7). 
70. Participação do etmóide lateral no escudo cefálico: (0) ausente; (1) presente (figs. 15-34). CI: 0,17; RI: 0,38.

O etmóide lateral é primitivamente um osso lateral do crânio, que não forma o escudo cefálico. Entretanto, em diversos Siluriformes (Ictaluridae, Ariidae, Pimelodidae, Aspredinidae, Sisoridae, Erethistidae, Claroteidae, Siluridae, Mochokidae, entre os analisados), o etmóide lateral faz parte do escudo cefálico (Alexander, 1965: 97).

O etmóide lateral faz parte do escudo cefálico em Doradoidea (exceto Centromochlus heckelii, Pseudotatia e Pseudauchenipterus). Apesar de Higuchi (1992: \#15) ter considerado que Wertheimeria não possui o etmóide lateral formando o escudo cefálico, os exemplares examinados no presente estudo apresentam o etmóide lateral formando o escudo cefálico.

71. Fenestra entre o etmóide lateral e o frontal: (0) ausente; (1) presente. CI: 0,14; RI: $\mathbf{0 , 5 4 .}$

Em Ariidae há uma grande fenestra entre o etmóide lateral e o frontal (Marceniuk, 2003). Em alguns outros grupos de Siluriformes (Diplomystidae, Pimelodidae, Heptapteridae, Siluridae, Mochokidae, Claroteidae, Pangasiidae, Ictaluridae), apesar de menor, ela também está presente (de Pinna, 1993: \#68; Britto, 2002: \#6). O único Doradoidea que possui esta fenestra é Pseudauchenipterus.

Esse caráter não foi observado em Pseudotatia.

72. Margem lateral do etmóide lateral: (0) lisa ou granulada; (1) serrilhada. CI: 1,00; RI: 1,00 . 
A margem do etmóide lateral é serrilhada em Scorpiodoras, Agamyxis e alguns exemplares de Acanthodoras (Higuchi, 1992: \#A14, \#A15; Birindelli, 2006: \#40; Sousa \& Birindelli, no prelo).

Acanthodoras foi considerado polimórfico para esse caráter $(0,1)$.

73. Processo lateral do esfenótico: (0) ausente (figs. 15-23, 25-26, 29-33); (1) presente (figs. 24, 27, 28, 34). CI: 0,20; RI: $0,76$.

Em alguns táxons analisados, como em Malapterurus, Amphilius, Tetranematichthys, Ageneiosus, Doras, 'Nemadoras', Hassar, Anduzedoras e Leptodoras, o esfenótico apresenta um distinto processo lateral (Royero, 1999: \#12; Akama, 2004: \#31; Birindelli, 2006: \#57).

74. Margem látero-posterior do esfenótico: (0) ligeiramente côncava (figs. 15-28, 30-32); (1) extremamente côncava, distintamente escavada (figs. 29, 33-34). CI: 0,50; RI: 0,88.

Em Glanidium, Ageneiosus, Tetranematichthys, “Amplexiglanis", Entomocorus, Auchenipterus, Epapterus e Pseudepapterus, a margem látero-posterior do esfenótico é distintamente escavada, expondo parte da articulação do hiomandibular com o neurocrânio (Royero, 1999: \#20; Akama, 2004: \#34). Esta característica varia um pouco entre os táxons mencionados acima, e está presente em menor grau em alguns outros auchenipterídeos.

75. Participação do frontal na margem orbital: (0) presente (figs. 15-30, 34); (1) ausente (figs. 31-33). CI: 0,20; RI: 0,60.

A margem orbital de Siluriformes, no geral, é formada pelos infra-orbitais, 
etmóide lateral e frontal. Entretanto, em Auchenipterus, Epapterus, Pseudepapterus, "Amplexiglanis", Liosomadoras, Trachycorystes, Asterophysus, Trachelyopterichthys, Auchenipterichthys, Parauchenipterus e Trachelyopterus, a margem orbital é formada pelos infra-orbitais, etmóide lateral e esfenótico (Britski, 1972: 13; Ferraris, 1988: \#N8; Higuchi, 1992: \#A21, \#34; Royero, 1999: \#1; Britto, 2002: \#5; Akama, 2004: \#17).

76. Participação do etmóide lateral na margem orbital: (0) presente (figs. 15-20, 22-34); (1) ausente (fig. 21). CI: 1,00; RI: 1,00.

Em Oxydoras, a margem orbital é recuada para trás, sendo formada pelos infraorbitais, frontal e esfenótico (Alexander, 1965; Higuchi, 1992: \#A21, \#A34; Birindelli, 2006: \#42), enquanto que nos demais táxons examinados, o etmóide lateral participa da margem orbital.

77. Processo ventral do pterótico: (0) ausente; (1) presente. CI: 0,50; RI: 0,50.

O pterótico em Mochokiella, Microsynodontis e Synodontis apresenta um distinto processo ventral (Vigliotta, 2008: \#11).

78. Fenestra entre parieto-supra-occipital, pterótico e pós-têmporo-supracleitro: (0) ausente; (1) presente. CI: 1,00; RI: 1,00 .

Dentre as espécies examinadas, algumas espécies de Synodontis (e.g., S. schall, S. membranacea e $S$. batensoda) apresentam uma fenestra entre o parieto-supra-occipital, pterótico e pós-têmporo-supracleitro. Apesar deste caráter não ter sido usado por Vigliotta (2008), ele parece ser informativo para as relações dentro do gênero Synodontis. 
79. Fenestra entre parieto-supra-occipital, pterótico e esfenótico: (0) ausente; (1) presente. CI: 1,$00 ; \mathrm{RI}: \mathbf{0 , 0 0}$.

Uma fenestra entre o parieto-supra-occipital, pterótico e esfenótico está presente apenas em Pseudepapterus, entre os táxons analisados.

80. Processo posterior do parieto-supra-occipital: (0) presente (fig. 15); (1) ausente (figs. 16-34). CI: 1,00; RI: 1,00.

Primitivamente em Siluriformes, o parieto-supra-occipital apresenta um processo posterior. Entretanto, em Mochokidae e Doradoidea esse processo está ausente (Royero, 1999: \#22). O processo posterior do parieto-supra-occipital é truncado em alguns Siluriformes, como em algumas espécies de Aspredinidae, ou curto, como em Malapterurus. Diogo (2004: \#131) considerou o truncamento do processo posterior do parieto-supra-occipital como uma sinapomorfia de um suposto clado contendo Malapteruridae, Mochokidae, Doradidae e Auchenipteridae; contudo, Malapteruridae claramente apresenta o processo posterior do parieto-supra-occipital enquanto os demais táxons mencionados não.

81. Contato entre esfenótico e parieto-supra-occipital: (0) presente (figs. 15-32, 34); (1) ausente (fig. 33). CI: 0,33; RI: 0,00.

Em Epapterus e Auchenipterus o frontal estende-se posteriormente até o pterótico, deixando o esfenótico sem contato com o parieto-supra-occipital (Chardon, 1968; Britski, 1972: 13; Ferraris, 1988, \#N10; Royero, 1999: \#2, \#18; Akama, 2004: \#19, \#26). Uma condição semelhante ocorre em Malapteruridae, Helogeninae e Clariidae (Mo, 1991; Britto, 2002: \#7; Diogo, 2004: \#97; de Pinna et al., 2007: \#34). 
82. Ossificação dérmica acessória entre frontal, esfenótico e parieto-supraoccipital: (0) ausente; (1) presente. CI: 1,00; RI: 0,00.

Entomocorus apresenta uma ossificação acessória entre frontal, esfenótico e parieto-supra-occipital (Britski, 1972: 14; Ferraris, 1988: \#N13; Akama, 2004: \#22).

83. Ossificação dérmica acessória entre esfenótico, pterótico e parieto-supraoccipital: (0) ausente; (1) presente. CI: 1,00; RI: 0,00.

Asterophysus apresenta uma ossificação acessória entre esfenótico, pterótico e parieto-supra-occipital (Britski, 1972: 14; Ferraris, 1988: \#N14; Akama, 2004: \#21).

84. Forma do vômer: (0) em T, com processos anteriores distintos (fig. 36a); (1) em I, com processos anteriores rudimentares (fig. 36b). CI: 0,25; RI: 0,91.

O vômer possui forma de T na maioria dos Siluriformes, contudo, em Diplomystes (Arratia, 1992: \#50), Nematogenys, Malapterurus, Doradini (exceto Oxydoras) (Higuchi, 1992: \#14; Birindelli, 2006: \#38), Ageneiosus e Tetranematichthys o vômer possui forma de I, com os ramos anteriores do vômer rudimentares (Britski, 1972: 23; Ferraris, 1988: \#N18; Walsh, 1990: \#3; Akama, 2004: \#24). Soares-Porto (1998: \#11) ainda cita este caráter para duas espécies de Centromochlus. 


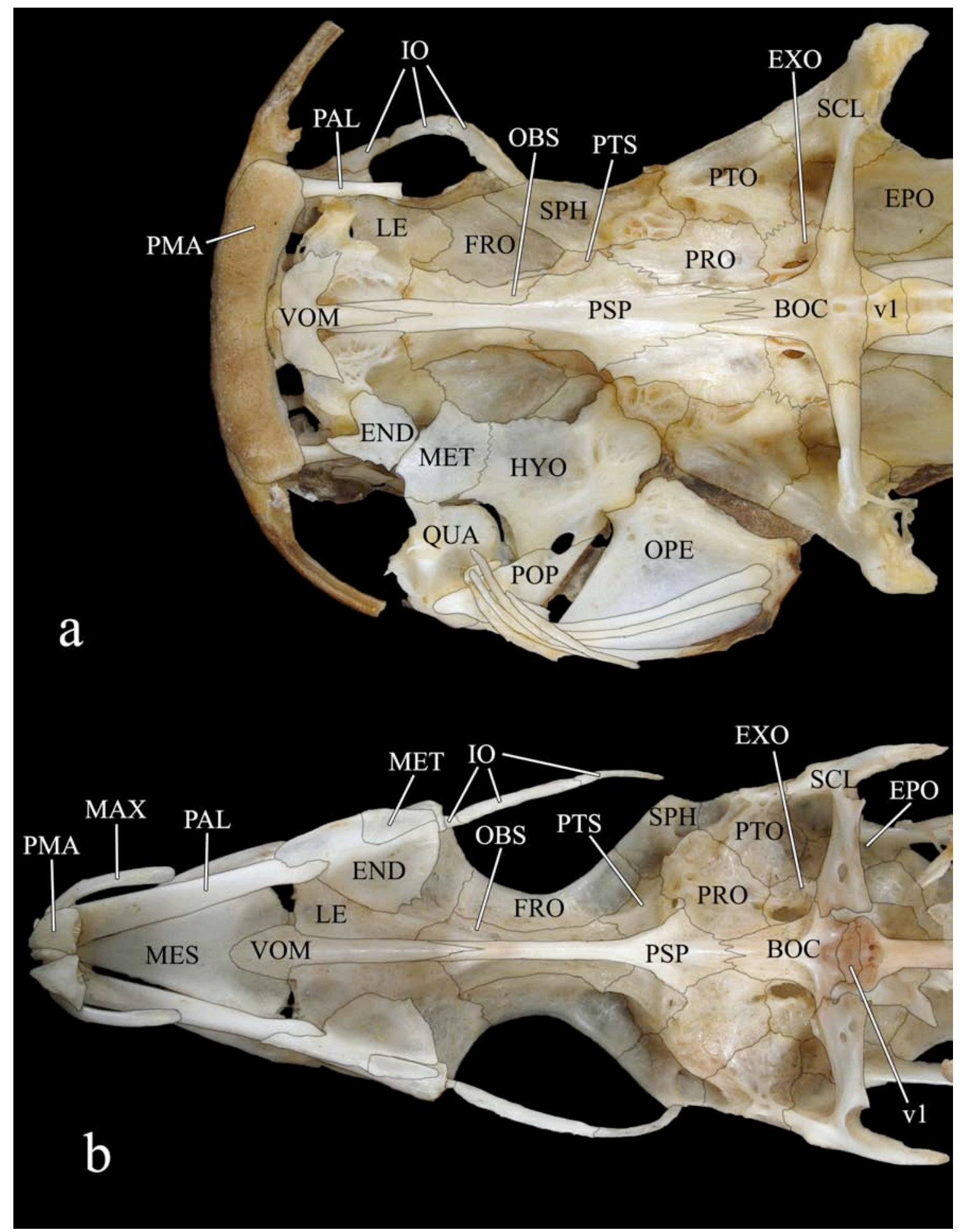

Figura 36. Crânio, em vista ventral, de: Wertheimeria maculata (a), MZUSP 93659 (270.0 mm); Doras higuchii (b), MZUSP 101693 (172.0 mm). BOC: basioccipital, END: ‘endopterigóide', EPO: epoccipital, EXO: exoccipital, FRO: frontal, HYO: hiomandibular, IO: infra-orbitais, LE: etmóide lateral, OBS: órbito-esfenóide, MET: metapterigóide, OPE: opérculo, PAL: autopalatino, PMA: pré-maxilar, POP: préopérculo, PRO: pró-ótico, PSP: para-esfenóide, PTO: pterótico, PTS: ptero-esfenóide, QUA: quadrado, 
SCL: pós-têmporo-supracleitro, SPH: esfenóide, v1: vértebra 1, VOM: vômer.

85. Dentes no vômer: (0) ausentes; (1) presentes. CI:0,25; RI: 0,40.

Alguns Siluriformes (Diplomystidae, Galeichthys, Pangasiidae, Pimelodidae, Claroteidae e Siluridae, entre os examinados) apresentam dentes no vômer (Lundberg, 1970; de Pinna, 1993: \#60; Britto, 2002: \#31; de Pinna et al., 2007: \#37). Apesar de nenhuma espécie de Doradoidea incluída no presente estudo apresentar dentes vomerianos, Mees (1974: 66) os reporta em Tatia intermedia, e Royero (1999: \#32) os reporta em uma espécie não descrita de Tatia. Akama (2004: \#52) reportou a presença de dentes vomerianos em Asterophysus, o que não foi corroborado no único exemplar diafanizado examinado dessa espécie.

86. Placas dentígeras acessórias ao vômer: (0) ausentes; (1) presentes. CI: 0,50; RI: 0,67 .

Em Ariidae, Pangasiidae, Schilbidae, Claroteidae e Hypsidoridae, há placas dentígeras acessórias ao vômer (Ferraris, 1988: \#J10; de Pinna, 1993: \#72; Royero, 1999: \#32; Britto, 2002: \#32; Akama, 2004: \#52).

87. Expansão látero-ventral do órbito-esfenóide: (0) ausente; (1) presente. CI: 0,50; RI: $\mathbf{0 , 0 0 .}$

Em Auchenipterus e Pseudepapterus há uma expansão látero-ventral no órbitoesfenóide (Royero, 1999: \#42).

88. Fenestra entre frontal e órbito-esfenóide: (0) ausente; (1) presente. CI: 0,33; RI: $\mathbf{0 , 3 3 .}$ 
Em Centromochlus, Glanidium, Pseudotatia e Pseudauchenipterus há uma fenestra entre o frontal e o órbito-esfenóide (Akama, 1999; Royero, 1999: \#45; Akama, 2004: \#25).

89. Quilha ventral do assoalho do neurocrânio: (0) ventralmente arredondada e curta (fig. 36a); (1) ventralmente afilada e longa (fig. 36b). CI:0,25; RI: 0,88.

Em Centromochlus, Auchenipterus, Trachydoras, Doras, Hemidoras, Nemadoras, "Nemadoras", Hassar, Anduzedoras e Leptodoras basais (Ferraris, 1988: \#N17; Akama, 2004: \#23; Higuchi, 1992: \#40), a quilha longitudinal ventral do assoalho do neurocrânio é afilada e longa, uma característica presente em espécies que possuem olhos grandes, convergente em doradídeos e auchenipterídeos.

90. Aberturas para passagem dos nervos óptico e trigêmio-facial no neurocrânio: (0) unidas num único forame; (1) separadas em dois forames. CI: 1,00; RI: 1,00.

Nos Siluriformes estudados (exceto em Diplomystes e Nematogenys) há dois forames separados para os nervos óptico e trigêmio-facial. Em Diplomystes e Nematogenys há um forame único que se estende entre os ossos órbito-esfenóide, pteroesfenóide, pró-ótico e paresfenóide (Alexander, 1965: 95).

91. Processo lateral do basioccipital: (0) ausente ou rudimentar; (1) presente (fig. 36). CI: 0,33; RI: 0,78 .

O processo lateral do basioccipital, que o conecta ao processo trans-escapular está presente em Galeichthys, Aspredinidae, Sisoridae, Erethistidae, Claroteidae, Mochokidae e Doradoidea (Royero, 1999: \#46; Vigliotta, 2008: \#13). Esta característica foi usada por Lundberg (1993: 180) para suportar a relação do fóssil, ainda não descrito, 
"Titanoglanis" com a subordem Doradoidei. Em alguns táxons examinados, há uma pequena variação: alguns exemplares não tem o processo lateral do basioccipital, enquanto outros o possuem rudimentar.

92. Extensão ventral no basioccipital (não ordenado): (0) ausente; (1) presente como um arco sob a artéria aorta (fig. 37c); (2) presente como um processo laminar (fig. 37d). CI: 1,00; RI: 1,00.

Em Hassar o basioccipital possui uma extensão ventral em forma de arco sob a artéria aorta, e em Trachydoras há uma extensão laminar grande no basioccipital (Higuchi, 1992: \#41; Birindelli, 2006: \#65).

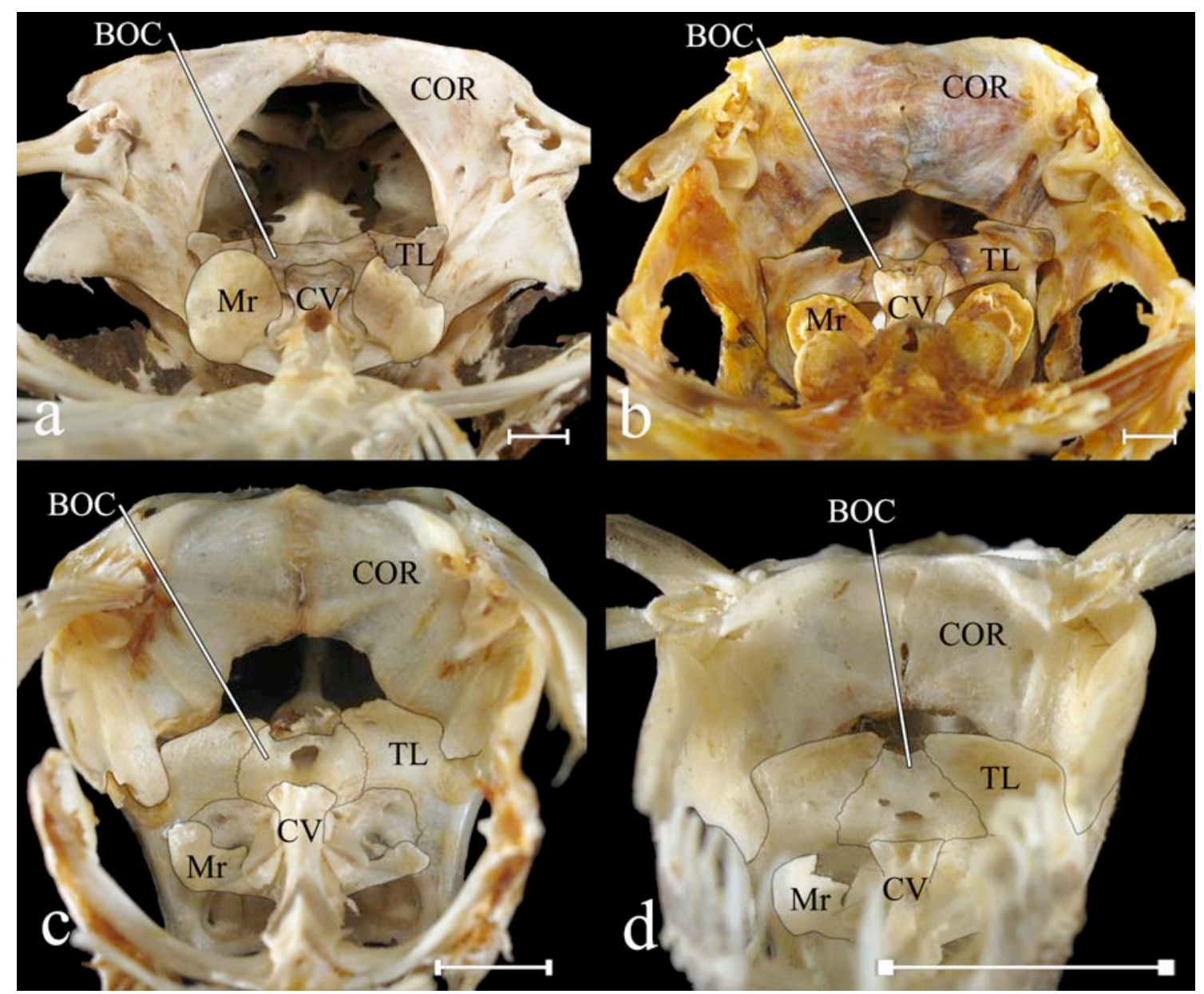

Figura 37. Cintura peitoral e vértebras anteriores, em vista posterior, de: Pterodoras rivasi (a), MZUSP 105825 (350.0 mm); Oxydoras sifontesi (b), MZUSP 105824 (413.0 mm); Hassar orestis (c), MZUSP 
32542 (220.0 mm); Trachydoras brevis (d), MZUSP 103087 (74.0 mm). BOC: basioccipital, COR: coracóide, CV: vértebra complexa, Mr: ramo de Müller, TL: processo trans-escapular. Barra de escala igual a $10 \mathrm{~mm}$.

93. Sutura entre exoccipital e arco neural da vértebra complexa: (0) ausente (fig. 55a); (1) presente (fig. 55g). CI: 1,00; RI: $1,00$.

Em Siluriformes, no geral, o exoccipital contacta via cartilagem o arco neural da vértebra complexa (Arratia, 1987: fig. 9). Entretanto, em Doradidae e Auchenipteridae o exoccipital é suturado ao arco neural da vértebra complexa (Ferraris, 1988: \#V1; de Pinna, 1993: \#190; Royero, 1999: \#49; Akama, 2004: \#45).

\section{Participação do epoccipital no escudo cefálico: (0) ausente (fig. 15); (1) presente} (fig. 16-34). CI: 1,00; RI: 1,00.

O epoccipital possui uma parte exposta dorsal que participa do escudo cefálico somente em Doradidae e Auchenipteridae (Regan, 1911; Ferraris, 1988: \#N3; de Pinna, 1993: \#77; Royero, 1999: \#29; Britto, 2002: \#48; Diogo, 2004: \#118; Akama, 2004: \#5, \#38). Royero (1999: 64) menciona que em Parauchenipterus galeatus o epoccipital é um osso composto por duas ossificações que se fundem ontogeneticamente, uma endocondral (o epoccipital, ventral) e uma dérmica (dorsal, chamado de parietal por Royero, 1999). Tendo isso em vista, é possível que o extra-escapular não tenha desaparecido em Doradoidea, mas esteja fusionado ao epoccipital, o que é coerente com a posição do extra-escapular nos demais Siluriformes. Royero (1999: \#15) ainda menciona esse caráter (epoccipital no escudo cefálico) para Mochokidae, o que não foi corroborado no presente estudo; em Mochokidae o epoccipital não possui qualquer parte dorsal, e não participa do escudo cefálico. Em alguns Ariidae derivados, uma 
condição semelhante ocorre, na qual o epoccipital é parcialmente fusionado ao extraescapular, mas nestes o epoccipital já apresenta uma porção dérmica, dorsal mesmo quando não está fusionado ao extra-escapular (Kailola, 2004: \#23; Marceniuk \& Menezes, 2007: fig. 12).

95. Participação do epoccipital na margem lateral do escudo cefálico: (0) ausente (figs. 15-21, 32); (1) presente (figs. 22-31, 33-34). CI: 0,25; RI: 0,89.

O epoccipital participa da margem lateral do escudo cefálico em Doradini (exceto Oxydoras) e Auchenipteridae (exceto Trachycorystes, Asterophysus, Liosomadoras). Este caráter está relacionado ao contato entre o pós-têmporo-supracleitro e a placa nucal mediana, descrito por alguns autores (Higuchi, 1992: \#34; Royero, 1999: \#13; Akama, 2004: \#33).

Esse caráter foi codificado como inaplicável para os táxons não pertencentes à Doradoidea, por não possuírem o epoccipital no escudo cefálico.

96. Processo posterior do epoccipital (ordenado): (0) ausente (figs. 15); (1) predominantemente ligamentoso (figs. 16-17, 19-21, 29-30, 32); (2) predominantemente ossificado (figs. 19, 22-28, 31, 33-34). CI: 0,17; RI: 0,81.

O epoccipital apresenta um processo posterior ligamentoso ou ossificado em Ariidae (Mo, 1991; Acero \& Betancur, 2007), Amphiliidae, Pangasiidae, Schilbidae, Sisoridae (de Pinna, 1993: \#85; de Pinna, 1996: \#29; Britto, 2002; \#50), Mochokidae, Doradidae (Birindelli, 2006: \#62) e Auchenipteridae (Chardon, 1968: 229; Britski, 1972: 15; Ferraris, 1988: \#N4; Lundberg, 1993; Royero, 1999: \#50; Akama, 2004: \#7). Esse processo é predominantemente ossificado em Ariidae, Amphiliidae, Auchenipteridae (exceto Centromochlinae, Liosomadoras, Tocantinsia e 
Trachycorystes) e Doradidae (exceto Wertheimeria, Kalyptodoras, Franciscodoras, Acanthodoras, Agamyxis, Centrochir, Platydoras, Centrodoras, Megalodoras, Doraops, Lithodoras, Orinodoras, Rhinodoras e Oxydoras).

Esse caráter não foi observado em Galeichthys.

97. Sutura entre o processo posterior do epoccipital e a placa nucal posterior: (0) ausente (figs. 16-27, 29-34); (1) presente (fig. 28). CI: 0,50; RI: 0,88.

O processo posterior do epoccipital é suturado à placa nucal posterior apenas em

Doras carinatus, D. micropoeus, D. higuchii, Hassar, Anduzedoras e Leptodoras (Higuchi, 1992: \#37, \#38; Birindelli, 2006: \#62, \#63, \#64).

Esse caráter foi codificado como inaplicável para os seguintes táxons: Diplomystidae, Claroteidae, Nematogenyidae, Ictaluridae, Pimelodidae, Pseudopimelodidae, Heptapteridae, Aspredinidae, Malapteruridae, Pangasiidae, Erethistidae e Siluridae, por não possuírem o processo posterior do epoccipital.

\section{Sutura entre o processo posterior do epoccipital e as parapófises das vértebras} 5 e 6: (0) ausente; (1) presente (figs. 33-34). CI: 0,25; RI: 0,57.

O processo posterior do epoccipital é suturado às parapófises das vértebras 5 e 6 apenas em Trachelyopterus, Trachelyichthys, Tetranematichthys, Ageneiosus, Auchenipterus, Epapterus e Pseudepapterus (Ferraris, 1988: \#N5, \#N7, \#V10; Curran, 1989: \#3; Walsh, 1990: \#19; Royero, 1999: \#51, \#52, \#53, \#54; Akama, 2004: \#8, \#9, \#10,\#11). Britski (1972: 17) sugere que o desenvolvimento do processo do epoccipital está inversamente relacionado ao desenvolvimento do escudo nucal, funcionando como uma sistema de reforço para a ligação entre o crânio e a nadadeira dorsal.

Esse caráter foi codificado como inaplicável para os seguintes táxons: 
Diplomystidae, Claroteidae, Nematogenyidae, Ictaluridae, Pimelodidae, Pseudopimelodidae, Heptapteridae, Aspredinidae, Malapteruridae, Pangasiidae, Erethistidae e Siluridae, por não possuírem o processo posterior do epoccipital.

\section{Sutura entre o processo posterior do epoccipital e a parapófise da vértebra} complexa: (0) ausente; (1) presente. CI: 1,00; RI: 0,00.

O processo posterior do epoccipital é suturado à parapófise da vértebra complexa apenas em Ariidae, exceto Galeichthys (Acero \& Betancur, 2007).

Esse caráter foi codificado como inaplicável para os seguintes táxons: Diplomystidae, Claroteidae, Nematogenyidae, Ictaluridae, Pimelodidae, Pseudopimelodidae, Heptapteridae, Aspredinidae, Malapteruridae, Pangasiidae, Erethistidae e Siluridae, por não possuírem o processo posterior do epoccipital.

100. Extra-escapular: (0) presente; (1) ausente. CI: 0,25; RI: 0,73.

Entre os táxons examinados, o extra-escapular está ausente em Aspredinidae, Auchenipteridae, Amphiliidae, Doradidae, Erethistidae, Mochokidae, Nematogenyidae e Siluridae (Lundberg, 1970: \#24; Arratia, 1992: \#43; Britto, 2002: \#51; Vigliotta, 2008: \#14).

Royero (1999) identifica um centro de ossoficação dérmico que se funde ao epocicpital em Auchenipteridae e Doradidae. Pelo posição que o extra-escapular ocupa em outros Siluriformes, e pelo fato dele estar aparentemente ausente em auchenipterídeos e doradídeos, é possível que a ossificação relatada por Royero (1999, erroneamente identificada como parietal) seja o extra-escapular, que seria então fusionado ao epoccipital em auchenipterídeos e doradídeos. 
101. Contato entre o pós-têmporo-supracleitro e o crânio: (0) por ligamentos (fig. 15); (1) por sutura óssea (figs. 16-34). CI: 0,33; RI: 0,82.

O pós-têmporo-supracleitro é firmemente suturado ao crânio em Akysidae, Amphiliidae, Astroblepidae, Auchenipteridae, Callichthyidae, Clariidae, Doradidae, Erethistidae, Loricariidae, Mochokidae, Nematogenyidae, Scoloplacidae e Sisoridae (Alexander, 1965: 119; Chardon, 1968: 229; de Pinna, 1993: \#26; Royero, 1999: \#16; Britto, 2002: \#38; Arratia, 2003: 130; Diogo, 2004: \#155; Vigliotta, 2008: \#15). Nos Loricarioidea mencionados, há ainda a fusão do pós-têmporo-supracleitro com o pterótico (Britto, 2002: \#39).

102. Contato entre o pós-têmporo-supracleitro e a parapófise da vértebra complexa: (0) ausente; (1) presente. CI: 1,00; RI: 1,00 .

O pós-têmporo-supracleitro é suturado à vértebra complexa em Aspredinidae, Sisoridae e Erethistidae (de Pinna, 1996: \#27; Britto, 2002; \#44).

103. Fossa supratemporal: (0) ausente; (1) presente. CI: 1,00; RI: 1,00 .

Em Aspredinidae, Erethistidae e Sisoridae há uma depressão entre o parietosupra-occipital, pterótico e pós-têmporo-supracleitro: a fossa supratemporal (de Pinna, 1996: \#24; Britto, 2002: \#55; Diogo, 2004: \#123).

104. Orientação do processo trans-escapular: (0) aproximadamente perpendicular ao eixo do corpo (figs. 54b-d, 55); (1) aproximadamente $45^{\circ}$ em relação ao eixo do corpo (fig. 54a). CI: 1,00; RI: 1,00.

O processo trans-escapular está a aproximadamente $45^{\circ}$ em relação ao eixo do corpo em Ageneiosus e Tetranematichthys (Royero, 1999: \#47; Akama, 2004: \#44). 
105. Forma do processo trans-escapular: (0) ventralmente arredondado (fig. 36a); (1) ventralmente afilado, como uma lâmina (fig. 36b). CI: 1,00; RI: 1,00.

Em Doradini, o processo trans-escapular é ventralmente afilado como uma lâmina formando, juntamente à expansão dorsal do coracóide, um diafragma ósseo (Eigenamnn, 1925: 287; Higuchi, 1992: \#29, \#30, \#41; Birindelli, 2006: \#59).

\subsubsection{Canais látero-sensoriais}

106. Forma do nasal: (0) tubular (figs. 15-16, 18-31, 33-34); (1) expandido dorsalmente, aparentemente exposto (figs. 17, 32). CI: 0,20; RI: 0,20.

O nasal de Siluriformes, no geral, é um osso tubular derivado do canal supraorbital que se dirige anteriormente a partir do frontal, e apresenta um ramo lateral ossificado em diferentes graus (o que é intra-especificamente variável em alguns táxons). Entre os táxons examinados, Kalyptodoras, Platydoras (exceto Platydoras sp. “xingu”), Parauchenipterus, Trachycorystes, Tatia e Trachelyopterichthys apresentaram o nasal expandido dorsalmente, visualmente exposto (Soares-Porto, 1998: \#5; Akama, 2004: \#91, \#93).

107. Contato entre infra-orbital 1 e etmóide lateral: (0) fraco (fig. 15); (1) forte (figs. 16-34). CI: 1,00; RI: 1,00 .

Em Doradidae e Auchenipteridae o contato entre o infra-orbital 1 e o etmóide lateral é forte, feito através de ligamentos fortes e sutura óssea, enquanto que nos demais Siluriformes esse contato é fraco (Britski, 1972: 13; Mo, 1991: \#55; de Pinna, 1993: \#113; Royero, 1999: \#8, \#106; Britto, 2002: \#65; Akama, 2004: \#29). 
108. Extensão do contato entre infra-orbital 1 e etmóide lateral: (0) pequeno (ou ausente) (figs. 16-32, 34); (1) amplo (fig. 33). CI: 1,00; RI: 1,00.

Em Auchenipterus, Epapterus e Pseudepapterus, o infra-orbital 1 é amplamente suturado ao etmóide lateral (Ferraris, 1988: \#I9; Royero, 1999: \#8; Akama, 2004: \#96). Em todos os demais Siluriformes, há um contato pequeno entre esses dois ossos (ou mesmo ausente em alguns exemplares).

109. Participação do infra-orbital 1 na margem orbital: (0) ausente (figs. 15-17, 19-34); (1) presente (fig. 18). CI: 0,33; RI: 0,93.

Em Auchenipteridae e nos doradídeos Agamyxis, Acanthodoras, Astrodoradinae, Pterodoras e Lithodoras, o infra-orbital 1 participa da margem orbital (Higuchi, 1992: \#A13; Birindelli, 2006: \#50). Nos demais táxons analisados, o infra-orbital 1 está excluído da margem orbital.

110. Processo ventral do infra-orbital 1: (0) ausente ou curto (figs. 15-32); (1) longo (figs. 33-34). CI: 0,33; RI: 0,71.

O infra-orbital 1, em algumas espécies de Auchenipteridae (Centromochlus, Auchenipterus, Entomocorus, Pseudepapterus, Epapterus, Tetranematichthys e Ageneiosus), possui um longo processo ventral (Ferraris, 1988: \#I2, Walsh, 1990: \#13; Soares-Porto, 1998: \#14; Akama, 2004; \#29). Os demais táxons examinados possuem esse processo ausente ou curto.

111. Crista transversal serrilhada no infra-orbital 1: (0) ausente (figs. 15-16, 18, 20-34); (1) presente (figs. 17, 19). CI: 0,50; RI: 0,78 .

Em Platydoras, Centrochir, Agamyxis, Acanthodoras, Centrodoras, Megalodoras, 
Scorpiodoras e juvenis de Anadoras o infra-orbital 1 apresenta uma crista transversal serrilhada (Eigenmann, 1925: 286; Higuchi, 1992: \#20, \#21; Birindelli, 2006: \#49; Higuchi et al., 2007).

Anadoras foi considerado polimórfico para esse caráter $(0,1)$.

112. Tamanho da porção anterior do infra-orbital 1: (0) pequena e afilada anteriormente, menor do que a porção posterior (figs. 15-27, 29-34); (1) grande e dilatada anteriormente, de tamanho semelhante à porção posterior (fig. 28). CI: 0,50; RI: 0,88 .

O infra-orbital 1 de Doradoidea, e na maioria dos Siluriformes, é um osso em forma de foice com a porção anterior pequena e anteriormente afilada (Lundberg, 1970: fig. 55; Arratia, 1987: fig. 13; Sabaj Pérez \& Birindelli, 2008: fig. 4A). Entretanto, em Doras higuchii, D. carinatus, D. micropoeus, Hassar, Anduzedoras e Leptodoras, o infra-orbital 1 possui a porção anterior à narina anterior dilatada, de tamanho similar à posterior (Birindelli, 2006: \#53; Sabaj Pérez \& Birindelli, 2008: fig. 4B-D).

113. Sutura óssea entre o infra-orbital 1 e o mesetmóide: (0) ausente (figs. 15-22, 24-34); (1) presente (fig. 23). CI: 1,00; RI: 1,00.

Em Trachydoras, o infra-orbital 1 é robusto e ventralmente suturado ao mesetmóide, formando um assoalho ósseo para a cápsula olfativa (Higuchi, 1992: \#A29; Birindelli, 2006: \#51).

114. Número de infra-orbitais (ordenado): (0) 7 ou 8; (1) 6; (2) 5; (3) 4. CI: 0,36; RI: $\mathbf{0 , 4 0 .}$

A grande maioria dos Doradoidea possui 4 infra-orbitais. Anadoras é uma 
exceção, com 5 infra-orbitais (Birindelli, 2006: \#56). Em Auchenipteridae, a maioria dos táxons apresenta os túbulos da série infra-orbital variavelmente ossificados, ou seja, o túbulo entre dois poros possui algumas porções descontínuas ossificadas, contínuas apenas em alguns exemplares. Como essa ossificação é variável nesses táxons (inclusive entre exemplares de uma mesma espécie), o número de túbulos entre dois poros foi considerado o número de infra-orbitais, independente do número de ossificações. Desta forma, há 4 infra-orbitais nos auchenipterídeos. Este caráter foi tratado de forma diferente por outros autores (Ferraris, 1988: \#I1; Akama, 2004: \#89).

Os mochokídeos possuem 4 infra-orbitais, exceto Synodontis zambezensis (obs. pess.) e Chiloglanidinae que têm 5 (Vigliotta, 2008: \#23).

Em Siluriformes, Diplomystidae e Ictaluridae possuem 7 ou 8 infra-orbitais (Arratia, 1987; Lundberg, 1970: \#28); Pangasiidae e Sisoridae têm 6; Heptapteridae, Amphiliidae, Claroteidae, Malapteruridae e Siluridae possuem 5; e Ariidae, Pimelodidae, Pseudopimelodidae e Erethistidae possuem 4 (Kulongowski, 2001).

Esse caráter foi codificado como inaplicável para Aspredinidae, que apresenta uma condição não comparável. Esse caráter não foi observado em Nematogenys e Pseudotatia. Glanidium $(1,2)$ e Oxydoras niger $(2,3)$ foram considerados polimórficos para esse caráter.

115. Expansão dos infra-orbitais (não ordenado): (0) ausente, infra-orbitais tubulares (figs. 15-16, 19, 21-31, 33-34); (1) três últimos expandidos (fig. 17); (2) penúltimo e último infra-orbitais expandidos (fig. 18); (3) somente o penúltimo infra-orbital expandido; (4) somente o último infra-orbital expandido (figs. 20, 32). CI: 0,57; RI: 0,57 .

Os infra-orbitais são geralmente tubulares em Siluriformes, porém eles podem ser 
expandidos em placas em alguns táxons. Em Kalyptodoras, Acanthodoras, Agamyxis e Platydoras armatulus, todos os infra-orbitais são expandidos (Higuchi, 1992: \#25; Birindelli, 2006: \#55). Em Lithodoras e Pterodoras, o penúltimo e o último infraorbitais são expandidos (além do infra-orbital 1) (Higuchi, 1992: \#26; Birindelli, 2006: \#55). Em Megalodoras, somente o penúltimo infra-orbital é expandido (Higuchi, 1992: \#27; Birindelli, 2006: \#55). Em Orinocodoras e Trachycorystes apenas o último infraorbital é expandido (Ferraris, 1988: \#I8; Akama, 2004: \#95).

116. Espinhos nos infra-orbitais: (0) ausentes (figs. 15-16, 18-24, 16-31, 33-34); (1) presentes (figs. 17, 25, 32). CI: 0,17; RI: 0,55 .

Os infra-orbitais apresentam pequenos espinhos em Platydoras, Agamyxis, Acanthodoras, Scorpiodoras, Trachydoras steindachneri, Hemidoras morrisi, $H$. stenopeltis, H. morei, Liosomadoras, Trachelyopterichthys e Trachycorystes (Britski, 1972: 13; Royero, 1999: \#102; Akama, 2004: \#100; Birindelli, 2006: \#54).

117. Saída do canal infra-orbital no esfenótico: (0) na porção anterior do esfenótico (figs. 15-21, 29-34); (1) na porção posterior do esfenótico (figs. 22-28). CI: 0,50; RI: 0,97.

Em Siluriformes, no geral, a saída do canal infra-orbital está localizada na porção anterior do esfenótico, entretanto, em Doradini, a saída está na porção posterior desse osso (Higuchi, 1992: \#24). Uma condição semelhante ocorre em Synodontis, que também possui a cabeça comprimida e olhos relativamente grandes.

118. Canal temporal no epoccipital: (0) ausente; (1) presente. CI: 1,00; RI: 1,00. Em Auchenipterus, Entomocorus, Pseudepapterus e Epapterus o canal temporal 
da linha sensorial cefálica passa pelo epoccipital (Royero, 1999: \#94; Akama, 2004: \#104).

119. Ramo pterótico do canal temporal: (0) presente; (1) ausente. CI: 1,00; RI: 1,00 .

Em Auchenipterus, Entomocorus, Pseudepapterus e Epapterus o ramo pterótico do canal temporal está ausente (Royero, 1999: \#96).

120. Poro acessório do ramo ótico: (0) ausente; (1) presente. CI: 1,00; RI: 1,00.

Em Auchenipterus, Entomocorus, Pseudepapterus e Epapterus há um poro acessório do ramo ótico da linha sensorial cefálica localizado na borda lateral do crânio (Royero, 1999: \#97; Akama, 2004: \#102).

121. Canal sensorial mandibular: (0) presente; (1) ausente. CI: 0,50; RI: 0,67.

Em Sisor, Conta, Glyptosternoides, Aspredinidae e Chiloglanidinae o canal sensorial mandibular está ausente (de Pinna, 1996: \#3; Britto, 2002: \#67). Em Gelanoglanis o canal sensorial mandibular é livre da mandíbula (Ferraris, 1988: \#I10).

122. Número de poros no canal sensorial mandibular (ordenado): (0) 2 ou 3; (1) 4; (2) 5 ou 6; (3) 7; (4) 8. CI: 0,24; RI: 0,86.

Em Siluriformes, no geral, há 5 ou 6 poros no canal sensorial mandibular (Lundberg, 1970: \#42). Entretanto, nos doradídeos há redução do número de poros, sendo que em Agamyxis, Acanthodoras, Centrodoras, Megalodoras e Oxydoras, há 4 e em Doradini (exceto Oxydoras) há apenas 3 poros. Já nos auchenipterídeos, há um aumento do número de poros em algumas espécies, como em Parauchenipterus e 
Trachelyopterus nos quais há 7, e em Trachycorystes, Asterophysus e Trachelyopterichthys, nos quais há 8.

Em mochokídeos há diminuição no número de poros no canal sensorial mandibular, havendo apenas 2 ou 3 poros (Vigliotta, 2008: \#87).

Apesar de variar dentro de algumas espécies de Siluriformes, auchenipterídeos (exceto os mencionados acima) possuem 6 poros, enquanto a maioria dos doradídeos (excluindo os mencionados acima) possui 5. Pimelodidae, Pseudopimelodidae, Claroteidae, Siluridae e Ariidae também possuem um elevado número de poros no canal sensorial mandibular (8); Amphiliidae tem 3; Malapteruridae tem 7.

Esse caráter não foi examinado em Tocantinsia, Pseudotatia, Doraops e Rhynchodoras. Esse caráter foi codificado como inaplicável em Sisor, Conta, Glyptosternoides, Aspredinidae e Chiloglanis, por não possuírem o canal mandibular.

123. Poros da linha lateral cefálica: (0) simples; (1) múltiplos. CI: 0,33; RI: 0,33.

Em alguns Siluriformes, como em ariídeos, pimelodídeos, plotosídeos e pangasiídeos (Lundberg, 1970; Arratia, 1992: \#64; de Pinna, 1993: \#109; Arratia \& Huaquin, 1995: \#1; Royero, 1999: \#98; Vigliotta, 2008: \#86) os poros da linha lateral cefálica (e do corpo) são múltiplos, ou seja, os canalículos mais externos se ramificam diversas vezes formando muitos poros.

\section{Forma da linha lateral: (0) reta; (1) sinuosa. CI: 1,00; RI: 1,00 .}

Em Auchenipterinae, a linha lateral é sinuosa (Ferraris, 1988: \#I12; Akama, 2004: \#97). Apesar de Ferraris (1988: \#I12) ter mencionado essa condição para Glanidium, Tatia e Centromochlus, e Akama (2004: \#97) tê-la mencionado para Glanidium e Tatia, os exemplares examinados de Centromochlinae (exceto Centromochlus heckelli) 
apresentam a linha lateral reta, não sinuosa como os Auchenipterinae.

125. Forma da porção posterior da linha lateral: (0) reta, não bifurcada na nadadeira caudal; (1) bifurcada com dois ramos divergentes. CI: 0,20; RI: 0,56.

Nos gêneros Asterophysus, Trachycorystes, Parauchenipterus, Trachelyopterus Auchenipterus, Epapterus, Pseudepapterus, Tetranematichthys, Ageneiosus, a linha lateral é bifurcada com dois ramos divergentes na nadadeira caudal. (Britski, 1972; Ferraris, 1988: \#I11; Royero, 1999: \#101, Akama, 2004: \#88). Em alguns táxons, como Parauchenipterus ou Auchenipterus osteomystax, esses ramos são quase paralelos enquanto que em outros, como Auchenipterus ambyacus e Asterophysus, eles são quase perpendiculares à linha lateral (Akama, 2004: \#88).

Esse caráter não foi observado em Pseudotatia, e foi codificado como inaplicável em Entomocorus, que possui a linha lateral interrompida no pedúnculo caudal.

126. Linhas verticais de neuromastos dorsais à linha lateral: (0) ausentes; (1) presentes. CI: 0,50; RI: 0,92 .

Os auchenipterídeos (exceto Entomocorus, Pseudepapterus, Epapterus, Auchenipterus, Ageneiosus e Tetranematichthys) possuem linhas verticais de neuromastos dorsais à linha lateral (Ferraris, 1988: \#I13). Apesar de claramente presente em alguns táxons, como em Auchenipterichthys, no qual a pele ao redor dos neuromastos é descolorida, estas linhas parecem estar presente em maior ou menor grau na maioria das espécies de Auchenipteridae.

Esse caráter não foi observado em "Amplexiglanis".

127. Escudos ósseos laterais, formados a partir dos túbulos da linha lateral 
(ordenado): (0) ausentes; (1) com desenvolvimento heterogêneo ao longo do corpo; (2) com desenvolvimento homogêneo ao longo do corpo. CI: 0,33; RI: 0,96 .

Os túbulos da linha lateral se ossificam formando uma série longitudinal de escudos ósseos laterais em todas as espécies da família Doradidae (Eigenmann, 1925; Ferraris, 1988: \#I15; Higuchi, 1992: \#87; Royero, 1999: \#103, \#105; Akama, 2004: \#99), sendo este o caráter mais conspícuo da família, reconhecido desde os primeiros estudos do grupo (e.g., Linnaeus, 1766). Em alguns táxons (Wertheimeria, Kalyptodoras, Doraops, Hassar, Doras micropoeus, Nemadoras hemipeltis e “Nemadoras" leporhinus), os escudos do meio do corpo estão pouco desenvolvidos (Eigenmann, 1925: 301; Higuchi, 1992: \#96; Birindelli, 2006: \#120, \#121), sendo a condição mais extrema encontrada em Wertheimeria, no qual apenas poucos escudos estão presentes. Isto levou os primeiros autores que estudaram este táxon a considerar a fileira de escudos ósseos ausente, e, baseados nisso, incluí-lo em Auchenipteridae (Steindachner, 1877a; Eigenmann, 1925; ver histórico em Vono \& Birindelli, 2007). Em todas as espécies de Doradidae não mencionadas acima os escudos estão bem desenvolvidos, formando uma série homogênea de escudos laterais.

128. Espinhos retrorsos nos escudos ósseos laterais: (0) ausentes (fig. 38a); (1) presentes (fig. 38b-f). CI: 1,00; RI: 0,00 .

Na maioria das espécies de doradídeos, os escudos ósseos laterais possuem espinhos retrorsos (em exemplares com mais de $75 \mathrm{~mm}$ de $\mathrm{CP}$ ). Contudo, em Wertheimeria os escudos laterais são lisos (sem espinhos) e cobertos por pele (Birindelli, 2006: \#116). Os escudos laterais do pedúnculo caudal de Wertheimeria se formam com espinhos retrorsos (visíveis em exemplares com até $75.0 \mathrm{~mm} \mathrm{CP}$ ), entretanto tais espinhos regridem e estão ausentes nos exemplares maiores. 
Esse caráter foi codificado como inaplicável nos demais táxons analisados (exceto Doradidae), por não possuírem escudos laterais.

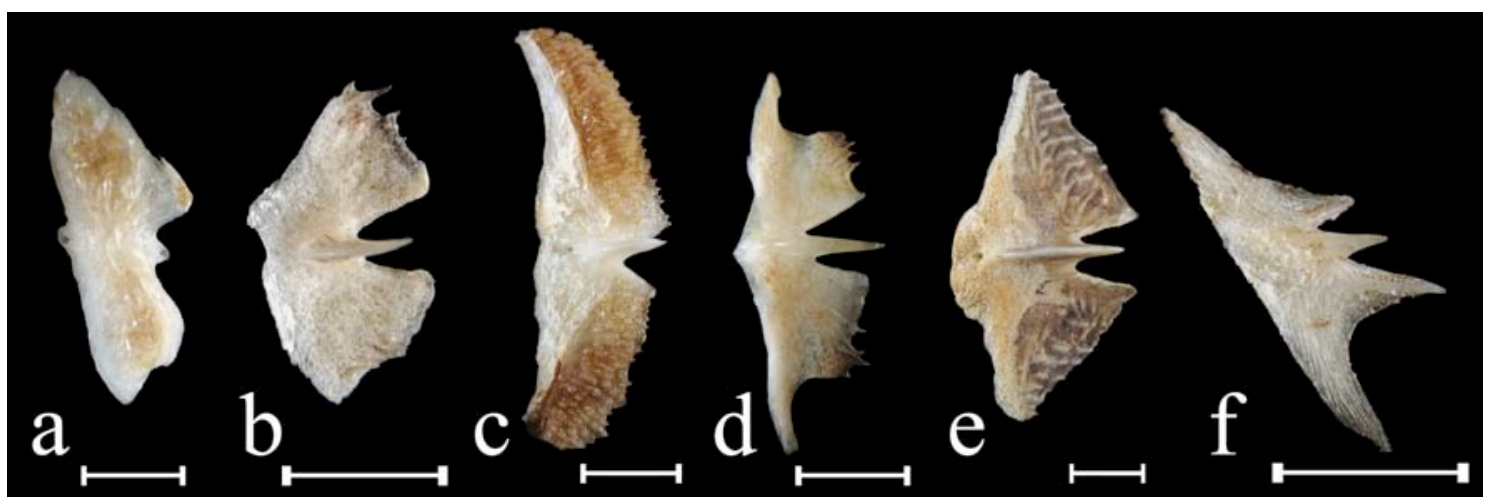

Figura 38. Escudos laterais da porção anterior do corpo de: Wertheimeria maculata (a), MZUSP 93659 (192.0 mm); Centrochir crocodili (b), MZUSP 150837 (150.8 mm); Platydoras armatulus (c), MZUSP 91686 (151.7 mm); Orinocodoras eigenmanni (d), FMNH 105276 (193.0 mm); Oxydoras niger (e), MZUSP 91658 (313.0 mm); Doras phlyzakion (f), MZUSP $82294(162.0 \mathrm{~mm})$. Barra de escala igual a 5 $\mathrm{mm}$.

129. Posição dos escudos ósseos laterais: (0) verticais em relação ao eixo do corpo (fig. 38a-e); (1) inclinados em relação ao eixo do corpo (fig. 38f). CI: 1,00; RI: 1,00. Em Doradini (exceto Oxydoras) os escudos laterais são inclinados a aproximadamente $60^{\circ}$ em relação ao eixo do corpo, com o lobo dorsal mais anterior que o ventral.

Esse caráter foi codificado como inaplicável nos demais táxons analisados (exceto Doradidae), por não possuírem escudos laterais.

130. Altura dos escudos ósseos laterais: (0) baixos, ocupando aproximadamente 1/2 a 1/5 da altura do corpo, ao nível da nadadeira anal (fig. 38a-b,d-f); (1) altos, ocupando mais da metade da altura do corpo, ao nível da nadadeira anal (fig. 38c). CI: 0,50; RI: 0,50. 
Em Platydoras armatulus, P. hancockii, P. brachylechis (Piorski et al., 2008), e em Acanthodoras e Agamyxis, os escudos laterais são altos, ocupando quase a altura do corpo, ao nível da nadadeira anal.

Esse caráter foi codificado como inaplicável nos demais táxons analisados (exceto Doradidae), por não possuírem escudos laterais.

131. Tamanho do terceiro escudo ósseo timpânico: (0) pequeno, distintamente menor do que os escudos laterais (figs. 18, 21-28); (1) grande, similar em tamanho aos escudos laterais (figs. 16-17, 19, 20). CI: 0,75; RI: 0,95 .

Em alguns doradídeos, como Wertheimeria, Kalyptodoras, Franciscodoras, Platydoras, Agamyxis, Acanthodoras, Anadoras, Scorpiodoras, Pterodoras, Lithodoras, Doraops, Centrodoras, Megalodoras, Orinocodoras e Rhinodoras, o terceiro escudo timpânico é expandido como os demais escudos laterais (Birindelli, 2006: \#122).

Esse caráter foi codificado como inaplicável nos demais táxons analisados (exceto Doradidae), por não possuírem escudos laterais. Centrochir e Rhinodoras dorbignyi foram considerados polimórficos $(0,1)$ para esse caráter.

132. Número de escudos ósseos laterais (ordenado): (0) de 15 a 18; (1) de 19 a 25; (2) de 26 a 31; (3) de 32 a 38; (4) de 39 a 46. CI: 0,47; RI: 0,68.

A contagem de escudos laterais em Doradidae foi padronizada como começando do escudo infranucal, aquele desenvolvido a partir do ligamento entre a placa nucal posterior e da primeira costela (Sabaj, 2005; Birindelli, 2006; Birindelli et al., 2007). Essa contagem serve para diagnosticar muitas espécies.

O número de escudos laterais de doradídeos varia de 15 e 46, sendo Megalodoras e Lithodoras os táxons com menos e Leptodoras e Anduzedoras os com mais escudos 
(Sabaj, 2002: \#21). O número de escudos laterais pode variar bastante dentro de um mesmo gênero, como é o caso de Oxydoras, mas varia relativamente pouco dentro de cada espécie. Veja a tabela 1 para distribuição dos doradídeos para esse caráter.

Esse caráter foi codificado como inaplicável nos demais táxons analisados (exceto Doradidae), por não possuírem escudos laterais.

Tabela 1. Número de escudos laterais nas espécies da família Doradidae.

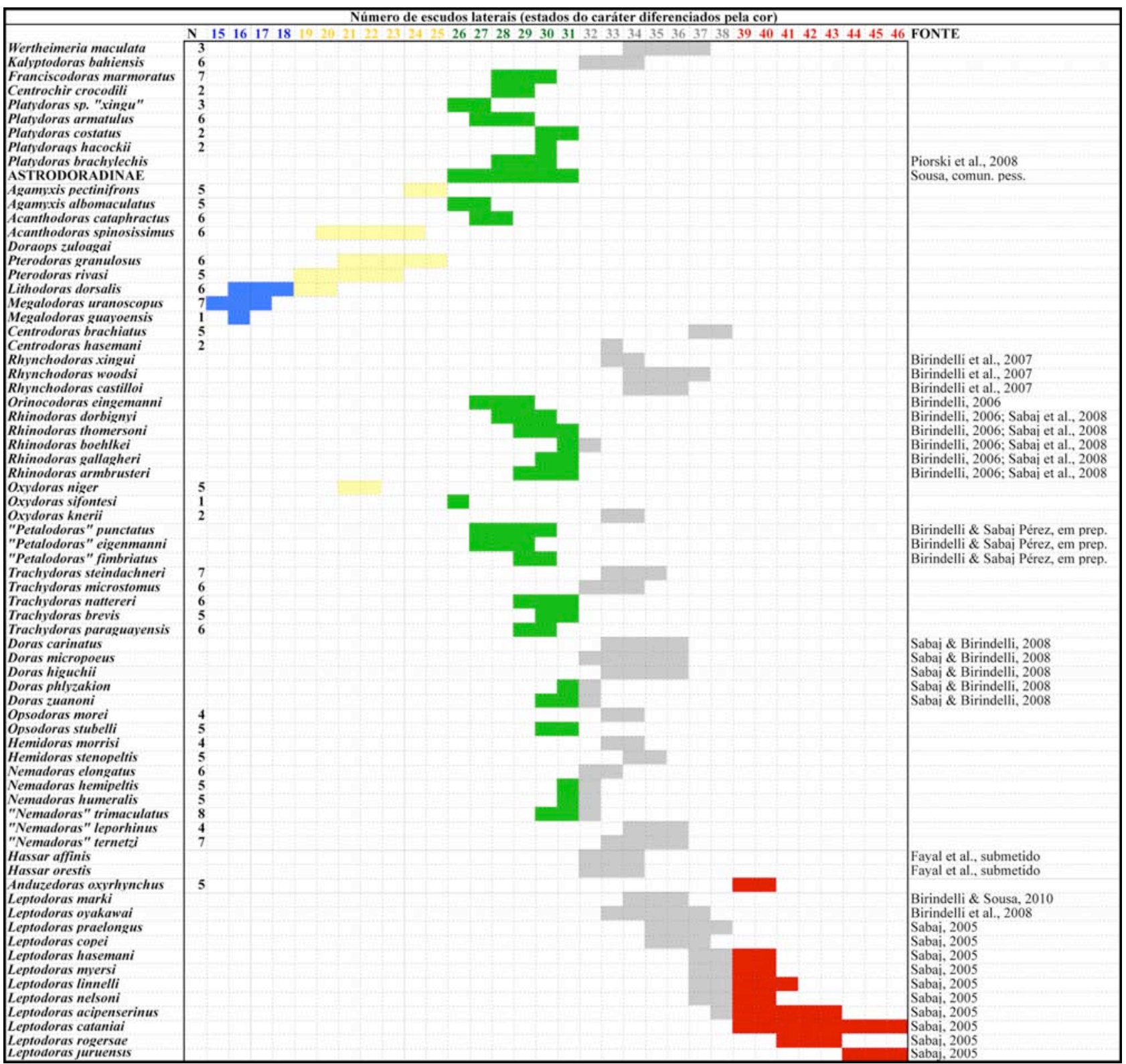

\subsubsection{Arco mandibular}


133. Forma do arco mandibular (como um todo): (0) normal; (1) em forma de bico orientado ventralmente. CI: 1,00; RI: 1,00 .

Em Rhynchodoras o dentário e o pré-maxilar são unidos medialmente e formam um bico orientado ventralmente (Birindelli et al., 2007; Birindelli, 2006: \#70, \#75).

134. Forma do pré-maxilar (não ordenado): (0) forma de uma placa retangular (largo e baixo) (fig. 39a-b); (1) forma de um cone com ápice dorsal (estreito e alto) (fig. 39c-d); (2) forma de um bloco quadrangular (largo e alto); (3) forma de uma placa, mas extremamente longa, ultrapassando bastante o limite lateral do mesetmóide (fig. 34). CI: 0,50; RI: 0,92.

O pré-maxilar em Siluriformes é geralmente uma placa retangular deprimida e com muitos dentes cônicos. Entretanto, alguns grupos apresentam modificações no formato do pré-maxilar. Por exemplo, Mochokidae (exceto Mochokus, Mochokiella, Acanthocleithron), tem o pré-maxilar na forma de um bloco quadrangular, largo e alto (Vigliotta, 2008: \#35, figs. 12-14). Doradini tem o pré-maxilar reduzido em tamanho, na forma de um cone com ápice dorsal (Higuchi, 1992: \#42, \#43; Birindelli, 2006: \#66). Pseudepapterus apresentam o pré-maxilar extremamente reduzido, mais ainda do que o encontrado em Doradini. Por outro lado, em Ageneiosus, Tetranematichthys e Asterophysus, o pré-maxilar é extremamente longo, ultrapassando bastante os limites do mesetmóide (Britski, 1972: 15; Royero, 1999: \#57); a expansão do pré-máxilar é acompanhada por uma expansão semelhante do dentário (Ferraris, 1988: \#J9; Akama, 2004: \#51). Uma condição semelhante ocorre no silurídeo Wallago (Britski, 1972).

Esse caráter foi tratado como inaplicável em Rhynchodoras, que apresenta o prémaxilar modificado. 


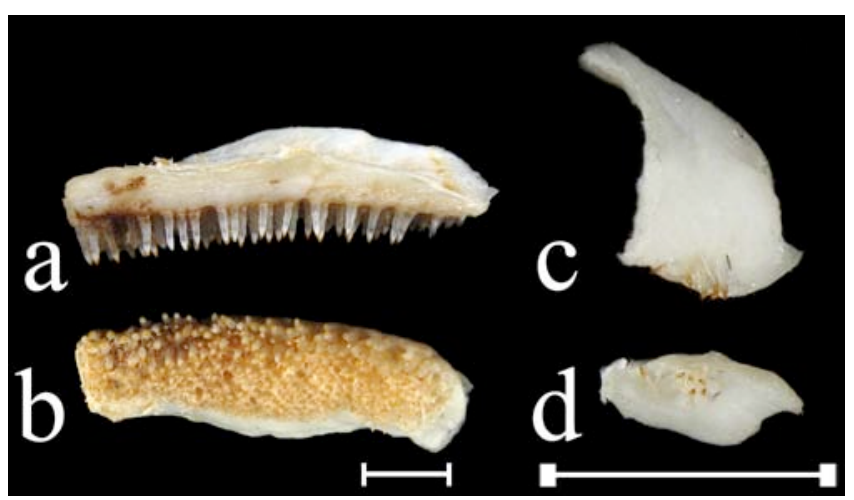

Figura 39. Pré-maxilar em vistas anterior (a, c) e ventral (b, d) de: Pterodoras granulosus (a, c), MZUSP 91655 (410.0 mm); e Doras higuchii (b, d), MZUSP 101693 (172.0 mm). Barra de escala igual a 5 mm.

135. Processo dorso-lateral no pré-maxilar: (0) ausente; (1) presente. CI: 0,33; RI: $\mathbf{0 , 5 0 .}$

Em alguns Siluriformes, como Pimelodidae, Pseudopimelodidae, Heptapteridae, Sisoridae, Claroteidae, há um processo dorso-lateral no pré-maxilar para acomodar o maxilar (de Pinna, 1993: \#40; Britto, 2002: \#135).

136. Projeção látero-posterior no pré-maxilar: (0) ausente; (1) presente. CI: 0,25; RI: $\mathbf{0 , 2 5 .}$

Alguns táxons de Siluriformes apresentam uma projeção látero-posterior no prémaxilar (Pimelodidae, Pseudopimelodidae, Hepapteridae). Uma condição semelhante é encontrada em Auchenipterus e Epapterus (Ferraris, 1988: \#J21; Akama, 2004: \#54).

137. Dentes no pré-maxilar (ordenado): (0) numerosos, arranjados em várias fileiras (fig. 39a-b); (1) reduzidos em número (fig. 39c-d); (2) ausentes. CI: 0,20; RI: $\mathbf{0 , 8 6 .}$

Entre os auchenipterídeos, Entomocorus e Auchenipterus (Ferraris \& Vari, 1999) tem os dentes do pré-maxilar reduzidos em número e arranjados em apenas uma a três 
fileiras mais externas (Ferraris, 1988: \#J7; Akama, 2004: \#49); e Pseudepapterus e Epapterus não têm dentes (Ferraris, 1988: \#J8). Entre os doradídeos, Doras carinatus, D. micropoeus, D. higuchii (Sabaj Pérez \& Birindelli, 2008), Hemidoras stenopeltis, Hassar, "Petalodoras" apresentam dentes em número reduzido no pré-maxilar; e Oxydoras, Trachydoras, Doras phlyzakion, D. zuanoni, Hemidoras morei, O. stubelii, H. morrisi, Nemadoras, "Nemadoras", Anduzedoras e Leptodoras não possuem dentes no pré-maxilar (Eigenmann, 1925: 282; Higuchi, 1992: \#42; Sabaj, 2002: \#13; Birindelli, 2006: \#67). Aspredinidae não tem dentes, e todos os demais táxons estudados tem numerosos dentes arranjados em diversas fileiras (de Pinna, 1996: \#7).

138. Forma dos dentes no pré-maxilar: (0) cônico; (1) em forma de S. CI: 1,00; RI: $\mathbf{1 , 0 0 .}$

Primitivamente, os dentes do pré-maxilar de Siluriformes são cônicos. Mochokídeos (exceto Mochokus, Mochokiella, Acanthocleithron) possuem os dentes do pré-maxilar longos e em forma de S (Vigliotta, 2008: \#37).

139. Tamanho do maxilar (não ordenado): (0) curto (figs. 15-20, 22, 29-32, 34, 36a); (1) longo e fino (figs. 21, 23-28, 33, 36b); (2) longo e robusto. CI: 0,29; RI: $\mathbf{0 , 8 5}$.

O maxilar da maioria dos Siluriformes é curto, entretanto, em Sisoridae, Siluridae, e nos Doradoidea Auchenipterus, Pseudepapterus, Epapterus, Entomocorus, Gelanoglanis, Centromochlus heckelii (Ferraris, 1988: \#J11) e Doradini (exceto "Petalodoras") (Higuchi, 1992: \#44) o maxilar é alongado. Em Chiloglanidinae o maxilar é longo e robusto (Vigliotta, 2008: \#33). 
140. Côndilos na extremidade proximal do maxilar: (0) ausentes; (1) presentes. CI: 1,00; RI: 0,00.

A maioria dos Siluriformes possui dois côndilos na maxila, sendo o ventral mais bem desenvolvido (com exceção de Heptapteridae que os possui de tamanho semelhante). Entretanto, as famílias Diplomystidae, Cetopsidae, Trichomycteridae e Scoloplacidae possuem o maxilar com apenas uma faceta articular (simples ou dupla, mas sem côndilos) (Arratia, 1992: \#3, \#4, \#5; Britto, 2002: \#145; de Pinna et al., 2007: $\# 2)$.

Apesar de outros autores (Mo, 1991: \#25; Britto, 2002: \#145) terem afirmado que em Doradidae, Auchenipteridae e Synodontis o côndilo dorsal do maxilar é mais alongado que o ventral, isto não foi corroborado no presente estudo.

141. Dentes no maxilar: (0) presentes; (1) ausentes. CI: 1,00; RI: 0,00.

O maxilar não apresenta dentes em Siluriformes (exceto Diplomystidae) (Regan, 1911: 556; Alexander, 1965: 91; Lundberg, 1970; Arratia, 1987; Arratia, 1992: \#1). Esta é uma das características que coloca Diplomystidae como o grupo irmão dos demais Siluriformes (de Pinna, 1993: 53; Britto, 2002: \#148; Diogo, 2004: \#259; de Pinna et al., 2007: \#3).

142. Forma do maxilar em machos maduros (ordenado): (0) similar ao de fêmeas e machos imaturos; (1) alongado, em relação ao de fêmeas e machos imaturos; (2) robusto e com espinhos. CI: 0,67; RI: 0,89.

Em diversas espécies de auchenipterídeos (i.e., Parauchenipterus, "Amplexiglanis", Tetranematichthys, Entomocorus, Auchenipterus, Pseudepapterus e Epapterus) o maxilar torna-se mais longo em manchos maduros (Ferraris, 1988: \#J13; 
Akama, 2004: \#171). Mas somente em machos maduros de Ageneiosus o maxilar (que é extremamente curto nas espécies desse gênero) torna-se robusto e com espinhos (Ferraris, 1988: \#J15; Walsh, 1990: \#22; Royero, 1999: \#129, \#130; Akama, 2004: \#172). O aumento da ossificação do maxilar em machos maduros é acompanhado por uma expansão anterior do autopalatino (Ferraris, 1988: \#J5; Walsh, 1990: \#15; Akama, 2004: \#175), que suporta o maxilar.

143. Osso corono-meckeliano: (0) presente; (1) ausente. CI: 0,50; RI: 0,80.

Em alguns grupos de Siluriformes (i.e., Loricariidae, Astroblepidae, Callichthyidae, Scoloplacidae, Malapteruridae, Mochokidae, Hoplomyzontinae) o osso corono-meckeliano está ausente (Arratia, 1992: \#47; de Pinna, 1993: \#23; Diogo, 2004: \#424; Vigliotta, 2008: \#26).

144. Contato entre o osso corono-meckeliano e o dentário: (0) fraco (fig. 40a,d); (1) forte por meio de sutura óssea (fig. 40b-c, e-f). CI: 0,50; RI: 0,97.

O osso corono-meckeliano é apenas encaixado no dentário e ângulo-articular de Siluriformes. Entretanto, em Wertheimeria, Kalyptodoras, Franciscodoras, Doradini, "Rhinodoradini" e em alguns exemplares de Pterodoras granulosus o osso coronomeckeliano é firmemente suturado ao dentário (de Pinna, 1993: \#51; Britto, 2002: \#159).

Pterodoras granulosus foi considerado polimórfico para esse caráter $(0,1)$. 


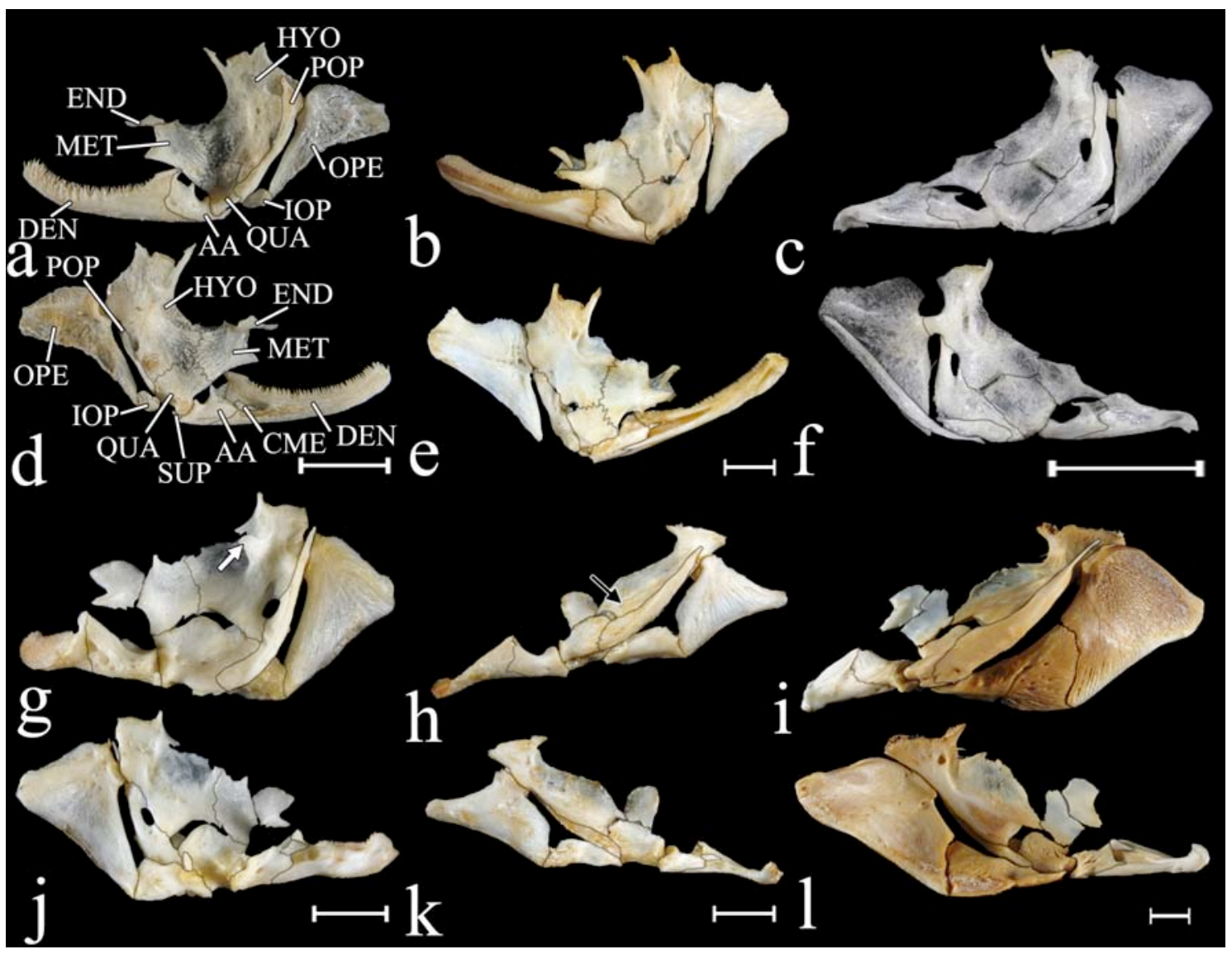

Figura 40. Suspensório, em vista lateral (a-c, g-i) e medial (d-, j-1), de: Glanidium melanodermatum (a, d), MZUP 64256 (112.0 mm); Trachycorystes trachycorystes (b, e), MZUSP 91659 (200.0 mm); Auchenipterus osteomystax (c, f), MZUSP 97375 (117.0 mm); Wertheimeria maculata (g, j), MZUSP 93659 (217.0 mm); Rhinodoras dorbignyi (h, k), MZUSP 40109 (196.0 mm); Oxydoras niger (i, 1), MZUSP $91654(550.0 \mathrm{~mm})$. Seta indica a crista do hiomandibular para inserção do músculo lavator arcus palatini. AA: ângulo-articular, CME: osso corono-meckeliano, DEN: dentário, END: 'endopterigóide', HYO: hiomandibular, IOP: interopérculo, MET: metapterigóide, OPE: opérculo, POP: pré-opérculo, QUA: quadrado, SUB: sub-pré-opérculo. Escala igual a $10 \mathrm{~mm}$.

145. Processo ascendente da cartilagem de Meckel: (0) presente; (1) ausente. CI: 0,20; RI: 0,50 .

O processo ascendente da cartilagem de Meckel, presente na maioria dos Siluriformes, está ausente em Mochokidae, Amphiliidae, Loricarioidea, Malapteruridae e Siluridae (Mo, 1991: \#35; de Pinna, 1993: \#22; Britto, 2002: \#155; Diogo, 2004: 
\#419; Vigliotta, 2008: \#24). Em algumas espécies de Synodontis examinadas no presente estudo, como por exemplo, S. batensoda, S. nigriventris, S. schall, a cartilagem de Meckel tem um processo dorsal na mandíbula semelhante ao processo ascendente presente em outros Siluriformes; entretanto, preferi seguir Vigliotta (2008) que examinou muito mais material e considerar o processo ascendente como ausente em todos os Mochokídeos.

146. Processo coronóide da mandíbula: (0) presente (fig. 40); (1) ausente. CI: 0,50; RI: $\mathbf{0 , 8 0 .}$

O processo coronóide da mandíbula está ausente apenas em Asterophysus e Mochokidae (de Pinna, 1993: \#50; Britto, 2002: \#151; Diogo, 2004: \#400; Vigliotta, 2008: \#27). Em Siluridae, o processo coronóide é extremamente pequeno, mas presente.

147. Ângulo das mandíbulas: (0) aproximadamente 90; (1) aproximadamente $135^{\circ}$ a $180^{\circ}$. CI: 1,00; RI: 1,00 .

Em Mochokidae (exceto Mochokus, Mochokiella, Acanthocleithron e Synodontis membranacea) as mandíbulas formam um arco com ângulo bastante obtuso, de aproximadamente $135^{\circ}$ a $180^{\circ}$ (Vigliotta, 2008: \#28). Condição semelhante é observada em Loricariidae.

148. Tecido de conexão paralelo ao ligamento primordial: (0) ausente; (1) presente. CI: 1,00; RI: 1,00 .

Em Anchariidae, Ariidae, Claroteidae, Auchenoglanidae, há um tecido de conexão entre o processo coronóide da mandíbula e o barbilhão maxilar, paralelo ao ligamento primordial (Mo, 1991: \#28; de Pinna, 1993: \#29; Royero, 1999: \#145; Britto, 2002: 
$\# 150)$.

149. Processo ventral no dentário: (0) ausente; (1) presente. CI: 0,33; RI: 0,60 .

Em alguns Siluriformes (Genidens, Malapteruridae, entre os examinados) e em Entomocorus, Auchenipterus, Epapterus, Pseudepapterus há um, ou dois, processos ventrais no dentário possivelmente ligados à inserção dos barbilhões mentonianos (Ferraris, 1988: \#J17; Akama, 2004: \#53).

150. Dentes no dentário (ordenado): (0) numerosos (figs. 40 a-b, d-e); (1) reduzidos em número; (2) ausentes (figs. 40c,f). CI: 0,44; RI: 0,89.

Em Entomocorus e Auchenipterus, os dentes nos dentários são reduzidos em número e arranjados em poucas fileiras, e em Epapterus e Pseudepapterus eles estão ausentes (Ferraris, 1988: \#J8; Akama, 2004: \#50).

Entre os doradídeos, "Petalodoras", Doras carinatus, D. micropoeus, D. higuchii, Hemidoras stubelii, H. stenopeltis, Nemadoras, "Nemadoras", Hassar e Anduzedoras possuem dentes em número reduzido no dentário (Higuchi, 1992: \#49, \#A41); e Oxydoras, Trachydoras, Hemidoras morei, H. morrisi, Leptodoras oyakawai e L. marki não possuem dentes no dentário (Higuchi, 1992: \#48; Sabaj, 2002: \#14; Birindelli, 2006: \#74).

Doras phlyzakion, Leptodoras praelongus e L. juruensis foram considerados polimórficos para esse caráter $(1,2)$.

151. Sulco no dentário para inserção de dentes especializados: (0) ausente; (1) presente. CI: 1,$00 ;$ RI: 1,00 .

Em mochokídeos (exceto Mochokus e Mochokiella), há um dentição distinta, 
especializada, inserida num sulco profundo do dentário (Vigliotta, 2008: \#30, \#32). Esta dentição é bastante similar a encontrada em Amphiliidae, Loricariidae Astroblepidae (de Pinna, 1993: \#49; Britto, 2002: \#160; Diogo, 2004: \#396). Alguns táxons de Mochokidae (i.e., Microsynodontis e a maioria das espécies de Synodontis) possuem, além desses dentes especializados, dentes regulares cônicos inseridos na superfície externa do dentário (Vigliotta, 2008: \#31).

152. Processo ventral na sínfise do dentário: (0) ausente; (1) presente. CI: 0,50; RI: 0,67 .

Em Claroteidae, Ariidae, Anchariidae, Schilbidae, Malapteruridae, Auchenoglanidae e Callichthyidae, há um processo ventral junto à sínfise do dentário no qual se origina o músculo intermandibulae (Britto, 2002: \#162).

\subsubsection{Suspensório}

153. Côndilo anterior do autopalatino: (0) duplo; (1) simples. CI: 1,00; RI: 0,00.

Em Diplomystidae, o autopalatino possui dois côndilos anteriores, associados ao maxilar (Lundberg, 1970; Arratia, 1987; Arratia, 1992: \#9; Britto, 2002: \#171), enquanto que nos demais Siluriformes há apenas um côndilo.

154. Forma do autopalatino: (0) deprimido, com extremidade anterior distintamente dilatada; (1) cilíndrico, aproximadamente uniforme. CI: 1,00; RI: 1,00 .

Em Diplomystidae e Nematogenyidae, o autopalatino é deprimido e com a extremidade anterior distintamente dilatada, enquanto que ele é cilíndrico nos demais Siluriformes, com a extremidade anterior apenas levemente maior do que a posterior 
(Arratia, 1992: \#7).

155. Comprimento do autopalatino: (0) curto; (1) longo. CI: 0,50; RI: 0,97.

$\mathrm{Na}$ maioria dos Siluriformes, o autopalatino é relativamente curto, mas em Centrodoras brachiatus, Doradini e "Rhinodoradini", o autopalatino é um osso extremamente longo, o que está associado ao alongamento do focinho (Eigenmann, 1925: 286; Higuchi, 1992: \#47; Birindelli, 2006: \#72).

156. Limite posterior do autopalatino: (0) margem orbital anterior; (1) meio da órbita. CI: 0,50; RI: 0,83.

O limite posterior do autopalatino é a margem anterior da órbita na maioria dos Siluriformes. Porém, em “Rhinodoradini” (Higuchi, 1992: \#A40; Birindelli, 2006: \#73; Birindelli et al., 2007) o autopalatino projeta-se posteriormente até o meio da órbita. Apesar do arranjo ser diferente, Diplomystes também possui o autopalatino projetado posteriormente até o meio da órbita.

157. Posição do autopalatino em relação ao etmóide lateral: (0) dorsal; (1) lateral. CI: 1,00; RI: 1,00.

Em Diplomystidae, Cetopsidae e Loricarioidea, o autopalatino é dorsal em relação ao etmóide lateral (Lundberg, 1970; Mo, 1991: \#3; de Pinna, 1993: \#59; Britto, 2002: \#13; Diogo, 2004: \#296; de Pinna et al., 207: \#14), enquanto que nos demais Siluriformes ele é lateral.

158. Comprimento da cartilagem anterior do autopalatino: (0) curta; (1) longa. CI: 1,00; RI: 1,00. 
A cartilagem anterior do autopalatino é extremamente alongada (quase ou maior do que $50 \%$ do comprimento do autopalatino) em Austroglanidinae, Anchariidae, Claroteidae e Ariidae (Mo, 1991; de Pinna, 1993: \#25; Britto, 2002: \#172; Diogo, 2004: \#277).

159. Cartilagem posterior do autopalatino: (0) presente; (1) ausente. CI: 0,67; RI: $\mathbf{0 , 0 0}$.

Em Malapteruridae, Chiloglanidinae e alguns exemplares de Amphiliidae a cartilagem posterior do autopalatino está ausente (Mo, 1991; Arratia, 1992; de Pinna, 1993: \#21; Diogo, 2004: \#283; Vigliotta, 2008: \#41).

Amphiliidae foi considerado polimórfico para esse caráter $(0,1)$.

160. Expansão mediana no hiomandibular: (0) presente (figs. 15-22, 29-34, 40); (1) ausente (figs. 23-28). CI: 1,00; RI: 1,00.

Em Doradini (exceto Oxydoras) o hiomandibular é extremamente alongado e não possui a expansão mediana onde parte do músculo adductor mandibulae se insere (Higuchi, 1992: \#54; Birindelli, 2006: \#77).

161. Crista no hiomandibular para inserção do músculo levator arcus palatini (ordenado): (0) ausente ou rudimentar; (1) pouco desenvolvida; (2) bem desenvolvida (fig. 40b). CI: 0,29; RI: 0,84 .

A crista no hiomandibular para inserção do músculo levator arcus palatini é pouco desenvolvida em Auchenipteridae, Franciscodoras e alguns outros Siluriformes (Bagridae, Cetopsidae, Claroteidae, Diplomystidae, Ictaluridae, Pangasiidae, Pseudopimelodidae, Nematogenyidae, entre os examinados) (Lundberg, 1970: \#62; 
Arratia, 1992: \#31). Entretanto, em Wertheimeria e Kalyptodoras a crista no hiomandibular para o levator arcus palatini é bem desenvolvida, formando um distinto processo. Esta crista encontra-se ausente (ou rudimentar) nos demais táxons estudados.

162. Orientação da crista no hiomandibular para inserção do músculo levator arcus palatini: (0) horizontal; (1) vertical (fig. 40b). CI: 1,00; RI: 1,00.

Em Nematogenyidae, Auchenipteridae, Wertheimeria, Kalyptodoras e Franciscodoras a crista para inserção do músculo levator arcus palatini é vertical, diferentemente dos demais Siluriformes que apresentavam a crista horizontal (Lundberg, 1970; Arratia, 1992: 117). Apesar de Diogo (2004: \#335) ter citado este caráter para Wallago e Silurus, não foi possível observá-lo no único exame de Wallago examinado.

Esse caráter foi tratado como inaplicável para os seguintes táxons: Pimelodidae, Heptapteridae, Siluridae, Aspredinidae, Sisoridae, Erethistidae, Malapteruridae, Ariidae, Amphiliidae, Mochokidae, Doradidae (exceto Wertheimeria, Kalyptodoras, Franciscodoras), por não possuírem a crista no hiomandibular.

163. Crista no hiomandibular para inserção da seção Aw do músculo adductor mandibulae: (0) ausente; (1) presente. CI: 1,00; RI: 1,00.

Em Rhinodoras, Orinocodoras e Rhynchodoras há uma crista na parte ventral do hiomandibular para inserção da seção Aw do músculo adductor mandibulae (Birindelli, 2006: \#78).

164. Processo no hiomandibular para inserção do músculo adductor hyomandibulae: (0) ausente ou rudimentar; (1) bem desenvolvido. CI: 0,33; RI: 
$\mathbf{0 , 6 0}$.

Há um processo no hiomandibular dorsal ao côndilo opercular para inserção do músculo adductor hiomandibulae em diversos grupos de Siluriformes (Ariidae, Claroteidae, Ictaluridae, Pangasiidae, Pimelodidae, entre os examinados) (Lundberg, 1970: 36; Pinna, 1993: \#92; Britto, 2002: \#184).

165. Processo medial no hiomandibular: (0) ausente; (1) presente. CI: 0,50; RI: $\mathbf{0 , 0 0}$.

Em Mochokiella, Microsynodontis e diversas espécies de Synodontis (S. schall e S. membranaceo, entre os examinados), há um processo medial no hiomandibular (Vigliotta, 2008: \#42).

166. Processo dorso-posterior no hiomandibular: (0) ausente (fig. 40 b-c, e-f); (1) presente (fig. 40a, d). CI: 0,33; RI: 0,88 .

$\mathrm{Na}$ maioria dos auchenipterídeos, há um distinto processo no hiomandibular posterior ao côndilo de articulação entre o hiomandibular e o neurocrânio. As exceções incluem Asterophysus, Auchenipterus, Entomocorus, Pseudepapterus e Epapterus (Royero, 1999: \#61; Akama, 2004: \#56).

167. Côndilo do opérculo no hiomandibular: (0) sobre um processo rudimentar; (1) sobre um distinto processo. CI: 0,50; RI: 0,75 .

Em Aspredinidae (de Pinna, 1996: \#23) e alguns auchenipterídeos (i.e., “Amplexiglanis", Entomocorus, Auchenipterus, Pseudepapterus e Epapterus) o côndilo do opérculo no hiomandibular encontra-se sobre um distinto processo (Royero, 1999: \#63; Akama, 2004: \#58). 
168. Abertura no hiomandibular para o ramo do nervo trigêmio-facial: (0) simples (fig. 40a, c, g, h, i); (1) dupla (fig. 40b). CI: 0,50; RI:0,50.

Em Trachelyopterus, Parauchenipterus e Trachycorystes há duas aberturas no hiomandibular para a passagem do ramo do nervo trigêmio-facial (Royero, 1999: \#60; Akama, 2004: \#55). A condição presente em Trachycorystes, uma abertura larga com uma constrição mediana, difere um pouco da presente em Parauchenipterus e Trachelyopterus (Akama, 2004).

169. Articulação entre hiomandibular e neurocrânio (ordenado): (0) através do esfenótico, pterótico e pró-ótico; (1) através do esfenótico e pterótico (fig. 36b); (2) através apenas do esfenótico (fig. 36a). CI: 0,17; RI: 0,57.

$\mathrm{Na}$ maioria dos Siluriformes, o hiomandibular articula-se com o neurocrânio através do pterótico e esfenótico. Entretanto, em Diplomystidae, Nematogenyidae e Mochokidae (exceto Mochokus) o hiomandibular articula-se através do esfenótico, pterótico e pró-ótico (Alexander, 1965: 97; Arratia, 1992: \#35; Vigliotta, 2008: \#10). E em alguns táxons (Ariidae, Erethistidae, Amphiliidae, Tatia, Trachycorystes, Auchenipterichthys, Asterophysus, Trachelyopterichthys, Parauchenipterus, Trachelyopterus, Entomocorus, Pseudepapterus, Epapterus, Auchenipterus, Wertheimeria, Kalyptodoras, Acanthodoras e Agamyxis, entre os examinados) o hiomandibular articula-se apenas através do esfenótico. Nos demais Siluriformes, o hiomandibular articula-se com o esfenótico e pterótico (Mo, 1991: \#21; Arratia, 1992: \#35; Royero, 1999: \#56; Britto, 2002: \#181).

170. Lâmina dorso-medial no quadrado: (0) ausente (fig. 40); (1) presente (fig. 
34b). CI: 0,50; RI: 0,67.

Em Centromochlus heckelii, C. existimatus, Ageneiosus e Tetranematichthys o quadrado é expandido com uma lâmina dorso-medial (Ferraris, 1988: \#J2; Walsh, 1990: \#1; Soares Porto, 1998: \#13; Royero, 1999: \#55, \#59; Akama, 2004: \#47).

171. Contato entre hiomandibular e metapterigóide: (0) presente (figs. 15-16, 40); (1) ausente (figs. 22-28). CI: 0,22; RI: 0,81.

$\mathrm{Na}$ maioria dos Siluriformes, o hiomandibular faz contato com o metapterigóide. Entretanto, em alguns táxons (Heptapteridae, Amphiliidae, Aspredinidae, Claroteidae e Malapteruridae, entre os examinados) tal contato não existe (Arratia, 1992: \#25; Britto, 2002: \#189). Alexander (1965) considerou a ausência de contato entre esses ossos como diretamente relacionada ao aumento do diâmetro do olho.

Dentre os Doradoidea, o hiomandibular não contacta o quadrado em Doradini, (exceto Oxydoras) (Birindelli, 2006: \#76), e em Centromochlus, Tetranematichthys, Ageneiosus (Britski, 1972: 23).

Tatia aulopygia foi considerada polimórfica para esse caráter $(0,1)$.

172. Tamanho do 'endopterigóide' (ordenado): (0) pequeno, menor do que o metapterigóide (figs. 15-21, 29-34, 36a, 40); (1) grande, maior do que o metapterigóide, mas não o envolvendo medialmente (figs. 22-23); (2) grande, bem maior do que o metapterigóide e o envolvendo medialmente (figs. 24-28, 36b). CI: 1,00; RI: 1,00.

Apesar da homologia do 'endopterigóide' ser ainda incerta (Arratia, 1992), em Siluriformes, o ‘endopterigóide' (ou 'entopterigóide’ dos tipos 3-7 de Arratia, 1992: fig. 2, que é formado no ligamento entre o metapterigóide e o etmóide lateral ou vômer) está 
ausente apenas em Astroblepidae, Callichthyidae, Loricariidae, Scoloplacidae e Trichomycteridae (Britto, 2002: \#186; Arratia, 1992: \#20-21; Vigliotta, 2008: \#44). No presente estudo o 'endopterigóide' foi codificado como ausente em Claroteidae e presente em Diplomystidae, contrariando os autores supracitados.

O 'endopterigóide' de Siluriformes é geralmente pequeno, menor do que o metapterigóide. Entretanto, em Doradini (exceto Oxydoras e "Petalodoras") o 'endopterigóide' é maior do que o metapterigóide e em Doradini (exceto Oxydoras, "Petalodoras" e Trachydoras) ele envolve medialmente o metapterigóide (Britski, 1972: 23; Higuchi, 1992: \#50, \#51; Birindelli, 2006: \#81).

Esse caráter foi codificado como inaplicável para Mochokus, Mochokiella (ver Vigliotta, 2008: \#44), e Claroteidae (que possui ‘endopterigóide’ ausente).

\section{3. 'Ectopterigóide': (0) ausente; (1) presente. CI: 0,33; RI: 0,67.}

Poucos grupos de Siluriformes apresentam 'ectopterigóide' (Ariidae, Bagridae, Claroteidae, Pangasiidae, Pimelodidae, Pseudopimelodidae e Sisoridae, entre os examinados) (Ferraris, 1988: \#J4; Arratia, 1992: \#18; Britto, 2002: \#188). O ‘ectopterigóide’ presente em Ariidae e Pangasiidae é um elemento ósseo localizado entre o autopalatino e o vômer, e apresenta dentes ventralmente, a homologia deste elemento é ainda desconhecida.

Esse caráter foi considerado polimórfico $(0,1)$ em Diplomystidae (ver Arratia, 1992)

\subsubsection{Série Opercular}

174. Supra-pré-opérculo: (0) ausente (figs. 16-28); (1) presente (figs. 29, 31-32, 34).

CI: 0,20; RI: 0,86. 
$\mathrm{Na}$ maioria dos Siluriformes (Diplomystidae, Nematogenyidae, Ictaluridae, Erethistidae, Sisoridae, Siluridae, Bagridae, Malapteruridae, Amphiliidae e Auchenipteridae, entre os examinados) há um ou mais ossos tubulares (raras vezes expandidos como placas) entre o pré-opéculo e o pterótico (Britski, 1972: 21; Lundberg, 1970: \#70; Britto, 2002: \#196).

175. Sub-pré-opérculo: (0) ausente; (1) presente (fig. 40). CI: 0,20; RI: 0,64.

A maioria dos grupos de Siluriformes possui uma pequena ossificação tubular entre o pré-opérculo e o ângulo-articular: o sub-pré-opérculo. Entre os Siluriformes examinados, o sub-pré-opérculo está presente em Amphiliidae, Auchenipteridae, Bagridae, Cetopsidae, Diplomystidae, Doradidae, Erethistidae, Heptapteridae, Ictaluridae, Malapteruridae, Nematogenyidae, Pangasiidae, Pimelodidae e Sisoridae (Britto, 2002: \#197).

176. Interopérculo: (0) coberto por pele espessa; (1) coberto por pele fina. CI: 1,00; RI: 0,00 .

O único táxon analisado a apresentar o interopérculo coberto por pele fina (visualmente exposto) é Trachydoras steindachneri (Birindelli, 2006: \#80).

\subsubsection{Arco hióide}

177. Expansões laminares ventrais no paruro-hial: (0) presentes (fig. 41a); (1) ausentes (figs. 41b, 42, 43). CI: 1,00; RI: 1,00.

O paruro-hial é uma ossificação dupla, derivada de dois tendões do músculo sternohyoideus e, como tal, uma apomorfia de Siluriformes (Arratia \& Schultze, 1990). O paruro-hial apresenta expansões laminares laterais bem desenvolvidas na maioria dos 
Siluriformes (Lundberg, 1970; Arratia \& Schultze, 1990), entretanto em Doradidae, Auchenipteridae e Mochokidae tais expansões estão ausentes (Mo, 1991: \#39; de Pinna, 1993: \#239; Royero, 1999: \#146; Britto, 2002: \#81; Vigliotta, 2008: \#46). Diogo (2004: \#388) cita que o paruro-hial é reduzido apenas em Synodontis. Como observado por Britto (2002: 98), alguns Sisoroidea, como, por exemplo, Glypteothorax e Pseuchecheneis (de Pinna, 1996: \#52), apresentam o paruro-hial reduzido como um todo, numa condição similar, entretanto, distinta (e não homóloga) à presente em Doradoidei.

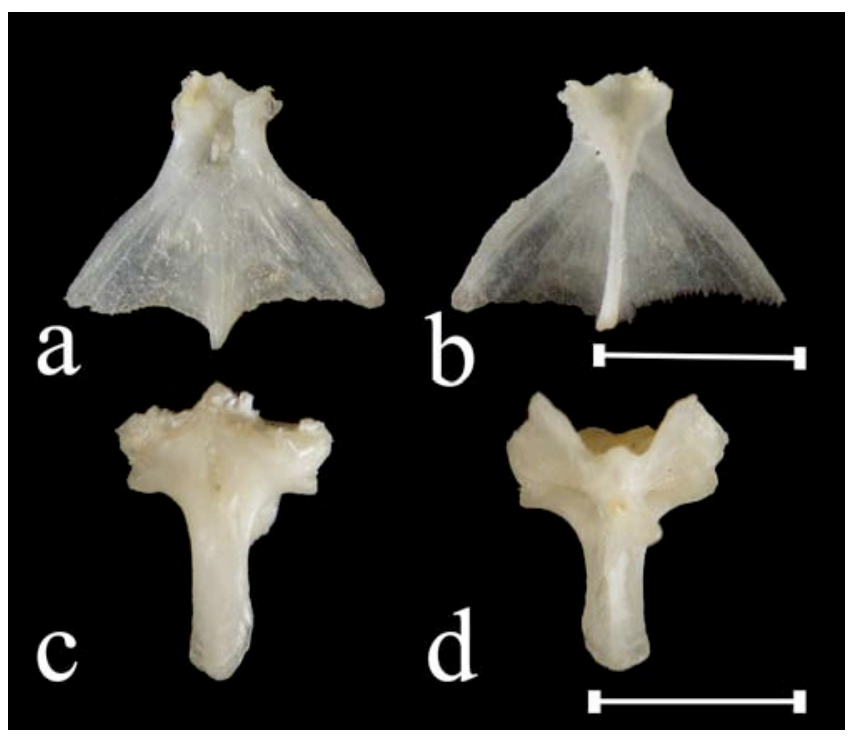

Figura 41. Paruro-hial, em vista ventral $(a, c)$ e dorsal $(b, d)$, de: Ictalurus punctatus (a-b), MZUSP 103256 (155.0 mm); e Kalptodoras bahiensis (c-d), MZUSP 87841 (233.0 mm). Barra de escala igual a 5 $\mathrm{mm}$.

178. Processo dorsal do paruro-hial: (0) pequeno, paruro-hial ventral aos hipohiais ventrais (fig. 42); (1) grande, interposto ao par de hipo-hiais ventrais (fig. 43). CI: 1,$00 ;$ RI: 1,00 .

Em Ageneiosus e Tetranematichthys, o paruro-hial apresenta um distinto processo dorsal que está interposto ao par de hipo-hiais ventrais (Ferraris, 1988: \#G7; Walsh, 
1990: \#9; Akama, 2004: \#82). Este processo é extremamente grande em Ageneiosus inermis, porém pequeno (mas evidente) em Tetranematichthys, Ageneiosus ucayalensis, A. brevis e A. atronasus (as demais espécies de Ageneiosus não foram examinadas).

Embora citado para Auchenipterus e Entomocorus por Walsh (1990: \#9) e para Doradini por Higuchi (1992: \#57), o processo dorsal do paruro-hial é distintamente grande e interposto aos hipo-hiais ventrais apenas em Ageneiosus e Tetranematichthys. O processo dorsal do paruro-hial está presente como uma pequena crista na maioria dos Siluriformes.

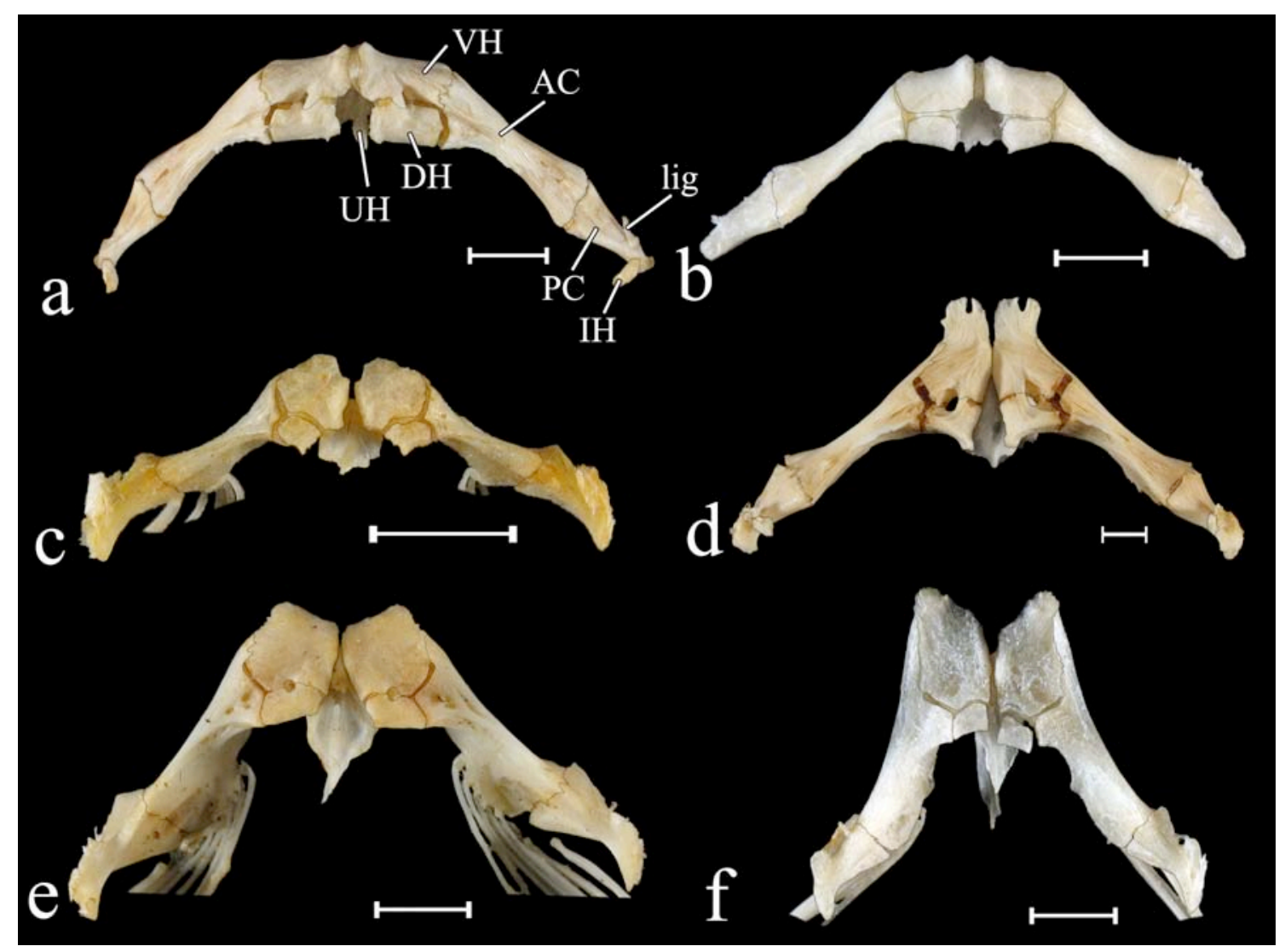

Figura 42. Arco hióide, em vist dorsal, de: Pterodoras granulosus (a), MZUSP 91655 (410.0 mm); Kalyptodoras bahiensis (b), MZUSP 87842 (152.0 mm); Trachydoras brevis (c), MZUSP 103087 (74.0 mm); Oxydoras niger (d), MZUSP 91658 (313.0 mm); Doras higuchii (e), MZUSP 96334 (165.0 mm); e Hemidoras morei (f), MZUSP 32526 (153.2 mm). AC: cerato-hial anterior, HD: hipial dorsal, HV: hipial ventral, IH: inter-hial; lig: ligamento; PC: ceratohial posterior, UH: paruro-hial. Escala igual a $10 \mathrm{~mm}$. 


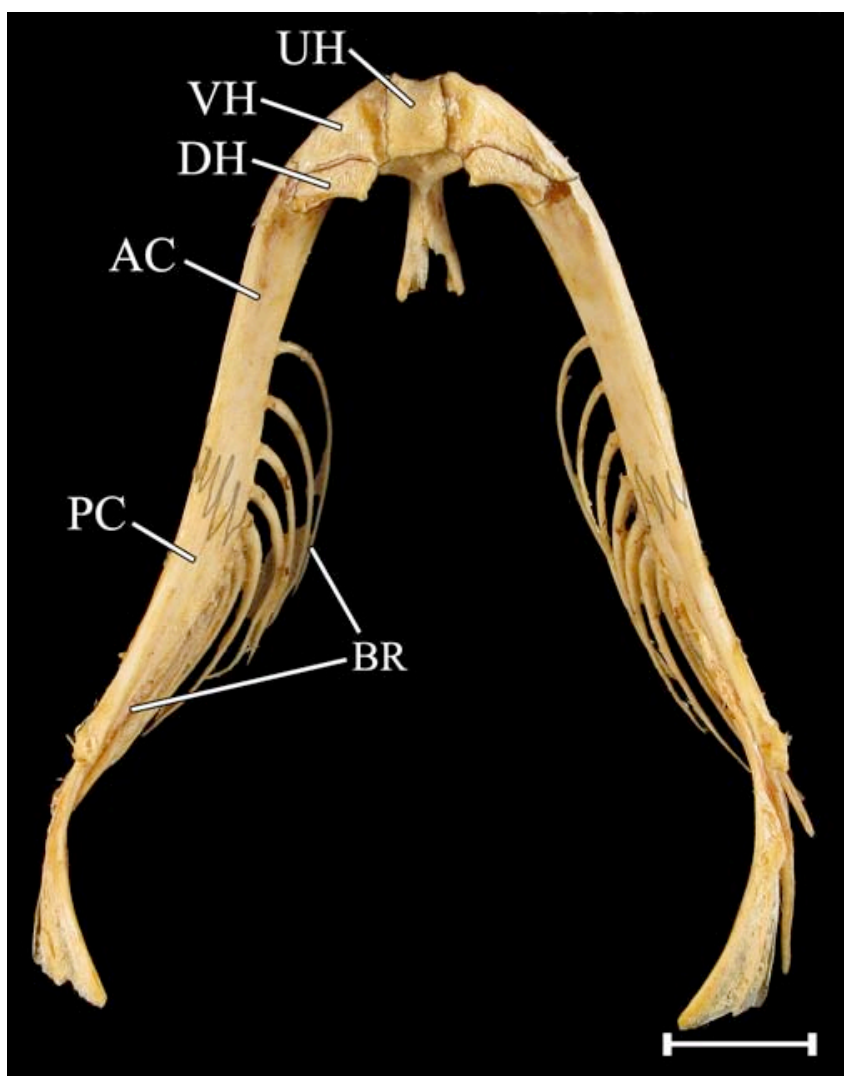

Figura 43. Arco hióide, em vista dorsal, de Ageneiosus inermis, MZUSP 91661 (320.0 mm). AC: ceratohial anterior, BR: raios ranquiostégios, DH: hipo-hial dorsal, PC: ceratohial posterior, UH: paruro-hial, VH: hipo-hial ventral. Escala igual a $10 \mathrm{~mm}$.

\section{Hipo-hial dorsal: (0) presente; (1) ausente. CI: 0,25; RI: 0,25.}

Em diversos Siluriformes, como Amphiliidae, Akysidae, Sisoridae, Aspredinidae, Pseudopimelodidae, Loricariidae, Astroblepidae, Trichomycteridae e alguns Mochokidae, o hipo-hial dorsal está ausente (Mo, 1991: \#43; Britto, 2002: \#75). Vigliotta (2008: \#47) considerou o hipo-hial dorsal fusionado ao hipo-hial ventral em Chiloglanis e Atopodontus; entretanto, a presença do hipo-hial dorsal rudimentar em espécimes pequenos de Chiloglanis polypogon indica que, nesses táxons, este elemento deve ter sido perdido e não fusionado ao hipo-hial ventral.

180. Forma do hipo-hial ventral: (0) retangular, curto, mais largo do que longo 
(figs. 42a-b, 43); (1) quadrangular, longo, mais longo do que largo (fig. 42d-f). CI: 1,00; RI: 1,00 .

O hipo-hial é primitivamente retangular, curto, mais largo do que comprido em Siluriformes. Entretanto, em Doradini, o hipo-hial ventral é aproximadaemnte quadrangular, mais comprido do que largo. O côndilo de articulação dos hipo-hiais ventrais ocupa primitivamente a maior porção da margem medial do osso, enquanto que em Doradini, ele ocupa apenas uma porção pequena da margem medial do osso (Birindelli, 2006: \#82).

181. Margem anterior do hipo-hial ventral: (0) lisa, sem espinhos (figs. 42a-c, 43); (1) com espinhos (fig. 42d-f). CI: 0,50; RI: 0,95.

Em Oxydoras, Doras, Hemidoras, Nemadoras, "Nemadoras", Hassar, Anduzedoras, Leptodoras, a margem anterior do hipo-hial ventral tem espinhos voltados ântero-lateralmente (Birindelli, 2006: \#83). Nos demais Siluriformes observados, a margem do hipo-hial é lisa, sem espinhos. Leptodoras oyakawai apresenta também espinhos no hipo-hial ventral; tais espinhos não foram ilustrados em Birindelli et al. (2008) por não estarem visíveis no ângulo em que a estrutura foi ilustrada.

182. Processo anterior do cerato-hial anterior (ordenado): (0) ausente (figs. 42a-b, 43); (1) pequeno (fig. 42c, e); (2) grande (fig. 42d, f). CI: 0,50; RI: 0,95.

Primitivamente, o cerato-hial anterior apresenta-se ligado ao hipo-hial ventral por uma articulação sincondral ou com uma pequena sutura. Trachydoras, "Petalodoras", Doras, Hassar, Leptodoras e Anduzedoras apresentam um processo pequeno no ceratohial anterior, que está suturado ao hipo-hial ventral. Já Oxydoras, Nemadoras, "Nemadoras", Hemidoras, possuem o processo anterior do cerato-hial anterior grande, 
formando uma extensa sutura com a margem lateral do hipo-hial ventral (Birindelli, 2006: \#84).

183. Sutura na articulação entre o hipo-hial ventral e cerato-hial anterior: (0) completamente ausente ou presente somente na face anterior da articulação; (1) presente nas faces anterior e posterior da articulação entre hipo-hial ventral e cerato-hial anterior (fig. 43). CI: 0,20; RI: 0,50.

Em Siluriformes, no geral, o contato entre o hipo-hial ventral e o cerato-hial anterior é basicamente sincondral, normalmente com uma pequena área de sutura na superfície anterior desses ossos. Essa sutura varia ontogeneticamente, estando presente somente em exemplares de maior porte em algumas espécies. Entretanto, em Ageneiosus, Tetranematichthys, Oxydoras, Rhinodoras e Lithodoras há uma outra área de sutura na face posterior dos ossos que, às vezes, torna-se contínua com a sutura da face anterior, restringindo a porção de contato sincondral a uma pequena área (Ferraris, 1898: \#G8; Walsh, 1990: \#10; Akama, 2004: \#83). Lundberg (1970: \#78) descreve uma condição semelhante para o ictalurídeo Pylodictis. Entre os táxons examinados, Amphiliidae apresentou uma condição semelhante. A sutura da face posterior só está ausente em exemplares de porte diminuto, como em Rhinodoras boehlkei (AMNH 58349, $51 \mathrm{~mm}$ de CP; estando presente em Rhinodoras cf. boehlkei INPA 508, $67 \mathrm{~mm}$ de CP).

Esse caráter não foi observado em Rhinodoras thomersoni e Megalodoras.

184. Interhial: (0) presente; (1) ausente. CI: 0,33; RI: $0,71$.

O interhial está ausente em Mochokidae, Akysidae, Amblycipitidae, Amphiliidae, Astroblepidae, Clariidae, Erethistidae, Scoloplacidae e Sisoridae (Mo, 1991: \#45; Britto, 
2002: \#79; Vigliotta, 2008: \#49).

185. Número de raios branquiostégios (ordenado): (0) de 4 a 6; (1) de 7 a 9; (2) de 9 a 12 ; (3) de 12 a 20 . CI: 0,29; RI: 0,38.

O número de raios branquiostégios varia de 3 a 20 em Siluriformes, sendo 8 o número mais comum (McAllister, 1968; Lundberg, 1970; Arratia, 2003a), dos quais 2 ou 3 estão ligados ao cerato-hial posterior, 4 a 5 ao cerato-hial anterior, e 1 ou 2 à cartilagem entre os cerato-hiais.

Alguns táxons examinados apresentam poucos raios branquiostégios, como Ariidae, Sisoridae, Aspredinidae (5-6), Mochokus niloticus (5), Mochokiella (4-5), Chiloglanis (5-6) (Vigliotta, 2008: \#52), Glanidium, Tatia, Centromochlus (6), Acanthodoras (6) e alguns exemplares de Platydoras armatulus (Birindelli, 2006: \#85).

Já outros táxons possuem muitos raios branquiostégios, como Nematogenys (10), Pangasius (10), Helogenys (11), Bagarius (12), Tetranematichthys, Ageneiosus (A. inermis, A. polystictus, A. ucayalensis, A. vittatus, A. valenciennesi) (Walsh, 1990: \#35), e Wallago (19).

Esse caráter não foi observado em Pseudotatia. Platydoras armatulus foi considerada polimórfica para esse caráter $(0,1)$.

\subsubsection{Arco branquial}

186. Pseudobrânquia: (0) presente; (1) ausente. CI: 1,00; RI: 1,00.

A pseudobrânquia está presente apenas em Diplomystidae e Nematogenyidae (Arratia, 1992: \#34).

187. Lamelas branquiais acessórias sobre o ceratobranquial (ordenado): (0) 
ausentes (figs. 44, 45a-f,i-j); (1) restritas aos arcos branquiais (fig. 45 g-h,k-l, 46aj); (2) estendidas sobre os filamentos branquiais (figs. 46k-I). CI: 0,67; RI: 0,96.

Em Doradini (exceto Trachydoras) há conspícuas lamelas na face medial dos arcos branquiais (mais conspícuas sobre os arcos 1 e 2) (Higuchi, 1992: \#A49, \#A50). Essas lamelas são ligeiramente desenvolvidas em alguns outros doradídeos, como em Rhinodoras. Estas lamelas estendem-se sobre os filamentos branquiais apenas em Leptodoras (Higuchi, 1992: \#A51; Sabaj, 2002: \#15; Sabaj, 2005; Birindelli et al., 2008; Birindelli \& Sousa, 2010).

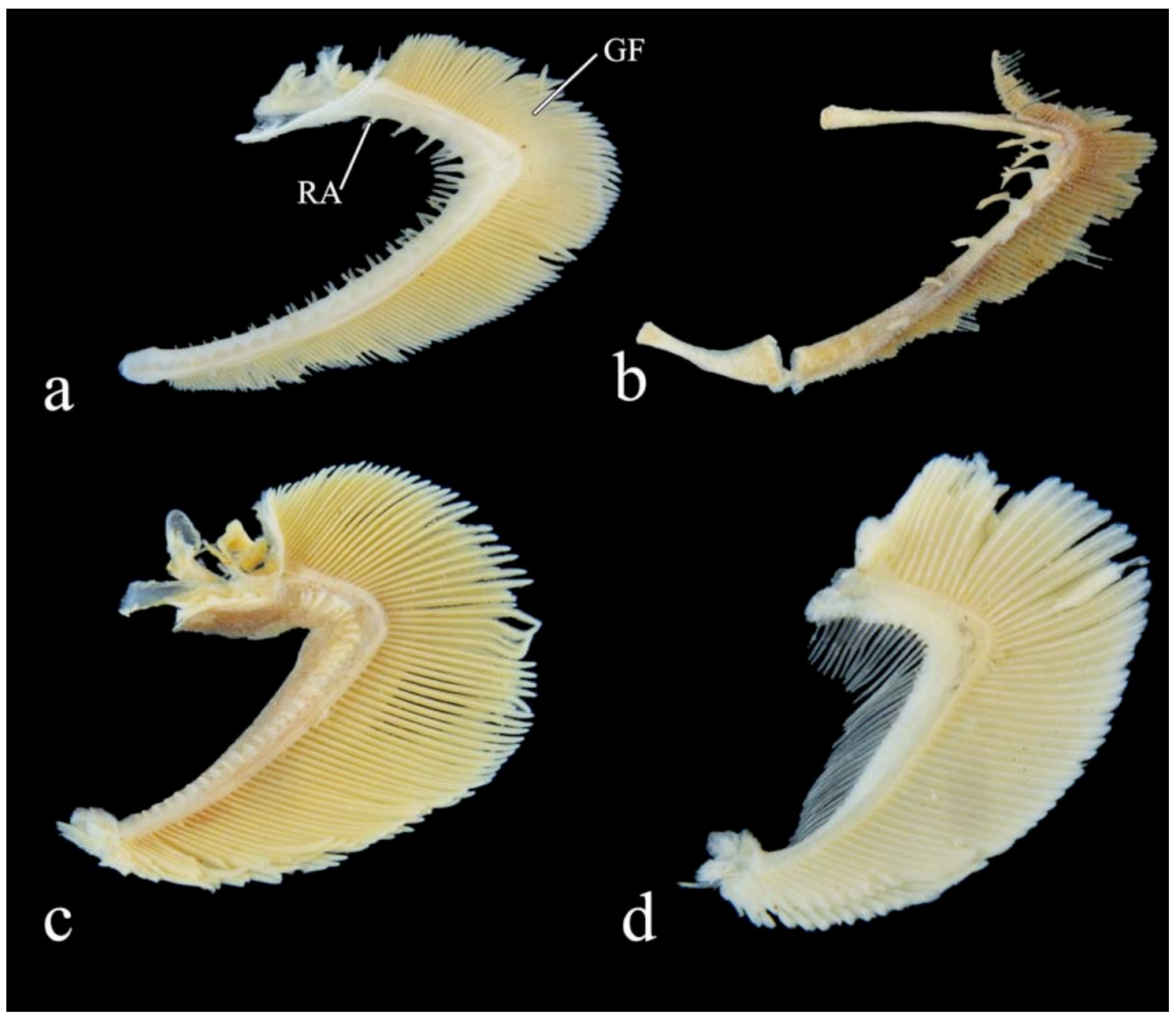

Figura 44. Primeiro arco branquial, em vista lateral, de: Ageneiosus inermis (a), MZUSP 101653 (202 mm); Tocantinsia piresi (b), MZUSP 100031 (430.0 mm); Trachycorystes trachycorystes, 7381 (136.8 mm); e Auchenipterus nuchalis (d), MZUSP 101618 (152.9 mm). GF: filamentos branquiais, RA: rastros. 


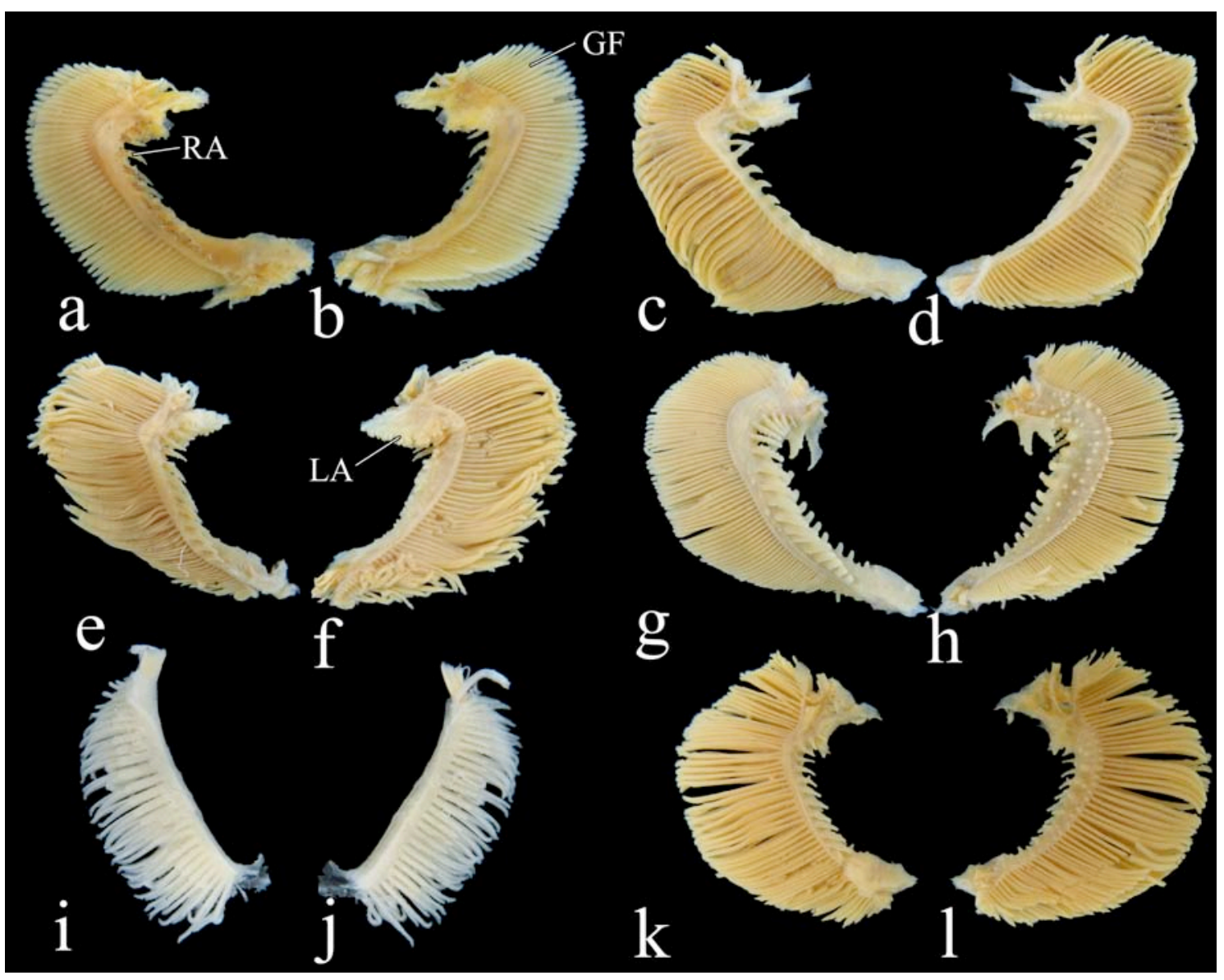

Figura 45. Primeiro aroco branquial, em vista lateral (a,c,e,g,i,k) e medial (b,d,f,h,j,l), de: Platydoras armatulus (a-b), MZUSP 94088 (135.4 mm); Centrodoras brachiatus (b-c), MZUSP 103892 (205 mm); Rhinodoras dorbignyi (e-f), MZUSP 36528 (141.6 mm); Oxydoras niger (g-h), MZUSP 56162 (154.6 mm); Trachydoras steindachneri (i-j), MZUSP 49526 (82.4 mm); e "Petalodoras" eigenmanni (k-1), MZUSP 5646 (95.4 mm). GF: filamentos branquiais, LA: lamelas branquiais, RA: rastros. 


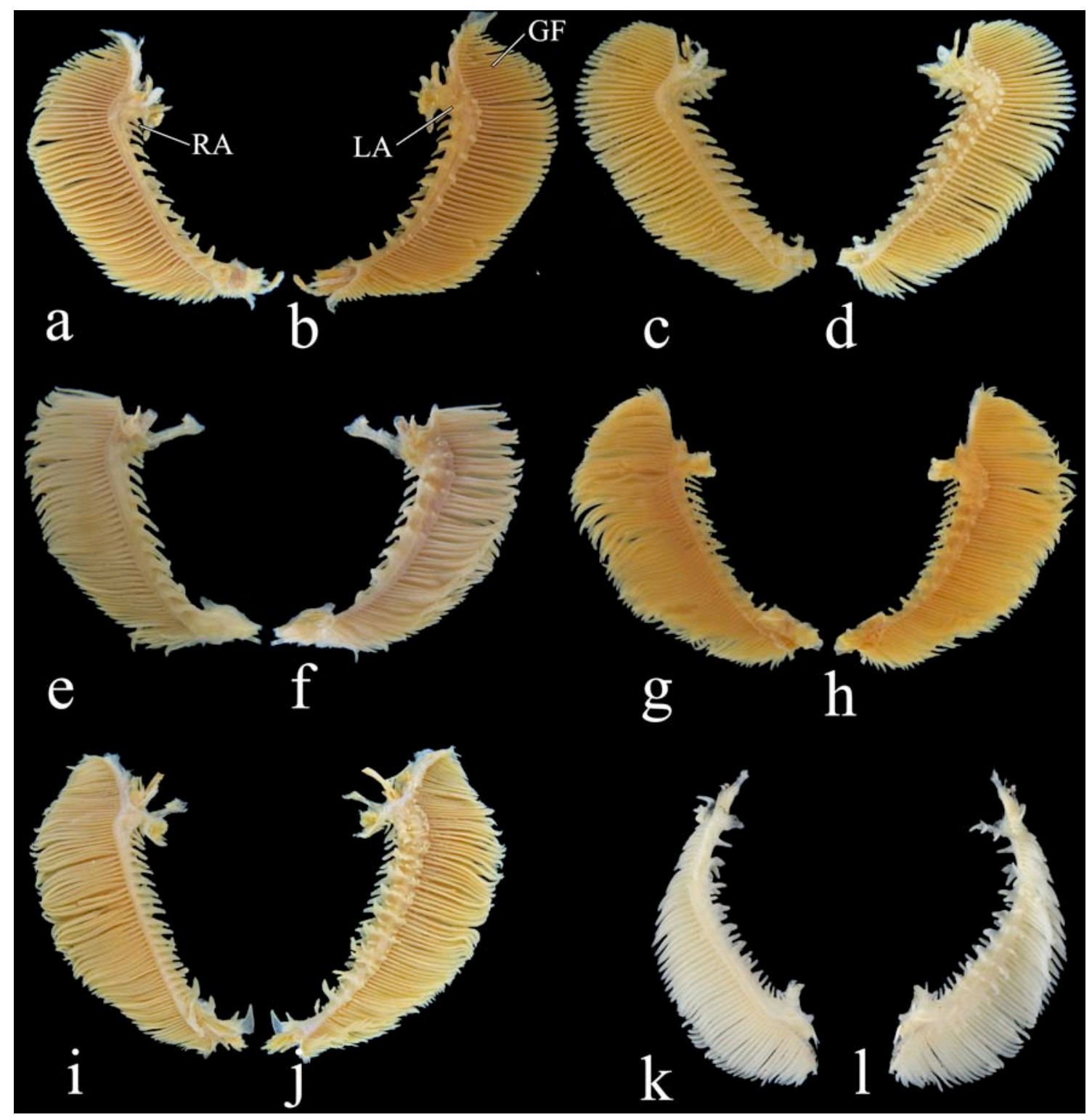

Figura 46. Primeiro arco branquial, em vista lateral (a,c,e,g,i,k) e medial (b,d,f,h,j,l), de: Hemidoras morrisi (a-b), MZUSP 28378 (161 mm); Nemadoras elongatus (c-d), MZUSP 83211 (121.7 mm); “Nemadoras" leporhinus (e-f), MZUSP 95617 (136.5 mm); Hassar affinis (g-h), MZUSP 43605 (157.0 mm); Anduzedoras oxyrhynchus (i-j), MZUSP 50838 (230.0 mm); e Leptodoras mark (k-1), MZUSP 103217 (83.2 mm). GF: filamentos branquiais, LA: lamelas branquiais, RA: rastros.

188. Lamelas branquiais acessórias sobre o epibranquial (não ordenado): (0) ausentes (figs. 44, 45a-f,i-j); (1) semelhantes às do ceratobranquial (figs. 45a-d,i-l, 46); (2) presentes como três grandes lamelas (fig. 45g-h); (3) presentes como um 


\section{lobo carnoso (fig. 45e-f). CI: 0,75; RI: $0,96$.}

Em Doradini (exceto Trachydoras) há lamelas branquiais acessórias sobre o epibranquial, similares às presentes sobre o cera-branquial (ver caráter anterior). Entretanto, em Oxydoras niger (demais congêneres não examinados) há 3 lamelas grandes e diferenciadas das presentes no ceratobranquial. E em Rhinodoras e Orinocodoras há um lobo carnoso formado pelas lamelas acessórias.

189. Número de fileiras de rastros branquiais (ordenado): (0) 2 fileiras nos arcos 1 a 4 (fig. 44a,c); (1) 1 fileira nos $\operatorname{arcos} 1$ e 2 e 2 fileiras nos $\operatorname{arcos} 3$ e 4 (figs. 44b,d, 45a-h,k-l, 46); (2) 1 fileira no arco 1, rastros ausentes nos $\operatorname{arcos} 2$ a 4; (3) rastros ausentes em todos os arcos (fig. 45i-j). CI: 0,20-0,21; RI: 0,65-0,68.

Em Siluriformes primitivos, como em Diplomystidae, Cetopsidae, Siluridae, Ariidae, há duas fileiras de rastros branquiais nos arcos branquiais 1 a 4 (nos ceratobranquiais e epibranquiais) (Lundberg, 1970; de Pinna, 1993: \#176; Britto, 2002: \#129; de Pinna et al., 2007: \#77). Entretanto, na maioria dos Siluriformes há apenas uma fileira de rastros branquiais na face anterior dos primeiros dois arcos branquiais e duas fileiras (uma anterior, outra posterior) nos arcos branquiais 3 e 4. Em Doradoidea, os únicos táxons que possuem duas fileiras de rastros nos dois primeiros arcos branquiais são: Liosomadoras, Pseudauchenipterus, Trachycorystes, Asterophysus, Auchenipterichthys, Trachelyopterichthys, Trachelyichthys, “Amplexiglanis", Tetranematichthys e Ageneiosus (Britski, 1972: 24; Royero, 1999: \#113; Akama, 2004: \#85). Em Doras, Hassar, Anduzedoras e espécies de Leptodoras basais há apenas uma fileira de rastros no primeiro arco branquial e nenhum rastro nos $\operatorname{arcos} 2$ a 4 . Em Leptodoras juruensis, L. myersi, L. cataniai e Trachydoras não há rastros branquiais em nenhum arco branquial. O rastros estão também ausentes em Aspredinidae. 
Esse caráter não foi observado em Pseudotatia.

190. Forma dos rastros branquiais (não ordenado): (0) rudimentares (fig. 44c); (1) curtos (figs. 44a, 45, 46); (2) longos (fig. 44d); (3) com margem serrilhada (fig. 44b). CI: 0,50; RI: 0,75 .

Os rastros branquiais estão ausentes em Leptodoras cataniai, L. myersi, L. juruensis (Sabaj, 2005) e Trachydoras (Birindelli, 2006: \#89), assim como em alguns outros Siluriformes (e.g, Pseudobunocephalus, vide Friel, 2008, Sisor, Chacidae, Akysidae, vide de Pinna, 1993: \#177, e Britto, 2002: \#128). Os rastros são rudimentares em diversos auchenipterídeos (Liosomadoras, Trachycorystes, Asterophysus, Pseudauchenipterus, Auchenipterichthys, Trachelyopterichthys, Trachelyichthys, Parauchenipterus e Trachelyopterus), assim como em alguns outros Siluriformes (e.g., Bunocephalus, Helogeninae, de Pinna et al., 2007: 781). Rastros longos e finos estão presentes nos mochokídeos Synodontis batensoda e S. membranaceus (anteriormente alocados em Hemisynodontis e Brachysynodontis, respectivamente; Vigliotta, 2008: \#51), e nos auchenipterídeos Auchenipterus, Pseudepapterus e Epapterus (Britski, 1972: 24; Ferraris, 1988: \#G4; Walsh, 1990: \#27; Akama, 2004: \#86). Rastros com margem serrilhada estão presentes em Tetranematichthys e Tocantinsia. Apesar de Higuchi (1992: \#A48) ter observado rastros serrilhados em Orinocodoras, os exemplares examinados não apresentam tal condição.

Royero (1999: \#112) cita rastros bífidos (=serrilhados) em Tetranematichthys e Ageneiosus magoi, entretanto, a condição nas espécies examinadas de Ageneiosus (i.e., A. atronasus, A. brevis, A. inermis) é de rastros simples. Foram vistos rastros rudimentares nos auchenipterídeos Trachelyichthys e Trachelyopterichthys, contrariando Royero (1999: \#111) e Akama (2004: \#84), que citam a ausência de rastros 
nestes táxons.

Esse caráter não foi observado em Pseudotatia; e foi codificado como inaplicável em Aspredinidae, Trachydoras e Leptodoras juruensis, por não terem rastros branquiais.

191. Base dos rastros branquiais: (0) fina como os rastros (fig. 44b-d, 45, 46); (1) larga (fig. 44a). CI: 0,33; RI: 0,00.

Entre os táxons examinados, Ageneiosus inermis e Tetranematichthys possuem os rastros com base larga e firmemente fixadas aos arcos. No grupo externo, Wallago (Siluridae) apresenta uma condição semelhante.

Esse caráter não foi observado em Pseudotatia; e foi codificado como inaplicável em Aspredinidae, Trachydoras e Leptodoras juruensis, por não terem rastros branquiais.

192. Número de rastros branquiais no primeiro arco branquial (não ordenado): (0) até 15 (fig. 44a-c, 45, 46a-h); (1) de 16 a 25 (fig. 46i-l); (2) mais de 30 (fig. 44d). CI: 0,33; RI: 0,50.

Na maioria dos Siluriformes há poucos rastros espaçados, entretanto em alguns táxons os rastros são menos espaçados e mais numerosos, como é o caso dos doradídeos Anadoras, Anduzedoras e Leptodoras (Sabaj, 2005; Birindelli et al., 2008; Birindelli \& Sousa, 2010), que possuem de 16 a 25 rastros, dos auchenipterídeos Auchenipterus (com 21 a 51 rastros, dependendo da espécie, Ferraris \& Vari, 1999: tabela 1), Pseudepapterus (com 16 a 22 ou 37, dependendo da espécie, Ferraris \& Vari, 2000: 103), e Epapterus (com 29 a 42, Vari \& Ferraris, 1998: 998, 1004) (Ferraris, 1988: \#G4), e dos mochokídeos Synodontis batensoda e S. membranaceus, com 59 a 65 e 39 a 
42 rastros, respectivamente (Poll, 1971: 32, 38). Segundo Poll (1971: 43) algumas espécies de Synodontis podem ter até 33 rastros, entretanto, as espécies examinadas desse gênero possuem menos (até 15).

Entre o grupo externo, Wallago (Siluridae) apresenta muitos rastros (em torno de $35)$.

Esse caráter não foi observado em Pseudotatia; e foi codificado como inaplicável em Aspredinidae, Trachydoras, Leptodoras juruensis, por não terem rastros branquiais.

193. Basibranquiais 2 e 3: (0) de tamanho normal (figs. 47, 48); (1) rudimentares (fig. 49). CI: 1,00; RI: 0,00.

Asterophysus possui os basibranquiais 2 e 3 rudimentares, se comparados aos de outras espécies e aos outros ossos da cesta branquial (Ferraris, 1988: \#G6; Akama, 2004: \#81). 


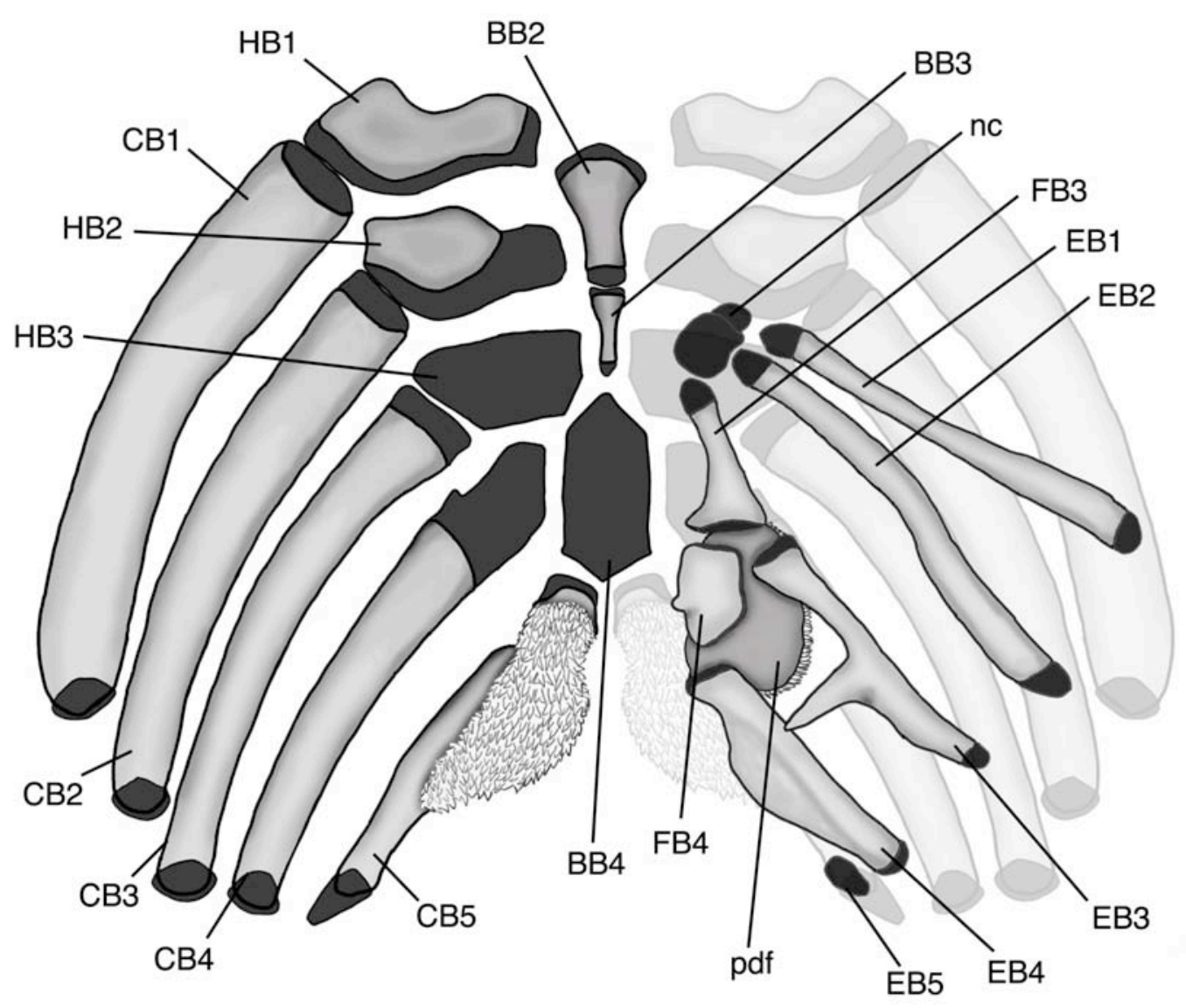

Figura 47. Aparalho branquial de Wertheimeria maculata, em vista dorsal. Desenho baseado no exemplar MZUSP 93658 (192.0 mm). BB: basibranquial, CB: ceratobranqual, FB: faringo-branquial, HB: hipo-branquial, nc: nódulo cartilaginoso; pdf: placa dentígera faringo-branquial. 


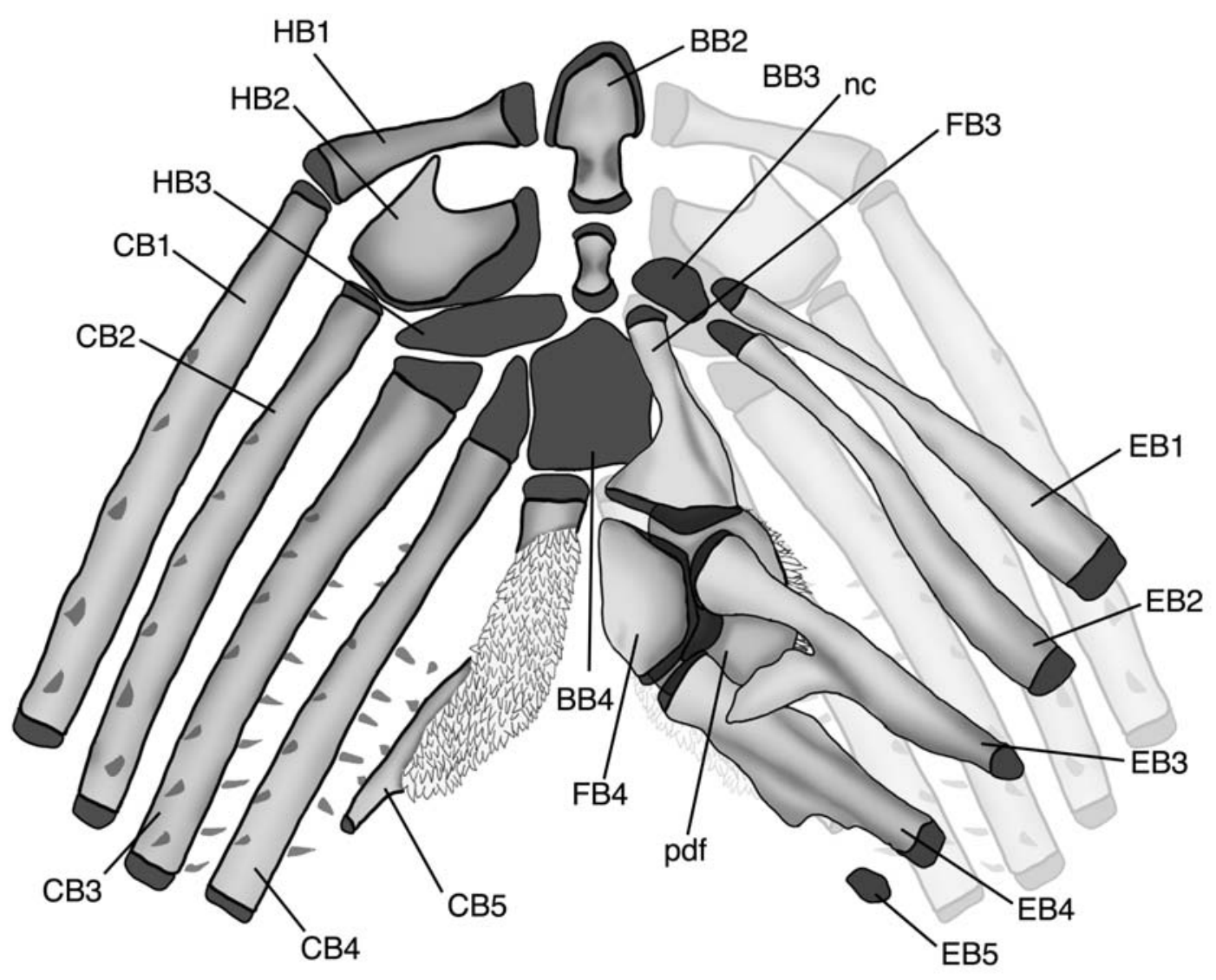

Figura 48. Aparalho branquial de Glanidium melanodermatus, em vista dorsal. Desenho baseado no exemplar MZUSP 51043 (107.9 mm). BB: basibranquial, CB: ceratobranqual, FB: faringo-branquial, HB: hipo-branquial, nc: nódulo cartilaginoso; pdf: placa dentígera faringo-branquial. 


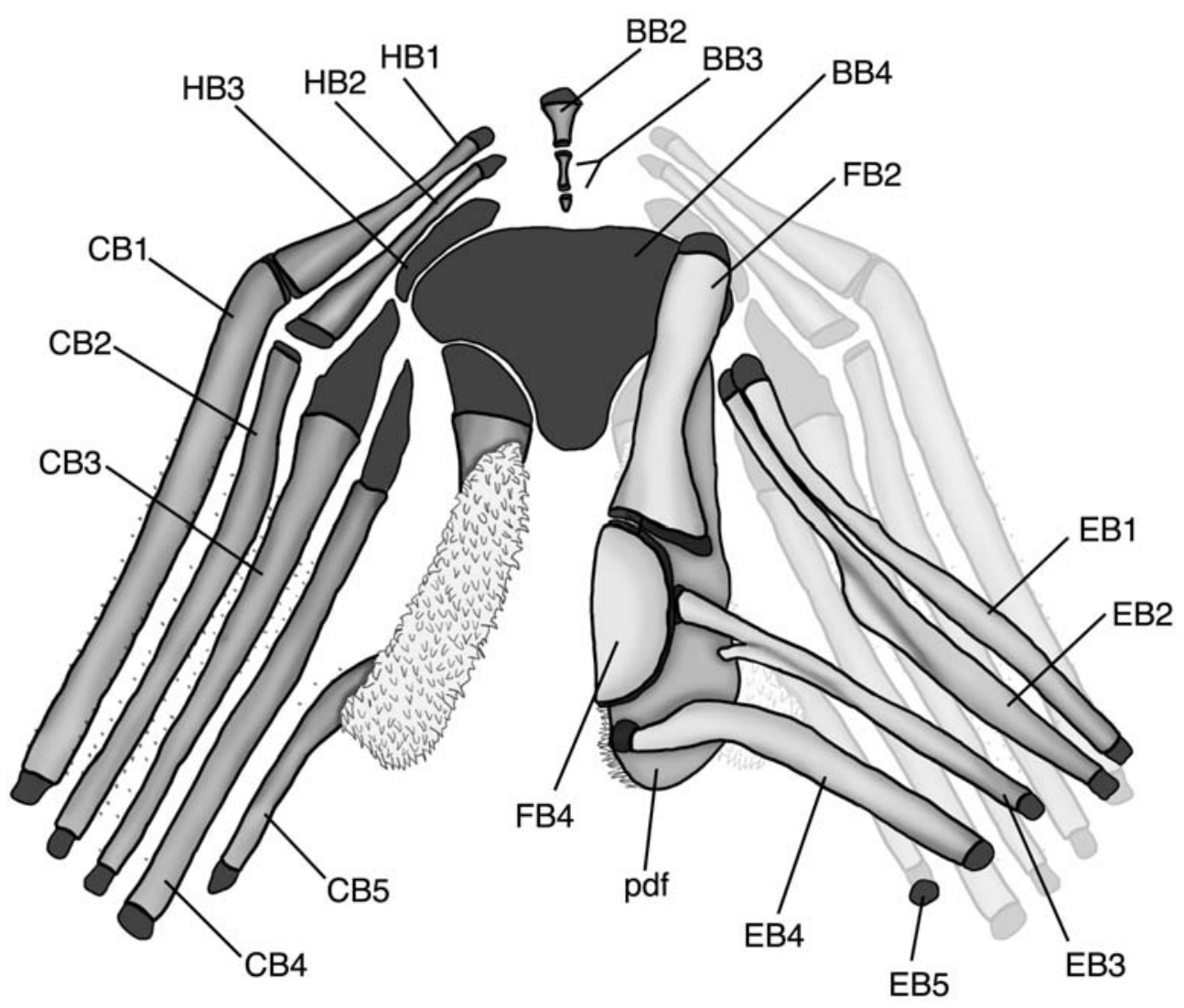

Figure 49. Aparelho branquial de Asterophysus batrachus, em vista dorsal. Desenho baseado no exemplar INPA 24119 (127.0 mm). BB: basibranquial, CB: ceratobranqual, FB: faringo-branquial, HB: hipo-branquial, pdf: placa dentígera faringo-branquial.

194. Comprimento do prolongamento posterior do processo ventral do basibranquial 4: (0) curto (figs. 47-49); (1) longo (fig. 50). CI: 1,00; RI: $1,00$.

Em Siluriformes no geral, o basibranquial 4 possui um processo ventral localizado próximo à ramificação do par posterior de artérias branquiais. Em Doradini, este processo prolonga-se posteriormente (Birindelli, 2006: \#88). Em algumas espécies de Doradidae (não Doradini) o processo do quarto basibranquial prolonga-se um pouco posteriormente, entretanto ele nunca é tão longo como nas espécies de Doradini. 
195. Forma da extremidade do processo ventral do basibranquial 4: (0) simples (fig. 47-49, 50a); (1) tripartida (fig. 50b). CI: 1,00; RI: 1,00.

Em Trachydoras a extremidade do processo ventral do basibranquial 4 é tripartida numa condição única, entre os táxons examinados.

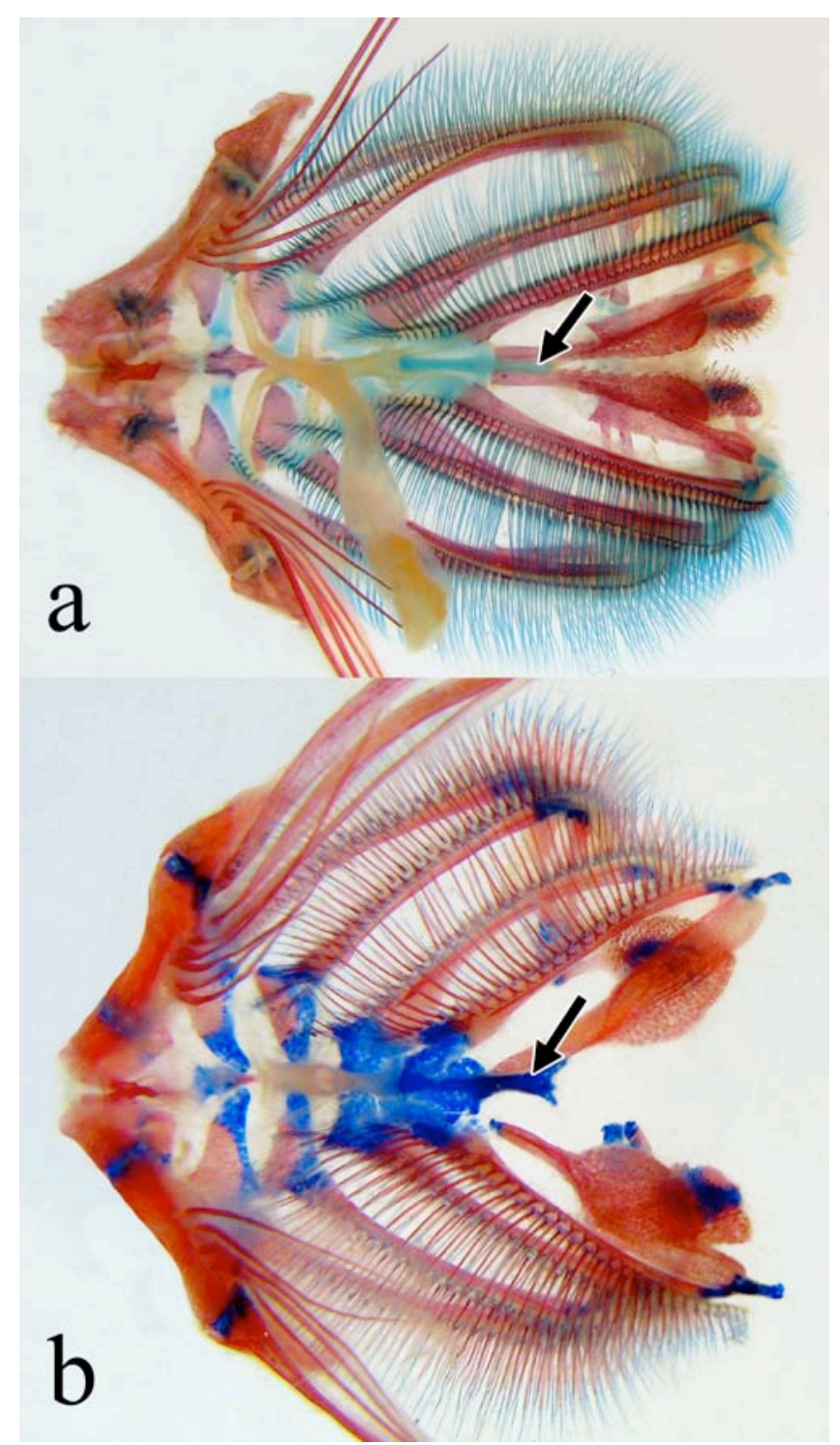

Figura 50. Aparelho branquial, em vista ventral, de: Doras phlyzakion (a), MZUSP 50836 (67.5 mm); e Trachydoras microstomus (b), MZUSP 57703 (76.6 mm). Seta indica o prolongamento do basibranquial 4.

196. Cartilagem acessória entre os basibranquiais 3 e 4: (0) ausente (figs. 47, 49); (1) presente (fig. 48). CI: 0,33-0,50; RI: 0,88-0,94. 
Em Auchenipteridae (exceto Centromochlinae e Asterophysus) há uma cartilagem acessória entre os basibranquiais 3 e 4 (Ferraris, 1988: \#G2; Akama, 2004: \#79). Uma estrutura homóloga está presente em alguns outros Siluriformes, como Akysidae e Sisoridae (de Pinna, 1993: \#184; de Pinna, 1996: \#41; Britto, 2002: \#90).

Esse caráter não foi observado em Pseudotatia.

197. Forma do hipobranquial 1: (0) discoidal (fig. 47); (1) tubular (figs. 48, 49). CI: 0,20; RI: 0,83.

O hipobranquial 1 é tubular nos auchenipterídeos Centromochlus, Tatia, Pseudotatia, Tocantinsia, Liosomadoras, Trachycorystes, Asterophysus, Pseudotatia, Pseudauchenipterus, Auchenipterichthys, Trachelyopterichthys, Trachelyichthys, Parauchenipterus, Trachelyopterus, “Amplexiglanis”, Tetranematichthys, Ageneiosus, e nos doradídeos Anduzedoras e Leptodoras (Higuchi, 1992: \#A46; Birindelli et al., 2008: fig. 10). Em alguns desses táxons (e.g., Asterophysus, Leptodoras) o segundo hipobranquial também é tubular. No grupo externo o hipobranquial 1 é tubular em Erethistidae e Aspredinidae (de Pinna, 1996: figs. 16-20).

198. Natureza do hipobranquial 2: (0) ossificado; (1) cartilaginoso. CI: 0,50; RI: $\mathbf{0 , 5 0 .}$

Em Nematogenys, Erethistidae e Aspredinidae, o segundo hipobranquial é cartilaginoso (de Pinna, 1996: \#38; Britto, 2002: \#92; de Pinna et al., 2007: \#38).

199. Forma do cerato-branquial 5: (0) com porção mediana gradualmente alargada (não pedunculado) (figs. 47-49, 50a); (1) pedunculado, com dentes distantes da extremidade anterior (figs. 50, 51b,c). CI: 1,00; RI: 1,00. 
O cerato-branquial 5 é um osso com a porção mediana gradualmente mais larga, e com uma área coberta por dentes geralmente próxima à extremidade anterior do osso. Entretanto, em Doradini, o cerato-branquial 5 é pedunculado e a área com dentes mais recuada posteriormente (Higuchi, 1992: \#60; Birindelli, 2006: \#90).

200. Disposição e número de dentes sobre o cerato-branquial 5: (0) dentes abundantes, ocupando boa parte do osso (fig. 51b); (1) dentes restritos a uma fileira na borda medial do osso (fig. 51c). CI: 1,00; RI: 1,00 .

O dentes cobrem boa parte do cerato-branquial da maioria dos Siluriformes. Entretanto, em Leptodoras eles estão restritos a uma ou duas fileiras na borda medial do osso (Birindelli et al., 2008: fig. 10). Uma condição semelhante ocorre em Xyliphius, Callichthyidae, Scoloplacidae e Trichomycteridae (de Pinna, 1993: \#148; Britto, 2002: $\# 102)$.

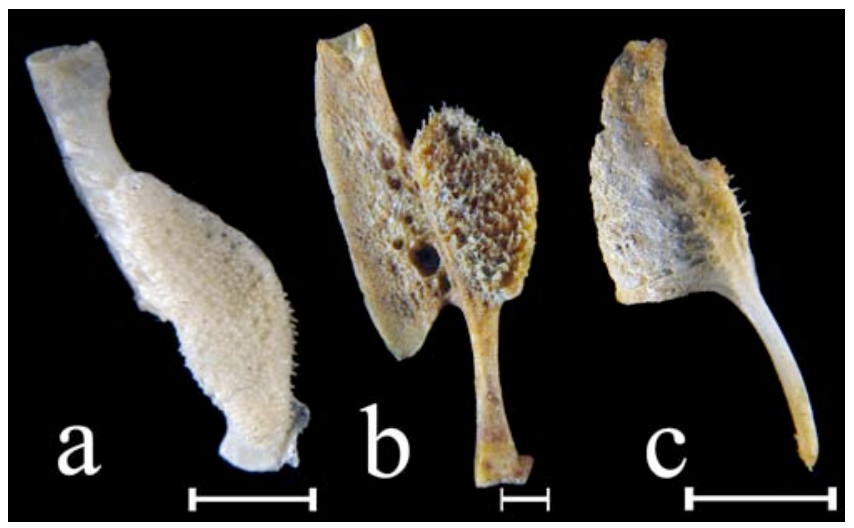

Figura 51. Cerato-branquial 5, em vista dorsal, de: Kalyptodoras bahiensis (a), MZUSP 87841 (233.0 mm); Oxydoras niger (b), MZUSP 91654 (550.0 mm); e Leptodoras juruensis (c), MZUSP 104532 (227.0 mm). Escala igual a $5 \mathrm{~mm}$.

201. Forma do epibranquial 1: (0) com extremidade medial não dilatada; (1) com extremidade medial dilatada. CI: 1,00; RI: 1,00 .

Em Ageneiosus e Tetranematichthys a extremidade medial do primeiro 
epibranquial é dilatada (Ferraris, 1988: \#G3; Walsh, 1990: \#8; Royero, 1999: \#109; Akama, 2004: \#77).

202. Comprimento da base do processo uncinado do epibranquial 3: (0) curto; (1) longo. CI: 1,00; RI: 0,00.

Em Chiloglanis, o processo uncinado do epibranquial 3 tem a base longa, que faz com o processo tenha um formato geral triangular (de Pinna, 1993: \#143; Britto, 2002: $\# 108)$.

203. Forma do processo uncinado do epibranquial 3: (0) simples (figs. 47-49); (1) bipartido (fig. 52). CI: 1,00; RI: 0,00.

Em Synodontis batensoda e $S$. membranaceus (anteriormente alocadas em Hemisynodontis e Brachysynodontis, respectivamente) o processo do epibranquial 3 é bipartido (ver fig. 52). S. batensoda ainda apresenta algumas outras modificações na esqueleto branquial, aparentemente únicas, como o formato dos epibranquiais 1 e 2 , e a presença de um processo anterior na placa dentígera.

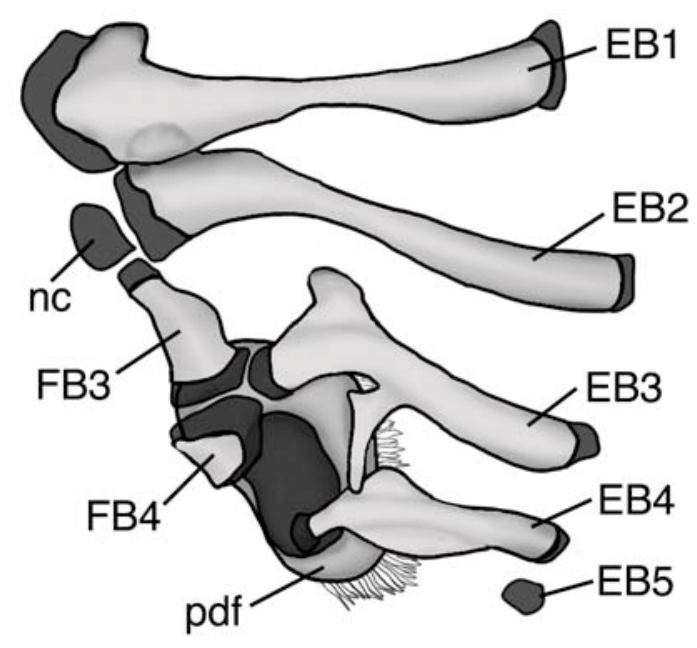

Figura 52. Parte dorsal do aparelho branquial, em vista dorsal, de Synodontis membranaceos. Desenho 
baseado no exemplar USNM 313407 (50.3 mm).

204. Epibranquial 5: (0) presente como um resquício cartilaginoso; (1) ausente. CI: 1,00; RI: 1,00 .

O epibranquial 5 está presente como um resquício cartilaginoso na maioria dos Siluriformes, entretanto em alguns táxons (e.g., Aspredinidae, Erethistidae) ele está completamente ausente (de Pinna, 1993: \#139; Britto, 2002: \#113).

205. Faringo-branquial 1: (0) presente; (1) ausente. CI: 0,33; RI: 0,50.

Dentre os Siluriformes, o faringo-branquial 1 está presente apenas em Ariidae (exceto Galeichthys, ver Marceniuk, 2003: \#150), Claroteidae, Diplomystidae, Pangasiidae, Schilbidae e Bagridae (Lundberg, 1970; Mo, 1991: \#47; de Pinna, 1993: \#140; Britto, 2002: \#116; de Pinna et al., 2007: \#75).

206. Faringo-branquial 2: (0) presente; (1) ausente. CI: 0,50; RI: 0,00.

Em Siluriformes, o faringo-branquial 2 está presente apenas em Diplomystidae (Arratia, 1987), Plotosidae e Pangasiidae (de Pinna, 1993: \#185; Britto, 2002: \#118; de Pinna et al., 2007: \#76).

207. Forma da placa dentígera faringo-branquial (não ordenado): (0) arredondada (fig. 53a); (1) alongada (fig. 53b); (2) extremamente longa (fig. 49). CI: 1,$00 ; \mathrm{RI}: 1,00$.

Em Siluriformes, no geral, a placa dentígera faringo-branquial é arredondada. Entretanto, em Doradini ela é alongada (Birindelli, 2006: \#91) e em Asterophysus ela é extremamente longa (Britski, 1972: \#25; Ferraris, 1988: \#G5; Akama, 2004: \#80). 


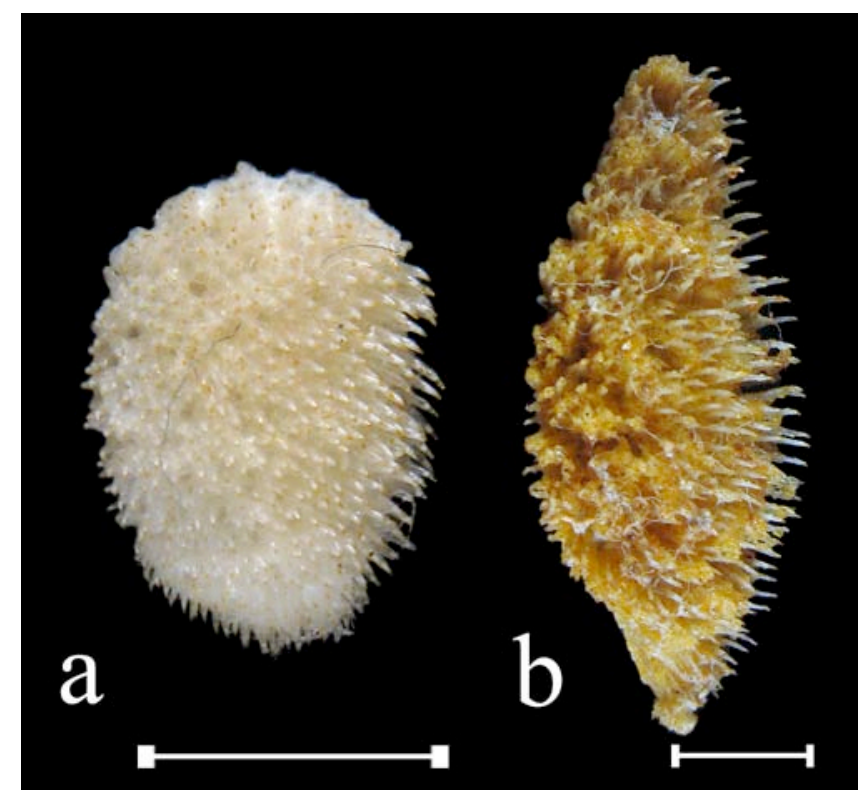

Figura 53. Placa dentígera farinago-branquial, em vista ventral, de: Kalyptodoras bahiensis (a), MZUSP 87841 (233.0 mm); e Oxydoras niger (b), MZUSP $91654(550.0 \mathrm{~mm})$. Escala igual a $5 \mathrm{~mm}$.

\subsubsection{Esqueleto axial}

Os peixes do grupo Otophysi são caracterizados pela presença do aparelho de Weber, que consiste em modificações nas primeiras vértebras e estruturas associadas que permitem que a vibração refletida na bexiga natatória seja propagada ao ouvido interno por uma cadeia de ossículos e ligamentos. Além desse complexo estrutural, alguns Siluriformes apresentam o elastic spring apparatus (ESA), primeiramente descrito em Auchenipterus, Doras, Synodontis e Malapterurus por Müller (1842a, 1842b), e posteriormente em Pangasius por Bridge \& Haddon (1892), e em Ariidae por Tavolga (1962). O ESA consiste numa modificação do ramo anterior da parapófise da vértebra complexa (ramo de Müller), que torna-se móvel e apresenta a inserção de uma musculatura modificada. A contração dessa musculatura (músculo sonoro, protractor Mülleriano de Bridge \& Haddon, 1892: 230, ou drumming muscle de Ladich, 2001: 297) faz a bexiga natatória vibrar produzindo, assim, som. O fato do músculo sonoro apresentar diferentes pontos de origem e inserção nos vários grupo em que ele ocorre 
(e.g. Pimelodidae, Doradidae), e o formato do ramo de Müller diferir de acordo com o grupo, indica que o ESA evoluiu independentemente nesses diferentes grupos. Com base nisso, caracteres independentes para a presença de cada tipo de musculatura sonora e estados distintos para cada tipo de ramo de Müller foram criados. Estudos anteriores (e.g., Chardon, 1965; Ferraris, 1988: \#V6; Vigliotta, 2008: \#76) haviam tratado a simples presença de musculatura sonora ou a presença de ramo de Müller (ou o estado livre da parapófise da vértebra complexa) como sinapomorfias para determinados grupos.

208. Expansão lateral na primeira vértebra: (0) ausente (fig. 54c-d); (1) presente (fig. 54b). CI: 1,00; RI: 1,00.

Em Rhinodoras e Orinocodoras, a primeira vértebra apresenta uma grande expansão lateral (Higuchi, 1992: \#63; Birindelli, 2006: \#92). 


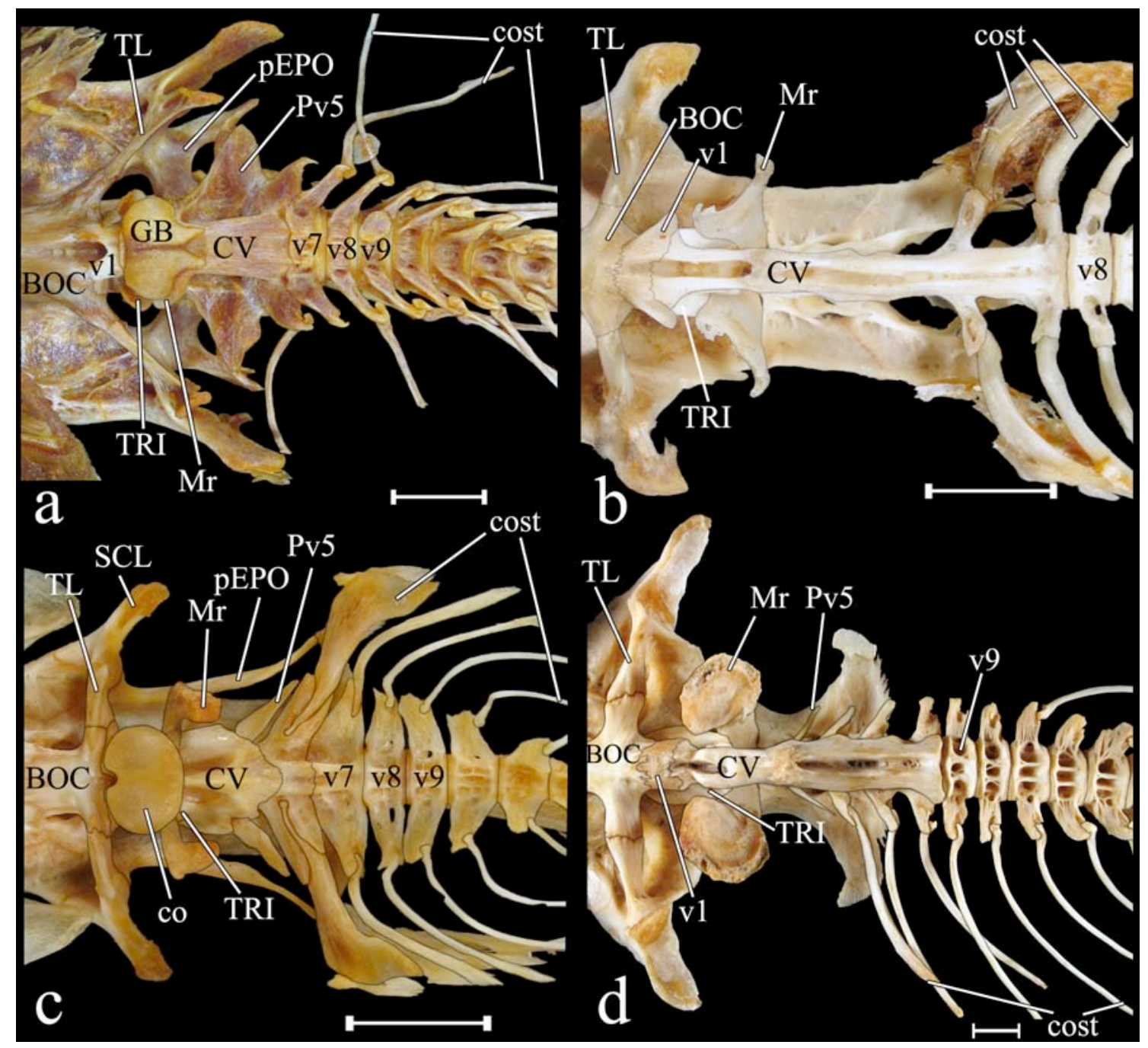

Figura 54. Vértebras anteriores, em vista ventral, de: Ageneiosus inermis (a), 91661 (320.0 mm); Rhinodoras dorbignyi (b), MZUSP 40109 (196.0 mm); Leptodoras juruensis (c), MZUSP 104532 (227.0 mm); Tocantinsia piresi (c), MZUSP 100031 (430.0 mm). BOC: basioccipital, co: cápsula óssea, cost: costelas, CV: vértebra complexa, GB: bexiga natatória, Pv5: parapófise da vértebra 5, rM: ramo de Müller, TL: processo trans-escapular, TRI: tripus, v1-9: vértebra1-9. Barra de escala igual a $10 \mathrm{~mm}$.

209. Cápsula óssea sobre as primeiras vértebras: (0) ausente; (1) presente. CI:

\section{1,00; RI: 1,00 .}

Em Anduzedoras e Leptodoras, as primeiras vértebras são revestidas ventralmente por uma cápsula óssea, originada da ossificação superficial (Higuchi, 1992: \#64; Birindelli et al., 2008; Birindelli \& Sousa, 2010). 
210. Forma da cápsula óssea sobre as primeiras vértebras: (0) curta, com abertura posterior grande; (1) curta, com abertura posterior pequena; (2) larga e globulosa, com abertura posterior pequena. CI: 1,00; RI: 1,00 .

Como discutido por Birindelli et al. (2008), a cápsula óssea varia ligeiramente em formato: curta e com abertura posterior pequena em Anduzedoras, curta com abertura posterior grande em Leptodoras marki e L. oyakawai, e globulosa com abertura posterior pequena nas demais espécies de Leptodoras (Sabaj, 2002: \#6; Birindelli \& Sousa, 2010).

Esse caráter foi tratado como inaplicável nos demais táxons analisados (exceto Anduzedoras e Leptodoras), por não possuírem cápsula óssea.

211. Grau de desenvolvimento do processo transformador do tripus: (0) bem desenvolvido como uma extensão óssea recurvada, fracamente ligada à parede da bexiga natatória (fig. 55a-f); (1) pouco desenvolvido como uma estrutura plana firmemente ligada à parede da bexiga natatória (figs. 54, 55g-h). CI: 1,00; RI: 1,00.

O processo transformador do tripus é geralmente uma extensão óssea mais fina recurvada ventralmente, posicionada lateralmente à vértebra complexa e fracamente ligada à parece da bexiga natatória (Arratia, 1987; Lechner \& Ladich, 2008). Entretanto, em Doradidae e Auchenipteridae, o processo é pouco desenvolvido, plano e fortemente ligado à parede da bexiga natatória (Bridge \& Haddon, 1890: 160, 233 [“"crescentic process"]; Britski, 1972: 19; Ferraris, 1988: \#V2; Royero, 1999: \#73; Akama, 2004: \#69). 


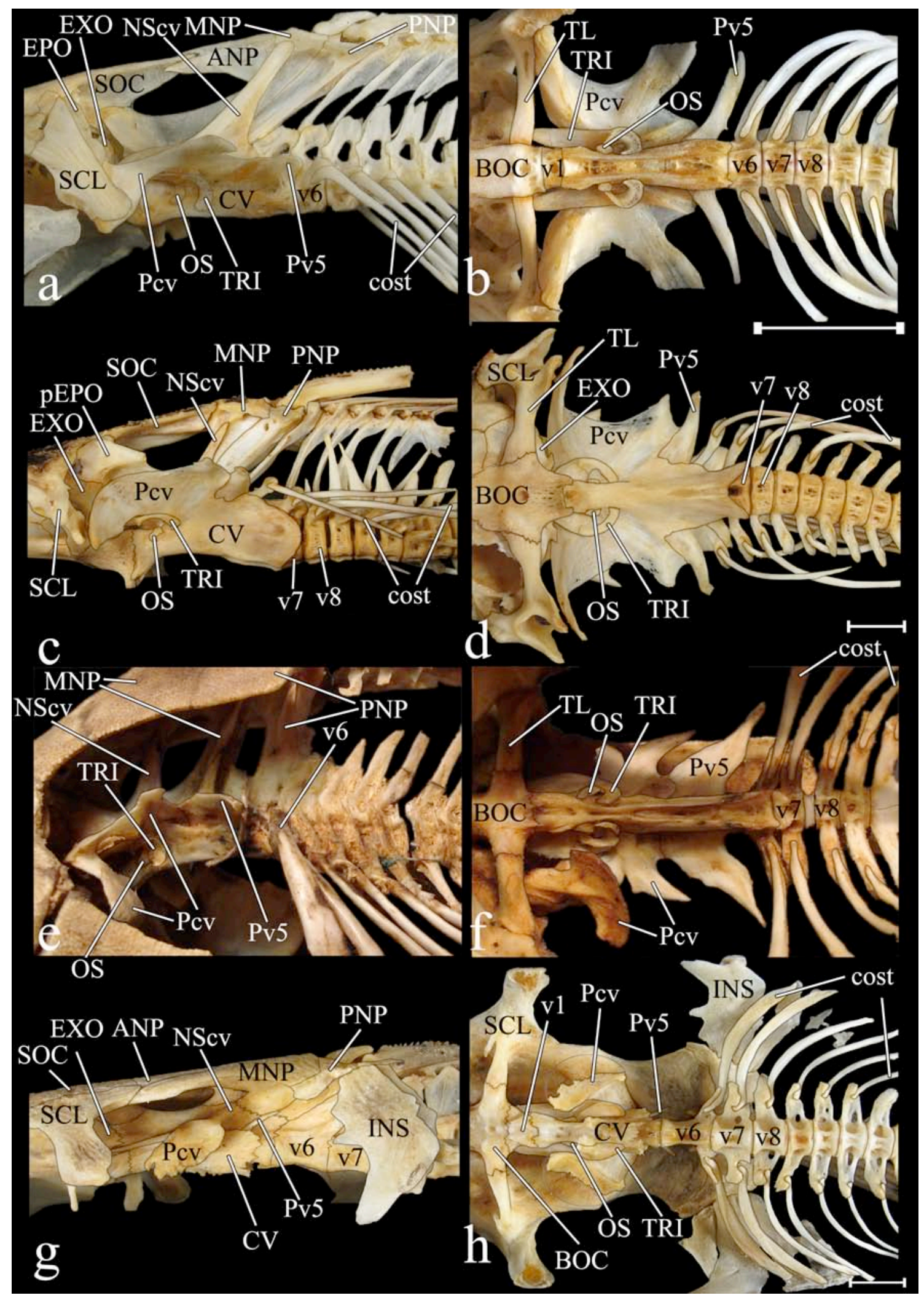

Figura 55. Vértebras anteriores, em vista lateral (1,c,d,f) e ventral (b,d,e,g), de: Ictalurus punctatus (a), MZUSP 103256 (155.0 mm); Genidens genidens (b), MZUSP 51693 (250.0 mm); Synodontis schall (c), ANSP 78057; e Wertheimeria maculata (d), MZUSP 93658 (220.0 mm). ANP : placa nucal anterior, cost: 
costelas, BOC: basioccipital, CV: vértebra complexa, EPO: epoccipital, EXO: exoccipital, INS: escudo infra-nucal, MNP: placa nucal mediana, NScv: espinho neural da vértebra complexa, Pcv: parapófise da vértebra complexa, pEPO: processo do epoccipital, PNP: placa nucal posterior, Pv5: parapófise da vértebra 5, OS: os suspensorium, SCL: pós-têmporo-supracleitro, SOC: parieto-supra-occipital, TL: processo trans-escapular, TRI: tripus, v6-8: vértebra 6-8. Escala igual a $10 \mathrm{~mm}$.

212. Grau de desenvolvimento do os suspensorium: (0) normalmente desenvolvido, fusionado à parapófise da vértebra complexa; (1) reduzido a um nódulo ósseo, ligado à parapófise da vértebra complexa apenas por ligamento. CI: 1,00; RI: 1,00.

O os suspensorium é bem diferenciado em Diplomystidae, entretanto nos demais Siluriformes ele está parcialmente fusionado à parapófise vértebra complexa e apresenta uma extensão ventral que passa entre a vértebra complexa e o tripus, com o qual se liga através de ligamento (Chardon et al., 2003). Em Doradidae e Auchenipteridae, o os suspensorium é reduzido a um nódulo ósseo localizado entre a vértebra complexa e o tripus, ligado à parapófise da vértebra complexa apenas por ligamento (Ferraris, 1988: \#V4; de Pinna, 1993: \#191; Royero, 1999: \#70; Britto, 2002: \#213; Akama, 2004: \#70).

\section{Músculo constritor (extrínseco) inserido diretamente na parede da bexiga} natatória: (0) ausente; (1) presente. CI: 1,00; RI: 0,00.

O músculo constritor (sonoro) inserido diretamente na parede da bexiga natatória está presente em Pimelodidae (maioria das espécies) e Pseudopimelodidae (Cephalosilurus e Lophiosilurus, ver Birindelli \& Shibatta, em preparação). Essa musculatura já havia sido descrita antes (Bridge \& Haddon, 1892: 118; Alexander, 1965: 110; Ladich, 2001; Diogo, 2004: \#258). Outro músculo relacionado ao descrito acima e exclusivo das espécies de Pimeldodidae é o tensor tripodis (Bridge \& Haddon, 1892: 117; Ladich, 2001). Nos demais Siluriformes, incluindo Heptapteridae (táxons 
observados: Goeldiella eques, Pimelodella cristata, Rhamdia quelen), tal musculatura está ausente.

\section{Músculo protractor (sonoro) do ramo de Müller com origem no teto do crânio: (0) ausente; (1) presente (fig. 56a-b). CI: 1,00; RI: 1,00.}

Em Doradidae e Auchenipteridae o músculo protractor do ramo de Müller se origina no teto do crânio, no soquete formado pelos ossos parieto-supra-occipital, exoccipital e epoccipital, e se insere na superfície ântero-dorsal do ramo de Müller (no próprio disco). O músculo sonoro presente em Doradoidea é inervado pelo nervo XI ou XII, ou pelo plexo occipito-espinhal.

O exoccipital de Siluriformes apresenta normalmente quatro saídas de nervos: a primeira anterior, de onde sai o nervo IX, glossofaríngeo, a segunda grande, posterior à primeira mas anterior ao processo trans-escapular, de onde sai o nervo X, vago (Arratia, 1987: 21; Freihofer, 1978: fig. 26); e duas pequenas aberturas posteriores ao processo trans-escapular, uma mais ventral, de onde sai um pequeno nervo para a musculatura sonoro de Doradoidea. Os nervos posteriores ao processo trans-escapular são possivelmente os nervos XI e XII (Kesteven, 1943: 107, fig. 50), ou fazem parte do plexo occipito-espinhal (Freihoffer, 1963: 90, fig. 13), de qualquer forma, devem ser nervos espinhais, que inervam, além de outras estruturas, a musculatura epaxial (Allis, 1903: 220). Isso é coerente com a hipótese de musculatura constritora do ramo de Müller é uma porção modificada da musculatura epaxial. Contrariando Royero (1999), que considerou essa musculatura como derivada do músculo supracarinalis anterior da nadadeira dorsal, que está ausente em diversas famílias de Siluriformes, incluindo aquelas que possuem forte conexão entre o crânio e a nadadeira dorsal. 

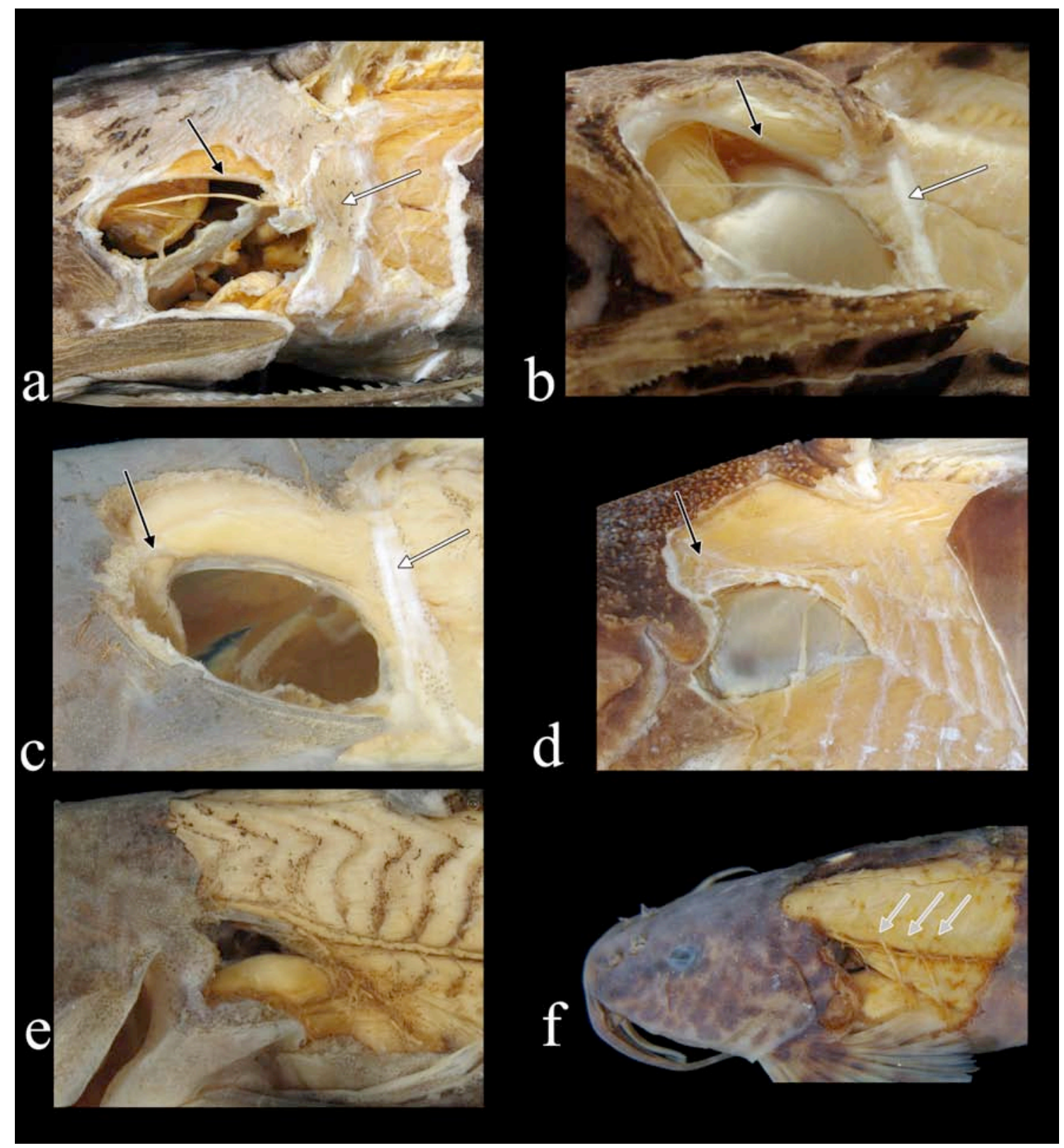

Figura 56. Área timpânica, em vista lateral, de: Wertheimeria maculata (a), MZUSP 93658 (186.0 mm); Liosomadoras oncinus (b), MZUSP 93497 (74.8 mm); Synodontis schall (c), MZUSP 84468 (76.0 mm); Arius herzbergi (d), MZUSP 52847 (192.0 mm); Diplomystes mesembrinus (e), MZUSP 62595 (99.2 mm); e Amphilius jacksoni (f), MZUSP 48636 (72.4 mm). Seta branca indica o ligamento entre a placa nucal posterior e a primeira costela; seta preta indica o ligamento do epoccipital; setas cinzas indicam ligamentos entre costela e fascia muscular.

215. Músculo protractor (sonoro) do ramo de Müller com origem na placa nucal posterior: (0) ausente; (1) presente (fig. 56c). CI: 1,00; RI: 1,00. 
Em Mochokidae, apesar do ramo de Müller estar presente e ser modificado num disco, como em Doradidae e Auchenipteridae, a musculatura associada a ele tem sua origem na placa nucal posterior (Taverne \& Aloulou-Triki, 1974; Diogo, 2004: \#256), passa dorsalmente à musculatura epaxial, rente ao escudo cefálico, e se insere na haste de sustentação da porção distal do ramo de Müller, num arranjo totalmente diferente ao encontrado em Doradidae e Auchenipteridae. Além disso, em Mochokidae, a musculatura epaxial se insere na porção posterior do crânio, próximo ao epoccipital (no soquete formado pelos ossos parieto-supra-occipital, exoccipital e epoccipital não há nenhuma musculatura inserida).

\section{Músculo protractor (sonoro) do ramo de Müller com origem (pelo menos} parcial) no ligamento epoccipital: (0) ausente; (1) presente (fig. 56d). CI: 1,00; RI: $\mathbf{0 , 0 0 .}$

Em Ariidae (exceto Galeichthys), a musculatura inserida no ramo de Müller tem sua origem parcialmente no teto do crânio e parcialmente no ligamento do epoccipital. Apesar da origem do músculo sonoro em Ariidae e Doradoidea ser similar, em Ariidae essa musculatura está no mesmo nível (superficial) da musculatura epaxial ( $v s$. medial, interno em Doradoidea) e está inserida amplamente na parapófise da vértebra complexa (vs. inserção apenas no disco do ramo de Müller em Doradoidea).

217. Divisão do músculo protractor do ramo de Müller: (0) ausente; (1) presente. CI: 0,50; RI: 0,00.

Em Ageneiosus (A. atronasus, A. brevis) e Centromochlus (C. heckelii) o músculo sonoro apresenta-se dividido em duas porções, uma com origem no teto do crânio e outra com origem no ligamento de Baudelot (Diogo, 2004: \#155; Parmentier \& 
Diogo, 2006: 54). Esta divisão é de difícil visualização e é possível que esteja presente em outros táxons.

218. Forma do ramo anterior da parapófise da vértebra complexa (ramo de Müller) (não ordenado): (0) truncado, suturado ao processo trans-escapular (fig. 55a-b); (1) afilado, livre do processo trans-escapular (mas pouco modificado) (fig. 55c-d); (2) modificado como um disco móvel com haste longa conectado ventralmente à bexiga natatória (fig. 55e-f); (3) modificado como um disco móvel com haste curta e conectado dorsalmente à bexiga natatória (fig. 55g-h). CI: 0,50; RI: $\mathbf{0 , 8 3 .}$

Primitivamente em Siluriformes o ramo anterior da parapófise da vértebra complexa é suturado ao processo trans-escapular. Entretanto, em alguns Siluriformes, este ramo é móvel e, portanto, livre do processo trans-escapular. Como discutido anteriormente, nestes táxons, o ramo anterior da parapófise da vértebra complexa é chamado ramo de Müller. Em Ariidae (exceto Galeichthys), Malapteruridae e Chiloglanidinae o ramo de Müller é móvel, mas não modificado em disco, e possui o mesmo formato presente em Siluriformes no geral. Em Ariidae, o ramo de Müller apresenta-se contínuo com o ramo posterior da parapófise da vértebra complexa, entretanto, em Malapteruridae ele é livre do ramo posterior da parapófise da quarta vértebra. Em Mochokidae (exceto Chiloglanidinae), a porção mais distal do ramo de Müller encontra-se modificada num disco que contacta ventralmente a bexiga natatória (Regan, 1911; Vigliotta, 2008: \#77, \#78). Em Pangasiidae a condição é similar mas o ramo de Müller é alongado.

Em Doradidae e Auchenipteridae, o ramo de Müller constitui-se numa haste curta e fina e num disco distal grande que contacta a bexiga natatória dorsalmente (Bridge \& 
Haddon, 1892; Regan, 1911; Alexander, 1965: 110; Chardon, 1968; Britski, 1972: 20; Curran, 1989: \#17; Royero, 1999: \#67, \#71; Akama, 2004: \#66, \#76).

219. Forma do disco do ramo de Müller (não ordenado): (0) largo e fino (figs. 54bd, 55g-h); (1) compacto e cônico (fig. 54c); (2) reduzido e afilado. CI: 0,67; RI: $0,97$.

Em Doradini (exceto Oxydoras) (Eigenmann, 1925: 297; Higuchi, 1992: \#67; Birindelli, 2006: \#93) e em Centromochlus heckelii (Britski, 1972: 20; Ferraris, 1988: \#V8; Soares-Porto, 1996: \#16; Royero, 1999: \#67; Akama, 2004: \#68), o disco do ramo de Müller é compacto e cônico, alongado posteriormente, inserido na bexiga natatória. Em espécies derivadas de Ageneiosus e Physopyxis o ramo de Müller é reduzido e afilado (Britski, 1972: 20; Ferraris, 1988: \#V3; Walsh, 1990: \#23; Higuchi, 1992: \#A52; Royero, 1999: \#74; Akama, 2004: \#67). Nos demais Doradoidea o ramo de Müller é largo, fino, e apenas contacta a bexiga natatória.

Esse caráter foi codificado como inaplicável nos demais táxons analisados (exceto Doradoidea), por não possuírem o disco do ramo de Müller.

220. Ramo posterior da parapófise da vértebra complexa: (0) presente (fig. 55a-f); (1) ausente (fig. 54, 55g-h). CI: 1,00; RI: $1,00$.

O ramo posterior da parapófise da vértebra complexa está ausente apenas em Doradidae e Auchenipteridae (Regan, 1911; Vigliotta, 2008: \#79).

221. Tamanho da parapófise da quinta vértebra (não ordenado): (0) grande, similar às das demais vértebras (figs. 54c, 55a-f); (1) reduzida (às vezes ausente), distintamente menor do que às das demais vértebras (figs. 54a-b,d, 56g-h); (2) 
extremamente grande, maior do que às demais vértebras. CI: 0,50; RI: 0,90.

Em Doradidae (exceto Leptodoras juruensis) e Auchenipteridae, a parapófise da quinta vértebra é reduzida ou ausente (Bridge \& Haddon, 1892: 230; Regam, 1911; Alexander, 1965: 111; Vigliotta, 2008: \#80). Em alguns exemplares de algumas espécies, a parapófise da quinta vértebra está presente em um dos lados, porém ausente no outro. Ferraris (1988: \#V11) considera esse um caráter presente apenas em algumas espécies de Parauchenipterus. Diferentemente dos outros doradídeos, Leptodoras jurunesis apresenta a parapófise da quinta vértebra bem desenvolvida, maior do que a parapófise da sexta vértebra (a condição deste caráter na maioria dos congêneres não foi observada).

Em Sisoroidea e Chiloglanis, a parapófise da quinta vértebra é expandida e deprimida (de Pinna, 1996: \#57, \#62; Britto, 2002: \#231; Diogo, 2004: \#138).

222. Ligamento entre o ramo de Müller e a linha lateral: (0) ausente; (1) presente (fig. 56a). CI: 1,00; RI: 1,00.

Este ligamento foi observado em Pterodoras granulosus por Sörensen (1892: 124) e Royero (1999), em Platydoras por Ladich (2001: 299), e está aparentemente presente em todas as espécies de Doradidae, sendo portanto, uma característica exclusiva do grupo. Este ligamento pode estar relacionado à propagação das vibrações do ramo de Müller para a série de escudos laterais, como sugerido por Sörensen (1892: 124).

223. Ligamento entre a primeira costela e a placa nucal posterior (ordenado): (0) ausente (fig. 56d-f); (1) presente e não ossificado (fig. 56 b-c); (2) presente e ossificado (fig. 56a). CI: 1,00; RI: 1,00. 
Em todos os auchenipterídeos (ou pelo menos em todos os examinados) há um ligamento entre a placa nucal posterior e a costela da sexta vértebra. Em Mochokidae (pelo menos em Synodontis schall), há dois ligamentos ligados à placa nucal posterior, um deles inserido na primeira costela e o outro na segunda. Em Doradidae, no mesmo local do ligamento, há uma ossificação suturada dorsalmente à placa nucal posterior e ventralmente à primeira costela, o escudo infranucal (Ferraris, 1988: \#D6; Royero, 1999: \#68, \#104; Akama, 2004: \#75). Como argumentado por Ferraris (1988), o escudo infranucal é homólogo ao ligamento de Auchenipteridae e Mochokidae, pela posição e associações que ele apresenta. Royero (1999: \#68) e Akama (2004: \#75) informaram que esse ligamento está ausente em Tetranematichthys, Ageneiosus, o que não foi corroborado no presente estudo.

Ferraris (1988: 45) citou ligamentos semelhantes (e possivelmente homólogos) ao descrito acima em outras famílias que bagres (Amphiliidae, Sisoridae). Entretanto, o presente estudo não corroborou esta observação. Em Amphiliidae há ligamentos entre as primeiras costelas e a fáscia da musculatura epaxial (fig. 55f). No único Sisoridae examinado, Pseudecheneis sulcatus, a presença de ligamento não foi constatada, porque a região timpânica desta espécie é modificada, sendo a costela coberta por uma dobra da musculatura epaxial. Entretanto, pela proximidade desta família com Amphiliidae e, por Ferraris (1988: 245) tê-la citado, é possível que esta família apresente uma condição semelhante a Amphiliidae.

Bailey \& Baskin (1976: 4) descreveram um osso entre a placa nucal posterior e a costela da sexta vértebra ("lateral bone") em Scoloplacidae, Astroblepidae e Loricariidae (ver também Schaefer, 1990: 193, fig. 18B e Armbruster, 2004: 32, fig. 28 “connecting bone"). Entretanto, o osso presente em Loricarioidea não é homólogo ao escudo infranucal dos Doradidae, pois ele não é formado pela associação entre um 
ligamento e a linha lateral (ver também Britto, 2002: \#243).

Esse caráter não foi observado em Mochokidae (exceto Synodontis).

224. Ligamento entre a segunda costela e a placa nucal posterior: (0) ausente (fig. 56a-b,d-f); (1) presente (fig. 56c). CI: 1,00; RI: 1,00.

Como apresentado anteriormente, em Mochokidae (pelo menos em Synodontis schall) há um ligamento adicional àquele descrito anteriormente, entre a placa nucal posterior e a segunda costela (a da sétima vértebra). Em Doradoidea, tal ligamento só foi encontrado em um exemplar de Tatia (Tatia cf. aulopygia, MZUSP 99309, $90 \mathrm{~mm}$ de CP).

Esse caráter não foi observado nos demais táxons da família Mochokidae.

225. Ligamento úmero-vertebral: (0) ausente; (1) presente. CI: 1,00; RI: 1,00.

O ligamento úmero-vertebral está presente na maioria das espécies de Sisoroidea, incluindo Aspredinidae (de Pinna, 1996: \#64; Diogo, 2004: \#164). Por apresentar diferenças em alguns táxons, de Pinna (1996: \# 64) definiu três estados quanto ao posicionamento do ligamento. Nas espécies analisadas no presente estudo, o ligamento encontra-se entre a extremidade posterior do processo posterior do cleitro e a parapófise modificada da quinta vértebra.

226. Canal aórtico: (0) ventralmente aberto (fig. 55b,f,h); (1) ventralmente coberto por ossificação superficial (figs. 54, 55d). CI: 0,42; RI: $0,67$.

A vértebra complexa é revestida ventralmente por uma ossificação superficial, que forma, na maioria dos táxons examinados, uma cobertura sobre o canal aórtico. Essa condição está presente em Aspredinidae, Erethistidae, Genidens (Alexander, 1964: 435; 
Arratia, 1992: \#55), Chiloglanis e nos auchenipterídeos (exceto Pseudotatia, Epapterus e Auchenipterus), e nos doradídeos (exceto Rhynchodoras). O grau de cobertura do canal aórtico varia inter e intra-espeficicamente (Higuchi, 1992: \#71, \#72; Birindelli, 2006: \#98).

Centromochlus, Tatia, Liosomadoras e Rhinodoras dorbignyi foram tratados como polimórficos para esse caráter.

227. Quinta vértebra: (0) livre da vértebra complexa; (1) parcialmente fusionada à vértebra complexa (figs. 54, 55). CI: 1,00; RI: 1,00.

A quinta vértebra só está livre da vértebra complexa em Diplomystidae e Nematogenyidae, entre os táxons examinados, sendo esta a condição primitiva em Siluriformes (Lundberg, 1970: \#86; Arratia, 1992: \#40; de Pinna, 1993: \#208; Viglitta, 2008: \#82; de Pinna et al., 2007: \#87).

228. Sexta vértebra: (0) livre da vértebra complexa (fig. 55b,h); (1) parcialmente fusionada à vértebra complexa (figs. 54, 55d,f). CI: 0,25; RI: 0,73.

A sexta vértebra está parcialmente fusionada à vértebra complexa em muitos táxons de Siluriformes. Entre os examinados, essa condição está presente em Genidens, Pimelodidae, Pangasiidae, Siluridae, Mochokidae, Auchenipteridae e Doradidae (Higuchi, 1992: \#68; Birindelli, 2006: \#95; Viglitta, 2008: \#82). Em Wertheimeria, Kalyptodoras e Franciscodoras, a sexta vértebra está ventralmente livre da vértebra complexa, porém dorsalmente fusionada a esta.

229. Sétima vértebra: (0) livre da vértebra complexa (figs. 55d,h); (1) parcialmente fusionada à vértebra complexa (figs. 54, 55d,f). CI: 0,25; RI: 0,87. 
Entre os táxons estudados, a sétima vértebra está fusionada à vértebra complexa apenas em Genidens, Auchenipteridae (exceto Pseudepapterus e Ageneiosus) (Britski, 1972: 19; Walsh, 1990; \#32), e Doradidae (exceto Wertheimeria, Kalyptodoras e Franciscodoras) (Higuchi, 1992: \#69; Birindelli, 2006: \#96).

230. Oitava vértebra: (0) livre da vértebra complexa (figs. 54a-c, 55); (1) parcialmente fusionada à vértebra complexa (fig. 54d). CI: 0,25; RI: 0,67.

Entre os táxons estudados, a oitava vértebra está fusionada à vértebra complexa apenas em Centromochlus, Trachycorystes, Tocantinsia, Auchenipterichthys, Trachelyopterichthys, Parauchenipterus, Trachelyopterus, Pterodoras, Doraops, Lithodoras, Megalodoras (Britski, 1972: 18; Higuchi, 1992: \#70; Birindelli, 2006: \#97).

231. Nódulo ósseo na parapófise da sexta vértebra: (0) ausente; (1) presente (fig. 21). CI: 1,00; RI: 0,00 .

Em Oxydoras niger e O. sifontesi, há um nódulo ósseo na parapófise da sexta vértebra (Higuchi, 1992: \#A53; Birindelli, 2006: \#99), ausente em O. kneri e nos demais táxons analisados.

232. Costela na sexta vértebra: (0) presente; (1) ausente. CI: 1,00; RI: 0,00.

Em Chiloglanis (obs. pess.) e Euchilichthys (vide Vigliotta, 2008: fig. 3C), a sexta vértebra não possui costela associada.

233. Articulação das primeiras costelas: (0) ventral (fig. 56b,d,f); (1) dorsal (figs. 54, 55h). CI: 1,00; RI: 1,00 .

As primeiras costelas se articulam com a face ventral das parapófise na maioria 
dos Siluriformes (as posteriores se articulam nas faces posterior e/ou dorsal). Já em Doradidae e Auchenipteridae as primeiras costelas se articulam com a face dorsal (e/ou posterior) das parapófises (Ferraris, 1988: \#V12; Vigliotta, 2008: \#84). Uma condição semelhante é encontrada em Trichomycterinae (Britto, 2002).

234. Forma da extremidade proximal das costelas: (0) reta (fig. 55b,d,f); (1) retorcida (figs. 54, 55h). CI: 0,50; RI: 0,94 .

Entre os táxons examinados, a extremidade proximal das costelas é retorcida em Auchenipteridae, Doradidae, Amphiliidae, Aspredinidae, Erethistidae, Sisoridae (Ferraris, 1988: \#V12; de Pinna, 1993: \#198; Britto, 2002: \#239; Vigliotta, 2008: \#84).

235. Número de costelas (ordenado): (0) de 3 a 5; (1) de 6 a 11; (2) de 12 a 18. CI: 0,39-0,41; RI: 0,56-0,60.

O número de costelas entre Siluriformes é bem reduzido quando comparado ao de outros Ostariophysi. Entre os Siluriformes, há uma gradual diminuição no número de costelas em muitos grupos (ver tabela 2), como em Sisoroidea (de Pinna, 1996: \#73).

A maioria dos Doradoidea possui 6 a 11 costelas. Entre as exceções estão Epapterus, Pseudepapterus e Ageneiosus brevis, com 4 a 5 costelas (Walsh, 1990: \#31), Glanidium, Centromochlus, Tocantinsia, Asterophysus, Ageneiosus inermis, Wertheimeria, Kalyptodoras, Platydoras, Pterodoras, Lithodoras, Megalodoras, Centrodoras e Oxydoras, normalmente com mais de 12 costelas (Birindelli, 2006: $\# 100)$.

Esse caráter não foi observado em Doraops e Oxydoras kneri. Centromochlus, Ageneiosus inermis, Platydoras armatulus e Oxydoras niger foram considerado polimórficos para esse caráter $(1,2)$. 
Tabela 2. Número de costelas nas espécies de Siluriformes examinadas.

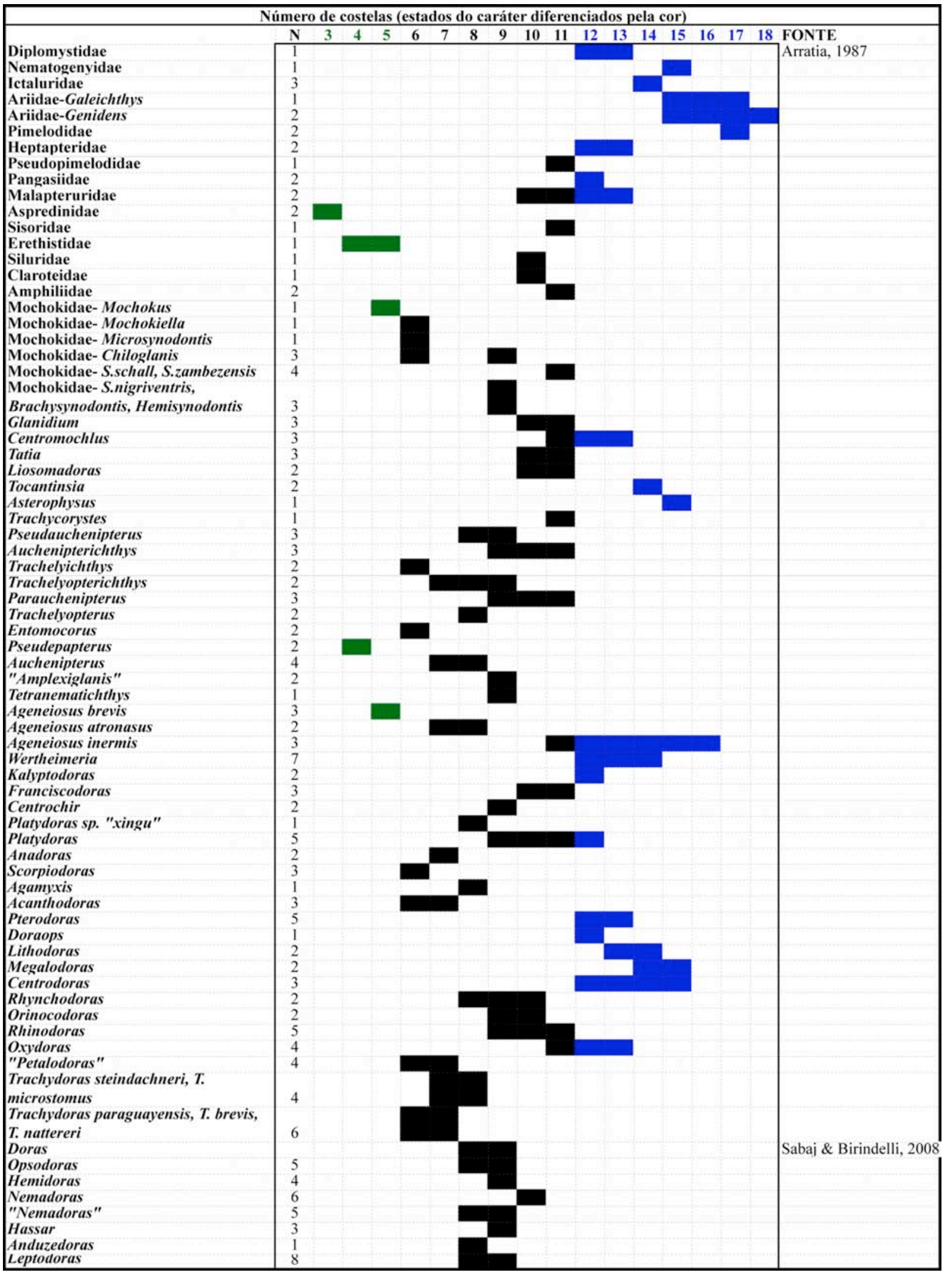

236. Número de vértebras (ordenado): (0) de 29 a 37; (1) de 38 a 45; (2) de 46 a 


\section{5; (3) de 56 a 75. CI: 0,37; RI: 0,67.}

A maioria dos Siluriformes, possui entre 38 e 45 vértebras. Entre os táxons examinados que apresentam aumento de vértebras estão: Ictaluridae, Ariidae, Pimelodidae e Heptapteridae com 46 a 53, e Siluridae com mais de 60 vértebras. Entre os táxons de Siluriformes estudados com menor número de vértebras estão: Aspredinidae, Erethistidae, Pseudopimelodidae, Sisoridae e Mochokidae (exceto Synodontis schall e S. zambezensis) com 29 a 37.

Entre os auchenipterídeos, há maior número de vértebras em Trachelyopterichthys, Parauchenipterus (polimórfico 1,2), Pseudepapterus, Auchenipterus, Tetranematichthys (polimórfico 1,2) com 46 a 55 vértebras, e Ageneiosus inermis com 57 a 60 vértebras (Walsh, 1990: \#28). Já entre os doradídeos, há 29 a 37 vértebras em Franciscodoras, Centrochir, Platydoras, Astrodoradinae, Agamyxis, Acanthodoras, Orinocodoras, Rhinodoras, "Petalodoras", Trachydoras, Doras (sendo D. carinatus, D. micropoeus e D. higuchii polimórficos 0,1), Hemidoras (sendo O. morris e H. stenopeltis polimórficos 0,1), Nemadoras, "Nemadoras" e Hassar; e de 46 a 55 nas espécies mais derivadas de Leptodoras (sensu Birindelli et al., 2008) e Lithodoras (polimórfico 1,2). Como discutido por Britski (1972: 18) parece haver mais vértebras em espécies com o corpo alongado.

Esse caráter não foi observado em Oxydoras kneri; e foi codificado como polimórfico para os táxons Doras higuchii, Hemidoras morrisi, Hemidoras stenopeltis $(0,1)$ e Lithodoras dorsalis, Tetranematichthys quadrifilis, Parauchenipterus galeatus $(1,2)$.

Tabela 3. Número de vértebras nas espécies de Siluriformes examinadas. 


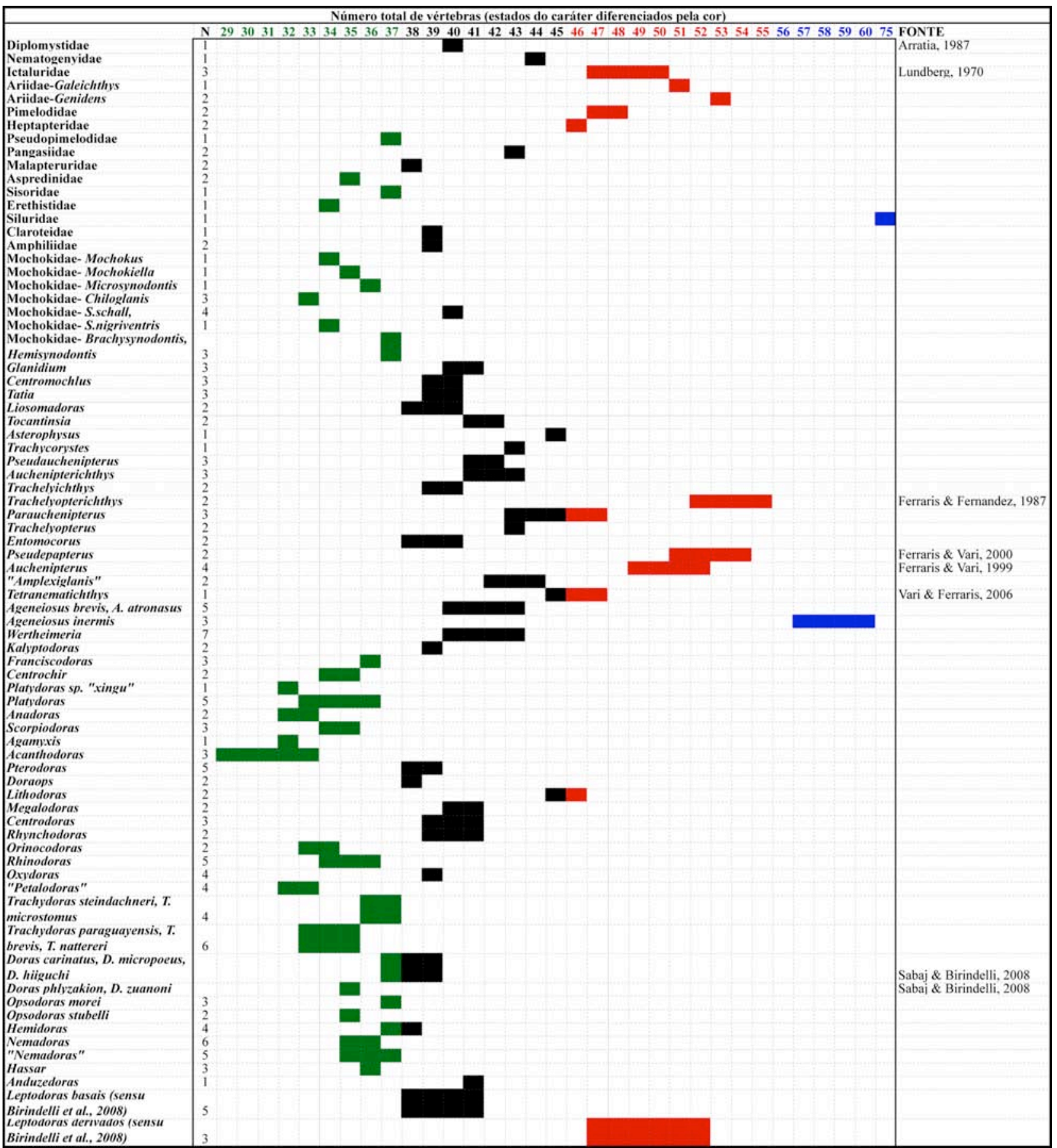

\subsubsection{Nadadeira dorsal}

A nadadeira dorsal é formada por dois raios indivisos, o primeiro reduzido em tamanho e modificado numa trava e o segundo modificado num espinho, normalmente serrilhado, e um número variado de raios ramificados. Todos estes elementos são 
suportados por pterigióforos (com radiais proximais e distais, exceto os dois anteriores); os dois primeiros pterigióforos são expandidos dorsalmente em placas dérmicas, chamadas placas nucais mediana e posterior, respectivamente. Anteriormente a estes dois elementos, há um supraneural, que também apresenta, geralmente, uma expansão dorsal em forma de placa dérmica, a placa nucal anterior. Cada um desses três elementos é formado por uma única ossificação (e sem a divisão entre radiais proximais e distais, que ocorre nos pterigióforos posteriores). Desta forma, a única diferença entre o supraneural e os primeiros dois pterigióforos é que estes últimos suportam raios. Alguns autores como, por exemplo, Arratia (2003b), optaram por nomear o primeiro elemento (que dá origem à placa nucal anterior) como primeiro pterigióforo. Como argumentado por Alexandre (1965), esta nomenclatura admite que houve a perda de um raio, suportado por este primeiro pterigióforo, sendo, portanto, mais parcimonioso supor que o primeiro elemento é derivado de um supraneural, que não suporta nenhum raio, e os demais elementos são pterigióforos modificados, que suportam raios.

\section{Ossos do escudo cefálico: (0) compactos; (1) trabeculados (fig. 34). CI: 1,00;}

\section{RI: $\mathbf{1 , 0 0 .}$}

No geral, o escudo cefálico de Siluriformes é formado por osso compactos, entretanto, em Tetranematichthys e Ageneiosus eles são trabeculados (Britski, 1972: 12; Royero, 1999: \#30). Em Pseudauchenipterus nodosus os ossos do crânio são hipertrofiados e alveolados (Britski, 1972: 12; Mees, 1974; Curran, 1989: \#21; Royero, 1999: \#30; Akama, 1999: 10; Akama, 2004: \#39) e em Entomocorus o escudo cefálico apresenta grandes cristas ósseas (Royero, 1999: \#31).

238. Perfil do corte transversal do escudo cefálico: (0) ligeiramente convexo 
dorsalmente, formando um ângulo próximo de $180^{\circ}$ (figs. 16, 29-34); (1) arqueado dorsalmente, formando um ângulo próximo de $90^{\circ}$ (figs. 17-28). CI: 0,33; RI: 0,95.

Em todas as espécies de Doradidae (exceto Wertheimeria, Kalyptodoras e Acanthodoras e Agamyxis) o perfil do corte transversal do escudo cefálico, na placa nucal mediana, é arqueado, formando um ângulo próximo de $90^{\circ}$ (Birindelli, 2006: \#105). Em Auchenipteridae, o escudo cefálico é ligeiramente convexo (em corte transversal), sendo um pouco mais arqueado em alguns táxons, como por exemplo Auchenipterus. Em Mochokidae, Synodontis possui o escudo cefálico arqueado (em corte transversal), o que confere a estes peixes um aspecto superficialmente similar ao de um Doradini.

239. Perfil (em vista lateral) do escudo cefálico em machos madurus: (0) aproximadamente reto, semelhante ao de fêmeas e machos imaturos; (1) distintamente côncavo, diferente de fêmeas e machos imaturos. CI: 1,00; RI: 1,00. Em "Amplexiglanis", Tetranematichthys, Ageneiosus, e algumas espécies de Parauchenipterus (como em P. striatulus e P. porosus), os machos maduros apresentam o perfil do escudo cefálico (em vista lateral) distintamente côncavo, enquanto as fêmeas e machos imaturos o apresentam reto (Ferraris, 1988: N19; Akama, 2004: \#173).

240. Supraneural: (0) presente; (1) ausente. CI: 0,25; RI: 0,00.

Primitivamente em Siluriformes, há um supraneural imediatamente anterior ao primeiro pterigióforo da nadadeira dorsal. Entretanto, em Malapteruridae, Trichomycteridae, Nematogenyidae, Clariidae, Amphiliidae, Siluridae, Amblycipitidae, Loricariidae e Astroblepidae, o supraneural está ausente (Britto, 2002: \#280; de Pinna et al., 2007: \#108). 
241. Forame nucal (ordenado): (0) ausente (figs. 15-24, 28-34); (1) presente e bem desenvolvido (figs. 25-27); (2) presente e pouco desenvolvido. CI: 0,50; RI: 0,90.

Em algumas espécies de Doradinae, entre elas, "Petalodoras" fimbriatus, Hemidoras, Nemadoras, "Nemadoras", Hassar, Anduzedoras, e Leptodoras, há um forame nucal, entre os ossos parieto-supra-occipital, epoccipital e placa nucal anterior (ou mediana, quando a placa nucal anterior é reduzida ou ausente) (Higuchi, 1992: \#82, \#83; Sabaj, 2002: \#19; Birindelli, 2006: \#106). Em Anduzedoras, Leptodoras praelongus, L. copei e L. oyakawai, o forame nucal encontra-se presente em exemplares de pequeno porte e reduzido ou completamente fechado nos exemplares de grande porte (Birindelli et al., 2008: 476; estado 2). Além dessa variação ontogenética, existe também variação intra-específica em algumas espécies, com exemplares de mesmo tamanho apresentando graus diferentes de desenvolvimento do forame nucal (ver Sabaj, 2002: fig. 66). A ordenação desse caráter foi baseada na mudança ontogenética que este caráter sofre nas espécies de doradídeos examinadas.

242. Placa nucal anterior: (0) presente (figs. 15-26, 28-33); (1) ausente (fig. 27, 34).

\section{CI: 0,13; RI: 0,36.}

Em algumas espécies de Doradidae, Auchenipteridae e Mochokidae, a placa nucal anterior está ausente, como em Rhynchodoras, "Nemadoras" trimaculatus, "Nemadoras" ternetzi, Nemadoras humeralis (Birindelli, 2006: \#107), Ageneiosus, Epapterus, Pseudepapterus, Glanidium cesarpintoi, algumas espécies de Centromochlus (Britski, 1972: 27; Ferraris, 1988: \#D1; Walsh, 1990: \#4; Soares-Porto, 1998: \#9; Royero, 1999: \#26; Akama, 2004: \#32, \#40), Synodontis (S. nigriventris, S. batesii, S. contracta), Chiloglanis, Atopodontus e Euchilichthys (Vigliotta, 2008: \#19). 
Apesar desta ausência ter sido explicada como fusão da placa nucal anterior à mediana (Royero, 1987: 132; Higuchi, 1992: 123; Akama, 2004: \#40) ou ao parieto-supraoccipital (Soares-Porto, 1996: 138; e não Soares-Porto, 1998, como está em Birindelli et al, 2007), o estudo de séries ontogenéticas indica que a ausência da placa nucal anterior deve ter sido causada pelo desaparecimento gradual do supraneural, o espaço sendo gradualmente ocupado pela placa nucal mediana (Birindelli et al., 2007: 680).

Segundo alguns autores (de Pinna, 1996: fig. 35; Britto, 2002: \#280), a placa nucal anterior está fusionada à placa nucal mediana em alguns grupos de Siluriformes (e.g. Sisoridae, Erethistidae, Akysidae, Scoloplacidae, Aspidoras e Corydoras).

Esse caráter foi codificado como inaplicável para Amphiliidae, Malapteruridae, Siluridae, Nematogenyidae, por não possuírem supraneural.

243. Sutura entre a placa nucal anterior e o parieto-supra-occipital: (0) ausente (fig. 15); (1) presente (figs. 16-34). CI: 1,00; RI: 1,00.

A placa nucal anterior encontra-se geralmente presente como uma pequena peça triangular que se encaixa ou tem a ponta direcionada ao parieto-supra-occipital (Arratia, 1987; Lundberg, 1970; Royero, 1987). Entretano, nas espécies de Doradidae, Auchenipteridae e Mochokidae a placa nucal anterior é suturada ao parieto-supraoccipital (Chardon, 1968: 229; Mo, 1991: \#99; Royero, 1999: \#25, \#27; Britto, 2002: \#282; Akama, 2004: \#40).

Esse caráter foi codificado como inaplicável em Amphiliidae, Malapteruridae, Siluridae, Nematogenyidae (por não possuírem supraneural); e Rhynchodoras, "Nemadoras" trimaculatus, "Nemadoras" ternetzi, Nemadoras humeralis, Ageneiosus, Pseudepapterus (por não terem placa nucal anterior). 
244. Contato entre a placa nucal anterior e o pós-têmporo-supracleitro: (0) ausente; (1) presente. CI: 1,00; RI: 1,00 .

A placa nucal anterior faz contato com o pós-têmporo-supracleitro apenas em Mochokus e Mochokiella (Vigliotta, 2008: \#18).

Esse caráter foi codificado como inaplicável em Amphiliidae, Malapteruridae, Siluridae, Nematogenyidae (por não possuírem supraneural); e Rhynchodoras, "Nemadoras" trimaculatus, "Nemadoras" ternetzi, Nemadoras humeralis, Ageneiosus, Pseudepapterus (por não terem placa nucal anterior).

245. Contato entre placa nucal mediana e parieto-supra-occipital: (0) ausente (figs. 15, 22, 25-27, 34); (1) presente (figs. 16-21, 23-24, 28-33). CI: 0,36; RI: 0,68.

O contato entre a placa nucal mediana e o parieto-supra-occipital só ocorre em algumas espécies de Doradidae, Auchenipteridae e Mochokidae, nas quais a placa nucal anterior está reduzida ou ausente. Entre estas estão: Rhynchodoras, "Petalodoras" aff. eigenmanni, "Petalodoras" eigenmanni, "Petalodoras" fimbriatus, Hemidoras, Nemadoras, "Nemadoras", Hassar, Anduzedoras, Leptodoras praelongus (Britski, 1972: 27; Higuchi, 1992: \#84; Sabaj, 2002: \#18; Birindelli, 2006: \#107), Ageneiosus, Pseudepapterus, Glanidium cesarpintoi e algumas espécies de Centromochlus ( Britski, 1972: 27; Ferraris, 1988: \#D3; Walsh, 1990: \#4; Soares-Porto, 1998: \#9; Royero, 1999: \#23; Akama, 2004: \#35, \#126), Synodontis (S. nigriventris, S. batesii, S. contracta), Chiloglanis, Atopodontus e Euchilichthys (Vigliotta, 2008: \#20). "Petalodoras" fimbriatus e Oxydoras niger foram consideradas polimórficas para este caráter $(0,1)$, por apresentarem exemplares com condições distintas nos diferentes lados do corpo.

Esse caráter foi tratado como inaplicável em Malapteruridae, por não possuir placa nucal mediana. 
246. Processo anterior do segundo pterigióforo articulado ao primeiro pterigióforo da nadadeira dorsal: (0) ausente; (1) presente. CI: 1,00; RI: 1,00.

Em Akysidae, Amphiliidae, Aspredinidae, Bagridae, Erethistidae e Sisoridae, há um processo anterior do segundo pterigióforo articulado ao promeiro pterigióforo da nadadeira dorsal (de Pinna, 1996: \#90; Britto, 2002: \#284).

Esse caráter foi tratado como inaplicável em Malapteruridae, que não possui placas nucais.

247. Faceta de articulação entre a extremidade proximal do primeiro pterigióforo e a extremidade distal do espinho neural da vértebra complexa: (0) lisa, não diferenciada do restante do osso; (1) rugosa e espessada em relação ao restante do osso. CI: 1,00; RI: 1,00 .

O estado derivado desse caráter está presente em Erethistidae, Sisoridae, Akysidae, Amblycipitidae, Aspredinidae e Amphiliidae (de Pinna, 1996: \#91; Britto, 2002: \#285), e é responsável, em Erethistidae e Sisoridae, pela formação de um aparelho estridulatório produtor de som (de Pinna, 1996).

Esse caráter foi tratado como inaplicável em Malapteruridae, que não possui pterigióforos da nadadeira dorsal.

248. Sutura entre os dois primeiros pterigióforos da nadadeira dorsal e os espinhos neurais: (0) ausente (fig. 15); (1) presente (figs. 16-34). CI: 1,00; RI: 1,00.

Em Doradidae, Auchenipteridae, Mochokidae e Chacidae os primeiros dois pterigióforos (e geralmente o supraneural) são suturados ao espinhos neural da vértebra complexa, ao contrário do que ocorre nos demais Siluriformes, nos quais os primeiros 
pterigióforos são apenas unidos aos espinhos neurais por ligamentos, ou separados deles (Britski, 1972: 26; Royero, 1987; Royero, 1999: \#75; Britto, 2002: \#286; Akama, 2004: \#125). Na superfamília Sisoroidea, o primeiro pterigióforo da nadadeira dorsal se encaixa ventralmente sobre o espinho neural da vértebra complexa (Royero, 1987; de Pinna, 1996: \#91), numa situação distinta porém semelhante à que ocorre em Auchenipteridae, Doradidae e Mochokidae.

Esse caráter foi tratado como inaplicável em Malapteruridae, que não possui pterigióforos da nadadeira dorsal.

249. Trava do acúleo da nadadeira dorsal: (0) presente; (1) ausente. CI: 0,20; RI: $\mathbf{0 , 0 0}$.

A trava do acúleo da nadadeira dorsal está ausente nos táxons de Amphiliidae, Aspredinidae, Astroblepidae, Cetopsidae, Clariidae, Malapteruridae, Nematogenyidae e Siluridae, Trichomycteridae (Britto, 2002: \#288).

250. Processos ventrais da trava da nadadeira dorsal: (0) curtos (figs. 57a); (1) longos (figs. 57b-c). CI: 1,00; RI: 1,00.

Primitivamente em Siluriformes, a trava do acúleo da nadadeira dorsal apresenta um par de pequenos processos ventrais articulados ao primeiro pterigióforo. Entretanto, em Erethistidae, Sisoridae (de Pinna, 1996: \#88), Doradidae, Auchenipteridae e Mochokidae, estes processos são longos, alcançando ventralmente aproximadamente até metade do comprimento do pterigióforo (Ferraris, 1988: \#D7; Royero, 1999: \#76; de Pinna, 1993: \#233; Britto, 2002: \#289). O mesmo estado é encontrado em Amblycipitidae e Akysidae (de Pinna, 1996: \#88, fig. 36). Apesar de alguns exemplares de Platydoras e Acanthodoras apresentarem esses processos ventrais subterminais 
(Birindelli, 2006: \#108), o exame de mais material demonstrou que isto é variável intraespecificamente.

Esse caráter foi tratado como inaplicável em Aspredinidae, Nematogenyidae, Siluridae, Malapteruridae e Amphiliidae, por não possuírem a trava da nadadeira dorsal.

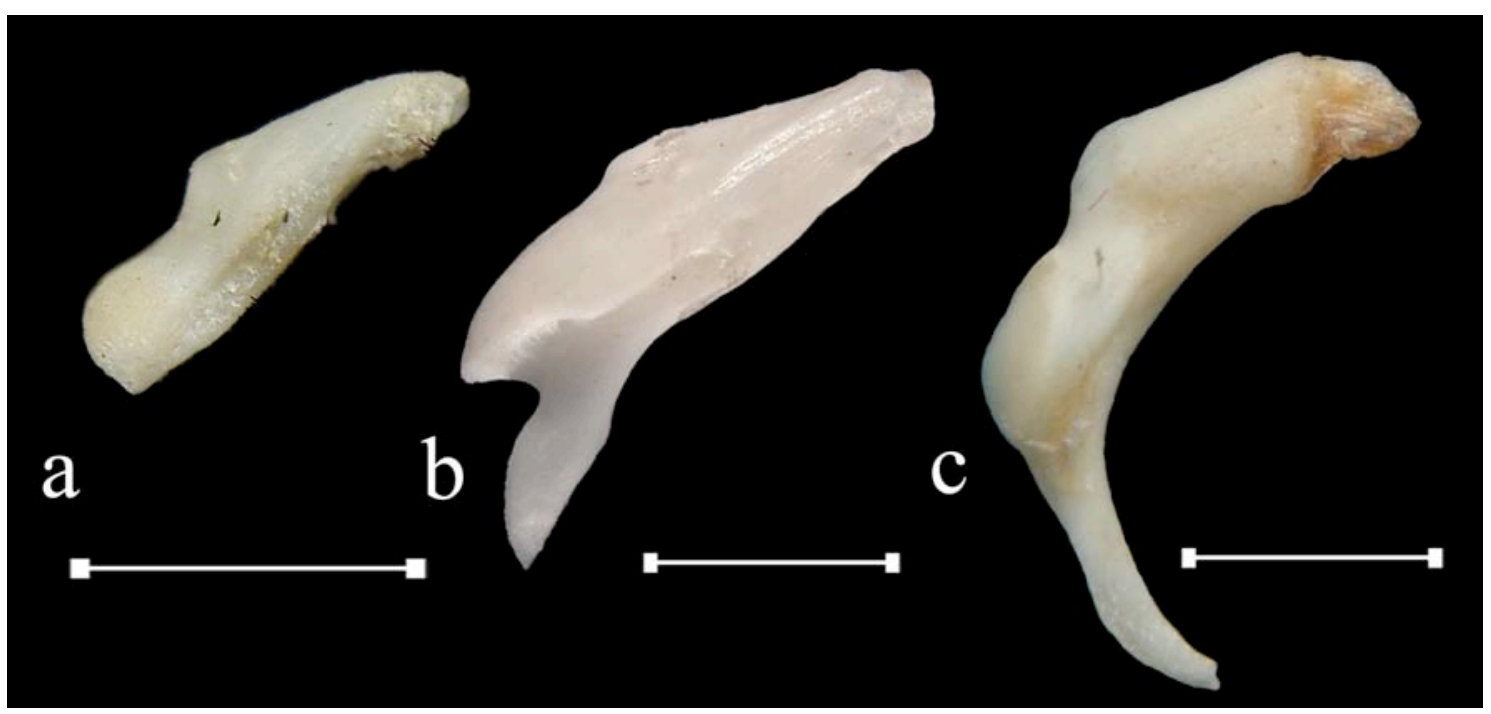

Figura 57. Trava do acúleo da nadadeira dorsal, em vista lateral, de: Ictalurus punctatus, MZUSP 103256 (155.0 mm); Platydoras brachylechis (b), MZUSP não catalogado (não medido); e Rhinodoras dorbygnyi (c), MZUSP 62688 (102 mm). Escala igual a $5 \mathrm{~mm}$.

251. Número de raios ramificados na nadadeira dorsal (ordenado): (0) de 6 a 8; (1) 5; (2) 4. CI: 0,22; RI: 0,53.

Normalmente em Siluriformes, há 6 ou 7 raios ramificados na nadadeira dorsal (Lundberg, 1970; Royero, 1987, 1999), sendo que em Diplomystidae, há 7 ou 8 raios (Arratia, 2003b). A maioria dos Doradidae e Auchenipteridae possuem 6 raios ramificados na nadadeira dorsal. Entretanto, Acanthodoras (Eigenmann, 1925: 283; Birindelli, 2006: \#115), Entomocorus, Parauchenipterus, Trachelyopterus, Trachycorystes, "Amplexiglanis" teaguei, Trachelyichthys, Centromochlus heckelii, Glanidium melanodermatum, Tatia aulopygia têm 5 raios (Britski, 1972: 29; Akama, 2004: \#128). E Epapterus e Trachelyopterichthys possuem apenas 4 raios ramificados 
(Ferraris, 1988: D13; Royero, 1999: \#78). O gênero Pseudepapterus apresenta variação no número de raios da nadadeira dorsal (P. cucuhyensis com 3 a 5, P. hasemani com 5 e às vezes 6, P. gracilis com 4; Ferraris \& Vari, 2000: 97). Em Mochokidae, a maioria possui 6 ou 7 raios, mas algumas espécies de Chiloglanis possuem 5 raios (Vigliotta, 2008: \#64).

Esse caráter foi tratado como inaplicável em Malapteruridae, que não possui os raios da nadadeira dorsal.

252. Comprimento do acúleo da nadadeira dorsal (não ordenado): (0) normal, mais curto do que 1/3 do comprimento padrão; (1) longo, mais longo do que 1/3 do comprimento padrão; (2) reduzido e delgado (fig. 13). CI: 1,00; RI: 1,00.

Em Centromochlus heckelii e C. existimatus (Soares-Porto, 1998: \#23) o acúleo da nadadeira dorsal é longo. Em Pseudepapterus e Epapterus o acúleo da nadadeira dorsal é extremamente reduzido e delgado (Britski, 1972: 27; Ferraris, 1988: \#D13; Curran, 1989: \#14; Ferraris, \& Vari, 2000; Akama, 2004: \#127). Há uma tendência de aumento do acúleo da nadadeira dorsal em Doradidae e Auchenipteridae, as espécies mais basais, como Wertheimeria, Kalyptodoras, Centromochlinae, tendo acúleos menores (Birindelli 2006: \#109).

Esse caráter foi tratado como inaplicável em Malapteruridae, que não possui o acúleo da nadadeira dorsal.

253. Arqueamento do acúleo da nadadeira dorsal em machos maduros: (0) ausente; (1) presente. CI: 1,00; RI: 1,00 .

Em machos maduros de Parauchenipterus ( $P$. porosus, P. striatulus), “Amplexiglanis", Ageneiosus, Tetranematichthys (Akama, 2004: \#165), o acúleo da 
nadadeira dorsal é arqueado.

Esse caráter foi tratado como inaplicável em Malapteruridae, que não possui o acúleo da nadadeira dorsal.

254. Capacidade de movimentação do acúleo da nadadeira dorsal num ângulo maior do que $90^{\circ}$ em machos maduros: (0) ausente; (1) presente. CI: 0,50; RI: 0,88. Ageneiosus, Auchenipterus, Entomocorus, "Amplexiglanis", Liosomadoras, Parauchenipterus (P. porosus, P. striatulus), Tetranematichthys, Pseudepapterus e Epapterus (Ferraris, 1988: \#D12; Royero, 1999: \#127; Akama, 2004: \#167) apresentam capacidade de movimentação do acúleo da nadadeira dorsal num ângulo maior do que $90^{\circ} \mathrm{em}$ machos maduros.

Esse caráter foi tratado como inaplicável em Malapteruridae, que não possui o acúleo da nadadeira dorsal.

255. Número de série de espinhos na margem anterior do acúleo da nadadeira dorsal em machos maduros: (0) nenhuma ou uma série; (1) duas séries. CI: 0,50; RI: $\mathbf{0 , 5 0 .}$

Em Ageneiosus, “Amplexiglanis”, Parauchenipterus (P. porosus, P. striatulus) há duas séries de espinhos na margem anterior do acúleo da nadadeira dorsal em machos maduros (Akama, 2004: \#164).

Esse caráter foi tratado como inaplicável em Malapteruridae, por não possuir o acúleo da nadadeira dorsal.

256. Distribuição dos espinhos da margem anterior do acúleo da nadadeira dorsal em machos maduros: (0) semelhante a de fêmeas e machos imaturos, normalmente 
distribuídos uniformemente ao longo do acúleo; (1) espinhos restritos à base e a porção distal do acúleo. CI: 1,00; RI: 0,00 .

Em Ageneiosus inermis e "Amplexiglanis" insignis, os espinhos são distribuídos na base e na porção distal do acúleo, porém ausentes na porção mediana deste (Royero, 1999: \#128; Akama, 2004: \#166). Nas demais espécies de "Amplexiglanis" e Ageneiosus essa característica não está presente.

Esse caráter foi tratado como inaplicável em Malapteruridae, que não possui o acúleo da nadadeira dorsal.

\section{Serra na margem anterior do acúleo da nadadeira dorsal: (0) ausente ou} rudimentar; (1) presente. CI: 0,10; RI: 0,64.

A presença de serra na margem anterior do acúleo da nadadeira dorsal varia entre e dentro das várias famílias de Siluriformes. Em Diplomystidae, a margem anterior do acúleo é lisa, sem serra (Arratia, 1987). Entre os táxons examinados, possuem serras na margem anterior do acúleo da nadadeira dorsal apenas Pseudopimelodidae, Ariidae, e alguns Doradoidei. Os Mochokidae (exceto Mochokus niloticus e algumas espécies de Synodontis) também não possuem serra, (Vigliotta, 2008: \#62). Em Doradidae, apenas Anadoras e algumas espécies de Amblydoras possuem a margem anterior do acúleo lisa, sem espinhos (Birindelli, 2006: \#110). Em Auchenipteridae, Trachelyopterus, Parauchenipterus galeatus, Pseudauchenipterus, Auchenipterus, Pseudepapterus, Epapterus, Entomocorus, Glanidium e Tocantinsia possuem espinhos reduzidos, rudimentares ou ausentes na margem anterior do acúleo da nadadeira dorsal (Royero, 1999: \#80; Akama, 2004; \#129). Em Doradinae (exceto Oxydoras), a serra na margem anterior do acúleo da nadadeira dorsal é bem desenvolvida apenas na porção proximal, sendo pouco desenvolvida distalmente (Birindelli, 2006: \#110); entretanto, esta é uma 
tendência, com variação ontogenética, inter- e intra-específica e, portanto, sem limite discreto entre dois estados.

Esse caráter foi tratado como inaplicável em Malapteruridae, que não possui o acúleo da nadadeira dorsal.

258. Serra na margem posterior do acúleo da nadadeira dorsal: (0) ausente, margem lisa, sem espinhos; (1) presente. CI: 0,16; RI: 0,47.

Assim como na margem anterior, a presença de serra com espinhos na margem posterior do acúleo da nadadeira dorsal varia entre e dentro das várias famílias de Siluriformes. Em Diplomystidae, a margem posterior do acúleo é lisa, sem serra (Arratia, 1987), assim como em Nematogenyidae, Ictaluridae, Pimelodidae, Heptapteridae, Siluridae, Aspredinidae, Sisoridae, Galeichthys e Amphiliidae, entre os examinados. Em Doradidae, Wertheimeria, Kalyptodoras, Franciscodoras, Acanthodoras, Agamyxis, Anadoras, Scorpiodoras, Leptodoras juruensis possuem a margem lisa, sem espinhos (Birindelli, 2006: \#112). Em Auchenipteridae, Glanidium, Tatia, Pseudotatia, Trachycorystes, Tocantinsia, Auchenipterus, Pseudepapterus, Epapterus, "Amplexiglanis" teaguei, Ageneiosus ucayalensis, A. inermis (e provavelmente os outros congêneres de médio porte), a margem posterior também é lisa, ou com espinhos vestigiais (Royero, 1999: \#79; Akama, 2004: \#130). Platydoras é um táxon que apresenta variação neste caráter, com espécimes com e outros sem espinhos. O desenvolvimento dos espinhos é variável entre e dentro de muitos táxons examinados, de modo que a delimitação de estados discretos entre caracteres tais como “espinhos antrorsos na metade do acúleo" ou "espaçamento dos espinhos" torna-se impossível. Entretanto, há uma tendência de espaçamento dos espinhos em algumas espécies de Auchenipteridae (Akama, 2004: \#130), e dos espinhos serem antrorsos, em 
vez de retrorsos em Doradini (exceto Oxydoras) (Birindelli, 2006: \#113). Em Mochokidae, Mochokiella, Microsynodontis, Synodontis, e algumas espécies de Chiloglanis, há serra na margem posterior do acúleo da dorsal (Vigliotta, 2008: \#63).

Esse caráter foi tratado como inaplicável em Malapteruridae, que não possui o acúleo da nadadeira dorsal.

259. Tamanho dos espinhos da margem posterior do acúleo da nadadeira dorsal em machos maduros: (0) semelhante ao de fêmeas e machos imaturos, normalmente distribuídos uniformemente ao longo do acúleo; (1) espinhos hipertrofiados na metade distal do acúleo. CI: 0,50; RI: 0,00.

Em Auchenipterichthys e Trachelyopterichthys, os espinhos da porção distal da margem posteiror do acúleo da nadadeira dorsal de machos maduros são hipertrofiados (Ferraris \& Fernandez, 1987; Ferraris et al., 2005; Akama, 2004: \#163). Esta característica não está presente nos exemplares de Liosomadoras examinados, contrariando o que foi anotado por Akama (2004: \#163).

Esse caráter foi tratado como inaplicável em Malapteruridae, que não possui o acúleo da nadadeira dorsal.

260. Espinhos nas margens laterais do acúleo da nadadeira dorsal: (0) ausentes; (1) presentes. CI: 1,00; RI: 1,00 .

Em Acanthodoras e Agamyxis há espinhos nas margens laterais do acúleo da nadadeira dorsal (Birindelli, 2006: \#114).

Esse caráter foi tratado como inaplicável em Malapteruridae, que não possui o acúleo da nadadeira dorsal. 
261. Número de pares de músculos inclinadores da nadadeira dorsal (ordenado): (0) um par; (1) dois pares (fig. 58a); (2) três pares (fig. 58b); (3) quatro pares. CI: 0,38; RI: 0,50.

Em Ageneiosus (A. atronasus, A. brevis, A. ucayalensis), “Amplexiglanis”, há dois pares. Em Ageneiosus (A. inermis, A. magoi), Parauchenipterus, Pseudepapterus, Trachelyopterus há três pares. Em Tetranematichthys há quatro pares (Akama, 2004: \#131; Royero, 1999: tabela 3). Na maioria dos Siluriformes examinados há apenas 1 par, com origem na placa nucal posterior (ver Royero, 1999: tabela 3).

Esse caráter foi tratado como inaplicável em Malapteruridae, por não possuir a nadadeira dorsal. Esse caráter não foi observado em Pseudotatia e Epapterus.

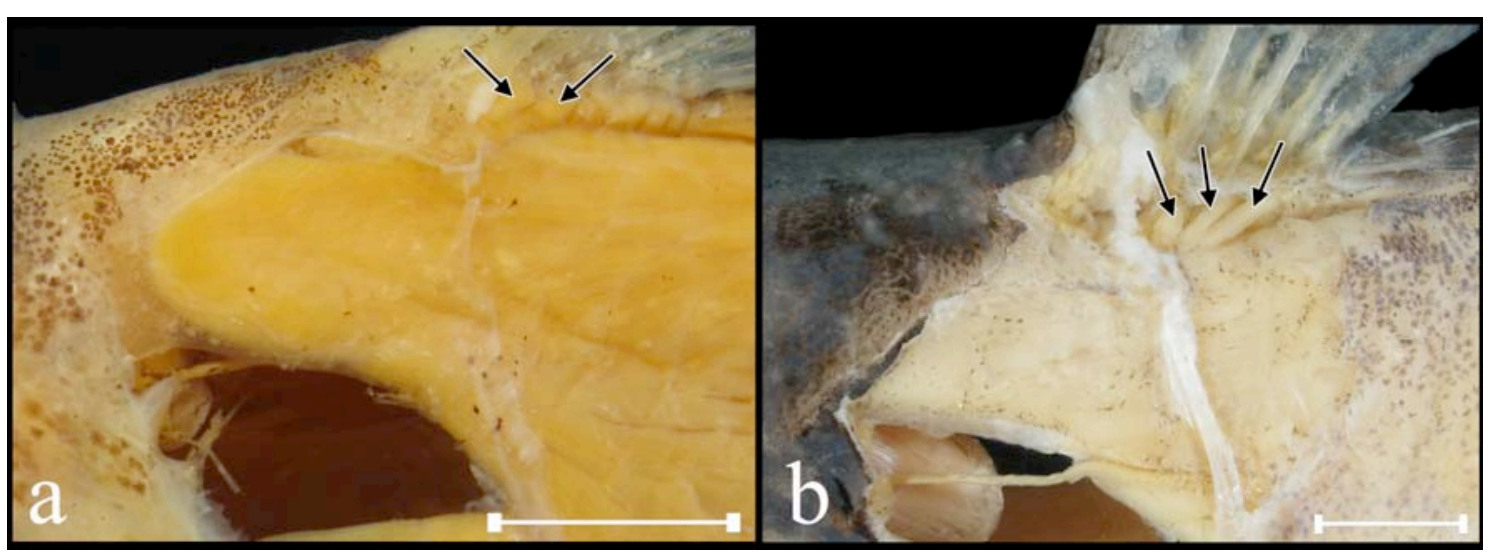

Figura 58. Base da nadadeira dorsal (com musculatura exposta), em vista lateral, de: Ageneiosus atronasus (a), MZUSP 52620 (80.1 mm); e Parauchenipterus striatulus (b), MZUSP 90742 (154.0 mm). Setas indicam os músculos inclinadores dos raios da nadadeira dorsal. Barra de escala igual a $5 \mathrm{~mm}$.

\subsubsection{Cintura peitoral}

262. Margem anterior da cintura peitoral (ordenado): (0) em forma de arco (ligeiramente convexa) (figs. 59d, 60e-f); (1) alongada anteriormente, com as margens convergentes e a extremidade truncada (fig. 59f); (2) alongada anteriormente, com as margens convergentes e a extremidade afilada (figs. 59e, 
60d). CI: 0,25; RI: 0,84.

Primitivamente em Siluriformes a cintura peitoral é em forma de arco, ligeiramente convexa. Entretanto, nos doradídeos Oxydoras, Doras, Hemidoras, Nemadoras, "Nemadoras", Hassar, Anduzedoras e Leptodoras basais, a cintura peitoral é alongada anteriormente, com as margens convergentes e a extremidade truncada. Já em Centromochlus, Tatia, Pseudauchenipterus, Pseudotatia, Entomocorus, Asterophysus (Britski, 1927; Soares-Porto, 1998: \#18), e em Leptodoras juruensis e Trachydoras (Higuchi, 1992: \#97; Birindelli, 2006: \#126), a cintura é alongada anteriormente, com as margens convergentes e a extremidade afilada.

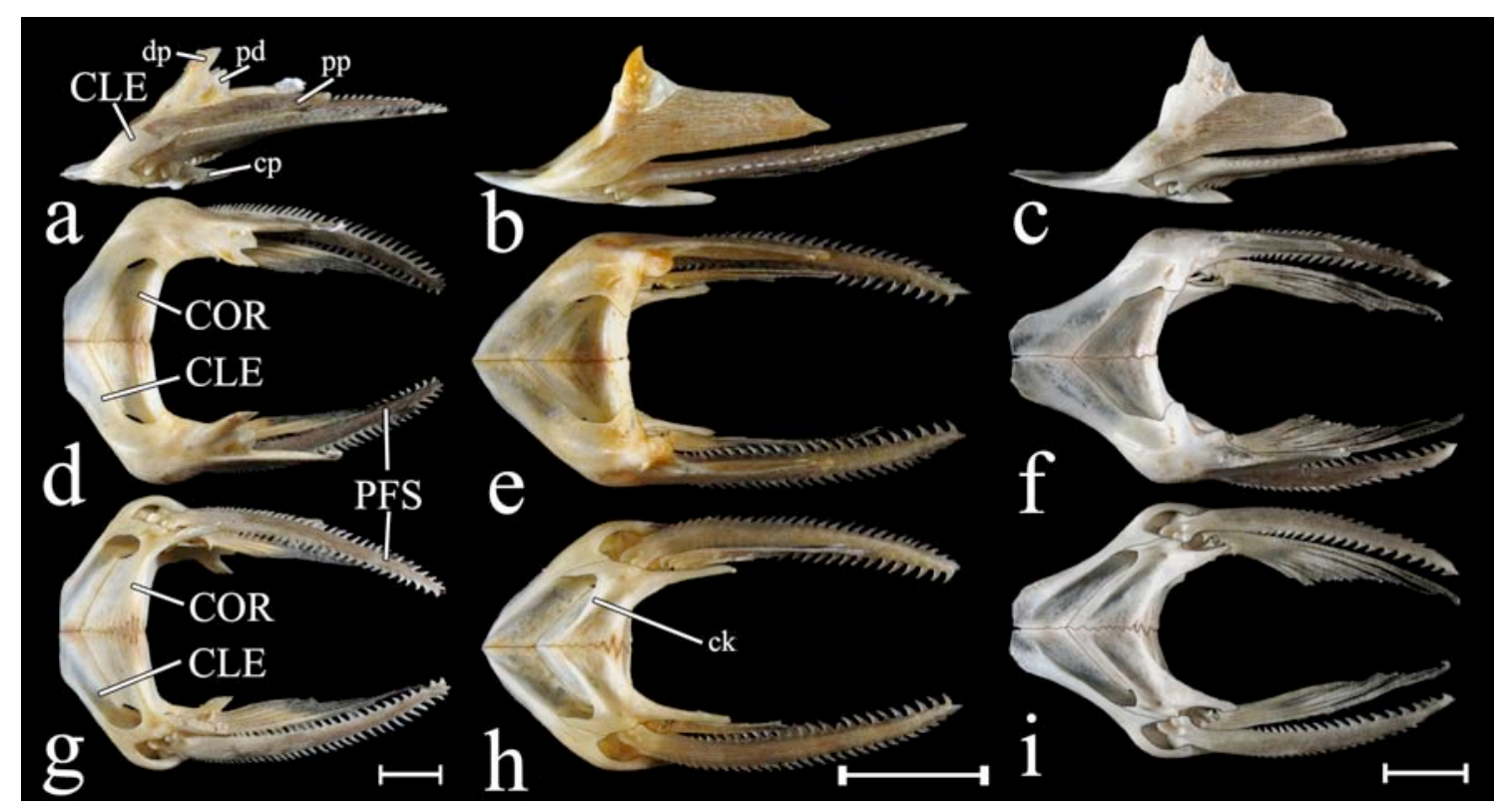

Figura 59. Cintura peitoral, em vistas lateral (a-c), dorsal (d-f) e ventral (g-i), de: Wertheimeria maculata (a,d,g), MZUSP 93658 (220.0 mm); Trachydoras brevis (b,e,h), MZUSP 103087 (74.0 mm); e Doras higuchii (c,f,i), MZUSP 101693 (172.0 mm). CLE: cleitro, ck: crista do coracóide, COR: coracóide, cp: processo posterior do coracóide, dp: processo dorsal do cleitro, pd: processo póstero-dorsal do cleitro, PFS: acúleo da nadadeira peitoal, pp: processo posterior do cleitro. Barra de escala igual a $10 \mathrm{~mm}$. 


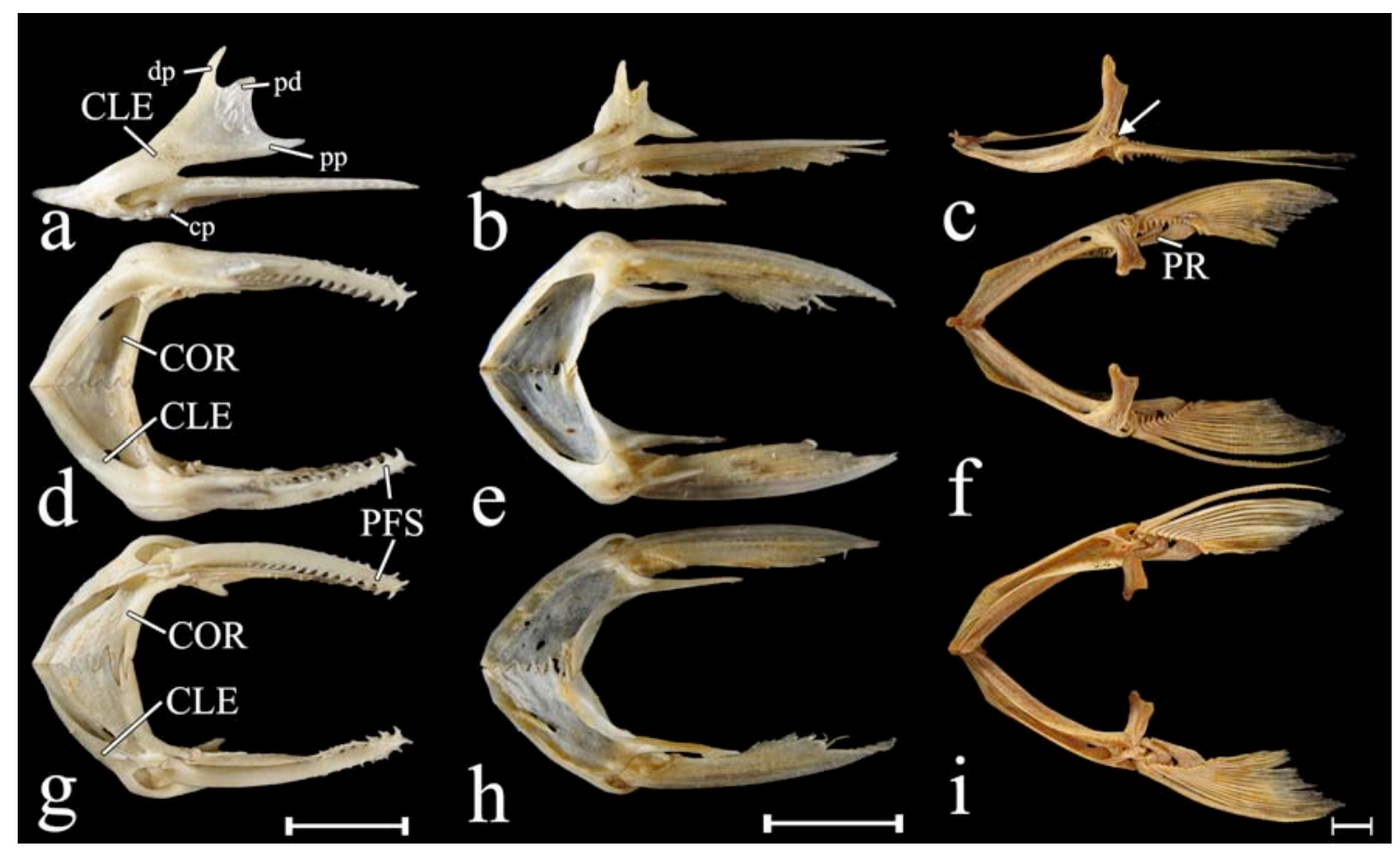

Figura 60. Cintura peitoral, em vistas lateral (a-c), dorsal (d-f) e ventral (g-i), de: Glanidium melanodermatum (a,d,g), MZUSP 64256 (112.0 mm); Auchenipterus osteomystax (b,e,h), MZUSP 89728 (141.0 mm); e Ageneiosus inermis (c,f,i), MZUSP 91661 (333.0 mm). CLE: cleitro, COR: coracóide, cp: processo posterior do coracóide, dp: processo dorsal do cleitro, pd: processo póstero-dorsal do cleitro, PFS: acúleo da nadadeira peitoal, pp: processo posterior do cleitro, PR: radiais proximais dos raios da nadadeira peitoral. Barra de escala igual a $10 \mathrm{~mm}$. Seta indica a fenestra lateral do cleitro.

\section{Mesocoracóide: (0) presente; (1) ausente. CI: 0,33; RI: 0,88.}

O mesocoracóide está presente na forma de um arco posterior na maioria dos Siluriformes, porém está ausente em Anchariidae, Ariidae, Aspredinidae, Auchenipteridae, e Doradidae (Ferraris, 1988: \#P1; Royero, 1999: \#82; Britto, 2002: \#247; Akama, 2004: \#105; Diogo, 2004: \#185; Vigliotta, 2008: \#55). Esta é uma característica conhecida desde Regan (1911).

264. Ponte entre o cleitro e coracóide: (0) presente; (1) ausente. CI: 0,50; RI: 0,00. Em Nematogenyidae, Malapteruridae e alguns Amphiliidae a ponte entre o 
coracóide e cleitro está ausente (Diogo, 2003: 420; Diogo, 2004: \#192).

265. Extensão da ponte entre o cleitro e coracóide: (0) restrita à fossa de articulação do acúleo da nadadeira peitoral; (1) contínua até o processo posterior do coracóide. CI: 1,00; RI: 0,00 .

Em Entomocorus, a ponte do cleitro ao coracóide é contínua até o processo posterior do coracóide.

Esse caráter foi tratado como inaplicável em Nematogenyidae e Malapteruridae, por não possuírem a ponte entre o cleitro e coracóide.

266. Fenestra do sistema de trava do acúleo da nadadeira peitoral: (0) presente; (1) ausente. CI: 0,20; RI: 0,89.

Primitivamente em Siluriformes, há uma fenestra no coracóide que funciona no sistema de trava do acúleo da nadadeira peitoral. A extremidade do processo medial da base do acúleo da nadadeira peitoral se encaixa nesta fenestra quando o acúleo encontra-se transversal ao eixo do corpo. Nenhuma espécie de Doradidae possui essa fenestra; apesar de ser possível ver a fenestra por transparência em algumas espécies, ela nunca está aberta. Os Auchenipteridae examinados possuem a fenestra no coracóide, exceto Parauchenipterus (pelo menos P. porosus e P. galeatus) e Trachelyopterus (Royero, 1999: \#83). Em Mochokidae, Chiloglanis (exceto C. macropterus), Atopodontus, Atopochilus e Euchilichthys (Vigliotta, 2008: \#57) não possuem a fenestra da trava do acúleo. A ausência desta fenestra também é notada, pelo menos, em Amphiliidae e Ariidae (Vigliotta, 2008: \#57).

267. Processos no primeiro radial proximal da nadadeira peitoral (ordenado): (0) 
ausentes; (1) processo ventral na porção proximal; (2) processos ventral e dorsal na porção proximal. CI: 0,33 ; RI: 0,56 .

Primitivamente em Siluriformes, o primeiro radial proximal da nadadeira peitoral não apresenta qualquer processo, entretanto em Claroteidae, Pangasiidae, Schilbidae e Mochokidae (Mochokiella, Microsynodontis, Synodontis, exceto S. contracta) há um processo ventral na porção proximal (Vigliotta, 2008: \#58). Em Ariidae e Mochokidae (Chiloglanis, Atopochilus e Euchilichthys), há dois processos, um ventral e um dorsal (Vigliotta, 2008: \#58). Britto (2004: \#253) cita ainda a presença de um ou dois processos, sem especificar, no primeiro radial proximal em Bagridae, Cranoglanidae, Pangasiidae e Plotosidae.

268. Tamanho do segundo radial proximal da nadadeira peitoral: (0) normal (figs. 59, 60d-e,g-h); (1) grande, suportando diversos de raios (fig. 60f,i). CI: 1,00; RI: 1,00 .

Em Ageneiosus e Tetranematichthys, o segundo radial proximal da nadadeira peitoral é expandido na forma de um leque suportando os raios mais posteriores da nadadeira (Ferraris, 1988: \#P9; Walsh, 1990: \#6; Royero, 1999: \#90; Akama, 2004: \#115). Em Ageneiosus atronasus a expansão não é tão distinta como nas demais espécies do gênero. Em algumas espécies de Tatia, Gelanoglanis e Centromochlus o segundo radial proximal está ausente (Ferraris, 1988: \#P10; Akama, 2004: \#115).

269. Processo dorsal na base do acúleo da nadadeira peitoral: (0) grande, helicoidal, encaixado firmemente ao cleitro (fig. 61); (1) pequeno, não helicoidal, encaixado frouxamente ao cleitro. CI: 1,$00 ;$ RI: 1,00 .

Em todas as espécies analisadas de Ageneiosus a base do acúleo peitoral não 
possui o processo dorsal bem desenvolvido, helicoidal (Royero, 1999: \#86; Akama, 2004: \#117), presente nos demais Doradoidea e na maioria dos Siluriformes.

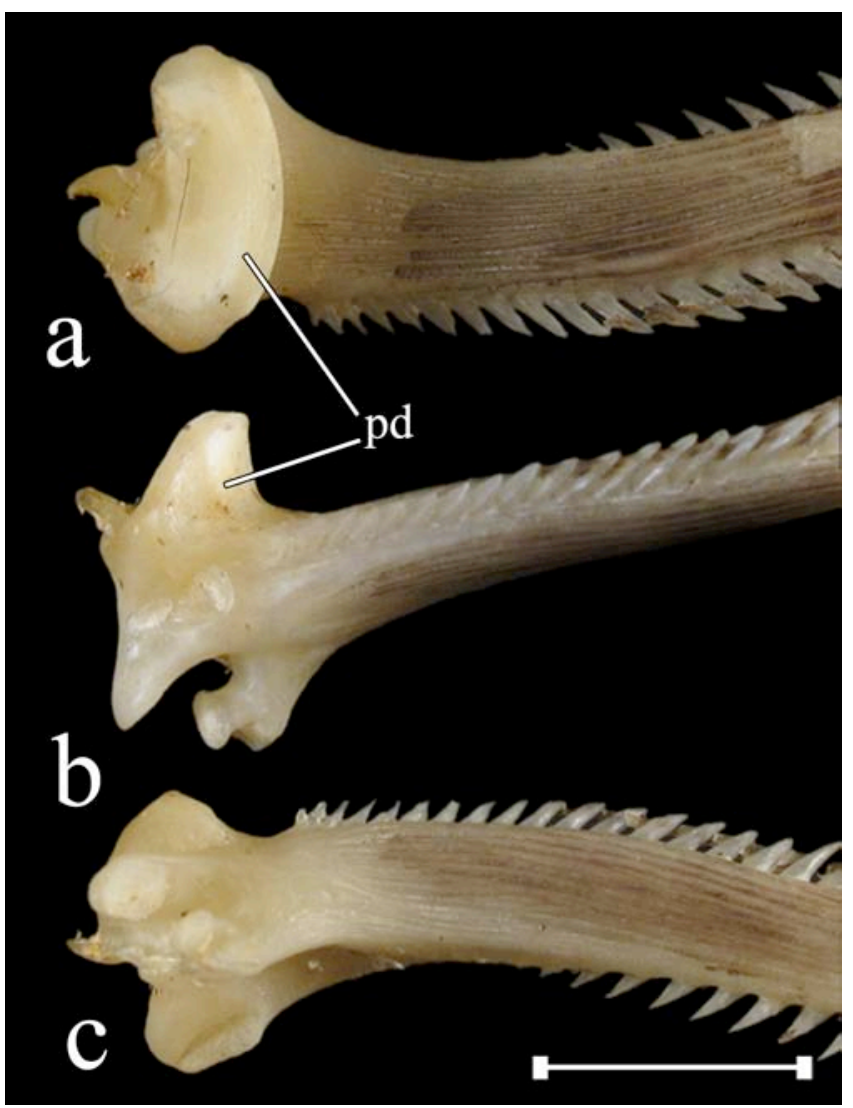

Figura 61. Acúleo da nadadeira peitoral, em vistas dorsal (a), anterior (b) e ventral (c), de: Wertheimeria maculata (a,c,e), MZUSP 93659 (270.0 mm). Barra de escala igual a $10 \mathrm{~mm}$.

270. Serra na margem anterior do acúleo da nadadeira peitoral: (0) ausente; (1) presente. CI: 0,10; RI: 0,40 .

A margem anterior do acúleo da nadadeira peitoral em Siluriformes, no geral, é lisa, sem serra, como em Diplomystidae (Arratia, 1987). Entretanto, há serra na margem anterior do acúleo da nadadeira peitoral (Britto, 2002: \#255; Vigliotta, 2008: \#59) em Ariidae, Aspredinidae (exceto Xyliphius), Clariidae, Bagridae, Claroteidae, Heptapteridae, Ictaluridae (exceto Pylodictis olivaris), Pangasiidae, Pimelodidae, Pseudopimelodidae, Schilbidae, Sisor e Mochokidae (Mochokus, Mochokiella, 
Synodontis).

Todas espécies de Doradidae e a maioria das espécies de Auchenipteridae possuem serra na margem anterior do acúleo peitoral. As exceções incluem Ageneiosus, Tetranematichthys, Pseudauchenipterus, Gelanoglanis, Auchenipterus, Epapterus, Pseudepapterus e Trachelyopterus (Ferraris, 1988: \#P7; Soares-Porto, 1998: \#20; Royero, 1999: \#88; Walsh, 1990: \#34; Akama, 2004: \#107).

271. Direção dos espinhos da margem anterior do acúleo da nadadeira peitoral: (0) espinhos antrorsos; (1) espinhos retrorsos. CI: 0,50; RI: 0,00.

Em Centromochlus heckelii e Tocantinsia, os espinhos da margem anterior do acúleo da nadadeira peitoral são retrorsos (Ferraris, 1988: \#P5), ao contrário da maioria das espécies de Siluriformes, que possui espinhos antrorsos em toda a extensão ou na porção mediana até a mais distal da margem anterior do acúleo. De acordo com outros autores (Ferraris, 1988: \#P6; Akama, 2004: \#109), tais espinhos são sutilmente dirigidos ventralmente em Entomocorus.

Esse caráter foi tratado como inaplicável em Diplomystidae, Nematogenyidae, Siluridae, Sisoridae, Erethistidae, Malapteruridae, Amphiliidae, Chiloglanis, Pseudauchenipterus, Ageneiosus, Tetranematichthys, Trachelyopterus, Auchenipterus, Pseudepapterus, por não possuírem a serra do acúleo da peitoral.

272. Serra na margem posterior do acúleo da nadadeira peitoral: (0) presente; (1) ausente. CI: 0,25; RI: 0,00.

Primitivamente, há serra na margem posterior do acúleo da nadadeira peitoral de Siluriformes. Algumas exceções incluem Malapteruridae, Amphiliidae (maioria) e Chiloglanis (exceto C. macropterus) (Vigliotta, 2008: \#60). 
273. Espinhos na face dorsal do acúleo da nadadeira peitoral (não ordenado): (0) ausentes; (1) presentes somente na margem ântero-dorsal do acúleo; (2) presente em toda a face dorsal do acúleo. CI: 1,00; RI: 1,00.

Espinhos na face dorsal do acúleo peitoral estão presentes somente na margem ântero-dorsal do acúleo em Parauchenipterus porosus, P. striatulus e Trachelyopterichthys taeniatus (Akama, 2004: \#110), e em toda a face dorsal do acúleo em Acanthodoras e Agamyxis (Birindelli, 2006: \#125).

274. Comprimento do acúleo da nadadeira peitoral: (0) normal, mais curto do que 1/3 do comprimento padrão; (1) longo, mais longo do que 1/3 do comprimento padrão. CI: 1,00; RI: 0,00.

Em Centromochlus heckelii e C. existimatus o acúleo da nadadeira peitoral é extremamente longo, mais longo do que 1/3 do CP (Ferraris, 1988: \#P2; Royero, 1999: \#91; Akama, 2004: \#106).

275. Número de raios ramificados na nadadeira peitoral (ordenado): (0) de 4 a 6; (1) de 6 a 9; (2) de 9 a 15. CI: 0,50; RI: 0,50.

A maioria dos Siluriformes apresenta 6 a 8 raios ramificados na nadadeira peitoral, sendo que Ictaluridae possui de 8 a 11 (Lundberg, 1970: 51). Entre os Auchenipteridae, as exceções (Walsh, 1990: \#30; Royero, 1999: \#87, \#151; Akama, 2004: \#118) incluem: Auchenipterus (10 a 14, Ferraris \& Vari, 1999: tabela 4), Epapterus (E. blohmi com 8 a 10, e E. dispilurus com 10 a 12, Vari \& Ferraris, 1998: 996), Tetranematichthys (9 a 11, Vari \& Ferraris, 2006: 174), Pseudepapterus (10 a 14, Ferraris \& Vari, 2000: tabela 3). 
Redução do número de raios ramificados ocorre em Acanthodoras, que possui 4 a 6 raios, e em Mochokus e Microsynodontis, que têm 5 ou 6 (Vigliotta, 2008: \#61).

Apesar da pequena sobreposição entre os estados, apenas em alguns exemplares de alguns táxons é possível encontrar o número correspondente à sobreposição, sendo que a maioria dos exemplares deste táxon possui um número de raios dentro dos intervalo dos estado.

276. Fenestra lateral no cleitro: (0) ausente (figs. 59a-c, 60a-b); (1) presente (fig. 60c). CI: 1,00; RI: 0,00.

Em Ageneiosus (exceto A. brevis, A. atronasus e possivelmente A. piperatus), há uma fenestra lateral no cleitro (Royero, 1999: \#85; Akama, 2004: \#116). Uma condição semelhante ocorre em Hypopththalmus (Diogo, 2004: \#160).

277. Processo póstero-dorsal do cleitro: (0) bem desenvolvido (figs. 59a, 60a-c); (1) ausente ou pouco desenvolvido (fig. 59b-c). CI: 0,50; RI: 0,98.

Primitivamente em Siluriformes, a extremidade dorsal do cleitro apresenta dois processos (um anterior e outro posterior, seguindo Tilak, 1963). Apesar de variar um pouco entre e dentro de algumas espécies, o processo póstero-dorsal do cleitro está ausente ou pouco desenvolvido em Doradidae (exceto em Wertheimeria, Kalyptodoras, Franciscodoras, e Leptodoras praelongus). Todos os auchenipterídeos examinados apresentam o processo póstero-dorsal do cleitro bem desenvolvido.

278. Processo posterior do cleitro (ordenado): (0) ausente (fig. 60c); (1) pequeno; (2) grande (figs. 59a-c, 60a-b). CI: 0,22; RI: 0,73.

O processo posterior do cleitro está ausente (ou rudimentar) em diversos táxons, 
como Amblycipitidae, Callichthyidae, Cetopsidae, Clariidae, Malapteruridae, Nematogenyidae, Siluridae e Trichomycteridae (Britto, 2002: \#246). Nos demais Siluriformes, o processo posterior do cleitro está presente, sendo normalmente pouco desenvolvido.

Os Doradoidea (exceto Ageneiosus) possuem o processo posterior do cleitro (Ferraris, 1988: \#P8; Walsh, 1990: \#5; Royero, 1999: \#84; Akama, 2004: \#112), sendo ele pouco desenvolvido em Glanidium, Tatia (pelo menos em T. aulopygia), Parauchenipterus (grupo galeatus, sensu Akama, 2004), “Amplexiglanis", Tetranematichthys, e nos Chiloglanidinae (Vigliotta, 2008: \#53). Já em todos os Doradidae, nos demais Auchenipteridae e nos mochokídeos Mochokus, Mochokiella, Acanthocleithron, Microsynodontis e Synodontis (Vigliotta, 2008: \#53), o processo posterior do cleitro é grande. Ageneiosus não possui o processo posterior do cleitro.

279. Forma do processo posterior do cleitro (não ordenado): (0) alongado, baixo e afilado posteriormente (figs. 59a, 60); (1) triangular, alto e curto (fig. 20, 25); (2) trapezóide (fig. 59b-c); (3) estreito (fig. 18). CI: 0,75; RI: 0,97.

O processo posterior do cleitro é geralmente alongado, baixo e afilado posteriormente. Entretanto, em Rhinodoras, Rhynchodoras e Orinocodoras, ele é triangular, alto, curto e afilado posteriormente (Higuchi, 1992: \#101). Em Doradini (exceto Oxydoras e Hemidoras) ele é trapezóide, alto e truncado posteriormente (Sabaj, 2002: \#20; Birindelli, 2006: \#127); e, finalmente em Pterodorasa porção exposta do processo posterior do cleitro é estreita, em relação à altura do processo como um todo (Higuchi, 1992: A73).

Esse caráter foi codificado como inaplicável em Nematogenyidae, Malapteruridae, Siluridae e Ageneiosus, por não possuírem o processo posterior do 
cleitro.

280. Espinhos na porção exposta do processo posterior do cleitro (não ordenado): (0) ausentes; (1) irregularmente distribuídos; (2) alinhados, distribuídos sobre cristas longitudinais. CI: 0,50; RI: 0,67.

Em Liosomadoras, Parauchenipterus porosus (Curran, 1989: \#11; Akama, 2004: \#113) e em Acanthodoras e Agamyxis (Eigenmann, 1925: 287; Higuchi, 1992: \#A70; Birindelli, 2006: \#129) há espinhos irregularmente distribuídos sobre o processo posterior do cleitro. Em "Amplexiglanis" fisheri, "Amplexiglanis" teaguei (Akama, 2004: \#113), Platydoras, Centrochir e Astrodoradinae (Higuchi, 1992: \#99, \#A72; Birindelli, 2006: \#129; Higuchi et al., 2007: 33) há espinhos alinhados, distribuídos sobre cristas longitudinais do processo posterior do cleitro. Em Anadoras e Platydoras, os espinhos desaparecem gradualmente em exemplares grandes, a partir de $100 \mathrm{~mm}$ de CP. Há espinhos no processo posterior do cleitro em exemplares pequenos de espécies de grande porte, como em Franciscodoras (MZUSP 97145, $30 \mathrm{~mm}$ de CP), Megalodoras (MZUSP 55838, 68 de mm CP), Pterodoras (MZUSP 82995, $60 \mathrm{~mm}$ de $\mathrm{CP})$.

Esse caráter foi codificado como inaplicável em Nematogenyidae, Malapteruridae, Siluridae e Ageneiosus, por não possuírem o processo posterior do cleitro.

281. Sutura entre os coracóides (ordenado): (0) reta; (1) interdigitada da extremidade anterior à posterior (figs. 59, 60); (2) interdigitada apenas na porção posterior do coracóide. CI: 0,67; RI: 0,50.

Em Diplomystidae, Cetopsidae, Nematogenyidae, Astroblepidae, 
Trichomycteridae, Siluridae, a sutura entre os coracóides é reta (Mo, 1991; de Pinna et al., 2007: \#103). Nos demais Siluriformes, a sutura entre os coracóides é interdigitada da extremidade anterior à posterior (Britto, 2002: 249). Em Pseudepapterus a sutura é interdigitada apenas na porção posterior da sínfise dos ossos.

282. Processo posterior do coracóide (não ordenado): (0) pequeno (figs. 59g,h,i, 60h,i); (1) grande, achatado ventralmente e coberto por pele fina; (2) grande e laminar (fig. 60h). CI: 0,40; RI: 0,70.

Em Diplomystidae e na maioria dos Siluriformes, o coracóide apresenta um pequeno processo posterior, que é extremamente rudimentar em alguns grupos (e.g.. Nematogenys, Britto, 2002: \#250). Contudo, o processo posterior do coracóide é bem desenvolvido, achatado ventralmente e coberto por pele fina em diversas espécies de Aspredinidae, Sisoridae e Erethistidae (Alexander, 1965: 119; de Pinna, 1996: \#79) e Scoloplacidae.

Em Doradoidea, o processo posterior do coracóide é grande, achatado ventralmente e coberto por pele fina (visualmente exposto) em Astrodoras, Physopyxis, "Petalodoras", Trachydoras paraguayensis (Eigenmann, 1925: 287; Higuchi, 1992: \#106, A75; Birindelli, 2006: \#132), Auchenipterichthys coracoideus e A. thoracatus (Ferraris et al., 2005). Já Auchenipterus e Pseudepapterus possuem o processo posterior do coracóide longo, laminar.

283. Margem posterior do coracóide: (0) levemente expandida dorsalmente (fig. 37a); (1) extremamente expandida dorsalmente, formando um diafragma ósseo (fig. 37b-d). CI: 1,00; RI: 1,00.

Em Doradini, a porção posterior do coracóide é extremamente expandida 
dorsalmente formando um diafragma ósseo, associado também à expansão ventral do processo trans-escapular (Higuchi, 1992: \#102; Birindelli, 2006: \#130).

284. Margem póstero-ventral do coracóide: (0) laminar, formando uma pequena aba ventral (figs. 59-60); (1) achatada ventralmente e aparentemente exposta. CI: 0,10; RI: 0,53.

A margem póstero-ventral do coracóide é normalmente coberta quase completamente por músculo e pele espessa em Siluriformes. Em Aspredinidae, Auchenipterichthys thoracatus, Trachelyopterus coriaceos, Centromochlus (SoaresPorto, 1998: \#35), Acanthodoras, Agamyxis, Anadoras, Scorpiodoras, Megalodoras, "Petalodoras", Trachydoras steindachneri, Hemidoras, ela é achatada ventralmente e coberta por pele fina (aparentemente exposta) (Higuchi, 1992: \#105; Birindelli, 2006: \#131). Essa é uma característica que varia entre as espécies de Astrodoradinae, que inclui espécies com a cintura peitoral quase completamente livre da musculatura, aparentemente exposta (Sousa \& Rapp Py-Daniel, 2005; Higuchi et al., 2007).

\section{Crista no coracóide que delimita os músculos abductor superficialis e arrector} ventralis: (0) ausente (fig. 60h); (1) presente (figs. 59g-i, 60g,i). CI: 0,20; RI: 0,78.

Em Siluriformes, os músculos abductor superficialis e arrector ventralis são adjacentes, sem qualquer crista os separando. Entretanto na maioria dos amphiliídeos, erethistídeos, mochokídeos, auchenipterídeos e doradídeos, há uma crista óssea no coracóide, que estende posteriormente até a ponte do cleitro ao coracóide, próximo à base do acúleo. Esta crista está ausente em Rhynchodoras (Birindelli et al., 2007: \#673; Birindelli, 2006: \#133), Auchenipterus e Pseudepapterus. 
286. Direção da crista no coracóide que delimita os músculos abductor superficialis e arrector ventralis: (0) oblíqua, curvada para frente (figs. 59g-i, 60h,i); (1) reta, mais ou menos transversal ao eixo do corpo. CI: 0,17; RI: 0,62.

Primitivamente em Siluriformes há três pares de músculos ventrais na cintura peitoral, o rotator pectoralis ventralis, o arrcetor ventralis e o abductor superficialis. Os dois últimos são delimitados por uma crista no coracóide, que normalmente é oblíqua, curvada para frente deixando bastante espaço para ambos os músculos. Entretanto, em Centrochir, Platydoras, Acanthodoras, Centrodoras, Megalodoras, Orinocodoras, Rhinodoras, "Petalodoras" fimbriatus, Hemidoras morrisi, Synodontis schall e S. nigriventris essa crista é mais ou menos transversal ao eixo do corpo, deixando pouco espaço para o músculo abductor superficialis (Birindelli, 2006: \#135).

Esse caráter foi tratado como inaplicável em Rhynchodoras, Auchenipterus, Pseudepapterus e nos demais Siluriformes (exceto Amphiliidae, Erethistidae, Doradidae, Auchenipteridae e Mochokidae), por não possuírem a crista no coracóide.

\subsubsection{Cintura pélvica}

287. Posição da cintura pélvica: (0) na metade posterior do corpo; (1) na metade anterior do corpo. CI: 1,00; RI: 1,00 .

Em Leptodoras, a cintura pélvica está inserida na metade anterior do corpo, diferentemente dos demais Siluriformes estudados (Higuchi, 1992: \#108; Birindelli, 2006: \#136; Birindelli \& Sousa, 2010).

288. Número de raios ramificados na nadadeira pélvica (ordenado): (0) 5; (1) 6; (2) 7; (3) 8; (4) de 9 a 16. CI: 0,22; RI: 0,69.

De acordo com Lundberg (1970) e Grande (1987), primitivamente, os 
Siluriformes possuem cinco raios ramificados na nadadeira pélvica.

As espécies de Mochokidae possuem seis raios ramificados, exceto Chiloglanis sp. "ntumbachushi", com sete raios (Vigliotta, 2008: \#65).

Da mesma forma, a maioria das espécies de Doradidae possui seis raios ramificados. As exceções incluem Wertheimeria, Kalyptodoras, Franciscodoras, Acanthodoras e Agamyxis, que possuem apenas cinco raios ramificados (Birindelli, 2006: \#139).

Em Auchenipteridae, a variação no número de raios ramificados da nadadeira pélvica é maior. As espécies de Centromochlinae (exceto algumas espécies de Glanidium, que têm 5 ou 6 raios ramificados, Mees, 1974: 93), "Amplexiglanis", Trachelyopterus, Parauchenipterus (Akama, 2004) e Entomocorus (Akama \& Ferraris, 2004) possuem 5. Pseudotatia, Tocantinsia, Tetranematichthys (Vari \& Ferraris, 2006) e Ageneiosus (Walsh, 1990: 119) apresentam 6 raios ramificados; Pseudauchenipterus possui 7 (Akama, 1999); Trachycorystes tem 8; e Auchenipterus (Vari \& Ferraris, 1998), Pseudepapterus (Ferraris \& Vari, 1999), Epapterus (Ferraris \& Vari, 2000), Trachelyichthys e Trachelyopterichthys (Ferraris \& Fernandez, 1987) apresentam 9 a 16 raios ramificados na nadadeira pélvica (Ferraris, 1988: \#PV3; Royero, 1999: \#92; Akama, 2004: \#112).

\section{Esquírola pélvica: (0) presente; (1) ausente. CI: 0,25; RI: 0,57.}

Como observado por Lundberg (1970: fig. 134) e Arratia (1987: 31), há um pequeno elemento ossificado anterior ao primeiro raio da nadadeira pélvica, a esquírola pélvica (ou "pelvic splint"), em Diplomystidae, Bagridae (exceto Batasio e Olyra), Cetopsidae, Cranoglanidae, Ictaluridae (exceto Trogloglanis), Pangasiidae, Schilbidae, Siluridae, Sisoridae e Trichomycteridae (Britto, 2002: \#279), e nos mochokídeos 
Synodontis batensoda, S. clarias, S. gambiensis, S. longirostris, S. membranacea, S. schall, S. sorex, Atopochilus savorgnani, Chiloglanis carnosus, C. congicus, C. macropterus, Euchilichthys (Vigliotta, 2008: \#66). Todas as espécies de Doradidae e Auchenipteridae não possuem esse elemento.

290. Radial cartilaginoso da nadadeira pélvica: (0) presente; (1) ausente. CI: 0,20; RI: $\mathbf{0 , 2 0 .}$

Primitivamente em Siluriformes, há um radial cartilaginoso (Lundberg, 1970), como em Diplomystidae, Aspredinidae, Auchenoglanidae, Chacidae, Malapteruridae, Bagarius (Britto, 2002: \#277), e nos mochokídeos Synodontis schall, S. nigriventris, S. zambezensis, e S. membranacea. Nos demais Siluriformes analisados (incluindo Doradidae, Auchenipteridae) o radial cartilaginoso da nadadeira pélvica está ausente.

291. Primeiro raio da nadadeira pélvica modificado em machos maduros: (0) ausente; (1) presente. CI: 1,$00 ;$ RI: 0,00 .

Em machos maduros de Entomocorus, o primeiro raio da nadadeira pélvica encontra-se modificado, expandido e achatado (Ferraris, 1988: \#PV2, Royero, 1999: \#133; Akama, 2004: \#170), como ilustrado por Akama \& Ferraris (2003).

292. Espinhos nos dois primeiros raios da nadadeira pélvica: (0) ausentes; (1) presentes. CI: 1,00; RI: 0,00.

Os dois primeiros raios da nadadeira pélvica apresentam espinhos apenas em Agamyxis.

293. Serra na margem anterior do primeiro raio da nadadeira pélvica: (0) 
ausente; (1) presente. CI: 1,$00 ;$ RI: 0,00 .

Uma serra na margem anterior do primeiro raio (indiviso) da nadadeira pélvica está presente apenas em exemplares de grande porte de Pterodoras granulosus (MZUSP 91655, $410 \mathrm{~mm}$ de CP).

294. Membrana unindo a porção medial das bases das nadadeiras pélvicas: (0) ausente; (1) presente. CI: 1,00; RI: 1,00 .

Em Auchenipterus, Pseudepapterus e Epapterus, há uma membrana unindo a porção medial das bases das nadadeiras pélvicas (Ferraris \& Vari, 1999: 393; Ferraris, 1988: \#PV6; Akama, 2004: \#123).

295. Fusão entre cartilagens mediais do basipterígio: (0) ausente, cartilagens livres entre si; (1) presente, cartilagens mediais fusionadas. CI: 0,33; RI: 0,00.

Em Akysidae, Amblycipitidae, Amphiliidae, Astroblepidae, Bagridae, Cetopsidae, Erethistidae, Heptapteridae, Loricariidae, Sisoridae e Trichomycteridae, as cartilagens mediais do basipterígio são fusionadas (Britto, 2004: \#259). Todas as espécies analisadas de Doradoidea possuem as cartilagens mediais do basipterígio livres, separadas, ao contrário do que foi visto por de Pinna (1993: \#209), para Leptodoras.

296. União das cartilagens dos ramos anteriores do basipterígio: (0) ausente, cartilagens separadas; (1) presente, cartilagens unidas. CI: 0,33; RI: 0,33.

As cartilagens dos ramos anteriores medial e lateral do basipterígio estão unidas em Sisoridae (exceto Pseudecheneis e Sisor), Erethistidae, Amphiliidae, e nos mochokídeos Chiloglanis, Atopodontus, Atopochilus e Euchilichthys (de Pinna, 1993: 212; Britto, 2004: \#263; Vigliotta, 2008: 68). 
297. Ramos anteriores do basipterígio: (0) presentes; (1) ausentes. CI: 1,00; RI: $\mathbf{0 , 0 0}$.

Primitivamente em Siluriformes, o basipterígio apresenta dois ramos anteriores (Fink \& Fink, 1980). Em Diplomystes (Arratia, 1987: fig. 73) e em estágios ontogenéticos iniciais de Silurus glanis (Shelden, 1937: 85, fig. 13) há um terceiro ramo mais medial, ausente nos demais Siluriformes. Em Aspredinidae, os ramos anteriores do basipterígio estão ausentes (de Pinna, 1993: \#218; Friel, 1994).

298. Relação entre o ramo ântero-medial do basipterígio e o basipterígio (ordenado): (0) ramo ântero-medial livre do basipterígio (figs. 62a, 63a); (1) ramo ântero-medial parcialmente incorporado ao basipterígio (fig. 62b); (2) ramo ântero-medial completamente incorporado ao basipterígio (figs. 62c, 63b-c). CI: 0,17; RI: 0,77 .

Primitivamente em Siluriformes, o ramo ântero-medial do basipterígio é livre (Shelden, 1937: 85). Nos doradídeos Acanthodoras, Doras, "Nemadoras" ternetzi, "Nemadoras" leporhinus, Hemidoras stubelii, O. stenopeltis, Hassar e Anduzedoras o ramo ântero-medial é parcialmente incorporado ao basipterígio (Higuchi, 1992: \#109, \#110; Birindelli, 2006: \#137), enquanto "Petalodoras", Trachydoras, Hemidoras morei e H. morrisi, o apresentam completamente incorporado ao basipterígio.

Os auchenipterídeos Auchenipterus, Pseudepapterus, Epapterus, Tetranematichthys e Ageneiosus possuem o ramo ântero-medial incorporado completamente ao basipterígio (ver Shelden, 1937: fig. 20).

Esse caráter foi codificado como inaplicável em Aspredinidae, por apresentarem os ramos ântero-mediais ausentes. 


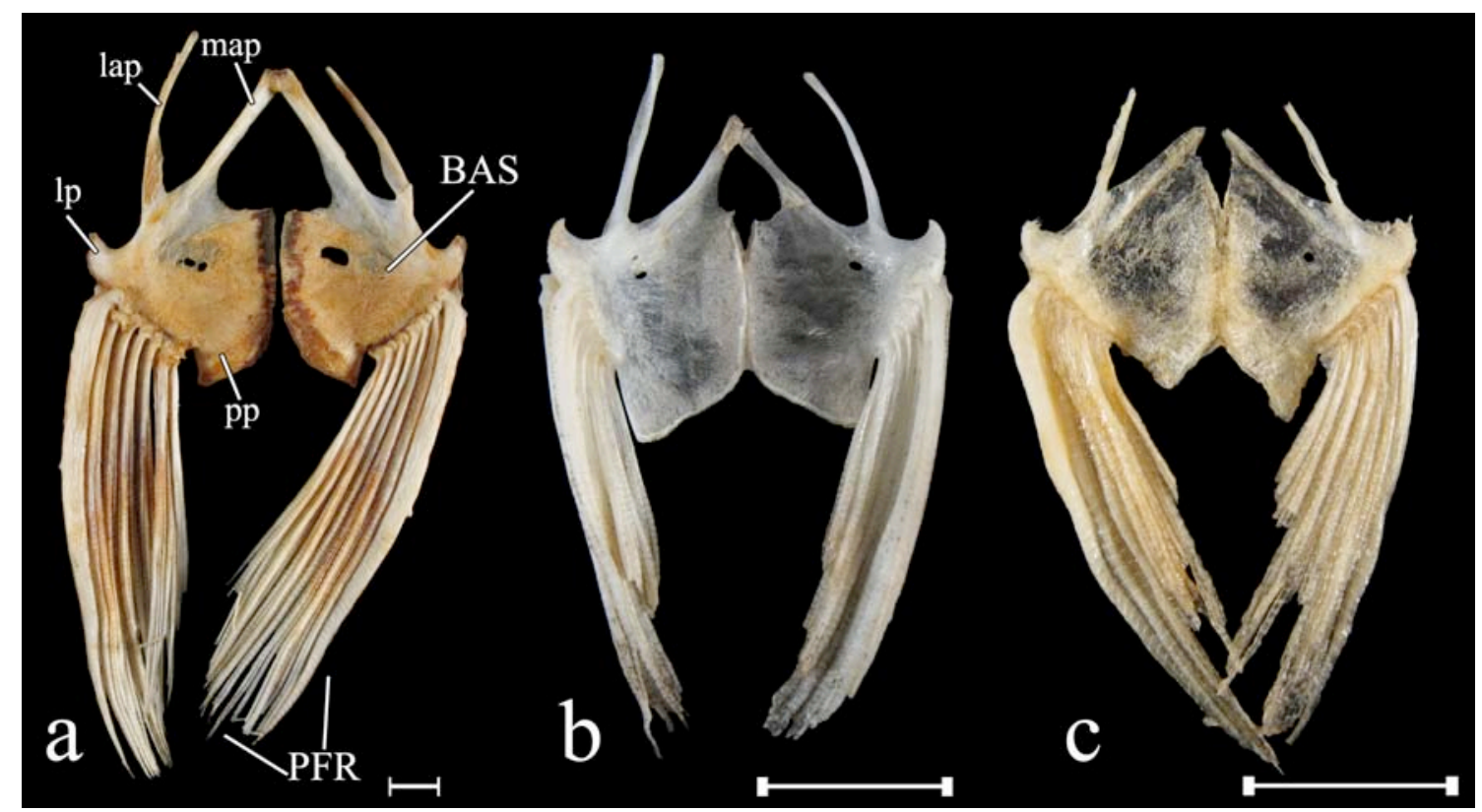

Figura 62. Cintura pélvica, em vista dorsal, de: Lithodoras dorsalis (a), MZUSP 91562 (450.0 mm); Doras higuchii (b), MZUSP 101693 (172.0 mm); e Hemidoras morei (c), MZUSP 32526 (153.2 mm). BAS: basipterígio, lap: processo ântero-lateral do basipterígio, lp: processo lateral do basipterígio, map: processo ântero-medial do basipterígio, PFR: raios da nadadeira pélvica, pp: processo psoterior do basipterígio. Barra de escala igual a $10 \mathrm{~mm}$.

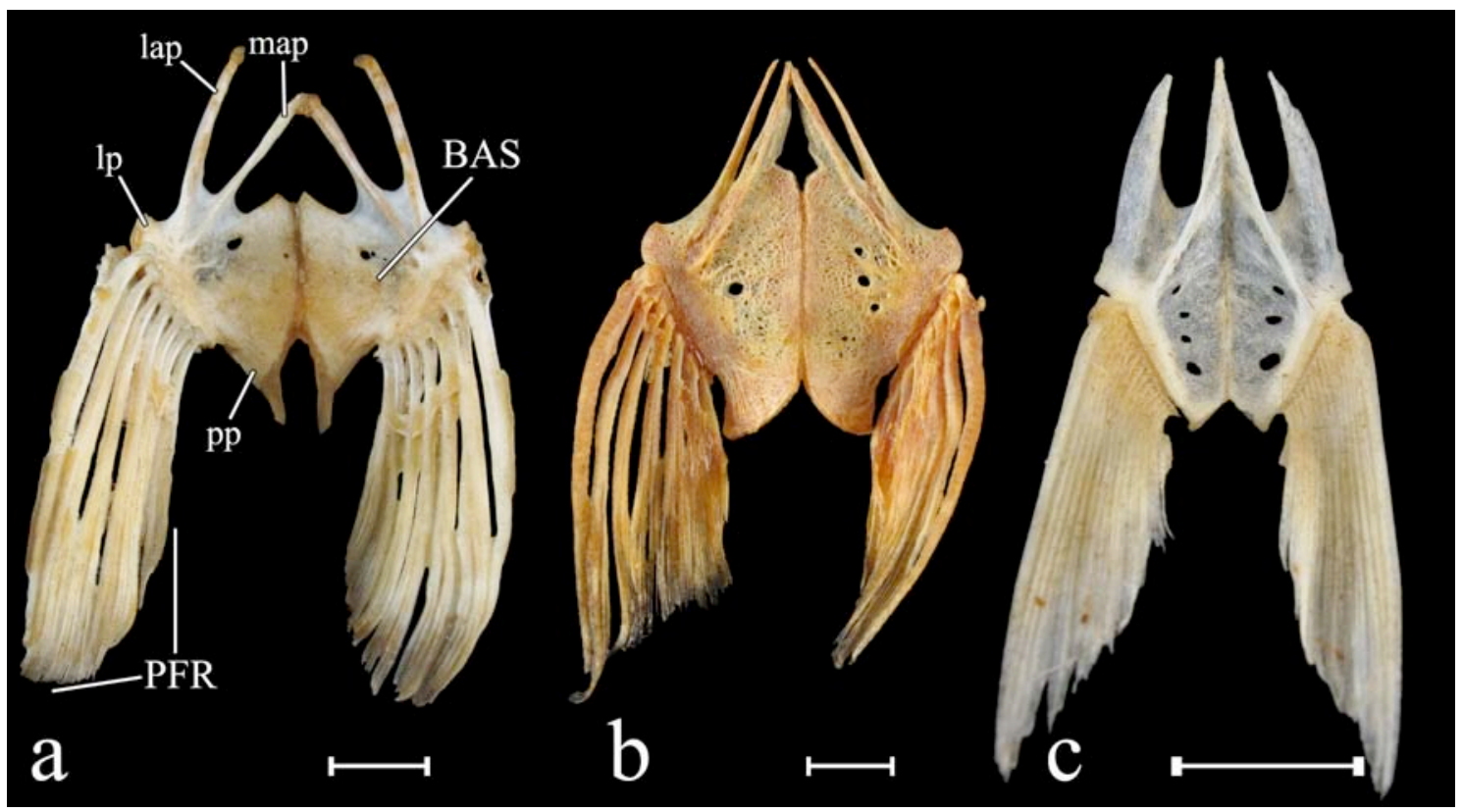

Figura 63. Cintura pélvica, em vista dorsal, de: Tocantinsia piresi (a), MZUSP 100031 (440.0 mm); Ageneiosus inermis (b), MZUSP 91661 (333.0 mm); e Auchenipterus osteomystax (c), MZUSP 89728 (141.0 mm). BAS: basipterígio, lap: processo ântero-lateral do basipterígio, lp: processo lateral do 
basipterígio, map: processo ântero-medial do basipterígio, PFR: raios da nadadeira pélvica, pp: processo psoterior do basipterígio. Barra de escala igual a $10 \mathrm{~mm}$.

299. Contato entre os ramos ântero-mediais do basipterígio: (0) ausente (figs. 62, 63a-b); (1) presente através de sutura (fig. 63c). CI: 1,00; RI: 1,00.

Em Entomocorus, Auchenipterus, Epapterus e Pseudepapterus os ramos ânteromediais do basipterígio são suturados entre si.

300. Processo lateral cartilaginoso do basipterígio: (0) ausente; (1) presente. CI: 0,25; RI: 0,77.

$\mathrm{Na}$ maioria dos Auchenipterídeos, a cartilagem lateral do basipterígio é expandida lateralmente formando um distinto processo lateral. As exceções incluem Tetranematichthys, Ageneiosus, Entomocorus, Auchenipterus, Pseudepapterus e Epapterus. Além destes, Glanidium melanodermatum aparentemente também não apresenta tal processo (o exame do material disponível, que não permitiu uma decisão definitiva sobre isso). Este processo aparentemente também está presente em Rhamdia e Plotosus (Shelden, 1937: figs. 21 e 43).

Esse caráter não foi observado em Glanidium e Pseudotatia.

301. Processo posterior (isquiático) do basipterígio: (0) presente; (1) ausente. CI: 0,33; RI: 0,00.

O processo posterior do basipterígio (assim denominado por Shelden, 1937; chamado processo isquiático por Weitzman, 1962) encontra-se presente na maioria dos Siluriformes, incluindo Diplomystidae, e também nos demais Ostariophysi (Shelden, 1937: 78; Arratia, 1987: fig. 37B), podendo estar extremamente bem desenvolvido em 
alguns grupos, como em Loricarioidea (ver por exemplo, Shelden, 1937: figs. 22-26). A presença deste processo gera (geralmente) um espaço na cartilagem lateral posterior à inserção posterior dos raios (caráter empregado por Pinna, 1993: \#210; e Britto, 2004: \#260). Espécies que conhecidamente não apresentam o processo posterior do basipterígio pertecem a Plotosus e Galeichthys (Shelden, 1937: 77, figs. 18 e 21).

$\mathrm{Na}$ maioria dos doradídeos o processo posterior encontra-se presente (Higuchi, 1992: \#112; Birindelli, 2006: \#138). Contudo, em Acanthodoras este processo encontrase ausente e a cartilagem lateral é contínua. Espécimes de pequeno porte de Wertheimeria maculata não apresentam processo posterior no basipterígio (o que me levou inicialmente a considerá-lo ausente neste táxon, Birindelli, 2006: \#138), entretanto espécimes de maior porte examinados no presente estudo possuem o processo posterior. O grau de desenvolvimento deste processo varia um pouco dentro das espécies de Doradidae, sendo que em Agamyxis ele é pequeno (mas mesmo assim a cartilagem lateral encontra-se interrompida).

Todas as espécies de Auchenipteridae e Mochokidae possuem o processo posterior do basipterígio.

302. Forma da cartilagem posterior do basipterígio: (0) posteriormente afilada; (1) posteriormente truncada. CI: 1,00; RI: 1,00 .

$\mathrm{Na}$ maioria dos Siluriformes, a cartilagem posterior do basipterígio é afilada posteriormente. Em Entomocorus, Auchenipterus, Pseudepapterus, a cartilagem posterior do basipterígio é expandida posteriormente formando um processo truncado (Akama, 2004: \#121).

Esse caráter não foi observado em Epapterus. 


\subsubsection{Nadadeira anal}

303. Número (total) de raios da nadadeira anal (ordenado): (0) de 8 a 11; (1) de 12 a 16; (2) de 17 a 34; (3) de 35 a 65 . CI: 0,19-0,20; RI: 0,61-0,64.

O número total de raios da nadadeira anal considerado para os Siluriformes, no geral (Lundberg, 1970: 101, \#100; Friel, 1994: \#196; Bockmann, 1998: 282, \#195, \#196), e presente em Diplomystidae (Arratia, 1987: 63), é em torno de 12 a 16 raios (sendo os dois ou três primeiros indivisos). Entre os táxons examinados, Ictalurus possui 27, Bunocephalus possui 8, Malapterurus possui 10, Pangasius possui 35 e Siluridae possui pouco mais de 60 raios.

Em diversas famílias de bagres há grande variação no número de raios da nadadeira anal. Em Ictaluridae e Heptapteridae, a variação é de 12 a 31 ou 35 raios, respectivamente (Lundberg, 1970: tabela 5; Bockmann, 1998: 282, \#195, \#196). Em Aspredinidae, há espécies com menos de 10 raios e espécies, como as de Aspredo, com mais de 50 (Friel, 1994: \#79).

As espécies de Doradidae possuem de 11 a 16 raios na nadadeira anal. Já as espécies de Auchenipteridae possuem grande variação (ver tabela 4).

Este caráter foi dividido em quatro estados, conforme apresentado na tabela 4. Os quatro estados usados no presente estudo difere daqueles usados nos estudos anteriores (Ferraris, 1988: \#A2; Walsh, 1990: \#29; Royero, 1999: \#93; Akama, 2004: \#132). Tendo por base o material estudado no presente estudo, aparentemente não há sobreposição entre os estados 1 a 3 , entretanto, espera-se encontrar sobreposição se houver aumento no número de espécies estudadas. Entre os estados 0 e 1, há alguma sobreposição, entretanto preferi considerar o estado 0 distinto do 1 para contemplar a evidente redução nos elementos da nadadeira anal que ocorre em Tatia e Centromochlus. Apenas alguns exemplares de algumas espécies de Tatia e 
Centromochlus possui 10 ou 11 raios.

Tabela 4. Número de raios (totais) da naddadeira ventral nas espécies de Siluriformes examinadas, com enfoque nas espécies da família Auchenipteridae.

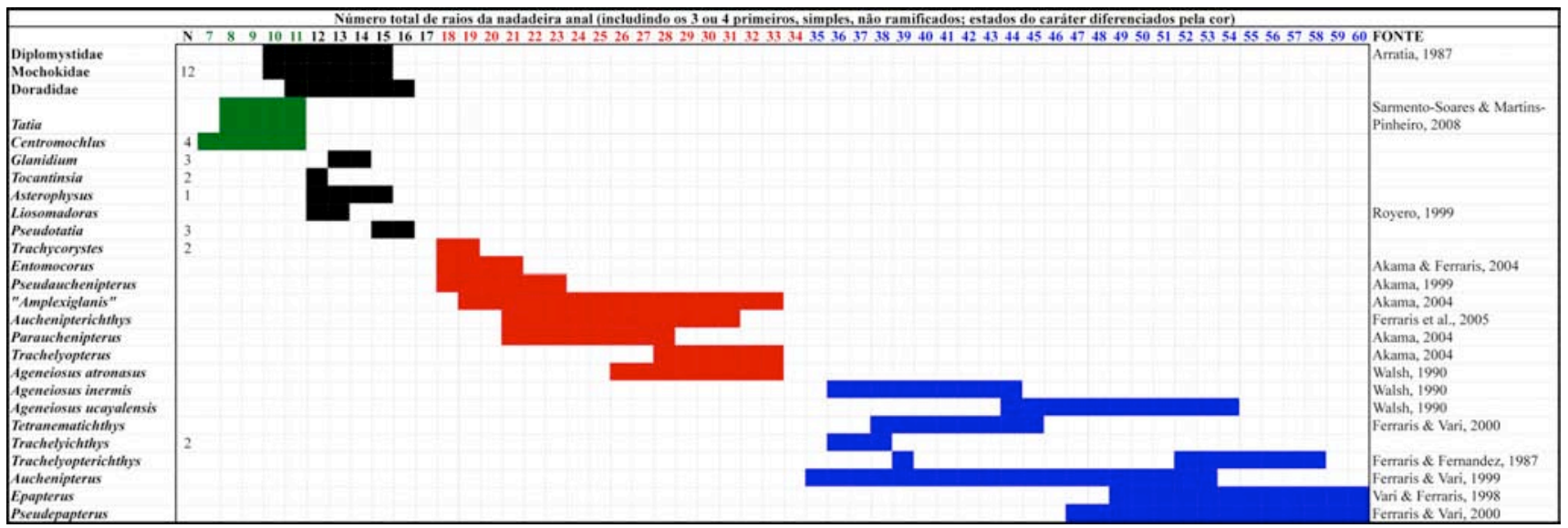

304. Orientação da nadadeira anal em machos: (0) normal, dirigida para baixo (fig. 13b-c); (1) oblíqua, orientada para trás (fig 13a). CI: 1,00; RI: 1,00.

Em Centromochlinae, a nadadeira anal é curta, oblíqua e orientada para trás em machos (Royero, 1999: \#132; Akama, 2004: \#147).

305. Orientação dos radiais proximais da nadadeira anal: (0) radiais proximais orientados paralelamente ao eixo do corpo, interdigitados com os espinhos hemais; (1) radiais proximais orientados obliquamente ao eixo do corpo, não interdigitados com os espinhos hemais. CI: 1,$00 ;$ RI: 1,00 .

Em Centromochlinae, os radiais proximais são orientados oblíquamente ao eixo do corpo, e não interdigitados com os espinhos hemais (Ferraris, 1988: \#A5, \#A6; Soares-Porto, 1998: \#28; Akama, 2004: \#133, \#152). Ferraris (1988: \#A6) ainda propôs outro caráter (orientação oblíqua da nadadeira anal em fêmeas) presente em Centromochlus e Gelanoglanis. 
306. Tamanho relativo da nadadeira anal de machos: (0) normal, comprimento dos raios mais longos da nadadeira anal maior que $10 \%$ do $\mathrm{CP}$; (1) pequena, comprimento dos raios mais longos da nadadeira anal menor do que $10 \%$ do CP. CI: 1,00; RI: 0,00.

Em Tatia, a nadadeira anal de machos é pequena, com o comprimento dos raios mais longos de 7.5 a 10\% do CP (Soares-Porto, 1998: \#27). A base da nadadeira anal em machos de Tatia também é menor do que em qualquer outro Doradoidea, com 3.3 a 8.0\% do CP (Sarmento-Soares \& Martins-Pinheiro, 2008: 498).

307. Fusão dos radiais proximais da nadadeira anal em machos (ordenado): (0) ausente, radiais proximais livres entre si; (1) parcial, radiais proximais parcialmente fusionados entre si; (2) completa, radiais proximais completamente fusionados entre si. CI: 1,00; RI: 1,00 .

Primitivamente em Siluriformes, e mesmo nos machos de Auchenipteridae, os radiais proximais da nadadeira anal são livres, separados. Entretanto, em Glanidium os radiais proximais se fundem parcialmente, ou seja, os anteriores se fundem porém os posteriores se mantém livres (Soares-Porto, 1998: \#30; Royero, 1999: \#139; Akama, 2004: \#153). Em machos de Centromochlus e Tatia, todos os radiais basais se fundem formando um osso único (Ferraris, 1988: \#A7; Soares-Porto, 1996: \#30). O único táxon que aparentemente representa uma exceção a este caráter é Glanidium bockmanni Sarmento-Soares \& Buckup (2005) que, apesar de descrito em Glanidium, apresenta a fusão completa.

308. Forma do quarto ou cinco radiais proximais mais posteriores da nadadeira anal: (0) cilíndricos, não expandidos; (1) expandidos. CI: 1,00; RI: 1,00. 
Em Auchenipterus, Pseudepapterus e Epapterus, os quatro ou cinco radiais proximais posteriores da nadadeira anal são expandidos, com lâminas ósseas anteriores e posteriores (Ferraris, 1988: \#A8; Akama, 2004: \#134).

309. Espinhos retrorsos póstero-laterais nos raios da nadadeira anal em machos: (0) ausentes; (1) presentes no último raio simples e no primeiro raio ramificado da nadadeira anal em machos. CI: 1,00; RI: 0,00 .

Em algumas espécies de Centromochlus, há espinhos retrorsos no último raio simples e no primeiro raio ramificado da nadadeira anal em machos (Ferraris, 1988: \#A9; Soares-Porto, 1998: \#38; Royero, 1999: \#134, \#136; Akama, 2004: \#157). Royero (1999: \#134; e Akama, 2004: \#154, \#157) ainda propôs um caráter para a simples presença de espinhos nos raios da nadadeira anal de machos como uma sinapomorfia de Tatia + Centromochlus.

310. Espinhos antrorsos e retrorsos ântero-laterais nos raios da nadadeira anal em machos: (0) ausentes; (1) presentes. CI: 1,00; RI: 0,00.

Em Tatia, há espinhos antrorsos na margem anterior do último raio indiviso e retrorsos ântero-laterais no primeiro raio ramificado da nadadeira anal de machos (Ferraris, 1988: \#A11; Soares-Porto, 1998: \#37, \#39; Royero, 1999: \#134, \#135, \#137; Akama, 2004: \#155,\#156). Em Glanidium, há pequenos espinhos na margem anterior do último raio indiviso da nadadeira anal (Akama, 2004: \#155, \#156), não tão desenvolvidos e, portanto, não homólogos aos de Tatia.

311. Gancho retrorso no terceiro raio indiviso da nadadeira anal de machos maduros: (0) ausente; (1) presente. CI: 1,00; RI: 0,00. 
Em Auchenipterus, há um gancho retrorso no terceiro raio indiviso da nadadeira anal de machos maduros (Akama, 2004: \#158).

312. Espinhos laterais na base dos raios da nadadeira anal: (0) ausentes; (1) presentes. CI: 1,00; RI: 0,00 .

Em Agamyxis, há espinhos laterais na base dos raios da nadadeira anal, similares aos espinhos distribuídos sobre os raios da nadadeira pélvica e caudal.

313. Forma do primeiro raio indiviso da nadadeira anal: (0) normal, não modificado em placa; (1) modificado em placa. CI: 1,00; RI: 0,00.

Em Agamyxis, o primeiro raio indiviso da nadadeira anal é modificado em placa.

314. Forma do último raio indiviso da nadadeira anal: (0) normal, não modificado em um espinho com serras anteriores e posteriores; (1) modificado em um espinho com serras anteriores e posteriores. CI: 1,00; RI: 0,00 .

Em exemplares de grande porte de Lithodoras (ver por exemplo MZUSP 91562, $450 \mathrm{~mm}$ de $\mathrm{CP}$ ), o último raio indiviso da nadadeira anal é modificado em um espinho com serras anteriores e posteriores. Em exemplares de grande porte de Pterodoras granulosus (MZUSP 96555, $410 \mathrm{~mm}$ de CP), o último raio da nadadeira anal possui alguns pequenos espinhos anteriores esparsos, mas que não se desenvolvem como as serras presentes no espinho de Lithodoras.

315. Segmentação do primeiro raio indiviso da nadadeira anal de machos maduros: (0) presente, raio segmentado; (1) ausente, raio não segmentado. CI: 1,00; RI: 0,00. 
Em Tatia (exceto T. brunnea) (Soares-Porto, 1998: \#33; Sarmento-Soares \& Martins-Pinheiro, 2008: 498), o primeiro raio indiviso da nadadeira anal de machos maduros não é segmentado.

316. Tamanho dos raios anteriores da nadadeira anal em machos maduros: (0) pequenos, semelhantes aos demais; (1) grandes, mais expandidos que os demais. CI: 1,00; RI: 1,00 .

Em alguns táxons de Auchenipteridae, como em Auchenipterichthys, "Amplexiglanis", Parauchenipterus, Trachelyopterichthys, Trachelyopterus, Ageneiosus, Auchenipterus, Pseudepapterus, Epapterus, Tetranematichthys, Trachycorystes e Trachelyichthys (Akama, 2004: \#148; Royero, 1999: \#131), os raios anteriores da nadadeira anal (último indiviso e primeiro ramificado) são grandes, maiores que os demais, em machos maduros. Em Pseudauchenipterus essa modificação é ainda mais extrema.

Esse caráter não foi observado em Pseudotatia.

\subsubsection{Esqueleto caudal}

317. Forma da nadadeira caudal (não ordenado): (0) bifurcada; (1) truncada; (2) arredondada. CI: 0,40; RI: 0,50 .

Primitivamente em Siluriformes, a nadadeira caudal é bifurcada como, por exemplo, em Diplomystidae. Alguns grupos possuem nadadeira caudal arredondada, como Malapteruridae. Em Doradidae, Acanthodoras possui a nadadeira distintamente arredondada (Higuchi, 1992: \#76; Birindelli, 2006: \#101). Em Auchenipteridae, alguns táxons possuem nadadeira caudal truncada, como Auchenipterichthys, Trachelyichthys, Tetranematichthys, Trachelyopterichthys, Parauchenipterus, Trachelyopterus, 
Ageneiosus inermis e A. polystictus (Ferraris, 1988: \#C1; Walsh, 1990: \#26; Royero, 1999: \#142; Akama, 2004: \#135). Higuchi (1992: \#74) descreve a nadadeira caudal de Amblydoras, Merodoras, Physopyxis como truncada, como nos auchenipterídeos citados, e a de Astrodoras e Hypodoras como lanceolada (Higuchi, 1992: \#75), táxons não incluídos no presente estudo. Em Mochokidae, Microsynodontis possui a nadadeira caudal levemente truncada (Vigliotta, 2008: \#75), entretanto não como nos Auchenipteridae citados acima.

318. Forma dos raios procorrentes: (0) cilíndricos, semelhantes aos demais raios da nadadeira caudal (figs. 64b-c, 65); (1) modificados em placas que cobrem o pedúnculo caudal dorsal e ventralmente (fig. 64a). CI: 0,25; RI: 0,67.

Como visto por Eigenmann (1925: 293, “fulcra”), entre outros (Higuchi, 1992: \#79; Birindelli, 2006: \#104), em diversas espécies de Doradidae, como as dos gêneros Franciscodoras, Agamyxis, Platydoras, Rhynchodoras, Rhinodoras e Orinocodoras, os raios procorrentes encontram-se modificados em placas que revestem o pedúnculo caudal dorsal e ventralmente. Como discutido por Birindelli et al. (2007), em Anadoras, Astrodoras, Hypodoras, "Petalodoras" fimbriatus, e em alguns exemplares de "Petalodoras" eigenmanni, os raios procorrentes mais anteriores, dorsais e ventrais, são levemente expandidos em placas, uma condição um pouco parecida com o estado 1 deste caráter. Em Lithodoras o pedúnculo caudal é revestido completamente por placas, entretanto, tais placas não são homólogas a raios procorrentes.

O número de raios procorrentes varia sutilmente entre as espécies de Doradidae, sendo geralmente de 10 a 16 . As espécies que possuem contagens fora deste intervalo são as espécies de Rhynchodoras, que possuem 17 a 20, e as de Agamyxis que possuem de 8 a 9. O mesmo ocorre em Auchenipteridae, que possuem usualmente de 14 a 18 
raios procorrentes, sendo que os casos mais extremos de redução de raios procorrentes na nadadeira caudal está associado ao aumento do número de raios principais. Dada a variação contínua e o fato dos casos mais extremos serem autapomórficos, não informativos, nenhum caráter que abordasse o número de raios procorrentes foi utilizado. Em outros Siluriformes, como por exemplo, em Malapteruridae que apresenta poucos, em torno de 3 raios procorrentes, este pode ser um caráter informativo.

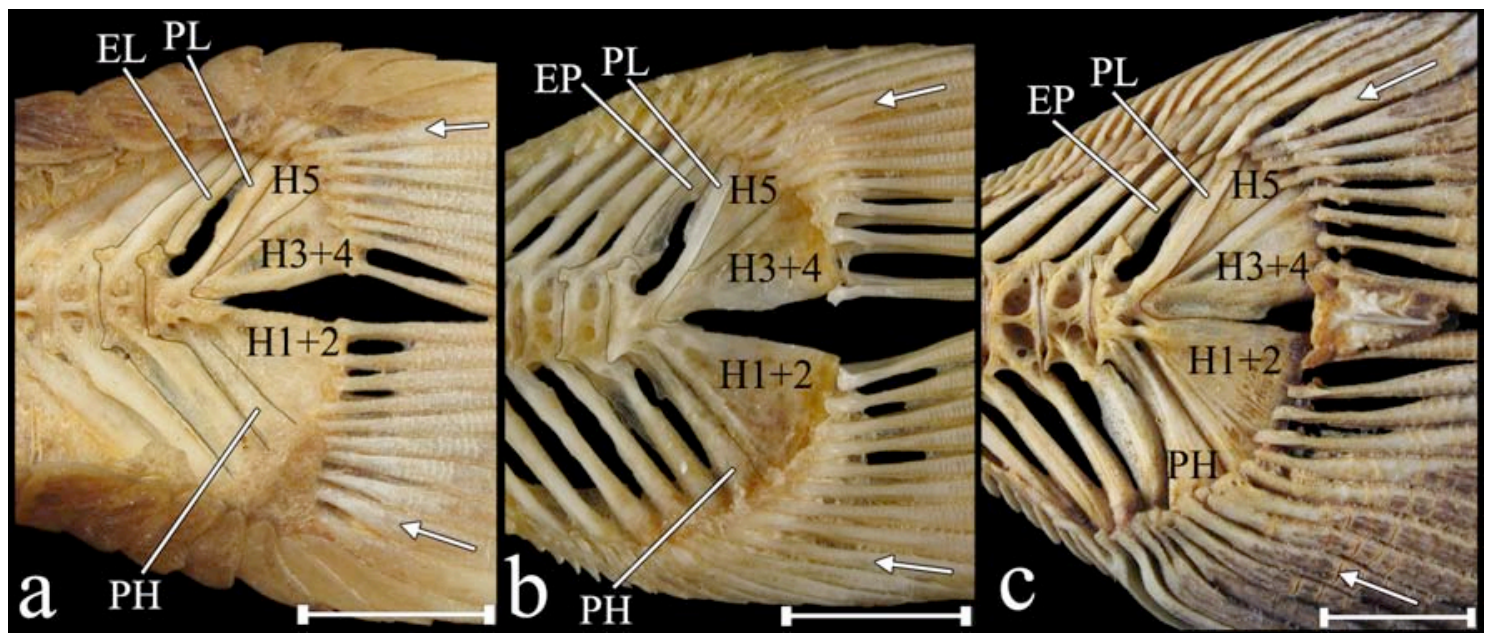

Figura 64. Nadadeira caudal, em vista lateral, de: Orinocodoras eigenmanni (a), FMNH 105276 (193.0 mm); Wertheimeria maculata (a), MZUSP 93659 (217.0 mm); e Oxydoras niger (c), MZUSP 91658 (113.0 mm). H1-5: hipurais 1-5, EP: epural, PH: paripural, PL: pleuróstilo. Setas brancas indicam raios principais indivisos, setas pretas indicam alguns dos raios procorrentes modificados em placas (fulcra). Barra de escala igual a $10 \mathrm{~mm}$.

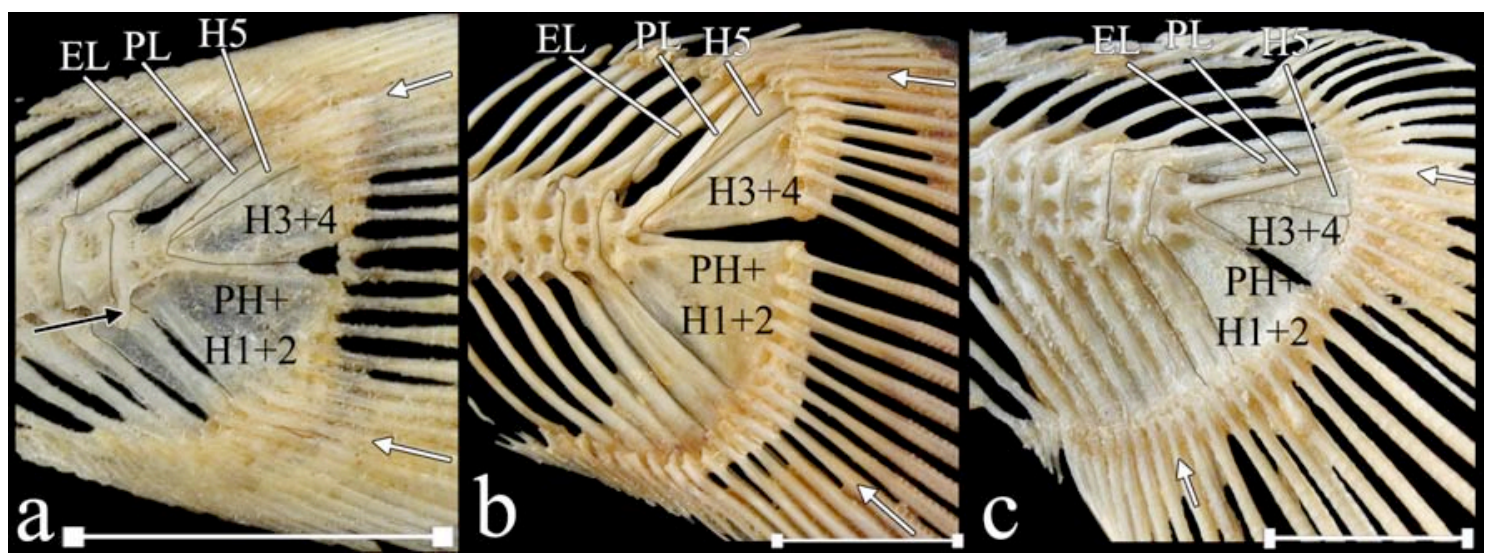

Figura 65. Nadadeira caudal, em vista lateral, de: Centromochlus heckelii (a), MZUSP 101767 (86.8 mm); Trachycorystes trachycorystes (b), MZUSP 91659 (200.0 mm); e Parauchenipterus galeatus (c), 
MZUSP 52088 (165.0 mm). H1-5: hipurais 1-5, EP: epural, PH: paripural, PL: pleuróstilo. Setas indicam raios principais indivisos; seta preta indica processo ventral da hipurapófise. Barra de escala igual a 10 $\mathrm{mm}$.

319. Espinhos laterais nos raios da nadadeira caudal: (0) ausentes; (1) presentes. CI: 1,00; RI: 1,00.

Em Agamyxis e Acanthodoras, os raios principais e os procorrentes possuem espinhos laterais (Higuchi, 1992: \#78; Birindelli et al., 2007: 681).

320. Forma da hipurapófise (não ordenado): (0) tipo A de Lundberg \& Baskin (1969: fig. 3A); (1) tipo B de Lundberg \& Baskin (1969: fig. 3B); (2) tipo C de Lundberg \& Baskin (1969: fig. 3C). CI: 0,67; RI: 0,67.

O arranjo primitivo da hipurapófise e hipurapófise secundária (tipo A de Lundberg \& Baskin, 1969) é encontrado em Diplomystidae, Ictaluridae, Schilbidae, Pangasiidae, e alguns Bagridae. Já o arranjo do tipo B é encontrado em Cetopsidae e Cranoglanididae. A maioria das espécies de Siluriformes possui o arranjo do tipo $\mathrm{C}$ (Lundberg \& Baskin, 1969: 14). O arranjo da hipurapófise em Ageneiosus, apesar de ser considerado do tipo B por Lundberg \& Baskin (1969) (e por Ferraris, 1998: \#C7 e Akama, 2004: \#141), é do tipo C, como afirmou Walsh (1990: 129). Lundberg \& Baskin (1969) ainda apresentam outros tipos (D-G), que caracterizam grupos mais restritos, não incluídos no presente estudo.

Esse caráter foi codificado como inaplicável para Siluridae e Nematogenyidae, que apresentam outro tipo de hipurapófise (ver Lundberg \& Baskin, 1969).

321. Processo ventral na hipurapófise: (0) ausente (figs. 64, 65b-c); (1) presente 


\section{(fig. 65a). CI: 1,00; RI: 1,00.}

Em Entomocorus, Auchenipterus, Pseudepapterus e Epapterus há um distinto processo ventral na hipurapófise (Ferraris, 1988: \#C5; Akama, 2004: \#139). Entre os táxons mencionados acima, o processo é um pouco mais desenvolvido em Entomocorus.

\section{Número de raios ramificados no lobo dorsal da nadadeira caudal (ordenado):} (0) 8; (1) 7 (figs. 64-65); (2) 6; (3) 5. CI: 0,25; RI: 0,10.

Diplomystidae é um dos poucos grupos de Siluriformes que possui nadadeira caudal com 18 raios principais (i, 8, 8, i), uma característica compartilhada por Ostariophysi não Siluriformes e, portanto, considerada primitiva para o grupo (Lundberg \& Baskin, 1969: 11, tabela 2; Arratia, 1992: \#38; de Pinna, 1993: \#237; Britto, 2002: \#293). A maioria dos demais Siluriformes possui a nadadeira caudal com i, 7, 8, i, exceções incluem, por exemplo, Malapteruridae com i, 6, 7, i e Amphiliidae com i, 5,6, i.

Entre os doradídeos, Agamyxis tem i, 6, 7, i. Wertheimeria, Kalyptodoras, Franciscodoras, Acanthodoras, Anadoras e Scorpiodoras têm i, 7, 7, i, enquanto que os demais Doradidae possuem i, 7, 8, i. A maioria das espécies de Auchenipteridae apresenta 7 raios no lobo dorsal da caudal, e geralmente 8 no ventral, embora algumas espécies possam apresentam um aumento no número destes últimos (ver próximo caráter). Em Mochokidae, a fórmula generalizada é igualmente i, 7, 8, i, entretanto há exceções, como por exemplo, Chiloglanis polypogon com i, 6, 7, i, Microsynodontis com i, 6, 6, i, Mochokiella com i, 6, 7, i, i, Mochokus brevis com i, 6, 7, i, e M. niloticus com i, 5, 6, i, e Synodontis contracta com i, 5, 6, i (Vigliotta, 2008: \#74). 
323. Número de raios ramificados no lobo ventral da nadadeira caudal (ordenado): (0) de 6 a 7; (1) 8 (figs. 64, 65a-b); 2 de 9 a 12 (fig. 65c). CI: 0,25; RI: 0,44 .

Como exposto no caráter anterior, a maioria dos Siluriformes possui 8 raios ramificados no lobo ventral da nadadeira caudal. Em Doradidae, Wertheimeria, Kalyptodoras, Franciscodoras, Acanthodoras, Agamyxis, Anadoras e Scorpiodoras possuem apenas 7 raios. Em Auchenipteridae, Trachelyichthys, Tetranematichthys, Trachelyopterus e Parauchenipterus possuem 9 a 12 raios ramificados no lobo ventral da nadadeira caudal (Ferraris, 1988: \#C2; Walsh, 1990: \#25; Akama, 2004: \#136). Um exemplar anômalo de Auchenipterichthys thoracatus (MZUSP 37518) possui 9 raios, o que levou Akama (2004) a considerar esta espécie como possuidora do estado derivado de seu caráter \#136, entretanto este número contraria a descrição da espécie, apresentada por Ferraris et al., 2005, e o presente exame de exemplares. Trachelyopterichthys foi considerado polimórfico (estados 1/2) para este caráter pois o exame de material (MZUSP 8496) evidenciou a presença de tanto exemplares com 8 como com 9 raios (Ferraris, 1988 tinha considerado o gênero com 8 raios enquanto Akama, 2004, com 9). Asterophysus, apesar de possuir o lobo ventral da caudal distintamente maior do que o dorsal, apresenta apenas 8 raios (Ferraris, 1988, considerou-o possuidor do estado derivado de seu caráter \#C2). Há uma pequena variação intra-específica no número de raios, como por exemplo, Parauchenipterus galeatus, que possui 9 ou 10 ou Trachelyopterus coriaceos com 10 ou 12 (Akama, 2004). Dada esta variação, não foi possível delimitar qualquer outro estado discreto que contemplasse intervalos menores dentro desta grande variação. Outras duas espécies derivadas, Ageneiosus inermis e A. marmoratus, também têm 9 raios ramificados no lobo ventral da nadadeira caudal (Walsh, 1990: \#25, 319, 337). Em Mochokidae, 
Chiloglanis polypogon, Mochokiella, Mochokus brevis possuem 7 e Microsynodontis, Mochokus niloticus e Synodontis contracta possuem apenas 6 (Vigliotta, 2008: \#74).

324. Ponto de articulação do raio principal indiviso do lobo ventral da nadadeira caudal: (0) paripural (figs. 64, 65a-b); (1) espinho hemal (fig. 65c). CI: 0,25; RI: $\mathbf{0 , 5 0}$.

Em “Amplexiglanis", Auchenipterichthys, Trachelyichthys, Tetranematichthys, Trachelyopterichthys, Trachelyopterus, Parauchenipterus (Ferraris, 1988: \#C3; Akama, 2004: \#137), o raio principal indiviso do lobo ventral da nadadeira caudal se articula com o segundo ao quinto último espinho hemal, em vez de se articular com o paripural como nos demais Siluriformes.

325. Segundo centro ural: (0) reduzido (tipo 1 de de Pinna \& Ng, 2004: 4); (1) bem desenvolvido (tipo 3 de de Pinna \& Ng, 2004: 4). CI: 0,20; RI: 0,20.

O segundo centro ural é bem desenvolvido (tipo 3 de de Pinna \& Ng, 2004: 4) em Entomocorus (Ferraris, 1988: \#C4; Akama, 2004: \#138) e Asterophysus (de Pinna \& Ng, 2004: 11). Em poucos outros Siluriformes, como em Akysidae, Amblycipitidae (exceto em Amblyceps), Amphiliidae, Aspredinidae, Cetopsidae (Helogenes), Erethistidae, Mochokidae (Chiloglanis polypogon), Pseudopimelodidae (Pseudopimelodus raninus), Sisoridae (exceto em Bagarius), o segundo centro ural encontra-se bem desenvolvido (Lundberg \& Baskin, 1969; Britto, 2002: \#291; de Pinna $\& \mathrm{Ng}, 2004)$.

326. Fusão dos elementos dorsais do esqueleto caudal (ordenado): (0) hipurais 3, 4 e 5 não fusionados $(3 ; 4 ; 5)$; (1) hipurais 3 e 4 fusionados, mas 5 livre $(3+4 ; 5)$ (figs. 
64, 65); (2) hipurais 3, 4 e 5 fusionados (3+4+5). CI: 0,33; RI: 0,71.

Primitivamente em Siluriformes, os hipurais 3, 4 e 5 são livre, como em Diplomystidae, Ictaluridae, Bagridae, Cranoglanidae, Schilbidae, Pangasiidae, Siluridae e Cetopsidae (3; 4; 5; Lundberg \& Baskin, 1969: 13).

Em Doradoidae, a grande maioria das espécies possuem os hipurais 3 e 4 fusionados, e o 5 livre $(3+4 ; 5)$. Em Acanthodoras, a placa hipural ventral é fusionada parcial ou totalmente à placa dorsal, formada pela fusão dos hipurais 3,4 e 5. Algumas espécies da subfamília Astrodoradinae apresentam ainda outras modificações nos hipurais não foram ratadas no presente estudo (Higuchi, 1992: 116). Em Mochokidae, a maioria das espécies possui os hipurais fusionados, exceto Chiloglanis sp. "igamba", Chiloglanis sp. "ntumbachushi”, Atopochilus e Euchilichthys (Vigliotta, 2008: \#72).

327. Fusão dos elementos ventrais do esqueleto caudal (ordenado): (0) paripural e hipurais 1 e 2 não fusionados (PH; 1; 2); (1) hipurais 1 e 2 fusionados porém paripural livre (PH; 1+2) (fig. 64); (2) paripural e hipurais fusionados $(\mathrm{PH}+1+2)$ (fig. 65). CI: 0,40; RI: 0,93.

Em Siluriformes, primitivamente o paripural e os hipurais 1 e 2 não são fusionados (condição presente em Diplomystidae, Ictaluridae, Bagridae, Cranoglanidae, Schilbidae, Pangasiidae, Siluridae e Cetopsidae; Lundberg \& Baskin, 1969: 13), entretanto, há uma tendência de redução no número de elementos hipurais livres, seja pela fusão ou perda dos mesmos (Lundberg \& Baskin, 1969: 12). Lundberg \& Baskin (1969: 12) argumentam que o sexto hipural aparentemente foi perdido em Siluriformes, enquanto que os outros hipurais aparentemente foram fusionados uns aos outros em diversos graus. Em exemplares pequenos de Franciscodoras (MZUSP 97145, 29.4 mm de CP) é possível ver o paripural e os 5 lobos hipurais livres, enquanto que em 
exemplares de maior porte (MZUSP 9380, $180 \mathrm{~mm}$ de CP), estes estão fusionados da seguinte forma $\mathrm{PH}+1+2 ; 3+4 ; 5$, indicando que tais elementos encontram-se realmente fusionados e não foram perdidos. Lundberg \& Baskin (1969: 12) argumentam que há muita convergência no padrão de fusão dos hipurais, citando, como exemplo, a família Mochokidae que primitivamente apresenta $\mathrm{PH}+1+2,3+4,5$ e secundariamente $\mathrm{PH}+1+2$, $3+4+5$, enquanto que Aspredinidae apresenta primitivamente $\mathrm{PH}, 1+2,3+4+5 \mathrm{e}$ secundariamente $\mathrm{PH}+1+2,3+4+5$. Lundberg \& Baskin (1969: 13) ainda reportaram que há uma grande variação intra-específica em algumas espécies de Siluriformes, como em Noturus spp..

Dentro dos Doradoidea, os Auchenipteridae, Wertheimeria, Kalyptodoras, Franciscodoras, Acanthodoras, Agamyxis, Scorpiodoras, Anadoras (e provavelmente outros Astrodoradinae), e Rhinodoras thomersoni possuem $\mathrm{PH}+1+2$, enquanto que os demais táxons possuem PH; 1+2 (ver Sabaj Pérez \& Birindelli, 2008: fig. 11). As espécies de Mochokidae possuem $\mathrm{PH}+1+2$, exceto Euchilichthys guentheri e E. royauxi com PH; 1+2 (Vigliotta, 2008: \#71).

Esse caráter não foi observado em Centrochir e Megalodoras.

328. Fusão dos elementos dorsais e ventrais do esqueleto caudal: (0) elementos dorsais e ventrais da nadadeira caudal livres; (1) elementos dorsais e ventrais da nadadeira caudal fusionados $(\mathrm{PH}+1+2+3+4+5)$. CI: 1,00; RI: 0,00 .

Em Doradoidea, o único táxon que apresenta os elementos dorsais e ventrais do esqueleto caudal fiusionados é Acanthodoras (Birindelli, 2006: \#102). Em um dos exemplares diafanizados (MZUSP 6831, $106 \mathrm{~mm}$ de CP) a fusão é parcial, enquanto que em dois outros exemplares (MZUSP 84667, $56 \mathrm{~mm}$ de CP) a fusão é total (como em Higuchi, 1992: fig. 33C). 


\subsection{Caracteres não utilizados:}

Muitos dos caracteres propostos por outros autores (i.e., Ferraris, Walsh, Higuchi, Curran, Soares-Porto, Royero, Akama, Sabaj) para espécies de Doradoidea não foram utilizados no presente estudo por uma série de fatores. O principal deles foi o aumento da amostragem de táxons e, por conseguinte, da variação morfológica, que tornou impossível delimitar estados discretos de caráter. Por exemplo: 'corpo alto, comprimido' (Higuchi, 1992: \#1 para Trachydoras, "Petalodoras", Nemadoras), 'escudo cefálico estreito em relação à cintura peitoral' (Higuchi, 1992: \#3 para Astrodoradinae), ‘barbilhão maxilar curto’ (Higuchi, 1992: \#7 para algumas espécie de Trachydoras). Este é um problema já descrito para análises filogenéticas de outros grupos de peixe (e.g., de Pinna, 1993; Schaefer, 1998). Alguns caracteres propostos anteriormente não foram utilizados simplesmente por não terem sido corroborados no presente estudo, como, por exemplo, 'fontanela redonda' (Higuchi, 1992: \#A19) em Kalyptodoras, que possui a fontanela alongada; 'pterótico fusionado ao pós-têmporosupracleitro' (Higuchi, 1992: A35) em Hassar, que possui o pterótico livre do póstêmporo-supracleitro; 'basibranquial 4 ossificado' (Higuchi, 1992: \#A44) em Doras, que possui o basibranquial 4 cartilaginoso, assim como os demais doradídeos. Alguns caracteres foram codificados de maneira diferente do proposto originalmente. Entre estes, o caráter usado no presente estudo 'crista transversal serrilhada no infra-orbital 1' refere-se aos caracteres \#20 e \#21 usados por Higuchi (1992): 'lacrimal com crista transversal serrilhada' e 'lacrimal com margem póstero-dorsal serrilhada', respectivamente; da mesma forma, 'capuz oral' refere-se aos caracteres \#A07 e \#A08 de Higuchi (1992): 'barbilhões mentonianos conectados ao lábio inferior por membrana' e 'estruturas bucais externas [barbilhões] modificados num capuz', respectivamente; ou 
ainda, 'mesetmóide coalescente' presente em Orinocodoras e Rhinodoras, refere-se aos caracteres \#A09 de Higuchi (1992), citado apenas para Orinocodoras; ou mesmo ‘mesetmóide largo, robusto' (Higuchi, 1992: \#9) citado para Pterodoras, Lithodoras, Doraops, Megalodoras, Centrodoras e Centrochir, mas presente apenas em Pterodoras, Lithodoras, Doraops e em Wertheimeria e Kalyptodoras. No geral foram utilizados entre 50 e $70 \%$ dos caracteres utilizados em cada um dos estudos relacionados à filogeneia de Doradoidea. Por outro lado, alguns casos específicos merecem explicações mais elaboradas (o que é feito abaixo).

- Nasal bifurcado. O canal sensorial que passa pelo osso nasal é sempre bifurcado, entretanto, a extensão da ossificação que passa pela ramificação varia bastante intra-especificamente nas espécies de Doradidae. Este caráter foi utilizado por diversos autores (Higuchi, 1992: \#A1; Ferraris, 1988: \#N15; Walsh, 1990: \#2; Royero, 1999: \#107; Akama, 2004: \#92) para caracterizar diferentes grupos (como Nemadoras e Ageneiosus).

- Narina posterior como um tubo dirigido látero-posteriormente. Higuchi (1992: \#A03) descreve este caráter para Centrochir. Este caráter não foi incluído pois poucos exemplares de Centrochir crocodili foram examinados para confirmá-lo com segurança.

- Partes expostas do esqueleto granulosas, espinhosas. Apesar deste caráter não ter sido incluído da forma como proposto por Higuchi (1992: \#A04) para Agamyxis, caracteres relacionados à presença de espinhos em diferentes ossos presentes em Agamyxis foram incluídos.

- Músculo depressor do acúleo da nadadeira dorsal com origem na face ventral do escudo nucal. Segundo Ferraris (1988: \#D8), o músculo depressor do acúleo da nadadeira dorsal, inserido no processo posterior da base do acúleo, tem sua 
origem na face ventral do escudo nucal em Centromochlus heckelii, e uma origem mista no escudo nucal e no pterigióforo em Anduzedoras oxyrhynchus, enquanto que nos demais Siluriformes, a origem deste músculo é na face posterior do pterigióforo. A visualização deste caráter é difícil, o que possivelmente levou os autores que estudaram o grupo (incluindo o presente autor) a não verificarem esta característica nos táxons. Mesmo Ferraris (1988) aparentemente observou este caráter em poucos táxons. Entretanto, esta pode ser uma interessante característica de doradídeos e auchenipterídeos, que precisa ser melhor estudada.

- União entre os cerato-hiais anterior e posterior. Segundo Britto (2002: \#77), o contato entre os cerato-hiais anterior e posterior se dá através de ligação cartilaginosa (sincondral), através de sutura óssea em apenas um dos lados do arco hióide, ou através de sutura óssea em ambos os lados do arco hióide. Segundo Britto (2002), as espécies de Doradidae (e mochokídeos como Synodontis) teriam contato sincondral, enquanto que as espécies de Auchenipteridae teriam sutura óssea em ambos os lados, exceto Asterophysus (e os mochokídeos como Chiloglanis, Microsynodontis e Mochokus) que tem sutura óssea em apenas um dos lados. Como Britto (2002) havia notado, este caráter tem grande variação ontogenética. O presente estudo comprovou que a diferença vista por Britto (2002) não se aplica aos Doradidae, Auchenipteridae e Mochokidae, pois tais diferenças são principalmente ontogenéticas. O único táxon examinado que teria uma condição única no contato entre cerato-hial anterior e o posterior é Ageneiosus inermis, que possui os dois ossos firmemente unidos por sutura (ver fig. 43).

- Primeiro e segundo hipo-branquiais fortemente côncavos anteriormente. Segundo muitos autores (Ferraris, 1988: G1; Walsh, 1990: \#7; Royero, 1999: \#108; Akama, 2004: \#78) o primeiro e o segundo hipo-branquiais em Ageneiosus e Tetranematichthys possuem uma condição única, na qual a margem anterior é 
distintamente côncava. Este caráter não foi usado pois a variação encontrada não permite uma clara distinção entre os estados propostos pelos autores citados acima. Muitos táxons analisados possuem condições semelhantes e/ou intermediárias, como Wertheimeria.

- Processo posterior do autopalatino. Esta característica, proposta para Auchenipterus e gêneros relacionados (Ferraris, 1988: \#J6; Walsh, 1990: \#11), não foi corroborada nos exemplares examinados.

- Metapterigóide cônico, sem (ou com pouca) extensão laminar. Este caráter foi usado para caracterizar Centromochlinae ou para espécies de Tatia e Centromochlus, dependendo do autor (Ferraris, 1988: \#J3; Royero, 1999: \#59; Akama, 2004: \#48). Entretanto, a variação do formato do metapterigóide em diferentes espécies de Centromochlus e Tatia é grande (ver, por exemplo, Soares Porto, 1998) e não permite traçar com segurança uma distinção segura entre dois estados de caráter. Soares Porto (1998: 338) interpretou a diminuição do metapterigóide como resultante do formato do hiomandibular em Tatia.

- Sulco mediano no escudo cefálico. O sulco mediano que está presente no escudo cefálico de alguns exemplares de algumas espécies é uma característica que apresenta grande variação ontogenética (sendo menos desenvolvida em exemplares maiores) e intra-específica. Entretanto, alguns autores utilizaram essa característica para diferentes grupos de Doradoidea (Higuchi, 1992: \#32, \#33; Royero, 1999: \#5).

- Delimitação do forame do nervo óptico. A delimitação do forame do nervo óptico varia dentro de alguns gêneros, como em Auchenipterus (ver Royero, 1999: fig. 71A-B), Parauchenipterus (ver codificações de Royero, 1999: \#36 e Akama, 2004: \#1), e mesmo dentro de algumas espécies (como em Parauchenipterus galeatus, obs. pess.). Apesar disso, essa característica foi utilizada por alguns autores para espécies de 
Auchenipteridae (Royero, 1999: \#36, \#38, \#40; Akama, 2004: \#1). Optei por não usar esse caráter porque considero que somente através de uma melhor amostragem será possível precisar com confiança os estados de caráter e a codificação destes nos auchenipterídeos.

- Abertura do forame do nervo trigêmio-facial. A abertura do nervo trigêmiofacial varia um pouco em algumas espécies de Auchenipteridae e Doradidae, sendo às vezes delimitado pelo pró-ótico e às vezes anterior a ele (Royero, 1999: \#35, \#39; Akama, 2004: \#3, \#4). Entretanto, dada a presença de variação intra-espefícica em outras espécies examinadas e a dificuldade na visualização deste caráter em algumas espécies, preferi não incluí-lo no presente estudo. Entretanto, ressalto que talvez ele seja informativo caso bastante material em bom estado de preparação e dissecção esteja disponível futuramente.

- Hipertrofização do músculo hyohyoides inferioris. Diogo (2004: \#35) descreve um caráter multi-estado ordenado sobre o formato do músculo hyohyoides inferioris, no qual o estado 1 está presente em Doradidae, Auchenipteridae, Mochokidae e Malapteruridae e o estado 2 em Bagridae e Amphiliidae. Apesar de poucos exemplares terem sido examinados para este caráter (Wertheimeria maculata, MZUSP 93658, Genidens genidens, MZUSP 46319, Diplomystes camposensis, MZUSP 88533 e Parauchenipterus galeatus, baseado na descrição de Royero, 1999), o músculo hyohyoides infeior presente em doradídeos parece ser tão hipertrofiado como em outras espécies de Siluriformes, como em Diplomystes ou Arius (ambos examinados para este caráter).

- Músculo hyohyoidei adductores. Diogo (2004: \#37) descreve um caráter multi-estado ordenado sobre o contato entre o músculo hyohyoidei adductores e a cintura peitoral, no qual o estado 1 está presente em Mochokidae, Auchenipteridae, 
Doradidae (além de Loricariidae), e o estado 2 em Callichhtyidae e Aspredinidae. Apesar de poucos exemplares terem sido examinados para este caráter (Wertheimeria maculata, MZUSP 93658, Genidens genidens, MZUSP 46319, Diplomystes camposensis, MZUSP 88533, Parauchenipterus galeatus, baseado na descrição de Royero, 1999), o músculo hyohyoidei adductores parece se sobrepor à cintura peitoral neste e em outros Siluriformes, apesar de desligado dela.

- Músculo abductor superficialis alcançando o cleitro. Diogo (2004: \#42) descreve o músculo adductor superficialis como alcançando o cleitro apenas em algumas famílias de Siluriformes, como Doradidae, Auchenipteridae, Mochokidae, Claroteidae, Pangasiidae, Akysidae, Auchenoglanidae, Amphiliidae, Nematogenyidae, Trichomycteridae, Sisoridae, Erethistidae, Loricariidae e Aspredinidae. Em Amphiliidae, Erethistidae, Mochokidae, Doradidae e Auchenipteridae, o coracóide apresenta uma quilha óssea ventral originada na ponte entre o cleitro e coracóide que demilita posteriormente o músculo abductor superficialis, deixando este sem contato com o cleitro (caráter esse usado no presente estudo). A condição do músculo abductor superficialis nos demais táxons analisados por Diogo (2004) não foi verificada.

- Projeção ântero-lateral do cleitro. A margem ântero-lateral do cleitro apresenta-se espassada de forma variável em Siluriformes. Essa variação entretanto é gradual, tornando imprecisa a delimitação de estados discretos de caráter. Apesar disso, Diogo (2004: \#168) considera esse caráter como uma sinapomorfia (não exclusiva) de Mochokidae, Auchenipteridae e Doradidae.

- Inserção do músculo adductor mandibulae, seção A2 na porção mesial do dentário. Esse caráter foi considerado uma sinapomorfia (não exclusiva) de Mochokidae, Auchenipteridae e Doradidae por Diogo (2004: \#210). Este caráter não foi verificado no presente estudo. 
- Músculo adductor operculi não inserido no hiomandibular (“hiomandíbulo-metapterigóide"). O músculo adductor hyomandibulae, se insere sobre uma crista no hiomandibular em diversos grupoos de Siluriformes (Ariidae, Claroteidae, Ictaluridae, Pangasiidae, Pimelodidae). Essa crista está ausente em diversas famílias, sendo sua presença usada como um caráter no presente estudo. Diogo (2004: \#248) considera o músculo adductor hyomandibulae não inserido no hiomandibular como uma sinapomorfia (não exclusiva) de Mochokidae, Auchenipteridae, Doradidae. Apesar desses táxons não possuírem a crista bem desenvolvida no hiomandibular, como verificado no presente estudo, o músculo adductor hyomandibulae insere-se no hiomandibular.

- Faceta de articulação do coracóide com o acúleo da nadadeira peitoral. Segundo Diogo (2004: \#190), a faceta de articulação do coracóide com o acúleo da nadadeira peitoral alongada é uma condição exclusiva de Auchenipteridae e Doradidae. Este caráter não foi corroborado no presente estudo, já que a faceta do coracóide presente em Doradidae e Auchenipteridae nada difere da condição encontrada em outras famílias de Siluriformes, como, por exemplo, Pimelodidae.

- Ponte entre coracóide e cleitro aumentada. Segundo Diogo (2004: \#194), a ponte entre coracóide e cleitro é aumentada em algumas famílias de Siluriformes, sendo esta uma sinapomorfia (não exclusiva) de Auchenipteridae e Doradidae. Esse caráter é variável entre as espécies de Auchenipteridae e Doradidae, e mesmo entre espécies de outras famílias, tornando a delimitação de estados discretos de caráter imprecisa.

- Processo ântero-dorsal do hiomandibular. Segundo Diogo (2004: \#334), o processo ântero-dorsal do hiomandibular é distintamente mais desenvolvido em Auchenipteridae, Doradidae, Ictaluridae e Aspredinidae. Entretanto, esse processo é variavelmente presente em diversas famílias de Siluriformes e, ao mesmo tempo, pouco 
desenvolvido em diversas espécies de Auchenipteridae e Doradidae.

\subsection{Análise de parcimônia}

A análise de parcimônia da matriz de 328 caracteres codificados para 98 táxons terminais, resultou em 4 cladogramas igualmente parcimoniosos com 1086 passos, índice de consistência 0,39 e índice de retenção 0,82 , a partir dos quais foi elaborado um cladograma de consenso estrito, apresentado na figura 66. O valor do suporte de Bremer foi calculado e apresentado na figura 67. A matriz completa de caracteres encontra-se no apêndice 2, e a lista das sinapomorfias comuns a todas as árvores fundamentais no apêndice 3. 


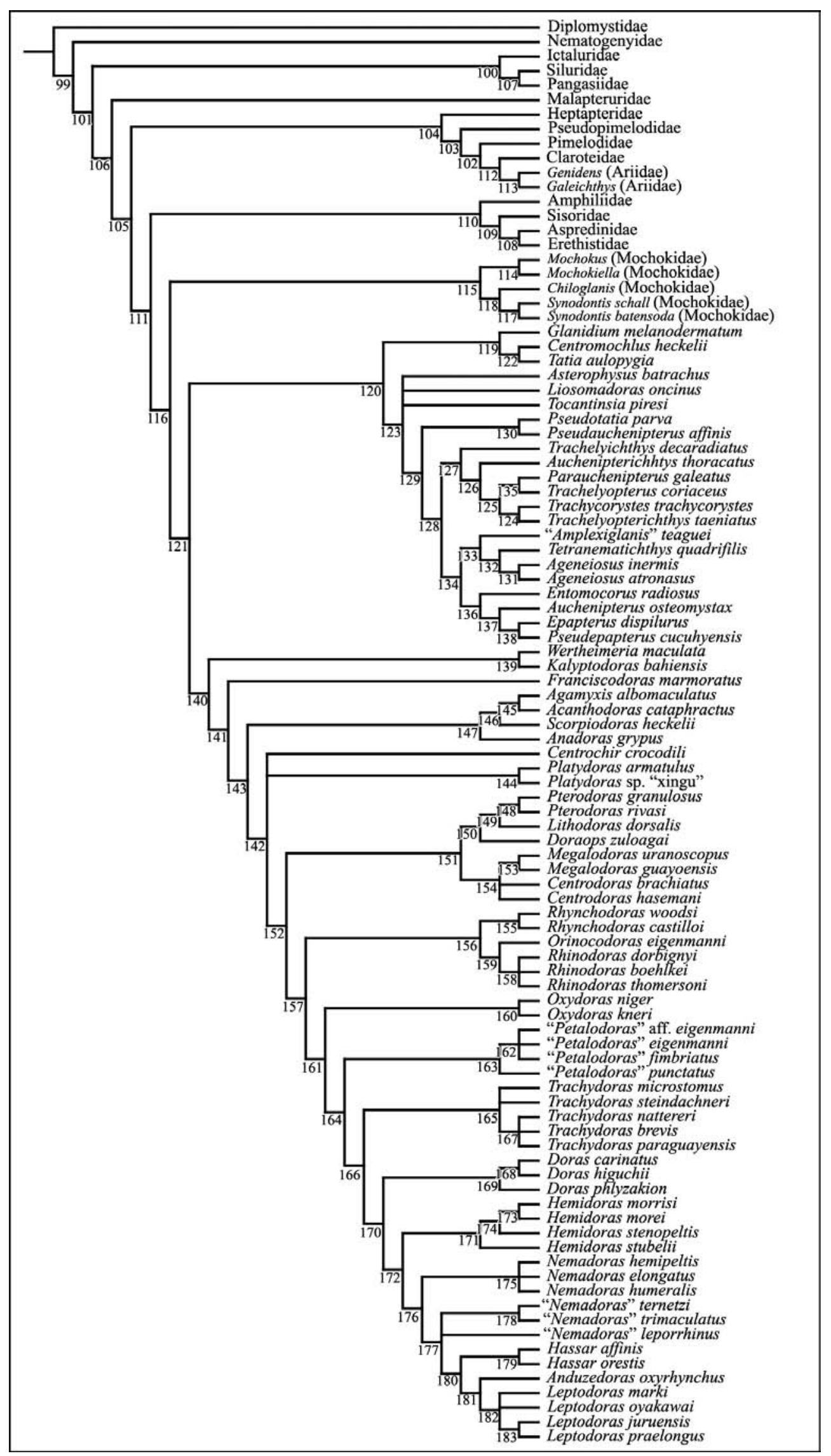

Figura 66. Cladograma de consenso estrito das 4 árvores fundamentais obtidas no presente estudo. 


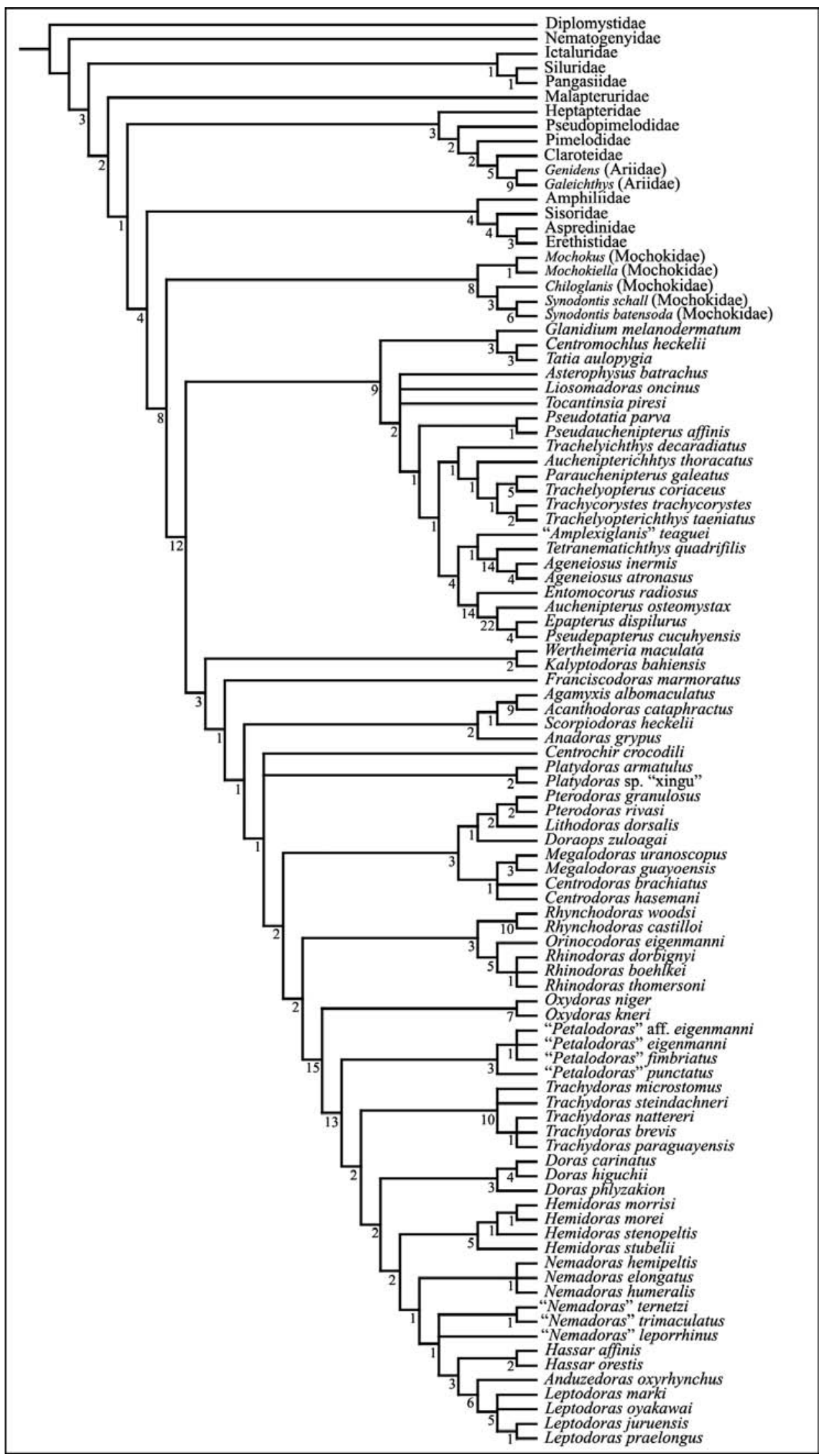

Figura 67. Cladograma de consenso estrito das 4 árvores fundamentais, com o índice de suporte de Bremer indicado em cada clado. 


\subsection{Sistemática da superfamília Doradoidea}

Nessa seção são diagnosticados os principais clados obtidos no presente estudo, especialmente as famílias, subfamílias, tribos e os gêneros da superfamília Doradoidea. Para os grupos maiores, a comparação só foi feita com famílias não incluídas na análise filogenética em casos específicos, nos quais a informação já estava disponível na literatura. Uma chave para identificação dos gêneros de Auchenipteridae e Doradidae é apresentada no apêndice 4.

\section{"Clado Doradoidei/Sisoroidea/Amphiliidae"}

Diagnose: Este grande grupo é diagnosticado por um conjunto de características não exclusivas: etmóide lateral formando o escudo cefálico (\#70, condição também presente em Ictaluridae, Ariidae, Pimelodidae, Claroteidae e Siluridae); processo lateral do basioccipital presente (\#91, condição também presente em Galeichthys e Claroteidae); epoccipital com processo posterior cartilaginoso ou ossificado (\#96, condição também presente em Ariidae, Pangasiidae, Schilbidae, mas ausente em Erethistidae e Aspredinidae); pós-têmporo-supracleitro suturado ao crânio (\#101, condição também presente em Akysidae, Astroblepidae, Callichthyidae, Clariidae, Loricariidae, Nematogenyidae e Scoloplacidae); processos ventrais da trava do acúleo da nadadeira dorsal longos (\#250, condição ausente em Amphiliidae e Aspredinidae); paripural e hipurais 1 e 2 fusionados entre si (\#327, condição também presente em Pseudopimelodidae e em alguns outros Siluriformes, ver detalhes em Lundberg \& Baskin, 1969).

Táxons incluídos: Auchenipteridae, Doradidae, Mochokidae, Amphiliidae, Aspredinidae, Sisoridae, Erethistidae, Akysidae, Amblycipitidae (as duas últimas não incluídas no presente estudo, mas consideradas integrantes da superfamília Sisoroidea 
por de Pinna, 1996).

Comentários: Essa é a primeira vez que um clado monofilético composto por Doradoidei, Sisoroidea e Amphiliidae é proposto. A relação de grupo irmão entre Amphiliidae e Sisoroidea já havia sido proposta por Diogo (2004). de Pinna (1993) e Britto (2002) consideraram Amphiliidae como relacionado à Loricarioidea, considerando este clado relacionado (ou próximo) à Sisoroidea.

\section{Subordem Doradoidei Bleeker, 1858}

Diagnose: A subordem Doradoidei é diagnosticada por cinco caracteres exclusivos: processo posterior do parieto-supra-occipital ausente (\#80); paruro-hial sem expansões laminares (\#177); ligamento entre a primeira costela e placa nucal posterior (\#223); placa nucal anterior suturada ao parieto-supra-occipital (\#243); processo posterior do cleitro grande (\#278, pequeno em Chiloglanis, Glanidium, Tatia, Parauchenipterus galeatus, "Amplexiglanis" e Tetranematichthys, e ausente em Ageneiosus); e por um conjunto de características não exclusivas: membrana branquial unida ao istmo por uma área extensa (\#5, condição também presente em Aspredinidae, Malapteruridae); extraescapular ausente (\#100, condição também presente em Aspredinidae, Amphiliidae, Erethistidae, Nematogenyidae e Siluridae); quatro infra-orbitais (\#114, condição também presente em Ariidae, Pimelodidae, Pseudopimelodidae, Erethistidae, porém ausente em Anadoras e Chiloglanis); sexta vértebra parcialmente fusionada à vértebra complexa (\#228, condição também presente em Genidens, Pimelodidae, Pangasiidae, Siluridae); sutura entre os dois pterigióforos da nadadeira dorsal e o espinho neural da vértebra complexa (\#248, condição também presente em Chacidae).

Táxons incluídos: Auchenipteridae, Doradidae e Mochokidae. 


\section{Família Mochokidae Jordan, 1923}

Synodontini Bleeker, 1862: 6 [para incluir Synodontis, Brachysynodontis, Pseudosynodontis, Hemisynodontis, Leiosynodontis].

Rhinoglanina Günther, 1864: 4 [para incluir Rhinoglanis (=Mochokus), Mochocus (sic), Callomystax (=Gagata, Sisoridae)].

Mochokidae Jordan, 1923: 150 [para substituir Synodontidae, pré-ocupado].

Chiloglanidinae Riehl \& Baensch, 1990: 396.

Atopochilini Vigliotta, 2008: 116 [para incluir Atopochilus, Atopodontus, Euchilichthys].

Observação: Simuldentinae Taverne \& Aloulou-Triki, 1974 é um nome supra-genérico não válido por não ter sido baseado num gênero válido (Ferraris, 2007).

Diagnose: A família Mochokidae é diagnosticada pelo músculo protractor do ramo de Müller inserido sobre a haste do ramo de Müller e com origem na placa nucal posterior (\#215); e por um conjunto de características não exclusivas: canal sensorial mandibular reduzido a 2 ou 3 poros (\#122, condição também presente em Amphiliidae e Doradini, mas indeterminada em Chiloglanidinae, que não possui o canal sensorial mandibular); osso corono-meckeliano ausente (\#143, condição também presente em Loricariidae, Astroblepidae, Callichthyidae, Scoloplacidae, Malapteruridae e Hoplomyzontinae); processo ascendente da cartilgagem de Meckel ausente (\#145, condição também presente em Amphiliidae, Loricarioidea, Malapteruridae e Siluridae); processo coronóide da mandíbula ausente (\#146, condição também presente em Asterophysus); sub-pré-opérculo ausente (\#175, condição também presente em Heptapteridae, Ariidae, Claroteidae, Aspredinidae e Siluridae); ligamento entre a segunda costela e a placa nucal posterior presente (\#224, caráter ambíguo, examinado somente em Synodontis, entre os mochokídeos, e também presente em Tatia cf. aulopygia); seis raios 
ramificados na nadadeira pélvica (\#288, condição também presente na grande maioria dos doradídeos, e em alguns poucos auchenipterídeos); hipurais 3, 4 e 5 fusionados (\#326, condição também presente em Sisoroidea, Claroteidae e Acanthodoras, ver Lundberg \& Baskin, 1969).

Táxons incluídos: Acanthocleithron, Atopochilus, Atopodontus, Chiloglanis, Euchilichthys, Microsynodontis, Mochokiella, Mochokus, Synodontis.

Comentários: Vigliotta (2008) recentemente realizou uma análise filogenética dos gêneros da família Mochokidae. Além das características mencionadas acima, Vigliotta (2008) menciona como caracteres diagnósticos para mochokídeos: inter-hial ausente (condição também presente em Amphiliidae, ver também Mo, 1991) e barbilhões mentonianos com barbelas, exceto Chiloglanidinae (condição também presente em alguns doradídeos).

\section{Superfamília Doradoidea Bleeker, 1858}

Diagnose: A superfamília Doradoidea é diagnosticada pelas seguintes características exclusivas: exoccipital suturado ao arco neural da vértebra complexa (\#93); epoccipital com uma porção dérmica formando o escudo cefálico (\#94); infra-orbital 1 fortemente ligado ao etmóide lateral (\#107); processo tranformador do tripus pouco desenvolvido, plano e firmemente ligado à parede da bexiga natatória (\#211); os suspensorium reduzido a um nódulo ósseo, ligado à parapófise da quarta vértebra apenas por ligamento (\#212); músculo protractor inserido no disco do ramo de Müller com origem no teto do crânio (\#214); ramo posterior da parapófise da vértebra complexa ausente (\#220); parapófise da quinta vértebra reduzida ou ausente (\#221, exceto nas espécies derivadas de Leptodoras); primeiras costelas articuladas à face dorsal das parapófises das vértebras (\#233); e por alguns caractes não exclusivos: fenestra entre etmóide lateral 
e frontal ausente (\#71, condição também presente em Sisoroidea, Ariidae, Nematogenyidae, Malapteruridae, Pseudopimelodidae, mas ausente em Pseudauchenipterus); crista no hiomandibular para inserção do levator arcus palatini pouco desenvolvida (\#161, condição presente em Diplomystidae, Ictatulidae, Nematogenyidae, Pangasiidae, Pseudopimelodidae, Claroteidae, porém ausente na maioria dos doradídeos); canal aórtico ventralmente coberto por ossificação ventral superficial (\#226, condição também presente em Aspredinidae, Erethistidae, Genidens, Chiloglanis, mas ausente em Pseudotatia, Epapterus, Auchenipterus, Rhynchodoras); serra na margem anterior do acúleo da nadadeira dorsal presente (\#257, condição também presente em Ariidae, Pseudopimelodidae, Mochokus, porém ausente em Glanidium, Tocantinsia, Pseudauchenipterus, Entomocorus, Aucheniterus, Epapterus, Pseudepapterus, Parauchenipterus, Trachelyopterus e Anadoras); mesocoracóide ausente (\#263, condição também presente em Anchariidae, Ariidae e Aspredinidae). Táxons incluídos: Auchenipteridae e Doradidae.

\section{Família Doradidae Bleeker, 1858 (figura 69)}

Observações: Centrodoradinae, Hemidoradinae e Lithodoradinae foram criados por Fowler (1951) numa lista simples, o que os tornava válidos na época; entretanto os nomes são atualmente considerados inválidos por terem sido tratados como tal por Ferraris \& de Pinna (1999), que seguiram o código vigente na época (ICZN, 1961) (ver ICZN, 1999; Ferraris, 2007).

Diagnose: A família Doradidae é diagnosticada por três caracteres exclusivos: escudos ósseos laterais, formados a partir dos túbulos da linha lateral (\#127); ligamento entre o ramo de Müller e a linha lateral (\#222); e ligamento ossificado entre a primeira costela e a placa nucal posterior (\#223). 
Táxons incluídos: Wertheimeria, Kalyptodoras, Franciscodoras, Agamyxis, Acanthodoras, Amblydoras, Anadoras, Astrodoras, Hypodoras, Merodoras, Physopyxis, Merodoras, Centrochir, Platydoras, Pterodoras, Lithodoras, Doraops, Centrodoras, Megalodoras, Rhynchodoras, Rhinodoras, Orinocodoras, Oxydoras, "Petalodoras", Trachydoras, Doras, Hemidoras, Nemadoras, "Nemadoras", Hassar, Anduzedoras e Leptodoras. 


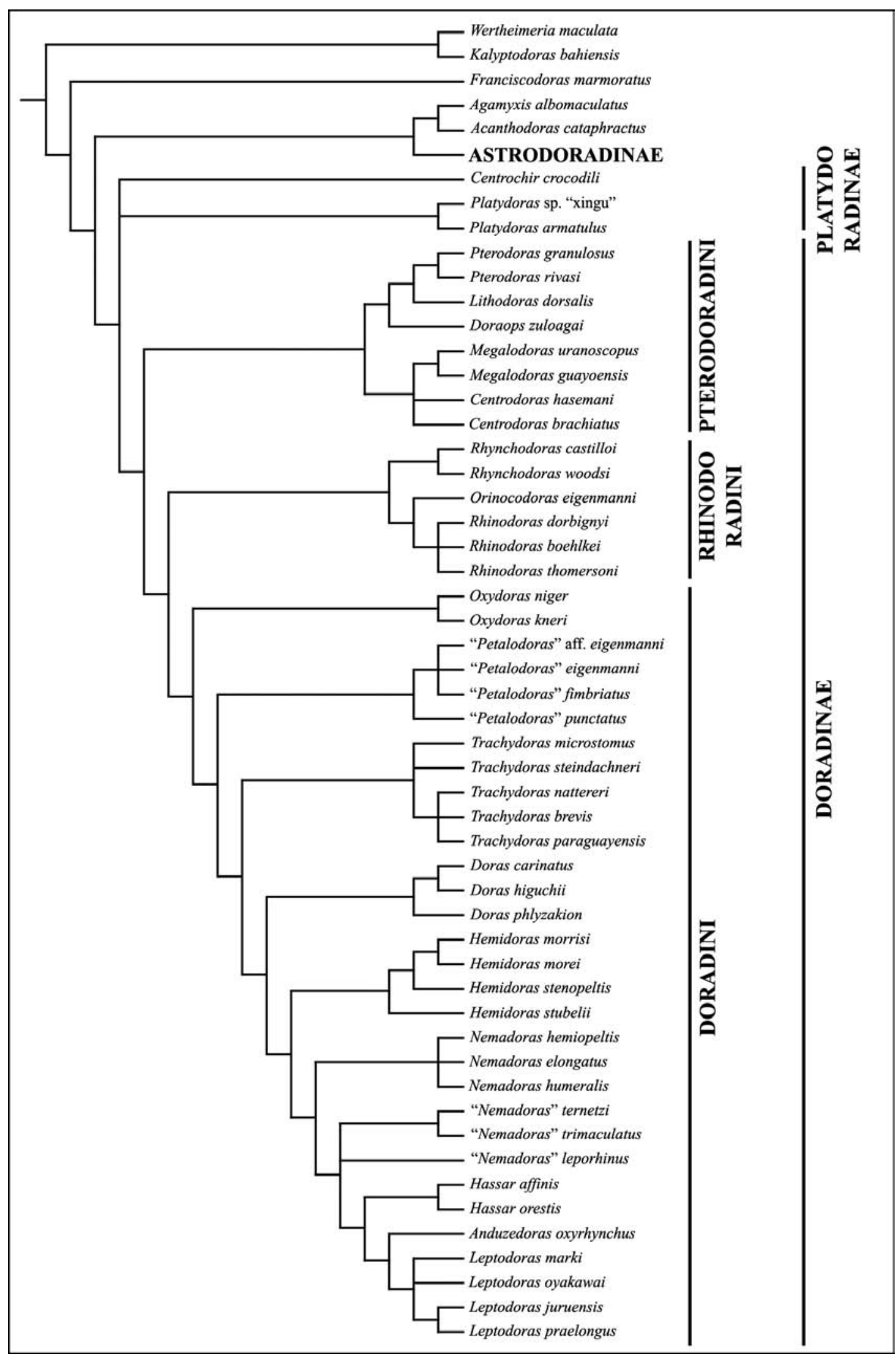

Figura 68. Cladograma resumido das relações filogenéticas na família Doradidae. 


\section{Wertheimeria Steindachner, 1877}

Wertheimeria Steindachner, 1877: 659 (espécie-tipo: Wertheimeria maculata Steindachner, por monotipia).

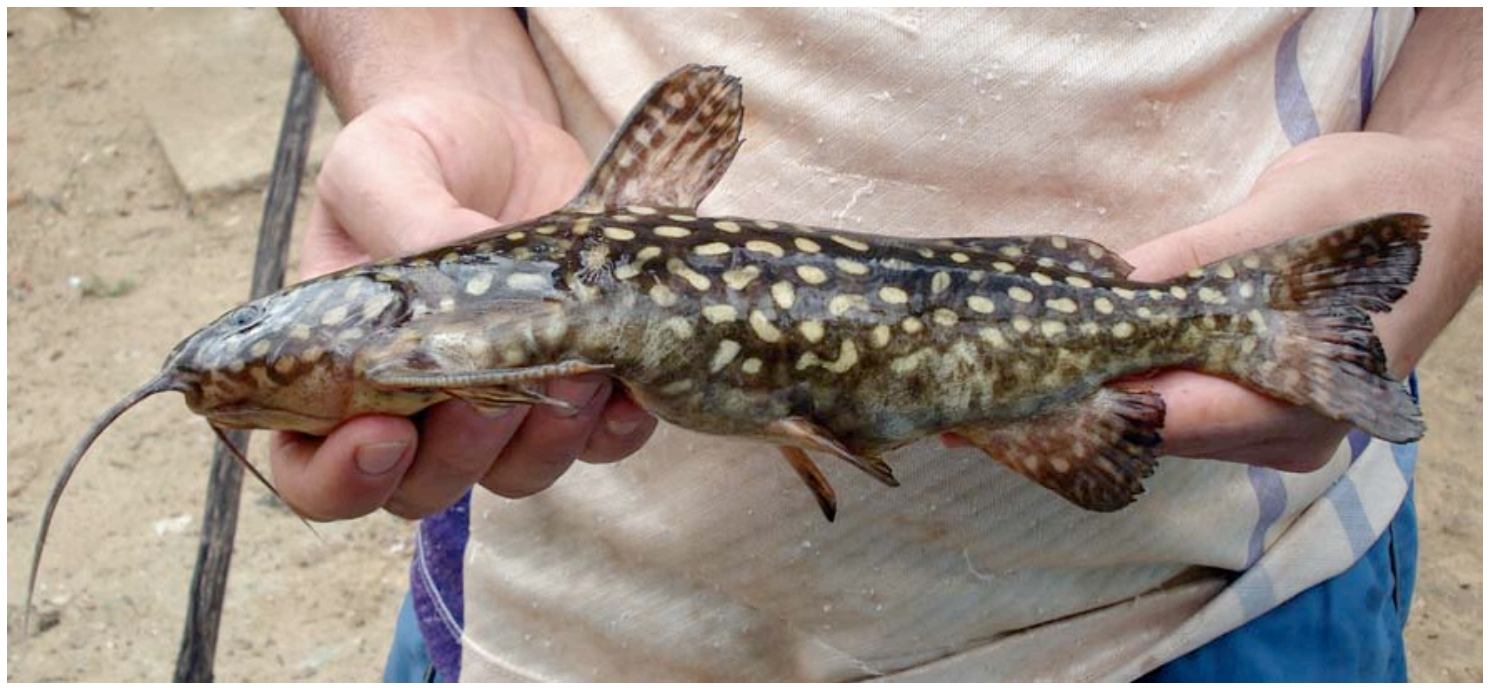

Figura 69. Wertheimeria maculata, MZUSP 93658, 238 mm, rio Jequitinhonha, Araçuaí, MG.

Diagnose: Wertheimeria maculata é diagnosticada pelo corpo escuro com manchas claras arredondadas (vermiculadas em juvenis) (Vono \& Birindelli, 2007); escudos laterais sem espinhos retrorsos, em exemplares com mais de $75 \mathrm{~mm}$ de CP (\#128); escudos laterais com desenvolvimento heterogênero ao longo do corpo (\#127, condição similar presente em Kalyptodoras, Doraops, Doras micropoeus, Nemadoras hemipeltis, "Nemadoras" leporhinus e Hassar); perfil dorsal do corte transversal do escudo cefálico ligeiramente convexo (\#138, condição também presente em Kalyptodoras, Acanthodoras e Agamyxis); sétima vértebra livre da vértebra complexa (\#229, condição também presente em Kalyptodoras e Franciscodoras); processo póstero-dorsal do cleitro bem desenvolvido (\#277, condição também presente em Kalyptodoras, Franciscodoras e algumas espécies de Leptodoras); seis raios ramificados na nadadeira pélvica (\#288, condição também presente em Kalyptodoras, Franciscodoras, Acanthodoras e Agamyxis). 
Táxon incluído: Wertheimeria maculata.

Comentários: Wertheimeria maculata foi considerada um auchenipterídeo desde Steindachner (1877) até recentemente (ver detalhes em Vono \& Birindelli, 2007), e é uma espécie endêmica das bacias dos rios Jequitinhonha e Pardo, no leste brasileiro.

\section{Kalyptodoras Higuchi, Britski \& Garavello, 1990}

Kalyptodoras Higuchi, Britski \& Garavello, 1990: 220 (espécie-tipo Kalyptodoras bahiensis Higuchi, Britski \& Garavello, por designação original).

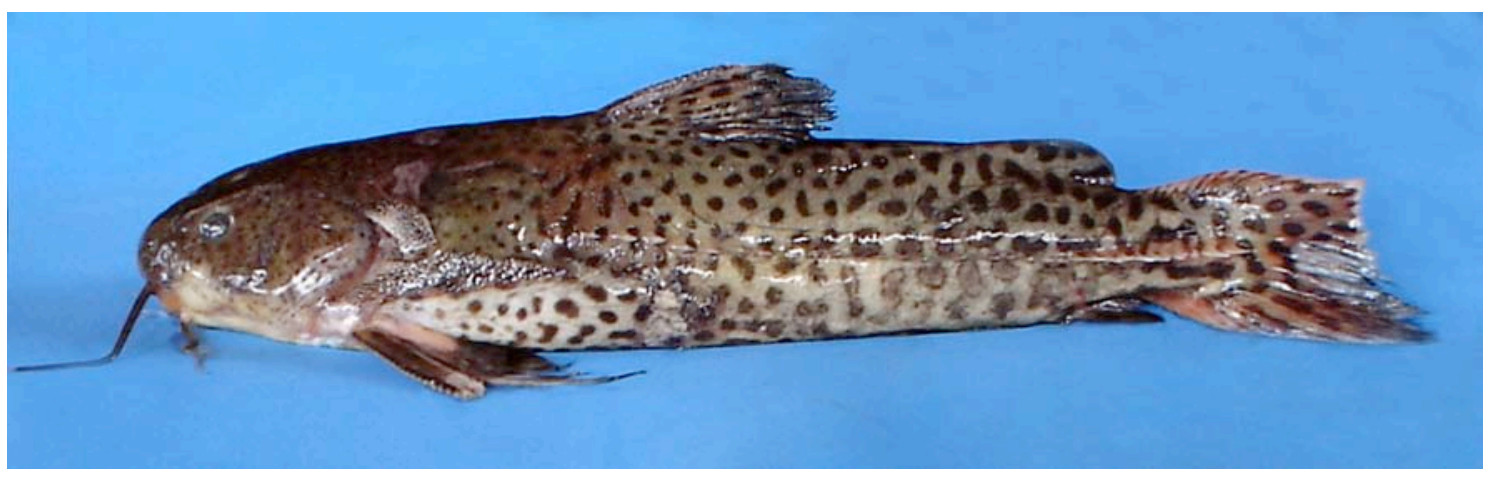

Figura 70. Kalyptodoras bahiensis, MZUSP 87839, 215 mm, rio Paraguassú, Iaçú, BA (foto de Osvaldo Oyakawa).

Diagnose: Kalyptodoras bahiensis é diagnosticada por ter corpo acinzentado ou amarronzado com manchas escuras pequenas e redondas e uma mancha clara na base da nadadeira peitoral; nasal expandido dorsalmente, aparentemente exposto (\#106, condição também presente em Platydoras); infra-orbitais expandidos em placas (\#115, condição também presente em Platydoras, Acanthodoras e Agamyxis); escudos laterais com desenvolvimento heterogênero ao longo do corpo (\#127, condição também presente em Wertheimeria, Doraops, Doras micropoeus, Nemadoras hemipeltis, "Nemadoras" leporhinus e Hassar); perfil dorsal do corte transversal do escudo cefálico ligeiramente convexo (\#138, condição também presente em Wertheimeria, Acanthodoras e Agamyxis); sétima vértebra livre da vértebra complexa (\#229, condição 
também presente em Wertheimeria e Franciscodoras); processo póstero-dorsal do cleitro bem desenvolvido (\#277, condição também presente em Wertheimeria, Franciscodoras e algumas espécies de Leptodoras); seis raios ramificados na nadadeira pélvica (\#288, condição também presente em Wertheimeria, Franciscodoras, Acanthodoras e Agamyxis).

Táxon incluído: Kalyptodoras bahiensis.

Comentários: Kalyptodoras bahiensis é uma espécie endêmica do rio Paraguassú na Bahia, e é considerada ameaçada à extinção (Birindelli, 2008).

\section{Franciscodoras Eigenmann, 1925}

Franciscodoras Eigenmann, 1925: 317 (espécie-tipo: Doras marmoratus Reinhardt, por designação original).

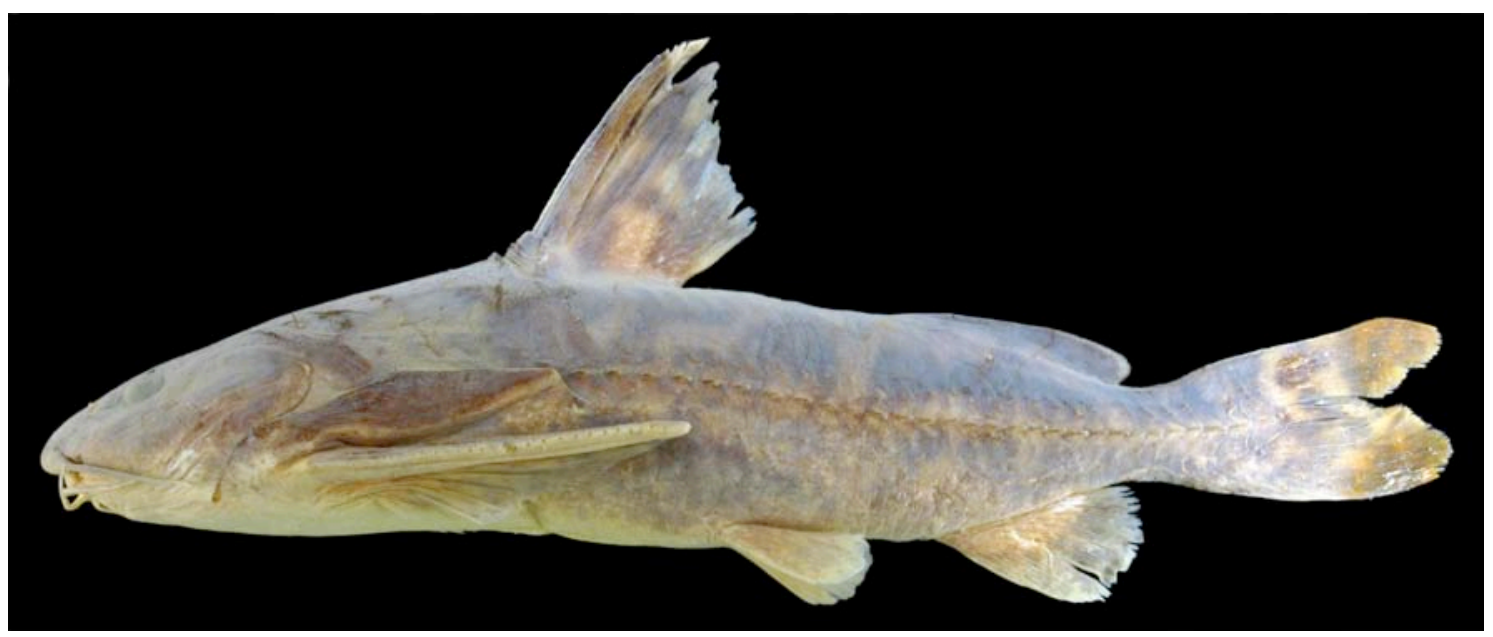

Figura 71. Franciscodoras marmoratus, MZUSP 95398, 190 mm, rio São Francisco, MG.

Diagnose: Franciscodoras marmoratus é diagnosticada por ter corpo escuro com vermiculações claras no dorso; raios procorrentes modificados em placas (\#318, condição também presente em Platydoras, Agamyxis e "Rhinodoradini"); sétima vértebra livre da vértebra complexa (\#229, condição também presente em Wertheimeria e Kalyptodoras); processo póstero-dorsal do cleitro bem desenvolvido (\#277, condição 
também presente em Wertheimeria, Kalyptodoras e algumas espécies de Leptodoras); seis raios ramificados na nadadeira pélvica (\#288, condição também presente em Wertheimeria, Kalyptodoras, Acanthodoras e Agamyxis).

Táxon incluído: Franciscodoras marmoratus.

Comentários: Francisocodoras marmoratus é uma espécie endêmcia da bacia do rio São Francisco.

\section{"Clado Astrodoradinae, Acanthodoras, Agamyxis"}

Astrodoradinae Higuchi, Birindelli, Sousa \& Britski, 2007: 33 (criado com base nos estudos não publicados de Higuchi, 1992, para incluir Amblydoras, Anadoras, Astrodoras, Hypodoras, Merodoras, Physopyxis e Merodoras).

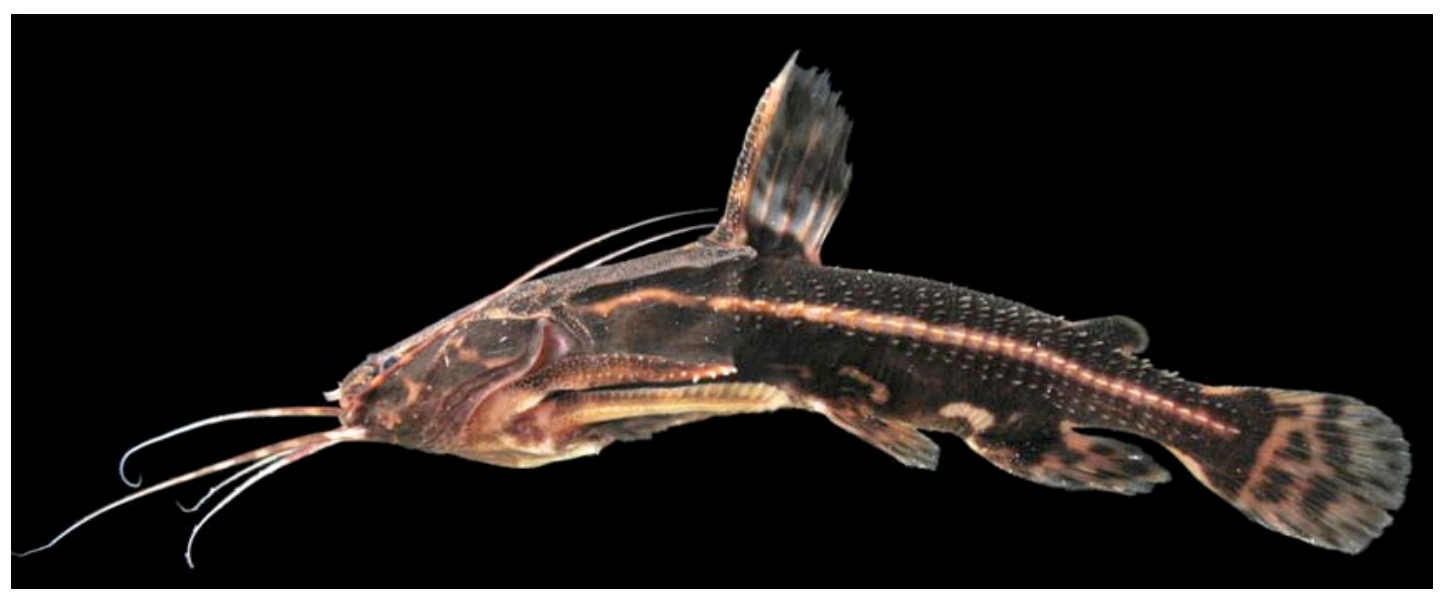

Figura 72. Acanthodoras cataphractus, MZUSP 103284, 76.6 mm, rio Jari, Monte Dourado, PA. 


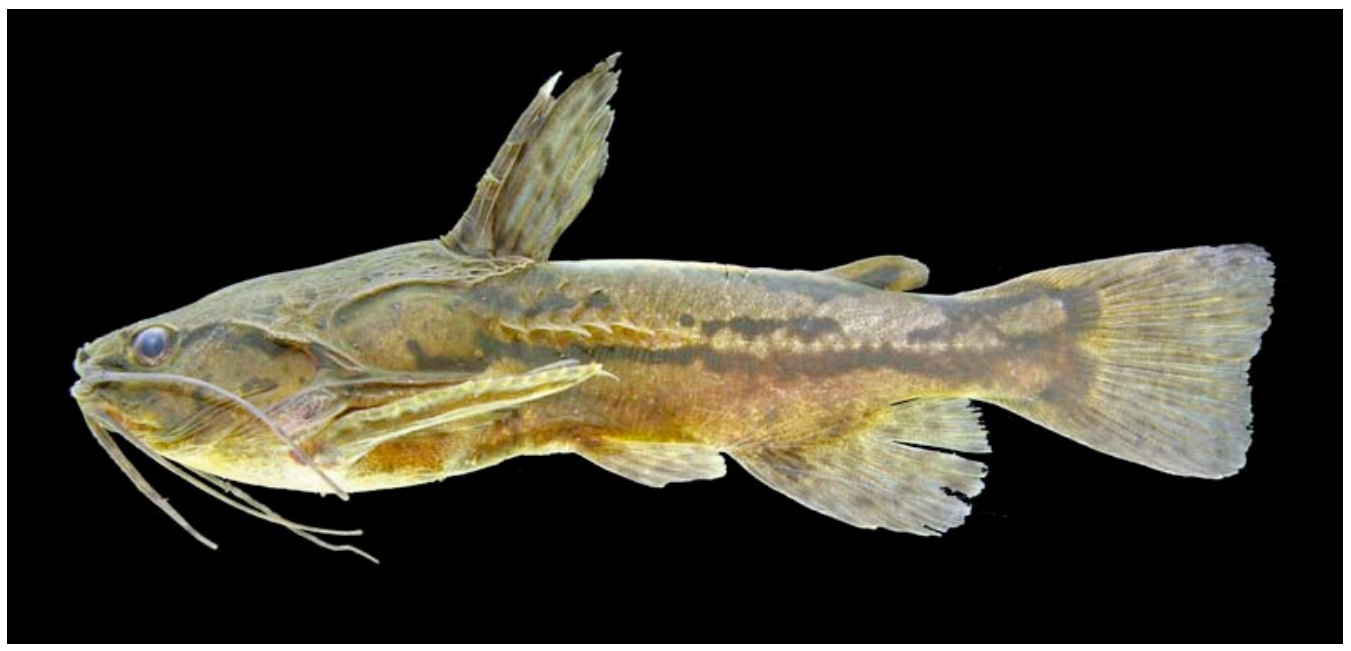

Figura 73. Merodoras nheco, MZUSP 96174, c.60 mm, Alagado, Barão de Melgaço, MT (foto de Mark Sabaj Pérez).

Diagnose: O clado Astrodoradinae, Agamyxis, Acanthodoras é diagnosticado pela nadadeira adiposa em forma de gota (\#4, condição presente em alguns exemplares de Platydoras); infra-orbital 1 participando da margem orbital (\#109, condição presente em Pterodoras e Lithodoras); margem póstero-ventral do coracóide achatada ventralmente e aparentemente exposta (\#284, condição também presente em Megalodoras, "Petalodoras", Trachydoras steindachneri e Hemidoras) ; sétima vértebra parcialmente fusionada à vértebra complexa (\#229, condição também presente em Doradinae e "Platydoradinae"); seis raios ramificados na nadadeira pélvica (\#288, condição também presente em Doradinae e "Platydoradinae", mas ausente em Acanthodoras e Agamyxis). Táxons incluídos: Acanthodoras, Agamyxis, Amblydoras, Anadoras, Astrodoras, Hypodoras, Merodoras, Physopyxis e Merodoras.

Comentários: Pelos resultados apresentados aqui, os gêneros Acanthodoras e Agamyxis deveriam ser incluídos na subfamília Astrodoradinae, expandindo o conceito da subfamília porposto por Higuchi et al. (2007). Os gêneros atualmente considerados como pertencentes à subfamília Astrodoradinae, estão sendo revisados por Sousa (durante sua tese de doutorado), e por isso não são abordados no presente estudo. 
Weitzel (2004), fez uma revisão taxonômica de Acanthodoras (ainda não publicada) e considerou que o gênero abriga 5 espécies, 2 delas ainda não descritas. $O$ gênero Agamyxis possui apenas duas espécies: A. albomaculatus (da bacia do rio Orinoco) e $A$. pectinifrons (da bacia do rio Amazonas), que, apesar de muito semelhantes, podem ser diferenciadas pela morfologia da bexiga natatória (Birindelli et al., 2009).

\section{Subfamília "Platydoradinae"}

Diagnose: A subfamília "Platydoradinae" é diagnosticada pela bexiga natatória sem divertículos laterais (\#44, condição também presente em Wertheimeria, Kalyptodoras, Franciscodoras, Acanthodoras, Agamyxis, Rhinodoras thomersoni, Rhynchodoras, "Petalodoras" punctatus, Leptodoras oyakawai, Doras e Astrodoradinae); sétima vértebra parcialmente fusionada à vértebra complexa (\#229, condição também presente em Doradinae); serra na margem posterior do acúleo da nadadeira dorsal (\#258, condição também presente em Doradinae); espinhos alinhados em cristas longitudinais do processo posterior do cleitro (\#280, condição também presente em Astrodoradinae); seis raios ramificados na nadadeira pélvica (\#288, presente também em Doradinae); oito raios ramificados no lobo ventral da nadadeira caudal (\#323, condição também presente em Doradinae); paripural livre dos hipurais 1+2 (\#327, condição também presente em Doradinae).

Táxons incluídos: Platydoras e Centrochir.

Comentários: A inclusão de Centrochir nessa subfamília é apenas tentativa. O monofiletismo desse clado foi corroborado por dados moleculares (Mariangeles Arce, com. pess.). Apesar de Higuchi (1992) ter usado o termo "subfamília Platydoradinae", esta se referia a um grupo formado por Platydoras, Acanthodoras, Agamyxis e Kalyptodoras. 


\section{Centrochir Agassiz, 1829}

Centrochir Agassiz, 1829: 14 (espécie-tipo: Centrochir crocodili, por monotipia).

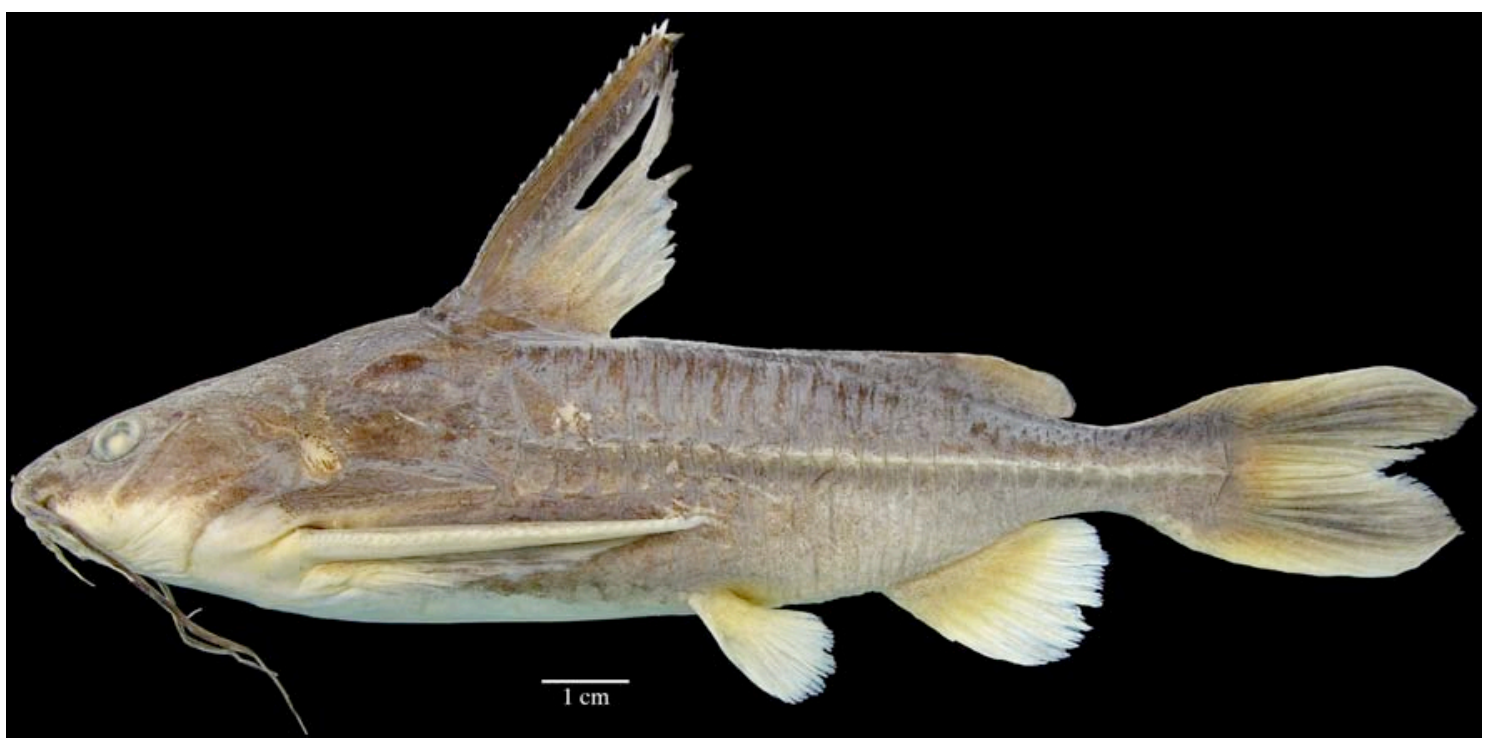

Figura 74. Centrochir crocodili, ANSP 189332, 152.5 mm (foto de Mark Sabaj Pérez).

Diagnose: Centrochir crocodili é diagnosticado pelo corpo homogeneamente acinzentado; bexiga natatória simples, sem divertículos ou câmara secundária (Birindelli et al., 2009); e raios procorrentes não modificados em placas (\#318).

Táxon incluído: Centrochir crocodili.

Comentários: Centrochir crocodili é uma espécie trans-andina endêmica do rio Magdalena na Colombia.

\section{Platydoras Bleeker, 1862}

Platydoras Bleeker, 1862: 5 (espécie-tipo: Silurus costatus Linnaeus, por designação original). 


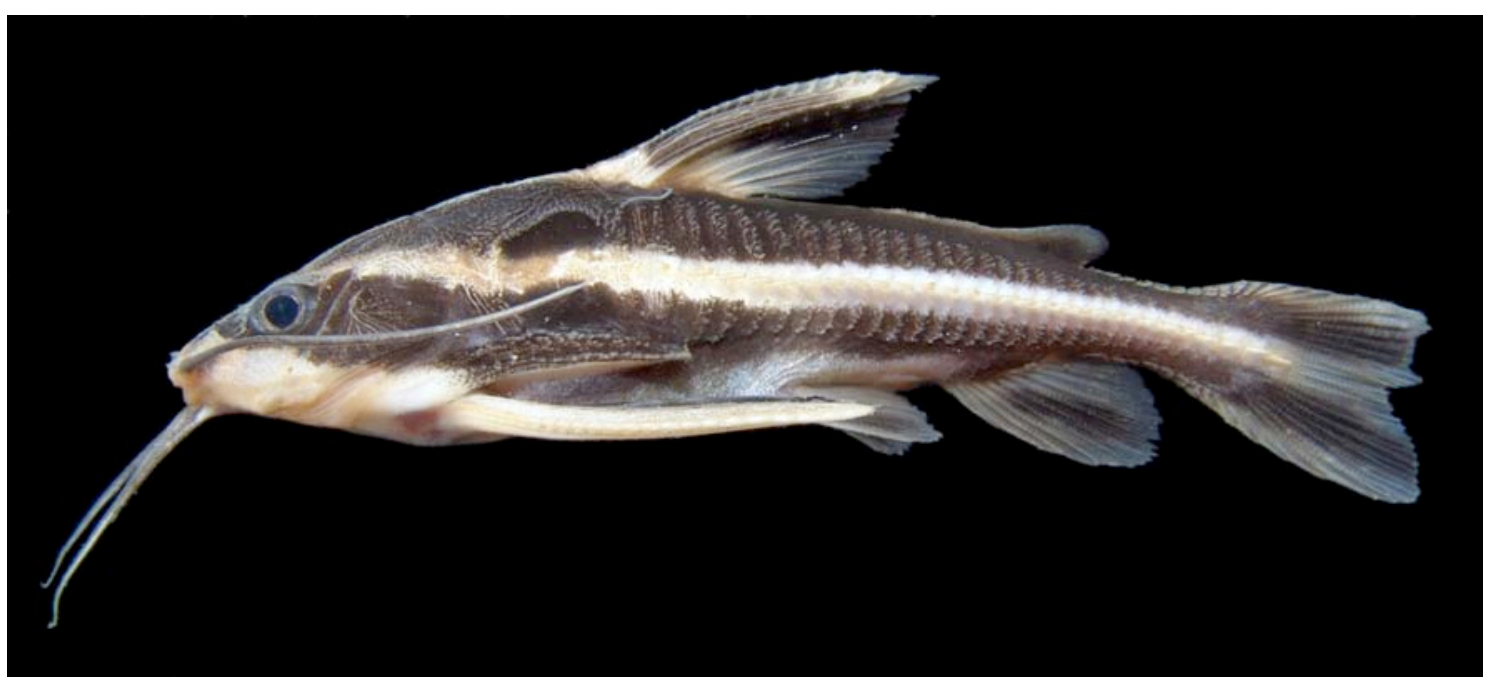

Figura 75. Platydoras armatulus, MZUSP 92759, c.55 mm, Rio Amazonas, Santarém, PA (foto de Leandro Sousa).

Diagnose: Platydoras é dianosticado pelo corpo escuro com uma faixa lateral clara (amarelada em vida) (exceto por $P$. costatus que possui o corpo homogeneamente acinzentado); raios procorrentes modificados em placas (\#318, condição presente em Franciscodoras, Agamyxis e "Rhinodoradini"); e bexiga natatória com câmara secundária sem septo longitudinal (\#40, ausente em Platydoras sp. “xingu”).

Táxons incluídos: Platydoras armatulus, P. brachylecis, P. costatus e P. hancokii.

Comentários: Recentemente Piorski et al. (2009) descreveram Platydoras brachylecis, rediagnosticando as demais espécies do gênero. Platydoras sp. "xingu" é uma espécie ainda não descrita que está sendo estudada por Leandro Sousa.

\section{Subfamília Doradinae Bleeker, 1858}

Diagnose: A subfamília Doradinae é diagnosticada por: divertículos laterais na bexiga natatória (\#44, ausentes em Rhinodoras thomersoni, Rhynchodoras, "Petalodoras" punctatus, Leptodoras oyakawai e na maioria das espécies de Doras); serra na margem posterior do acúleo da nadadeira dorsal (\#258, condição também presente em "Platydoradinae"); oito raios ramificados no lobo ventral da nadadeira caudal (\#323, 
condição também presente em "Platydoradinae"); paripural livre dos hipurais $1+2$ (\#327, condição também presente em "Platydoradinae"); sétima vértebra parcialmente fusionada à vértebra complexa (\#229, condição também presente em Astrodoradinae e "Platydoradinae"); seis raios ramificados na nadadeira pélvica (\#288, condição também presente em Astrodoradinae e "Platydoradinae").

Táxons incluídos: Pterodoras, Lithodoras, Doraops, Centrodoras, Megalodoras, Rhynchodoras, Rhinodoras, Orinocodoras, Oxydoras, "Petalodoras", Trachydoras, Doras, Hemidoras, Nemadoras, "Nemadoras", Hassar, Anduzedoras e Leptodoras.

Comentários: A subfamília Doradinae inclui a grande maioria das espécies da família, e, por isso, abrange uma grande variedade de formas. Isso faz com que poucas sejam as características que sirvam para diagnosticar o grupo como um todo. $\mathrm{O}$ arranjo adotado para a subfamília Doradinae, no presente estudo, é o mesmo de Higuchi (1992).

\section{Tribo "Pterodoradini"}

Diagnose: A tribo "Pterodoradini" é diagnosticada pelo grande porte (entre 300 e 1000 $\mathrm{mm}$ de $\mathrm{CP}$, condição também presente apenas em Oxydoras); bexiga natatória com câmara secundária com septo interno (\#40, condição também presente em Orinocodoras, Rhinodoras dorbignyi, R. thomersoni e Scorpiodoras), e divertículos laterais, presentes inclusive na câmara secundária (\#45); 15 a 25 escudos laterais (\#132, condição também presente em Agamyxis, Acanthodoras e Oxydoras niger); mais de 12 costelas (\#235, condição também presente em Wertheimeria, Kalyptodoras, e alguns exemplares de Platydoras e Oxydoras); oitava vértebra parcialmente fusionada à vértebra complexa (\#230, condição ausente em Centrodoras).

Táxons incluídos: Pterodoras, Lithodoras, Doraops, Centrodoras e Megalodoras.

Comentários: Esse agrupamento foi parcialmente corroborado no estudo de Higuchi 
(1992), que considerava Centrochir relacionado a esse grupo, chamando esse grupo, com a adição Centrochir, de Centrochirini.

\section{Pterodoras Bleeker, 1862}

Pterodoras Bleeker, 1862: 5 (espécie-tipo: Doras granulosus Valenciennes, por designação original).

Apuredoras Fernández-Yépez, 1950: 195 (espécie-tipo: Apuredoras rivasi FernándezYépez, por designação original).

Parapterodoras Risso \& Morra, 1964: 1 (espécie-tipo: Parapterodoras parnensis Risso \& Mora [=Doras granulosus Valenciennes], por designação original).

Sachsdoras Fernández-Yérpez, 1968: 66 (espécie-tipo: Sachsdoras apurensis Fernández-Yépez [=Apuredoras rivasi Fernández Yépez], por designação original).

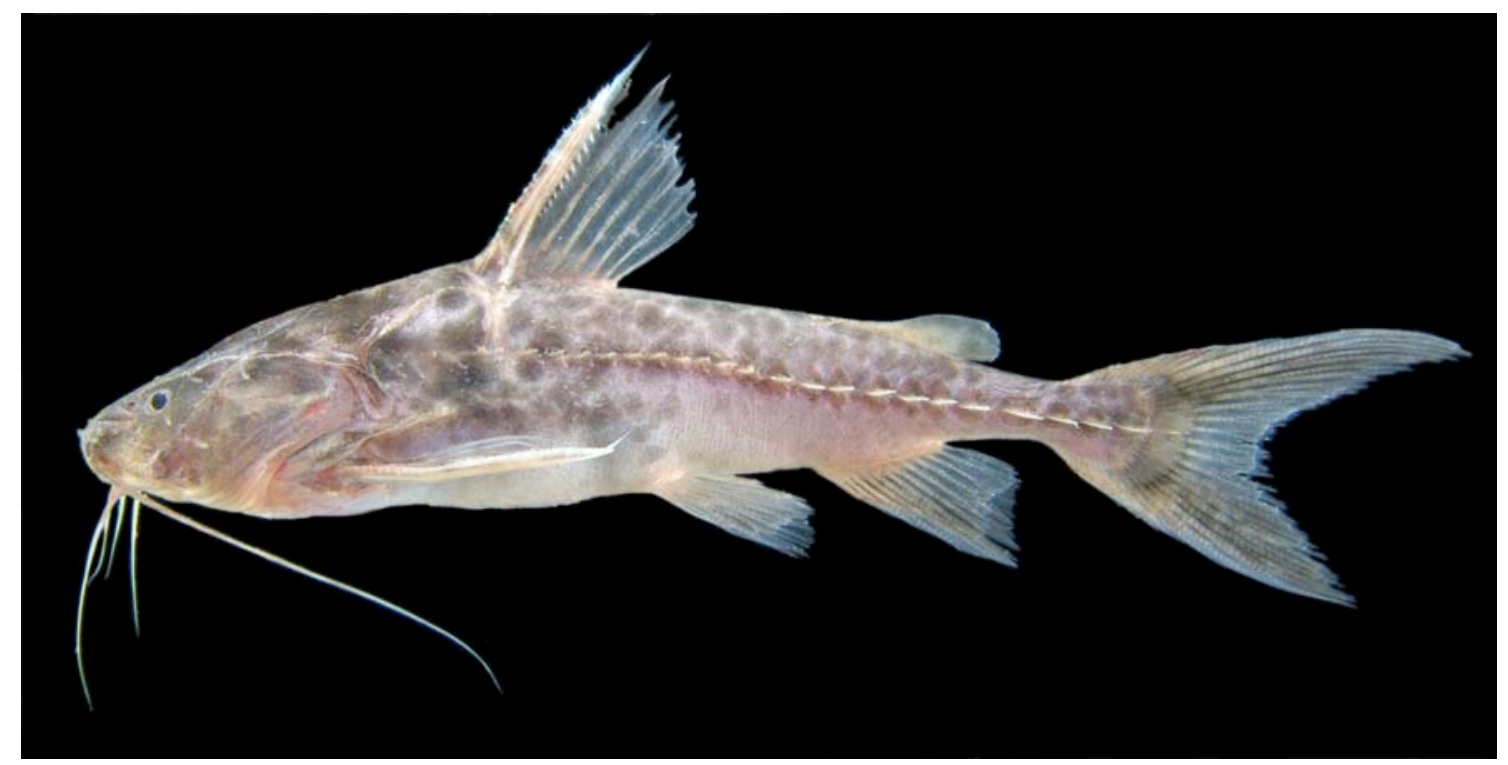

Figura 76. Pterodoras granulosus, INPA sem nº rio Solimões, Manaus, AM (foto de Leandro Sousa).

Diagnose: Pterodoras é diagnosticado por apresentar processo posterior do epoccipital predominantemente ossificado (\#96, condição também presente em Rhynchodoras, algumas espécies de Astrodoradinae e na grande maioria dos Doradini); porção exposta do processo posterior do cleitro estreita, em relação a altura total do processo (\#79); 
penúltimo e último infra-orbitais expandidos em placas (\#115, condição também presente em Lithodoras).

Táxons incluídos: Pterodoras granulosus e $P$. rivasi.

Comentários: $\mathrm{O}$ gênero Pterodoras possui duas espécies reconhecidas como válidas: $P$. rivasi, endêmica da bacia do rio Orinoco na Venezuela, e distinta por ter câmara secundária na bexiga natatória; e $P$. granulosus, amplamente distribuída pelas bacias dos rios Amazonas e Paraguai, e que possui a bexiga natatória com dois grandes divertículos posteriores. Os espécimes de Pterodoras granulosus da bacia do Paraguai são muito similares aos da bacia amazônica, exceto por apresentarem o escudo nucal (em corte transversal) ligeiramente mais angulado.

\section{Lithodoras Bleeker, 1862}

Lithodoras Bleeker, 1862: 5 (espécie-tipo: Doras lithogaster Kner [=Doras dorsalis Valenciennes], por designação original).

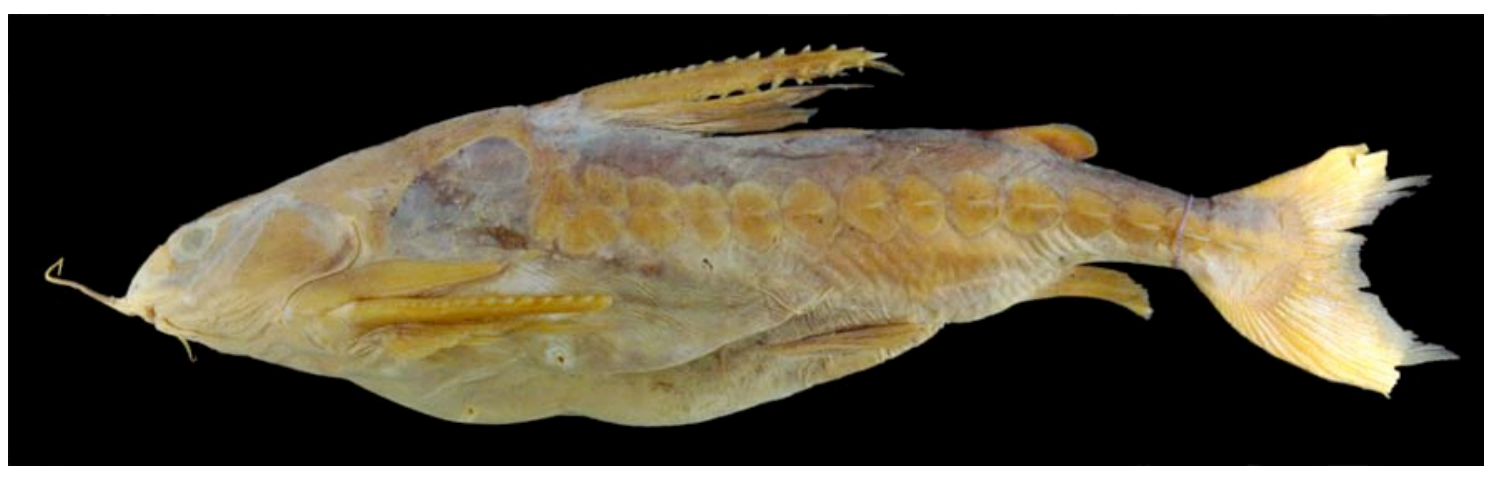

Figura 77. Lithodoras dorsalis, MZUSP 103889, 220 mm, Ilha do Marajó, PA.

Diagnose: Lithodoras dorsalis é diagnosticada por apresentar escudos ósseos cobrindo todo o corpo, em exemplares de médio a grande porte (\#34); o último raio indiviso da nadadeira anal modificado num espinho com serras anterior e posteriomente, em exemplares de grante porte (\#314); penúltimo e último infra-orbitais expandidos em placas (\#115, condição também presente em Pterodoras). 
Táxon incluído: Lithodoras dorsalis.

Comentários: Lithodoras dorsalis é uma espécie que ocorre amplamente nos trechos mais inferiores da bacia amazônica, sendo mais comum a leste de Santarém.

\section{Doraops Schultz, 1944}

Doraops Schultz, 1944: 270 (espécie-tipo: Doraops zuloagai Schultz, por designação original).

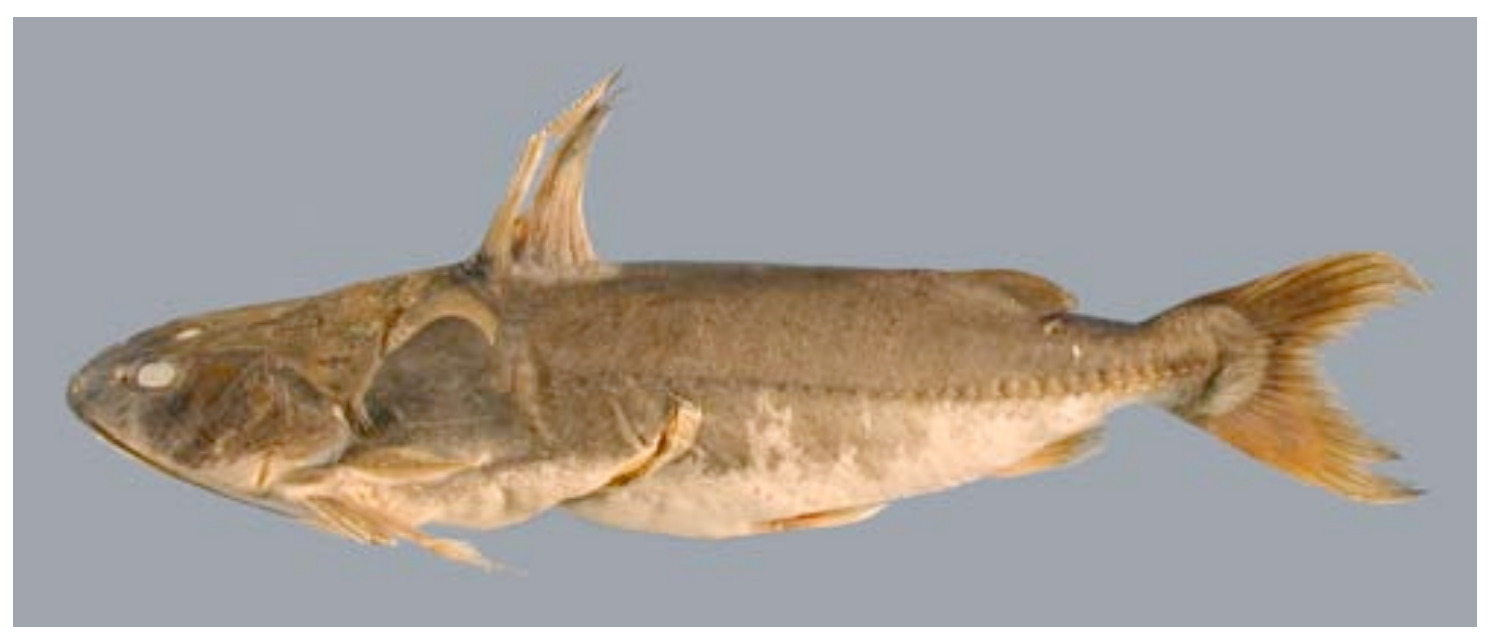

Figura 78. Doraops zuloagai, INHS 54804 (foto de Mark Sabaj Pérez).

Diagnose: Doraops zuloagai é diagnosticada por escudos ósseos laterais com desenvolvimento heterogêneo ao longo do corpo (\#127, condição também presente em Wertheimeria, Kalyptodoras, Hassar, Doras micropoeus, Nemadoras hemipeltis e "Nemadoras" leporhinus); e bexiga natatória com câmara secundária dividida na base (Birindelli et al., 2009).

Táxon incluído: Doraops zuloagai.

Comentários: Doraops zuloagai é uma espécie trans-andina, endêmica da bacia do Lago Maracaibo, na Venezuela. 
Megalodoras Eigenmann, 1925: 306 (espécie-tipo: Megalodoras irwini Eigenmann [=Doras unanoscopus Eigenmann \& Eigenmann], por designação original).

Hoplodoras Eigenmann, 1925: 310 (espécie-tipo Doras uranoscopus Eigenmann \& Eigenmann, por designação original).

Deltadoras Fernádez-Yépez, 1968: 36 (espécie-tipo: Deltadoras guayoensis FernándezYépez, por designação original).

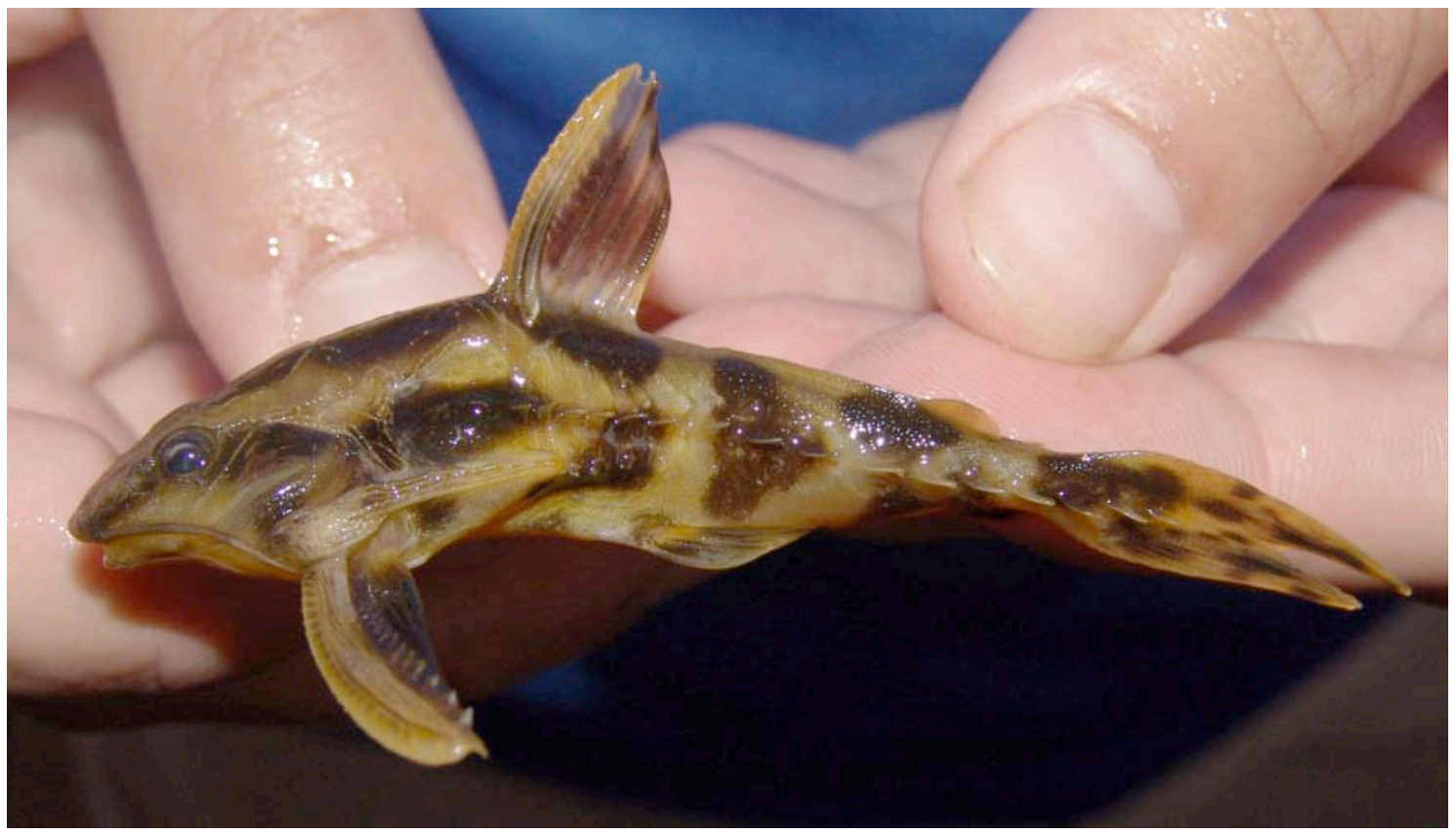

Figura 79. Megalodoras uranoscopus, MZUSP 92656, 66 mm, rio Tapajós, Itaituba, AM.

Diagnose: Megalodoras é diagnosticado pelo penúltimo infra-orbital expandido (\#115); 15 a 18 escudos laterais (\#132, condição também presente em Lithodoras); margem póstero-ventral do coracóide achatada ventralmente e coberta por pele fina (\#284).

Táxons incluídos: Megalodoras guayoensis e M. uranoscopus.

Comentários: M. uranoscopus (da bacia amazônica) e M. guayoensis (da bacia do rio Orinoco) diferem, segundo Sabaj (2002), por sutilezas do padrão de colorido.

\section{Centrodoras Eigenmann, 1925}

Centrodoras Eigenmann, 1925: 309 (espécie-tipo: Doras brachiatus Cope, por 
designação original).

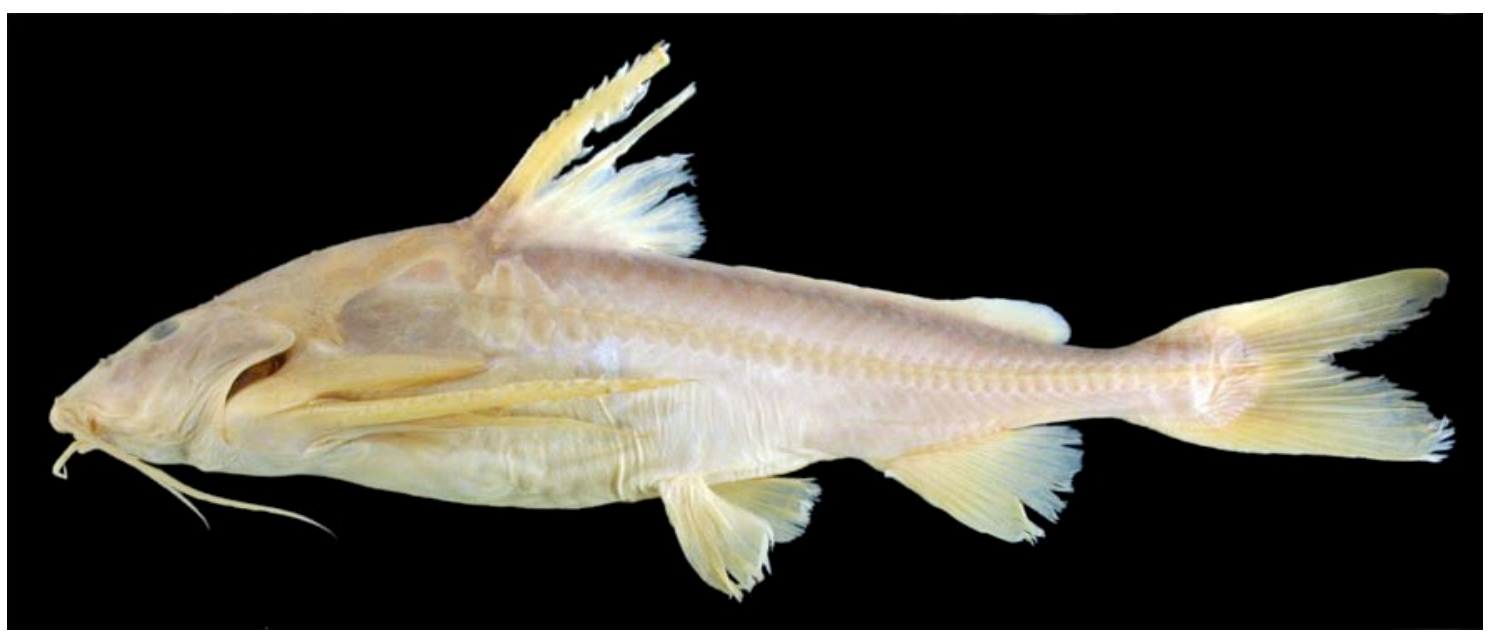

Figura 80. Centrodoras brachiatus, MZUSP 103891, 163 mm, rio Amazonas, Oriximiná, PA.

Diagnose: Centrodoras é diagnosticado por 30 a 40 escudos laterais (\#132); infraorbitais tubulares (não expandidos) (\#115, condição presente na maioria dos doradídeos).

Táxons incluídos: Centrodoras brachiatus e C. hasemani.

Comentários: Centrodoras brachiatus é uma espécie amplamente distribuída na bacia amazônica, exceto na bacia do rio Negro, enquanto que C. hasemani é aparentemente restrita à bacia do rio Negro. As duas espécies podem ser diferenciadas pelo número de escudos laterais (ver tabela 1) e pela morfologia da bexiga natatória (Birindelli et al., 2009).

\section{Tribo "Rhinodoradini"}

Diagnose: A tribo "Rhinodoradini" é diagnosticada pelo mesetmóide com ramos anteriores coalescidos (\#63); autopalatino alcançando posteriormente o meio da órbita (\#156); crista presente no hiomandibular para inserção da seção Aw do músculo adductor mandibulae (\#163); processo posterior do cleitro triangular (\#279); raios procorrentes da nadadeira caudal modificados em placas (fulcra) (\#318, condição 
também presente em Franciscodoras, Agamyxis e Platydoras).

Táxons incluídos: Rhynchodoras, Rhinodoras, Orinocodoras.

Comentários: O arranjo usado no presente estudo para tribo "Rhinodoradini" é o mesmo encontrado por Higuchi (1992).

\section{Rhynchodoras Klausewitz \& Rössel, 1961}

Rhynchodoras Klausewitz \& Rössel, 1961: 45 (espécie-tipo: Rhynchodoras xingui Klausewitz \& Rössel, por designação original).

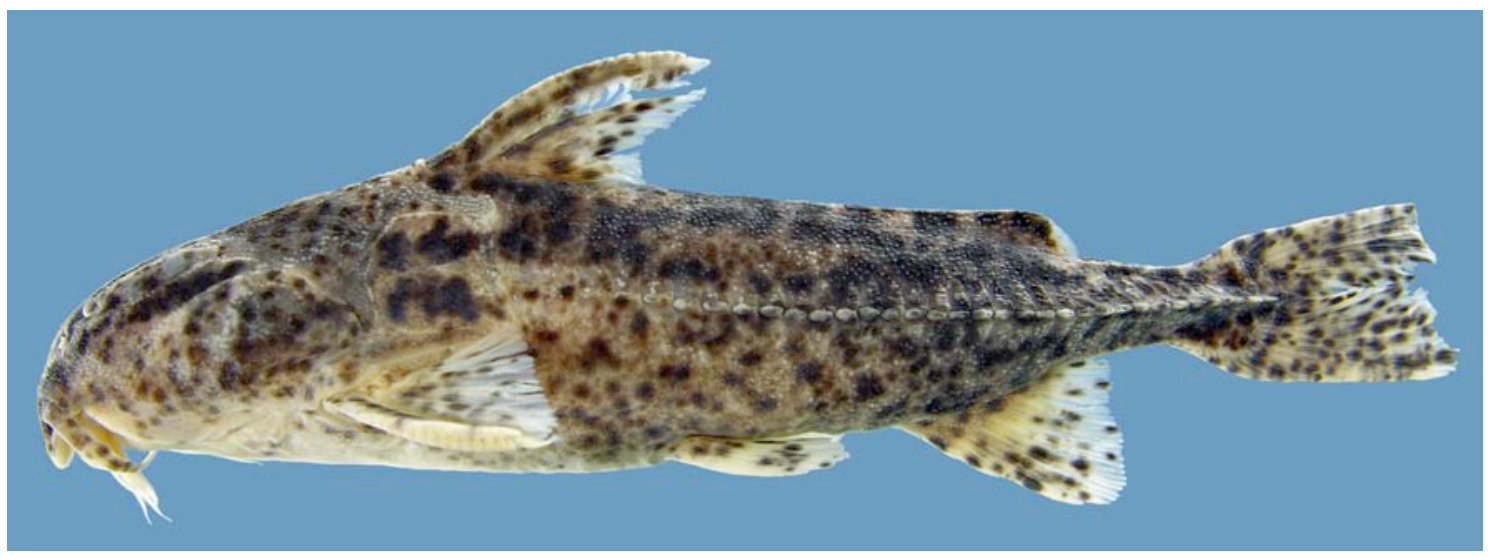

Figura 81. Rhynchodoras castilloi, MCNG 54510, $79.8 \mathrm{~mm}$, holótipo, Caño Bravo (tributário do rio Apure), Barinas, Venezuela (foto de Mark Sabaj Pérez).

Diagnose: Rhynchodoras é diagnosticado por uma série de caracteres exclusivos: barbilhões mentonianos unidos na base (\#21); bexiga natatória reduzida em tamanho e com um par de divertículos posteriores sem constrição basal (\#35, \#41); arco mandibular modificado em forma de bico orientado ventralmente (\#133); placa nucal anterior ausente (\#242, condição também presente em "Nemadoras" trimaculatus, "Nemadoras" ternetzi e Nemadoras humeralis); crista no coracóide que delimita os músculos abductor superficialis e arrector ventralis ausente (\#285).

Táxon incluído: Rhynchodoras castilloi, R. woodsi e R. xingui.

Comentários: O gênero Rhynchodoras foi revisado recentemente (Birindelli et al., 
2007).

\section{Rhinodoras Bleeker, 1862}

Rhinodoras Bleeker, 1862: 5 (espécie-tipo: Doras (Oxydoras) dorbignyi Kner, por designação original).

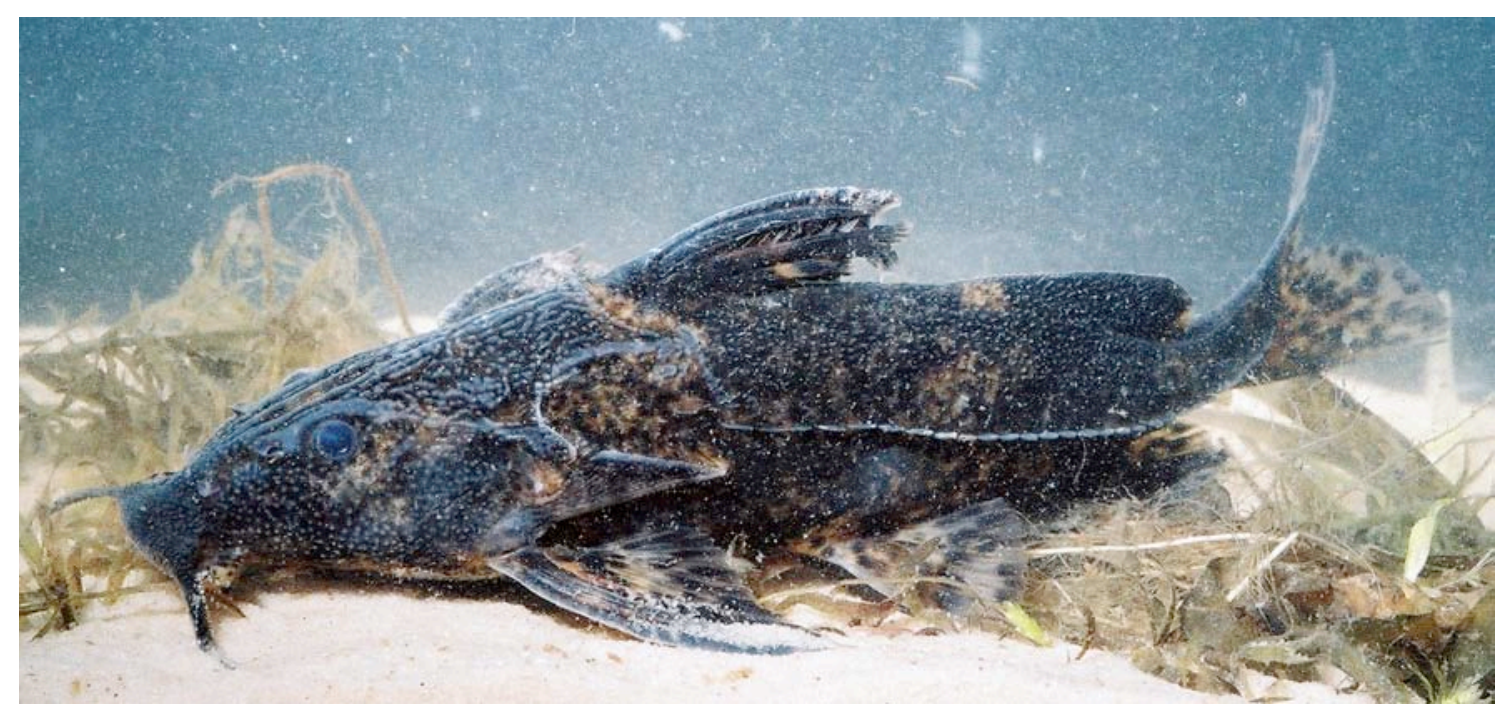

Figura 82. Rhinodoras cf. boehlkei, MZUSP 86808, 99 mm, rio Curisevo, Gaúcha do Norte, MT (foto de Cézar Nolasco).

Diagnose: Rhinodoras é diagnosticado pelo corpo amarronzado com manchas escuras; estrias nos barbilhões (\#15, condição presente também em Orinocodoras eigenmanni); lábios grossos com projeções látero-posteriores (\#183, condição presente também em Orinocodoras eigenmanni); superfície ventral da bexiga natatória com pregas (\#43, condição presente também em Orinocodoras eigenmanni); lamelas branquiais presentes no epibranquial como um lobo carnoso (\#188, condição presente também em Orinocodoras eigenmanni); primeira vértebra expandida lateralmente (\#208, condição presente também em Orinocodoras eigenmanni).

Táxons incluídos: Rhinodoras armbrusteri, R. boehlkei, $R$. dorbignyi, R. gallagheri e $R$. thomersoni. 
Comentários: O gênero Rhinodoras foi recentemente revisado (Birindelli, 2006) e duas espécies foram descritas (Sabaj et al., 2008). Apesar de Rhinodoras thomersoni e $R$. dorbignyi serem espécies de fácil identificação, a identificação de espécimes das bacias dos rios Amazonas, Orinoco e Essequibo é difícil e ainda há dúvidas quanto a validade das espécies recentemente descritas para essas drenagens.

\section{Orinocodoras Myers, 1927}

Orinocodoras Myers, 1927: 124 (espécie-tipo: Orinocodoras eigenmanni Myers, por designação original).

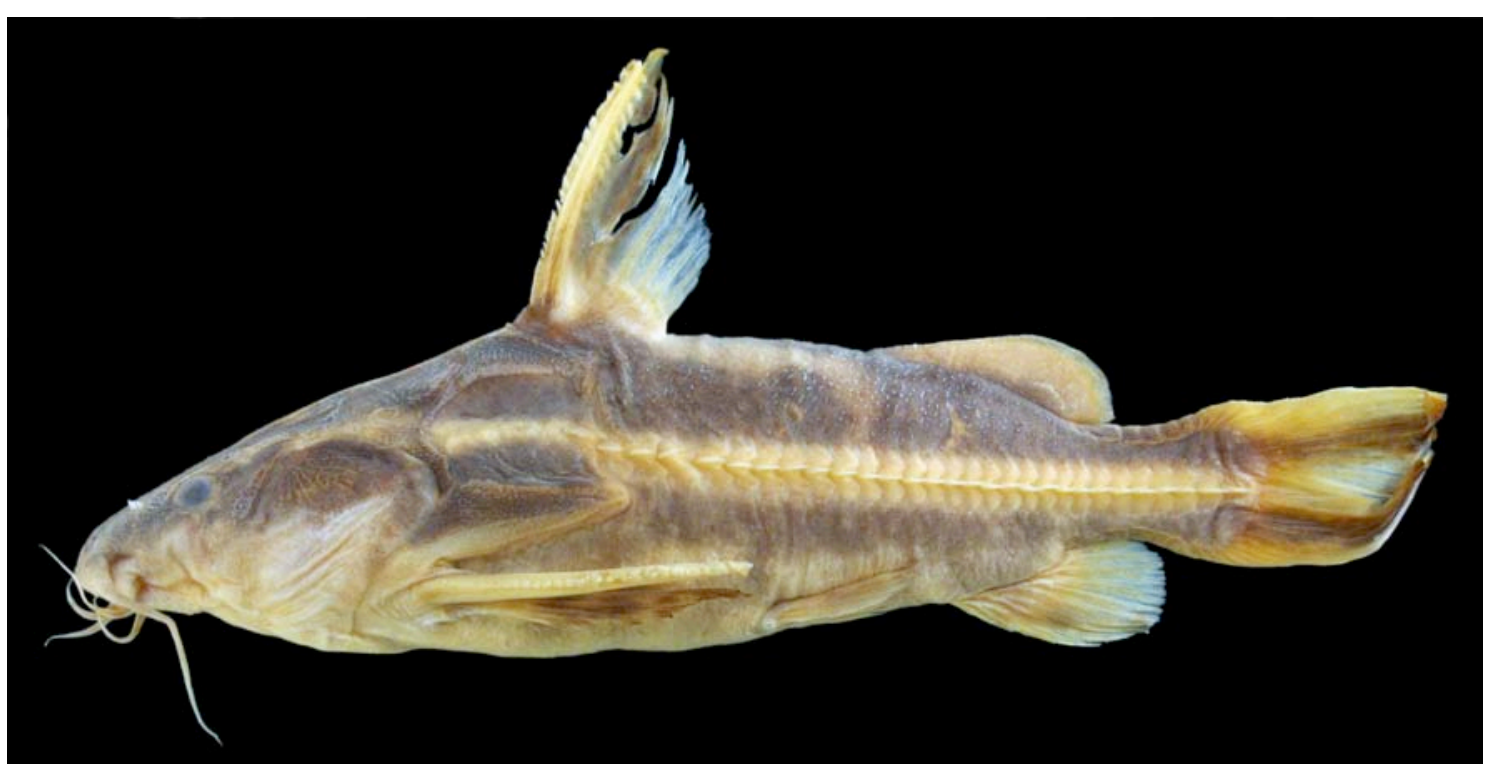

Figura 83. Orinocodoras eigenmanni, MZUSP 86807, 123 mm, rio Apure, Arismendi, Venezuela.

Diagnose: Orinocodoras eigenmanni é diagnosticada pelo corpo preto com uma faixa clara (amarelada em vida, semelhante às espécies de Platydoras); último infra-orbital expandido (\#118); lábios grossos com projeções látero-posteriores (\#183, condição presente também em Rhinodoras); superfície ventral da bexiga natatória com pregas (\#43, condição presente também em Rhinodoras); lamelas branquiais presentes no epibranquial como um lobo carnoso (\#188, condição presente também em Rhinodoras); primeira vértebra expandida lateralmente (\#208, condição presente também em 
Rhinodoras).

Táxons incluídos: Orinocodoras eigenmanni.

Comentários: Orinocodoras eigenmanni é endêmica da bacia do rio Orinoco, na Venezuela.

\section{Tribo Doradini Bleeker, 1858}

Doradini Bleeker, 1858: 48 (criado para incluir todos os doradídeos conhecidos até então: Doras, Hemidoras e Pseudodoras).

Diagnose: A tribo Doradini é diagnosticada por diversos caracteres exclusivos: mesetmóide em forma de caneta tinteira, com dilatação mediana (\#60); mesetmóide com quilha ântero-ventral (\#65); processo trans-escapular ventralmente afilado, como uma lâmina (\#105); canal infra-orbital saindo pela porção porterior do esfenótico (\#119); pré-maxilar em forma de um cone com ápice dorsal (\#134); dentes reduzidos em número no pré-maxilar (\#137), e no dentário (\#150); hipo-hial ventral quadrangular, longo (\#180); lamelas acessórias presentes nos arcos branquiais (\#187, exceto em Trachydoras); basibranquial 4 com prolongamento posterior no processo ventral (\#194); quinto cerato-branquial pedunculado, com dentes distantes da extremidade anterior (\#199); placa dentígera faringo-branquial alongada (\#207); margem posterior do coracóide expandida dorsalmente, formando um diafragma ósseo (\#283).

Táxons incluídos: Oxydoras, "Petalodoras", Trachydoras, Doras, Hemidoras, Nemadoras, "Nemadoras", Hassar, Anduzedoras e Leptodoras.

Comentários: O clado 164, composto pelos doradídeos de barbilhões fimbriados (ou seja, Doradini exceto Oxydoras) também é diagnosticado por uma série grande de sinapomorfias: nadadeira adiposa em forma de gota (\#4, condição também presente em Astrodoradinae, Agamyxis e Acanthodoras); barbelas na face ventral do barbilhão 
maxilar (\#11); barbilhões mentonianos de comprimentos semelhantes (\#18); vômer em forma de I (\#84); epoccipital participando da margem lateral do escudo cefálico (\#95); canal sensorial mandibular com apenas 2 a 3 poros (\#122); escudos laterais inclinados, em relação ao eixo do corpo (\#129); expansão mediana do hiomandibular ausente (\#160); contato entre hiomandibular e metapterigóide ausente (\#171); ramo de Müller compacto e cônico (\#219). A tribo Doradini e o clado dos doradídeos de barbilhões fimbriados são os dois grupos suportados por mais sinapomorfias, no presente estudo. $\mathrm{O}$ conceito usado no presente estudo para a tribo Doradini é o mesmo de Higuchi (1992).

\section{Oxydoras Kner, 1855}

Oxydoras Kner, 1855: 115 (espécie-tipo: Doras niger Valenciennes, por designação subseqüente de Eigenmann \& Eigenmann, 1890: 246).

Pseudodoras Bleeker, 1858: 53 (espécie-tipo: Doras niger Valenciennes, por designação subseqüente de Jordan, 1919: 278).

Hildadoras Fernández-Yépez, 1968: 41 (espécie-tipo: Hildadoras orinocensis [=Oxydoras sifontesi Fernández-Yépez], por designação original).

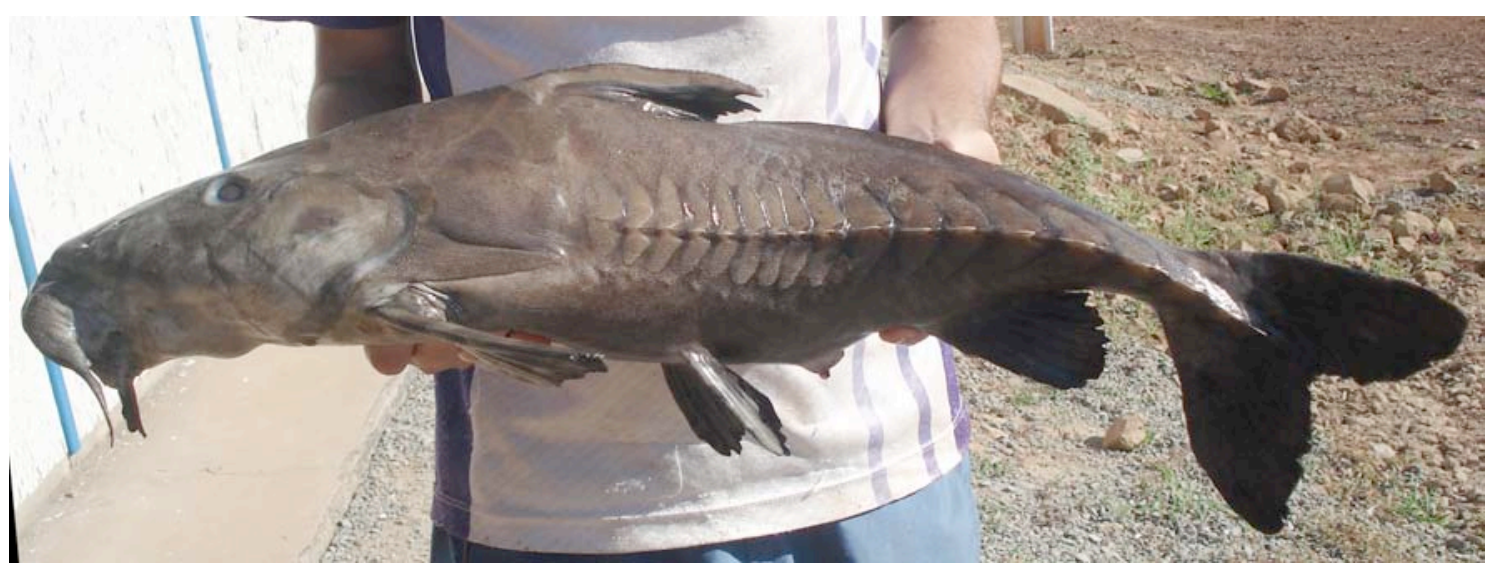

Figura 84. Oxydoras niger, MZUSP 94967, c.750 mm, rio Culuene, Paranatinga, MT.

Diagnose: Oxydoras é diagnosticado pelo grande porte, alcançando até aproximadamente $1000 \mathrm{~mm}$ de CP (condição similar ocorre em "Pterodoradini”); 
bexiga natatória com câmara secundária sem septo interno (\#40, condição também presente em Platydoras e algumas espécies de Doras); fontanela posterior pequena, quase completamente fechada (\#68, condição também presente em Nemadoras elongatus e $N$. humeralis); etmóide lateral excluído da margem orbital (\#76); dentes ausentes no pré-maxilar (\#137, condição também presente em espécies de Trachydoras, Doras, Hemidoras, Nemadoras, "Nemadoras", Anduzedoras e Leptodoras) e no dentário (\#150, condição também presente em Trachydoras, Hemidoras morei, $H$. morrisi, Leptodoras marki e L. oyakawai).

Táxons incluídos: Oxydoras kneri, O. niger e O. sifontesi.

Comentários: Três espécies de Oxydoras são reconhecidas como válidas: Oxydoras kneri, da bacia do rio Paraguai, com mais escudos laterais que as congêneres e sem o nódulo óssea na parapófise da quinta vértebra; $O$. niger da bacia amazônica, e $O$. sifontesi, da bacia do rio Orinoco. As duas últimas são extremamente semelhantes e talvez sejam sinônimas, como havia proposto Higuchi (1992).

\section{"Petalodoras" Higuchi, 1992}

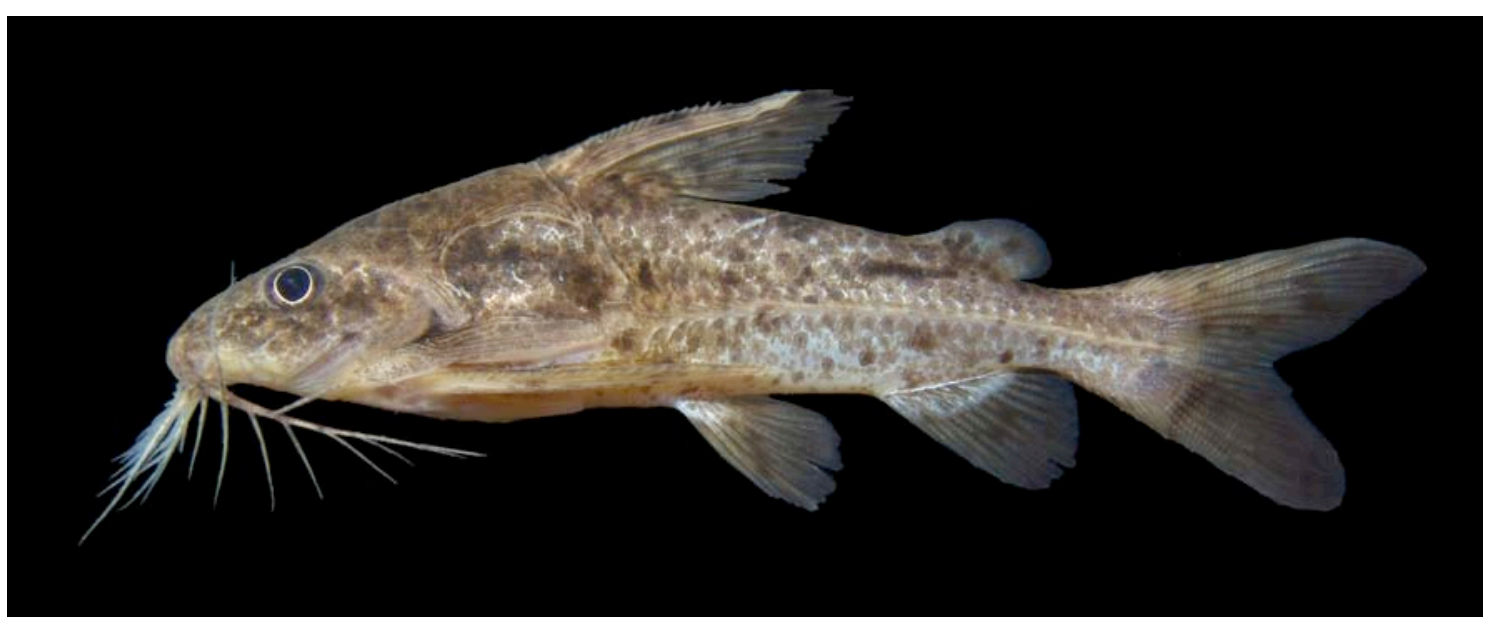

Figura 85. "Petalodoras" aff. eigenmanni, MZUSP 92783, c.60 mm, rio Solimões, Manaus, AM (foto de Leandro Sousa). 
Diagnose: "Petalodoras" é diagnosticado por um conjunto de caracteres não exclusivos: processo posterior do coracóide grande e coberto por pele fina (\#282, condição também presente em Trachydoras paraguayensis e algumas espécies de Astrodoradinae); margem póstero-ventral do coracóide achatada ventralmente e coberta por pele fina (\#284, condição também presente em Trachydoras steindachneri, Hemidoras, Megalodoras e Astrodoradinae); múltiplos poros imediatamente ventrais ao processo posterior do cleitro ausentes (\#31, condição presente também em Oxydoras, Hemidoras, e em algumas espécies de Leptodoras, entre os Doradini); quilha ventral do assoalho do crânio arredondada (\#89, condição presente em Oxydoras e algumas espécies de Leptodoras, entre os Doradini); 'endopterigóide' menor do que o metapterigóide (\#172, condição presente apenas em Oxydoras, entre os Doradini).

Táxons incluídos: "Petalodoras" eigenmanni, "Petalodoras" fimbriatus e "Petalodoras" punctatus.

Comentários: Higuchi (1992) considerou três espécies, originalmente descritas em Doras e Oxydoras, como pertencentes a um gênero novo, "Petalodoras", relativamente basal na tribo Doradini. Sabaj \& Ferraris (2003) consideraram essas três espécies como incertae sedis em Doradidae. A descrição do gênero, revisão das espécies "Petalodoras" eigenmanni, "Petalodoras" fimbriatus, "Petalodoras" punctatus, e descrição de uma nova espécie congenérica ("Petalodoras" aff. eigenmanni), previamente diagnosticada por Birindelli et al. (2009), está em preparação por Birindelli \& Sabaj Pérez.

\section{Trachydoras Eigenmann, 1925}

Trachydoras Eigenmann, 1925: 337 (espécie-tipo: Trachydoras atripes [=Trachydoras steindachneri Perugia], por designação original). 


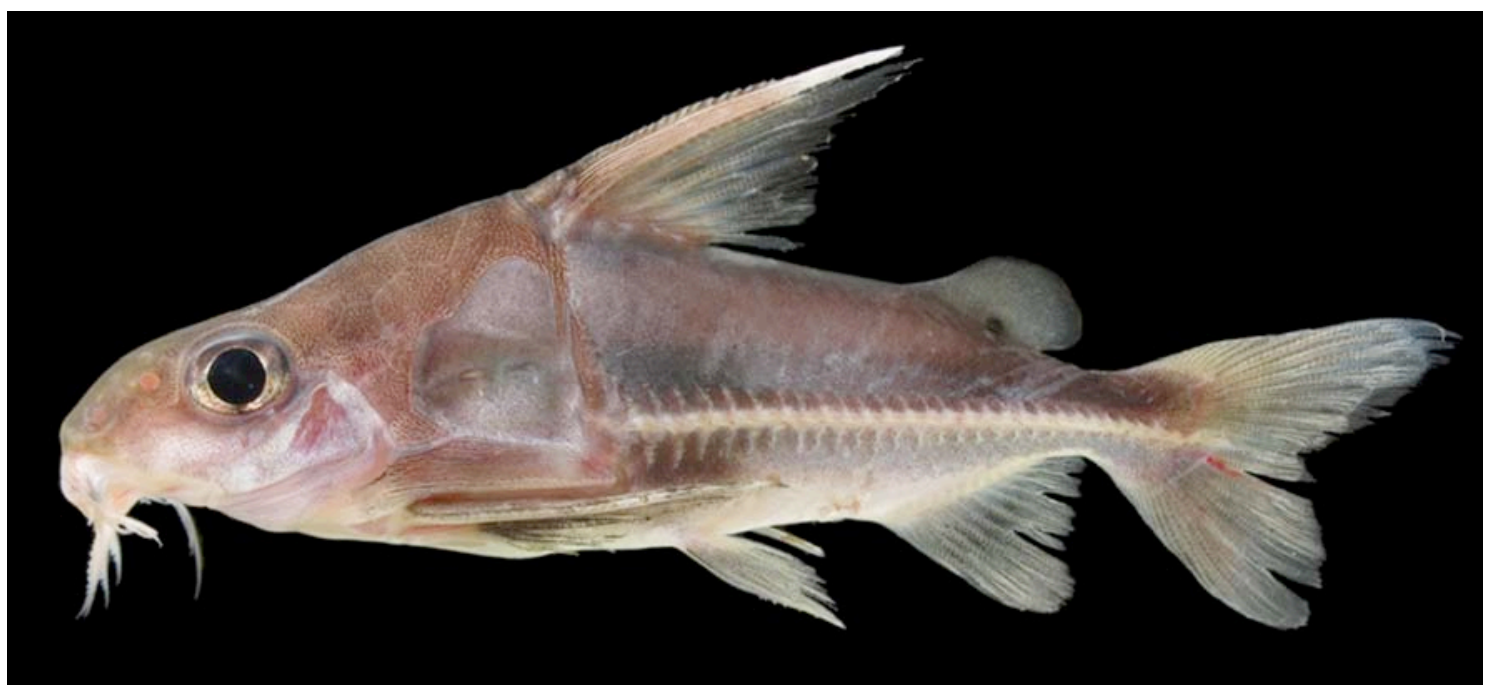

Figura 86. Trachydoras brevis, MZUSP 104775, c.85 mm, rio Jari, Monte Dourado, PA.

Diagnose: Trachydoras é diagnosticado por uma série de caracteres exclusivos: boca distintamente ventral; basioccipital com um processo ventral laminar (\#92); infra-orbital 1 ventralmente suturado ao mesetmóide (\#113); quilha ântero-ventral do mesetmóide presente como um processo ventral (\#65); lamelas branquiais ausentes (\#187, exclusivo em Doradini); rastros branquiais ausentes (\#189); extremidade do processo ventral do basibranquial 4 tripartida (\#195); e por alguns caracteres não exclusivos: bexiga natatória com divertículos terminais distalmente separados (\#39, condição presente também em "Petalodoras" punctatus e Doras zuanoni); fontanela posterior grande (\#68; condição presente também em "Nemadoras", Hassar, Anduzedoras e Leptodoras); margem anterior da cintura peitoral alongada anteriormente, com margens convergentes e extremidade afilada (\#262, condição também presente em algumas espécies de Leptodoras).

Táxons incluídos: Trachydoras brevis, T. microstomus, T. nattereri, T. paraguayensis e T. steindachneri.

Comentários: As espécies de Trachydoras podem ser diferenciadas pelo grau de expansão do infra-orbital 1: não expandido em T. microstomus e T. brevis, ligeiramente 
expandido em T. nattereri e bem expandido em T. paraguayensis e T. steindachneri; pelo comprimento do processo posterior do coracóide: curto, coberto por pele espessa em T. microstomus, ligeiramente longo e coberto por pele fina em T. brevis, T. nattereri e T. steindachneri, e longo (tão longo quanto o do cleitro) e coberto por pele fina em $T$. paraguaynesis, pelo crânio alto (perfil côncavo) em $T$. brevis, $T$. natereri e $T$. paguayensis, e pelo interopérculo coberto por pele fina (visualmente exposto) em $T$. steindachneri.

\section{Doras Lacepède, 1803}

Doras Lacepède, 1803: 116 (espécie-tipo: Silurus carinatus Linnaeus, por designação subseqüente de Bleeker, 1862).

Mormyrostoma Miranda Ribeiro, 1911: 192 (espécie-tipo: Silurus carinatus Linnaeus, por designação original).

Mormyropsis Miranda Ribeiro, 1911: 436 (nome em substituição a Mormyrostoma e, portanto, com a mesma espécie-tipo).

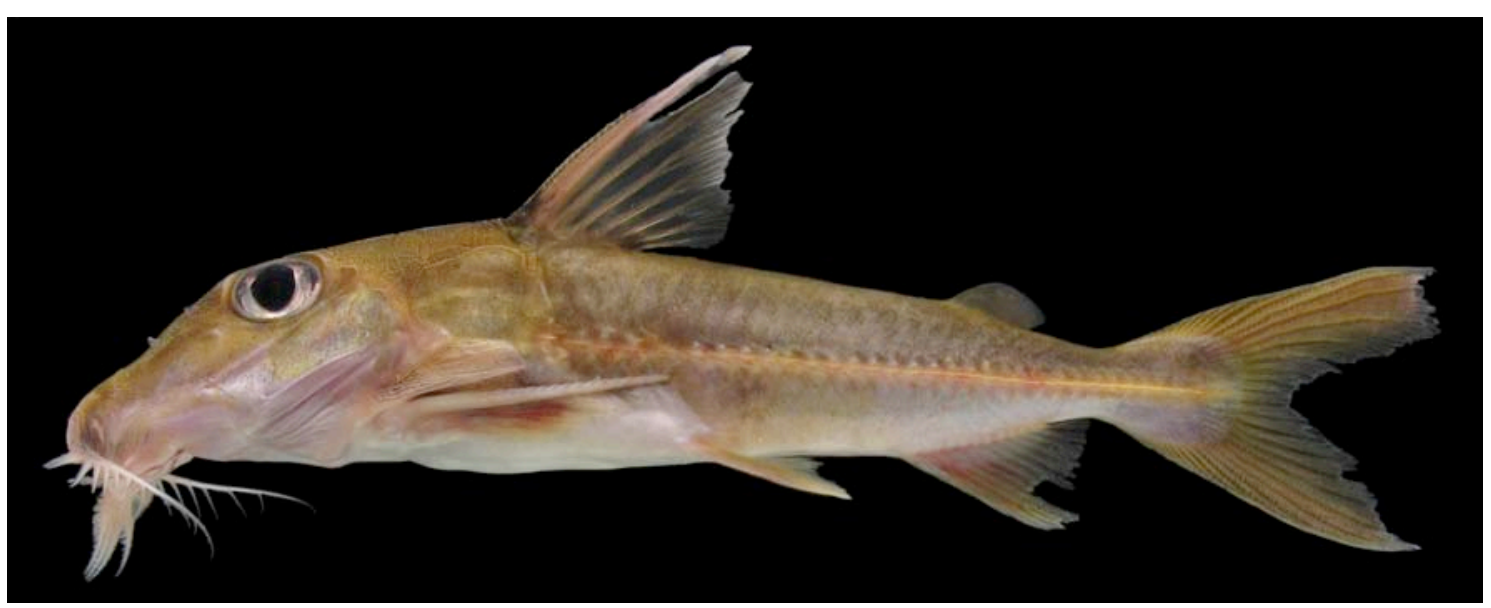

Figura 87. Doras higuchii, MZUSP 103459, c.120 mm, rio Jari, Monte Dourado, PA.

Diagnose: Doras é diagnosticado pelos múltiplos poros na parte ventral do corpo (\#32);

e por um conjunto de características não exclusivas: mesetmóide longo (\#61, condição 
presente também em Hemidoras, Nemadoras, "Nemadoras", Hassar, Anduzedoras e Leptodoras); forame nucal ausente (\#241, condição presente apenas em Oxydoras, "Petalodoras" punctatus, Trachydoras e algumas espécies de Leptodoras, entre Doradini); contato entre placa nucal mediana e parieto-supra-occipital ausente (\#246, condição presente apenas em Oxydoras, "Petalodoras" punctatus, Trachydoras e algumas espécies de Leptodoras, entre Doradini).

Táxons incluídos: Doras carinatus, D. higuchii, D. micropoeus, D. phlyzakion e D. zuanoni.

Comentários: Sabaj Pérez \& Birindelli (2008) recentemente revisaram o gênero Doras, re-descrevendo $D$. cariantus, D. micropoeus, e descrevendo três espécies como novas: D. higuchii, D. phlyzakion e D. zuanoni.

\section{Hemidoras Bleeker, 1858}

Hemidoras Bleeker, 1858: 53 (espécie-tipo: Doras (Oxydoras) stenopeltis Kner, por monotipia).

Opsodoras Eigenmann, 1925: 348 (espécie-tipo: Opsodoras orthacanthus Eigenmann [=Opsodoras stubelii Steindachner $]$ ).

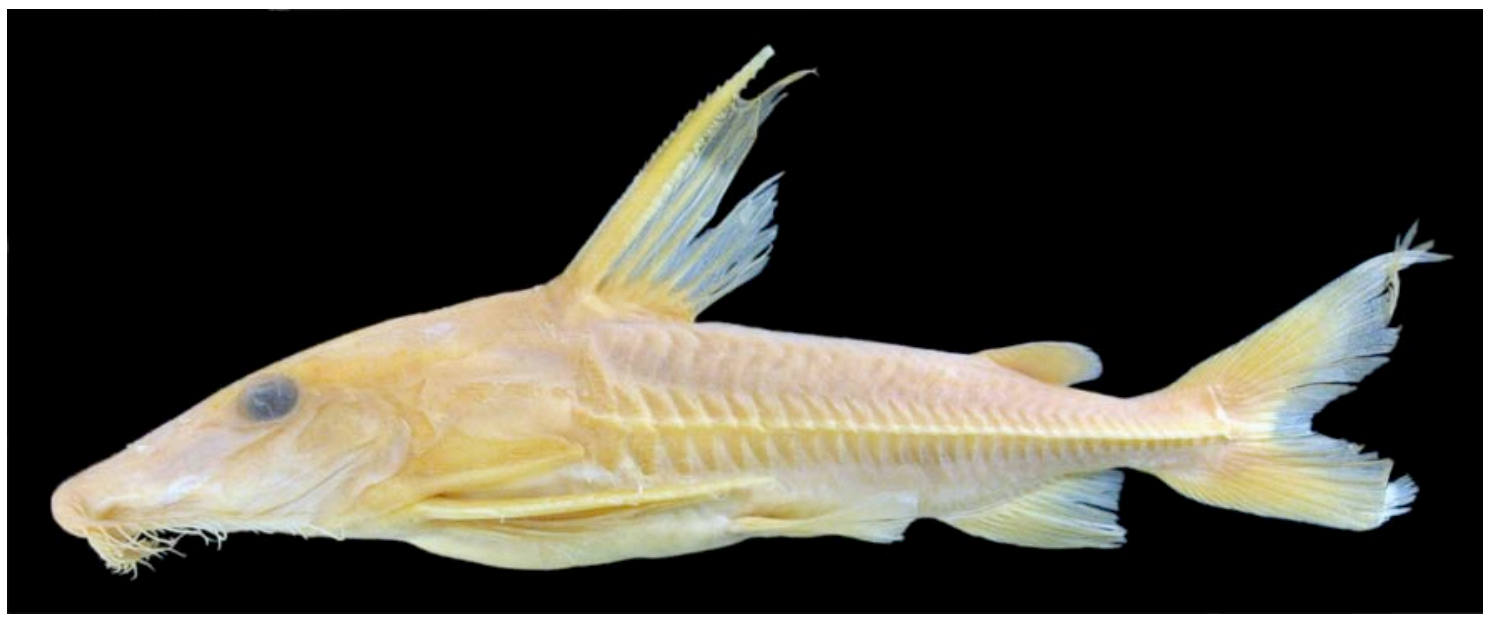

Figura 88. Hemidoras morei, MZUSP 56165, 139 mm, rio Negro, AM. 
Diagnose: Hemidoras é diagnosticado por apresentar duas fileiras de barbelas nos barbilhões mentonianos (\#17, condição também presente em "Petalodoras" fimbriatus); processo posterior do cleitro alongado, baixo e afilado posteriormente (\#279, condição também presente apenas em Oxydoras, entre Doradini); margem póstero-ventral do coracóide achatada ventralmente e coberta por pele fina (\#285, condição também presente em "Petalodoras" e Trachydoras steindachneri); múltiplos poros imediatamente ventrais ao processo posterior do cleitro ausentes (\#31, condição também presente em Oxydoras, "Petalodoras" e espécies de Leptodoras, entre Doradini).

Táxons incluídos: Hemidoras boulengeri, H. morei, H. morrisi, H. stenopeltis e $H$. stubelii.

Comentários: O presente estudo corroborou o estudo anterior (Birindelli, 2006), por considerar Hemidoras morrisi grupo irmão de H. morei, e desta forma, considerar Opsodoras um sinônimo júnior de Hemidoras. Além disso, H. boulengeri talvez seja um sinônimo de H. morei, o que precisa ser melhor estudado. As espécies de Hemidoras podem ser diferenciadas pela presença de escudos ósseos entre as nadadeiras dorsal e adiposa e entre o ânus e a nadadeira anal em H. stenopeltis e H. morrisi (em exemplares maiores do que $60 \mathrm{~mm}$ de CP), pela conspícua mancha escura na porção distal dos raios ramificados da nadeira dorsal em H. stenopeltis, e pelo focinho longo (diâmetro orbital 2.6 a 3.2 vezes no comprimento do focinho) em H. morrisi, H. morei e H. boulengeri.

\section{Nemadoras Eigenmann, 1925}

Nemadoras Eigenmann, 1925: 359 (espécie-tipo: Oxydoras elongatus Boulenger, por designação original). 


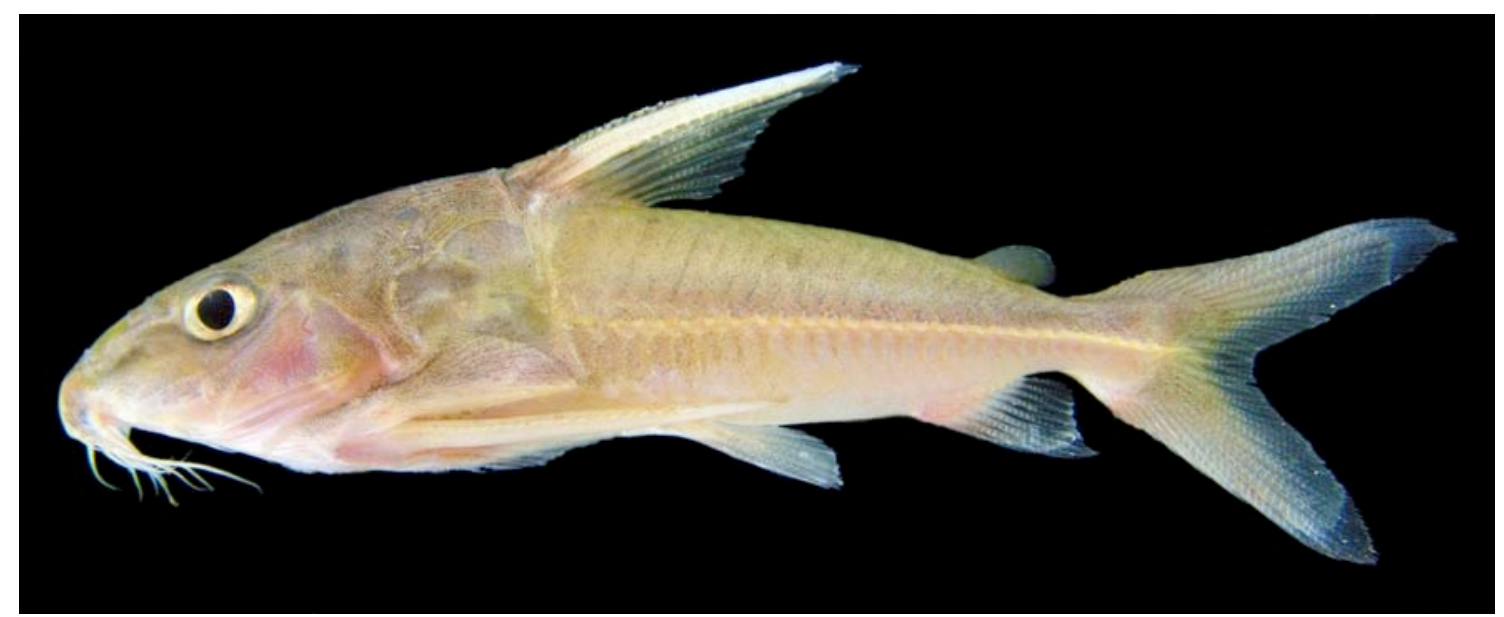

Figura 89. Nemadoras humeralis, INPA sem $n^{\circ}$, rio Solimões, Manaus, AM (foto de Leandro Sousa).

Diagnose: Nemadoras é diagnosticado por apresentar divertículos extremamente abundantes na bexiga natatória, presentes inclusive nas superfícies ventral e dorsal da bexiga (\#48); e por uma série de características não exclusivas: pálpebra adiposa pouco desenvolvida (\#1, condição também presente Oxydoras, "Petalodoras", Trachydoras e Doras, entre os Doradini); fontanela posterior presente, pequena ou grande (\#68, condição presente também em Oxydoras, Trachydoras, "Nemadoras", Hassar, Anduzedoras e Leptodoras); forame nucal grande (\#241, condição também presente em “Petalodoras" fimbriatus, "Nemadoras", Hassar e algumas espécies de Leptodoras).

Táxons incluídos: Nemadoras elongatus, N. hemipeltis e N. humeralis.

Comentários: O presente estudo corroborou o estudo anterior (Birindelli, 2006), no qual o gênero Nemadoras foi considerado como restrito a $N$. elongatus, $N$. hemipeltis e $N$. humeralis. As espécies de Nemadoras podem ser identificadas por: escudos laterais heterogeneamente desenvolvidos ao longo do corpo em N. hemipeltis, e placa nucal anterior ausente em $N$. humeralis.

\section{"Nemadoras"}




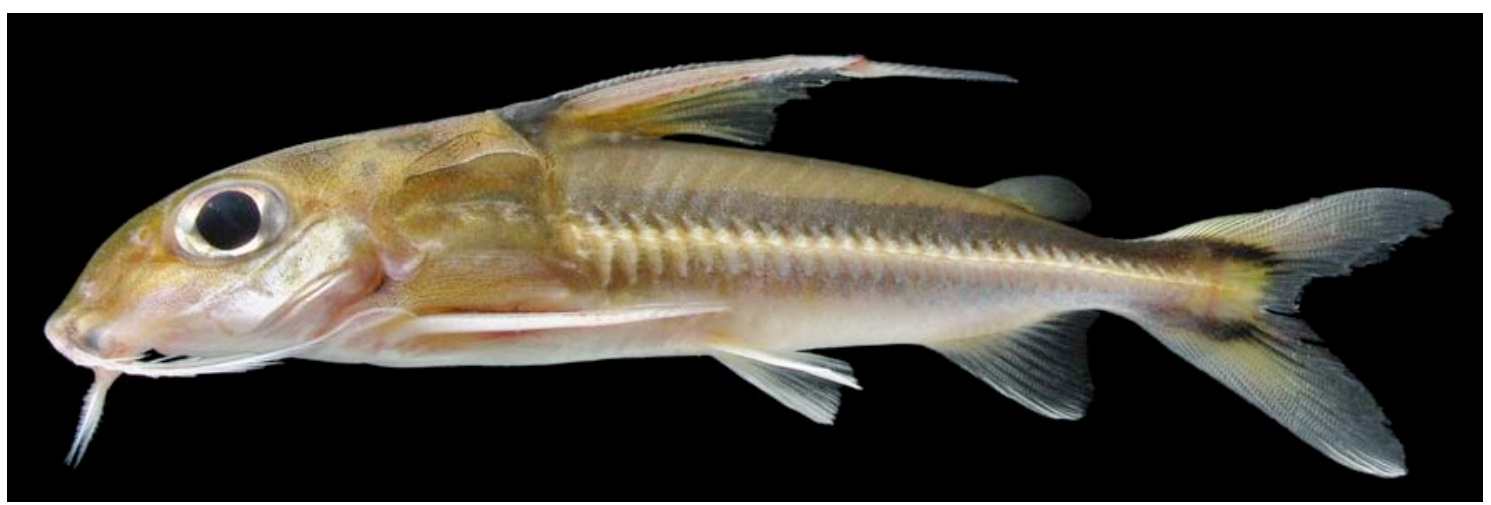

Figura 90. "Nemadoras" ternetzi, MZUSP 103245, 84.5 mm, rio Jari, Monte Dourado, PA.

Diagnose: "Nemadoras" é diagnosticado pelo corpo claro com uma faixa escura longitudinal imediatamente dorsal aos escudos laterais, e uma faixa escura longitudinal na porção mediana de cada lobo da nadadeira caudal; e por alguns caracteres não exclusivos: pálpebra adiposa bem desenvolvida (\#1, condição também presente em Hassar, Anduzedoras e algumas espécies de Leptodoras); fontanela posterior grande (\#68, condição também presente em Trachydoras, Nemadoras e Hassar); esfenótico com processo lateral (\#73, condição também presente em Doras, Hassar, Anduzedoras e Leptodoras); processo posterior do epoccipital não suturado à placa anucal posterir (\#97, condição também presente em Oxydoras, Trachydoras, "Petalodoras" e Nemadoras, entre Doradini); infra-orbital 1 com porção anterior gradualmente afilada (\#112; condição também presente em Oxydoras, Trachydoras, "Petalodoras", Nemadoras, Doras phlyzakion e D. zuanoni, entre Doradini); 2 fileiras de rastros branquiais nos arcos branquiais 3 e 4 (\#189, condição também presente em Oxydoras, Trachydoras, "Petalodoras", Nemadoras).

Táxons incluídos: "Nemadoras" trimaculatus, "Nemadoras" ternetzi e "Nemadoras" leporhinus.

Comentários: O presente estudo corroborou os resultados obtidos anteriormente (Birindelli, 2006), que apontavam as espécies Nemadoras trimaculatus, N. leporhinus e 
Opsodoras ternetzi, como mais relacionadas ao clado Hassar, Anduzedoras, Leptodoras do que a seus congêneres. Birindelli (2006) considerou "Nemadoras" um grupo monofilético suportado por um caráter de colorido: corpo claro com uma faixa escura longitudinal imediatamente dorsal aos escudos laterais, e uma faixa escura longitudinal na porção mediana de cada lobo da nadadeira caudal. Apesar desse caráter não ter sido incluído no presente estudo, ele parece ser consistente e sustentar o monofiletismo do grupo. As três espécies de "Nemadoras" podem ser facilmente diferenciadas pela mancha escura na base do acúleo da nadadeira dorsal em "Nemadoras" trimaculatus e "Nemadoras" leporhinus, mancha escura na trava (mas ausente no acúleo) da nadadeira dorsal em "Nemadoras" ternetzi, e escudos laterais com desenvolvimento heterogêneo ao longo do corpo em "Nemadoras" leporhinus. Há ainda uma espécie não descrita relacionada à esses táxons, ilustrada e identificada como Nemadoras aff. leporhinus por Sabaj (2002).

\section{Hassar Eigenmann \& Eigenmann, 1888}

Hassar Eigenmann \& Eigenmann, 1888: 158 (espécie-tipo: Oxydoras affinis Steindachner, por designação original).

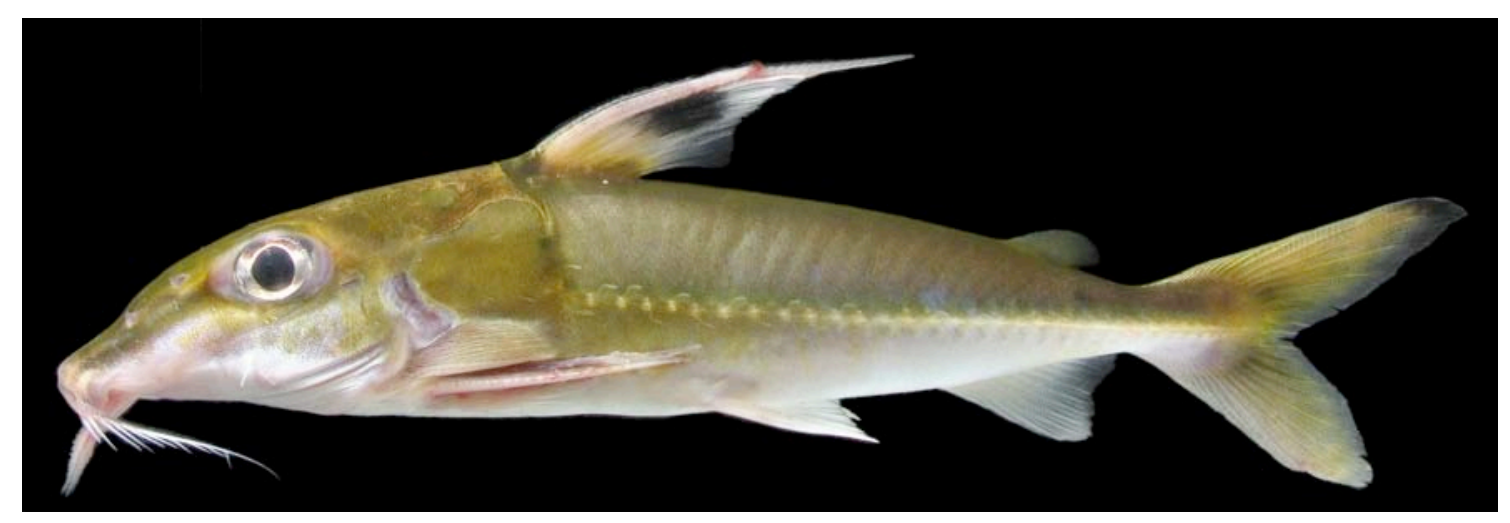

Figura 91. Hassar orestis, MZUSP 103327, 107.4 mm, rio Jari, Monte Dourado, PA.

Diagnose: Hassar é diagnosticado por possuir uma mancha escura na porção mediana 
ou distal dos raios ramificados da nadadeira dorsal (presente também em Leptodoras marki e L. hasemani); extensão ventral do basioccipital em forma de arco sob a artéria aorta (\#92); escudos laterais com desenvolvimento heterogêneo ao longo do corpo, sendo os anteriores reduzidos (\#128, condição também presente em Doras micropoeus e Nemadoras hemipeltis, entre Doradini).

Táxons incluídos: Hassar affinis, H. orestis e H. wilderi.

Comentários: A taxonomia das espécies do gênero Hassar ainda precisa ser melhor estudada. O exame do holótipo de Hassar iheringi Fowler indica que sua localidadetipo ("rio Parnahyba, Therezina") deve estar errada. Os exemplares de Hassar procedentes do nordeste (bacias dos rios Parnaíba, Mearim, Pindaré e Itapecuru), identificados como Hassar affinis (sendo $H$. woodi seu sinônimo júnior), possuem bexiga natatória sem divertículos laterais ( $v s$. divertículos presentes nos congêneres, ver Birindelli et al., 2009), e a mancha escura restrita à porção mais distal dos raios ramificados da nadadeira dorsal (vs. sobre a porção mediana dos raios ramificados da nadadeira dorsal nos congêneres). Já os exemplares procedentes das bacias Amazônica (incluindo Tocantins) e do Orinoco são extremamente similares entre si, e possivelmente pertençam a uma só espécie: Hassar orestis.

\section{Anduzedoras Fernández-Yépez, 1968}

Anduzedoras Fernández-Yépez, 1968: 28 (espécie-tipo: Anduzedoras arleoi FernándezYépez [=Doras oxyrhychus Valenciennes], por designação original). 


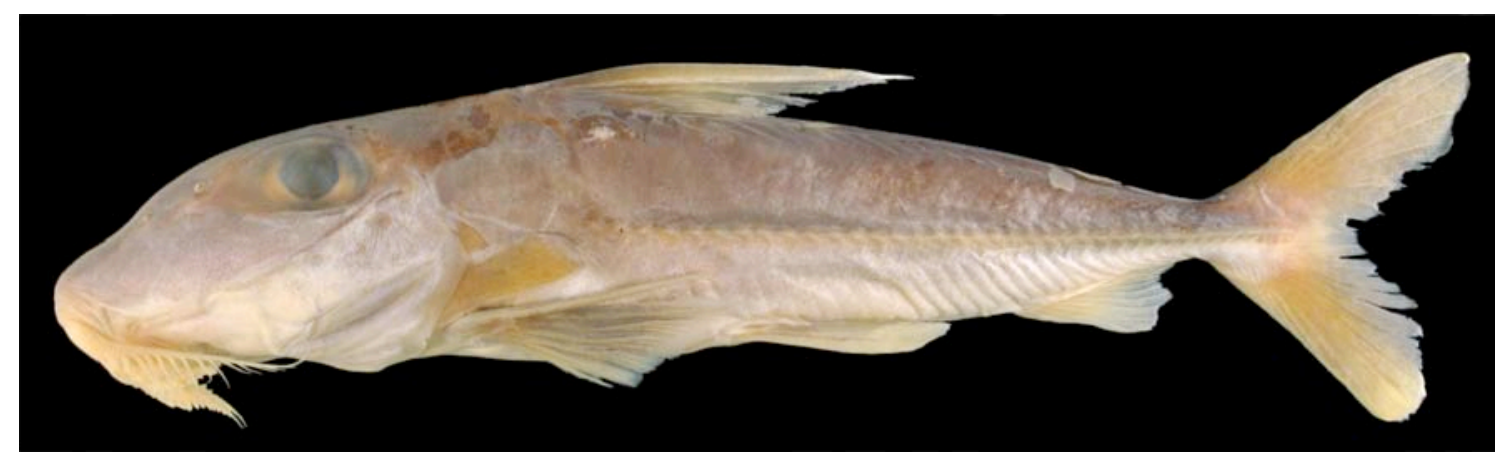

Figura 92. Anduzedoras oxyrhynchus, MZUSP 93443, 186 mm, rio Tiquié, AM.

Diagnose: Anduzedoras oxyrhynchus é diagnosticada por apresentar uma cápsula óssea curta sobre as primeiras vértebras, com abertura posterior grande (\#210); e por um conjunto de caracteres compartilhados apenas com espécies de Leptodoras: 39 a 40 escudos laterais (\#133); barbilhões fracamente unidos formando um capuz oral (\#7); 16 a 25 rastros branquiais no primeiro arco branquial (\#192); hipo-branquial 1 tubular (\#197); cápsula óssea sobre as primeiras vértebras (\#209); forame nucal presente em exemplares de pequeno porte, mas reduzido e quase completamente fechado em exemplares maiores (\#241).

Táxon incluído: Anduzedoras oxyrhynchus.

Comentários: Anduzedoras oxyrhynchus é uma espécie que ocorre nas águas negras dos rios Negro, Trombetas e Alto rio Orinoco.

\section{Leptodoras Boulenger, 1898}

Leptodoras Boulenger, 1898: 28 (espécie-tipo: Oxydoras acipenserinus Günther, por designação subseqüente de Eigenmann, 1910: 395). 


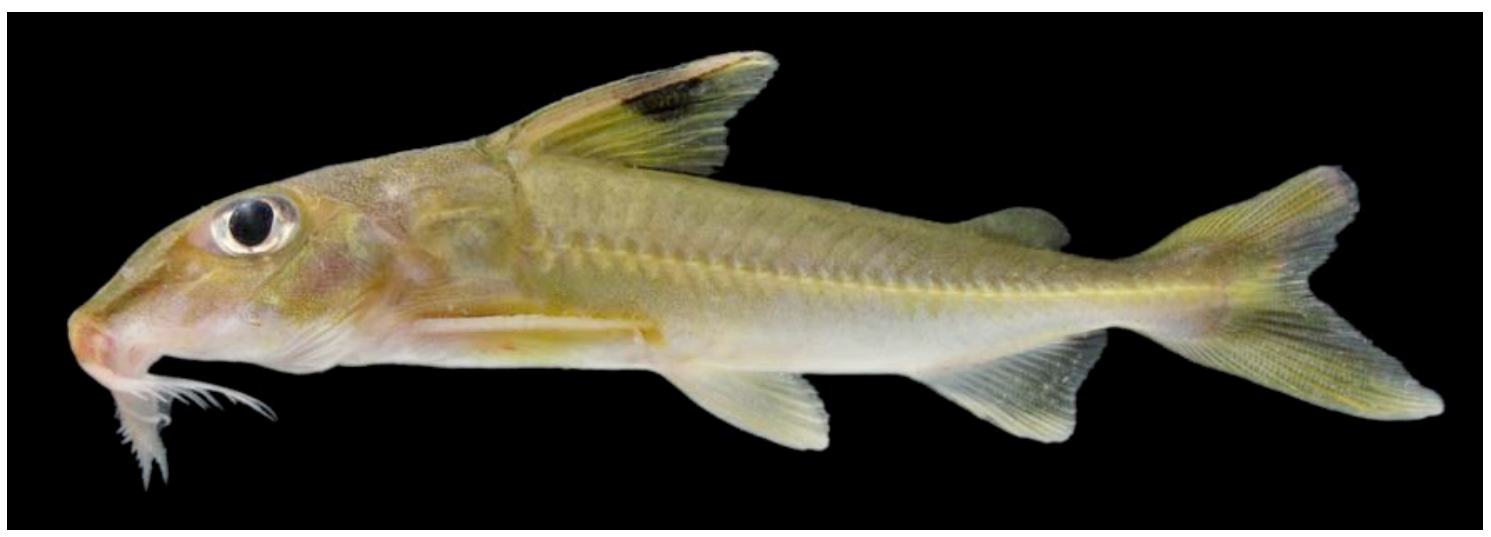

Figura 93. Leptodoras marki, MZUSP 103217, 80.3 mm, parátipo, rio Fresco, São Felix do Xingu, PA.

Diagnose: Leptodoras é diagnosticado por três caracteres exclusivos: lamelas branquiais acessórias estendidas sobre os filamentos branquiais (\#187); uma só fileira medial de dentes no quinto cerato-branquial (\#200); e cintura pélvica posicionada na metade anterior do corpo (\#287). Leptodoras é também diagnosticado por uma série de caracteres compartilhados apenas com Anduzedoras oxyrhynchus: barbilhões unidos formando um capuz oral (\#7); 16 a 25 rastros branquiais no primeiro arco branquial (\#192); hipo-branquial 1 tubular (\#197); cápsula óssea sobre as primeiras vértebras (\#208).

Táxons incluídos: Leptodoras acipenserinus, L. cataniai, L. copei, L. hasemani, L. juruensis, L. linnellii, L. myersi, L. marki, L. nelsoni, L. oyakawai, L. praelongus e L. rogersae.

Comentários: Esse é o gênero de doradídeo com maior número de espécies. Sabaj (2005) fez uma revisão taxonômica das espécies, descrevendo três delas como novas. Birindelli et al. (2009) descreveram Leptodoras oyakawai; e Birindelli \& Sousa (2010) descreveram Leptodoras marki. De acordo com esses autores e com o presente estudo, L. oyakawai e L. marki são grupos irmão de suas congêneres. 


\section{Família Auchenipteridae Bleeker, 1862 (figura 68)}

Diagnose: A família Auchenipteridae é diagnosticada pelas seguintes características exclusivas: fecundação interna através de inseminação; barbilhão maxilar com movimentação dorsal (\#13); sulco suborbital (\#14); abertura urogenital na base ou na extremidade dos raios anteriores da nadadeira anal em machos (\#51); abertura urogenital imediatamente anterior à nadadeira anal em fêmeas (\#57); linhas verticais de neuromastos dorsais à linha lateral (\#126, ausentes em Auchenipterus, Pseudepapterus, Epapterus, Tetranematichthys, Ageneiosus); e pelos seguintes caracteres não exclusivos: nadadeira adiposa em forma de gota (\#4, condição presente em diversos outros Siluriformes, incluindo Doradini); infra-orbital 1 participando da margem orbital (\#109; condição presente em alguns doradídeos); sétima vértebra parcialmente fusionada à vértebra complexa (\#229, condição presente em Genidens e na maioria dos doradídeos); e processo lateral cartilaginoso do basipterígio (\#300; condição também presente em Rhamdia, Plotosus, mas ausente em Tetranematichthys, Ageneiosus, Entomocorus, Auchenipterus e Pseudepapterus, Epapterus).

Táxons incluídos: Ageneiosus, "Amplexiglanis", Asterophysus, Auchenipterichthys, Auchenipterus, Centromochlus, Gelanoglanis, Glanidium, Entomocorus, Epapterus, Liosomadoras, Pseudauchenipterus, Pseudepapterus, Pseudotatia, Parauchenipterus, Tatia, Tetranematichthys, Tocantinsia, Trachelyichthys, Traachelyopterichthys, Trachelyopterus, Trachycorystes. 


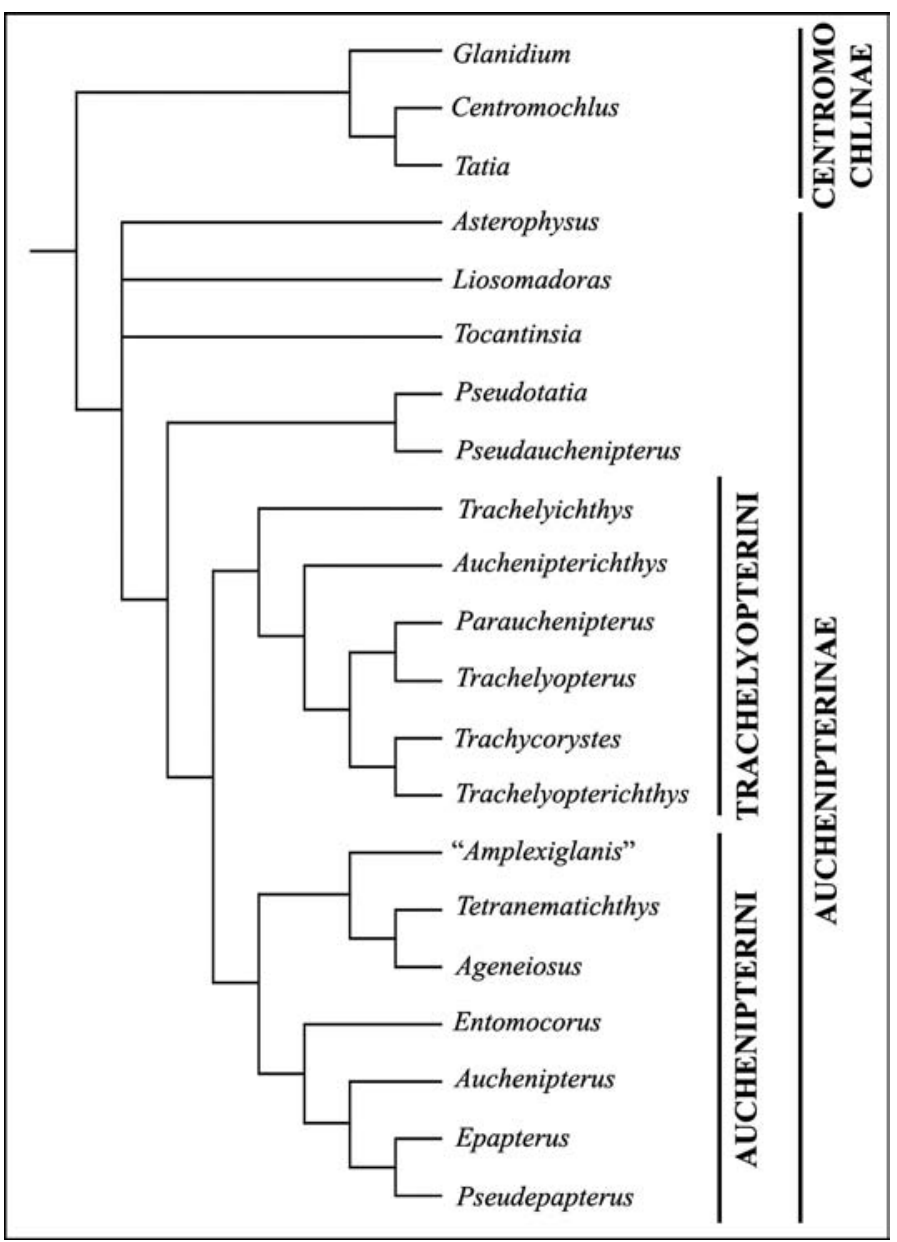

Figura 94. Cladograma resumido das relações filogenéticas na família Auchenipteridae.

\section{Subfamília Centromochlinae Bleeker, 1862}

Centromochli Bleeker, 1862: 7 (criado para Centromochlus).

Diagnose: A subfamília Centromochlinae é diagnosticada pelos seguintes caracteres exclusivos: nadadeira anal oblíqua em machos (\#304); radiais proximais da nadadeira anal em machos paralelos ao eixo do corpo e não interdigitados aos espinhos hemais (\#305); radiais proximais da nadadeira anal em machos parcial ou completamente fusionados entre si (\#307); e pelos seguintes caracteres não exclusivos: quatro a seis raios branquiostégios (\#185); cinco raios ramificados na nadadeira dorsal (\#251, condição também presente em Entomocorus, Parauchenipterus, Trachelyopterus, Trachycorystes, "Amplexiglanis" teaguei e Trachelyichthys). 
Táxons incluídos: Centromochlus, Gelanoglanis, Glanidum e Tatia (não incluído no presente estudo).

Comentários: Esse grupo foi proposto com esse arranjo pela primeira vez por Ferraris (1988). Miranda Ribeiro (1968) havia proposto um grupo parecido (Centromochlidae), mas que incluía Pseudauchenipterus e Entomocorus, além dos gêneros referidos acima. Soares-Porto (1998) definiu os gêneros de Centromochlinae e apresentou uma proposta de relacionamento entre a maioria das espécies. Apesar disso, os limites entre os gêneros de Centromochlinae ainda é assunto de debate, como é possível verificar ao comparar os conceitos de Soares-Porto (1998), Ferraris $(2003,2007)$ e Sarmento-Soares \& Martins-Pinheiro (2008).

\section{Glanidium Lütken, 1874}

Glanidium Lütken, 1874: 31 (espécie-tipo: Glanidium albescens Reinhardt, por monotipia).

Gephyromochlus Hoedeman, 1961: 135 (espécie-tipo: Centromochlus (Gephyromochlus) leopardus Hoedeman, por designação original).

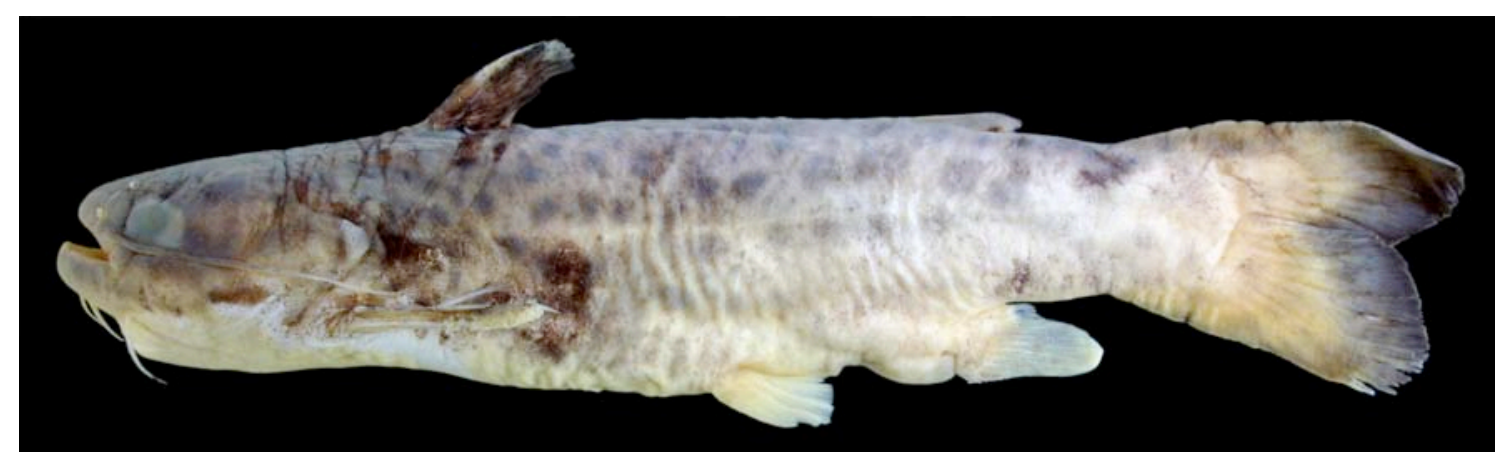

Figura 95. Glanidium melanodermatum, MZUSP 100847, 157 mm, rio Grande, Trajano de Moraes, RJ.

Diagnose: O gênero Glanidium é diagnosticado por apresentar a margem láteroposterior do esfenótico distintamente escavada, côncava (\#74, também presente em Auchenipterini); 10 a 14 raios (totais) na nadadeira anal (\#303, condição presente 
também em Tocantinsia, Asterophysus, Liosomadoras); radiais proximais da nadadeira anal parcialmente fusionados entre si em machos (\#307, condição ausente em algumas espécies de Glanidium).

Táxons incluídos: Glanidium albescens, G. bockmanni, G. catharinensis, $G$. cesarpintoi, G. leopardum, G. melanodermatum e G. ribeiroi.

Comentários: Soares-Porto (1998) define o gênero Glanidium apenas pela margem escavada do esfenótico, e inclui no gênero as sete espécies citadas acima. Entretanto, há diferenças morfológicas marcantes entre as espécies de Glanidium mais litorâneas, como G. albecens, G. catharinensis, G. melanodermatum e G. ribeiroi e as espécies distribuídas nas porções mais internas do continente, como G. bockmanni, $G$. cesarpintoi e G. leopardum. Essas diferenças incluem principalmente a fusão dos radiais proximais da nadadeira anal de machos (\#307, parcial no primeiro grupo, completa no segundo, assim como nos demais Centromochlinae), a presença da placa nucal (\#242, presente no primeiro grupo, e ausente no segundo, assim como em diversas espécies de Centromochlus). Isso indica que o monofiletismo e a conseqüente definição do gênero Glanidium ainda precisa ser melhor investigado. O estudo mais recente com o grupo foi a descrição de Glanidium bockmanni por Sarmento-Soares \& Buckup (2005).

\section{Centromochlus Kner, 1857}

Centromochlus Kner, 1857: 430 (espécie-tipo: Centromochlus megalops Kner [=species inquirienda segundo Ferraris, 2007], por designação subseqüente de Bleeker, 1862: 7). 


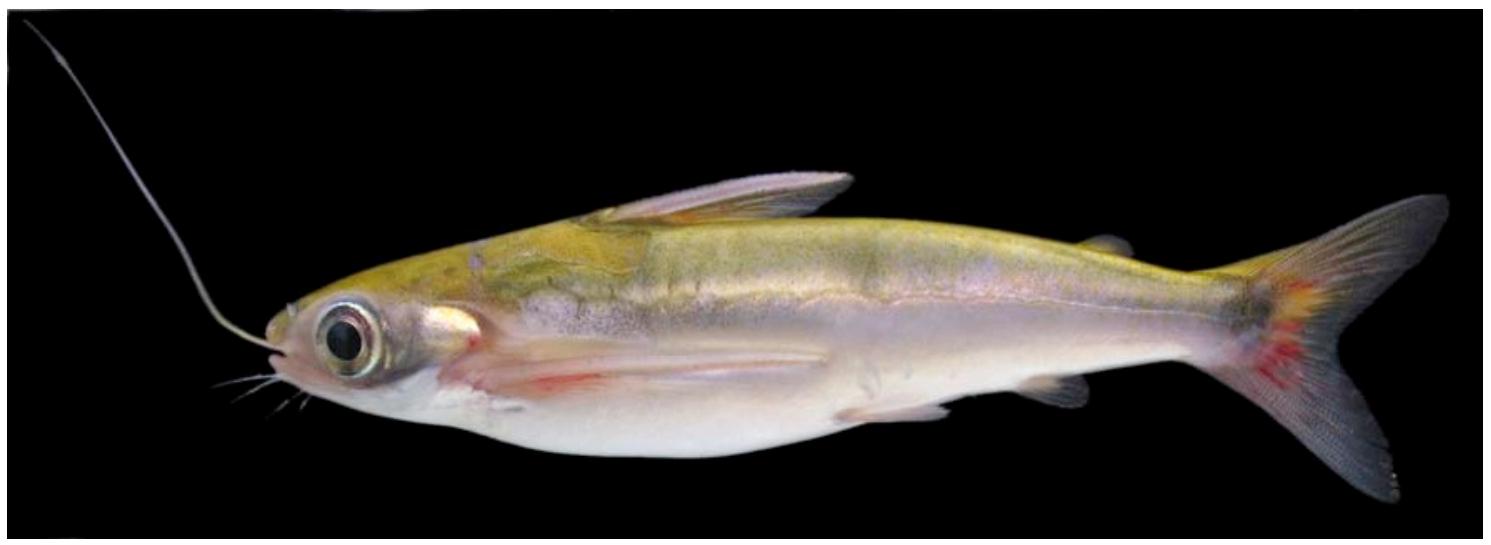

Figura 96. Centromochlus heckelii, MZUSP 104793, c.100 mm, rio Jari, Monte Dourado, PA.

Diagnose: O gênero Centromochlus é diagnosticado por: quilha ventral do assoalho do crânio (\#89); maxilar longo e fino (\#139, condição também presente em Gelanoglanis); radiais proximais da nadadeira anal completamente fusionados entre si em machos (\#307, condição também presente em Tatia e Gelanoglanis); espinhos retrorsos pósterolaterais nos raios da nadadeira anal em machos (\#309, condição ausente em algumas espécies de Centromochlus); 7 a 11 raios (totais) na nadadeira anal (\#303, condição presente também em Tatia).

Táxons incluídos: Centromochlus altae, C. concolor, C. existimatus, C. heckelii, C. macracanthus, C. musaicus, C. perugiae, C. punctatus, C. reticulatus, C. romani e $C$. schultzi, C. simplex (Ferraris, 2007; Sarmento-Soares \& Martins-Pinheiro, 2008).

Comentários: O gênero Centromochlus abriga espécies de morfologia bastante variada, sendo que C. heckelii, C. existimatus e C. macracanthus, podem ser definidas por uma série de sinapomorfias (ver lista de sinapomorfias para C. heckelii no presente estudo), enquanto que alguns de seus congêneres pouco diferem de espécies dos outros gêneros de Centromochlinae.

Gelanoglanis Bohlke, 1980

Gelanoglanis Bohlke, 1980: 150 (espécie-tipo: Gelanoglanis stroudi Boehlke, por 
designação original).

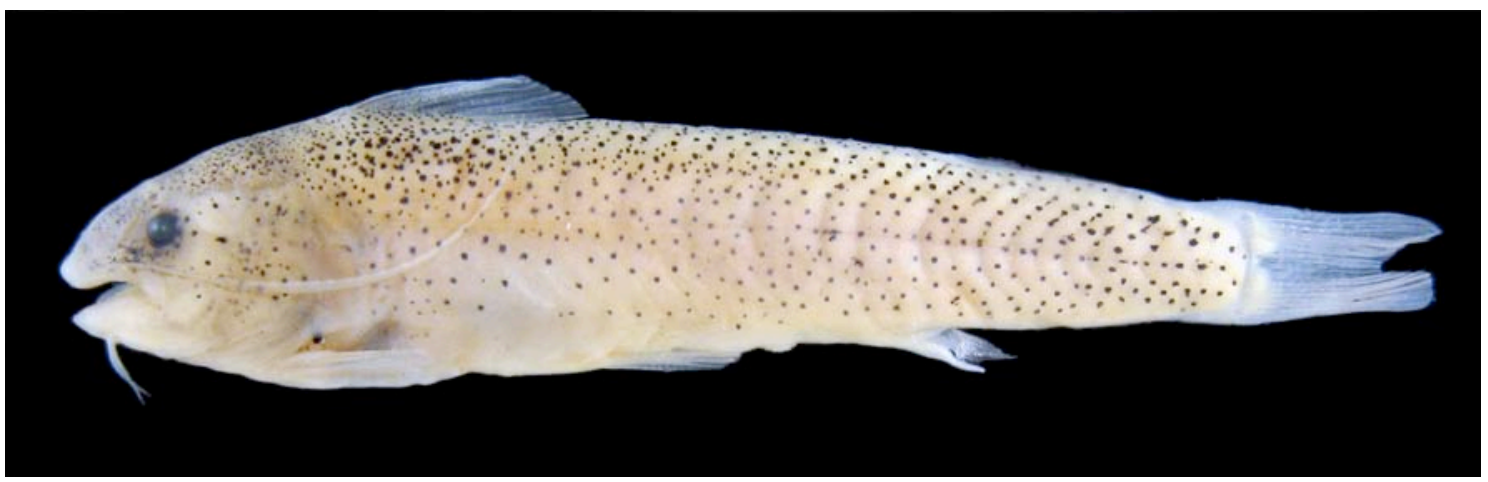

Figura 97. Gelanoglanis cf. stroudi, MZUSP 96032, 26.2 mm, rio Teles Pires, Itaúba, MT.

Diagnose: O gênero Gelanoglanis é diagnosticado por apresentar apenas um par de barbilhões mentonianos; pré-maxilares longos e separados anteriormente; olhos diminutos; fontanelas cranianas ausentes; 'endopterigóide' diminuto; vômer ausente; canal mandibular da linha sensorial cefálica livre do dentário; boca com abertura grande e sinuosa (Bohlke, 1980; Soares-Porto et al., 1999).

Táxons incluídos: Gelanoglanis nanonoctilus, G. stroudi e G. travieso.

Comentários: O gênero Gelanoglanis foi considerado sinônimo de Centromochlus por Soares-Porto (1998), entretanto, a mesma autora o considerou válido um ano depois (Soares-Porto et al., 1999). Recentemente, Rengifo et al. (2008) descreveram Gelanoglanis travieso, coletada no Peru, e apresentaram uma chave de identificação das espécies do gênero.

\section{Tatia Miranda Ribeiro, 1911}

Tatia Miranda Ribeiro, 1911: 360 (espécie-tipo: Centromochlus intermedius Steindachner, por designação subseqüente de Jordan, 1920: 545). 


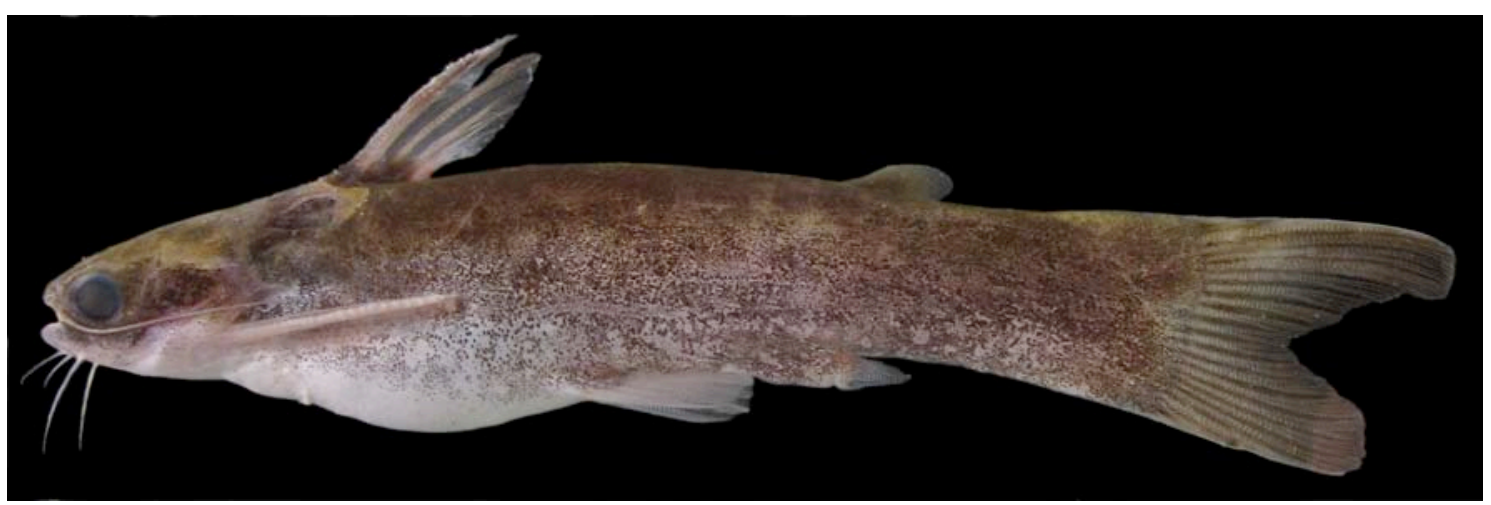

Figura 98. Tatia intermedia, MZUSP 104756, c.90 mm, rio Jari, Monte Dourado, PA.

Diagnose: Tatia é diagnosticado pela nadadeira anal de machos pequena, comprimento dos raios mais longos menor do que $10 \%$ do comprimento padrão (\#306); espinhos antrorsos e retrorsos ântero-laterais nos raios da nadadeira anal em machos (\#301, condição ausente em algumas espécies de Tatia); radiais proximais da nadadeira anal completamente fusionados entre si em machos (\#307, condição também presente em Centromochlus e Gelanoglanis); primeiro raio indiviso da nadadeira anal de machos não segmentado (\#315, condição ausente em T. brunnea); 8 a 11 raios (totais) na nadadeira anal (\#303, condição presente também em Centromochlus).

Táxons incluídos: Tatia aulopygia, T. boemia, T. brunnea, T. caxianensis, T. dunni, T. galaxias, T. gyrina, T. intermedia, T. jaracatia, T. meesi, T. neivai, T. nigra e T. strigata (Sarmento-Soares \& Martins-Pinhiero, 2008).

Comentários: Sarmento-Soares \& Martins-Pinheiro (2008) recentemente revisaram o gênero Tatia, diagnosticando o gênero por alguns outros caracteres, como hiomandibular alongado ântero-dorsalmente; pedúnculo caudal comprimido e alto (altura entre 10.1 e $18.6 \%$ no compimento padrão), com quilha dorsal posterior à nadadeira adiposa. Sarmento-Soares \& Martins-Pinheiro (2008) reconheceram 12 espécies válidas em Tatia, sendo três delas descritas como novas. Pavanelli \& Bifi (2009) descreveram Tatia jaracatia da bacia do rio Iguaçu, no Paraná. 


\section{Subfamília Auchenipterinae Bleeker, 1862}

Pseudauchenipterini Bleeker, 1862: 6 [criado para Pseudauchenipterus, Trachycorystes, Parauchenipterus, Auchenipterichthys].

Astrophysi [=Asterophysi] Bleeker, $1862: 7$ [criado para Asterophysus].

Observações: ver demais nomes supra-genéricos disponíveis para Auchenipterinae na sinopse das tribos Auchenipterini e Trachelyopterini.

Diagnose: A subfamília Auchenipterinae é diagnosticada por duas características exclusivas: abertura urogenital na extremidade dos raios anteriores da nadadeira anal em machos (\#51), e linha lateral sinuosa (\#124); e pelos seguintos caracteres não exclusivos: cartilagem acessória entre os basibranquiais 3 e 4 (\#196; condição ausente em Asterophysus); duas fileiras de rastros branquiais nos arcos branquiais 1 a 4 (\#189, condição também presente em Diplomystidae, Cetopsidae, Siluridae e Ariidae, mas ausente em Tocantinsia, Parauchenipterus, Trachelyopterus, Entomocorus, Auchenipterus, Epapterus e Pseudepapterus); rastros branquiais rudimentares (\#190, condição também presente em Bunocephalus e Helogenys, mas ausente em Tocantinsia e Auchenipterini).

Táxons incluídos: Ageneiosus, "Amplexiglanis", Asterophysus, Auchenipterichthys, Auchenipterus, Entomocorus, Epapterus, Liosomadoras, Pseudauchenipterus, Pseudepapterus, Pseudotatia, Parauchenipterus, Tetranematichthys, Tocantinsia, Trachelyichthys, Traachelyopterichthys, Trachelyopterus e Trachycorystes.

Comentários: O conceito da subfamília Auchenipterinae, no presente estudo, é o mesmo de Ferraris (1988). 
Asterophysus Kner, 1858: 402 (espécie-tipo: Asterophysus batrachus Kner, por monotipia).

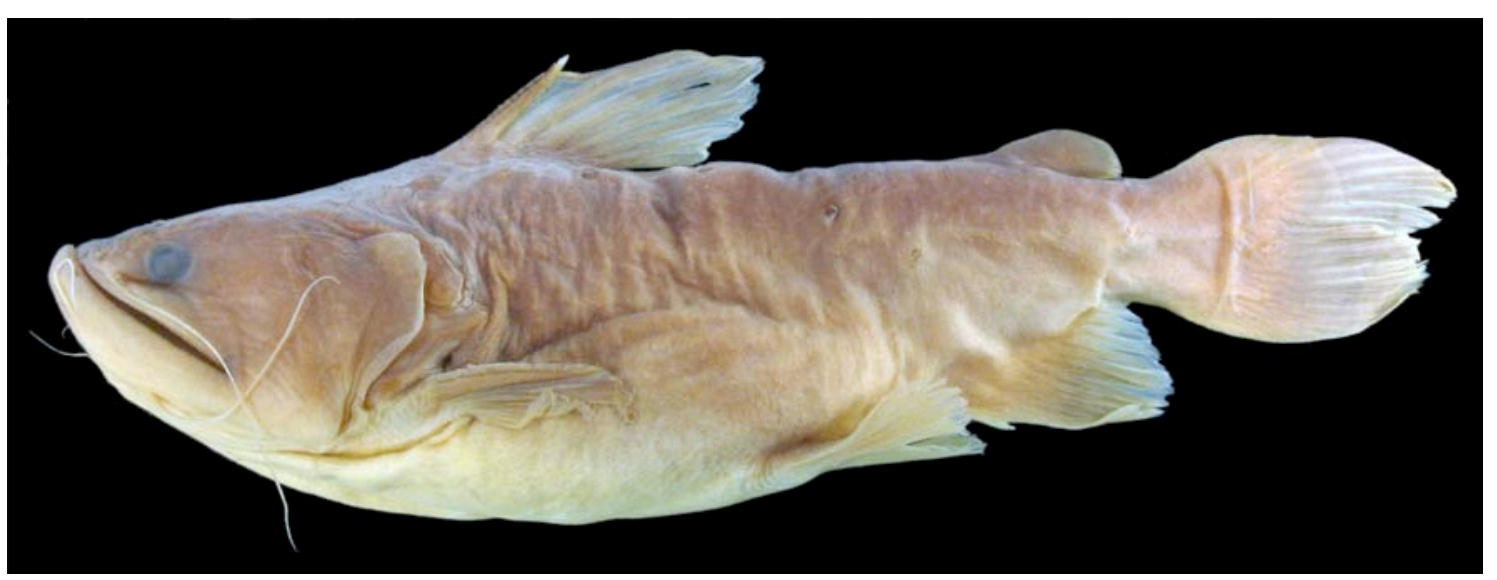

Figura 99. Asterophysus batrachus, MZUSP 33407, 149.5 mm, rio Negro, AM.

Diagnose: Asterophysus batrachus é diagnosticada por uma série de autapomorfias: bexiga natatória com divertículos laterais densamente distribuídos lateral, dorsal e ventralmente (\#45, \#48); ossificação dérmica acessória entre esfenótico, pterótico e parieto-supra-occipital (\#83); dentário e pré-maxilar extremamente longos, ultrapassando bastante o limite lateral do mesetmóide (\#134, condição presente também em Ageneiosus e Tetranematichthys); processo coronóide da mandíbula ausente (\#146); basibranquiais 2 e 3 rudimentares (\#193); placa dentígera faringo-branquial extremamente longa (\#207); 12 a 15 raios (totais) na nadadeira anal (\#303, condição presente também em Glanidium, Liosomadoras, Tocantinsia e Pseudotatia); segundo centro ural bem desenvolvido (\#325, condição presente também em Entomocorus); raios anteriores da nadadeira anal de machos maduros semelhantes aos demais em tamanho (\#317, condição também presente em Centromochlinae, Liosomadoras e Tocantinsia).

Táxon incluído: Asterophysus batrachus. 
Liosomadoras Fowler, 1940: 226 (espécie-tipo: Liosomadoras morrowi Fowler, por designação original).

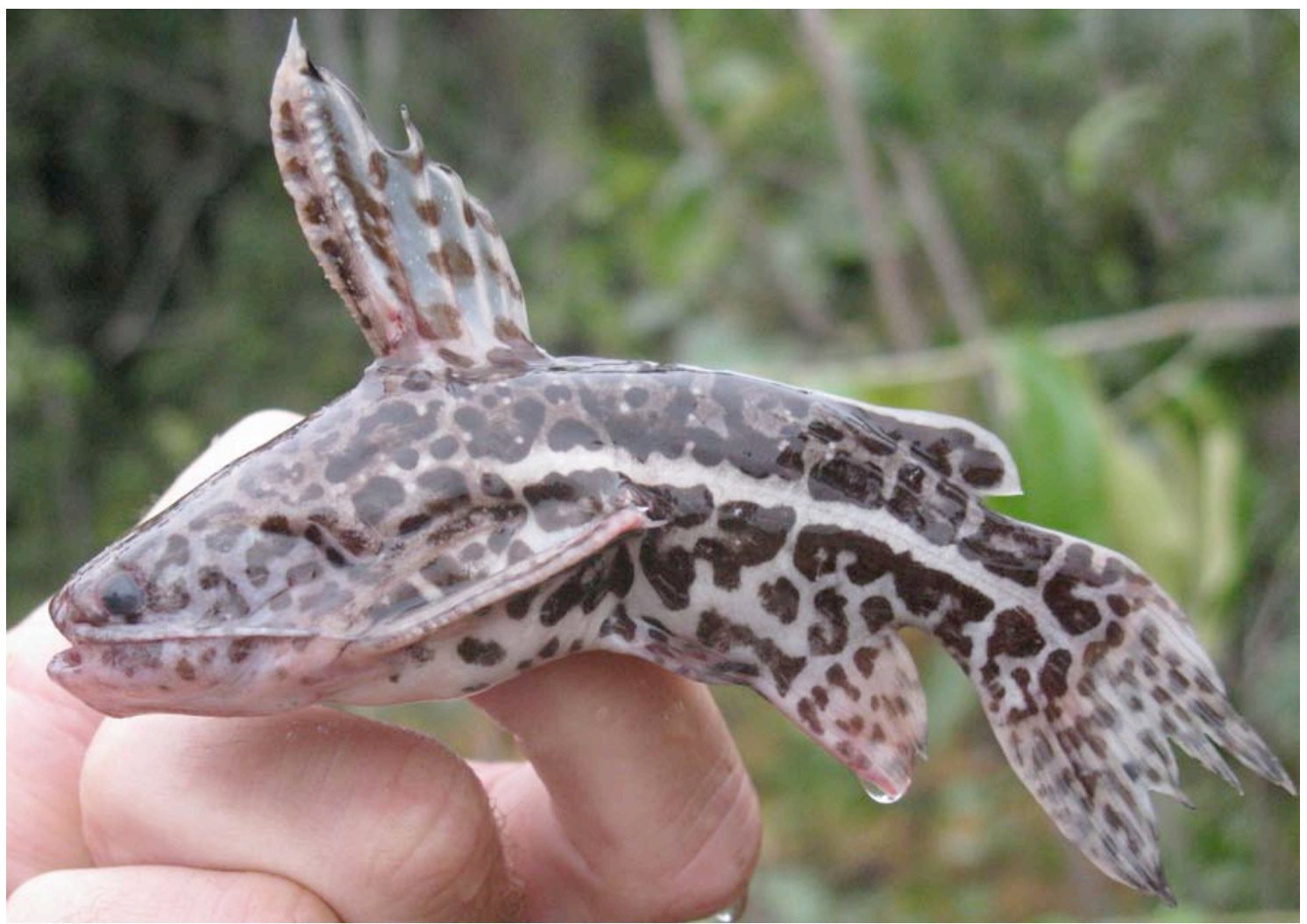

Figura 100. Liosomadoras oncinus, MZUSP 105828, 98 mm, rio Ventuari, Manapiari, Venezuela.

Diagnose: Liosomadoras é diagnosticado pelo corpo beje com manchas escuras, formando um padrão de colorido semelhante ao da onça pintada; espinhos espalhados sobre a porção exposta do processo posterior do cleitro (\#280, condição também presente em Parauchenipterus porosus); acúleo da nadadeira dorsal de machos maduros com serra anterior desalinhada e com movimentação maior do que $90^{\circ}$ (\#254, condição também presente em Auchenipterini e Paracuehnipterus); 12 a 13 raios (totais) na nadadeira anal (\#303, condição presente também em Glanidium, Asterophysus e Tocantinsia); raios anteriores da nadadeira anal de machos maduros semelhantes aos demais em tamanho (\#317, condição também presente em Centromochlinae, Asterophysus e Tocantinsia).

Táxons incluídos: Liosomadoras morrowi e L. oncinus. 
Comentários: Esse gênero foi considerado como um doradídeo, de Fowler a Mees (1974), o primeiro a considerar Liosomadoras um gênero de Auchenipteridae. A validade das duas espécies do gênero é ainda uma questão não resolvida.

\section{Tocantinsia Mees, 1974}

Tocantinsia Mees, 1974: 108 (espécie-tipo: Tocantinsia depressa Mess [=Glanidium piresi Miranda Ribeiro], por designação original).

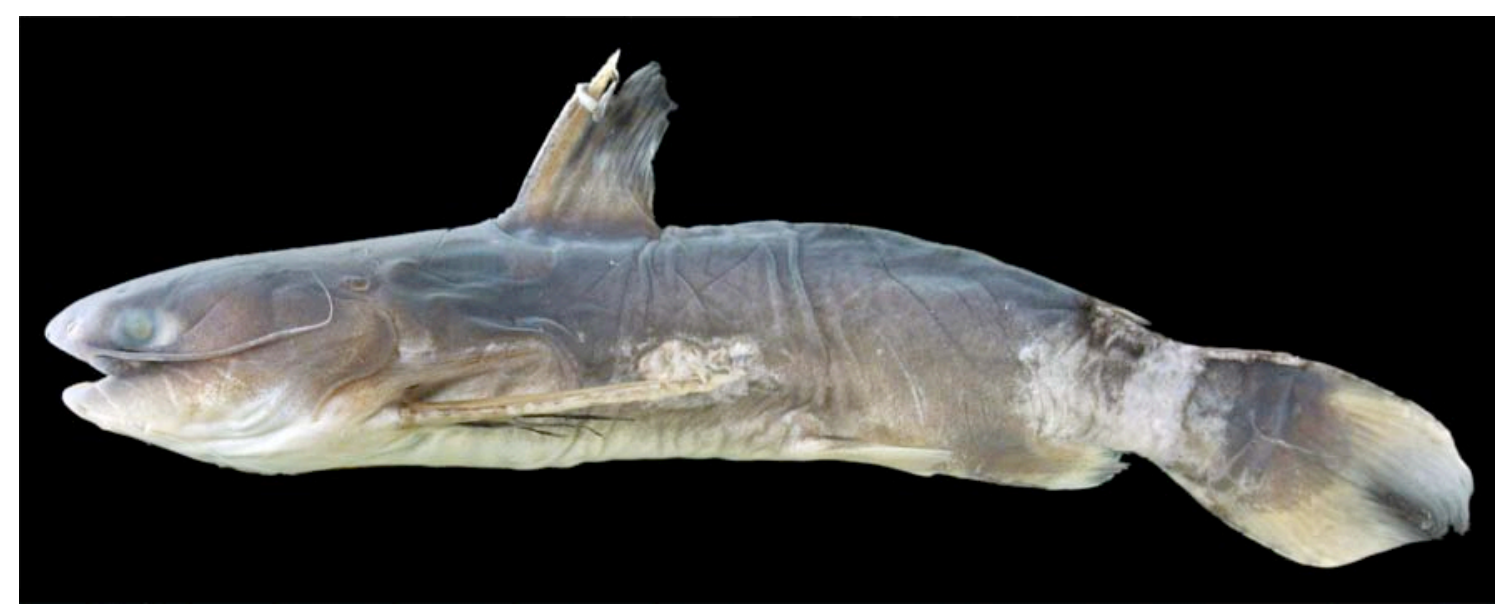

Figura 101. Tocantinsia piresi, MZUSP 103415, 160 mm, rio Jari, Monte Dourado, PA.

Diagnose: Tocantinsia piresi é diagnosticada por apresentar um par de divertículos posteriores digitiformes na bexiga natatória (\#41, condição presente também em Trachycorystes); uma fileira de rastros branquiais nos dois primeiros arcos branquiais (\#189, condição presente também em Centromochlinae, Auchenipterus, Epapterus e Pseudepapterus); rastros branquiais com margem serrilhada (\#190, condição também presente em Tetranematichthys); 12 raios (totais) na nadadeira anal (\#303, condição presente também em Glanidium, Asterophysus e Liosomadoras); raios anteriores da nadadeira anal de machos maduros semelhantes aos demais em tamanho (\#317, condição também presente em Centromochlinae, Asterophysus e Liosomadoras).

Táxon incluído: Tocantinsia piresi. 
Comentários: Essa é uma das poucas espécies que leva o nome em referência a dois rios distintos. Miranda Ribeiro (1920) descreveu Glanidium piresi, nome dado em referência ao rio Teles Pires, bacia do rio Tapajós, e Mees (1974) descreveu Tocantinsia depressa (sinônimo de Tocantinsia piresi), nome genérico dado em referência ao rio Tocantins. Tocantinsia piresi é conhecida dos rios Tocantins, Tapajós, Xingu e Jari.

\section{Pseudauchenipterus Bleeker, 1862}

Pseudauchenipterus Bleeker, 1862: 6 (espécie-tipo: Silurus nodosus Linnaeus, por designação originial).

Silvaichthys Fernández Yépez, 1973: 3 (espécie-tipo Silvaichthys aguilerae FernándezYépez [=Silurus nodosus Linnaeus], por designação original).

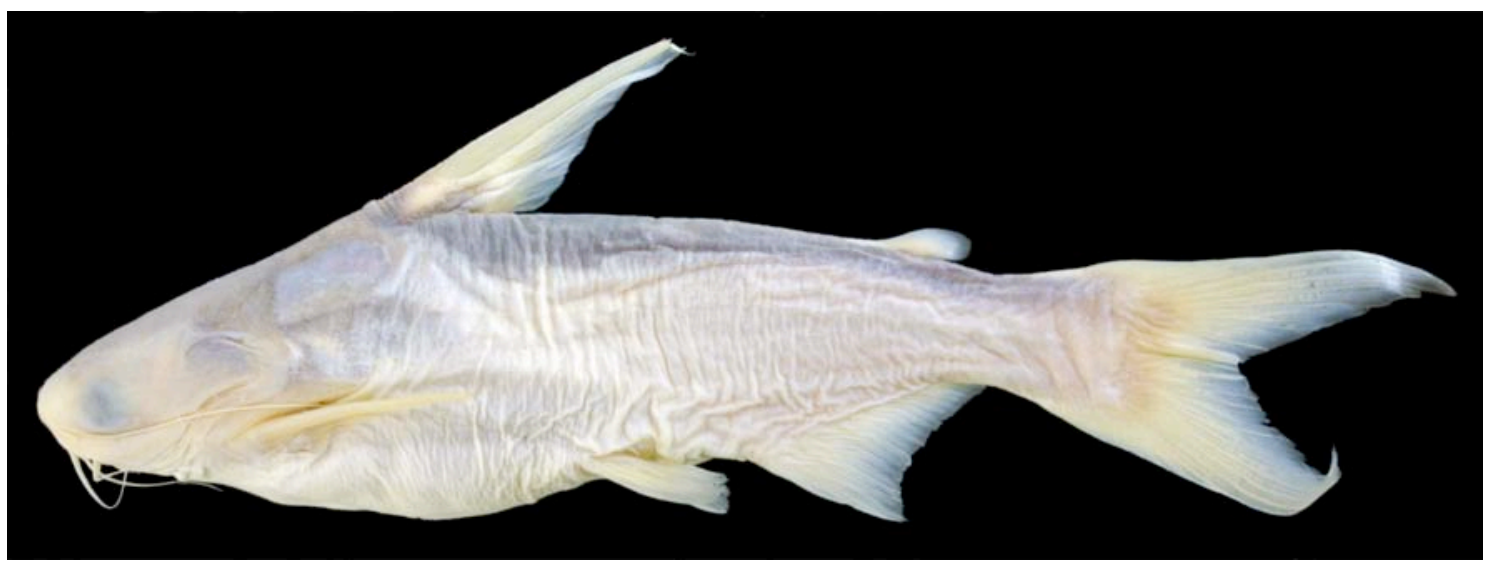

Figura 102. Pseudauchenipterus nodosus, MZUSP 54069, 107.5 mm, Mangue, São Luiz, MA.

Diagnose: Pseudauchenipterus é diagnosticado pelos tubérculos dérmicos em forma de papilas sobre a região timpânica (\#30); vesícula terminal no gonopódio de machos maduros (\#53); etmóide lateral não participando do escudo cefálico (\#70, condição presente também em Centromochlus e Pseudotatia); margem anterior da cintura peitoral alongada anteriormente, com as margens convergentes e extremidade afilada (\#262, condição presente também em Centromochlus, Tatia, Pseudotatia, Entomocorus e Asterophysus); sete raios ramificados na nadadeira pélvica (\#288); 18 a 23 raios (totais) 
na nadadeira anal (\#303, condição presente também em Trachycorystes, Entomocorus, Auchenipterichthys, “Amplexiglanis" e Parauchenipterus).

Táxons incluídos: Pseudauchenipterus affinis, P. flavecens, $P$. jequitinhonhae e $P$. nodosus.

Comentários: O gênero Pseudachenipterus foi revisado por Akama (1999).

\section{Pseudotatia Mees, 1974}

Pseudotatia Mees, 1974: 105 (espécie-tipo: Pseudotatia parva Mess, por designação original).

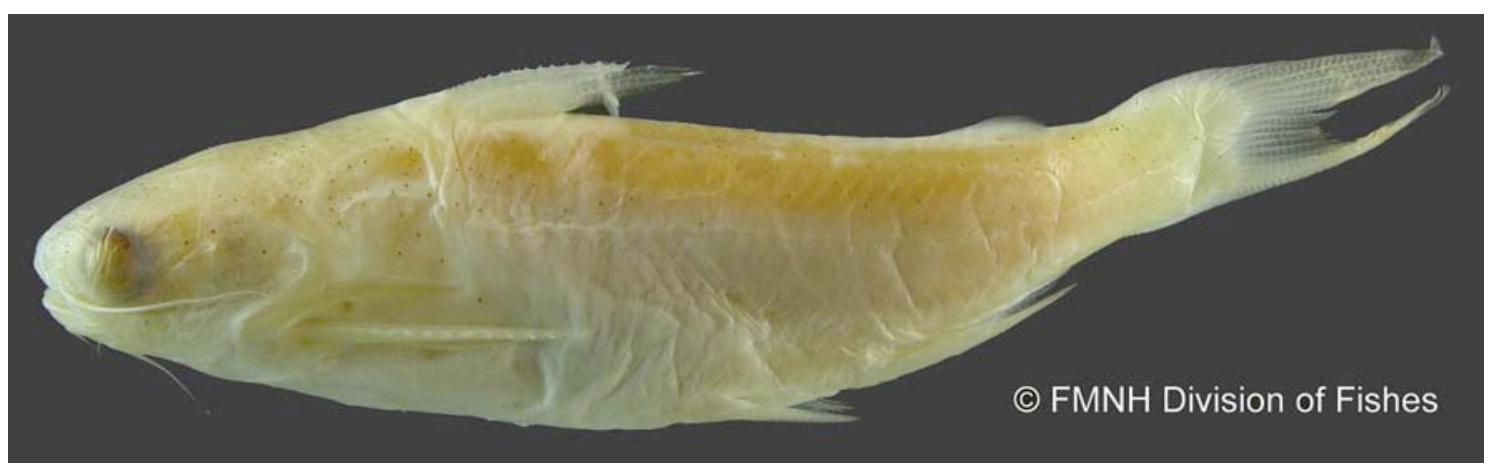

Figura 103. Pseudotatia parva, FMNH 70580, 46 mm, holótipo, rio São Francisco, Joazeiro, BA.

Diagnose: Pseudotatia parva é diagnosticada por possuir o canal aórtico aberto (\#226, condição presente em Auchenipterus e Epapterus); etmóide lateral não participando do escudo cefálico (\#70, condição presente também em Centromochlus e Pseudauchenipterus); margem anterior da cintura peitoral alongada anteriormente, com as margens convergentes e extremidade afilada (\#262, condição presente também em Centromochlus, Tatia, Pseudauchenipterus, Entomocorus e Asterophysus); 15 a 16 raios (totais) na nadadeira anal (\#303, condição presente também em Asterophysus).

Táxon incluído: Pseudotatia parva.

Comentários: Pseudotatia parva é uma espécie conhecida apenas dos 17 exemplares da série tipo, coletados por John Haseman no rio São Francisco em Joazeiro na Bahia em 
1907.

\section{Tribo Auchenipterini Bleeker, 1862}

Euanemini Bleeker, 1858: 49 [criado para Euaenemus (=Auchenipterus), Ageneiosus, Tetranematichthys].

Ageneiosi Bleeker, 1862: 14 [criado para Ageneiosus, Pseudageneiosus, Tetranematichthys].

Auchenipterini Bleeker, 1862: 14 [criado para Auchenipterus, já reconhecendo Euanemus como sinônimo].

Diagnose: A tribo Auchenipterini é diagnosticada por uma série de caracteres: maxilar alongado em machos maduros (\#142, condição também presente em Parauchenipterus, mas ausente em Ageneiosus); capacidade de movimentação do acúleo da nadadeira dorsal num ângulo maior do que $90^{\circ}$ em machos maduros (\#254, condição também presente em Liosomadoras e Parauchenipterus); linhas verticais de neuromastos dorsais à linha lateral ausentes (\#126); e tubérculos dérmicos (nupciais) na superfície dorsal do crânio de machos maduros (\#26, condição também ausente em Ageneiosus e Tetraematichthys); margem látero-posterior do esfenótico extremamente côncava (\#74, condição presente também em Glanidium), rastros branquiais não rudimentares (\#190, condição presente em Tocantinsia).

Gêneros incluídos: Ageneiosus, "Amplexiglanis", Auchenipterus, Entomocorus, Epapterus, Pseudepapterus e Tetranematichthys.

Comentários: O arranjo proposto no presente estudo para a tribo Auchenipterini equivale à união dos grupos denominados Auchenipteridae e Ageneiosidae por Miranda Ribeiro (1911) e dos grupos “Ageneiosus group" e "Auchenipterus group” de Ferraris (1988). 


\section{"Amplexiglanis"}

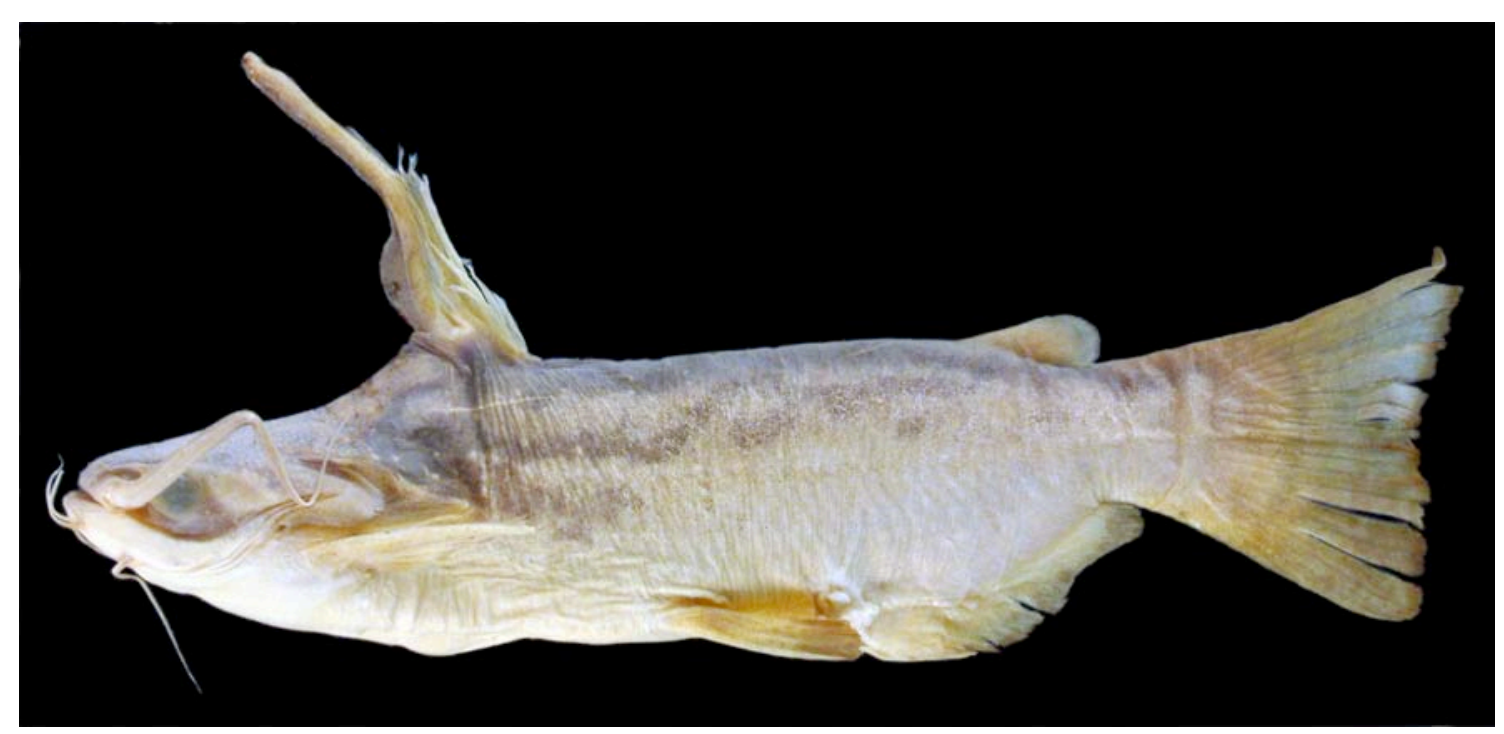

Figura 104. "Amplexiglanis" insignis, MZUSP 79458, $136 \mathrm{~mm}$, rio Limon, Carrasqueso, Zulia, Venezuela.

Diagnose: “Amplexiglanis” é diagnsoticado por possuir bexiga natatória com câmara secundária ligada dorsalmente à bexiga e dividida na base; tubérculos dérmicos nupciais sobre o acúleo da nadadeira dorsal em machos maduros (\#25, condição também presente em Entomocorus); 19 a 33 raios (totais) na nadadeira anal (\#303, condição também presente em Trachycorystes, Entomocorus, Auchenipterichthys, Pseudauchenipterus, Parauchenipterus, Trachelyopterus e algumas espécies de Ageneiosus).

Táxons incluídos: "Amplexiglanis" amblops, "Amplexiglanis" fisheri, "Amplexiglanis" insignis e "Amplexiglanis" teaguei.

Comentários: Este gênero foi proposto por Royero (1999), que considerou as espécies "Amplexiglanis" peloichthys e "Amplexiglanis" badeli como válidas. Estas duas espécies foram consideradas sinônimas de "Amplexiglanis" insignis por Akama (2004), que apresentou uma revisão das espécies do gênero. 


\section{Tetranematichthys Bleeker, 1858}

Tetranematichthys Bleeker, 1858: 357 (espécie-tipo: Ageneiosus quadrifilis Kner, por monotipia).

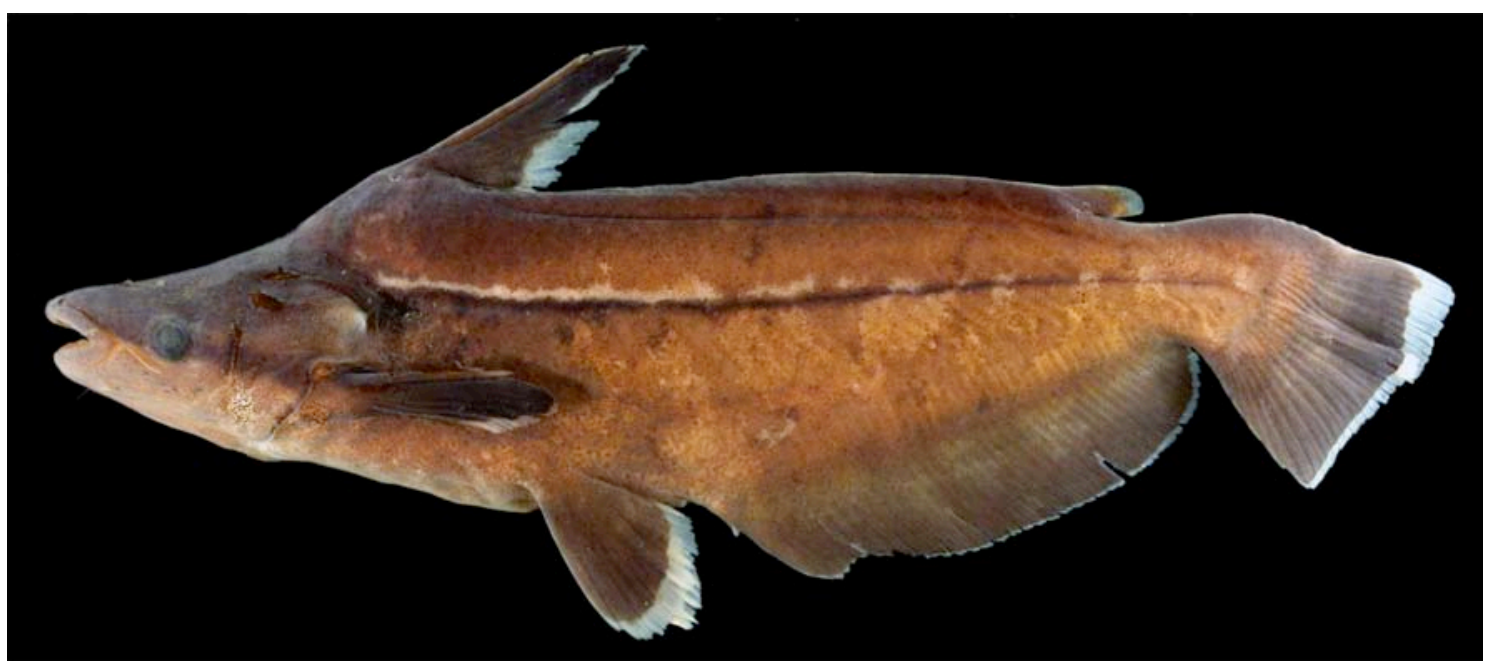

Figura 105. Tetranematichthys wallacei, MZUSP 93457, 118.8 mm, rio Tiquié, AM.

Diagnose: Tetranematichthys é diagnosticado por apresentar bexiga natatória com câmara secundária com septo interno e ligada dorsalmente à bexiga; barbilhão maxilar curto, não alcançando a margem anterior da órbita (\#10, condição também presente em Ageneiosus); apenas um par de barbilhões mentonianos (\#16, condição também presente em Gelanoglanis); rastros branquiais com margem serrilhada (\#190, condição também presente em Tocantinsia); 9 a 11 raios ramificados na nadadeira peitoral (\#275, condição presente também em Auchenipterus, Epapterus e Pseudepapterus); quatro pares de músculos inclinadores da nadadeira dorsal (\#261); 9 a 11 raios ramificados na nadadeira peitoral (\#275, condição similar em Auchenipterus, Epapterus e Pseudepapterus); 38 a 45 raios (totais) na nadadeira anal (\#303, condição presente também em Trachelyichthys, Trachelyopterichthys anduzei e Auchenipterus); 9 a 12 raios ramificados no lobo ventral da nadadeira caudal (\#323, condição presente em Trachelyichthys, Trachelyopterus e Parauchenipterus). 
Táxons incluídos: Tetranematichthys barthemi, T. quadrifilis e T. wallacei.

Comentários: O gênero Tetranematichthys foi revisado por Vari \& Ferraris (2006), que restringiram o nome $T$. quadrifilis para espécimes do rio Guaporé, e descreveram $T$. wallacei como uma espécie amplamente distribuída nas bacias dos rios Amazonas e Orinoco. Recentemente, Peixoto \& Wosiacki (2010) descreveram Tetranematichthys barthemi como uma espécie nova, com material dos rios Trombetas e Negro, e citaram, como material examinado, espécimes identificados como Tetranematichthys quadriflis procedentes dos rios Amazonas e Tapajós, contrariando os resultados de Vari \& Ferraris (2006).

\section{Ageneiosus Lacépede, 1803}

Ageneiosus Lacepède, 1803: 132 (espécie-tipo: Ageneiosus armatus Eigenmann [=Silurus inermis Linnaeus], por designação subseqüente de Eigenmann \& Eigenmann, 1888: 299).

Ceratorhynchus Spix \& Agassiz, 1829: 10 (espécie-tipo: Ageneiosus militaris (Valenciennes), por monotipia).

Agenius Agassiz, 1846: 11 (espécie-tipo: Ageneiosus armatus Lacepède [=Ageneiosus inermis (Linnaeus), nome em substituição a Ageneiosus, e portanto, com a mesma espécie-tipo).

Davalla Bleeker, 1858: 11 (espécie-tipo: Davalla schomburgkii Bleeker, por monotipia).

Pseudageneisus Bleeker, 1862: 14 (espécie-tipo: Ageneiosus breivifilis Valenciennes [=Silurus inermis Linnaeus], por designação original.

Tympanopleura Eigenmann, 1912: 203 (espécie-tipo: Tympanopleura piperata Eigenmann, por designação original. 


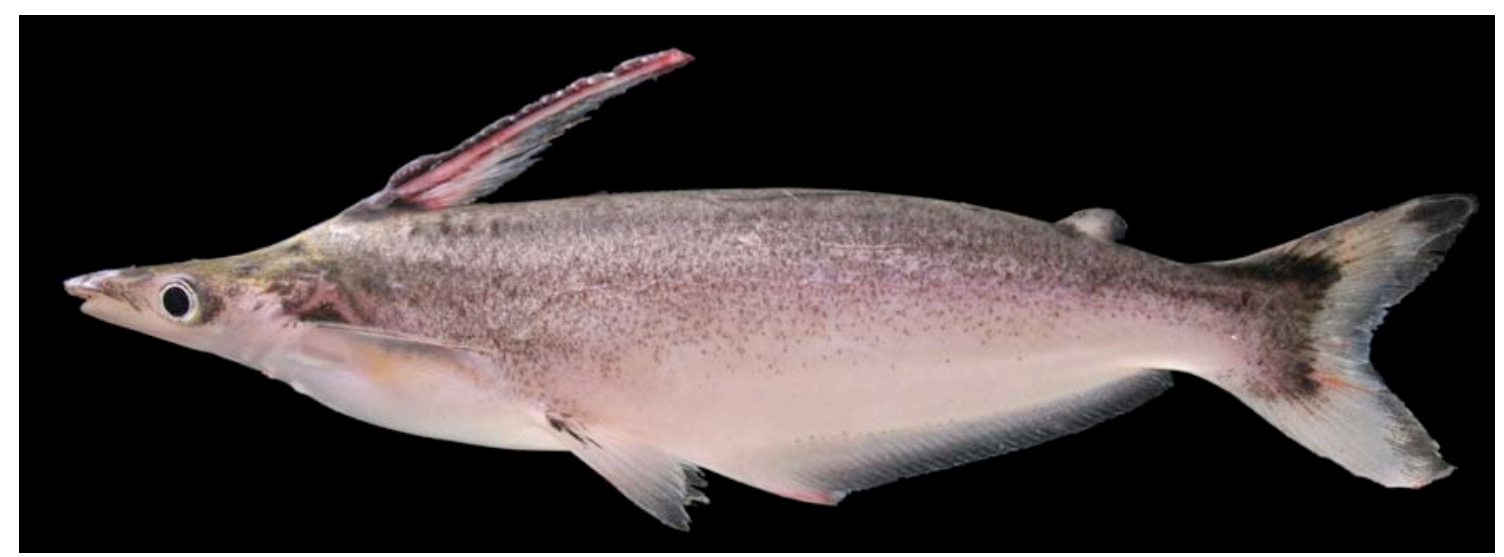

Figura 106. Ageneiosus ucayalensis, MZUSP 104791, 171 mm, rio Jari, Monte Dourado, PA.

Diagnose: Ageneiosus é diagnosticado por apresentar barbilhão maxilar curto, não alcançando a margem anterior da órbita (\#10, condição também presente em Tetranematichthys); barbilhões mentonianos ausentes (\#16); um par de divertículos posteriores na bexiga natatória (\#41, ausentes em A. ucayalensis e A. pardalis); lóbulos posteriores do testículo rudimentares ou ausentes (\#49, condição também presente em Auchenipterus); placa nucal anterior ausente (\#242, condição também presente em Epapterus e Pseudepapterus); contato entre a placa nucal mediana e o parieto-supraoccipital (\#245, condição presente também em Epapterus e Pseudepapterus); processo dorsal da base do acúleo da nadadeira peitoral ausente (\#269); processo posterior do cleitro ausente (\#278); 26 a 54 raios (totais) na nadadeira anal (\#303, condição presente também em Trachelyopterus, Auchenipterichthys, “Amplexiglanis”, Parauchenipterus, Trachelyichthys, Trachelyopterichthys, Auchenipterus, Epapterus e Pseudepapterus).

Táxons incluídos: Ageneiosus atronasus, A. brevis, A. inermis, A. magoi, A. marmoratus, A. militaris, A. pardalis, A. piperatus, A. polystictus, A. ucayalensis, A. uranophthalmus e A. vittatus.

Comentários: Eigenmann (1912) criou o gênero Tympanopleura para espécies de pequeno porte e com bexiga natatória e pseudo-tímpano bem desenvolvidos (i.e., A. atronasos, A. brevis, A. piperatus), reconhecendo Ageneiosus para espécies de grande 
porte e com bexiga natatória e pseudo-tímpano reduzidos em tamanho. Estas três espécies citadas foram consideradas por Walsh (1990) como as três espécies de relações incertas (numa politomia) e irmãs das demais espécies de Ageneiosus. Walsh (1990), ainda reconheceu uma nova espécie relacionada à Ageneiosus vittatus, amplamente distribuída nas bacias dos rios Amazonas e Orinoco. Recentemente, Ribeiro \& Rapp PyDaniel (2010) descreveram Ageneiosus uranophthalmus da Amazônia central.

\section{Entomocorus Eigenmann, 1917}

Entomocorus Eigenmann, 1917: 403 (espécie-tipo: Entomocorus benjamini Eigenmann, por monotipia).

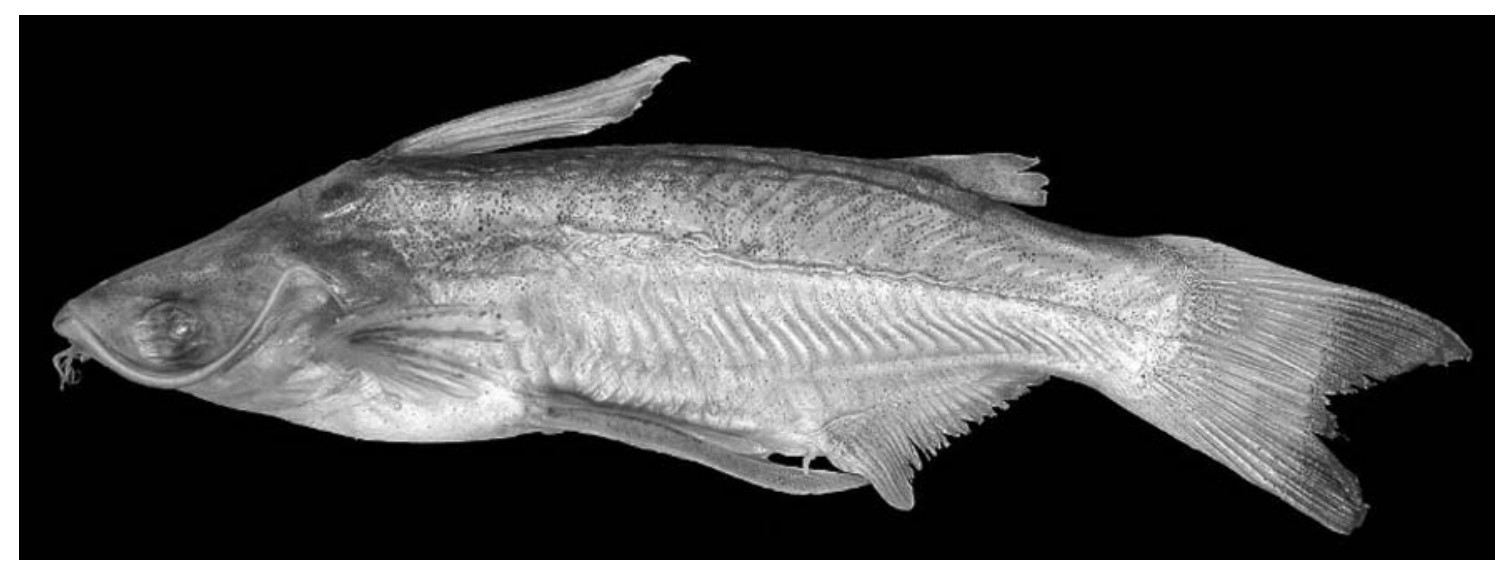

Figura 107. Entomocorus radiosus, MCP 38966, 52.9 mm, rio Cuiabá, Barão de Melgaço, MT (foto de Reis \& Borges, 2006: Fig. 7).

Diagnose: Entomocorus é diagnosticado por ter tubérculos dérmicos nupciais sobre o acúleo da nadadeira dorsal em machos maduros (\#25, condição presente também em “Amplexiglanis"); tubérculos dérmicos nupciais sobre o abdôme e região gular em machos maduros (\#28); extremidade do tubo urogenital localizada numa papila que segue paralela até aproximadamente a metade da margem anterior da nadadeira anal (\#55); ossificação dérmica acessória entre o frontal, esfenótico e parieto-supra-occipital (\#82); ponte entre o cleitro e coracóide estendida ao processo posterior do coracóide 
(\#265); dentes reduzidos em número no pré-maxilar (\#138, condição também presente em Auchenipterus) e no dentário (\#151, condição também presente em Auchenipterus); primeiro raio da nadadeira pélvica modificado, expandido e achatado, em machos maduros (\#291); 18 a 21 raios (totais) na nadadeira anal (\#303, condição presente também em Trachycorystes, Pseudauchenipterus, Auchenipterichthys, "Amplexiglanis", Parauchenipterus); segundo centro ural bem desenvolvido (\#325, condição também presente em Asterophysus).

Táxons incluídos: Entomocorus benjamini, E. gameroi, E. melaphareus e E. radiosus.

Comentários: Recentemente, Akama \& Ferraris (2003) descreveram Entomocorus melaphareus e Reis \& Borges (2006) descreveram E. radiosus, durante a revisão taxonômica do gênero.

\section{Auchenipterus Valenciennes, 1840}

Auchenipterus Valenciennes, 1840: 207 (espécie-tipo: Hypophthalmus nuchalis Spix \& Agassiz, por designação subseqüente de Bleeker, 1862: 15).

Euanemus Müller \&Troschel, 1842: 203 (espécie-tipo: Euanemus colymbetes Müller \& Troschel [=Auchenipterus dentatus Valenciennes], por monotipia).

Auchenopterus Agassiz, 1846: 40 (espécie-tipo: Hypophthalmus nuchalis Spix \& Agassiz, nome em substituição a Auchenipterus e, portanto, com a mesma espécie-tipo). Ceratocheilus Miranda Ribeiro, 1918: 644 (espécie-tipo: Ceratocheilus osteomystax Miranda Ribeiro, por monotipia).

Osteomystax Whitley, 1940: 242 (espécie-tipo: Ceratocheilus osteomystax Miranda Ribeiro, nome em substituição a Ceratocheilus, preocupado e, portanto, com a mesma espécie-tipo). 


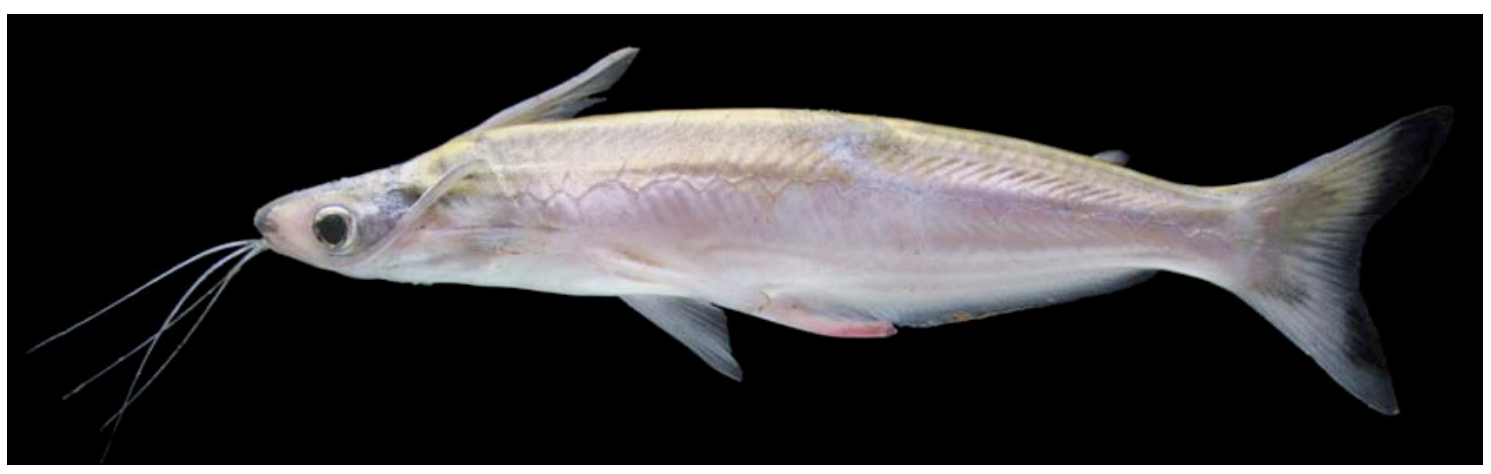

Figura 108. Auchenipterus nuchalis, MZUSP 103352, 133 mm, rio Jari, Monte Dourado, PA.

Diagnose: O gênero Auchenipterus é diagnosticado pelos lóbulos posterior do testículo rudimentares ou ausentes (\#49, condição também presente em Ageneiosus); fontanela anterior dividida em duas porções por uma extensa ponte entre os frontais (\#67); quilha ventral do assoalho do crânio ventralmente afilada e longa (\#89, presente também em Centromochlus); dentes reduzidos em número no pré-maxilar (\#138, condição também presente em Entomocorus) e no dentário (\#151, condição também presente em Entomocorus); 10 a 14 raios ramificados na nadadeira peitoral (\#275, condição presente também em Pseudepapterus, Epapterus e Tetranematichthys); 9 a 16 raios ramificados na nadadeira pélvica (\#288, condição presente também em Epapterus, Pseudepapterus, Trachelyichthys e Trachelyopterichthys); 35 a 53 raios (totais) na nadadeira anal (\#303, condição presente também em Tetranematichthys, Trachelyopterichthys, Trachelyichthys, Epapterus, Pseudepapterus e algumas espécies de Ageneiosus); gancho retrorso no terceiro raio indiviso da nadadeira anal de machos maduros (\#311).

Táxons incluídos: Auchenipterus ambyiacus, A. brachyurus, A. brevior, A. britskii, A. demerarae, A. dentatus, A. fordicei, A. menezesi, A. nigripinnis, A. nuchalis e A. osteomystax.

Comentários: O gênero Auchenipterus, um dos mais diversos da família Auchenipteridae, foi revisado por Ferraris \& Vari (1999). 


\section{Epapterus Cope, 1878}

Epapterus Cope, 1878: 677 (espécie-tipo: Epapterus dispilurus Cope, por monotipia).

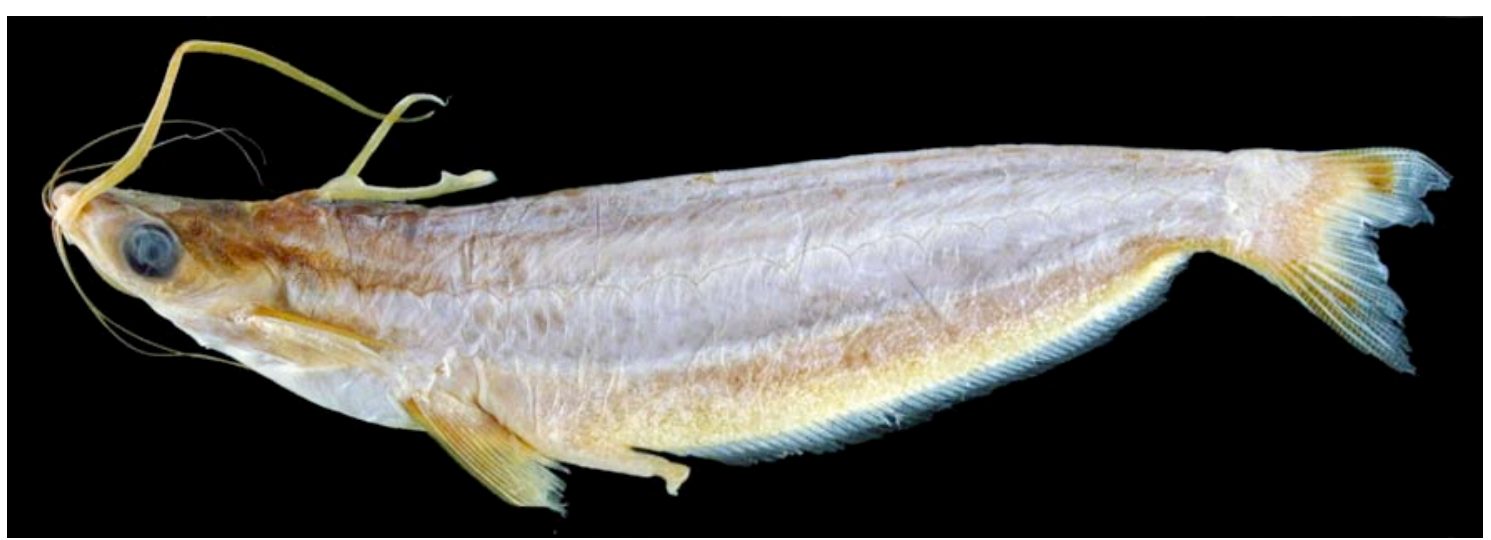

Figura 109. Epapterus dispilurus, MZUSP 26318, 106.4 mm, Ucayali, Pucallpa, Peru.

Diagnose: O gênero Epapterus é diagnosticado pela nadadeira adiposa ausente (\#3, condição também presente em Trachelyichthys, Trachelyopterichthys e Trachelyopterus); espaço entre o gonopódio e o restante da nadadeira anal (\#54); dentes ausentes no pré-maxilar (\#138, condição também presente em Pseudepapterus) e no dentário (\#151, condição também presente em Pseudepapterus); quatro raios ramificados na nadadeira dorsal (\#251, condição presente também em Trachelyopterichthys e Pseudepapterus); 8 a 12 raios ramificados na nadadeira peitoral (\#275, condição presente também em Auchenipterus, Pseudepapterus e Tetranematichthys); 9 a 16 raios ramificados na nadadeira pélvica (\#288, condição presente também em Auchenipterus, Pseudepapterus, Trachelyichthys e Trachelyopterichthys); 49 a 60 raios (totais) na nadadeira anal (\#303, condição presente também em Trachelyopterichthys, Auchenipterus, Pseudepapterus e algumas espécies de Ageneiosus).

Táxons incluídos: Epapterus blohmi e E. dispilurus.

Comentários: O gênero Epapterus foi revisado por Vari \& Ferraris (1998). 


\section{Pseudepapterus Steindachner, 1915}

Pseudepapterus Steindachner, 1915: 199 (espécie-tipo: Auchenipterus (Pseudepapterus) hasemani Steindachner, por monotipia).

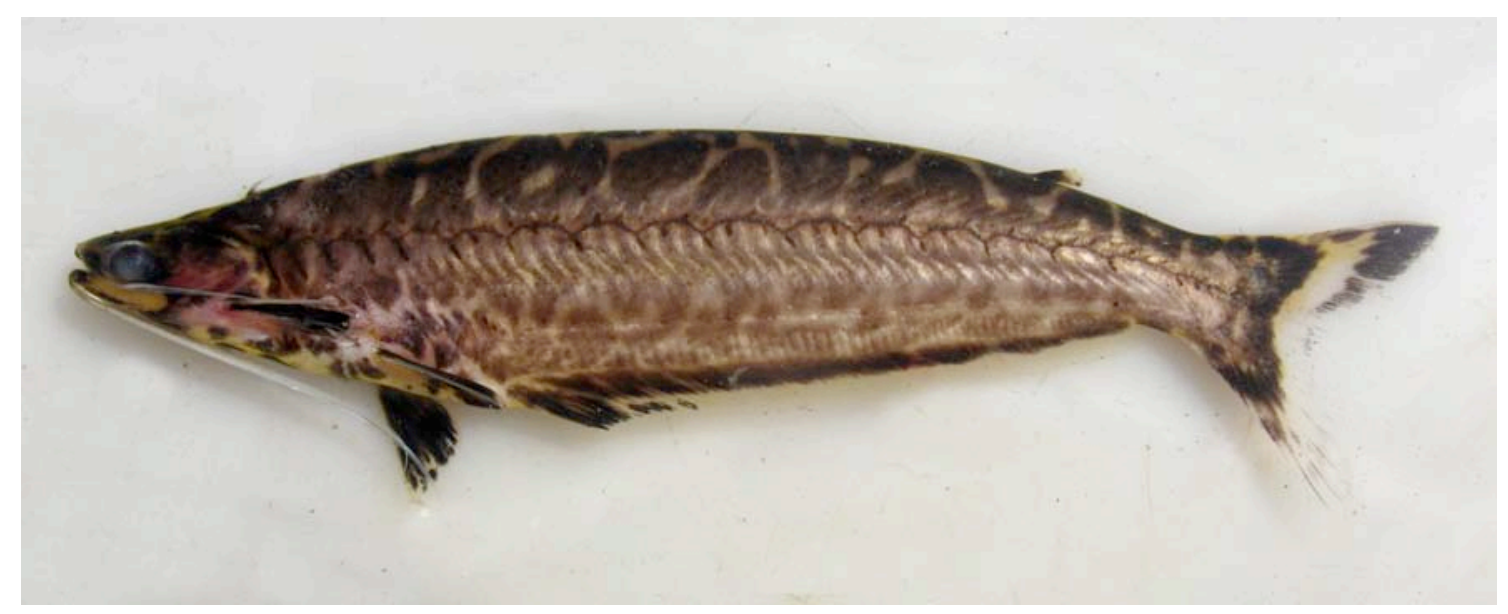

Figura 110. Pseudepapterus hasemani, MZUSP 104772, 115.2 mm, rio Jari, Monte Dourado, PA.

Diagnose: O gênero Pseudepapterus é diagnosticado pela borda espessa e marcada da abertura urogenital, em relação à pele entorno, de fêmeas (\#58); pré-maxilar extremamente diminuto (\#134); dentes ausentes no pré-maxilar (\#138, condição também presente em Epapterus) e no dentário (\#151, condição também presente em Epapterus); 21 a 51 rastros branquiais longos, no primeiro arco branquial (\#190,\#192); sétima vértebra livre da vértebra complexa (\#229, condição também presente em Ageneiosus); 3 a 5, raramente 6 raios ramificados na nadadeira dorsal (\#251, condição presente também em Epapterus e Trachelyopterichthys); 10 a 14 raios ramificados na nadadeira peitoral (\#275, condição presente também em Auchenipterus, Epapterus e Tetranematichthys); sutura interdigitada entre os coracóides restritia à porção posterior da sínfise (\#281); 9 a 16 raios ramificados na nadadeira pélvica (\#288, condição presente também em Epapterus, Auchenipterus, Trachelyichthys e Trachelyopterichthys); 47 a 60 raios (totais) na nadadeira anal (\#303, condição presente também em Trachelyopterichthys, Auchenipterus, Epapterus e algumas espécies de 
Ageneiosus).

Táxons incluídos: Pseudepapterus cucuhyensis, $P$. gracilis e P. hasemani.

Comentários: O gênero Pseudepapterus foi revisado por Ferraris \& Vari (2000).

\section{Tribo Trachelypterini Bleeker, 1862}

Trachelyopterini Bleeker, 1858: 49 [criado para Trachyopterus].

Trachycorystidae Miranda Ribeiro, 1911: 352 [criado para incluir todas as espécies de auchenipterídeos até então conhecidos, exceto Auchenipterus, Pseudepapterus, Epapterus, Ageneiosus e Tetranematichthys].

Comentários: Trachycorystidae foi criada como uma família a parte de Auchenipteridae e Ageneiosidae por Miranda Ribeiro em 1911 (ou 1914, de acordo com Eschemeyer, 2010), entretanto foi ignorada nos trabalhos de Ferraris \& de Pinna (1999) e Ferraris (2007), apesar de ter sido mencionada em Ferraris (1988).

Diagnose: A tribo Trachelyopterini é diagnosticada pela nadadeira caudal truncada (\#317, condição também presente em Tetranematichthys, Ageneiosus inermis, A. polystictus, mas ausente em Trachycorystes); 9 a 12 raios ramificados no lobo ventral da nadadeira caudal (\#323, condição também presente em Tetranematichthys, porém ausente em Tracycorystes e Auchenipterichthys); oitava vértebra parcialmente fusionada à vertebra complexa (\#230, condição também presente em Centromochlus, Tocantinsia, mas ausente em Trachelyichthys).

Gêneros incluídos: Auchenipterichthys, Parauchenipterus, Trachelyichthys, Trachelyopterichthys, Trachelyopterus e Trachycorystes.

\section{Trachelyichthys Mees, 1974}

Trachelyichthys Mees, 1974: 111 (espécie-tipo: Trachelyichthys decaradiatus Mees, por 
designação original).

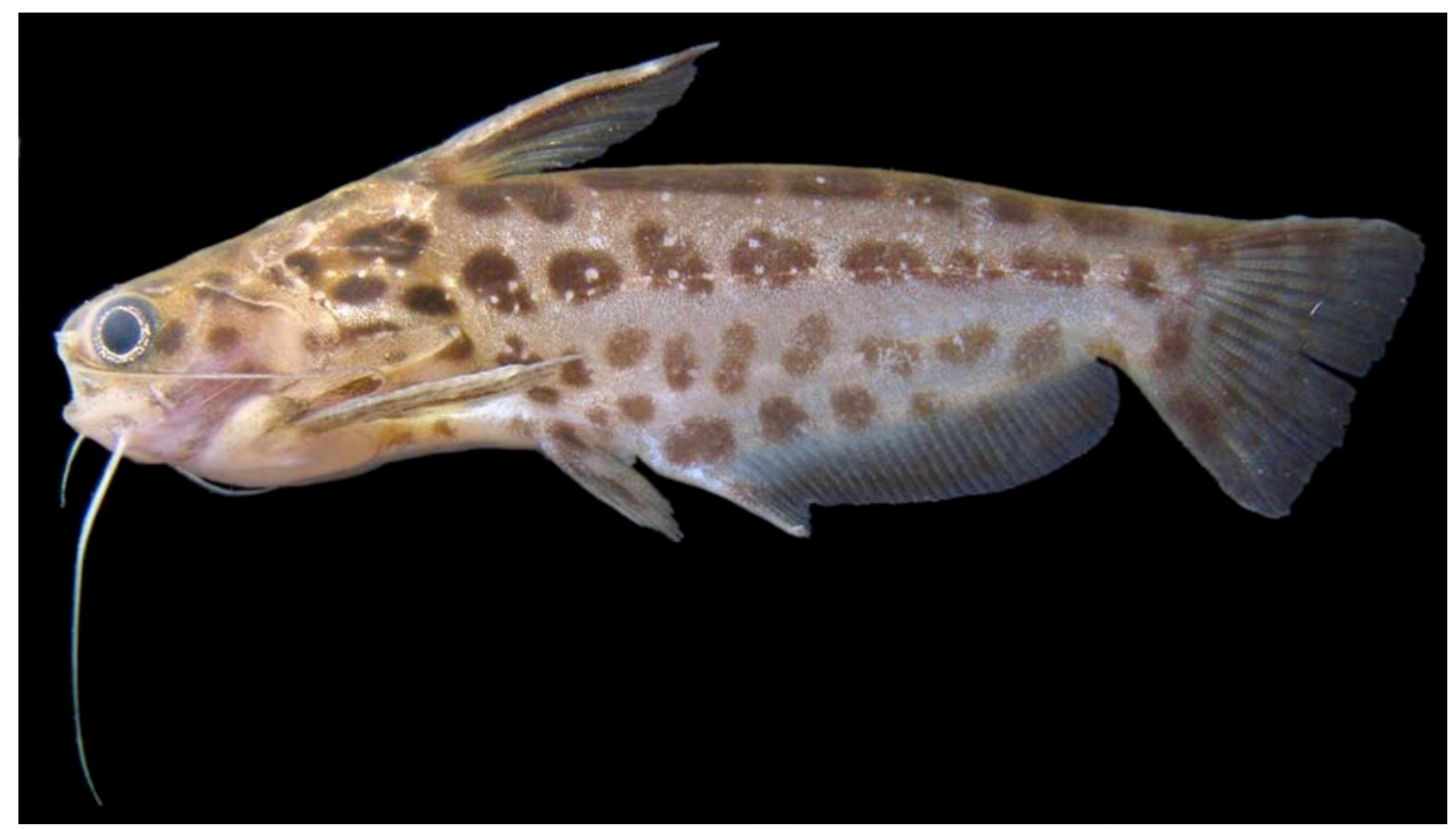

Figura 111. Trachelyichthys decaradiatus, MZUSP 92829, c. 40 mm, rio Amazonas, Santarém, PA (foto de Leandro Sousa).

Diagnose: Trachelyichthys é diagnosticado pela nadadeira adiposa ausente (\#3, condição presente também em Epapterus, Trachelyopterichthys e Trachelyopterus); fontanela anterior redonda (\#66); 9 a 16 raios ramificados na nadadeira pélvica (\#288, condição presente também em Auchenipterus, Pseudepapterus, Epapterus e Trachelyopterichthys); 36 a 40 raios (totais) na nadadeira anal (\#303, condição presente também em Tetranematichthys, Auchenipterus e algumas espécies de Ageneiosus); 9 a 12 raios ramificados no lobo ventral da nadadeira caudal (\#323, condição presente também em Tetranematichthys, Trachelyopterus e Parauchenipterus).

Táxons incluídos: Trachelyichthys decaradiatus e T. exilis.

Comentários: Britski (1972), em sua tese não publicada, havia proposto o nome "Pseudotrachelyopterus hossnei" para a espécie decrita dois anos depois por Mees como Trachelyichthys decaradiatus. As duas espécies de Trachelyichthys consideradas válidas (Ferraris, 2007) são extremamente semelhantes e diferenciáveis, segundo os 
autores de Trachelyichthys exilis, apenas por proporções morfométricas do processo posterior do cleitro e do corpo (Greenfield \& Glodek, 1974). Há uma espécie nova do gênero que ocorre nos rios Negro e Orinoco (Royero, 1999), distinguível das congêneres pelo número total de raios da nadadeira anal (mais de 38, vs. menos de 38) e pelo corpo escuro uniforme ( $v s$. claro com manchas escuras).

\section{Auchenipterichthys Bleeker, 1862}

Auchenipterichthys Bleeker, 1862: 7 (espécie-tipo: Auchenipterus thoracatus Kner, por designação original).

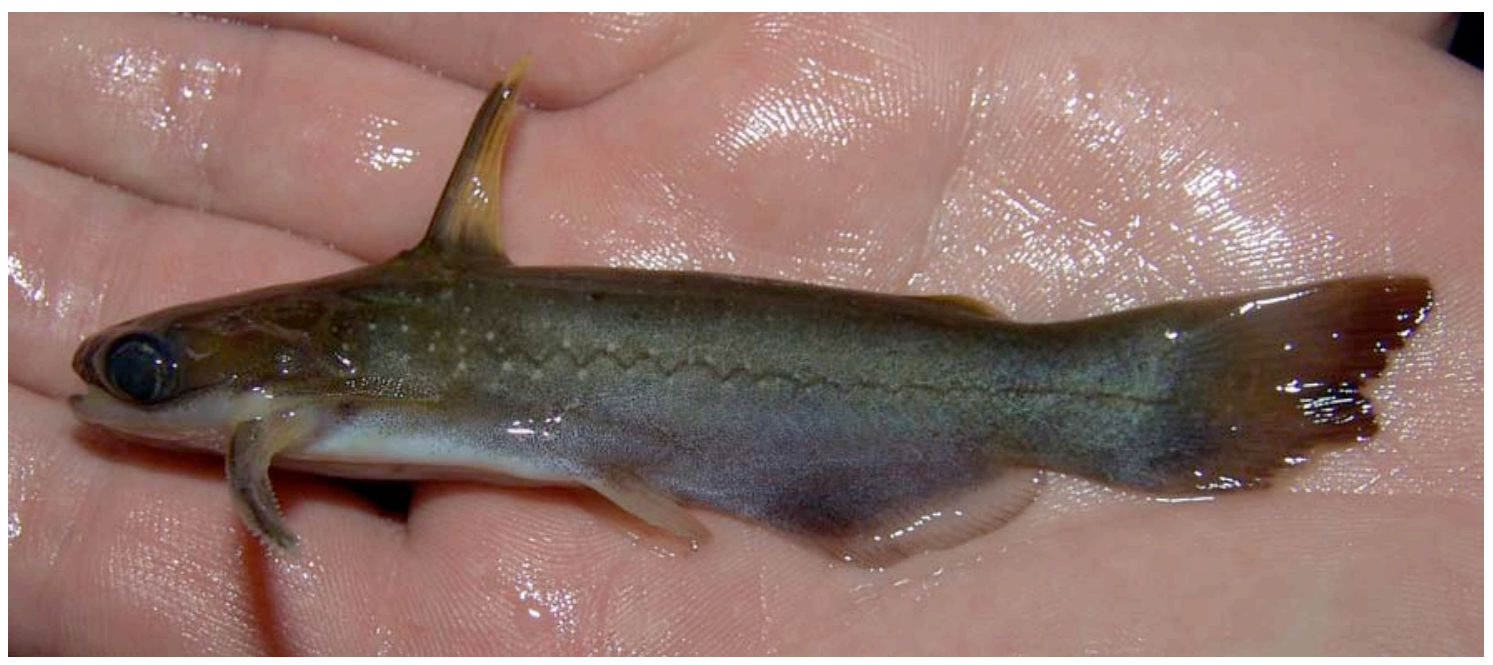

Figura 112. Auchenipterichthys longimannus, INPA sem $\mathrm{n}^{\circ}, \mathrm{c} .80 \mathrm{~mm}$, rio Tapajós, Itaituba, PA.

Diagnose: Auchenitperichthys é diagnoticado pela bexiga natatória com câmara secundária pequena (\#40); espinhos hipertrofiados na margem posterior do acúleo da nadadeira dorsal em machos maduros (\#259, condição presente também em Trachelyopterichthys); 21 a 31 raios (totais) na nadadeira anal (\#303, condição presente também em Entomocorus, Pseudauchenipterus, "Amplexiglanis", Parauchenipterus, Trachelyopterus e algumas espécies de Ageneiosus).

Táxons incluídos: Auchenipterichthys coracoideus, A. longimanus, A. punctatus e A. thoracatus. 
Comentários: O gênero Auchenipterichthys foi recentemente revisado por Ferraris et al., (2005).

\section{Parauchenipterus Bleeker, 1862}

Parauchenipterus Bleeker, 1862: 7 (espécie-tipo: Silurus galeatus Linnaeus, por designação original).

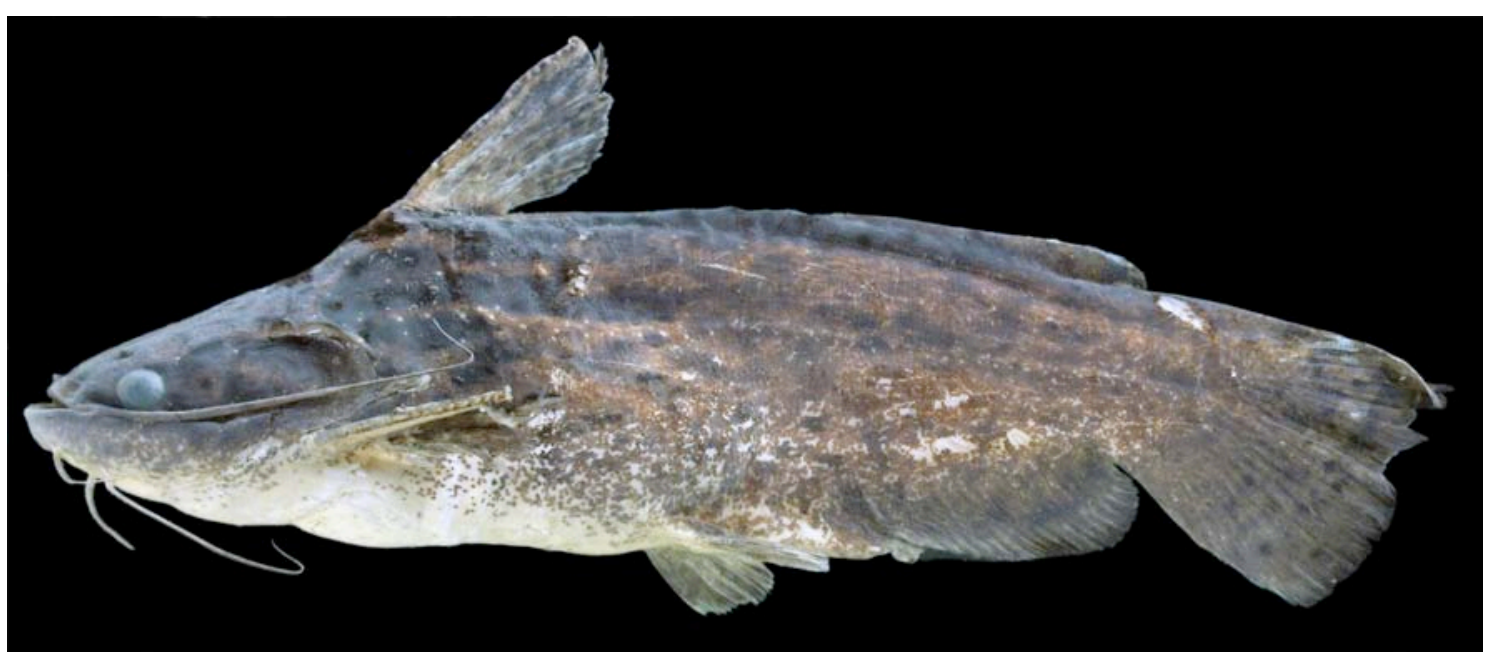

Figura 113. Parauchenipterus galeatus, MZUSP 104794, 113.8 mm, rio Jari, Monte Dourado, PA.

Diagnose: Parauchenipterus é diagnosticado pela um par de divertículos terminais distalmente separados (\#39); maxilar alongado em machos maduros (\#142, condição presente também em Tetranematichthys, Entomocorus, Auchenipterus, Pseudepapterus, Epapterus e "Amplexiglanis"); três pares de músculos inclinadores dos raios da nadadeira dorsal (\#261, condição presente também em Trachelyopterus, Pseudepapterus e algumas espécies de Ageneiosus); 21 a 28 raios (totais) na nadadeira anal (\#303, condição presente também em Entomocorus, Pseudauchenipterus, "Amplexiglanis", Auchenipterichthys, Trachelyopterus e algumas espécies de Ageneiosus); 9 a 12 raios ramificados no lobo ventral da nadadeira caudal (\#324, condição presente também em Tetranematichthys, Trachelyopterus e Trachelyichthys).

Táxons incluídos: Parauchenipterus ceratophysus, $P$. galeatus, $P$. porosus e $P$. 
striatulus.

Comentários: Akama (2004) fez uma revisão taxonômica das espécies de Parauchenipterus e Trachelyopterus, considerando os dois gêneros válidos e grupos irmãos. Ferraris (2007) considerou os dois gênero sinônimos, reunindo todas as espécies em Trachelyopterus.

\section{Trachelyopterus Valenciennes, 1840}

Trachelyotperus Valenciennes, 1840: 220 (espécie-tipo: Trachelyopterus coriaceus Valenciennes, por monotipia).

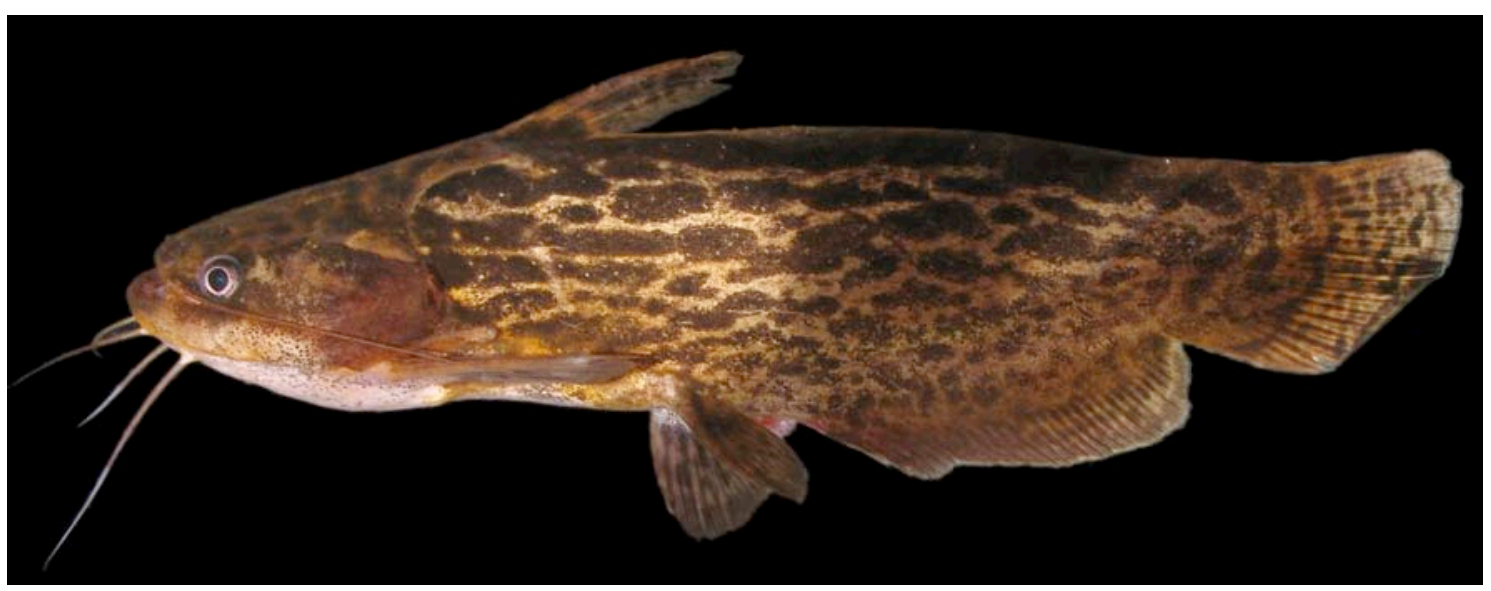

Figura 114. Trachelyopterus coriaceus, MZUSP 104773, 112.2 mm, rio Jari, Monte Dourado, PA.

Diagnose: Trachelyopterus é diagnosticado pela nadadeira adiposa ausente (\#3, condição presente também em Epapterus, Trachelyichthys e Trachelyopterichthys); barbilhões mentonianos longos, ultrapassando a base da nadadeira peitoral (\#19, condição presente também em Auchenipterus, Entomocorus, Pseudauchenipterus, Pseudepapterus e Epapterus); aba na extremidade do gonopódio (\#55); margem póstero-ventral do coracóide achatada ventralmente, aparentemente exposta (\#284, condição presente também em algumas espécies de Auchenipterichthys); três pares de músculos inclinadores dos raios da nadadeira dorsal (\#261, condição presente também 
em Parauchenipterus, Pseudepapterus e algumas espécies de Ageneiosus); 28 a 33 raios (totais) na nadadeira anal (\#303, condição presente também em Parauchenipterus, “Amplexiglanis", Auchenipterichthys, e algumas espécies de Ageneiosus); 9 a 12 raios ramificados no lobo ventral da nadadeira caudal (\#324, condição presente também em Tetranematichthys, Parauchenipterus, Trachelyichthys).

Táxon incluído: Trachelyopterus coriaceus.

Comentários: Akama (2004) fez uma revisão taxonômica das espécies de Parauchenipterus e Trachelyopterus, considerando os dois gêneros válidos. Trachelyopterus coriaceus é uma espécie que ocorre na bacia amazônia, enquanto que há uma nova especie do gênero que ocorre na bacia do rio Paraguai (Akama, 2004).

\section{Trachycorystes Bleeker, 1858}

Trachycorystes Bleeker, 1858: 200 (espécie-tipo: Auchenipterus trachycorystes Valenciennes, por tautonomia).

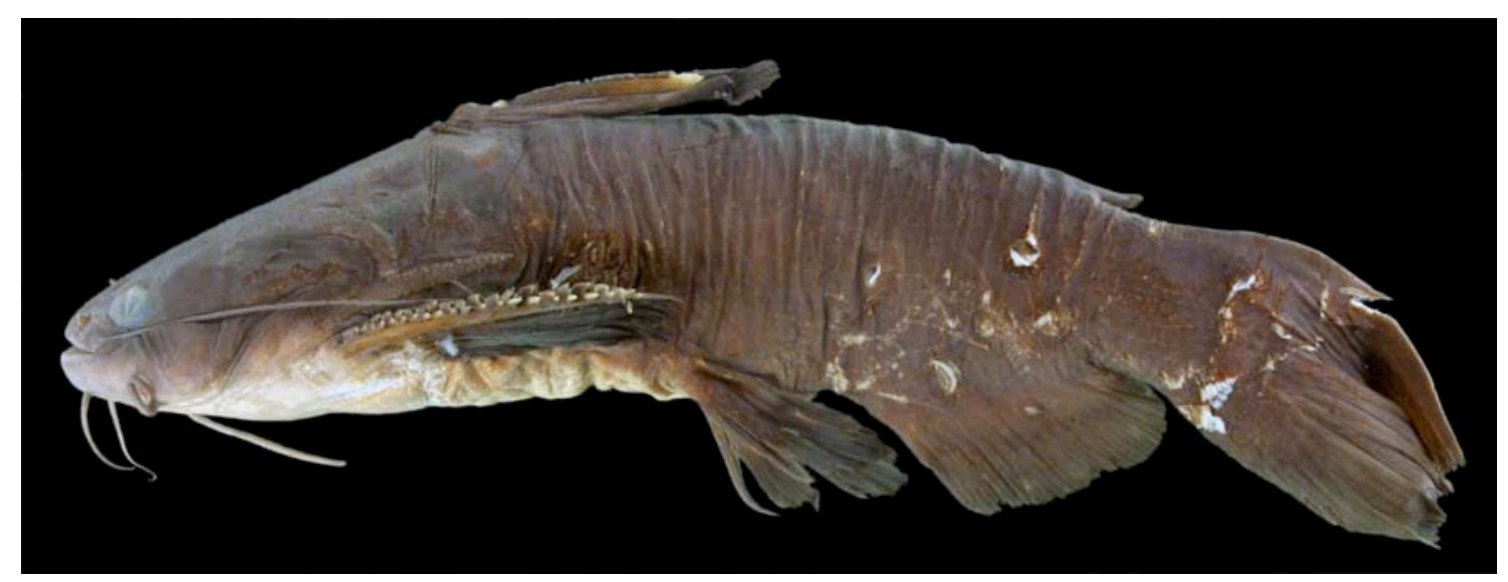

Figura 115. Trachycorystes trachycorystes, MZUSP 103186, 163.9 mm, rio Tiquié, AM.

Diagnose: Trachycorystes é diagnosticado pela bexiga natatória com divertículos terminais (\#39) e divertículos posteriores digitiformes (\#41, presentes também em Tocantinsia); epoccipital participando da margem lateral do escudo cefálico (\#95, condição presente também em Asterophysus e Liosomadoras); processo posterior do 
epoccipital predominantemente cartilaginoso (\#96, condição presente também em Centromochlinae, Liosomadoras e Tocantinsia); último infra-orbital expandido (\#115); 8 raios ramificados na nadadeira pélvica (\#288); 18 a 19 raios (totais) na nadadeira anal (\#303, condição presente também em Entomocorus, Pseudauchenipterus e “Amplexiglanis").

Táxons incluídos: Trachycorystes cratensis e T. trachycorystes.

Comentários: Britski et al. estão descrevendo uma nova espécie do gênero Trachycorystes.

\section{Trachelyopterichthys Bleeker, 1862}

Trachelyopterichthys Bleeker, 1862: 16 (espécie-tipo: Trachelyopterus taeniatus Kner, por designação original).

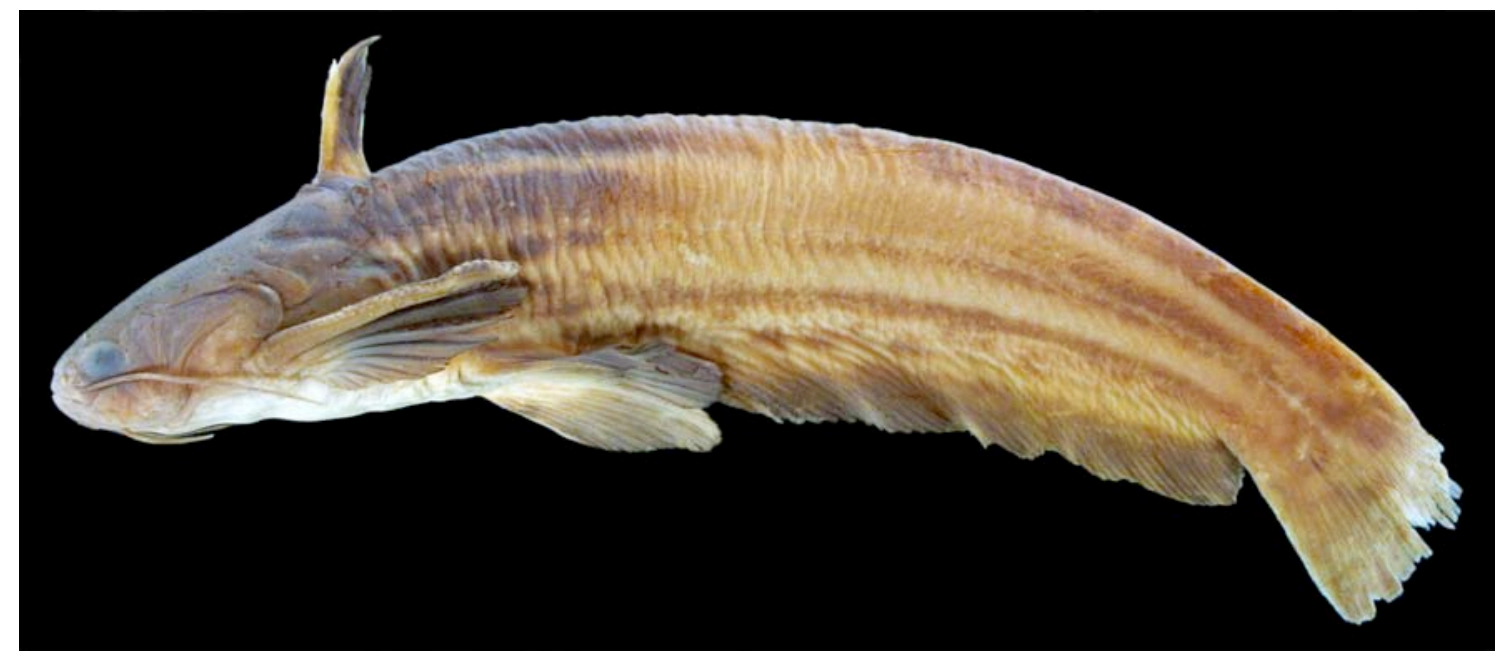

Figura 116. Trachelyopterichthys taeniatus, MZUSP 8496, 114 mm, rio Mapiri, Santarém, PA.

Diagnose: Trachelyopterichthys é diagnosticado pela nadadeira adiposa ausente (\#3, condição presente também em Epapterus, Trachelyotperus e Trachelyichthys); abertura urogenital de fêmeas espassa e intumescida (\#58); 4 raios ramificados na nadadeira dorsal (\#251, condição presente também em Epapterus e Pseudepapterus); espinhos hipertrofiados na metade distal do acúleo da nadadeira dorsal de machos maduros 
(\#259, condição presente também em Auchenipterichthys); espinhos na face dorsal do acúleo da nadadeira peitoral (\#273, condição presente também em algumas espécies de Parauchenipterus); 9 a 16 raios ramificados na nadadeira pélvica (\#288, condição presente também em Trachelyichthys, Epapterus, Pseudepapterus e Auchenipterus); 39 ou 52 a 58 raios (totais) na nadadeira anal (\#303, condição similar em algumas espécies de Tetranematichthys, Ageneiosus, Auchenipterus, Epapterus e Pseudepapterus).

Táxons incluídos: Trachelyopterichthys anduzei e T. taeniatus.

Comentários: O gênero Trachelyopterichthys foi revisado por Ferraris \& Fernandez (1987).

\section{Capítulo 5. Discussão}

\subsection{Relações filogenéticas da superfamília Doradoidea}

A relação entre a subordem Doradoidei e os demais Siluriformes é, assim como o estudo sobre relações filogenética entre famílias de Siluriformes, um assunto complexo e difícil de ser estudado, dado principalmente o hiato morfológico que há entre as famílias (Howes, 1983). O presente estudo não corroborou a relação entre Ariidae e Doradoidei, proposta por Royero (1987, 1999) e Lundberg (1993) com base em três caracteres: processo lateral do basioccipital presente, processo do epoccipital ligado à parapófise da vértebra complexa e ramo anterior da parapofise da vértebra complexa, móvel, modificado formando o ramo de Müller do elastic spring apparatus. Como visto na descrição dos caracteres, o processo lateral do basioccipital está presente em muitas outras famílias de Siluriformes, e o processo do epoccipital e o ramo de Müller possuem morfologias diferentes em Ariidae e Doradoidea. Ao invés disso, a relação entre Doradoidei, Sisoroidea e Amphiliidae foi corroborada por uma série de 
caracteres não exclusivos (ver 'Sistemática da superfamília Doradoidea'). A relação entre a família africana Amphiliidae e a superfamília asiática/neotropical Sisoroidea já havia sido proposta por Diogo (2004). de Pinna (1993, 1998) e Britto (2002) consideraram Amphiliidae como relacionada à superfamília Loricarioidea, considerando este clado relacionado (ou próximo) à Sisoroidea.

A relação de grupo irmão entre a superfamília neotropical Doradoidea e a família africana Mochokidae foi proposta e corroborada por diversos autores desde Günther (1864). No presente estudo, dez sinapomorfias foram encontradas suportando essa relação, das quais cinco são exclusivas em Siluriformes. Esses dados corroboram os estudos morfológicos anteriores e fornecem ainda mais evidências a favor da hipótese de relação entre Mochokidae e Doradoidea, contrariando, assim, os dados moleculares recentes (Sullivan et al., 2006; Sullivan et al., 2008).

Apesar da relação de grupo irmão entre Mochokidae e Doradoidea ter sido corroborada, esse estudo foi importante para rever e testar as sinapomorfias que sustentavam esse grupo nas hipóteses prévias. Como visto na discussão dos caracteres, algumas das sinapomorfias para Mochokidae e Doradoidea foram aqui consideradas simplesiomorfias, presentes também em outras famílias de Siluriformes (e.g. processo posterior do epoccipital, Chardon, 1968). Já alguns outros caracteres que também foram considerados sinapomorfias do grupo por outros autores, como a simples presença de elastic spring apparatus (Regan, 1911; Chardon, 1968), ao serem estudados em profundidade mostraram ser convergentes em muitos aspectos: o ramo de Müller e a musculatura sonora associada apresentam morfologias e arranjos completamente diferentes nos dois grupos. Por outro lado, caracteres que pareciam comuns a diversos grupos de Siluriformes (Ferraris, 1988), como o ligamento entre a primeira costela e a placa nucal posterior se revelaram sinapomorfias exclusivas de Mochokidae e 
Doradoidea.

De forma similar, o presente estudo encontrou nove autapomorfias exclusivas da superfamília Doradoidea, além de algumas outras não exclusivas; entre elas: o músculo protractor do ramo de Müller com origem do teto do crânio e inserção na haste do ramo de Müller; o ramo anteiror da parapófise da vértebra complexa (ramo de Müller) móvel e modificado num disco com haste curta e conectado dorsalmente à parede da bexiga natatória; e a parapófise da quinta vértebra rudimentar ou ausente. Estas características já havia sido vistas e descritas por alguns autores, porém não haviam sido utilizadas dessa forma, ou seja, como sinapomorfias exclusivas das famílias Doradidae e Auchenipteridae.

\subsection{Relações filogenéticas da família Doradidae}

O monofiletismo da família Doradidae foi suportado por três características exclusivas: o ligamento ossificado entre a placa nucal posterior e a costela da sexta vértebra (=escudo infranucal), o ligamento entre o ramo de Müller e os escudos timpânicos, e a ossificação dos túbulos da linha lateral formando a série de escudos laterais. Duas das características citadas já haviam sido porpostas como sinapomorfias para Doradidae por outros autores. Contudo, o ligamento entre o ramo de Müller e os escudos timpânicos, apesar de já ter sido descrito para algumas espécies há muito tempo (Sörensen, 1895; Ladich, 2001), não havia sido mencionado em estudos de sistemática do grupo, apesar de constituir uma sinapomorfia exclusiva da família, aparentemente presente em todas as espécies do grupo.

A hipótese obtida no presente estudo também corrobora a proposta de Higuchi (1992), por considerar Wertheimeria e Franciscodoras táxons relativamente basais na família, por considerar a subfamília Doradinae monofilética e composta por três tribos. 
Mas difere da mesma principalmente por considerar Kalyptodoras grupo irmão de Wertheimeria, Centrochir não relacionado aos "Pterodoradini", Acanthodoras e Agamyxis relacionados às espécies da subfamília Astrodoradinae, a tribo "Rhinodoradini" grupo irmão da tribo Doradini, a subtribo "Trachydoradina" (sensu Higuchi, 1992) parafilética, e por considerar Nemadoras polifilético. Os resultados de Higuchi (1992) foram baseados em relativamente poucos exemplares e, na matriz de caracteres havia apenas uma espécie de cada gênero. Além disso, alguns caracteres relacionados a estruturas mais internas e, portanto, mais difíceis de serem visualizadas, foram codificados erroneamente, influenciando a hipótese final obtida por Higuchi (1992).

Moyer et al. (2004), com base em dados moleculares, obtiveram uma hipótese de relacionamento de doradídeos bastante estranha em alguns pontos, mas interessante em outros. Moyer et al. (2004) consideraram "Nemadoras" ternetzi como relacionado a "Nemadoras" trimaculatus, sugerindo que gênero Nemadoras fosse polifilético; e também não corroboraram o monofiletismo da subtribo Trachydoradina (sensu Higuchi, 1992). Por outro lado, Moyer et al. (2004) consideraram Oxydoras como relacionado a Pterodoras e Doraops (e não aos Doradini), algo que destoa de todos os estudos morfológicos desde Cuvier \& Valenciennes (1840); além de terem considerado "Pterodoradini" polifilético, e Acanthodoras e Agamyxis gêneros não relacionados entre si.

O presente estudo difere da hipótese anterior (Birindelli, 2006) principalmente pela maior representatividade de táxons (55 espécies incluídas, vs. 46), por considerar a “subfamília Platydoradinae” (sensu Higuchi, 1992) polifilética, sendo Acanthodoras e Agamyxis relacionados às espécies de Astrodoradinae, ao relacionamento entre Platydoras e Doradinae, e ao relacionamento dos gêneros de "Pterodoradini". 


\subsection{Relações filogenéticas da família Auchenipteridae}

O monofiletismo da família Auchenipteridae é suportado por algumas características exclusivas, como a abertura urogenital na base ou na extremidade dos raios anteriores da nadadeira anal em machos, abertura urogenital imediatamente anterior à nadadeira anal em fêmeas, sulco suborbital e linhas de neuromastos dorsais à linha lateral. Algumas dessas, e muitas das sinapomorfias dos clados dentro de Auchenipteridae, estão relacionadas à reprodução com fecundação interna através de inseminação e ao dimorfismo sexual, características únicas de Auchenipterdiae entre Siluriformes.

O presente estudo corroborou muitos dos caracteres propostos para espécies e grupos de espécies de auchenipterídeos pelos autores anteriores (i.e., Britski, Ferraris, Walsh, Curran, Royero, Akama). Com isso, muitas da hipóteses anteriores foram corroboradas, como a divisão da família em duas subfamílias: Centromochlinae e Auchenipterinae (proposta inicialmente por Ferraris, 1988, e corroborada por SoaresPorto, 1998, e Akama, 2004); os dois clados compostos por "Amplexiglanis", Tetranematichthys e Ageneiosus, e Entomocorus, Auchenipterus, Epapterus e Pseudepapterus, corroborados por todos os estudos desde Miranda Ribeiro (1968a,1968b, 1968c) e Britski (1972); e a tribo Auchenipterini, formada por "Amplexiglanis", Tetranematichtys, Ageneiosus, Entomocorus, Auchenipterus, Pseudepapterus e Epapterus, corroboradas por Ferraris (1988) e Akama (2004).

Na hipótese de Royero (1999), o clado Entomocorus, Auchenipterus, Pseudepapterus e Epapterus apresenta-se como grupo irmão dos demais auchenipterídeos. Isso se deve principalmente pelo fato de Entomocorus possuir, além 
de muitos caracteres compartilhados com Auchenipterus, Pseudepapterus e Epapterus, muitos caracteres que são únicos entre os auchenipterídeos, e compartilhados apenas com outros Siluriformes (Reis \& Borges, 2006). Essa combinação de características faz com que todo o clado Entomocorus, Auchenipterus, Pseudepapterus e Epapterus seja considerado basal em Auchenipteridae quando poucos caracteres compartilhados entre esses táxons e os demais da tribo Auchenipterini são incluídos, principalmente aqueles relacionados às características secundárias de dimorfismo sexual.

A tribo Trachelyopterini, um grupo monofilético composto pelos gêneros Trachelyichthys, Auchenipterichthys, Parauchenipterus, Trachelyopterus, Trachycorystes e Trachelyopterichthys, havia sido apenas parcialmente obtida em outros estudos. Britski (1972) considerou esse grupo, com exceção de Trachelyichthys, monofilético, e Akama (2004) considerou o grupo monofilético com a inclusão de Liosomadoras; enquanto os outros autores (i.e., Ferraris, Royero) o consideraram parafilético. A posição relativamente basal dos gêneros Asterophysus, Tocantinsia, Liosomadoras, Pseudauchenipterus e Pseudotatia em Auchenipterinae, corrobora também, no geral, o que havia sido obtido por outros autores. A relação de Pseudauchenipterus e Pseudotatia, apesar de corroborada por alguns poucos caracteres é também interessante dada a distribuição desses táxons: Pseudauchenipterus restrito às bacias costeiras, principalmente no leste do Brasil, e Pseudotatia endêmica do rio São Francisco. Esse resultado corrobora o que foi encontrado por Akama (1999).

\subsection{Padrões biogeográficos da superfamília Doradoidea}

A hipótese de relacionamento entre a superfamília Neotropical Doradoidea e a família Africana Mochokidae é interessante por ser o único exemplo de um grupo de Siluriformes e um dos poucos exemplos em peixes de água doce que se originou na 
Gondwana (Lundberg, 1993). A fragmentação desse supercontinente data de 90 a 112 milhões de anos (Lundberg et al., 1998), o que pode ser interpretado como a idade da cladogênese entre Doradoidea e Mochokidae.

Dentro da família Doradidae, a elevação da Serra do Mar, como resultado da fragmentação da Gondwana e do deslocamento da América do Sul para oeste, e a conseqüente formação das drenagens litorâneas do leste brasileiro (Ribeiro, 2006), é um evento importante que pode ser interpretado como responsável pela cladogênese entre o clado Wertheimeria, Kalyptodoras, e os demais doradídeos. Esse evento teria ocorrido logo depois da separação da América do Sul e da Africa, no fim do Cretáceo, entre 75 e 90 milhões de anos atrás (Ribeiro, 2006). De forma similar, Franciscodoras marmoratus, uma espécie endêmica do rio São Francisco e grupo irmão dos demais doradídeos (exceto Wertheimeria e Kalyptodoras), pode ser interpretada também como uma espécie de distribuição relictual, isolada das demais linhagens de doradídeos pela formação da bacia do rio São Francisco, no fim do Cretáceo, começo do Cenozóico.

Em Auchenipteridae, a subfamília Centromochlinae apresenta uma situação semelhante, com Glanidium basicamente restrito às bacias do Sudeste do Brasil, enquanto que as espécies de Tatia e Centromochlus ocorrem nas bacias do Prata, Amazonas, Orinoco e das Guianas. Dentro de Auchenipterinae, esse padrão não é encontrado, e gêneros relativamente derivados apresentam grande distribuição geográfica como, por exemplo, Parauchenipterus.

Ambas as famílias Auchenipteridae e Doradidae possuem táxons endêmicos em bacias trans-andinas, como a do rio Magdalena e do Lago Maracaibo. Esses táxons são, no geral, espécies de gêneros com ampla distribuição cis-andina, como é o caso de Centrochir crocodili (possivelmente relacionada à Platydoras), Rhinodoras thomersoni, Doraops zuloagai (relacionada a Pterodoras e Lithodoras dorsalis), Ageneiosus 
pardalis e "Amplexiglanis". A idade de cada um dos eventos cladogênicos que deu origem a esses táxons deve datar entre 8 a 11.8 milhões de anos, pois esta é a idade da elevação da porção mais ao norte dos Andes, responsável pela formação dessas bacias trans-andinas (Lundberg et al., 1998).

Por outro lado, o estudo da distribuição de algumas espécies de auchenipterídeos e doradídeos evidencia a recente ligação que existiu entre as bacias Amazônica e do Paraguai através das chamadas bacias de anti-país, resultantes da ainda ativa urogênese andina (Lima \& Ribeiro, em preparação). Entre elas estão os doradídeos Platydoras armatulus, Pterodoras granulosus, Trachydoras paraguayensis, "Petalodoras" punctatus, e os auchenipterídeos A. ucayalensis, Auchenipterus osteomystax e Epapterus dispilurus, que ocorrem tanto na bacia Amazônica como na do Paraguai. A distribuição de espécies que ocorrem em áreas baixas das bacias Amazônica e do Orinoco, como Platydoras armatulus, Ageneiosus vittatus, Auchenipterichthys longimanus e Auchenipterus ambyacus, pode ser entendida como resultante do mesmo processo geológico (Lima \& Ribeiro, em preparação). Já a distribuição dos doradídeos Acanthodoras cataphractus, Hassar orestis, Leptodoras praelongus, L. linnelli, L. copei, L. hasemani, "Nemadoras" trimaculatus, "Nemadoras" ternetzi, "Nemadoras" leporhinus, Hemidoras stubelii, Physopyxis ananas, Platydoras hanchoki, Scorpiodoras heckelii, Trachydoras microstomus, e dos auchenitperídeos Asterophysus batrachus, Auchenipterichthys punctatus, Centromochlus heckelii, Gelanoglanis stroudi, Liosomadoras oncinus, Tatia galaxias, Tetranematichthys wallacei e Trachycorystes trachycorystes, que ocorrem também nas bacias Amazônica e do Orinoco, deve-se provavelmente à ligação entre estas bacias através do canal de Cassiquiare ("Brazo Cassiquiari”) e rios nos entornos.

Assim como ocorre com a outros grupos de peixes de água doce, a maior 
diversidade de espécies está na bacia Amazônica, o que é explicado principalmente pela grande área ocupada por esta drenagem, por sua enorme diversidade de habitats e estabilidade climáticas ao longo do tempo geológico. Além disso, no caso dos doradídeos e auchenipterídeos, a maioria das espécies ocorre preferencialmente nas áreas baixas das planícies de inundação, sendo menor o número de espécies que vivem nas áreas altas dos escudos cristalinos (Sabaj \& Ferraris, 2003; Birindelli \& Sousa, 2010). Esse mesmo padrão difere do encontrado em ancistrínes, hypoptopomatínes, anostomídeos, parodontídeos, entretanto coincide com o padrão encontrado em os cichlídeos, pimelodídeos, cetopsídeos, e pode ser entendido pela ecologia das espécies, que preferem ambientes maiores, com rítmo sazonal mais marcado, e com maior a oferta de alimento. 


\section{Referências bibliográficas citadas}

Acero P., A. \& R. Betancur-R. 2007. Monophyly, affinities, and subfamilial clades of sea catfishes (Siluriformes: Ariidae). Ichthyological Explorations of Freshwaters, 18(2): 133-143.

Agostinho, A. A., Gomes, L. C., Suzuki, H. I \& H. F. Júlio Jr.. 2003. Migratory fishes of the Upper Paraná River Basin, Brazil. Pp. 19-98 in Carolsfeld, J., Harvey, B., Ross, C. \& A. Baer (eds.), Migratory fishes of South America: Biology, Fisheries and Conservation Status. IDRC and World Bank, 372p.

Akama, A. 1999. Sistemática do gênero Pseudauchenipterus Bleeker, 1862 (Siluriformes, Auchenipteridae). Dissertação de mestrado não publicada, Universidade de São Paulo, São Paulo, 123p.

Akama, A. 2004. Revisão sistemática dos gêneros Parauchenipterus Bleeker, 1862 e Trachelyopterus Valenciennes, 1840 (Siluriformes, Auchenipteridae). Tese de doutorado não publicada, Universidade de São Paulo, São Paulo, 375p.

Akama, A. \& C. J. Ferraris Jr. 2003. Entomocorus melaphareus, a new species of auchenipterid catfish (Osteichthyes: Siluriformes) from the lower and middle reaches of the rio Amazonas. Neotropical Ichthyology, 1(2): 77-82.

Alexander, R. M. 1964. The structure of the Weberian Apparatus in the Siluri. Proceedings of the Zoological Society of London, 142(3): 419-440.

Alexander, R. M. 1965. Structure and function in the catfish. Journal of Zoology, 148: 88-152.

Alexander, R. M. 1966. Physical aspects of swimbladder funtion. Biological Reviews, 41: 141-176.

Allis, E. P. 1903. The skull and cranial and first spinal muscles and nerves of Scomber scomber. Journal of Morphology, 18: 45-328.

Amorim, D. S. 2002. Fundamentos de Sistemática Filogenética. Holos Editora, Ribeirão preto, $156 \mathrm{p}$.

Armbruster, J. W. 2004. Phylogenetic relationships of the suckermouth armoured catfishes (Loricariidae) with emphasis on the Hypostominae and Ancistrinae. Zoological Journal of the Linnean Society, 141: 1-80.

Arratia, G. 1987. Description of the primitive family Diplomystidae (Siluriformes, Teleostei, Pisces): morphology, taxonomy and phylogenetic implications. Bonner Zoologische Monographien, 24: 1-120.

Arratia, G. 1992. Development and variation of the suspensorium of primitive catfishes (Teleostei: Ostariophysi) and their phylogenetic relationships. Bonner Zoologische Monographien, 32: 1-149.

Arratia, G. 2003a. Catfish Head Skeleton, an overview. Pp. 3-46. In: Arratia, G., B. G. Kapoor, M. Chardon \& R. Diogo (Eds.). Catfishes. Enfield, Science Publishers, Inc., $812 p$.

Arratia, G. 2003b. The Siluriform Postcranial Skeleton, an overview. Pp. 121-158. In: Arratia, G., B. G. Kapoor, M. Chardon \& R. Diogo (Eds.). Catfishes. Enfield, 
Science Publishers, Inc., 812p.

Arratia, G. \& L. Huaquin. 1995. Morphology of the lateral line system and of the skin of Diplomystid and certain primitive Loricarioid catfishes and systematic and ecological considerations. Bonner, Zoologische Monographien, 36: 1-109.

Arratia, G. \& H. P. Schultz. 1990. The urohyal: development and homology within osteoichthyans. Journal of Morphology, 203: 247-282.

Bailey, R. M. \& J. N. Baskin. 1976. Scoloplax dicra, a new armored catfish from the Bolivian Amazon. Occasional Papers of the Museum of Zoology, 674: 1-14.

Baskin, J. N. 1973. Structure and relationships of Trichomycteridae. Tese de doutorado não publicada, The City University of New York, New York, 389p.

Berg, L. S. 1940. Classification of fishes, both recent and fóssil. Trudy Instituta Zoologii/Akademiia Nauk, Azerbaidzhanskoi SSR, 5: 87-517.

Birindelli, J. L. O. 2006. Revisão taxonômica do gênero Rhinodoras Bleeker, 1862 (Siluriformes, Doradidae) Dissertação de mestrado não publicada, Universidade de São Paulo, São Paulo, 274p.

Birindelli, J. L. O. 2008. Kalyptodoras bahiensis. Pp. 203-204. In: Machado, A. B. M., G. M. Drummond \& A. P. Paglia. Livro Vermelho da Fauan Brasileira Ameaçada de Extinção. Brasília, Ministério do Meio Ambiente, 906p.

Birindelli, J. L. O., A. Akama \& H. A. Britski (em preparação). Morphology of the gas bladder in driftwood catfishes (Siluriformes: Auchenipteridae).

Birindelli, J. L. O., M. H. Sabaj, D. C. Taphorn. 2007. New Species of Rhynchodoras from the Río Orinoco, Venezuela, with Comments on the Genus (siluriformes: Doradidae). Copeia, 2007(3): 672-684.

Birindelli, J. L. O., L. M. Sousa \& M. H. Sabaj Pérez. 2008. New species of thorny catfish, genus Leptodoras Boulenger (Siluriformes: Doradidae), from Tapajós and Xingu basins, Brazil. Neotropical Ichthyology, 6(3): 465-480.

Birindelli, J. L. O., L. M. Sousa \& M. H. Sabaj Pérez. 2009. Morphology of the gas blader in thorny catfishes (Siluriformes: Doradidae). Proceedings of the Academy of Natural sciences of Philadelphia, 158: 261-296.

Birindeli, J. L. O. \& L. M. Sousa. 2010. New Species of Thorny Catfish Genus Leptodoras (Siluriformes: Doradidae) from Rio Fresco, Xingu Basin, Brazil. Copeia 2010(2): 293-300.

Birindelli, J. L. O. \& Sabaj Pérez. (em preparação). A new genus of thorny catfish with redescription of three species and description of a new species.

Birindelli, J. L. O. \& O. A. Shibatta (em preparação). Morphology of the gas bladder in bumblebee catfishes (Siluriformes: Pseudopimelodidae).

Bleeker, P. 1858. De visschen van den Indischen Archipel. Beschreven en toegelicht. Siluri. Acta Societatis Regiae Scientiarum Indo-Neêrlandicae, 4: 1-370.

Bleeker, P. 1862-1863. Atlas ichthyologique des Indes Orientales Néêrlandaises, publié sous les auspices du Gouvernement colonial néêrlandais. Tome II. Siluroïdes, Chacoïdes et Hétérobranchoïdes. Amsterdam. Atlas ichthyologique des Indes Orientales Néêrlandaises, publié sous les auspices du Gouvernement colonial 
néêrlandais, 2: 1-112.

Bleeker, P. 1863a. Sur quelques genres nouveauz du groupe des Doras. Nederlansch Tisjdschrift voor de Dierkunde, 1: 10-18.

Bleeker, P. 1863b. Systema Silurorum revisium. Nederlansch Tisjdschrift voor de Dierkunde, 1: 77-122.

Bleeker, P. 1864. Description des espèces de Silures de Suriname, conservées aux Musées de Leide et d'Amsterdam. Natuurkundige Verhandelingen van de Hollandsche Maatschappij der Wetenschappen te Haarlem (Ser. 2), 20: 1-104.

Bloch, M. E. 1794. Naturgeschichte der Ausländischen Fische. Volume 8, Berlin, 174p.

Bloch, M. E. \& J. G. Schneider. 1801. M. E. Blochii, Systema Ichthyologiae Iconibus cx Illustratum. Post Obitum Auctoris Opus Inchoatum Absolvit, Correxit, Interpolavit Jo. Gottlob Schneider, Saxo, Sumtibus Austoris Impressum et Bibliopolio Sanderiano Commissum, Berolini, 584p.

Bockmann, F. A. 1998. Análise filogenética da família Heptapteridae (Teleostei, Ostariophysi, Siluriformes) e redefinição de seus gêneros. Tese de doutorado não publicada, Universidade de São Paulo, São Paulo, 599p.

Bremer, K. 1994. Branch support and tree stability. Cladistics, 10: 295-304.

Bridge, T. W. \& A. C. Haddon. 1892. Contributions to the anatomy of fishes. II. The air-bladder and weberian ossicles in the Siluridae. Phylosophical Transactions of the Royal Society of London (série B), 84: 65-333.

Britski, H. A. 1972. Sistemática e evolução dos Auchenipteridae e Ageneiosidae (Teleostei, Siluriformes). Tese de doutorado não publicada, Universidade de São Paulo, São Paulo, 142p.

Britto, M. R. 2002. Análise filogenética da ordem Siluformes com ênfase nas relações da superfamília Loricarioidea (Teleostei: Ostariophysi). Tese de doutorado não publicada, Universidade de São Paulo, São Paulo, 512p.

Britto, M. R. \& F. C. T. Lima. 2003. Corydoras tukano, a new species of corydoradine catfish from the rio Tiquié, upper rio Negro basin, Brazil (Ostariophysi: Siluriformes: Callichthyidae). Neotropical Ichthyology, 1(2): 8392.

Burgess, W. E. 1989. An Atlas of Freshwater and Marine Catfishes. A preliminary survey of the Siluriformes. Neptune City, T.F.H. Publications, 784p.

Carvalho, F. M. \& E. K. Resende. 1984. Aspectos da Biologia de Tocantinsia depressa (Siluriformes, Auchenipteridae). Amazoniana, 8(3): 327-337.

Castro, R. M. C. \& M. M. C. Castro. 1987. Proposta de uma nomenclatura osteológica para Characiformes (Pisces: Ostariophysi). Boletim do Museu Paraense Emílio Goeldi, série Zoologia, 3: 25-32.

Casteby, M. 1771. The natural history of Carolina, Florida and the Bahamas Island; contaning the figures of birds, beasts, fishes, serpents...with their descriptions in English and French, etc. $3^{\circ}$ edição, 2 volumes. London. [Rejeitado pelo ICZN (opiniões 89 e 259), com exceção do apêndice de Edwards].

Castelnau, F. L. 1855. Poissons. In: Animaux Nouveaux or Rares Recueillis Pendant 
l'Expédition dans les Parties Centrales de l'Amérique du Sud, de Rio de Janeiro à Lima, et de Lima au Para; Exécutée par Ordre du Gouvernement Français Pendant les Années 1843 a 1847, P. Bertrand, Paris, 112p.

Chardon, M. 1968. Anatomie comparée de l'appareil de Weber et structures connexes chez les Siluriformes. Annales de Musée Royale de l'Afrique Central (sér. $8^{\circ}$ ), Sciences Zoologiques, 169: 1-277.

Chardon, M., E. Parmentier \& P. Vandewalle. 2003. Pp. 71-120. In: Arratia, G., B. G. Kapoor, M. Chardon \& R. Diogo (Eds.). Catfishes. Enfield, Science Publishers, Inc., 812p.

Collette, B. B. 1977. Epidermal breeding tubercles and bony contact organs in fishes. Symposium of Zoological Society of London, 39: 225-268.

Cope, E. D. 1878. Synopsis of the fishes os the Peruvian Amazon obtained by Professor Orton during his expedition of 1873 and 1877. Proceedings of the American Philosophical Society, 17(101): 673-701.

Curran, D. J. 1989. Phylogenetic relationships among the catfish genera of the family Auchenipteridae (Teleostei: Siluroidea). Copeia, 1989(2): 408-419.

Cuvier, G. 1817. Le règne animal distribué d'après son organisarion, pour servir de base á l'histoire naturelle des animaux et d'introduction a l'anatomie comparée. Avec figures dessinées d'apès nature. Tome II, contenant les reptiles, les poissons, les mollusques et les annelides. Paris, Deterville, 532p.

Cuvier, G. 1836-1849. Le règne animal distribué d'après son organization pour servir de base a l'histoire naturelle des animaux, et d'introduction a l'anatomie comparee...par une reunion de disciples de Cuvier, MM. Audoin, Blanchard, Deshayes, Alcide D’Orbignyi, Doyère, Dugèws, lenciennes. Paris, F. Masson, 20 volumes.

Cuvier, G. \& A. Valenciennes. 1840. Histoire Naturelle des Poissons. Volume 15. Paris, Strasbourg, Bertrand, Levrault, 540p.

Devincenzi, G. J. \& G. W. Teague. 1942. Ictiofauna del rio Uruguai medio. Anales del Museo de Historia Natural de Montevideo (série 2), 5(4): 1-100.

Diogo, R. 2003. Anatomy, Phylogeny and Taxonomy of Amphiliidae. Pp. 353-384. In: Catfishes. 2 volumes, Enfield, Science Publishers, Inc., 812p.

Diogo, R. 2004. Morphological evolution, adaptations, homoplasies, constraints and evolutionary trends: Catfishes as a case study on generral phylogeny and macroevolution. Enfield, Science Publisher, Inc., 600p.

Eigenmann, C. H. 1925. A review of the Doradidae, a family of South American nematognathi or catfishes. Transactions of the American Philosophical Society, 22: $280-365$.

Eigenmann, C. H. \& R. S. Eigenmann. 1888. Preliminary notes on South American Nematignathi. Proceedings of the California Academy of Sciences (Series 2), 1: 119-172.

Eigenmann, C. H. \& R. S. Eigenmann. 1889. Preliminary notes on South American Nematognathi. II. Proceedings of the California Academy of Sciences (Series 2), 2: $28-56$. 
Eigenmann, C. H. \& R. S. Eigenmann. 1890. A revision of the South American Nematignathi or Catfishes. Occasional Papers of California Academy of Sciences, 1: $1-508$.

Eigenmann, C. H. \& R. S. Eigenmann. 1891. A catalogue of the fresh-water fishes of South America. Proceedings of the United States National Museum, 14(842): 181 .

Eschmeyer, W. N. (Ed.) 2010. Catalog of Fishes electronic version (6 May 2010). http://research.calacademy.org/ichthyology/catalog/fishcatmain.asp

Fernández-Yépez, A. 1950. Un nuevo pez de la familia Doradidae. Memoria, Sociedad de Ciencias Naturales La Salle, 10, 195-198.

Fernández-Yépez, A. 1968. Contribución al conocimiento de la familia Doradidae en Venezuela. Boletín do Instituto Oceanografico de la Universidad del Oriente, 7(1): 7-72.

Ferraris Jr., C. J. 1988. The Auchenipteridae: putative monophyly and sistematics, with classification of the neotropical Doradoid catfishes (Ostariphysi: Siluriformes). Tese de doutorado não publicada, City University of New York, New York, 229p.

Ferraris Jr., C. J. 2003. Family Auchenipteridae. Pp. 470-487. In: R. E. Reis, S. O. Kullander \& C. J. Ferraris Jr. (Eds.). Check list of the freshwater fishes of South and Central America. Porto Alegre, Edipucrs, 729p.

Ferraris Jr., C. J. 2007. Checklist of catfishes, recent and fossil (Osteichthyes: Siluriformes), and catalogue of siluriform primary types. Zootaxa, 1418: 1- 628.

Ferraris Jr., C. J. \& J. Fernandez. 1987. Trachlyopterichthys anduzei, a new species of auchenipterid catfih from the upper Río Orinoco of Venezuela with notes ob $T$. taeniatus (Kner). Proceedings of the Biological Society of Washington, 100(2): 257-261.

Ferraris Jr., C. J. \& R. P. Vari. 1999. The South American catfish genus Auchenipterus Valenciennes, 1840 (Ostariophysi: Siluriformes: Auchenipteridae): monophyly and relationships, with a revisionary study. Zoological Journal of the Linnean Society, 126: 387-450.

Ferrari Jr., C. J. \& R. P. Vari. 2000. The deep-water South American catfish genus Pseudepapterus (Ostariophysi: Auchenipteridae). Ichthyological Explrations of Freshwaters, 11(2): 97-112.

Ferraris Jr., C. J., R. P. Vari \& S. J. Raredon. 2005. Catfishes of the genus Auchenipterichthys (Osteichthyes: Siluriformes: Auchenipteridae). Neotropical Ichthyology, 3(1): 89-106.

Fink, S. V. \& W. L. Fink. 1981. Interrelationships of the ostariophysian fishes (Teleostei). Zoological Journal of the Linnean Society, 72: 297-353.

Fowler, H. 1951. Os peixes de água doce do Brasil. Arquivos de Zoologia do Estado de São Paulo, 6: 405-625.

Freihofer, W. C. 1963. Patterns of the ramus lateralis accessorius and their systematic significance in teleostean fishes. Stanford Ichthyological Bulletin, 8(2): 80-189. 
Freihofer, W. C. 1978. Cranial Nerves of a Percoid Fish, Polycentrus schomburgkii (Family Nandidae), a Contribution to the Morphology and Classification of the Order Perciformes. Occasional Papers of the California Academy of Sciences, 128: $1-78$.

Friel, J. P. 1994. A phylogenetic study of the Neotropical banjo catfishes (Teleostei: Siluriformes: Aspredinidae). Tese de doutorado não publicada, Duke University, Durham, 256p.

Friel, J. P. 2008. Pseudobunocephalus, a new genus of banjo catfish with the description of a new species from the Orinoco River system of Colombia and Venezuela (Siluriformes: Aspridinidae). Neotropical Ichthyology, 6(3): 293-300.

Ferriz, R. A., Villar, C. A., Colautti, D \& C. Bonetto. 2000. Alimentacion de Pterodoras granulosus (Valenciennes) (Pisces, Doradidae) en la baja cuenca del Plata. Revista del Museo Argentino de Ciencias Natureles, 2(2): 151-156.

Fugi, R., Agostinho, A. A. \& N. S. Hahn. 2001. Trophic morphology of five benthicfeeding fish species of a tropical floodplain. Revista Brasileira de Biologia, 61(1): 27-33.

Gill, T. N. 1870. On some new species of fishes obtained by Prof. Orton from the Maranon, or Upper Amazon, and Napo Rivers. Proceedings of the Academy of Natural Sciences of Philadelphia, 22: 92-96.

Gill, T. 1872. Arrangement of the families of fishes, or classes Pisces, Marsipobranchii, and Leptocardii. Smithsonian Miscellaneous Collections, 11(247): 1-49.

Goulding, M. 1979. Ecologia da pesca do rio Madeira. Manaus, INPA, 172p.

Goulding, M. 1980. The fishes and the forest, explorations in Amazonian natural history. University of California Press, Berkeley, 280p.

Goloboff, P. A., J. S. Farris \& K. C. Nixon. 2008. TNT, a free program for phylogenetic analysis. Cladistics, 24(2008): 774-786.

Gosline, W. A. 1945. Catálogo dos nematognatos de água doce da America do Sul e Central. Boletim do Museu Nacional do Rio de Janeiro, 33: 1-138.

Goulding, M. 1979. Ecologia da pesca do rio Madeira. Manaus, INPA, 172p.

Goulding, M. 1980. The fishes and the forest, explorations in Amazonian natural history. University of California Press, Berkeley, 280p.

Grande, L. 1987. Redescription of Hypsidoris farsonensis (Teleostei: Siluriformes), with a reassessment of its phylogenetic relationships. Journal of Vertebrate Paleontology, 7(1): 24-54.

Grande, L. \& J. T. Eastman. 1986. A review of antartic ichthyofaunas in the light of new fossil discoveries. Palaeontology, 29(1): 113-137.

Greenwood, P. H., D. E. Rosen, S. H. Weitzman \& G. S. Myers. 1966. Phyletic studies of Teleostean Fishes, with a provisional classification of living forms. Bulletin of the American Museum of Natural History, 131(4): 339-456.

Günther, A. 1864. Catalogue of fishes in the British Museum. Catalogue of the Physostomi, containing the families Siluridae, Characinidae, Haplochitonidae, Sternoptychidae, Scopelidae, Stomiatidae in the collection of the Britsih Museum. 
Volume 5, 455p.

Günther, A. 1880. A contribution to the knowledge of the fish fauna of the Rio de la Plata. Annals and Magazine of Natural History (Series 5), 6(31): 7-13.

Hahn, N. S., Fugi, R. \& I. F. Adrian. 1991. Espectro e atividade alimentares do armadinho, Trachydoras paraguayensis (Doradidae, Siluriformes) em distintos ambientes do rio Paraná. Revista Unimar, Maringá, 13(2): 177-194.

Hahn, N. S., Monfredinho Jr., A., Fugi, R. \& A. A. Agostinho. 1992. Aspectos da alimentação do armado, Pterodoras granulosus (Ostariophisi, Doradidae) em distintos ambientes do Alto Rio Paraná. Revista Unimar, Maringá, 14(supl.): 163176.

Hahn, N. S., Almeida, V. L. L. \& K. D. G. Luz. 1997. Alimentação e ciclo alimentar diário de Hoplosternum littorale (Hancock) (Siluriformes, Callichthyidae) nas lagoas Guaraná e Patos da planície do alto rio Paraná, Brasil. Revista Brasileira de Zoologia, 14(1): 57-64.

Hennig, W. 1950. Grundzüge einer Theorie der phylogenetischen Systematik. Deutsche Zentralverlag, Berlin, 370p.

Hennig, W. 1966. Phylogenetic Systematics. Urbana, University of Illinois Press, 263p.

Higuchi, H. 1992. A phylogeny of the south american thorny catfishes (Osteichthyes; Siluriformes; Doradidae). Tese de doutorado não publicada, Havard University, Boston, 372p.

Higuchi, H., H. A. Britski \& J. C. Garavello. 1990. Kalyptodoras bahiensis, a new genus and species of thorny catfish from northeastern Brazil (Siluriformes, Doradidae). Ichthyological Exploration of Freshwaters, 1(3): 219-225.

Higuchi, H., J. L. O. Birindelli, L. M. Sousa \& H. A. Britski. 2007. Merodoras nheco, new genus and species of doradid from Pantanal Matogrossense, with nomination of the new subfamily Astrodoradinae (Siluriformes, Doradidae). Zootaxa, 1446: 31-42.

von Ihering, R. 1937. Ovicucal fertilization in South American Catfish, Trachycorystes. Copeia, 1937(4): 201-205.

von Ihering, R. \& P. Azevedo. 1934. A curimatã dos açudes nordestinos (Prochilodus argenteus). Archivos do Instituto Biológico de São Paulo, 5: 143-1184.

Jardine, W. 1841. The naturalist's library (Volume 32). Ichthyology. Vol. III. Fishes of Guiana. Part I. Edinburgh, 263p.

Jordan, D. S. 1917. The genera of Fishes from Linnaeus to Cuvier, 1758-1833, seventy-five years, with the accepted type of each. A contributuion to the stability of Scientific Nomenclature. California, Stanford University, 159p.

Jordan, D. S. 1929. Manual of the vertebrate animals of the northeastern United States inclusive of marine species. $13^{\circ}$ Edição. World Book Co., 446p.

Kailola, P. J. 2004. A phylogenetic exploration of the catfish family Ariidae (Otophysi: Siluriformes). The Beagle, Records of the Museums and Art Galleries of the Northern Territory, 2004(20): 87-166.

Kesteven, H. L. 1943. The evolution of the skull and cephalic muscles. I. The fishes. 
Memoir of the Australian Museum, 8(2): 65-132.

Kner, R. 1854. Ueber einige Sexual-Unterschiede bei der Gattung Callichthys und die Schwimmblase dei Doras C. Val. Sitzungsber. Akademie der Wissenschaften in Wien, 11: 138-146.

Kner, R. 1855. Ichthyologische Beuträge [Subtitles I-III]. Sittzungsber. Akademie der Wissenschaften in Wien, 17: 92-162.

Kner, R. 1858. Kritische Bemerkungen über Castelnau's Siluroiden. Archiv fur Naturgeschichte, 24, 344-350.

Kulongowski, C. 2001. The anatomy and taxonomy of the marine catfish genus Galeichthys Valenciennes (Siluriformes; Ariidae). Dissertação de mestrado não publicada, Rhodes University, Grahamstown, 150p.

Lacepède, B. G. E. 1803. Histoire naturelle des poisons. Volume 5, 803p.

Ladich, F. 2001. Sound-generating and -detecting motor system in catfish: design of swimbladder muscles in Doradids and Pimelodids. The Anatomical Records, 263: 297-306.

Lechner, W \& F. Ladich. 2008. Size matters: diversity in swimbladders and Weberian ossicles affects hearing in catfishes. The Journal of Experimental Biology, 211: 1681-1689.

Linnaeus, C. 1758. Systemae Naturae. $10^{\circ}$ edição, volume 1, 824p.

Linnaeus, C. 1766. Systemae Naturae. $12^{\circ}$ edição, volume $1,532 p$.

Loir, M., C. Cauty, P. Planquete \& P. Y. le Bail. 1989. Comparative study of the male reprodutive tract in seven families of South American catfishes. Aquatic Living Resources, 2(1): 45-56.

Lowe-McConnel, R. H. 1975. Fish communities in tropical freshwaters: their distribution, ecology and evolution. New York, Longman, 337p.

Lundberg, J. G. 1970. The evolutionay history of North American catfishes, family Ictaluridae. Tese de doutorado não publicada, University of Michigan, Ann Arbor, $524 \mathrm{p}$.

Lundberg, J. G. 1993. African-South American freshwater fish clades and continental drift: problems with a paradigm. Pp. 156-199. In: Goldblatt (Ed.). Biological relationships between Africa and South America. New Haven, Yale University Press, 630p.

Lundberg, J. G. 1998. The Temporal Context for the Diversification of Neotropical Fishes. Pp. 49-58. In: Malabarba, L., R. E. Reis, R. P. Vari, Z. M. S. Lucena \& C. A. S. Lucena (Eds.). Phylogeny and Classification of Neotropical Fishes. Porto Alegre, Edipucrs, 603p.

Lundberg, J. G. \& A. Akama. 2005. Brachyplatystoma capapretum, a new species of goliath catfish from the Amazon basin, with reclassification of allied catfishes (Siluriformes; Pimelodidae). Copeia, 2005(3): 492-516.

Lundberg, J. G. \& J. N. Baskin. 1969. The caudal skeleton of the catfishes, order Siluriformes. American Museum Novitates, 2398: 1-49. 
Lundberg, J. G., L. G. Marshall, J. Guerero, B. Horton, M. C. S. L. Malabarba \& F. Wesselingh. 1998. The stage for neotropical fish diversification: a history of tropical south american rivers. Pp. 13-48. In: Malabarba, L., R. E. Reis, R. P. Vari, Z. M. S. Lucena \& C. A. S. Lucena (Eds.). Phylogeny and Classification of Neotropical Fishes. Porto Alegre, Edipucrs, 603p.

Lundberg, J. G. \& L. A. McDade. 1986. On the South American catfish Brachyrhamdia imitator Myers (Siluriformes, Pimelodidae), with phylogenetic evidence for a large intrafamilial lineage. Notulae Naturae of the Academy of Natural Sciences of Philadelphia, 463: 1-24.

Lütken, C. F. 1874. Siluridæ novæ Brasiliæ centralis a clarissimo J. Reinhardt in provincia Minae-geraës circa oppidulum Lagoa Santa, præcipue in flumine Rio das Velhas et affluentibus collectæ, secundum characteres essentiales breviter descriptæ a Chr. Lütken. Oversigt over det Kongelige Danske Videnskabernes Selskabs Forhandlinger og dets Medlemmers Arbejder i Aaret 1874(1): 29-36.

McAllister, D. E. 1968. The evolution of branchiostegals and associated opercular, gular, and hyoid bones and the classification of teleostome fishes, living and fossil. Bulletin of the National Museum of Canada, 221(77): 1-239.

Madison, D. R. \& W. P. Madison. 2005. MacClade 4, release version 4.08 (for OS X). Sinauer Associates, Inc.

Marceniuk, A. F. 2003. Relações filogenéticas e revisão dos gêneros da família Ariidae (Osteichthys, Siluriformes). Tese de doutorado não publicada, Universidade de São Paulo, São Paulo, 383p.

Marceniuk, A. F. \& J. L. O. Birindelli. (no prelo). Morphology of the Gas Bladder in Sea Catfishes (Siluriformes: Ariidae). Zootaxa.

Marceniuk, A. F. \& N. A. Menezes. 2007. Systematics of the family Ariidae (Ostariophysi, Siluriformes), with a redefinition of the genera. Zootaxa, 1416: 1126.

Mees, G. F. 1974. The Auchenipteridae and Pimelodidae of Suriname (Pisces, Nematognathi). Zoologische Verhandelingen, 132: 1-256.

Menezes, R. S. 1949. Alimentação do mandi bicudo, Hasssar affinis (Steindachner), da bacia do rio Parnaíba, Piauí (Actinopterygii, Doradidae, Doradinae). Revista Brasileira de Biologia, 9 (1): 93-96.

Menezes, R. S. \& M. F. Menezes. 1948. Alimentação de "graviola", "Platydoras costatus" (Linnaeus) da Lagoa de Nazaré, Piauí (Actinopterygii, Doradidae). Revista Brasileira de Biologia, 8 (2): 255-260.

Miranda Ribeiro, A. 1911. Fauna brasiliensis. Peixes IV(a). Eleutherobranchios Aspirophoros. Archivos do Museu Nacional do Rio de Janeiro, 16: 1-504.

Miranda Ribeiro, A. 1918. Lista dos Peixes Brasileiros do Museu Paulista ( $1^{\circ}$ parte). Revista do Museu Paulista, 10(2): 706-736.

Miranda Ribeiro, P. 1968a. Sobre o dimorfismo sexual no gênero auchenipterus Valanciennes, 1840 (Pisces-Auchenipteridae). Boletim do Museu Nacional do Rio de Janeiro, Nova Série, Zoologia, 261: 1-11.

Miranda Ribeiro, P. 1968b. Apontamentos ictiológicos III. Boletim do Museu 
Nacional do Rio de Janeiro, Nova Série, Zoologia, 263: 1-14.

Miranda Ribeiro, P. 1968c. Apontamentos ictiológicos V. Boletim do Museu Nacional do Rio de Janeiro, Nova Série, Zoologia, 264: 1-5.

Mo, T.-P. 1991. Anatomy, Relationships and Systematics of the Bagridae (Teleostei: Siluroidei) and Siluroid Phylogeny. Theses Zoologicae, 17: 1-216.

Moyer, G., B. M. Burr \& C. Krajewski. 2004. Phylogenetic relationships of thorny catfishes (Siluriformes: Doradidae) inferred from molecular and morphological data. Zoological Journal of the Linnean Society, 140: 551-575.

Müller, J. 1842a. Über die Schwimmblase der Fische, mit Bezug auf eínige neue Fishgattungen. Königlichen Preussische Akademie des Wissenschaften zu Berlin, 1842: 202-210.

Müller, J. 1842b. Beobachtungen über die Schwimmblase der Fische, mit Bezug auf einige neue Fischgattungen. Archiv für Anatomie, Physiologie und wissenschaftliche Medicin (Müller), Jahr, 1842: 307-329.

Müller, H. 1843. Untersuchungen über die Eingeweide der Fische, Schulufs der vergleichenden Anatomie der Myxinoiden. Abhanglungen der Königlichen Akademie der Wissenschaften, 1843: 111-170.

von Müller, J. W. \& F. H. Troschel. 1849. Horae Ichthyologicae. Beschreibung und Abbildung neuer Fische. Número 3. Berlin, Veit \& Comp., 27p.

Nelson, G. 1973. Relationships of Clupeomorphs, with remarks on the structure of the lower jaw in fishes. Zoological Journal of the Linnean Society, 53: 333-349.

Nelson, J. S. 2006. Fishes of the world. $4^{\circ}$ edição. New York, John Wiley \& Sons, Inc, $601 \mathrm{p}$.

Ortega-Lara, A \& P. Lehmann A. 2006. Cruciglanis, a new genus of Pseudopimelodid catfish (Ostariophysi: Siluriformes) with description of a new species from the Colombian Pacific coast. Neotropical Ichthyology, 4 (2): 147156.

Parmentier, E. \& R. Diogo. 2006. Evolutionary trends of swimbladder sound mechanism in some teleost fishes. Pp. 43-68. In: Ladich, F., S. P. Collin, P. Moller \& B. G. Kapoor (Eds.). Communication in Fishes. Science Publisher, Inc., $870 \mathrm{p}$.

Pavanelli, C. S. \& A. G. Bifi. 2009. A new Tatia (Ostariophysi: Siluriformes: Auchenipteridae) from the rio Iguaçu basin, Paraná State, Brazil. Neotropical Ichthyology, 7(2): 199-204.

Peixoto, L. A. W. \& W. B. Wosiacki. 2010. Description of a new species of Tetranematichthys (Siluriformes: Auchenipteridae) from the lower Amazon basin, Brazil. Neotropical Ichthyology, 8(1): 69-76.

de Pinna, M. C. C. 1991. Concepts and tests of homology in the cladistic paradigm. Cladistics, 7: 367-394.

de Pinna, M. C. C. 1993. Higher-level phylogeny of Siluriformes (Teleostei, Ostariophysi), with a new classification of the order. Tese de doutorado não publicada, City University of New York, New York, 474p. 
de Pinna, M. C. C. 1996. A phylogenetic analysis of the Asian catfish families Sisoridae, Akysidae, and Amblycipitidae, with a hypothesis on the relationships of Neotropical Aspredinidae (Teleostei, Ostariophysi). Fieldiana, 1478: 1-83.

de Pinna, M. C. C. 1998. Phylogenetic relationships of neotropical Siluriformes (Teleostei: Ostariophysi): historical overview and synthesis of hypotheses. Pp. 279-330. In: Malabarba, L., R. E. Reis, R. P. Vari, Z. M. S. Lucena \& C. A. S. Lucena (Eds.). Phylogeny and Classification of Neotropical Fishes. Porto Alegre, Edipucrs, 603p.

de Pinna, M. C. C. \& C. J. Ferraris Jr. 1992. Anatomy, Relationships and Systematics of the Bagridae (Teleostei: Siluroidei) and Siluroid Phylogeny [review of]. Copeia, 1992(4): 1132-1134.

de Pinna, M. C. C. \& Ng, H. H. 2004. The Second Ural Centrum in Siluriformes and Its Implication for the Monophyly of Superfamily Sisoroidea (Teleostei, Ostariphysi). American Museum Novitates, 3437: 1-23.

de Pinna, M. C. C., C. J. Ferraris Jr. \& R. P. Vari. 2007. A phylogenetic study of the neotropical catfish family Cetopsidae (Osteichthyes, Ostariophysi, Siluriformes), with a new classification. Zoological Journal of the Linnean Society, 150: 755813.

Piorski, N. M., J. C. Garavello, M. Arce H. \& M. H. Saba Pérez. 2008. Platydoras brachylecis, a new species of thorny catfish (Ssiluriformes: Doradidae) from northeastern Brazil. Neotropical Ichthyology, 6(3): 481-493.

Poll, M. 1971. Révision des Synodontis Africains (Famille Mochocidae). Annales du Musée Royal de 1'Afrique Centrale, $8^{\circ}$ series, Sciences Zoologiques, 191: 1-497.

Rapp Py-Daniel, L. \& C. Cox- Fernandes. 2005. Dimorfismo sexual em Siluriformes e Gymnotiformes (Ostariophysi) da Amazônia. Acta Amazonica, 35(1): 97-110.

Rafinesque, C. S. 1815. Analyse de la Nature, ou Tableau de l'Univers et des Corps Organisés, Palerme, 224p.

Regan, C. T. 1911. The classification of the teleostean fishes of the order Ostariophysi. 2. Siluroidea. Annals and Magazine of Natural History, 8: 553-577.

Reis, R. E. 1998. Anatomy and phylogenetic analysis of the neotropical callichthyid catfishes (Ostariophysi, Siluriformes). Zoological Journal of the Linnean Society, 124: $105-168$.

Reis, R. E. \& T. A. K. Borges. 2006. The South Americn Catfish Genus Entomocorus (Ostariophysi: Siluriformes: Auchenipteridae), with the Description of a New Species from the Paraguay River Basin. Copeia, 2006(3): 412-422.

Rengifo, B., N. K. Lujan, D. Taphorn \& P. Petry. 2008. A new species of Gelanoglanis (Siluriformes: Auchenipteridae) from the Marañon River (Amazon Basin), northeastern Perú. Proceedings of the Academy of Natural Sciences of Philadelphia, 157: 181-188.

Ribeiro, A. C. 2006. Tectonic history and biogeography of the freshwater fishes from the coastal drainages of eastern Brazil: an example of faunal evolution associated with a divergent continental margin. Neotropical Ichthyology, 4(2): 225-246.

Ribeiro, F. R. V. \& L. H. Rapp Py-Daniel. 2010. Ageneiosus uranophthalmus, a new 
species of auchenipterid catfish (Osteichthys: Siluriformes) from river channels of the central Amazon basin, Brazil. Neotropical Ichthyology, 8(1): 97-104.

Roberts, T. R. 1982. Unculi (Horny Projections Arising from Single Cells), an adaptative feature of the epidermis of Ostariophysan fishes. Zoologica Scripta, 11(1): 55-76.

Royero, R. 1987. Morfologia de la aleta dorsal en los bagres (Teleostei: Siluriformes), con especial referencia a las familias amaricanas. Tese de Licenciatura não publicada, Universidad Central de Venezuela, Caracas, 285p.

Royero, R. 1999. Studies on the systematics and phylogeny of the catfish family Auchenipteridae (Teleostei: Siluriformes). Tese de doutorado não publicada, University of Bristol, London, 534p.

Sabaj, M. H. 2002. Taxonomy of the neotropical thorny catfishes (Siluriformes: Doradidae) and revision of the genus Leptodoras. Tese de doutorado não publicada, University of Illinois, Urbana-Champaign, 242p.

Sabaj, M. H. 2005. Taxonomy assessment of Leptodoras (Siluriformes: Doradidae) with description of three new species. Neotropical Ichthyology, 3(4): 637-678.

Sabaj, M. H. \& C. J. Ferraris. 2003. Family Doradidae. Pp. 456-469. In: R. E. Reis, S. O. Kullander \& C. J. Ferraris Jr. (Eds.). Check list of the freshwater fishes of South and Central America. Porto Alegre, Edipucrs, 729p.

Sabaj, M. H. \&D. C. Taphorn \& O. E. Castillo G. 2008. Two New Species of Thicklip Thornycats, Genus Rhinodoras (Teleostei: Siluriformes: Doradidae). Copeia 2008(1): 209-226.

Sabaj Pérez, M. H. \& J. L. O. Birindelli. 2008. Taxonomic revision of extant Doras Lacepède, 1803 (Siluriformes: Doradidae) with descriptions of three new species. Proceedings of the Academy of Natural Sciences of Philadelphia, 157: 189-233.

Sabaj Pérez, M. H., O. A. Aguilera S. \& J. G. Lundberg. 2007. Fossil catfishes of the families Doradidae and Pimelodidae (Teleostei: Siluriformes) from the Miocene Urumaco Formation of Venezuela. Proceedings of the Academy of Natural Sciences of Philadelphai, 156: 157-194.

Sarmento-Soares, M. H. \& P. A. Buckup. 2005. A new Glanidium from the Rio São Francisco basin, Brazil (Siluriformes: Auchenipteridae: Centromochilinae). Copeia, 2005 (4): 846-853.

Sarmento-Soares, L. M. \& R. F. Martins-Pinheiro. 2008. A systematic review of the genus Tatia (Siluriformes: Auchenipteridae: Centromochlinae). Neotropical Ichthyology, 6(3): 495-542.

Sato, Y., Fenerich-Verani, N., Nuñer, A. P. O., Godinho, H. P. \& J. R. Verani. 2003. Padrões reprodutivos de peixes da bacia do São Francisco. Pp. 229-274. In: Godinho, H. P. \& A. L. Godinho (eds.). Águas, peixes e pescadores do São Francisco das Minas Gerais. Belo Horizonte, PUC Minas, 468p.

Schaefer, S. A. 1990. Anatomy and relationships of the scoloplacid catfishes. Proceedings of the Academy of Natural Sciences of Philadelphia, 142: 167-210.

Schultz, L. P. 1944. The catfishes of Venezuela, with descriptions of thirty-eight new forms. Proceedings of United States National Museum, 94(3172): 173-338. 
Shelden, F. F. 1937. Osteology, miology and probable evolution of the Nematognath pelvic dirgle. Annals of the New York Academy of Sciences, 37(1): 1-96.

von Spix, J. B. \& L. Agassiz. 1829-1831. Selecta Genera et Species Piscium quos in Itinere per Brasiliam Annos MDCCCXVII-MDCCCXX Jussu et Auspiciis Maximiliani Josephi I.... Colleget et Pingendso Curavit Dr J. B. de Spix, Typis C. Wolf, Monachii.

Soares-Porto, L. M. 1996. Análise filogenética dos Centromochlidae. Redefinição e resisão taxonômica de Tatia Mirada Ribeiro, 1911 (Osteichthys, Siluriformes, Doradoidea). Tese de doutorado não publicada, Universidade de São Paulo, São Paulo, 278p.

Soares-Porto, L. M. 1998. Monophyly and interrelationships of the Centromochlidnae (Siluriformes: Auchenipteridae). Pp. 331-350. In: Malabarba, L. R., R. E. Reis, R. P. Vari, Z. M. S Lucena \& C. A. S. Lucena (Eds.). Phylogeny and classification of neotropical fishes. Porto Alegre, Edipucrs, 603p.

Sörensen, W. 1894-1895. Are the extrinsic muscles of the air-bladder in some Siluroidae and the "elastic spring" apparatus of others subordinate to the voluntary production of sounds? What is, according to our present knowledge, the function of the Weberian ossicles? A contribution to the biology of fishes. Journal of anatomy and Physiology, 29(1-4): 109-139 [Out 1894], 205-229 [Jan 1895], 399423 [Abr 1895], 518-552 [Jul 1895].

Sousa, L. M. \& J. L. O. Birindelli. (submetido). Review of the genus Scorpiodoras Eigenmann (Siluriformes, Doradidae) with resurrection of Scorpiodoras calderonensis Vaillant and description of a new species. Copeia.

Sousa, L. \& L. H. Rapp Py-Daniel. 2005. Description of two new speices of Physopyxis and redescription of P. lyra (Siluriformes: Doradidae). Neotropical Ichthyology, 3(4): 625-636.

Starks, E. C. 1913. The fishes of the Stanford Expedition to Brazil. Stanford University Publication, University series, 1-14.

Steindachner, F. 1877. Die Süsswasserfische des südöstlichen Brasilien (III). Sitzungsberichte der Kaiserlichen Akademie der Wissenschaften. MathematischNaturwissenschaftliche Class, 74: 559-694.

Steindachner, F. 1880. Beitäge zur Kenntniss der Flussfische Sü damerikas, II, und Ichthyologische Beiträge, IX. Anzeiger der Kaiserlichen Akademie der Wissenschaften, Mathematisch- Naturwissenschaftlichen Classe, 17: 157-159.

Steindachner, F. 1910. Über einige Ageneiosus- und Farlowella-Arten, etc. Annalen des K. K. Naturhistorischen Hofmuseums, Wien, 24: 399-408.

Steindachner, F. 1915. Breiträge zur Kenntnis der Flussfische Sü damerikas. V. Denkschriften der kaiserlichen Akademie der Wissenschaften, mathematischnaturwissenschaftliche Klasse, 93: 15-106.

Stewart, D. J. 1985. A review of the South American catfish tribe Hoplomyzontini (Pisces, Aspredinidae), with descriptions of new species from Ecuador. Fieldiana Zoology (New Series), 25: 1-19.

Sullivan, J. P., J. G. Lundberg \& M. Hardman. 2006. A phylogenetic analyis of the 
major groups of catfishes (Teleostei: Siluriformes) using rag1 and rag2 nuclear gene sequences. Molecular Phylogenetics and Evolution, 41: 636-662.

Sullivan, J. P., Z. Peng, J. G. Lundberg, J. Peng \& S. He. 2008. Molecular evidence for diphyly of the Asian catfish family Amblycipitidae (Teleostei: Siluriformes) and exclusion of the South American Aspredinidae from Sisoroidea. Proceedings of the Academy of Natural scicens of Philadelphia, 157(1): 51-65.

Taverne, L. \& A. Aloulou-Triki. 1974. Étude anatomique, myologique et ostéologique du genre Synodontis Cuvier (Pisces: Siluriformes: Mochokidae). Annalen du Musée Royal de l'Afrique Centrale, 210: 1-69.

Tavolga, W. N. 1962. Mechanisms of sound production in the ariid catfishes Galeichthys and Bagre. Bulletin of the American Museum of Natural History, 124: 1-30.

Taylor, W. R. \& G. C. Van Dyke. 1985. Revised procedures for staining and clearing small fishes and other vertebrates for bone and cartilage study. Cybium, 9(2): 107119.

Tilak, R. 1963. The osteocranium and the weberian apparatus of a few representatives of the family Siluridae and Plotosidae (Siluroidea): a study of inter0relationship. Zoologische Anzeiger, 171: 424-439.

Valenciennes, A. 1840. Des Pimélodes. Pp. 123-206. In: Cuvier, G.; \& Valenciennes, A. Histoire Naturelle des Poissons. Volume 15. Paris, Strasbourg, Bertrand e Levrault. 540p.

Van der Stigchel, J. W. R. 1947. The South American Nematognathi of the Museuns at Leiden and Amsterdam Zoological Meded. (Leiden), 27: 1-204.

Vari, R. P. 1983. Phylogenetic relationships of the families Curimatidae, Prochilodontidae, Anostomidae, and Chilodontidae (Pisces: Characiformes). Smithsonian Contributions to Zoology, 378: 1-60.

Vari, R. P. \& C. J. Ferraris Jr. 1998. The neotropical catfish genus Epapterus Cope (Siluriformes: Auchenipteridae): a reappraisal. Proceedings of the Biological Society of Washington, 111: 992-1007.

Vari, R. P. \& C. J. Ferraris Jr. 2006. The Catfish Genus Tetranematichthys (Auchenipteridae). Copeia, 2006(2): 168-180.

Veitenheimer, I. L. \& M. C. D. Mansur, 1975. Primeiras observações de bivalves dulciaquícolas como alimento do "Armado-amarillo" Rhinodoras d'orbignyi (Kroyer, 1855) Bleeker, 1862. Iheringia, 46: 25-31.

Vigliotta, T. R. 2008. A phylogenetic study of the African catfish family Mochokidae (Osteichhtyes, Ostariophysi, Siluriformes), with a key to genera. Proceedings of the Academy of Natural Sciences of Philadelphia, 157: 73-136.

Vono, V. \& J. L. O. Birindelli. 2007. Natural History of Wertheimeria maculata, a primitive doradid endemic to eastern Brazil (Siluriformes, Doradidae). Ichthyological Explorations of Freshwaters, 18(2): 183-191.

Walsh, S. J. 1990. A systematic revision of the Neotropical catfish family Ageneiosidae (Teleostei: Ostariophysi: Siluriformes). Tese de doutorado não publicada, University of Florida, Florida, 363p. 
Weitzman, S. H. 1962. The osteology of Brycon meeki, a generalized characid fish, with an osteological definition of the family. Stanford Ichthyological Bulletin, 8: $1-77$.

Wiley, B. B. \& M. L. Collette. 1970. Breeding tubercles and contact organs in fishes: their occurrence, structure, and significance. Bulletin of the American Museum of Natural History, 143(3): 145-216.

Wiley, E. O. 1981. Philogenetics, the theory and practice of phylogenetic systematics. New York, John Wiley \& Sons, Inc., 439p.

Winterbottom, R. 1974. A descriptive synonym of the striated muscles of the Teleostei. Proceedings of the Academy of Natural Sciences of Philadelphia, 125: 225-317. 


\section{Apêndice 1. Material Examinado.}

Os exemplares estudados listados a seguir, estão organizados por grupo interno, grupo externo, e em ordem alfabética de famílias, gêneros e espécies. Para cada lote, aparece o número de registro e, entre parênteses, o número de exemplares e o comprimento padrão $(\mathrm{CP})$ do menor e maior exemplar. Os exemplares estão devidamente indicados conforme sua preparação: preservados em álcool (alc), corados e diafanizados (cs), ou esqueletos seco (sk). As acronímias das instituições segue Ferraris (2007). Os exemplares foram coletados no Brasil, exceto por aqueles indicados como coletados em outros países. As espécies utilizadas na matriz de caracteres filogenéticos aparecem sublinhadas.

Grupo interno: Auchenipteridae: Ageneiosus atronasus: MZUSP 52620 (20 alc, 80.1-

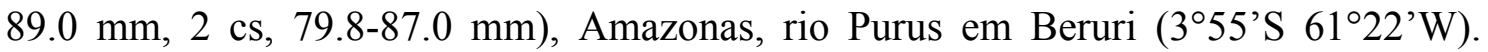

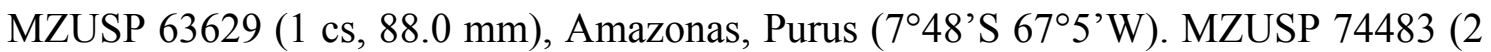

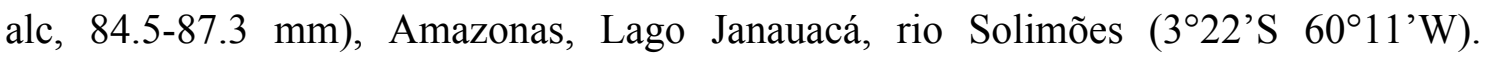
Ageneiosus brevis: MZUSP 34417 (567 alc, 52.8-60.4 mm, $3 \mathrm{cs}, 53.0-61.6 \mathrm{~mm}$ ), Rondônia, rio Madeira em Calama (8³’S 6253’W). MZUSP 56660 (1, 95.6 mm), Amazonas, rio Purus (4³'48'’S 61³3'49'’W). Ageneiosus inermis: MZUSP 89519 (1 sk, $250 \mathrm{~mm}$ ), Goias, Luís Alves, rio Verde, afluente do rio Araguaia (139'28'’S 50³0’22’’W). MZUSP 91661 (2 sk, 260.0-320.0 mm), Goias, Luís Alves, rio Verde, afluente do rio Araguaia (139'28'’S 50³0’22'’W). MZUSP 92005 (1 sk, 420 mm), Mato Grosso, Canarana, rio Culuene, afluente do rio Xingu $\left(13^{\circ} 49^{\prime} \mathrm{S} 53^{\circ} 15^{\prime} \mathrm{W}\right)$. MZUSP 96189 (3 sk, 255-315 mm), Amazonas, Manaus, Porto Ceasa. Ageneiosus militaris: MZUSP 21114 (1 alc, 179 mm), Paraná, Guaíra, rio Paraná, acima de Sete 


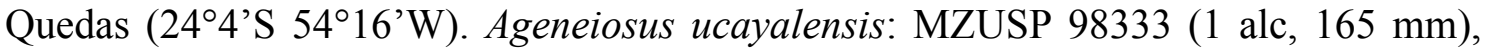
Pará, Jacareacanga, rio Teles Pires, afluente do rio Tapajós $\left(9^{\circ} 19^{\prime} 1^{\prime}\right.$ 'S $56^{\circ} 46^{\prime} 44^{\prime}$ 'W). Ageneiosus vittatus: MZUSP 92185 (1 alc, 168 mm), Amazonas, Igarapé Castanha, afluente do rio Tiquié, bacia do rio Negro (24'41'’N 6941'26'’W). MZUSP 101771

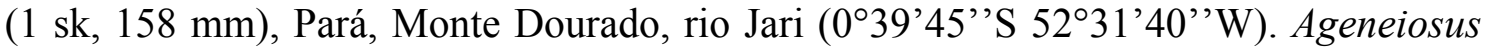
sp. (=Ageneiosus sp.n. sensu Walsh, 1990): MZUSP 92639 (1 alc, 106 mm), Pará, Itaituba, rio Tapajós (4²1'34’'S 56 $10^{\circ} 3$ '”W). “Amplexiglanis” teaguei: MCP 18423 (2 cs, 115.8-123.8 mm), Santa Catarina, Concórdia, rio do Peixes em Volta Grande, bacia do rio Uruguai $\left(27^{\circ} 21^{\prime}\right.$ S 51 $\left.59^{\circ} \mathrm{W}\right)$. “Amplexiglanis” peloichthys: MZUSP 79458 (5 alc, 109.3-135.2 mm), Venezuela, Zulia, Carrasquero, Río Limón, bacia do Lago Maracaibo. Asterophysus batrachus: INPA 24119 (1 cs, $127.0 \mathrm{~mm})$, Amazonas, Novo Airão, rio Negro, Arquipélogo de Anavilhanas (2³7’S 6050’W). MZUSP 12420 (1 alc, $129.7 \mathrm{~mm})$, Amazonas, Paricatuba, rio Negro (0³1’S 65¹’W). MZUSP 33410 (1 alc, $149.8 \mathrm{~mm})$, Amazonas, São Gabriel da Cachoeira, rio Negro ( $\left.0^{\circ} 7^{\prime} \mathrm{S} 67^{\circ} 5^{\prime} \mathrm{W}\right)$. Auchenipterichthys longimanus: MZUSP 52103 (1 sk, 167 mm), Amazonas, Igapó entre

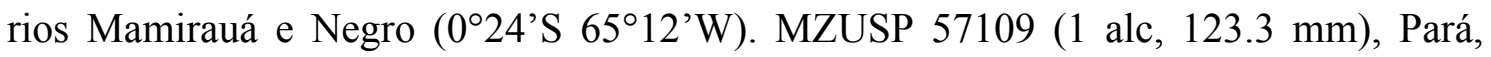
Capim, rio Capim (2²'S $\left.47^{\circ} 45^{\prime} \mathrm{W}\right)$. Auchenipterichthys punctatus: MZUSP 43333 (1 alc, $119.7 \mathrm{~mm})$, Amazonas, rio Jutaí (31's $\left.67^{\circ} 5^{\prime} \mathrm{W}\right)$. Auchenipterichthys coracoideos: MZUSP 86218 (1 alc, $91.2 \mathrm{~mm}$ ), Mato Grosso, Cocalinho, Corixo da Saudade, afluente

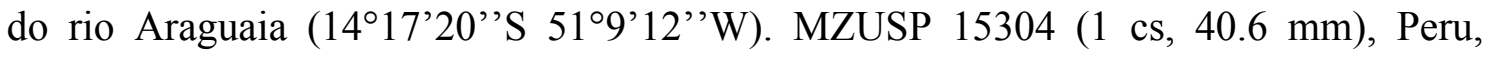
Loreto, Iquitos, Río Nanay ( $\left.3^{\circ} 41^{\prime} \mathrm{S} 73^{\circ} 13^{\prime} \mathrm{W}\right)$. Auchenipterichthys thoracatus: MZUSP 63034 (1 alc, 101.9 mm), Mato Grosso, Vila Bela da Santíssima Trindade, rio Guaporé, afluente do rio Madeira (15¹'17'’S 5957'90'’W). MZUSP 37518 (1 cs, $78.7 \mathrm{~mm})$, Mato Grosso, Vila Bela da Santíssima Trindade, rio Guaporé, afluente do rio Madeira (15¹'17''S 5957'90'’W). Auchenipterus ambyacus: MZUSP 30611 (1 cs, 103 mm), 
Amazonas, Tefé, rio Tefé $\left(3^{\circ} 22^{\prime} \mathrm{S} 64^{\circ} 43^{\prime} \mathrm{W}\right)$. Auchenipterus osteomystax: MZUSP 33414 (1 cs, $141 \mathrm{~mm})$, Pará, Itaituba, rio Tapajós (4²7’S 56¹5’ W). MZUSP 89728 (1 alc, $130.5 \mathrm{~mm}, 1 \mathrm{sk}, 135.2 \mathrm{~mm}$ ), Mato Groso, Canarana, rio Culuene, afluente do rio

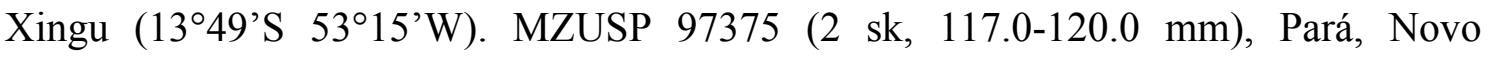

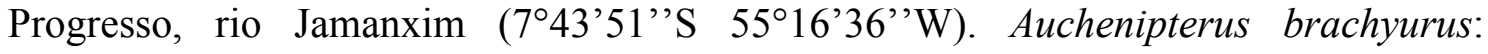
MZUSP 49830 (1 alc, $121 \mathrm{~mm}$ ), Acre, rio Acre. Centromochlus heckelii: MZUSP 49529 (2 alc, 80.5-97.4 mm, $2 \mathrm{cs}, 68.1-83.4 \mathrm{~mm}$ ), Amazonas, rio Purus ( $8^{\circ} 44^{\prime} \mathrm{S}$ 67²4’W). MZUSP 101767 (4 sk, 82.7-84.0 mm), Pará, Monte Douraado, rio Jari (0³9'45'’S 52³1'40’'W). Entomocorus radiosus: MZUSP 59465 (1 alc, 36.8 mm, 2 cs, 37.2-41.2 mm), Mato Grosso do Sul, rio Miranda, afluente do rio Paraguai (19³7'22'’S 56 57'27'’W). MZUSP 59327 (1 cs, $35 \mathrm{~mm})$, comprado em loja de aquário. Epapterus dispilurus: MZUSP 26410 (1 cs, 62.0 mm), Perú, Amazonas, Río Ucayali, Pucallpa (8²3'S 74³3’W). Glanidium melanodermatum: MZUSP 51043 (1 cs, 107.9 mm), São Paulo, rio Ribeira de Iguape (24³5’S 48³6’W). MZUSP 51275 (2 cs, 74.7-79.9 mm), São Paulo, Registro, rio Ribeira de Iguape (24³5’S 4751’W). MZUSP 64256 ( 1 alc, 105.0 mm, 1 cs, 108.4 mm, 2 sk, 110.0-112.0 mm), São Paulo, Iporanga, rio Ribeira de Iguape $\left(24^{\circ} 35^{\prime} \mathrm{S} 48^{\circ} 35^{\prime} \mathrm{W}\right)$. Liosomadoras oncinus: MZUSP 46015 (1 alc, 55.4 mm), comprado em loja de aquário. MZUSP 93497 (2 alc, 65.8-74.8 mm, $1 \mathrm{cs}, 70.7 \mathrm{~mm}$ ), obtidos em exportadores de peixes ornamentais. MZUSP 105828 (3 sk, 110-120 mm), Venezuela, Amazonas, Río Ventuari (44'39’’N 6652’6’'W). MYNRG 17640 (1 cs, 125 mm), sem dados. Parauchenipterus ceratophysus: MZUSP

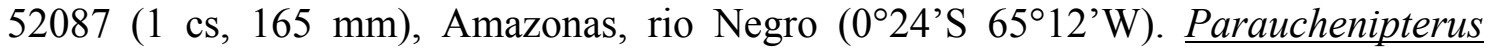
galeatus: MZUSP 90831 (2 alc, 127.2-138.8 mm), Minas Gerais, Várzea da Palma, rio São Francisco (17³6’56’'S 4440’33'’W). MZUSP 9304 (2 cs, 98.3-99.4 mm),

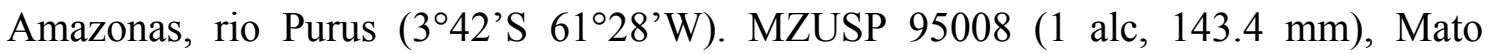


Grosso, Barão de Melgaço, rio Miranda, afluente do rio Paraguai (16¹9'30'’S 5549'59'’W). Parauchenipterus porosus: MZUSP 75365 (1 cs, $81.3 \mathrm{~mm}$ ), Amazonas, Manaus, Lago Janauari, rio Negro ( $\left.3^{\circ} 12^{\prime} \mathrm{S} 60^{\circ} 1^{\prime} \mathrm{W}\right)$. MZUSP 75364 (2 cs, 65.5-77.3 mm), Amazonas, Manaus, Ilha da Marchantaria, rio Solimões. MZUSP 31889 (1 cs, $106.6 \mathrm{~mm}$ ), Pará, Alter do Chão, rio Tapajós (2³0’S 5457’W). Parauchenipterus striatulus: MZUSP s/nº (3 sk, 81.1-93.7 mm), sem dados. MZUSP 90742 (2 alc, 151$154 \mathrm{~mm})$, Espírito Santo, Anchieta, rio Salinas (2044'15''S 4041'59', W). Pseudauchenipterus affinis: MZUSP 51718 (2 alc, 75.3-86.5 mm, 1 cs, $63 \mathrm{~mm}$ ), Espírito Santo, Linhares, rio Doce (19²4’S 40¹’W). MZUSP 51720 (1 cs, $68.6 \mathrm{~mm}$ ), Espírito Santo, São Mateus, rio São Mateus (1844’S 3950’W). MZUSP 60075 (1 cs, $88.7 \mathrm{~mm}$ ), Bahia, Mucurí, rio Mucurí (186’S 39³2’W). Pseudauchenipterus nodosus: ANSP 179581 (1 sk, não medido), Guiana, Georgetown, comprado no mercado de peixes. Pseudepapterus hasemani: MZUSP 53323 (12 alc, 54.0-70.6 mm, 2 cs, 64.2$64.8 \mathrm{~mm}$ ), Pará, Porto de Moz, rio Acaraí, afluente do rio Xingu (2³’47’'S 52¹8’45’'W). MZUSP 104772 (1 alc, 115.2 mm), Pará, Monte Dourado, rio Jari (047'55's 52'31'50''W). Pseudotatia parva: FMNH 57807 (2 alc, c.35 mm, 2 cs, c.34 mm), Bahia, Juazeiro, rio São Francisco (9²6’S 40³0’W). Tatia aulopygia: MZUSP 37599 (2 alc, 60.8-71.1 mm, 2 cs, 48.6-58.6 mm), Mato Grosso, Aripuanã, Igarapé do Aeroporto, bacia do rio Madeira ( $\left.9^{\circ} 58^{\prime} \mathrm{S} 59^{\circ} 19^{\prime} \mathrm{W}\right)$. Tatia cf. aulopygia: MZUSP 99309 (2 sk, 89.0-94.0 mm), sem dados. Tatia intermedia: MZUSP 89376 (2 cs, 35.2-66.0 mm), Goiás, Crixás, Córrego da Taboca, bacia do rio Araguaia (14'19’27'’S 50¹2’32'’W). Tetranematichthys quadrifilis: MZUSP 37517 (1 cs, 114 mm), Mato Grosso, Vila Bela da Santíssima Trindade, rio Guaporé, afluente do rio Madeira (15'1'17'’S 5957'90'’W). Tetranematichthys wallacei: MZUSP 85497 (1 alc,

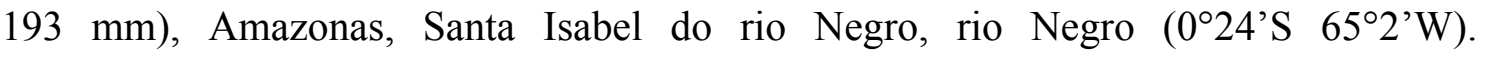


Tocantinsia piresi: MZUSP 98301 (1 sk, 250.0 mm), Pará, Jacareacanga, rio Teles Pires (9·18'56'’S 56 47'10',W). MZUSP 100031 (2 sk, 430.0-440.0 mm), Pará,

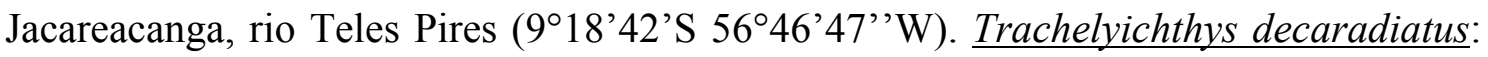
MZUSP 92829 (1 alc, 66.3 mm, 4 cs, 35.0-54.0 mm), Pará, Santarém, Igarapé Juá, bacia do rio Tapajós (2²6’0'S 5446’51',W). MZUSP 6830 (2 cs, 53.1-55.8 mm), Amazonas, Manaus, Igarapé afluente do Tarumãzinho, bacia do rio Negro $\left(3^{\circ} 10^{\prime} \mathrm{S}\right.$ $\left.60^{\circ} 0^{\prime} \mathrm{W}\right)$. Trachelyopterichthys taeniatus: MZUSP 8496 (1 alc, $107.0 \mathrm{~mm}, 2 \mathrm{cs}, 53.8$ $82.4 \mathrm{~mm})$, Pará, Santarém, Igarapé afluente do rio Mapiri (2²6’S 5444’W). Trachelyopterus coriaceus: MZUSP 92767 (3 cs, 73.0-94.2 mm), Pará, Santarém, Lago Maiacá (2॰27'54'’S 54³9’31'’W). Trachycorystes trachycorystes: ANSP 78079 (1 sk, não medido), Guiana, Essequibo. ANSP 179152 (1 sk, não medido), Guiana, Rupununi, Simoni River ( $\left.3^{\circ} 43^{\prime} 9^{\prime \prime} \mathrm{N} 5^{\circ} 9^{\circ} 5^{\prime} 40^{\prime \prime} \mathrm{W}\right)$. MZUSP 7381 (1 cs, $128.8 \mathrm{~mm}$ ), Amazonas,

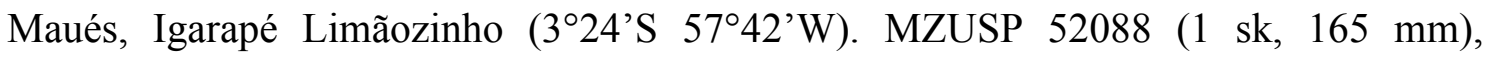
Amazonas, rio Negro, Anavilhanas (242’S 6045’W). MZUSP 52095 (1 alc, 310 mm), Amazonas, São Pedro, Alto rio Negro. MZUSP 91659 (1 sk, 200.0 mm), sem dados. MZUSP 99308 (1 sk, 180.0 mm), sem dados. Doradidae: Acanthodoras cataphractus: MZUSP $6831(1,119.0 \mathrm{~mm}, 1 \mathrm{cs}, 112.0 \mathrm{~mm})$, Amazonas, Manaus, Igarapé afluente do Tarumãzinho (3¹0’S 600’W). MZUSP 82295 (2 alc, 156.2-185.5 mm), rio Branco, Cachoeira Bem-Querer. MZUSP 84667 (2 cs, 57.0-58.0 mm), comprado em loja de aquário. Acanthodoras spinosissimus: ANSP 179341 (1 sk, não medido), Guiana,

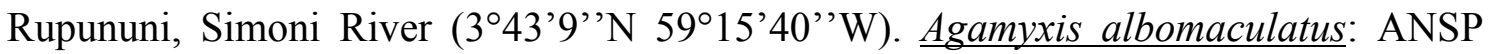
180889 (1 alc, 68.4 mm), Venezuela, Río Orinoco na Isla Portuguesa. MZUSP 88607 (3, 64.3-97.7 mm, $1 \mathrm{cs}, 72.2 \mathrm{~mm}$ ), Venezuela, Delta Amacuro, Río Orinoco

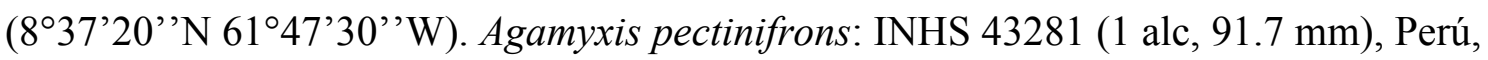
Río Itaya. MZUSP 5177 (1 alc, $82.3 \mathrm{~mm}$ ), Mato Grosso, rio Papagaio, bacia do rio 


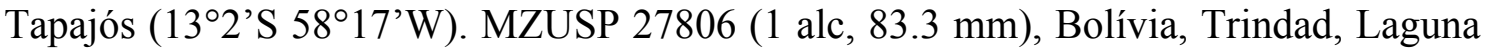
San José. MZUSP 57766 (1 alc, 49.4 mm), Amazonas, rio Purus (3 $58^{\circ} 47^{\prime \prime} \mathrm{S}$ 61²9'6’’W). Anadoras grypus: ANSP 166262 (1 alc, 114.3 mm), Perú, Río Marañon. ANSP 179558 (1 sk, não medido), Peru, Loreto, Maynas, Caño Moena (346'19'’S 73¹4'16’'W). MZUSP 5934 (1 alc, 150 mm), Amazonas, rio Purus (342’S 61²8’W).

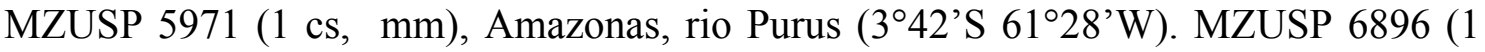

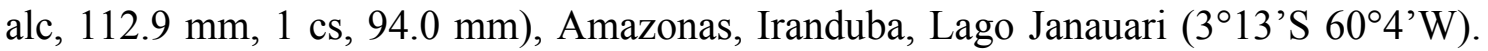
MZUSP 50136 (1 alc, $115.7 \mathrm{~mm}$ ), Amazonas, Itacoatiara, Ilha Amatari (318’ S 5857’W). MZUSP 50148 (1 alc, 92.5 mm), Amazonas, Lago Janauacá (3²5’S 60 $\left.17^{\prime} \mathrm{W}\right)$. MZUSP 74864 ( 1 alc, $140.0 \mathrm{~mm}, 1 \mathrm{sk}, 123.2 \mathrm{~mm}$ ), Amazonas, Lago Janauacá $\left(3^{\circ} 22^{\prime}\right.$ S $\left.60^{\circ} 11^{\prime} \mathrm{W}\right)$. Anduzedoras oxyrhynchus: ANSP 160628 (1 alc, 108.2 mm), Venezuela, Amazonas, Río Sipapo (452’N 6753’W). ANSP 178551 (1 sk, não medido), Amazonas, rio Negro (1¹2’34’'S 62¹3'47’'W). MZUSP 29021 (2 alc, 92.1$115.7 \mathrm{~mm}$ ), Amazonas, rio Negro (031'S 6450’W). MZUSP 29028 (2 alc, 34.5-56.8 $\mathrm{mm})$, Amazonas, rio Negro ( $\left.0^{\circ} 24^{\prime} \mathrm{S} 6^{\circ} 5^{\circ} 12^{\prime} \mathrm{W}\right)$. MZUSP 29029 (215, 31.0-92.3 mm, 2 cs, 56.0-92.3 mm), Amazonas, rio Negro (058’S 6257’W). MZUSP 91454 (1 alc, $228.0 \mathrm{~mm})$, Amazonas, Vista Alegre, rio Negro ( $\left.0^{\circ} 21^{\prime} \mathrm{S} 68^{\circ} 27^{\prime} \mathrm{W}\right)$. Centrochir crocodili: MZUSP 105837 (1 sk, 150.8 mm), Colombia, Tolima, Río Magdalena (5'12’16'’N 7444’03’'W). CU 47930 (1 cs, 130.0 mm), Colombia, Río Magdalena. Centrodoras brachiatus: ANSP 179155 (1 sk, não medido), Amazonas, rio Solimões (244'15'’S 6656'7' W). ANSP 179164 (1 sk, não medido), Amazonas, Santo Antônio do Iça, rio Solimões (36’S 6756’W). ANSP 181021 (1 alc, 81.5 mm), Pará, Vila Canaã, rio Amazonas. MZUSP 31306 (1 alc, 186.0 mm), sem dados. MZUSP 42335 (1 cs, 264.0 mm), Amazonas, Tefé, rio Solimões. MZUSP 51039 (1 alc, 230.0 mm), Pará, Juriti, (29'S 566'W). MZUSP 55776 (1 cs, $76.2 \mathrm{~mm})$, Amazonas, rio Solimões 
(315'4'’S 6445'19'’W). MZUSP 83313 (1 sk, $158.0 \mathrm{~mm})$, Amazonas, rio Madeira, (3³8'14'’S 59²'17'’W). Centrodoras hasemani: ANSP 17955 (1 sk, não medido), Amazonas, rio Negro (3¹'18'’S 60²4'55'’W). ANSP 177907 (1 alc, 209 mm), Amazonas, na confluência entre os rios Negro e Branco. ANSP 181031 (1 alc, 69 mm), Amazonas, rio Negro. INPA 11338 (1 alc, 147.2 mm), Amazonas, Novo Airão, rio Negro (2³7’S 6056’W). MZUSP 56037 (1 cs, $71.9 \mathrm{~mm}$ ), Amazonas, rio Negro (37'17'’S 608'20' W). MZUSP 91675 (1 alc, $202.0 \mathrm{~mm})$, Amazonas, rio Uaupés, bacia do rio Negro. Doraops zuloagai: ANSP 179558 (2 sk, não medidos), Venezuela, Zulia, rio Catatumbo, bacia do Lago Maracaibo. INHS 54804 (1 alc, 273 mm), Venezuela, bacia do Lago Maracaibo. MCNG 33457 (1 alc, 103.8 mm), Venezuela, Zulia, rio Escalante, bacia do Lago Maracaibo. Doras carinatus: ANSP 177276 (1 alc,

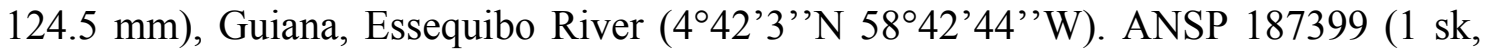
$170.0 \mathrm{~mm})$, Guiana, Lawa River, bacia do Maroni River ( $\left.3^{\circ} 19^{\prime} 31^{\prime \prime} \mathrm{N} 54^{\circ} 3^{\prime} 48^{\prime \prime} \mathrm{W}\right)$. ANSP 180986 (a sk, 170.0 mm), Guiana, Essequibo River (154'53'’N 58³1'14'). AMNH 96798 (1 alc, 302 mm), Venezuela, Bolivar, Río Crapo (5³0’40’’ N 63³0'40'’W). Doras higuchii: ANSP 181056 (1 cs, $60.0 \mathrm{~mm})$, Mato Grosso, rio Curisevo $\left(13^{\circ} 2^{\prime} 5^{\prime}\right.$ 'S 5325'10’'W). ANSP 181057 (1 alc, $160.0 \mathrm{~mm}$ ), Pará, Belom Monte, rio Xingu $\left(3^{\circ} 7^{\prime} \mathrm{S} 51^{\circ} 42^{\prime} \mathrm{W}\right)$. INPA 5568 (1 alc, $\left.83.8 \mathrm{~mm}\right)$, Amazonas, rio Trombetas. MZUSP 96334 (1 sk, 165.0 mm), Pará, Altamira, rio Curuá (8¹9’7’’S 555'23’'W). MZUSP 101693 (2 sk, 105.0-172.0 mm), Pará, monte dourado, rio Jari (0³3'59''S 52॰34'40’'W). Doras micropoeus: ANSP 78070 (1 sk, $160 \mathrm{~mm})$, sem dados 'Hyrtl Collection'. ANSP 178703 (1 alc, 222 mm), Guiana, Essequibo River

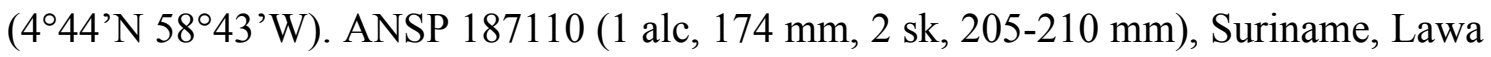

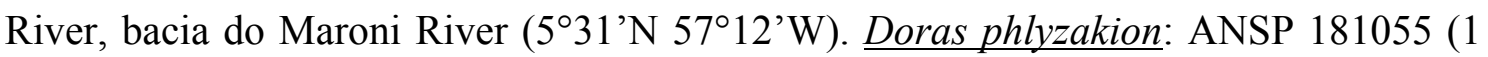

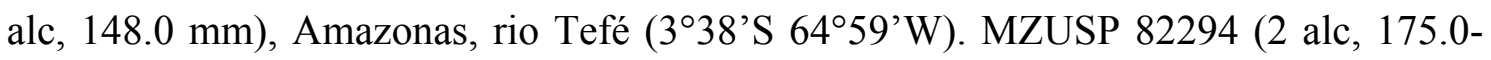


$180.0 \mathrm{~mm}, 1 \mathrm{sk}, 162.0 \mathrm{~mm})$, Amazonas, rio Tefé. MZUSP 50836 (1 cs, $67.5 \mathrm{~mm})$, Amazonas, Lagoa Central, bacia do rio Negro. Doras zuanoni: MZUSP 96328 (1 alc, $96.0 \mathrm{~mm})$, Tocantins, Caseara Lago Paredão, bacia do rio Araguaia $\left(9^{\circ} 17^{\prime} \mathrm{S} 49^{\circ} 58^{\prime} \mathrm{W}\right)$. Franciscodoras marmoratus: MZUSP 2201 (1 cs, 99.0 mm), Bahia, rio São Francisco. MZUSP 9380 (1 cs, 183.0 mm), Minas Gerais, Buritis, rio Urucuia, bacia do rio São

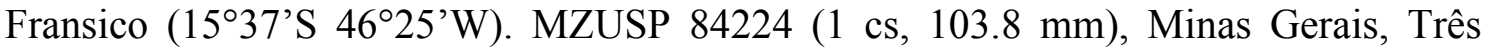
Marias, rio São Francisco. MZUSP 97145 (3 cs, 29.4-33.0 mm), Minas Gerais, Três Maria, rio São Fracisco. Hassar affinis: MZUSP 74890 (1 cs, 85.9 mm), Parnaíba. MZUSP 43604 (1 alc, 152.0 mm), Piauí, Teresina, rio Parnaíba. MZUSP 89935 (1 cs, 108.7 mm), Piauí, Parnaguá, Lagoa de Parnaguá (10¹4'41'’S 44³8'50’’W). MZUSP 90583 (1 alc, $54.4 \mathrm{~mm}$ ), Piauí, Guadalupe, rio Parnaíba (645'44'’s 43³3'53'’W). Hassar orestis: ANSP 180294 (1 sk, não medido), Venezuela, Amazonas, rio Ventuari

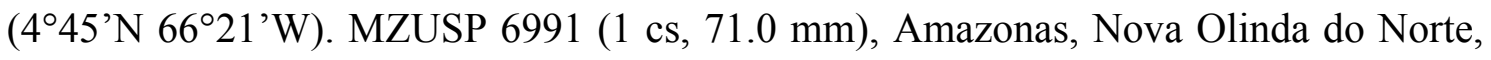
rio Madeira ( $\left.3^{\circ} 53^{\prime} \mathrm{S} 59^{\circ} 5^{\prime} \mathrm{W}\right)$. MZUSP 15512 ( 1 alc, $\left.132.0 \mathrm{~mm}\right)$, Pará, Trombetas, rio Trombetas (1²0’S 56 $\left.51^{\prime} \mathrm{W}\right)$. MZUSP 32542 (2 sk, 205.0-220.0 mm), Pará, Belo Monte, rio Xingu ( $\left.3^{\circ} 7^{\prime} \mathrm{S} 51^{\circ} 42^{\prime} \mathrm{W}\right)$. MZUSP 46010 (1 cs, $\left.76.9 \mathrm{~mm}\right)$, Amazonas, Coari,

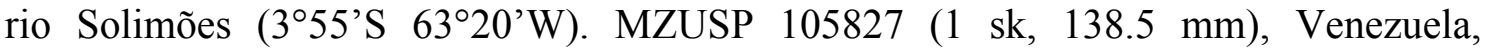
Amazonas, Río Ventuari $\left(4^{\circ} 13^{\prime} 7^{\prime \prime} \mathrm{N} 6^{\circ} 25^{\prime} 26^{\prime \prime} \mathrm{W}\right)$. Hemidoras boulengeri: MZUSP 62641 (1 alc, 147.3 mm), Amazonas, Manaquiri, Lago Janauacá, rio Solimões (3²5’S 60¹7’W). Hemidoras morei: MZUSP 26316 (1 alc, 102.3-115.2 mm), Perú, Pucallpa. MZUSP 27844 (1 cs, 90.6 mm), Bolívia, Bení, Trindad, Río Ibare, bacia do rio Madeira. MZUSP 31104 (1 alc, $167.7 \mathrm{~mm}$ ), Amazonas, Santa Isabel do rio Negro, rio Marauiá, bacia do rio Negro ( $0^{\circ} 24^{\prime} \mathrm{S}$ 651’W). MZUSP 32526 (3 alc, 135.0-138.0 mm, 2 sk, 137.7-153.2 mm), Amazonas, rio Negro ( $\left.0^{\circ} 7^{\prime} \mathrm{S} 67^{\circ} 5^{\prime} \mathrm{W}\right)$. MZUSP 82288 (1 alc, $154.1 \mathrm{~mm}$ ), sem dados. Hemidoras morrisi: ANSP 180191 (1 sk, não medido), Perú, 
Loreto, Maynas, rio Nanay $\left(3^{\circ} 46^{\prime} 45^{\prime}\right.$ 'S $\left.73^{\circ} 22^{\prime} 6^{\prime \prime} \mathrm{W}\right)$. MZUSP 28378 (2 alc, 157.0$164.0 \mathrm{~mm})$, Rondônia, Lago Piauí, foz do rio Jamari, bacia do rio Madeira $\left(8^{\circ} 27^{\circ} \mathrm{S}\right.$ 63³0’W). MZUSP 56044 (2 alc, $58.2 \mathrm{~mm}$ ), Amazonas, rio Jutaí (252’36’'S 6659’20’'W). MZUSP 56683 (1 cs, 93.2 mm), Amazonas, Benjamin Constant, rio Solimões (4²4’S 6949’W). Hemidoras stenopeltis: ANSP 179240 (1 sk, não medido), Amazonas, rio Solimões (2॰35'29'’S 65²9'52'’W). MZUSP 7541 (1 alc, $114.1 \mathrm{~mm})$, Amazonas. MZUSP 7612 (2 alc, 55.3-96.0 mm, 1 cs, 74.8 mm), Amazonas, Urucará ( ${ }^{\circ} 37^{\prime} \mathrm{S}$ 57²2'). MZUSP 29052 (2 cs, 67.9-69.4 mm), Rondônia, rio Madeira em Calama ( $\left.8^{\circ} 3^{\prime} \mathrm{S} 62^{\circ} 53^{\prime} \mathrm{W}\right)$. MZUSP 42772 (1 alc, $\left.108.7 \mathrm{~mm}\right)$, Amazonas, rio Aripuanã. Hemidoras stubellii: MZUSP 26316 (2 alc, 102.3-114.9 mm), Perú, Pucallpa, Río Ucayali. MZUSP 56879 (1 cs, $64.5 \mathrm{~mm}$ ), Amazonas, rio Purus (351'9''s $\left.61^{\circ} 23^{\prime} 25^{\prime \prime} \mathrm{W}\right)$. MZUSP 57620 (1 alc, $59.6 \mathrm{~mm}$ ), Amazonas, rio Negro (34’4'’s 60¹4'58'’W). Kalyptodoras bahiensis: MZUSP 87841 (1 sk, $233.0 \mathrm{~mm})$, Bahia, Itaberaba, rio Paraguassú. MZUSP 87842 (8 alc, 129.0-196.0mm, 1 sk, 152.0 mm), Bahia, Iaçu, rio Paraguassú. Leptodoras acipenserinus: ANSP 178467 (1 alc, 106.7 mm), Peru, Río Nanay. Leptodoras copei: ANSP 162461 (1 alc, 96.5 mm), Venezuela, Amazonas, Río Orinoco. Leptodoras hasemani: ANSP 175888 (1 cs, 81.8 mm), Guiana, Essequibo River. ANSP 179209 (não medido), Guiana, Rupununi, Rupununi River, Essequibo drainage. MZUSP 37009 (1 alc, 132.8 mm), Roraima, Boa Vista, rio Branco (2 $\left.{ }^{\circ} 50^{\prime} \mathrm{N} 60^{\circ} 40^{\prime} \mathrm{W}\right)$. Leptodoras juruensis: ANSP 179168 (1 sk, não medido), rio Amazonas. INHS 39465 (1 alc, 117.4 mm), Peru, Río Amazonas. MZUSP 57054 (1 cs,

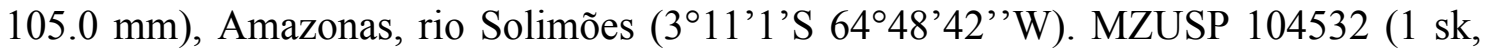
227.0 mm), Rondônia, Porto Velho, rio Madeira (8³2'12'’S 63³4'5'’W). Leptodoras marki: MZUSP 103217 (1 alc, 80.3 mm, 1 cs, 83.2 mm), Pará, São Felix do Xingu, Igarapé Manguari $\left(6^{\circ} 35^{\prime} 42^{\prime} ’\right.$ S 51 $48^{\prime} 48^{\prime}$ 'W). Leptodoras myersi: MZUSP 55839 (1 cs, 
$83.8 \mathrm{~mm})$, Amazonas, rio Solimões ( $3^{\circ} 11^{\prime} 17^{\prime}$ 'S $\left.64^{\circ} 48^{\prime} 47^{\prime \prime} \mathrm{W}\right)$. Leptodoras oyakawai: ANSP 187336 (1 sk, 120 mm), Pará, Novo Progresso, rio Jamanxim, tributário do rio

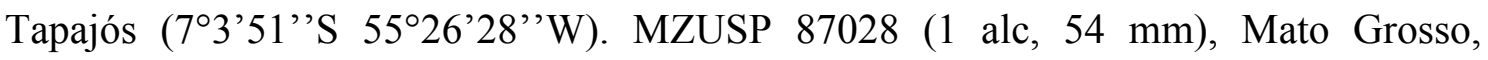
Gaúcha do Norte, rio Curisevo, tributário do rio Xingu (13²'5's 53²3'19', W). MZUSP 97722 (1 cs, $73.0 \mathrm{~mm})$, Mato Grosso, Paranaíta, rio Teles Pires (9²7’7' $\mathrm{S}$ 56³0'46”'W). Leptodoras praelongus: ANSP 162463 (1 alc, $142 \mathrm{~mm}$ ), Venezuela, Río Pamoni. ANSP 179156 (1 sk, não medido), Roraima, rio Branco, afluente do rio Negro (1²0’34’'S 6152’21'’W). MZUSP 31694 (1 alc, Pará, Belo Monte, rio Xingu (37’S 51²'W). MZUSP 56674 (1 cs, $82.7 \mathrm{~mm}$ ), Roraima, rio Branco (1¹8'49'’S 6152’3'’W). Lithodoras dorsalis: MZUSP 9379 (1 cs, $134.0 \mathrm{~mm}$ ), Pará, Icoaraci

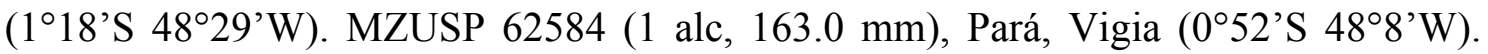
MZUSP 62585 (2 alc, 115.0-118.0 mm), Pará, Icoaraci (1 $\left.{ }^{\circ} 18^{\prime} \mathrm{S} 48^{\circ} 29^{\prime} \mathrm{W}\right)$. MZUSP

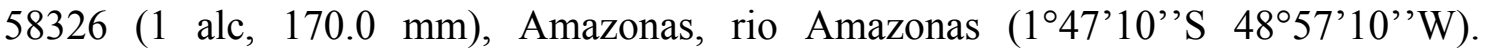
MZUSP 13955 (1 alc, 740.0 mm), Rondônia, rio Machado, bacia do rio Madeira. MZUSP 91562 (1 sk, 478.0 mm), Pará, Belém, mercado de Icoaraci. Megalodoras uranoscopus: MZUSP 8284 (1 alc, 337.0 mm), Pará, Oriximiná, Lago Paru, bacia do rio Trombetas (152’S 5550’W). MZUSP 5647 (1 alc, 570.0 mm), Pará, Oriximiná, Lago

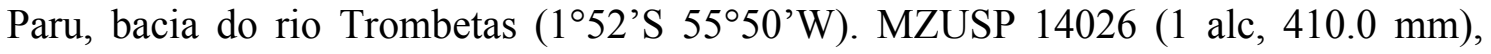
Rondônia, rio Machado, bacia do rio Madeira. MZUSP 25308 (1 alc, 315.0 mm), Pará, Itapacura, rio Tapajós (437’'S 56 $\left.18^{\circ} \mathrm{W}\right)$. MZUSP 46007 (1 alc, $16.02 \mathrm{~mm}$ ), Tocantins. MZUSP 55838 (1 cs, $73.0 \mathrm{~mm})$, Amazonas, Jutaí, rio Solimões (2³1'37’S 66³6'27'’W). Megalodoras guayoensis: ANSP 177980 (143.9 mm), Venezuela, Río Orinoco. ANSP 179167 (1 sk, não medido), Venezuela, Delta Amacuro, Río Orinoco (8²8’24'’N 61¹7'12’’W). Nemadoras elongatus: ANSP 179239 (2 sk, não medidos), Amazonas, rio Solimões, 254'34'’S 6750'1'’W). MZUSP 56013 (1 alc, 99.2 mm, 1 
cs, $92.0 \mathrm{~mm}, 1 \mathrm{sk}, 101.6 \mathrm{~mm})$, Amazonas, Barcelos, rio Negro (1²3'1', $\mathrm{S}$ 61 55'50'’W). MZUSP 56021 (1 alc, $46.1 \mathrm{~mm}$ ), Amazonas, rio Negro (38'24'’S 607'20’'W). Nemadoras hemipeltis: MZUSP 56688 (1 cs, $81.8 \mathrm{~mm}$ ), Amazonas, Benjamin Constant, rio Iça (4²4’S 6949’W). Nemadoras humeralis: ANSP 179157 (2 sk, não medido), Amazonas, rio Amazonas (3²1'22'’'S 58³8'52'’W). MZUSP 6990 (1

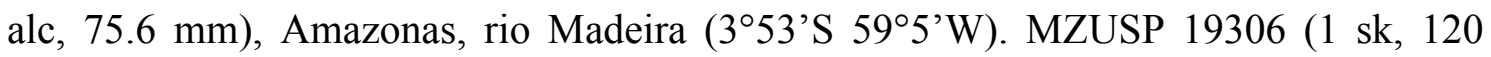
$\mathrm{mm})$, Amazonas, Manaus, rio Negro ( $\left.3^{\circ} 10^{\prime} \mathrm{S} 60^{\circ} 0^{`} \mathrm{~W}\right)$. MZUSP 55996 (1 cs, $58.0 \mathrm{~mm}$, 1 alc, $60.1 \mathrm{~mm}$ ), Amazonas, rio Juruá (2³7'5’’S 6547’43’’W). MZUSP 56014 (1 alc, 103.8 mm), Amazonas, rio Içá (38'56'’S 68¹'59'’W). MZUSP 56606 (1 cs, 86.4

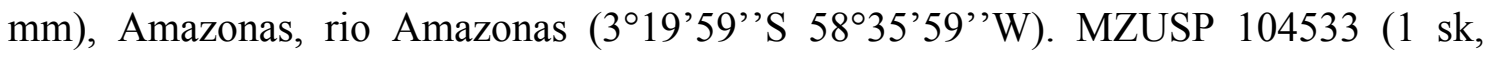
124.1 mm), Rondônia, Porto Velho, rio Madeira (851'43'’S 64³'37'W). "Nemadoras" leporhinus: MZUSP 96596 (3 cs, 42.0-43.0 mm), Mato Grosso, Peixoto de Azevedo, rio Teles Pires, afluente do rio Tapajós (10¹3'14'’S 5458'2'’W). MZUSP 95617 (2 alc, 89.0-138.1 mm), Mato Grosso, Paranaíta, rio Teles Pires, afluente do rio Tapajós (9²7’7'’S 56³0'46’’W). MZUSP 88612 (1 alc, 75.3 mm, 1 cs, $73.8 \mathrm{~mm}$ ), Venezuela, Amazonas, Río Ventuari, afluente do Río Orinoco (4²45’0'S 66²1'13'’W). MZUSP 105832 (1 sk, 97.2 mm), Venezuela, Bolivar, Río Caura, bacia do Río Orinoco (7²’37’’S 6457’41’’W). “Nemadoras” ternetzi: ANSP 179587 (2 sk, não medidos), Amazonas, rio Negro (142’4'’S 61²9'1'’W). MZUSP 56694 (1 sk,

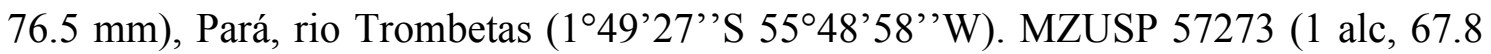
mm, 2 cs, 51.6-56.7 mm), Pará, Monte Dourado, rio Jari $\left(0^{\circ} 43^{\prime} 7^{\prime} ' \mathrm{~S} 52^{\circ} 29^{\prime} 43^{\prime \prime} \mathrm{W}\right)$. MZUSP 76422 (2 alc, 98.4-117.2 mm, 1 cs, 111.2 mm), Pará, Santarém, rio Tapajós (2²3’S 5446’W). MZUSP 57682 (1 alc, $110.9 \mathrm{~mm})$, Pará, rio Tapajós (240’41'’S 558'48'’W). MZUSP 103246 (5 sk, 63.4-91.4 mm), Pará, monte Dourado, rio Jari (041'28'’S 52³0’44’'W). MZUSP 105833 (1 sk, 87.6 mm), Venezuela, Bolivar, Río 
Caura, afluente do Río Orinoco $\left(7^{\circ} 22^{\prime} 37^{\prime} \mathrm{N} 64^{\circ} 57^{\prime} 41^{\prime \prime} \mathrm{W}\right)$. “Nemadoras" trimaculatus: MZUSP 29030 ( 1 cs, 51.3-56.0 mm), Rondônia, rio Madeira (8³’S 6253’W). MZUSP 52314 (1 alc, 83.8-84.4 mm), Mato Grosso, Araguaiana, rio Araguaia. MZUSP 53834 (1 alc, $75.6 \mathrm{~mm}$ ), Mato Grosso, Araguaiana, rio Araguaia. MZUSP 56706 (1 alc, 46.9 mm), Amazonas, rio Jutaí (2॰56’41’’s 670'52’’W). MZUSP 57272 (1 cs, $70.1 \mathrm{~mm}$ ),

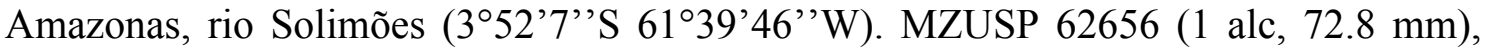
Amazonas, Fonte Boa, rio Solimões ( $\left.2^{\circ} 31^{\prime} \mathrm{S} 66^{\circ} 6^{\prime} \mathrm{W}\right)$. MZUSP 92206 (1 alc, $93.9 \mathrm{~mm}$ ), Amazonas, rio Tiquié, bacia do rio Negro ( $0^{\circ} 8^{\prime} 40^{\prime}$ 'N 69¹2'48' W). Nemadoras sp. “juvenil”: MZUSP 74280 (2 cs, 14.8-15.7 mm), Amazonas, Anavilhanas, rio Negro ( $2^{\circ} 42^{\prime} \mathrm{S} 60^{\circ} 45^{\prime} \mathrm{W}$, coletados em fevereiro). Orinocodoras eigenmanni: ANSP 177996 (1 sk, não medido), Venezuela, Delta amacuru, Río Orinoco ( $8^{\circ} 37^{\prime} 20^{\prime}$ 'N 6147’30'’W). AUM 5318 (1 alc, 119.6 mm), Venezuela, Portuguesa, Caño Maraca, bacia do Río Orinoco ( $\left.8^{\circ} 49^{`} \mathrm{~N} 69^{\circ} 20^{`} \mathrm{~W}\right)$. INHS 40330 (1 cs, $\left.57.8 \mathrm{~mm}\right)$, Venezuela, Caño Guaritico, bacia do rio Orinoco $\left(7^{\circ} 33^{\prime} \mathrm{N}\right.$ 69³9’W). FMNH 105276 (1 sk, $\left.193.0 \mathrm{~mm}\right)$, Venezuela, Caño Anabata, afluente do rio Orinoco (8³7’20'’N 6147’33'’ W). Oxydoras niger: ANSP 179438 (3 sk, não medidos), Perú, Loreto, Iquitos. MZUSP 9079 (1 alc, 550.0 mm), Amazonas, Manaus. MZUSP 13366 (1 alc, 315.0 mm), Pará, rio Tapajós. MZUSP 14019 (1 alc, 420.0 mm), Rondônia, rio Machado, bacia do rio Madeira. MZUSP 43466 (1 alc, 109.5 mm), Pará, Baião, Lagoa marginal do rio Tocantins ( $\left.2^{\circ} 50^{`} \mathrm{~S} 49^{\circ} 40^{`} \mathrm{~W}\right)$. MZUSP 56162 (1 alc, 138 mm), Amazonas, rio Solimões (2³5'22'’S 65³0’18'’W).

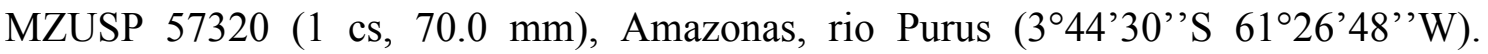
MZUSP 91654 (1 sk, $550.0 \mathrm{~mm}$ ), Goiás, Luís Alves, rio Verde, afluente do rio Araguaia (139'28'’S 50³0’22'’W). MZUSP 91658 (1 sk, 313.0 mm), Amazonas, Manaus, Porto Ceasa. Oxydoras kneri: MZUSP 14847 (1 alc, 393.0 mm), Mato Grosso, rio Paraguay na Ilha de Taiamã. Oxydoras sifontesi: MZUSP 105824 (1 sk, 413.0 mm), 
Venezuela, Amazonas, Puerto Ayaycucho. INHS 33986 (1 alc, 187 mm), Venezuela, Río Orinoco $\left(8^{\circ} 6^{\prime} 0^{\prime}{ }^{\prime} \mathrm{N} 63^{\circ} 45^{\prime} 50^{\prime}\right.$ 'W). “Petalodoras" aff. eigenmanni: MZUSP 5646 (1 alc, 95.4 mm), Pará, Oriximiná, Lago Paru. MZUSP 7543 (2 alc, 50.2-73.5 mm, 1 cs, 77.3 mm), Amazonas, Urucará, rio Amazonas. MZUSP 7838 (1 sk, 65.3 mm), Pará, Faro Nhamundá, Paraná do Jacaré. MZUSP 56699 (1 alc, 85.7 mm), Pará, rio Trombetas ( $\left.1^{\circ} 47^{\prime} 30^{\prime \prime} \mathrm{S} 55^{\circ} 51^{\prime} 27^{\prime \prime} \mathrm{W}\right)$. MZUSP 84665 (1 alc, $\left.85.7 \mathrm{~mm}\right)$, Mato Grosso, Vila Bela da Santíssima Trindade, rio Guaporé, afluente do rio Madeira (15 ${ }^{\circ}{ }^{\prime} 17^{\prime}$ 'S 5957'90’’W). “Petalodoras” eigenmanni: MZUSP 38176 (2 alc, 85.5-86.2 mm), Mato Grosso, Corumbá, rio Miranda, afluente do rio Paraguai (19²1'S 56858’W). MZUSP

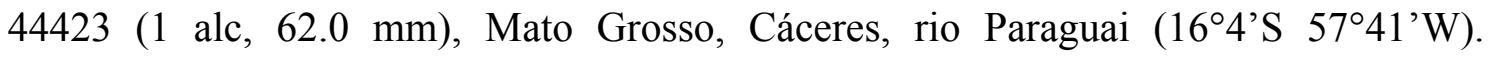
MZUSP 95024 (2 alc, 38.3-65.3 mm, 3 cs, 35.1-65.6 mm), Mato Grosso, Barão de

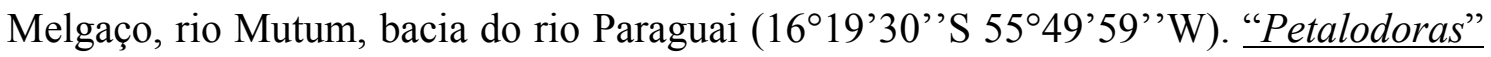
fimbriatus: MZUSP 55833 (4 alc, 45.0-62.2 mm, 1 cs, $46.9 \mathrm{~mm}$ ), Amazonas, rio Jutaí (254'25'’S 670'12'’W). MZUSP 56703 (1 cs, $59.0 \mathrm{~mm})$, Amazonas, rio Jutaí (2॰57'6’'S 670'29'’W). “Petalodoras" punctatus: MZUSP 7839 (1 alc, 72.6 mm, 1 cs, $61.6 \mathrm{~mm})$, Pará, Faro Nhamundá, Paraná do Jacaré. MZUSP 7540 (1 cs, $61.7 \mathrm{~mm})$, Amazonas, Urucará, rio Uatumã. MZUSP 26265 (1 alc, 34.2 mm), Perú, Pucallpa, Río Ucayali. MZUSP 41096 (1 alc, 59.3 mm), Mato Grosso do Sul, Corumbá, rio Miranda (20¹4’S 56²2’W). MZUSP 95000 (1 alc, $65.8 \mathrm{~mm}$ ), Mato Grosso, Vila Bela da

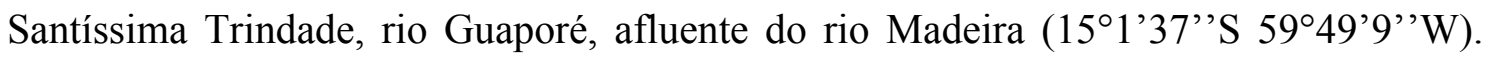
NUP 3542 (1 alc, 65.4 mm), Mato Grosso, Santo Antônio do Leverger, rio Cuiabá, afluente do rio Paraguai $\left(15^{\circ} 58^{\prime} 27^{\prime} ' S\right.$ 5 5 56'27' W). Platydoras armatulus: ANSP 149463 (1 alc, 119.9 mm), Venezuela, Delata Amacuru, Río Orinoco. ANSP 163478 (1 alc, $111.7 \mathrm{~mm}$ ), Venezuela, Guarico, Río Portuguesa, bacia do Río Orinoco. ANSP 178748 (1sk, não medido), Guiana, Rupununi River, afluente do Essequibo River. 
MZUSP 5645 (1 alc, 200.0 mm), Pará, Oriximiná, Lago Paru (152’S 5550’W). Pará, rio Trombetas. MZUSP 40577 (1 cs, 87.0 mm), Goiás, Iaciara, rio Paranã, bacia do rio tocantins $\left(14^{\circ} 6^{\prime} \mathrm{S} 46^{\circ} 38^{\prime} \mathrm{W}\right)$. MZUSP $86217(1 \mathrm{cs}, 52.5 \mathrm{~mm})$, Mato Groso, Cocalinho, Corixo da Saudade, bacia do rio Araguaia (14²17'20'’S 519'12'’W). MZUSP 91686 (1 sk, 151.7 mm), Goiás, Minaçu, rio Tocantins. MZUSP 94088 (1 alc, $144.0 \mathrm{~mm}$ ), Mato

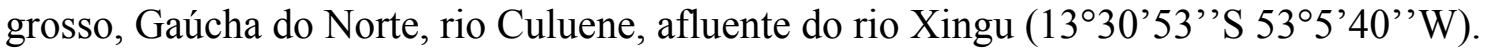
MZUSP 105041 (1 sk, 123.8 mm), sem dados. Platydoras brachylechis: MZUSP 5122 (1 cs, 108 mm), Piauí, rio Parnaíba. Platydoras sp. “xingu”: MPEG 6713 (1 cs, 107.0 mm), Pará, Altamira, rio Xingu. Pterodoras granulosus: ANSP 178799 (2 sk, não medidos), Argentina, Buenos Aires, Río La Plata (3453’S 589’W). ANSP 179166 (1 sk, não medido), Amazonas, rio Solimões. MZUSP 5681 (1cs, 203 mm), Pará, Oriximiná, rio Trombetas (152’S 5550’W). MZUSP 38177 (1 sk, $220 \mathrm{~mm}$ ), Mato

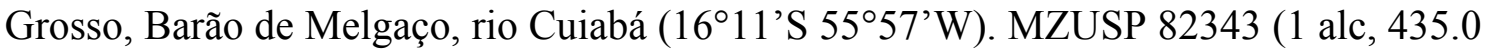
mm), sem dados. MZUSP 82995 (1 cs, 60.5 mm), Amazonas, rio Amazonas. MZUSP

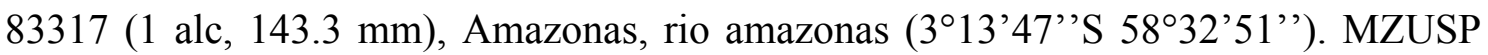
89624 (2 sk, 208.0-262.0 mm), Mato Grosso do Sul, rio Cuiabá. MZUSP 91441 (1 alc, 330.0 mm), Amazonas, Nova Olina do Norte, rio Madeira. MZUSP 91655 (8 sk, 260.0$410.0 \mathrm{~mm}$ ), Goiás, Minaçu, rio Tocantins em Serra da Mesa. Pterodoras rivasi: ANSP 177895 (1 alc, $336.1 \mathrm{~mm}$ ), Colombia, Lago Mozambique, drenagem do Río Meta, bacia do Río Orinoco. MZUSP 88609 (1 alc, 82.2 mm), Venezuela, Bolivar, Río Guariquito, bacia do Río Orinoco (7³9’36’’N 66²0’0’'W). MZUSP 105825 (1 sk, 350.0 mm), Venezuela, Amazonas, Puerto Ayacucho, Río Orinoco (540’S 67³8’W). MZUSP 105830 (2 sk, 114.0-147.0 mm), V enezuela, Bolivar, Caicara del Orinoco, Río Orinoco

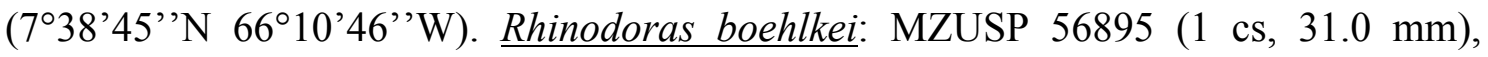
Amazonas, rio Solimões ( $\left.3^{\circ} 35^{\prime} \mathrm{S} 61^{\circ} 5^{\prime} \mathrm{W}\right)$. MZUSP 86812 (1 alc, $\left.95.0 \mathrm{~mm}\right)$, Amazonas, 
rio Solimões $\left(3^{\circ} 36^{\prime} 16^{\prime}\right.$ 'S $\left.61^{\circ} 21^{\prime} 12^{\prime \prime} \mathrm{W}\right)$. MZUSP 86814 (1 alc, $41.0 \mathrm{~mm}, 1 \mathrm{cs}, 54.0$ mm), Amazonas rio Solimões (3²6’22'’S 61²0'14'’W). Rhnidoroas cf. boelkei: INPA 508 (1 cs, 69.0 mm), Pará, Tucuruí, rio Tocantins (342’S 3942’W). INPA 22056 (1, $36.9 \mathrm{~mm})$, Pará, Tucuruí, rio Tocantins $\left(3^{\circ} 42^{\prime} \mathrm{S} 39^{\circ} 42^{\prime} \mathrm{W}\right)$. Rhinodoras dorbignyi: ANSP 179535 (1 alc, 194 mm), Rio Grande do Sul, São Borja, rio Uruguai (28³8’S 56²'W). MZUSP 9381 ( 1 cs, 94.0 mm), São Paulo, rio Paraná (2043’S 51³7’W). MZUSP 27724 (1 alc, 207.7 mm), Mato Grosso do Sul, Coxim, rio Taquari, bacia do rio Paraguai (18³0’S 56²0’W). MZUSP 40109 (1 sk, 196.0 mm), Rio Grande do Sul, São

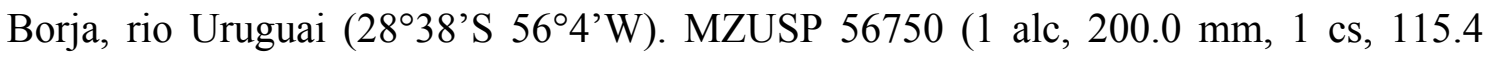
$\mathrm{mm})$, Mato Grosso, Nobres, rio Cuiabazinho, bacia do rio Paraguai $\left(14^{\circ} 44^{\prime} \mathrm{S} 56^{\circ} 20^{\prime} \mathrm{W}\right)$. MZUSP 61456 (2 cs, 70.4-121.9 mm), São Paulo, Pirassununga, rio Mogi Guaçu, bacia do rio Paraná $\left(21^{\circ} 55^{\prime} \mathrm{S} 47^{\circ} 23^{\prime} \mathrm{W}\right)$. MZUSP 62683 (1 alc, $185.6 \mathrm{~mm}, 8$ cs, 45.3-89.9 mm), São Paulo, Ilha Solteira, rio Paraná $\left(20^{\circ} 15^{\prime} S 5^{\circ} 7^{\prime} \mathrm{W}\right)$. MZUSP 78461 (1 alc, $168.0 \mathrm{~mm}$ ), Rio Grande do Sul, rio Uruguai. Rhinodoras gallagheri: AMNH 58349 (1 cs, $52.4 \mathrm{~mm}$ ), Venezuela, Río Apure, afluente do Río Orinoco. Rhinodoras thomersoni: MHNLS 0109 (1 cs, 60.9 mm), Venezuela, Lago Maracaibo. Rhynchodoras castilloi: ANSP 181181 (1 alc, 58.3 mm), Venezuela, Portuguesa, Barinas, Caño Bravo, bacia do Río Orinoco ( $\left.8^{\circ} 0^{`} \mathrm{~N} 67^{\circ} 59^{`} \mathrm{~W}\right)$. MZUSP 88604 (2 alc, 39.1-60.6 mm, 1 cs, $45.5 \mathrm{~mm}$ ), Venezuela, Portuguesa, Barinas, Caño Bravo, bacia do Río Orinoco ( $\left.8^{\circ} 0^{`} \mathrm{~N} 67^{\circ} 59^{`} \mathrm{~W}\right)$. Rhynchodoras woodsi: ANSP 181042 (1 alc, $72.5 \mathrm{~mm}, 1 \mathrm{cs}, 88.4 \mathrm{~mm}$ ), Perú, Río

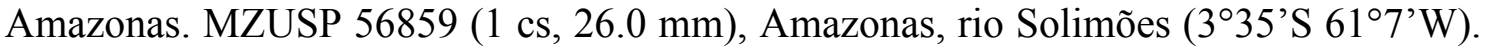
MZUSP 56872 (3 alc, 22.5-37.3 mm, $1 \mathrm{cs}, 23.1 \mathrm{~mm}$ ), Amazonas, rio Amazonas (3²0’S 58³6’W). MZUSP 57316 (42.6 mm), Amazonas, rio Amazonas (3²0’28'’S $\left.58^{\circ} 36^{\prime} 25^{\prime \prime} \mathrm{W}\right)$. MZUSP 57992 (2 alc, 35.0-45.0 mm), Amazonas, rio Amazonas ( $3^{\circ} 20^{\prime} \mathrm{S}$ 58³5'W). MZUSP 86815 (1 cs, $48.2 \mathrm{~mm}$ ), Amazonas, rio Amazonas (3²0’9'’S 
58³6'11'’W). ROM 62601 (1 alc, $44.2 \mathrm{~mm}$ ), Guiana, Essequibo River (440’S $\left.58^{\circ} 40^{\prime} \mathrm{W}\right)$. Rhynchodoras xingui: SMF 5282 (1 alc, $\left.44.5 \mathrm{~mm}\right)$, Alto rio Xingu. INPA 26540 (2 alc, 62.8-64.2 mm), Pará, Tucuruí, rio Tocantins (3²4’'S 4942’ W). Scorpiodoras heckelii: MZUSP 84743 (2 alc, 138.0-145.0 mm), Amazonas, Santa Isabel do rio Negro, rio Negro. MZUSP 7941 (2 cs, 36.6-76.6 mm), Amazonas, Terra Santa, rio Jamari, bacia do rio Amazonas. MZUSP 8493 (1 sk, 114.4 mm), Pará, Santarém, rio Mapiri (2²6’S 5444’W). MZUSP 84203 (1 alc, 148.0 mm), Pará, Lago Jacupá, bacia do rio Amazonas. Trachydoras brevis: MZUSP 29075 (1 cs, 33.0 mm), Rondônia, rio Machado, bacia do rio Madeira. MZUSP 55840 (1 cs, 43.9 mm), Amazonas, rio Jutaí (253’26’'S 66 $\left.57^{\circ} 55^{\prime \prime} \mathrm{W}\right)$. MZUSP 56713 (1 alc, $\left.66.1 \mathrm{~mm}\right)$, Amazonas, rio Jutaí (2'57’22'’S 670'28',W). MZUSP 93094 (1 alc, $93.7 \mathrm{~mm})$, Amazonas, Igarapé Castanha, bacia do rio Negro $\left(0^{\circ} 11^{\prime} \mathrm{N}\right.$ 69³5'W). MZUSP 93374 (1 alc, $\left.46.5 \mathrm{~mm}\right)$, Amazonas, rio Tiquié, bacia do rio Negro $\left(0^{\circ} 8^{\prime} 40^{\prime \prime} \mathrm{N} 69^{\circ} 12^{\prime} 41^{\prime \prime} \mathrm{W}\right)$. MZUSP 103087

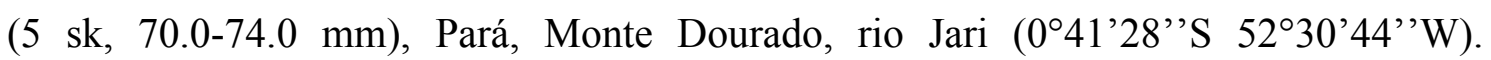
Trachydoras microstomus: MZUSP 56702 (1 cs, $49.8 \mathrm{~mm})$, Amazonas, rio Jutaí (251'6’'S 66 58'7',W). MZUSP 57331 (1 cs, $57.5 \mathrm{~mm}$ ), Pará, rio Amazonas (1²7’52'’S 52³'13’’W). MZUSP 57703 (3 alc, 43.6-76.6 mm), Amazonas, Manaus, rio Negro (36'8',S 60¹0'2''W). MZUSP 105831 (1 sk, $50.0 \mathrm{~mm}$ ), Venezuela, Bolivar, Río Caura, afluente do Río Orinoco $\left(7^{\circ} 2^{\prime} 37^{\prime} ’ \mathrm{~N} 64^{\circ} 37^{\prime} 41^{\prime \prime} \mathrm{W}\right)$. Trachydoras nattereri: MZUSP 7837 (2 cs, 55.4-58.5 mm), Pará, Faro Nhamundá, Paraná do Jacaré, bacia do rio Amazonas. MZUSP 55854 (1 alc, 48.7 mm), Roraima, Caracaraí, rio Negro

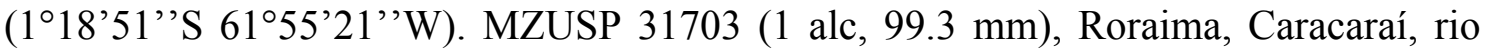
Negro (1¹8'51'’S 6155'21'’W). Trachydoras paraguayensis: ANSP 178699 (1 alc, $79.2 \mathrm{~mm}$ ), Mato Grosso, Cácares, rio Paraguai. MZUSP 21109 (1 alc, $80.2 \mathrm{~mm}$ ), Paraná, Bandeiras, rio Paraná (2410’S 54¹9’W). MZUSP 27801 (1 alc, 84 mm), 
Bolívia, Santa Cruz, Laguna San José, bacia do rio Madeira. MZUSP 29047 (1 alc,

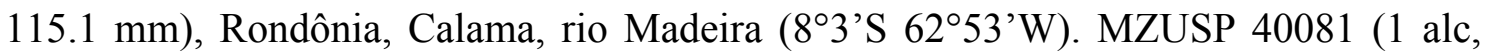
$101.0 \mathrm{~mm}$ ), Mato Grosso do Sul, Aquidauana, rio Aquidauana, bacia do rio Paraguai (20²8’S 5548’W). MZUSP 48315 (1 cs, $54.3 \mathrm{~mm}$ ), Mato Grosso do Sul, Coxim, rio Paraguai (18³0’S 5445’W). Trachydoras steindachneri: ANSP 179171 (1 sk, não medido), Amazonas, rio Solimões (254'15’’S 6747'53'’W). MZUSP 7611 (1 cs, 75.8 mm, 1 sk, 63.6 mm), Amazonas, Urucará, Paraná do Mocambo, bacia do rio amazonas ( $\left.{ }^{\circ} 37^{\prime} \mathrm{S} 57^{\circ} 43^{\prime} \mathrm{W}\right)$. MZUSP $7836(1 \mathrm{cs}, 70.0 \mathrm{~mm})$, Pará, Faro Nhamundá, Paraná do Jacaré. MZUSP 62696 (3 alc, 38.7-77.0 mm), Amazonas, Fonte Boa, rio Solimões (2³1'S 66'W). MZUSP 74867 (1 alc, $75.7 \mathrm{~mm}$ ), Amazonas, rio Solimões. Wertheimeria maculata: MCZ 91317 (1 cs, $65.0 \mathrm{~mm}$ ), Minas Gerais, Itira, rio Jequitinhonha (16 $\left.46^{\prime} \mathrm{S} 42^{\circ} 2^{\prime} \mathrm{W}\right)$. MZUSP 40229 (10 alc, 46.7-145.0 mm, 3 cs, 25.0$112.0 \mathrm{~mm}$ ), Minas Gerais, Itira, rio Jequitinhonha (16 $47^{\prime}$ 'S $\left.42^{\circ} 3^{\prime} \mathrm{W}\right)$. MZUSP 88614 (1 sk, 124.0 mm), Minas Gerais, rio Jequitinhonha. MZUSP 93659 (2 sk, 195.0-217.0 mm), Minas Gerais, Araçuaí, rio Jequitinhonha. MZUSP 93658 (1 alc, 168.0 mm, 1 sk, $192.0 \mathrm{~mm})$, Minas Gerais, Itira, rio Jequitinhonha (16 ${ }^{\circ} 45^{\prime} 44^{\prime}$ 'S $\left.42^{\circ} 0{ }^{\prime} 37^{\prime \prime} \mathrm{W}\right)$.

Grupo externo: Amphiliidae: Amphilius jacksoni: UMMZ 199987 (4 cs, 30.9-100.0 mm), Zambia, Mpika, rio Lwitikila. Ariidae: Arius herzbergi: MZUSP 52847 (1 alc, 192.0 mm), Alagoas, Coqueiro Seco, Lagoa Mandaú (9³7’S 3548’W). Galeichthys peruvianus: MZUSP 94844 (1 alc, 105 mm, 1 sk, 208.0 mm), Perú, Lima, Callao (12 $\left.12^{\prime} 35^{\prime} ' \mathrm{~S} 77^{\circ} 5^{\prime} 15^{\prime \prime} \mathrm{W}\right)$. Genidens genidens: MZUSP 51721 (1 cs, $\left.128 \mathrm{~mm}\right)$, Bahia, Nova Viçosa, rio Peruíba, (1754’S 39²2’W). MZUSP 51693 (1 sk, 250.0 mm), São Paulo, Juréia, Ilha do Bom Abrigo. MZUSP 49319 (1 alc, 115 mm), São Paulo, Cananéia. Aspredinidae: Bunocephalus coracoideus: MZUSP 28835 (1 cs, 68.6 mm), sem dados. MZUSP 30713 (1 alc, $71.0 \mathrm{~mm}$ ), Amazonas, Tefé, rio Tefé ( $3^{\circ} 22^{\prime} \mathrm{S}$ 
64²3’W). MZUSP 103254 (1 sk, $67.0 \mathrm{~mm}$ ), Amapá, Lanranjal do Jari, Igarapé Arapiranga, afluente do rio Jari $\left(0^{\circ} 47^{\prime} 41^{\prime}\right.$ 'S 52 27'10'’W). Pseudobunocephalus bifidus: MZUSP 50107 (2 cs, 33.3-54.0 mm), Acre, Manoel Urbano, rio Purus $\left(8^{\circ} 48^{\prime} \mathrm{S}\right.$ 69¹5’W). Clariidae: Clarias sp.: MZUSP 91656 (1 sk, $430.0 \mathrm{~mm})$, Espírito Santo, Anchieta, rio Grande (2042'23''S 40³9'0''W). Claroteidae: Chrysichthys auratus: MZUSP 27171 (1 cs, 101.0 mm), Egito, Nilo, Nasarah. Diplomystidae: Diplomystes campoensis: MZUSP 88533 (1 sk, 172.5 mm), Chile, Los Lagos/ VIII Región, rio San Pedro, sistema Lago Riñihue. Diplomystes mesembrinus: MZUSP 62595 (1 alc, 99.2 $\mathrm{mm})$, Argentina, Chubut, Los altares, rio Chubut $\left(43^{\circ} 49^{\prime} \mathrm{S} 67^{\circ} 54^{\prime} \mathrm{W}\right)$. Erethistidae: Conta conta: USNM 44759 (1 cs, 52.0 mm), Myanmar, Meetan. Heptapteridae: Rhamdia quelen: MZUSP 36505 (1 alc, 170.0 mm), São Paulo, rio Ribeira de Iguape. MZUSP 79083 (1 sk, 233.0 mm), Paraná, Represa de Vossoroca, bacia do rio Paraná. MZUSP 102800 (1 sk, 160.0 mm), São Paulo, Biritiba Mirim, rio Tietê, bacia do rio Paraná (2334'5'’S 460'38''W). Goeldiella eques: MZUSP 33190 (1 cs, 103.5 mm), Amazonas, rio Negro. MZUSP 45907 (1 cs, 79.0 mm), Pará, rio Trombetas. Ictaluridae: Ictalurus punctatus: MZUSP 62602 (1 cs, não medido). MZUSP 103256 (1 cs, 50.0, $1 \mathrm{sk}, 155.0 \mathrm{~mm}$ ), sem dados. Malapteruridae: Malapterurus beninensis: MZUSP 84464 (2 alc, 64.2-69.6, 2 cs, 30.6-64.2 mm), Benin, Quémé, Azowlissé, Quémé River $\left(1^{\circ} 40^{\prime} 29^{\prime} \mathrm{N} 2^{\circ} 29^{\prime} 15^{\prime}\right.$ 'E). Mochokidae: Chiloglanis disneyi: USNM 303505 (3 cs, 50.5-53.7 mm), Camaroon, Sistema Akpa-Yafe, SW Korup. Chiloglanis paratus: MZUSP 65810 (3 alc, 60.5-61.3 mm), África do Sul, Mabunga Rapids. Chiloglanis polypogon: USNM 304264 (4 cs, 25.3-28.9 mm), Camaroon, Sistema Munaya River. Euchilichthys guentheri: AMNH6507 (2 alc, 183.5-221.0 mm), Congo, Orientale Province, Stanleyville. Microsynodontis christyi: ZSM 22895 (1 cs, 29.8 mm), Congo, Stanley-Pool, Leopoldville. Microsynodontis batesii: SU 47485 (2 alc, 51.4- 
$53.8 \mathrm{~mm}$ ), Camaroon, Congo River. Mochokiella paynei: AMNH 58398 (1 alc, 36.7 mm, 1 cs, $38.0 \mathrm{~mm}$ ), sem dados. Mochokus brevis: CAS 211322 (1 alc, $21.7 \mathrm{~mm})$, Egito. Mochokus niloticus: USNM 229657 (1 cs, $28.8 \mathrm{~mm})$, Nigeria. Synodontis batensoda: AMNH 230635 (2 alc, 54.1-62.8 mm). MNHN 1959-525 (1 cs, $48.4 \mathrm{~mm}$ ), Tchad, Kousseri, Lake Tchad. Synodontis membranaceus: USNM 313407 (1 cs, 50.3 mm), Gana, White Volta. Synodontis nigriventris: MZUSP 59326 (1 cs, $39.8 \mathrm{~mm})$, sem dados. Synodontis schall: ANSP 78057 (1 sk, não medido), Egito, Sudan, Khartoum. MZUSP 84468 (2 alc, 63.1-76.0 mm, 8 cs, 43.0-80.0 mm), Benin, Quémé, Azwlissé, Quémé River (140’29’'S 2²9’15’'E). Synodontis sorax: ANSP 78053 (1 sk, não medido), Egito, Sudan, Khartoum. Synodontis zambezensis: MZUSP 62621 (2 cs, 45.7$52.7 \mathrm{~mm}$ ), África do Sul, KwaZulu, Natal Phongola, Ngodo pan. Nematogenyidae: Nematogenys inermis: MZUSP 75256 (1 sk, $210 \mathrm{~mm}$ ), Chile, Aguas de La Gloria, Estero Aguas de La Gloria (3650’30’'S 7256'4'’W). Pangasiidae: Pangasius pangasius: MZUSP 62587 (1 alc, $130 \mathrm{~mm}$ ), Myanmar, Thanlyin. Pangasius sutchi: MZUSP 102779 (2 cs, 56.4-61.0 mm), sem dados. Pangasius sp.: MZUSP 60075 (1 cs, $45.1 \mathrm{~mm}$ ), sem dados. Pimelodidae: Steindachneridion scriptum: MZUSP 90279 (6 cs, 19.0-23.0 mm), Santa Catarina, rio Uruguai. Steindachneridion parahybae: MZUSP 100672 (1 sk, 329.0 mm, 4 cs, 74.8-93.7 mm), São Paulo, rio Paraíba do Sul. Pseudopimelodidae: Pseudopimelodus bufonius: MZUSP 94855 (1 alc, 168.0 mm, 1 cs, $68.0 \mathrm{~mm}, 2 \mathrm{sk}, 170.0 \mathrm{~mm})$, Mato Grosso Paranating, rio Culuene (13²49'S $\left.53^{\circ} 15^{\prime} \mathrm{W}\right)$. Lophiosilurus alexandri: MZUSP 73817 (1 alc, $\left.127.8 \mathrm{~mm}\right)$, Minas Gerais,

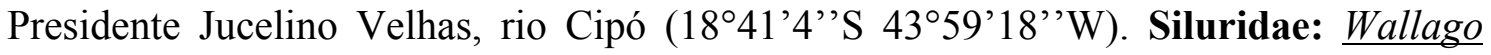
attu: BMNH 1889.9.26.48-50 (1 cs, $175.0 \mathrm{~mm})$, Deola, Rajputana. Sisoridae: $\underline{\text { Bagarius }}$ bagarius: USNM 186793 (1 cs, 98.5 mm), Thailand, Ubon. 
Apêndice 2. Matriz de caracteres filogenéticos.

Diplomystidae

0000110000000000?000000?00000000000000000000???00000???0000000000000001 $00000000000011000000000 ? 0 ? ? ? 0000000000000000000000200000 ? ? ? ? ? 0000000000$ $000000000000010000100000000000\{01\} 110000000001000010000000000000000000$ ? $00000000 ? 000000000000000210000000000000000000000000000000010 ? 1001001000$ $0000 ? 000000000000000010000000000000000000100000$

Nematogenyidae

$001 ? 0000000000010000000 ? 00000000000022000000 ? ? ? 00000 ? ? ? 0000000000000000$ 00000000000010000000000?0???11000000000000?0000000200000?????00000001100 $010000000100000001000000000000110000000002000110000000100000011000 ? 000$ $00000 ? 0000000000000002100010 ? ? 000001 ? 00000000000001 ? 00010 ? 0001000 ? ? 0000$ $0 ? 001100000000001010000000000000000 ? 02000000$

Ictaluridae $00020000000000020000010 ? 00000000000000000000 ? ? ? 00000 ? ? ? 0000000000000011$ $00000000000000000010000 ? 0 ? ? ? 0000000000000000000000200000 ? ? ? ? ? 0000000110$ $0000000000110010001001000010000110000000000100110000000000000011000 ? 00$ 000000?000000010000000220000000000000000000000000000000011000010010010 000?000100000000000020000000000000000001100000

Pimelodidae $00000000000000020010000 ? 00000000000000000100 ? ? ? 00000 ? ? ? 0001000000002011$ $00000000000001000010000 ? 0 ? ? ? 0000000000000030000000410000 ? ? ? ? ? 0011000110$ $0000000000110010000 ? 01000010001010000000001100110000000000000011000 ? 001$ 00000?0000000110000002200000000000000000000000000000000110000100100100 $00 ? 001100000000000010000000000000000201100010$

Pseudopimelodidae $00000000000000020000000 ? 00000000000010000000 ? ? ? 00000 ? ? ? 0001000000002100$ $00000000000000000010000 ? 0 ? ? ? 0000000000000030000000400000 ? ? ? ? ? 0011000110$ $0000000000110010001000000010001000001000001100110000000000000011000 ? 00$ 000000?000000010000000100000000000000000000011000000000011000010010010 000?001100000000000000000000000000000202101120

Heptapteridae $00000000000000020000000 ? 00000000000000000100 ? ? ? 00000 ? ? ? 0001000000002001$ 00000000000000000010000?0???0000000000000020000000200000?????0011000110 $0000000000110010000 ? 00000010100000000000001100110000000000000011000 ? 000$ 00000?0000000100000002200000000000000000000000000000000110000100100100 $00 ? 001100001000010010000000000000000201100110$

Siluridae

$001 ? 0000000000020000000 ? 00000000000000000000 ? ? ? 00000 ? ? ? 0001000000000011$ $00000000000001000010000 ? 0 ? ? ? 1000000000000020000000400000 ? ? ? ? ? 0300001110$ $0010000000110010000 ? 00000010000100000000003100011100000000000011000 ? 000$ 00000?0000000110000001300010???00001?00000000000000000010?0001000??0000 $0 ? 000100000000000030000000000000000 ? 01100000$

Aspredinidae

$001 ? 2000000000020000001000000000000010000000 ? ? ? 00000 ? ? ? 0001 ? 00 ? 00100010$ $00000000000000000011000 ? 0 ? ? ? 10110000000000 ? 0000001 ? 00000 ? ? ? ? ? 00002001100$ $000000000110010000 ? 000010101000000010000001003 ? 0000001100000111000 ? 0000$ 0000?020001110000001200000000001101?00000000000010000011000010010011010 
?00100000001?000000000000000000000103001220

Sisoridae

$00001100000000020000011100000000000021000000 ? ? ? 00000 ? ? ? 0001000000002010$ $00000000000000000011000 ? 10000111000000000010000001 ? 00000 ? ? ? ? ? 0010001110$ $0000000000110010000 ? 00000010001110001000012100110000010000000011000 ? 000$ $00000 ? 020001010000001100000010001100100000000000000000010 ? 0001001001100$ $0 ? 000000001100000010000000000000000201100220$

Erethistidae $00001100000000020000011100000000000021000000 ? ? ? 00000 ? ? ? 0001000000002010$ $00000000000000000011000 ? 0 ? ? ? 1111000000000030000001 ? 00000 ? ? ? ? ? 00000001100$ $000000000110010000 ? 00000020000110000000010100110000001100000111000 ? 0000$ 0000?020001110000001200000010001100100000001000000000010?00010010011001 0001100000100000010000000000000000201101220

Malapteruridae $00002000000000020000000 ? 000000000000000100000 ? ? 00000 ? ? ? 0000000000002000$ $01000000010010000010000 ? 0 ? ? ? 0000000000000020000000300000 ? ? ? ? ? 0000000110$ $1010001001110010100 ? 00000010100110000000001100110000000000000011000 ? 000$ 00001?000000010000000(12)100010???????1???????????001?00010?1001001001000 $0 ? 001000000000000000000000000000000202000110$

Pangasiidae 00020000000000010000010?00000000000000010000???00000???0001000000000001 $00000000000001100010000 ? 10000000000000000010000000210000 ? ? ? ? ? 0000000110$ $0000000000110010001001000010001010000000002100110000000000000000000 ? 00$ 000002?000000011000000210000000000000000000001000000001011000010010010 000?000100000000000030000000000000000001100000

Claroteidae

$00000000000000020000010 ? 00000000000000000000 ? ? ? 00000 ? ? ? 0001000000000011$ 00000000000001100011000?0???0000000000000020000000400000?????0010000110 $00000100011100110010010000101 ? 100000000000 ? 100110000000000000001000 ? 000$ 00000?0000000100000001100000000000000000000010000000010110000100100100 $00 ? 001100000000000010000000000000000101100210$

'Ariidae-Genidens' $00023100000000020010000 ? 00000000000000000100 ? ? ? 00000 ? ? ? 0001000000000010$ $00000000000000100010000 ? 20010000000000000030000000410000 ? ? ? ? ? 0000000110$ $0000011001110011000 ? 01000020001000000000000100010000000000000001000 ? 000$ $00101 ? 0000001111000002200000000000000000000110000100120110000100100100$ $00 ? 001100000000000010000000000000000202100110$

'Ariidae-Galeichthys'

$00003100000000020010000 ? 00000000000000000100 ? ? ? 00000 ? ? ? 0001000000000010$ $00000000000001100011000 ? ? ? ? ? 0000000000000030000000410000 ? ? ? ? ? 00000001100$ $000010001110011000 ? 01000020001000000000000100010000000000000001000 ? 0000$ 0000?00000001000000022000000000000000000001000001001201100001001001000 00001100000000001010000000000000000201000110

Amphiliidae $00000000000000020000000 ? 00000000000021000000 ? ? ? 00000 ? ? ? 0001000000000011$ $01000000000000000011000 ? 10000100000000000020000000200000 ? ? ? ? ? 0000000110$ $001000000011 ? ? 10(01) 00 ? 00000020100110001000111100110000000000000011000$ ? $00000000 ? 0000000100000012000010 ? ? ? 01101 ? 00000000000000010010 ? 1001001001$ $000100011000011000000000000000000000002 ? 3001120$ 
'Mochokidae-Mochokus' $00002000000000021000000 ? 00000000000000000000 ? ? ? 00000 ? ? ? 0001000000100111$ $00000000100000000011000 ? 10001100000000000030000000000000 ? ? ? ? ? 0000000110$ $1011000000110010000 ? 000000100 ? 0000100000010100110000000000000011000 ? 000$ $01002 ? 0001 ? 001100000000000000110001010000001000000000001100000002001000$ 10011100000000000010000000000000000203000220

'Mochokidae-Mochokiella' $00002000000000021000000 ? 00000000000000000000 ? ? ? 00000 ? ? ? 0001000000000011$ $00000100100000000011000 ? 10001100000000000030000000000000 ? ? ? ? ? 0000000110$ $1011000000110010000 ? 001000000 ? 0000100000010100110000000000000011000 ? 000$ $01002 ? 0001 ? 001100000010000000110001010000000100000000101100001002001000$ 10011100000000000010000000000000000202000220

'Mochokidae-Synodontis batensoda' $00002000100000022000000 ? 00000000000000000000 ? ? ? 00000 ? ? ? 0001100000000011$ $00000110100000000011000 ? 10001100000000000030010000000000 ? ? ? ? ? 0200010110$ $1011100010110010000 ? 00000000000000100000011100120200000000001011000 ? 000$ $01002 ? 0001100110000001001000010000101000000010000000010110000100200100$ 010010000000000000010000000000000000201100220

'Mochokidae-Synodontis schall' 00002000000000022000000?00000000000000000000???00000???0001100000000011 $00000110100000000011000 ? 10001100000000000030010000000000 ? ? ? ? ? 0200010110$ $1011100010110010000 ? 00100000000000100000011100110000000000000011000 ? 000$ $01002 ? 0001100110000001101000010000101000000010000000010110000100200100$ 010010000000000000010000000000000000201100220

'Mochokidae-Chiloglanis' $0000200000000002 ? 000001000000000000010000000 ? ? ? 00000 ? ? ? 0001 ? 00 ? 00002011$ $00000000100000000011000 ? 10001100000000000020000001 ? 00000 ? ? ? ? ? 0200012110$ $1011100010110010100 ? 00000000000000101000010100110000000000010011000 ? 000$ 01001?0201?011100010010000001??10010110000000000000012010?1001001001000 10010100000100000010000000000000000201100220

Glanidium_melanodermatum 00022000000011020000000?00000000000000000000???010100001101100000002010 $001000001000000010110111100011000001010000(12) 0000000200010 ? ? ? ? ? 00000001$ 100000000000110010001100010010000110100000000100110000000000000011000 ? 1101000301101001111000112100000010000101100000000000100000110000100100 $1000100011000000000 ? 0011101000000000000201100120$

Centromochlus_heckelii

$000220000000 \overline{1} 1020000000 ? 00000000000000100000 ? ? ? 001100000001100000012000$ $00000000100000001111011110001100000101100030000000200010 ? ? ? ? ? 0000001110$ $0000000000110010001100010011100110100000000100110000001000000011000 ? 11$ $0100131110100(01) 11110011(12) 1000000100001011100001100011000001110011002$ 00100110001100000000010001102010000000000201100120

Tatia_aulopygia $00022000000011020000000 ? 00000000000000000000 ? ? ? 001100000101100000012010$ $00000000100000000011011110001100001101000030000000200010 ? ? ? ? ? 0000000110$ $0000000000110010001100010020(01) 00110100000000100110000001000000011000$ ? $110100030110100(01) 1110001111000000100001011000001000011000001100001001$ 00100010001100000000010001112001000010000201100120

Asterophysus_batrachus 
$00022000000011020000000 ? 00000000000000000001 ? 00101200001101100000002010$ $00010000100100000011011020001100000101000030000000401110 ? ? ? ? ? 0300000110$ $0001000000110010001100000020000110100000001100000010001000000011200 ? 11$ 0100030110100111100011210000001000010100000011000110000011000010020010 0010001100000000010000000000000000000201101120

Liosomadoras_oncinus

$000220000000 \overline{1} 11020000000 ? 00000000000000000000 ? ? ? 010200001101101000012010$ $00010000100000000011011010001100000101000030100000201010 ? ? ? ? ? 0000000110$ $0000000000110010001100010010000110100000001100000000011000000011000 ? 11$ $0100030110100(01) 111000111100000010000101000100110000100000110000100201$ 100010001100000000010000000000000000000201100120

Trachycorystes_trachycorystes 00022000000011020000000?00000000000000101000???010200001101101000012010 $00010000100000000011011010001100001101000034100000401110 ? ? ? ? ? 0000000110$ $0000000000110010001100010120000110100000001100000000011000000011000 ? 11$ 0100030110100111110011110000001000010110000010000010000011000010020010 0010031100000000010020000000000001000201100120

Tocantinsia_piresi $00022000000011020000000 ? 00000000000000001000 ? ? ? 010200001101100000012010$ $00000000100000000011011110001100000101000030000000 ? 01010 ? ? ? ? ? 0000000110$ $0000000000110010001100010010000110100000001100130000011000000011000 ? 11$ 0100030110100111110011210000001000010100000000000010000011100010020010 0010011100000000010000000000000000000201100120

Pseudotatia parva 00022000000011020000000?00000000000000?????????0??2????110110000000200?0 $00000001000000010110111200011000001010000 ? 0000000 ? 01 ? 10 ? ? ? ? ? 00000001100$ $00000000011001000110001001000011010000000 ? 100 ? ? ? ? 000 ? 1000000011000 ? 1101$ $0003011010001110001111000000100001010000001000 ? 11000001100001002001000$ $100111000000000 ? 001000000000000 ? 000201100120$

Pseudauchenipterus_affinis $00022000000011020010000 ? 00000100000000000000 ? ? ? 010201001101100000002001$ $00000000100000001011011120001100000101000030000000201010 ? ? ? ? ? 0000000110$ $0000000000110010001100010010000110100000001100000000011000000011000 ? 11$ $0100030110100111100011110000001000010100000001000110000010 ? 00010020010$ 0010021100000000010020000000000001000201100120

Auchenipterichthys_thoracatus $00022000000011020000000 ? 000000000000000100000 ? ? 010200001101100000012010$ $00010000100000000011011120001100000101000030000000201010 ? ? ? ? ? 0000000110$ $0000000000110010001100010020000110100000001100000000011000000011000 ? 11$ 0100030110100111110011110000001000010100000011100010000011000010020011 0110001100000000010020000000000001100201110120

Ageneiosus_inermis 0002200001001100?000000?00000000001100002000???020200001101100000012010 $01100000100010000011011120101100100101100030000000201100 ? ? ? ? ? 0300000112$ $0000000000110010001100010011100110110000102100111000011000100011000 ? 11$ 0100032110100111100011(12)3101001??10010100111110002010000100?0001100??1 00010011100000002000030000000000001100201100120

Ageneiosus_atronasus

0002200001001100?000000?00000000000000002000???020200001101100000002010 
$01100000100010000011011120101100100101100030000000201100 ? ? ? ? ? 0300000112$ $0000000000110010001100010011100110110000101100010000011000100011000 ? 11$ $010013011010011110001111101001 ? ? 10010100111010001010000100 ? 0001000 ? ? 100$ 010011100000002000020000000000001000201100120

Tetranematichthys_quadrifilis $00022000010011010000000 ? 010000000000000100000 ? ? 010200001101100000012010$ $01100000100010000011011120101100100101100030000000201100 ? ? ? ? ? 0300000111$ $0000000000110010001100010011100110110000102100031000011000100011000 ? 11$ $01000301101001111000111(12) 1010001000010100110011003010000110 ? 000200100$ 100010011100000002000030000000000001100201210120

"'Amplexiglanis" teaguei' $00022000000011020000000 ? 11100000000000010000 ? ? ? 010200001101100000012010$ $001100001000000000110111200011000001010000300000002010 ? 0 ? ? ? ? ? 0000000111$ $0000000000110010001100010010000110100000001100010000011000000011000 ? 11$ 0100030110100111100011110010001000010110111010001010000011000010010010 0010001100000000010020000000000001000201110120

Parauchenipterus_galeatus 00022000000011020000000?00000000000000200000???010200001101101000012010 $00010000100000000011011120001100001101000030000000301110 ? ? ? ? ? 0000000111$ $0000000000110010001100010120000110100000001100100000011000000011000 ? 11$ $01000301101001111100111(12) 00000010000101100000010020100100110000100100$ 100010001100000000010020000000000001100201210120

Trachelyopterus_coriaceus $001 ? 2000000011020010000 ? 00000000000000000000 ? ? ? 010200011101101000012010$ $00010000100000000011011120101100000101000030000000301110 ? ? ? ? ? 0000000110$ $0000000000110010001100010120000110100000001100100000011000000011000 ? 11$ $0100030110100111110011110000001000010110000001002010010010 ? 00010020010$ 0110001100000000010020000000000001100201210120

Trachelyichthys_decaradiatus $001 ? 2000000011020000000 ? 00000000000000000000 ? ? ? 010200001101100000102010$ $00000000100000000011011120101100000101000030000000201010 ? ? ? ? ? 0000000110$ $0000000000110010001100010010000110100000001100000000011000000011000 ? 11$ 0100030110100111100011110000001000010110000011000010000011000010020010 0010041100000000010030000000000001100201210120

Trachelyopterichthys_taeniatus $001 ? 2000000011020000000 ? 00000000000000000000 ? ? ? 010200001121101000012010$ $00010000100000000011011120001100001101000030100000401010 ? ? ? ? ? 0000000110$ $0000000000110010001100010020000110100000001100000000011000000011000 ? 11$ 0100030110100111110011120000001000010120000011100010000011001010020010 $0010041100000000010030000000000001100201(12) 10120$

Entomocorus_radiosus

$00022000000011020010000 ? 11110000000000000000 ? ? ? 0 ? ? 200001101000000002010$ $00100000101000000011011120001100000101100030001110201 ? 00 ? ? ? ? ? 0000101111$ $0000001100110010001100001020000110100000001100110000010000000011000 ? 11$ 0100030110100111100011110000001000010110010001000110100011000010020010 0010001110000000100120000000000001000211101120

Auchenipterus_osteomystax

$00022000000011020111000 ? 01101000000000000000 ? ? ? 020210001101000000022010$ $00110000110000010111011120101100000111100030001110201100 ? ? ? ? ? 0001101111$ 
$0000001100110010001100001020000110100000001100120200010000000011000 ? 11$ $0100030110100011100011120000001000010100010000000010000010 ? 00020020012$ 000?041100010002100130000100100001000211100120

Pseudepapterus cucuhyensis $00022000000011020111000 ? 01101000000000000000 ? ? ? 010210001111000000002010$ $00110001100000010011011120101100000111100030001110201100 ? ? ? ? ? 0100201111$ $0000001200110010001100001020000110100000001100120100010000000011000 ? 11$ $010003011010011100001102000001 ? ? 10010122010000002010000010 ? 000200200220$ 00?041100010002100130000100000001000211100120

Epapterus_dispilurus

$001 ? 2000000011020111000 ? 01 ? 01000000000000000 ? ? ? 0 ? ? 210101101000000002010$ $00110000110000000011011120101100000111100030001110201100 ? ? ? ? ? 0001201111$ $0000001200110010001100001020000110100000001100120200010000000011000 ? 11$ $010003011010001110001102000001 ? ? 1001012201000000 ? 010000010 ? 000200200120$ $00 ? 041100010002100 ? 30000100000001000211100120$

Wertheimeria_maculata $00002000000000020000000 ? 00000000000000000000 ? ? ? 00000 ? ? ? 00011000000(01) 20$ 1000000000100000000011011010001100000100000030000000200001000130000000 1100100000000110010002100000020000010100000001100110000000000000011000 ? 110100030111200111000011210000001000010100000010000010010011000010020 0100010001100000000000010000000000000000201000120

Kalyptodoras_bahiensis 00002000000000020000000?00000000000000000000???00000???00011000000(01)20 1000000000100000000011011010001100001100000031000000200001100130000000 1100100000000110010002100000020000010100000001100110000000000000011000 ? 110100030111200111000011210000001000010100000010000010010011000010020 0100010001100000000000010000000000000000201000120

Franciscodoras_marmoratus $00002000000000020000000 ? 00000000000000000000 ? ? ? 00000 ? ? ? 0001000000002010$ 0000000010000000001101101000110000010000003000000020000210012000000011 $00100000000110010001100000010000010100000001100110000000000000011000 ? 1$ 1010003011120011100001110010000100001010000001000001001001100001002001 00010001100000000000010000000000000010201000120

Centrochir crocodili 000(01)2000000000020000000?00000000000000000000???00000???00010000000020 $1000000000100000000011011010001100000100010030000000200002100(01) 200000$ $001100000000000110010000 ? 000000100000101000000011001100000000000000110$ $00 ? 1101000301112001111000111001000010000101000000110000100100110000101$ $2021000110111000000000000100000000000000002011001 ? 0$

Platydoras_armatulus 000(12)2000000000020000000?00000000000000020000???00000???00010000000(01) 2010000000001000000000110110100011000011000100311000000000021011200000 $001100000000000110010000 ? 0000001000001010000000(01) 10011000000000000001$ 1000 ? $110100030111200111100011(12) 0010000100001010000001(01) 0000100100110$ 000101202100011011100000000000010000000000000010201100110

'Platydoras sp. "xingu"'

000(12)2000000000020000000?00000000000000000000???00000???00010000000020 1000000000100000000011011010001100000100010030100000200002100120000000 $1100000000000110010000 ? 00000010000010100000001100110000000000000011000$ ? 
$11010003011120011110001110010000100001010000001(01) 00001001001100001012$ 02100011011100000000000010000000000000010201100110

Acanthodoras cataphractus

$00022000000000020000000 ? 00000000000000100000 ? ? ? 00000 ? ? ? 00010000000(01) 20$ 10(01)00000001000000000110110100011000001010100311000001000021011100000 $001100000000000110010000 ? 000000200000101000000001001100000000000000110$ $00 ? 1101000301112001111000111000000010000101100000100100100100110020001$ 201100111001100000001001010000000000000201201000221

Agamyxis albomaculatus $00022000000000020000000 ? 00000000000000101000 ? ? ? 00000 ? ? ? 0001000000012010$ 1000000010000000001101101000110000010101003110000010000210112000000011 $00000000000110010000 ? 00000020000010100000001100110000000000000011000 ? 11$ 0100030111200111100011100000001000010100000010010010010011002010120110 0110001101000000000010000000011000011202000120

Anadoras_grypus $00022000000000020000000 ? 00000000000000000000 ? ? ? 00000 ? ? ? 0001000000012010$ $000000001000000000110110200011000001010(01) 0020000000200002100120000000$ $1100000000000110010000 ? 00000010000010100000001100110100000000000011000$ ? 1101000301112001111000111001000010000101000000000000100100110000101202 100110011100000000000010000000000000000201000120

Scorpiodoras heckelii 00022000000000020000000?000000000000000100000??00000???0001000010002010 1000000010000000001101102000110000010101003010000020000210012000000011 $00000000000110010000 ? 00000010000010100000001100110000000000000011000 ? 11$ 0100030111200111100011100100001000010100000010000010010011000010120210 0110011100000000000010000000000000000201000120

Pterodoras_granulosus 0000200000000002000000100000000000000000310110100000???00011000000(01)2 0100000000010000000001101102000110000010100003200000020000210011000000 $01100\{01\} 00000000110010000 ? 00000010000010100000001100110000000000000011$ 000 ? 110100030111200111110011210100001000010100000011000010010011000010 1230100010011100100000000010000000000000000201100110

Pterodoras_rivasi $0000200000000002000000100000000000000001010110100000 ? ? ? 0001100000002010$ 0000000010000000001101102000110000010100003200000020000210011000000011 $00000000000110010000 ? 00000010000010100000001100110000000000000011000 ? 11$ 0100030111200111110011210100001000010100000011000010010011000010123010 0010011100000000000010000000000000000201100110

Doraops_zuloagai 00002000000000020000000?0000000000000001010110100000???0001100000012010 $00000000100000000011011010001100000100000030000000 ? 000011001 ? 0000000110$ $0000000000110010000 ? 00000010000010100000001100110000000000000011000 ? 110$ $100030111200111110011 ? 101000010000101000000110000100100110000101200100$ 010011100000000000010000000000000000201100110

Lithodoras dorsalis $0000200000000002000000100000000001000001010110100000 ? ? ? 0001100000002010$ $0000000010000000001101101000110000010100003200000020000210 ? 11000000011$ $00000000000110010000 ? 00000010000010100000101100110000000000000011000 ? 11$ $01000301112001111100112(12) 01000010000101000000110000100100110000101200$ 
100010011100000000000010000000000100000201100110

Megalodoras_uranoscopus

$0001200000000002000000100000000000000001010111100000 ? ? ? 0001000000002010$ 0000000010000000001101101000110000010001003300000010000210010000000011 $00000000000110010000 ? 00000010000010100000001100110000000000000011000 ? 11$ 0100030111200111110011210100001000010100000011000010010011000010120010 $01110111000000000000100000000000000002011001 ? 0$

Megalodoras_guayoensis $0001200000000002000000100000000000000001010111100000 ? ? ? 0001000000002010$ 0000000010000000001101101000110000010001003300000010000210010000000011 $00000000000110010000 ? 00000010000010100000001100110000000000000011000 ? 11$ 0100030111200111110011210100001000010100000011000010010011000010120010 $01110111000000000000100000000000000002011001 ? 0$

Centrodoras brachiatus $0001200000000002000000100000000000000001000111100000 ? ? ? 0001000000002010$ 0000000010000000001101101000110000010001003000000010000210013000000011 $00000000000111010000 ? 00000010000010100000001100110000000000000011000 ? 11$ 0100030111200111100011210100001000010100000011000010010011000010120010 0011011100000000000010000000000000000201100110

Centrodoras_hasemani $0001200000000002000000100000000000000001000111100000 ? ? ? 0001000000002010$ 0000000010000000001101101000110000010001003000000010000210013000000011 $00000000000110010000 ? 00000010000010100000001100110000000000000011000 ? 11$ 0100030111200111100011210100001000010100000011000010010011000010120010 0011011100000000000010000000000000000201100110

Rhynchodoras_castilloi 00002000000000020000101000000010001000002000???00000???0001000100002010 $00000000100000000011011020001100000100000030000000 ? 00002100031 ? 00000110$ $0100000000111110000 ? 10000010000010100000001100110000000000000011000 ? 110$ $10003011120001110001111010001 ? ? 1001010000001100001001001100001012101000$ $0 ? 011100000000000010000000000000010201100110$

Rhynchodoras_woodsi

$00002000000000020000101000000010001000002000 ? ? ? 00000 ? ? ? 0001000100002010$ $00000000100000000011011020001100000100000030000000 ? 00002100031 ? 00000110$ $0100000000111110000 ? 10000010000010100000001100110000000000000011000 ? 110$ $10003011120001110001111010001 ? ? 1001010000001100001001001100001012101000$ $0 ? 011100000000000010000000000000010201100110$

Rhinodoras thomersoni $01002000000000120000001000000000000000010110 ? ? ? 00000 ? ? ? 0001000100002010$ 0000000010000000001101101000110000010000003000000020000210012000000011 $00100000000111110000 ? 10000010000010100000 ? 01103110000000000000011010$ ? 11 0100030111200111100011100100001000010100000011000010010011000010121010 0011011100000000000010000000000000010201100120

Rhinodoras_dorbignyi $01002000000000120000001000000000000000010111 ? 0000000 ? ? ? 0001000100002010$ $00000000100000000011011010001100000100000030000000200002100(01) 20000000$ $1100100000000111110000 ? 10000010000010100000101103110000000000000011010$ ? $110100030111200(01) 1110001110010000100001010000001100001001001100001012$ 10100011011100000000000010000000000000010201100110 
Rhinodoras boehlkei

$01002000000000120000001000000000000000000111 ? 0000000 ? ? ? 0001000100002010$ $000000001000000000110110100011000001000000300000002000021001(23) 0000000$ $1100100000000111110000 ? 10000010000010100000101103110000000000000011010$ ? 1101000301112001111000111001000010000101000000110000100100110000101210 100011011100000000000010000000000000010201100110

Orinocodoras_eigenmanni

$01002000000000020000001000000000000000010111 ? 0000000 ? ? ? 0001000100002010$ 0000000010000000001101101000110000010000003400000020000210012000000011 00100000000111110000 ? $10000010000010100000001103110000000000000011010 ? 11$ 0100030111200111100011100100001000010100000011000010010011000010121010 0011011100000000000010000000000000010201100110

Oxydoras niger

$0000200000000002000000100000000000000002010100000000 ? ? ? 0001200001001010$ $000010001000000000110110100011000101000000(23) 0010000100002100010100201$ $1100100000200111010000 ? 00000010000010100112101112110001000010000011100$ ? $110100030111200111101011(12) 101000010(01) 0010100000011000110010011000010$ 1200101010011100000000000010000000000000000201100110

Oxydoras_kneri $0000200000000002000000100000000000000002010100000000 ? ? ? 0001200001001010$ 0000100010000000001101101000110001010000003001000010000210003010020111 $00100000200111010000 ? 00000010000010100112101112110001000010000011100 ? 11$ $0100030111200111100011 ? ? 01000010(01) 00101000000110001100100110000101200$ 101010011100000000000010000000000000000201100110

"'Petalodoras" fimbriatus'

$00022000001100022100000 ? 00000000000000000001 ? 1100000 ? ? ? 0001200001002010$ 0000000010001000001101112000110001010000003001000000000211002010010011 $00100000100111010010 ? 00000010100010100101001111110001000010000011100 ? 11$ $01000311112001111000111001001010(01) 00101000000110000100100110000101220$ 111111011100000002000010000000000000000201100110

"'Petalodoras" asterophysis'

$00022000001100021100000 ? 00000000000000000001 ? 1100000 ? ? ? 0001200001002010$ 0000000010001000001101112000110001010000003001000000000211002010010011 $00100000100111010010 ? 00000010100010100101001111110001000010000011100 ? 11$ 0100031111200111100011100100001010010100000011000010010011000010122011 1110011100000002000010000000000000000201100110

"'Petalodoras" eigenmanni'

$00022000001100021100000 ? 00000000000000000001 ?(01) 100000 ? ? ? 00012000010020$ 1000000000100010000011011120001100010100000030010000000002110020100100 $1100100000100111010010 ? 00000010100010100101001111110001000010000011100$ ? 1101000311112001111000111001000010100101000000110000100100110000101220 111110011100000002000010000000000000000201100110

"'Petalodoras" punctatus' 00022000001000020100000?00000000000000200000???00000???0001200001002010 0000000010001000001101112000110001010000003001000000000211002010010011 $00100000100111010010 ? 00000010100010100101001111110001000010000011100 ? 11$ 0100031111200111100011100100001000010100000011000010010011000010122011 1110011100000002000010000000000000000201100110

Trachydoras_steindachneri 
$00022000001000020100000 ? 00000010000000200001 ? 1100000 ? ? ? 0001201002000010$ 0000000010001000011121112000110001010000013011000000000211003010020111 $00100000200111010010 ? 000000101100111001010011003 ? ? ? 01100010000011100 ? 11$ 0100031111200111100011100100001000010100000011000210010011000010122010 1110011100000002000010000000000000000201100110

Trachydoras_microstomus

$0002200000 \overline{1} 000020100000 ? 00000010000000200001 ? 1100000 ? ? ? 0001200002000010$ 0000000010001000011121112000110001010000013001000000000211003010020111 $00100000200111010010 ? 000000101100101001010011003 ? ? ? 01100010000011100 ? 11$ 0100031111200111100011100100001000010100000011000210010011000010122010 1010011100000002000010000000000000000201100110

Trachydoras_nattereri 00022000001000020100000?00000010000000200001?0100000???0001200002000010 0000000010001000011121112000110001010000013001000000000211002010020111 $00100000200111010010 ? 000000101100101001010011003 ? ? ? 01100010000011100 ? 11$ 0100031111200111100011100100001000010100000011000210010011000010122010 1010011100000002000010000000000000000201100110

Trachydoras_brevis $00022000001000020100000 ? 00000010000000200001 ? 0100000 ? ? ? 0001200002000010$ 0000000010001000011121112000110001010000013001000000000211002010020111 $00100000200111010010 ? 000000101100101001010011003 ? ? ? 01100010000011100 ? 11$ 0100031111200111100011100100001000010100000011000210010011000010122010 1010011100000002000010000000000000000201100110

Trachydoras_paraguayensis $00022000001000020100000 ? 00000010000000200001 ? 0100000 ? ? ? 0001200002000010$ 0000000010001000011121112000110001010000013001000000000211002010020111 $00100000200111010010 ? 000000101100101001010011003 ? ? ? 01100010000011100 ? 11$ 0100031111200111100011100100001000010100000011000210010011000010122011 1110011100000002000010000000000000000201100110

Doras_carinatus 00022000001000020100000?000000110000000200000??00000???0001210001002010 0100000010001000011101112100110001010000103001000000000211003010010111 $00100000100111010010 ? 00000010120010100111001111210001000010000011100 ? 11$ $01000311112001111000111(01) 01000010000101000000110001100100110000101220$ 101010011100000001000010000000000000000201100110

Doras_higuchii 00022000001000020100000?000000110000000200000??00000???0001210001002010 0100000010001000011101112100110001010000103001000000000211003010010111 $00100000100111010010 ? 00000010120010100111001111210001000010000011100 ? 11$ $01000311112001111000111(01) 01000010000101000000110001100100110000101220$ 101010011100000001000010000000000000000201100110

Doras_phlyzakion 00022000001000020100000?00000011000000001000???00000???0001210001002010 $010000001000100001110111200011000101000000300100000000021100(23) 0100201$ $1100100000\{12\} 00111010010 ? 000000101200101001110011112100010000100000111$ 00 ? 1101000311112001111000111001000010000101000000110001100100110000101 220101010011100000001000010000000000000000201100110

Hemidoras_stubelii 00022000001000022100000?00000000000000100001?1100000???0001210001002010 
0000000010001000011101112000110001010000003001000000000211002010020111 $00100000100111010010 ? 00000010120010100112001111110001000010000011100 ? 11$ 0100031111200111100011100100101010010100000011000110010011000010120010 1110011100000001000010000000000000000201100110

Hemidoras morei

$00022000001000022100000 ? 00000000000000100001 ? 1100000 ? ? ? 0001210001002010$ 0000000010001000011101112000110001010000003011000000000211003010020111 $00100000200111010010 ? 00000010120010100112001111110001000010000011100 ? 11$ 0100031111200111100011100100101010010100000011000110010011000010120010 1110011100000002000010000000000000000201100110

Hemidoras morrisi

$00022000001000022100000 ? 00000000100000100001 ? 1100000 ? ? ? 0001210001002010$ 0000000010001000011101112000110001010000003011000000000211003010020111 $00100000200111010010 ? 00000010120010100112001111110001000010000011100 ? 11$ $01000311112001111000111(01) 01001010100101000000110001100100110000101200$ 101111011100000002000010000000000000000201100110

Hemidoras_stenopeltis $00022000001000022100000 ? 00000000100000100001 ? 1100000 ? ? ? 0001210001002010$ 0000000010001000011101112000110001010000003011000000000211003010010111 $00100000100111010010 ? 00000010120010100112001111110001000010000011100 ? 11$ $01000311112001111000111(01) 01001010100101000000110001100100110000101200$ 101110011100000001000010000000000000000201100110

Nemadoras humeralis $00022000001000020100000 ? 00000010000000000001 ? 1110000 ? ? ? 0001210001001010$ $000000001000100001110111200011000101000000300100000000021100(23) 0100201$ $1100100000100111010010 ? 00000010120010100112001111110001000010000011100$ ? $11010003111120011110001110010011 ? ? 1001010000001100011001001100001012201$ 01010011100000000000010000000000000000201100110

Nemadoras elongatus $00022000001000020100000 ? 00000010000000000001 ? 1110000 ? ? ? 0001210001001010$ 0000000010001000011101112000110001010000003001000000000211003010020111 $00100000100111010010 ? 00000010120010100112001111110001000010000011100 ? 11$ 0100031111200111100011100100101010010100000011000110010011000010122010 1010011100000000000010000000000000000201100110

Nemadoras hemipeltis $00022000001000020100000 ? 00000010000000000001 ? 1110000 ? ? ? 0001210001000010$ $000000001000100001110111200011000101000000300100000000011100(23) 0100201$ $1100100000100111010010 ? 00000010120010100112001111110001000010000011100$ ? 1101000311112001111000111001001010100101000000110001100100110000101220 101010011100000000000010000000000000000201100110

"'Nemadoras" leporhinus' $10022000001000020100000 ? 00000010000000000001 ? 1100000 ? ? ? 0001210001000010$ 0100000010001000011101112000110001010000003001000000000111003010020111 $00100000100111010010 ? 00000010120010100112001111110001000010000011100 ? 11$ 0100031111200111100011100100101010010100000011000110010011000010122010 1010011100000001000010000000000000000201100110

"'Nemadoras" trimaculatus'

$10022000001000020100000 ? 00000010000000000001 ? 1100000 ? ? ? 0001210001000010$ $010000001000100001110111200011000101000000300100000000021100(23) 0100201$ 
$1100100000100111010010 ? 00000010120010100112001111110001000010000011100 ?$ $11010003111120011110001110010011 ? ? 1001010000001100011001001100001012201$ 01010011100000000000010000000000000000201100110

"'Nemadoras" ternetzi' $10022000001000020100000 ? 00000010000000000001 ? 1100000 ? ? ? 0001210001000010$ 0100000010001000011101112000110001010000003001000000000211003010020111 $00100000100111010010 ? 00000010120010100112001111110001000010000011100 ? 11$ $010003111120011110001110010011 ? ? 100101000000110001100100110000101220101$ 010011100000001000010000000000000000201100110

Hassar_affinis $10022000001000020100000 ? 00000010000000000001 ? 0100000 ? ? ? 0001210001000010$ 0100000010001000011111112100110001010000103001000000000111003010010111 $00100000100111010010 ? 00000010120010100111001111210001000010000011100 ? 11$ 0100031111200111100011100100101010010100000011000110010011000010122010 1010011100000001000010000000000000000201100110

Hassar_orestis

$10022000001000020100000 ? 00000010000000000001 ? 1100000 ? ? ? 0001210001000010$ 0100000010001000011111112100110001010000103001000000000111003010010111 $00100000100111010010 ? 00000010120010100111001111210001000010000011100 ? 11$ 0100031111200111100011100100101010010100000011000110010011000010122010 1010011100000001000010000000000000000201100110

Anduzedoras_oxyrhynchus

$10022010001000020100000 ? 00000010000000000001 ? 1100000 ? ? ? 0001210001000010$ 0100000010001000011101112100110001010000103001000000000211004010020111 $00100000100111010010 ? 0000001012001010011100111121010100101000001110121$ 1010003111120011110001111010020101001010000001100011001001100001012201 01010011100000001000010000000000000000201100110

Leptodoras_oyakawai $10022010001000020100000 ? 00000010000000000000 ? ? ? 00000 ? ? ? 0001210001000010$ 0100000010001000011101112100110001010000103001000000000211003010020111 $00100000200111010010 ? 0000001012001010011100112121010100101100001110111$ 1010003111120011110001111010020100001010000001100011001001100001012201 01010111100000000000010000000000000000201100110

Leptodoras marki $10022010001000020100000 ? 00000010000000000001 ? 0100000 ? ? ? 0001210001000010$ 0100000010001000011101112100110001010000103001000000000211003010020111 $00100000200111010010 ? 0000001012001010011100112121010100101100001110111$ 1010003111120011110001111010020100001010000001100011001001100001012201 01010111100000000000010000000000000000201100110

Leptodoras_praelongus $10022010001000020100000 ? 00000010001000002001 ? 0100000 ? ? ? 0001210001000010$ 0100000010001000011101112100110001010000103001000000000211003010020111 00100000(12)00111010010?00000010120010100111001121210101001011000011101 3110100031111200111100011110100201010010100000011000110010011000010022 0101010111100000000000010000000000000000201100110

Leptodoras_juruensis

$00022011001000020100001000000000001000002001 ? 0100000 ? ? ? 0001210001000010$ 0100000010001000001101112100110001010000103001000000000211004010020111 00100000(12)00111010010?000000101200101001110011213???01001011000011101 
3110100031101200111100011020100101000010100000010000210010011000010122 0101010111100000000000010000000000000000201100110

Apêndice 3. Lista de sinapomorfias.

A seguir são listadas todas as sinapomorfias comuns a todas as quatro árvores fundamentais (os números dos clados referem-se aos clados da árvore de consenso estrito, figura 66). As transições ambíguas estão sublinhadas.

Diplomystidae: sem autapomorfias.

Nematogenyidae: \#3: 0>1; \#37: 0>2; \#38: 0>2; \#71: 1>0;\#100: 0>1;\#101: 0>1; \#145: 0>1; \#185: 1>2;\#198: 0>1; \#240: 0>1; \#249: 0>1; \#264: 0>1; \#278: 1>0; \#301: 0>1; \#322: 1>2; \#323: 1>0.

Ictaluridae: \#185: 1>0.

Pimelodidae:\#175: 0>1; \#213: 0>1; \#228: 0>1; \#326: 1>0.

Pseudopimelodidae: \#37: 0>1; \#69: 0>1; \#71: 1>0; \#161: 0>1; \#179: 0>1; \#235: 2>1; \#236: 1\&2>0; \#257: 0>1; \#303: 1>0;\#322: 1>2;\#325: 0>1; \#327: 1>2.

Heptapteridae: \#171: 0>1; \#295: 0>1; \#300: 0>1.

Siluridae: \#3: 0>1; \#100: 0>1; \#114: 1>2; \#122: 2>4; \#134: 0>3; \#139: 0>1; \#145: 0>1; \#161: 1>0;\#175: 1>0;\#185: 2>3;\#188: 1>0; \#191: 0>1;\#192: 0>1; \#235: 2>1; \#236: 1\&2>3; \#240: 0>1; \#251: 0>1; \#278: 1>0; \#281: 1>0.

Aspredinidae: \#3: 0>1; \#5: 1>2;\#37: 2>1;\#38: 1>0;\#66: 0>1; \#67: 2>0; \#100: 1>0; \#137: 0>2; \#167: 0>1;\#171: 0>1;\#176: 1>0;\#175: 1>0; \#184: 1>0; \#189: 1>3; \#249: 0>1; \#263: 0>1; \#270: 0>1; \#284: 0>1; \#296: 1>0; \#297: 0>1; \#303: 1>0; \#320: 2>1; \#322: 1>3; \#323: 1>0.

Sisoridae: \#114: 2>1; \#135: 0>1; \#139: 0>1; \#173: 0>1; \#185: 1>2; \#196: 0>1; \#235: 2>1; \#289: $1>0$.

Erethistidae: \#169: 1>2; \#179: 1>0; \#258: 0>1.

Malapteruridae: \#5: 0>2; \#40: 0>1; \#71: 1>0; \#73: 0>1; \#81: 0>1; \#122: 2>3; \#143: 0>1; \#145: 0>1; \#149: 0>1; \#152: 0>1; \#159: 0>1; \#171: 0>1; \#218: 0>1; \#240: 0>1; 
\#249: 0>1;\#264: 0>1; \#272: 0>1;\#288: 1>0;\#303: 1>0;\#322: 1>2;\#323: $1>0$.

Pangasiidae: \#16: 2>1; \#40: 0>1; \#86: 0>1; \#96: 0>1; \#123: 0>1; \#173: 0>1; \#174: 1>0; \#205: 1>0;\#206: 1>0; \#218: 0>2; \#258: 0>1; \#267: 0>1.

Claroteidae: \#22: 0>1; \#114: 3>2; \#161: 0>1; \#171: 0>1; \#235: 2>1; \#320: 2>1; \#326: $1>2$.

Genidens (Ariidae): \#4: 0>2; \#85: 1>0; \#149: 0>1; \#216: 0>1; \#218: 0>1; \#226: 0>1; \#228: 0>1; \#229: 0>1; \#322: $1>2$.

Galeichthys (Ariidae): \#301: 0>1; \#323: 1>0 .

Amphiliidae: \#68: 2>0; \#73: 0>1; \#145: 0>1; \#169: 1>2; \#171: 0>1; \#183: 0>1; \#240: 0>1; \#248: 0>1; \#266: 0>1; \#272: 0>1; \#303: 1>0; \#322: 1>3; \#323: 1>0.

Mochokus (Mochokidae): \#66: 0>1; \#69: 0>1; \#235: 1>0; \#257: 0>1; \#275: 1>0; \#322: $2>3$.

Mochokiella (Mochokidae): \#77: 0>1; \#165: 0>1; \#258: 0>1.

Synodontis batensoda (Mochokidae): \#9: 0>1; \#190: 1>2; \#192: 0>2; \#203: 0>1.

Synodontis schall (Mochokidae): \#165: 0>1; \#236: 0>1.

Chiloglanis (Mochokidae): \#23: 0>1; \#37: 0>1; \#114: 3>2; \#121: 0>1; \#139: 0>2; \#159: 0>1; \#179: 0>1; \#202: 0>1; \#218: 2>1; \#221: 0>2; \#226: 0>1; \#232: 0>1; \#242: 0>1; \#247: 0>1; \#251: 0>1; \#266: 0>1; \#267: 1>2;\#270: 1>0;\#272: 0>1; \#278: 2>1; \#296: $0>1$.

Glanidium melanodermatum: \#74: 0>1; \#114: 3>1\&2; algumas árvores: \#49: 0>1; \#257: $1>0$.

Centromochlus heckelii: \#39: 0>1; \#57: 1>0; \#70: 1>0; \#89: 0>1; \#110: 0>1; \#139: 0>1; \#170: 0>1; \#217: 0>1; \#219: 0>1; \#230: 0>1; \#252: 0>1; \#258: 0>1; \#271: 0>1; \#274: 0>1; \#284: 0>1;\#309: 0>1.

Tatia aulopygia: \#106: 0>1; \#169: 1>2;\#306: 0>1; \#310: 0>1; \#315: 0>1.

Asterophysus batrachus: \#44: 0>1; \#48: 0>1; \#50: 0>1; \#83: 0>1; \#122: 2>4; \#125: 0>1; \#134: 0>3; \#146: 0>1; \#169: 1>2; \#193: 0>1; \#207: 0>2; \#262: 0>1; \#325: 0>1; algumas árvores: \#49: 1>0; \#96: 1>2; \#166: 1>0; \#196: 1>0. 
Liosomadoras oncinus: \#62: 0>1; \#116: 0>1; \#254: 0>1; \#280: 0>1; algumas árvores: \#67: $0>1$.

Trachycorystes trachycorystes: \#39: 0>1; \#41: 0>1; \#95: 1>0; \#96: 2>1; \#115: 0>4; \#258: 1>0; \#317: 1>0; \#324: 1>0.

Tocantinsia piresi: \#41: 0>1; \#230: 0>1; \#271: 0>1; algumas árvores: \#67: 0>1; \#189: 0>1; \#190: 0>3; \#257: 1>0.

Pseudotatia parva: \#226: $1>0$.

Pseudauchenipterus affinis: \#19: 0>1; \#30: 0>1; \#257: 1>0; \#270: 1>0; \#288: 1>2; algumas árvores: \#258: 0>1.

Auchenipterichthys thoracatus: \#40: 0>1; \#251: 1>0; \#259: 0>1; \#282: 0>1; \#284: $0>1$.

Ageneiosus inermis: \#35: 0>1; \#36: 0>1; \#189: 0>1; \#219: 0>2; \#236: 1>3; \#256: 0>1; \#274: $0>1$.

Ageneiosus atronasus: \#67: 1>0; \#217: 0>1.

Tetranematichthys quadrifilis: \#190: 1>3; \#261: 1\&2>3; \#275: 1>2; \#323: 1>2; algumas árvores: \#258: 0>1.

"Amplexiglanis" teaguei: \#25: 0>1; \#75: 0>1; algumas árvores: \#288: 1>0.

Parauchenipterus galeatus: \#39: 0>2; \#142: 0>1; \#278: 2>1.

Trachelyopterus coriaceus: \#3: 0>1; \#19: 0>1; \#55: 0>1; \#98: 0>1; \#270: 1>0; \#284: $0>1$.

Trachelyichthys decaradiatus: \#3: 0>1; \#66: 0>1; \#98: 0>1; \#288: 0\&1>4; \#303: 2>3; \#323: $1>2$.

Trachelyopterichthys taeniatus: \#3: 0>1; \#58: 0>2; \#236: 1>2; \#251: 1>2; \#259: 0>1; \#273: 0>1; \#288: 3>4; \#303: 2>3.

Entomocorus radiosus: \#25: 0>1; \#28: 0>1; \#82: 0>1; \#262: 0>1; \#265: 0>1; \#291: 0>1; \#325: 0>1; algumas árvores: \#258: 0>1; \#288: 1>0.

Auchenipterus osteomystax: \#49: 1>2; \#67: 0>2; \#89: 0>1; \#251: 1>0; \#311: 0>1.

Pseudepapterus cucuhyensi: \#58: 0>1; \#79: 0>1; \#133: 0>1; \#192: 2>1; \#229: 1>0; 
\#281: $1>2$.

Epapterus dispilurus: \#3: 0>1; \#54: 0>1.

Wertheimeria maculata: \#128: 1>0.

Kalyptodoras bahiensis: \#106: 0>1; \#115: 0>1.

Franciscodoras marmoratus: \#318: 0>1.

Centrochir crocodili: sem autapomorfias.

Platydoras armatulus: \#40: 0>2; \#106: 0>1; \#115: 0>1; \#122: 2>0; \#130: 0>1.

Platydoras sp. 'xingu': sem autapomorfias.

Acanthodoras cataphractus: \#132: $>>1$; \#185: 1>0; \#251: 0>1; \#275: 1>0; \#286: 0>1; \#298: 0>1; \#301: 0>1;\#317: 0>2;\#327: 1>2;\#328: 0>1.

Agamyxis albomaculatus: \#41: 0>1; \#292: 0>1; \#312: 0>1; \#313: 0>1; \#318: 0>1; \#322: $1>2$.

Anadoras grypus: \#114: 3>2; \#192: 0>1; \#257: 1>0.

Scorpiodoras heckelii: \#40: 0>1; \#64: 0>1.

Pterodoras granulosus: \#40: 1>0; \#41:0>3; \#293: 0>1.

Pterodoras rivasi: sem autapomorfias.

Doraops zuloagai: \#23: 1>0; \#127: $2>1$.

Lithodoras dorsalis: \#34: 0>1; \#183: 0>1; \#314: 0>1.

Megalodoras uranoscopus: sem autapomorfias.

Megalodoras guayoensis: sem autapomorfias.

Centrodoras brachiatus: \#155: 0>1.

Centrodoras hasemani: sem autapomorfias.

Rhynchodoras castilloi: sem autapomorfias.

Rhynchodoras woodsi: sem autapomorfias.

Rhinodoras thomersoni: \#44: 1>0; \#327: 1>2.

Rhinodoras dorbignyi: sem autapomorfias. 
Rhinodoras boehlkei: \#40: 1>0.

Orinocodoras eigenmanni: \#115: 0>4.

Oxydoras niger: \#132: 3>1; \#231: $0>1$.

Oxydoras kneri: sem autapomorfias.

"Petalodoras" fimbriatus: \#16: 1>2; \#241: 0>1; \#286: 0>1.

"Petalodoras" asterophysi: sem autapomorfias.

"Petalodoras" eigenmanni: sem autapomorfias.

"Petalodoras" punctatus: \#39: 0>2; \#44: 1>0.

Trachydoras steindachneri: \#62: 0>1; \#116: 0>1; \#176: 0>1; \#284: 0>1.

Trachydoras microstomus: sem autapomorfias.

Trachydoras nattereri: sem autapomorfias.

Trachydoras brevis: sem autapomorfias.

Trachydoras paraguayensis: \#282: 0>1; \#284: 0>1.

Doras carinatus: sem autapomorfias.

Doras higuchii: sem autapomorfias.

Doras phlyzakion: \#41: 0>1.

Hemidoras stubelii: \#132: 3>2.

Hemidoras morei: sem autapomorfias.

Hemidoras morrisi: \#286: 0>1.

Hemidoras stenopeltis: \#137: 2>1.

Nemadoras humeralis: \#242: 0>1.

Nemadoras elongatus: sem autapomorfias.

Nemadoras hemipeltis: \#68: 1>0; \#127: 2>1.

'Nemadoras' leporhinus: \#127: 2>1.

'Nemadoras' trimaculatus: \#298: 1>0. 
'Nemadoras' ternetzi: sem autapomorfias.

Hassar affinis: \#46: 1>0.

Hassar orestis: sem autapomorfias.

Anduzedoras oxyrhynchus: \#132: 3>4.

Leptodoras oyakawai: \#44: $1>0$.

Leptodoras marki: sem autapomorfias.

Leptodoras praelongus: \#245: 0>1; \#277: 1>0.

Leptodoras juruensis: \#1: 1>0; \#8: 0>1; \#23: 0>1; \#31: 1>0; \#89: 1>0; \#132: 3>4; \#189: 2>3; \#221: 1>0; \#235: 1>0;\#236: 1>2;\#241: 2>1; \#258: 1>0; \#262: $1>2$.

Clado 99: sem ninapomorfias.

Clado 100: \#4: 0>2; \#303: $1>2$.

Clado 101: \#16: 1>2; \#90: 0>1; \#154: 0>1; \#157: 0>1; \#169: 0>1; \#186: 0>1; \#227: 0>1; \#281: 0>1.

Clado 102: \#70: 0>1; \#84: 0>1; \#164: 0>1.

Clado 103: \#114: 2>3; \#122: 2>4; \#173: 0>1.

Clado 104: \#135: 0>1; \#136: 0>1; \#175: $1>0$.

Clado 105: \#59: 0>1.

Clado 106: \#68: 0>2; \#114: 0\&1>2; \#161: 1>0; \#320: 0>2; \#327:0>1; \#328: 0>1.

Clado 107: \#59: 0>1; \#85: 0>1; \#185: 1>2; \#228: 0>1; \#303: $2>3$.

Clado 108: \#96: 1>0; \#100: 0>1; \#185: 1>0; \#197: 0>1; \#198: 0>1; \#204: 0>1; \#226: $0>1$.

Clado 109: \#5: 0>1; \#23: $0>1$; \#71: 1>0; \#102: 0>1; \#103: $0>1$; \#121: $0>1$; \#221: $0>2$; \#225: 0>1; \#282: 0>1; \#326: 1>2.

Clado 110: \#37: 0>2; \#38: 0>1; \#179: 0>1; \#246: 0>1; \#247: 0>1; \#296: 0>1.

Clado 111 (clado Doradoidei, Sisoroidea, Amphiliidae): \#70: 0>1; \#91: 0>1; \#96: 0>1; \#101: 0>1; \#250: 0>1; \#327: 1>2.

Clado 112: \#68: 2>0; \#86: 0>1; \#136: 1>0; \#148: 0>1; \#152: 0>1; \#158: 0>1; \#205: 
1>0; \#267: 0>1.

Clado 113: \#5: 0>3; \#6: 0>1; \#71: 1>0; \#135: 1>0; \#169: 1>2; \#189: 1>0; \#257: 0>1; \#263: 0>1; \#266: 0>1; \#267: $1>2$.

Clado 114: \#244: 0>1; \#322: 1>2; \#323: $1>0$.

Clado 115 (Família Mochokidae): \#122: 2>0; \#143: 0>1; \#145: 0>1; \#146: 0>1; \#175: 1>0; \#215: 0>1; \#224: 0>1; \#288: 0>1;\#326: $1>2$.

Clado 116 (Subordem Doradoidei): \#5: 0>2; \#80: 0>1; \#100: 0>1; \#114: 2>3; \#176: 0>1; \#223: 0>1; \#228: 0>1; \#243: 0>1; \#248: 0>1; \#278: 1>2.

Clado 117: \#77: 0>1; \#78: 0>1; \#117: 0>1; \#238: 0>1; \#258: 0>1; \#290: 1>0.

Clado 118: \#134: 0>2; \#138: 0>1; \#147: 0>1; \#151: 0>1; \#289: 1>0.

Clado 119 (Subfamília Centromochlinae): \#185: 1>0; \#251: 0>1; \#304: 0>1; \#305: 0>1; \#307: 0>1; algumas árvores: \#95: 0>1.

Clado 120 (Família Auchenipteridae): \#4: 0>2; \#13: 0>1; \#14: 0>1; \#51: 0>1; \#57: 0>1; \#109: 0>1; \#126: 0>1; \#229: 0>1; \#300: 0>1; algumas árvores: \#166: 0>1.

Clado 121 (Superfamília Doradoidea): \#71: 1>0; \#93: 0>1; \#94: 0>1; \#107: 0>1; \#161: 0>1; \#211: 0>1; \#212: 0>1; \#214: 0>1;\#220: 0>1; \#221: 0>1; \#226: 0>1; \#233: 0>1; \#263: 0>1; algumas árvores: \#257: 0>1.

Clado 122: \#50: 0>1; \#67: 0>1; \#262: 0>1; \#307: 1>2; algumas árvores: \#303: $1>0$.

Clado 123 (Subfamília Auchenipterini): \#51: 1>2; \#124: 0>1; algumas árvores: \#189: 1>0; \#190: 1>0; \#196: 0>1.

Clado 124: \#116: 0>1; \#122: 3>4; \#288: 0\&1>3.

Clado 125: \#62: 0>1; \#122: 2>3.

Clado 126: \#75: 0>1; \#169: 1>2; \#230: 0>1; algumas árvores: \#67: 0>1.

Clado 127 (Tribo Trachelyopterini): \#317: 0>1; algumas árvores: \#258: 0>1.

Clado 128: \#251: $0>1$.

Clado 129: \#316: 0>1; algumas árvores: \#96: 1>2; \#303: 0>1\&2.

Clado 130: \#70: 1>0; \#88: 0>1; \#262: 0>1. 
Clado 131: \#16: 1>0; \#26: 1>0; \#41: 0>2; \#49: 1>2;\#142: 1>2; \#242: 0>1; \#245: 0>1; \#269: 1>0; \#278: $1>0$.

Clado 132: \#10: 0>1; \#16: 2>1; \#73: 0>1; \#84: 0>1; \#98: 0>1; \#104: 0>1; \#134: 0>3; \#170: 0>1; \#171: 0>1; \#178: 0>1; \#183: 0>1; \#201: 0>1; \#237: 0>1; \#251: 1>0; \#268: 0>1; \#270: 1>0; \#298: 0>2.

Clado 133: \#239: 0>1; \#253: 0>1; \#259: 0>1; \#278: 2>1; algumas árvores: \#67: 0>1.

Clado 134 (Tribo Auchenipterini): \#26: 0>1; \#74: 0>1; \#126: 1>0; \#142: 0>1; \#190: 0>1; \#254: 0>1.

Clado 135: \#189: 0>1; \#257: 1>0; \#261: 0>2; \#266: 0>1; \#323: $1>2$.

Clado 136: \#19: 0>1; \#60: 1>0; \#118: 0>1; \#129: 0>1; \#119: 0>1; \#137: 0>1; \#139: 0>1; \#149: 0>1;\#150: 0>1; \#166: 1>0;\#167: 0>1; \#169: 1>2; \#189: 0>1; \#197: 1>0; \#257: 1>0; \#299: 0>1; \#302: 0>1;\#321: 0>1.

Clado 137: \#18: 0>1; \#20: 0>1; \#29: 0>1; \#52: 0>1; \#75: 0>1; \#98: 0>1; \#108: 0>1; \#190: 1>2;\#192: 0>2; \#236: 1>2; \#270: 1>0;\#275: 1>2;\#282: 0>2; \#285: 1>0; \#288: 0\&1>4; \#294: 0>1; \#298: 0>2; \#303: 2>3; \#308: 0>1.

Clado 138: \#137: 1>2; \#150: 1>2; \#235: 1>0; \#242: 0>1; \#245: 0>1; \#251: 1>2; \#252: $0>2$.

Clado 139: \#144: 0>1; \#161: 1>2; \#169: $1>2$.

Clado 140 (Família Doradidae): \#127: 0>1; \#222: 0>1; \#223: 1>2; \#266: 0>1; \#323: $1>0$.

Clado 141: \#127: 1>2; \#238: 0>1.

Clado 142: \#258: 0>1; \#286: 0>1; \#323: 0>1; \#327: 2>1.

Clado 143: \#111: 0>1; \#161: 1>0; \#229: 0>1; \#277: 0>1; \#280: 0>2; \#288: 0>1.

Clado 144: \#4: 0>12; \#116: 0>1; \#318: 0>1.

Clado 145: \#39: 0>1; \#115: 0>1; \#122: 2>1; \#130: 0>1; \#169: 1>2; \#238: 1>0; \#260: 0>1; \#273: 0>2; \#280: 2>1; \#288: 1>0; \#319: 0>1.

Clado 146: \#72: 0>1; \#116: $0>1$.

Clado 147 (clado Astrodoradinae, Acanthodoras, Agamyxis): \#4: 0>2; \#109: 0>1; 
\#284: $0>1$.

Clado 148: \#96: 1>2; \#279: 0>3.

Clado 149: \#109: 0>1; \#115: 0>2.

Clado 150: \#42: 0>1; \#60: 0>1; \#230: 0>1; \#286: $1>0$.

Clado 151 (Tribo "Pterodoradini"): \#40: 0>1; \#45: 0>1; \#47: 0>1; \#235: 1>2.

Clado 152 (Subfamília Doradinae): \#23: 0>1; \#44: 0>1; \#132: 2>3; \#280: 2>0.

Clado 153: \#42: 0>1; \#115: 0>3; \#132: 3>0; \#230: 0>1; \#284: $0>1$.

Clado 154: \#4: 0>1; \#46: 0>1; \#122: $2>1$.

Clado 155: \#21: 0>1; \#31: 0>1; \#35: 0>1; \#41: 0>2; \#44: 1>0; \#96: 1>2; \#133: 0>1; \#226: 1>0; \#242: 0>1; \#245: 0>1; \#285: 1>0.

Clado 156 (Tribo “Rhinodoradini"): \#63: 0>1; \#156: 0>1; \#163: 0>1; \#279: 0>1; \#318: $0>1$.

Clado 157: \#144: 0>1; \#155: 0>1.

Clado 158: \#15: 0>1; \#183: 0>1.

Clado 159: \#2: $0>1$; \#40: $0>1$; \#42: $0>1$; \#43: $0>1$; \#132: 3>2; \#188: 0>3; \#208: $0>1$.

Clado 160: \#40: 0>2; \#42: 0>1; \#68: 2>1;\#76: 0>1;\#150: 1>2;\#181: 0>1;\#182: 1>2; \#183: $0>1$.

Clado 161 (Tribo Doradini): \#60: 0>2; \#65: 0>1; \#105: 0>1; \#117: 0>1; \#122: 2>1; \#134: 0>1; \#137: 0>1\&2; \#150: 0>1; \#180: 0>1; \#182: 0>1; \#187: 0>1; \#194: 0>1; \#199: 0>1; \#207: 0>1; \#283: 0>1; \#286: 1>0.

Clado 162: \#12: 0>1; \#17: 0>1; \#245: 0>1.

Clado 163: \#132: 3>2; \#282: 0>1; \#284: 0>1.

Clado 164: \#4: $0>2$; \#11: $0>1$; \#18: 0>1; \#23: 1>0; \#46: 0>1; \#47: 0>1; \#84: 0>1; \#95: 0>1; \#96: 1>2; \#122: 1>0; \#129: 0>1;\#160: 0>1; \#171: 0>1; \#219: 0>1; \#279: 0>2; \#298: 0>1\&2.

Clado 165: \#39: 0>2; \#65: 1>2; \#68: 2>0; \#92: 0>2; \#113: 0>1;\#150: 1>2;\#187: 1>0; \#189: 1\&2>3; \#195: 0>1; \#262: 1>2. 
Clado 166: \#31: 0>1; \#89: 0>1; \#172: $0>1$.

Clado 167: \#46: 1>0; \#132: 3>2.

Clado 168: \#40: 0>2; \#97: 0>1; \#112: 0>1; \#137: $2>1$.

Clado 169: \#32: 0>1; \#44: 1>0; \#73: $0>1$.

Clado 170: \#61: 0>1; \#172: 1>2; \#181: $0>1$.

Clado 171: \#17: 0>2; \#31: 1>0; \#39: 0>1; \#279: 2>0; \#284: $0>1$.

Clado 172: \#182: 1>2; \#241: 0>1; \#245: 0>1.

Clado 173: \#150: 1>2; \#298: $1>2$.

Clado 174: \#116: 0>1.

Clado 175: \#48: 0>1; \#298: $1>0$.

Clado 176: \#68: $2>1$.

Clado 177: \#1: $0>1$; \#68: 1>0; \#73: $0>1$.

Clado 178: \#242: 0>1.

Clado 179: \#92: 0>1; \#127: 2>1; \#137: $2>1$.

Clado 180: \#97: 0>1; \#112: 0>1; \#182: 2>1; \#189: $1>2$.

Clado 181: \#7: 0>1; \#192: 0>1; \#197: 0>1; \#209: 0>1; \#236: 0>1; \#241: $1>2$.

Clado 182: \#46: 1>0; \#150: 1>2; \#187: 1>2; \#200: 0>1; \#245: 1>0; \#287: 0>1; \#298: $1>0$.

Clado 183: \#35: 0>1; \#41: 0>2; \#210: $1>3$. 
Apêndice 4. Chave para identificação dos gêneros da superfamília

\section{Doradoidea.}

Os peixes da superfamília Doradoidea ocorrem amplamente nos rios da América do Sul. Eles podem ser facilmente reconhecidos dentre os demais Siluriformes neotropicais por possuírem escudo cefálico bem desenvolvido, largo e contínuo até o acúleo da nadadeira dorsal, processo posterior do cleitro geralmente bem desenvolvido, ligamento entre a placa nucal posterior e a primeira costela (ossificado e normalmente visível em Doradidae, ou ligamentoso e normalmente apalpável externamente em Auchenipteridae), e nadadeira anal de machos maduros modificada num gonopódio (em Auchenipteridae) ou uma fileira de escudos ósseos laterais (em Doradidae).

A. Sulco suborbital presente; ligamento entre o escudo nucal posterior e a primeira costela não ossificado; túbulos da linha lateral não ossificados como escudos laterais; machos com a nadadeira anal modificada num gonopódio para inseminação interna, e com abertura urogenital imediatamente anterior a nadadeira anal nas fêmeas e na base ou na extremidade dos raios anteriores da anal nos machos ... Auchenipteridae

B. Sulco suborbital ausente; ligamento entre o escudo nucal posterior e a primeira costela ossificado como um escudo ósseo lateral (=escudo infranucal) (geralmente com um espinho retrorso); túbulos da linha lateral ossificados formando escudos laterais, presentes como dois ou três escudos depois do infranucal ou, mais comumente, como uma fileira de escudos laterais com espinhos retrorsos; machos com nadadeira anal não modificada, machos e fêmeas com abertura urogenetal distante da nadadeira anal ... Doradidae

\section{Chave para identificação dos gêneros da família Doradidae}

1A. Babilhão maxilar simples; barbilhões mentonianos externos mais longos do que os internos; escudos laterais perpendiculares em relação ao eixo do corpo; processo posterior do cleitro longo, baixo e afilado posteriormente (salvo poucas exceções, mas nunca trapezóide) ... 2

2A. Base da nadadeira adiposa curta (mais curta do que a da anal); nadadeira caudal truncada ou arredondada; processo posterior do cleitro com espinhos; infra-orbital 1 com crista tranversal serrilhada e formando a órbita ... $\mathbf{3}$ 
3A. Corpo preto com manchas claras (amareladas em vida), às vezes formando uma faixa lateral; infra-orbitais expandidos; acúleo da nadadeira dorsal com espinhos laterais; acúleo da nadadeira peitoral com espinhos dorsais ... 4

4A. Raios procorrentes da nadadeira caudal modificados em placas (fulcra); corpo com manchas claras (sem faixa lateral); nadadeira caudal truncada ... Agamyxis

4B. Raios procorrentes da nadadeira caudal não modificados em placas (fulcra); corpo com manchas claras geralmente formando uma faixa lateral; nadadeira caudal arredondada ... Acanthodoras

3B. Corpo claro com manchas escuras; infra-orbitais não expandidos; acúleo da nadadeira dorsal sem espinhos laterais (salvo poucas exceções); acúleo da nadadeira peitoral sem espinhos dorsais ... $\mathbf{5}$

5A. Infra-orbital 1 liso; acúleo da nadadeira dorsal liso ... Anadoras

5B. Infra-orbital 1 serrilhado; acúleo da nadadeira dorsal liso ou com serra anterior ... 6

6A. Cintura peitoral não coberta ventralmente por musculatura (aparentemente exposta); acúleo da nadadeira dorsal liso ou com serra somente na porção proximal (raramente com serra em toda a margem do acúleo) ... 7

7A. Pequeno porte (até $3 \mathrm{~cm}$ de $\mathrm{CP}$ ); processo posterior do coracóide longo (mais longo do que o do cleitro) ... Physopyxis

7B. Médio porte (mais de $3 \mathrm{~cm}$ de $\mathrm{CP}$ ); processo posterior do coracóide curto (mais curto do que o do cleitro) ... 8

8A. Linha lateral incompleta (escudos laterais só até o meio do corpo) ... Merodoras

8B. Linha lateral completa (escudos laterais contínuos até a nadadeira caudal) ... Amblydoras

6B. Cintura peitoral ventralmente coberta por musculatura; acúleo da nadadeira dorsal liso ou com serra ao longo de toda a margem anterior... 9

9A. Um escudo ósseo dorsal anterior à nadadeira adiposa; acúleo da nadadeira dorsal liso ... Hypodoras

9B. Escudo ósseo dorsal anterior à nadadeira adiposa ausente; acúleo da nadadeira dorsal com serra na margem anterior ... 10

10A. Infra-orbital 1 com borda lateral lisa, margem lateral do etmóide lateral com espinhos ... Scorpiodoras 
10B. Infra-orbital 1 com borda lateral serrilhada, margem lateral do etmóide lateral granulosa (mas sem espinhos) ... Astrodoras

2B. Base da nadadeira adiposa longa (mais longa do que a da anal); nadadeira caudal furcada; processo posterior do cleitro geralmente sem espinhos; infra-orbital 1 anterior à órbita e, geralmente, sem crista tranversal serrilhada ... 11

11A. Escudos laterais visualmente ausentes ou pouco desenvolvidos no meio do corpo... 12

12A. Escudos laterais visualmente ausentes em todo o corpo, e sem espinhos retrorsos (em exemplares maiores do que $7 \mathrm{~cm}$ de $\mathrm{CP}$ )... Wertheimeria

12B. Escudos laterais com espinhos retrorsos e visíveis em quase todo o corpo, exceto na porção mediana do corpo ... 13

13A. Corpo com manchas escuras grandes, infra-orbitais expandidos ... Kalyptodoras

13B. Corpo de colorido uniforme; infra-orbitais não expandidos ... Doraops

11B. Escudos laterais bem desenvolvidos como uma fileira contínua ... 14

14A. Raios procorrentes da nadadeira caudal modificados em placas (fulcra) ... 15

15A. Boca em forma de pinça orientada ventralmente, barbilhões mentonianos com bases unidas; placa nucal anterior reduzida (em exemplares pequenos) ou ausente (em exemplares grandes) ... Rhynchodoras

15B. Boca normal, subterminal; barbilhões mentonianos com bases separadas; placa nucal anterior bem desenvolvida ... 16

16A. Lábios grossos, com expansões laterais; processo posterior do cleitro alto, triangular; tubérculos dérmicos bem desenvolvidos ... 17

17A. Corpo preto com faixa clara (amarelada em vida); barbilhões sem estrias transversais ... Orinocodoras

17B. Corpo amarronzado com manchas escuras; barbilhões com estrias transversais ... Rhinodoras

16B. Lábios finos, sem expansões laterais; processo posterior do cleitro baixo e longo; tubérculos dérmicos pouco desenvolvidos ... 18

18A. Corpo amarronzado com vermiculações claras dorsais ... Franciscodoras 
18B. Corpo preto com faixa clara (amarelada em vida) ou uniformemente acinzentado ... Platydoras

14B. Raios procorrentes da nadadeira caudal não modificados em placas (fulcra) ... 19

19A. Cabeça comprimida (mais alta do que larga); lábios grossos; prémaxilar e dentário sem dentes ... Oxydoras

19B. Cabeça deprimida (mais larga do que alta); lábio finos; pré-maxilar e dentário com dentes ... 20

20A. Pequeno porte (até $20 \mathrm{~cm}$ de $\mathrm{CP}$ ); 28 a 29 escudos laterais; processo posterior do cleitro com espinhos ... Centrochir

20B. Médio a grande porte (mais de $20 \mathrm{~cm}$ de CP); 15 a 25 ou mais de 30 escudos laterais; processo posterior do cleitro sem espinhos nos adultos ... 21

21A. Médio porte (até $40 \mathrm{~cm}$ de CP); 30 a 40 escudos laterais ... Centrodoras

21B. Grande porte (mais de $40 \mathrm{~cm}$ de $\mathrm{CP}$ ); 15 a 25 escudos laterais ... 22

22A. Nadadeira adiposa com lobo pequeno, mas base longa; 15 a 17 escudos laterais; corpo com um mosaico de manchas claras e escuras ... Megalodoras

22B. Nadadeira adiposa com lobo grande e base longa; 16 a 25 escudos laterais; corpo de colorido uniforme, ou com manchas escuras pequenas ... 23

23A. Corpo completamente coberto por escudos ósseos (em exemplares a partir de $15 \mathrm{~cm}$ de $\mathrm{CP}$ ); 16 a 20 escudos laterais; corpo com colorido uniforme ... Lithodoras

23B. Corpo não coberto por escudos ósseos; 19 a 25 escudos laterais; corpo amarronzado com manchas escuras pequenas ... Pterodoras

1B. Babilhão maxilar com barbelas; barbilhões mentonianos de comprimento similar; escudos laterais inclinados em relação ao eixo do corpo; processo posterior do cleitro geralmente trapezóide ... 24

24A. Barbilhões maxilar e mentonianos unidos por membrana, formando um capuz oral; 33 a 46 escudos laterais ... 25

25A. Barbilhões maxilar e mentonianos unidos por membrana em toda a sua 
extensão; lamelas acessórias do primeiro arco branquial estendidas sobre os filamentos branquiais; bexiga natatória geralmente reduzida com poucos divertículos laterais (exceto em Leptodoras marki e Leptodoras oyakawai que possuem bexiga natatória bem desenvolvida e com poucos ou nenhum divertículo lateral); 33 a 46 escudos laterais ... Leptodoras

25B. Barbilhões maxilar e mentonianos unidos por membrana apenas na base; lamelas acessórias do primeiro arco branquial não estendidas sobre os filamentos branquiais; bexiga natatória bem desenvolvida e com muitos divertículos laterais; 39 a 40 escudos laterais ... Anduzedoras

24B. Barbilhões maxilar e mentonianos livres; 26 a 37 escudos laterais ... 26

26A. Forame nucal ausente ... 27

27A. Processo posterior do coracóide longo (aproximadamente tão longo quanto do cleitro); fontanela posterior ausente; pré-maxilar e dentário geralmente com muitos dentes (mais de 15); tecido glandular ventral ao processo posterior do cleitro ausente ... "Petalodoras"

27B. Processo posterior do coracóide normalmente curto (mais curto do que o do cleitro); fontanela posterior presente; pré-maxilar e dentários geralmente com poucos dentes (menos de 15); tecido glanular ventral ao processo posterior do cleitro geralmente presente ... $\mathbf{2 8}$

28A. Focinho arredondado e curto (diâmetro orbital maior do que $50 \%$ do comprimento do focinho); barbilhão maxilar curto (não alcançando a abertura branquial); fontanela posterior presente ... Trachydoras

28B. Focinho afilado e longo (diâmetro orbital menor do que 50\% do comprimento do focinho); barbilhão maxilar longo (ultrapassando a abertura branquial); fontanela posterior ausente ... Doras

26B. Forame nucal presente ... 29

29A. Nadadeira dorsal com mancha escura na porção distal dos raios ramificados; escudos laterais anteriores reduzidos ... Hassar

29B. Nadadeira dorsal hialina ou com mancha escura na porção proximal dos primeiros raios; escudos laterais anteriores geralmente bem desenvolvidos ... 30

30A. Uma mancha escura na porção proximal dos primeiros raios da nadadeira dorsal e outra no meio de cada um dos lobos da nadadeira caudal ... "Nemadoras"

30B. Nadadeiras hialina, de colorido uniforme ... 31

31A. Processo posterior do cleitro triangular, com extremidade posterior afilada; tecido glandular ventral ao processo posterior do cleitro ausente; 
escudos ósseos entre as nadadeiras dorsal e adiposa presentes em algumas espécies; barbelas nos barbilhões mentonianos bem desenvolvidas ... Hemidoras

31B. Processo posterior do cleitro trapezóide, com extremidade truncada; tecido glandular ventral ao processo posterior do cleitro geralmente presente; escudos ósseos entre as nadadeiras dorsal e adiposa sempre ausentes; barbelas nos barbilhões mentonianos pouco desenvolvidas ... Nemadoras

\section{Chave para identificação dos gêneros da família Auchenipteridae}

1A. Sete a 16 raios (totais) na nadadeira anal ... 2

2A. Machos com nadadeira anal bastante inclinada, a mais ou menos $45^{\circ}$ em relação ao eixo do corpo; machos com abertura urogenital na base dos raios da nadadeira anal; 5 raios ramificados na nadadeira pélvica; 3 a 5 raios ramificados na nadadeira dorsal ... 3

3A. Doze a 14 raios (totais) na nadadeira anal ... Glanidium

3B. Sete a 11 raios (totais) na nadadeira anal ... 4

4A. Um par de barbilhões mentonianos; pequeno porte (alcançando até $4 \mathrm{~cm}$ de $\mathrm{CP}$ ); olhos pequenos (menos de $10 \%$ do comprimento da cabeça) ... Gelanoglanis

4B. Dois pares de barbilhões mentonianos; médio porte (alcançando mais de 4 $\mathrm{cm}$ de CP); olhos grandes (20 a 40\% do comprimento da cabeça) ... 5

5A. Nadadeira anal relativamente longa (mais de $8 \%$ do $\mathrm{CP}$ ); pedúnculo caudal relativamente baixo (menos de $10 \%$ do CP) ... Centromochlus

5B. Nadadeira anal relativamente curta (entre 3.3 e $8 \%$ do $\mathrm{CP}$ ); pedúnculo caudal relativamente baixo (entre 10.1 e $18.6 \%$ do CP) ... Tatia

2B. Machos com nadadeira anal pouco inclinada, em relação ao eixo do corpo; machos com abertura urogenital localizada na extremidade dos raios anteriores da nadadeira anal; 6 ou mais raios ramificados na nadadeira pélvica; 6 raios ramificados na nadadeira dorsal ... 6

6A. Boca extremamente grande, com fenda bucal inclinada; 9 a 10 raios ramificados na nadadeira pélvica ... Asterophysus

6B. Boca normal, com fenda bucal mais ou menos longitudinal; 6 raios ramificados na nadadeira pélvica ... 7 
7A. Corpo pardo com grandes manchas escuras; nadadeira adiposa com base longa (aproximadamente tão longa quanto a da nadadeira anal) ... Liosomadoras

7B. Corpo com colorido uniforme; nadadeira adiposa com base curta (mais curta do que a da nadadeira anal) ... 8

8A. Olhos pequenos (10 a 20\% do comprimento da cabeça), escudo cefálico plano (em corte transversal) ... Tocantinsia

8B. Olhos grandes (20 a 40\% do comprimento da cabeça), escudo cefálico angulado (em corte transversal) ... Pseudotatia

1B. Dezoito a 60 raios (totais) na nadadeira anal ... 9

9A. Dezoito a 34 raios (totais) na nadadeira anal ... 10

10A. Barbilhões mentonianos ausentes; 6 raios ramificados na nadadeira pélvica ... Ageneiosus

10B. Barbilhões mentonianos presentes; 5,7 ou 8 raios ramificados na nadadeira pélvica ... 11

11A. Nove a 12 raios ramificados no lobo inferior da nadadeira caudal ...12

12A. Nadadeira adiposa presente; 21 a 28 raios (totais) na nadadeira anal ... Parauchenipterus

12B. Nadadeira adiposa ausente; 28 a 33 raios (totais) na nadadeira anal ... Trachelyopterus

11B. Oito raios ramificados no lobo inferior da nadadeira caudal... 13

13A. Cinco raios ramificados na nadadeira pélvica ... 14

14A. Pré-maxilar e dentário com poucos dentes; nadadeira pélvica expandida em machos maduros; tudo urogenital como uma papila na base da nadadeira anal ... Entomocorus

14B. Pré-maxilar e dentário com muitos dentes; nadadeira pélvica não modificada em machos maduros; tubo urogenital carnoso associado aos primeiros raios da nadadeira anal... "Amplexiglanis"

13B. Sete ou 8 raios ramificados na nadadeira pélvica ... $\mathbf{1 5}$

15A. Sete raios ramificados na nadadeira pélvica; 6 raios ramificados na nadadeira dorsal ... Pseudauchenipterus

15B. Oito raios ramificados na nadadeira pélvica; 5 raios ramificados na 


\section{nadadeira dorsal ... Trachycorystes}

9B. Trinta e cinco a 60 raios (totais) na nadadeira anal ... 16

16A. Barbilhões mentonianos ausentes ou em apenas um par; 6 raios ramificados na nadadeira pélvica ... 17

17A. Um par de barbilhão mentoniano; 9 a 11 raios ramificados na nadadeira peitoral; 9 a 12 raios ramificados no lobo ventral da nadadeira caudal ... Tetranematichthys

17B. Barbilhão mentoniano ausente; 6 raios ramificados na nadadeira peitoral; 8 raios ramificados no lobo ventral da nadadeira caudal ... Ageneiosus

16B. Dois pares de barbilhões mentonianos; 9 a 16 raios ramificados na nadadeira pélvica ... 18

18A. Nadadeira adiposa ausente ... 19

19A. Cinco raios ramificados na nadadeira dorsal; 9 a 12 raios ramificados no lobo ventral da nadadeira caudal ... Trachelyichthys

19B. Quatro raios ramificados na nadadeira dorsal; 8 raios ramificados no lobo ventral da nadadeira caudal ... 20

20A. Seis a 9 raios ramificados na nadadeira peitoral; pré-maxilar e dentário com dentes; nadadeira dorsal normalmente desenvolvida ... Trachelyopterichthys

20B. Oito a 12 raios ramificados na nadadeira peitoral; pré-maxilar e dentário sem dentes; nadadeira dorsal reduzida em tamanho (exceto em machos maduros) ... Epapterus

18B. Nadadeira adiposa presente ... 21

21A. Nadadeira dorsal normalmente desenvolvida, com 6 ou 7 raios ramificados ... Auchenipterus

21B. Nadadeira dorsal reduzida em tamanho, com 3 a 5 raios ramificados ... Pseudepapterus 


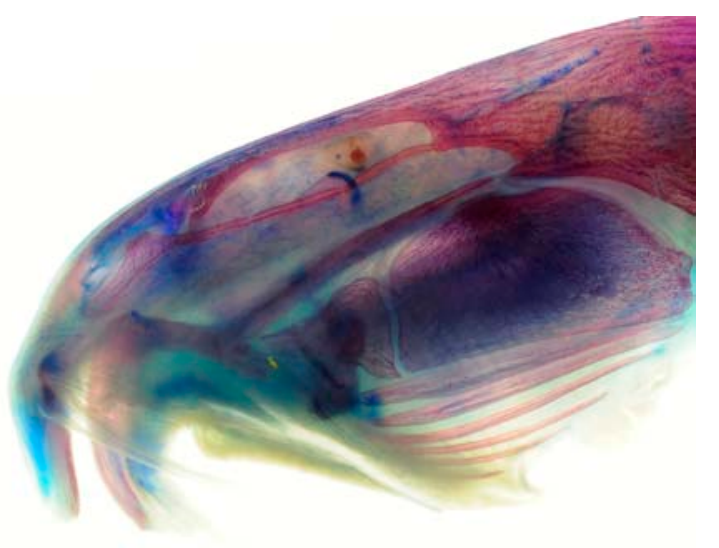

